\section{Pacific Northwest}

National Laboratory

Operated by Battelle for the

U.S. Department of Energy

\title{
Laboratory Testing of Bulk Vitrified Low-Activity Waste Forms to Support the 2005 Integrated Disposal Facility Performance Assessment
}
E. M. Pierce
K. N. Geizler
B. P. McGrail
S. R. Baum
L. M. Bagaasen
L. R. Reed
E. A. Rodriguez
J. V. Crum
D. M. Wellman
H. T. Schaef

March 2005

Prepared for the U.S. Department of Energy under Contract DE-AC05-76RL01830 


\title{
DISCLAIMER
}

This report was prepared as an account of work sponsored by an agency of the United States Government. Neither the United States Government nor any agency thereof, nor Battelle Memorial Institute, nor any of their employees, makes any warranty, expressed or implied, or assumes any legal liability or responsibility for the accuracy, completeness, or usefulness of any information, apparatus, product, or process disclosed, or represents that its use would not infringe privately owned rights. Reference herein to any specific commercial product, process, or service by trade name, trademark, manufacturer, or otherwise does not necessarily constitute or imply its endorsement, recommendation, or favoring by the United States Government or any agency thereof, or Battelle Memorial Institute. The views and opinions of authors expressed herein do not necessarily state or reflect those of the United States Government or any agency thereof.

\author{
PACIFIC NORTHWEST NATIONAL LABORATORY \\ operated by \\ BATTELLE MEMORIAL INSTITUTE \\ for the \\ UNITED STATES DEPARTMENT OF ENERGY \\ under Contract DE-AC05-76RLO 1830
}




\title{
Laboratory Testing of Bulk Vitrified Low-Activity Waste Forms to Support the 2005 Integrated Disposal Facility Performance Assessment
}

\author{
E. M. Pierce \\ B. P. McGrail \\ L. M. Bagaasen \\ E. A. Rodriguez \\ D. M. Wellman \\ K. N. Geizler \\ S. R. Baum \\ L. R. Reed \\ J. V. Crum \\ H. T. Schaef
}

March 2005

Prepared for

the U.S. Department of Energy

under Contract DE-AC06-76RLO 1830

Pacific Northwest National Laboratory

Richland, WA 


\section{Summary}

The Hanford Site in southeastern Washington State has been used extensively to produce nuclear materials for the U. S. strategic defense arsenal by the U. S. Department of Energy (DOE). A large inventory of radioactive and mixed waste has accumulated in 177 single- and double-shell tanks. Waste recovered from the tanks will be pre-treated to separate the low-activity fraction from the high-level and transuranic wastes. The low-activity fraction will be among the largest volumes of radioactive waste within the DOE complex and is one of the largest inventories of long-lived radionuclides planned for disposal in a low-level waste facility. Currently, the DOE Office of River Protection (ORP) is evaluating several options for immobilization of low-activity tank wastes for eventual disposal in a shallow subsurface facility at the Hanford Site. A significant portion of the waste will be converted into immobilized low-activity waste (ILAW) glass with a conventional Joule-heated ceramic melter. In addition to ILAW glass, DOE is considering a supplemental treatment technology; bulk vitrification (BV), to treat a portion of the low-activity waste (LAW). The use of a supplemental treatment technology is expected to accelerate the overall cleanup mission at the Hanford site by at least 35 years. CH2M Hill Hanford Group, Inc. (CH2M HILL) requested that Pacific Northwest National Laboratory (PNNL) perform the testing on BV outlined in the strategy document of McGrail et al. (2003a) in support of the 2005 Integrated Disposal Facility (IDF) performance assessment (PA).

A critical component of the development and testing strategy will be to provide estimates of radionuclide release rates from the engineered portion of the disposal facilities (source term). These data will be used for Subsurface Transport Over Reactive Multi-phases (STORM) simulations of the BV waste package. Documented in this report are data related to 1) kinetic rate law parameters for glass and refractory dissolution, 2) sodium $\left(\mathrm{Na}^{+}\right)$-hydrogen $\left(\mathrm{H}^{+}\right)$ion exchange rate, 3 ) chemical reaction network of secondary phases that form in accelerated weathering tests, and 4) thermodynamic equilibrium constants assigned to these secondary phases for BV vitrified product. The kinetic rate law and $\mathrm{Na}^{+}-\mathrm{H}^{+}$ion exchange rate were determined from single-pass flow-through (SPFT) experiments. Product consistency (PCT) tests were used for accelerated weathering or aging of the glasses to determine a chemical reaction network of secondary phases that form. The majority of the thermodynamic data used in this data package were extracted from the thermodynamic database package provided with the geochemical code EQ3/6, version 8.0.

Results from SPFT tests suggest that rate law parameters derived for BV glasses are comparable to those determined for WTP glass formulations. SPFT tests also were used to calculate a bounding release rate for the mullite castable refractory block (CRB). The presence of multiple mineral phases in and the uncertainty regarding the true reactive surface area of the CRB may have a significant effect on the reported rates. Therefore, we recommend that rate law parameters be developed for the pure mineral phases identified in the CRB. These results should be combined with literature values to develop a scientifically defensible conclusion regarding the dissolution of the mullite CRB and the potential impact the CRB may have on BV waste package performance.

In addition to the experimentally derived input data for the BV waste form, this report contains results on the soluble fraction of $\operatorname{Re}$ (chemical analogue for ${ }^{99} \mathrm{Tc}$ ) from five non-radioactive tests (ES-31A, ES31B, ES-31C, ES-31D, and ES-31E), one test using a ${ }^{99}$ Tc spike (ES-32A), and one test using actual Hanford tank waste (ES-32B). Soluble ${ }^{99} \mathrm{Tc}$ was determined for ES-32A and ES-32B, and soluble Cs was determined for ES-31B. Results from these seven individual ES tests were used to determine an average 
recommended best estimate of the soluble ${ }^{99} \mathrm{Tc}$ inventory that would be leachable from the CRB. Based on these ES tests the average best estimate of the ${ }^{99} \mathrm{Tc}$ inventory that would be soluble from the CRB is $0.34 \pm 0.06 \%$. This value is significantly lower than the FY03 ES tests that indicated $2 \mathrm{wt} \%$ of the ${ }^{99} \mathrm{Tc}$ inventory waste stream ended up in the sand insulation and scoria layer after vitrification. Although the $\mathrm{CRB}$ is the major source of soluble ${ }^{99} \mathrm{Tc}$ in the ES waste packages, other areas also contain smaller quantities of soluble ${ }^{99} \mathrm{Tc}$. These other areas include the surface of the glass block where small amounts of nonglassy materials collect, the refractory sand liner, and the ICV box lid that acts as a cover during the melting process but also serves as the disposal lid. Estimates of the amounts of soluble ${ }^{99} \mathrm{Tc}$ in these areas for ES-32A and ES-32B are reported in Kim et al. (2004) and AMEC (2005a). The best estimate of the total soluble ${ }^{99} \mathrm{Tc}$ fraction from all areas in the ES tests is $0.45 \pm 0.07 \%$. Currently, additional analysis is underway to estimate the soluble fraction in full-scale BV waste packages. 


\section{Quality Assurance}

The work described in this report was performed under the PNNL Nuclear Quality Assurance Requirements Description (NQARD) procedures in accordance with the Supplemental Treatment Technologies Support Program, Tank Waste Support Quality Assurance Plan Rev. 6. These project quality assurance procedures and the project QA plan are compliant with the national standard ASME/NQA-1 as required in the project sponsor's statement of work. Testing documented in this report was performed in accordance with Test Plan: "Cast Refractory Extraction Technique," 46611-2004-01, Rev.0, Kinetic Parameter Measurements on "Bulk Vitrified Immobilized Low-Activity Waste Using the Single-Pass FlowThrough Test Method," 44832-2004-01, Rev.0, and "Product Consistency Test Measurements on Bulk Vitrified Low-Activity Waste Simulants," 46611-2004-01, Rev. 0. 


\section{Acknowledgments}

A portion of this research was performed in part using Nuclear Magnetic Resonance Spectrometers in the William R. Wiley Environmental Molecular Sciences Laboratory, a national scientific user facility sponsored by the U. S. Department of Energy's Office of Biological and Environmental Research and located at PNNL. PNNL is operated for the U.S. Department of Energy by Battelle. The authors would like to thank Dr. Wendy Shaw of PNNL for her help in collecting the MAS-NMR glass spectra. 


\section{Acronyms}

\begin{tabular}{|c|c|}
\hline AMEC & AMEC Earth and Environmental, Inc. \\
\hline ASTM & American Society for Testing and Materials \\
\hline BET & Brunauer-Emmett-Teller (gas adsorption surface area analysis) \\
\hline $\mathrm{BV}, \mathrm{BKV}$ & bulk vitrification \\
\hline CRB & castable refractory block \\
\hline CH2M HILL & CH2M HILL Hanford Group, Inc. \\
\hline DBVS & Demonstration Bulk Vitrification System \\
\hline DIW & deionized water \\
\hline DOE & Department of Energy \\
\hline ES, EST & engineering-scale test \\
\hline FS & full-scale test \\
\hline HLW & high-level waste \\
\hline ICP-OES & inductively coupled plasma-optical emission spectroscopy \\
\hline ICP-MS & inductively coupled plasma-mass spectrometry \\
\hline $\mathrm{ICV}$ & in-container vitrification \\
\hline IDF & integrated disposal facility \\
\hline IEX & alkali-hydrogen exchange \\
\hline ILAW & immobilized low activity waste \\
\hline ISV & in-situ vitrification \\
\hline LAW & low-activity waste \\
\hline LLW & low-level waste \\
\hline MAS-NMR & magic-angle spinning nuclear magnetic resonance spectroscopy \\
\hline MLLW & mixed-low level waste \\
\hline NQARD & nuclear quality assurance requirements description \\
\hline PA & performance assessment \\
\hline PCT & product consistency test \\
\hline PFA & perfluoro alkoxy alkane \\
\hline PNNL & Pacific Northwest National Laboratory \\
\hline QA & quality assurance \\
\hline QAPD & quality assurance program documents \\
\hline RA & risk assessment \\
\hline SEM & scanning electron microscope \\
\hline SPFT & single-pass flow-through (glass test) \\
\hline STORM & Subsurface Transport Over Reactive Multiphases (computer code) \\
\hline $\mathrm{S} / \mathrm{V}$ & surface area-to-solution volume ratio \\
\hline THAM & tris (hydroxymethyl) aminomethane \\
\hline
\end{tabular}


TMS

TST

WTP

XRD
Tetrakis (trimethylsilyl) silane

transition state theory

Waste Treatment Plant

X-ray diffraction 


\section{Contents}

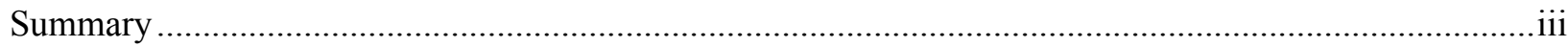

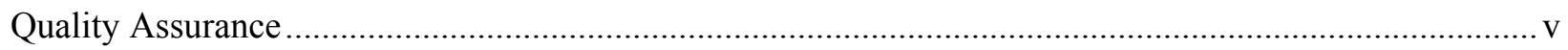

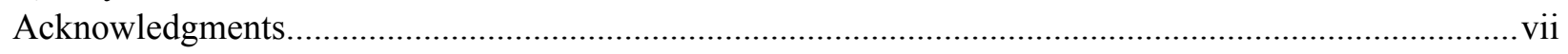

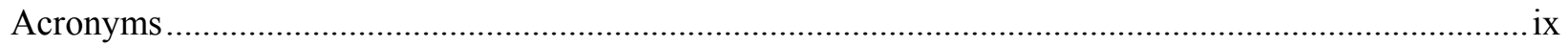

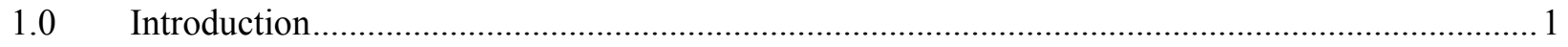

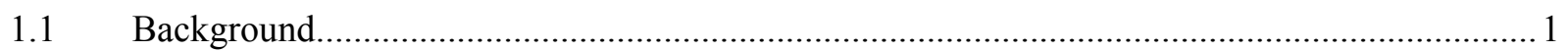

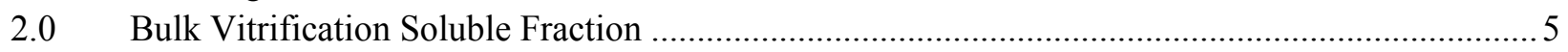

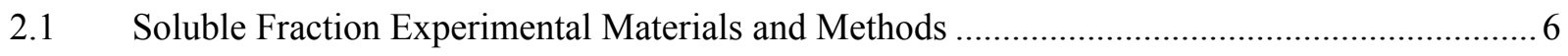

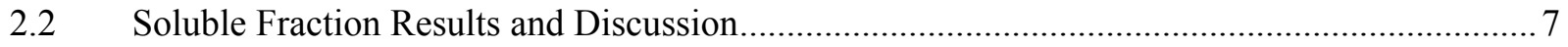

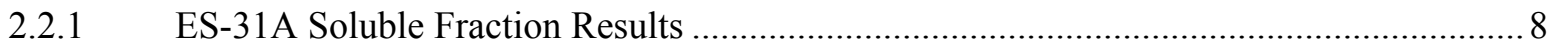

2.2.2 ES-31B Soluble Fraction Results............................................................................... 10

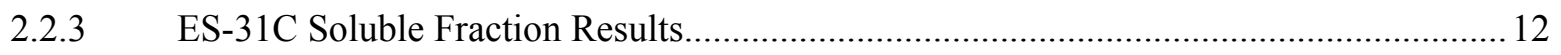

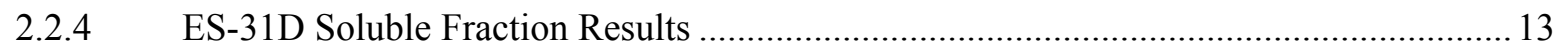

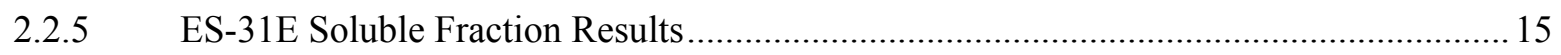

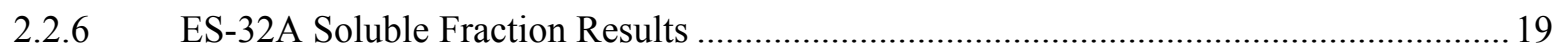

2.2.7 ES-32B (ES-13) Soluble Fraction Results ..................................................................... 20

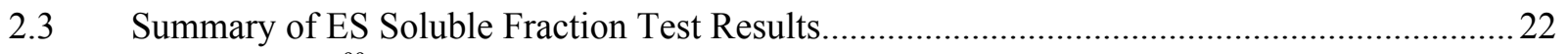

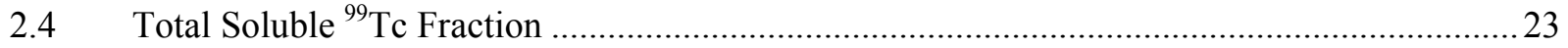

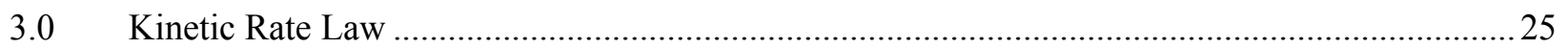

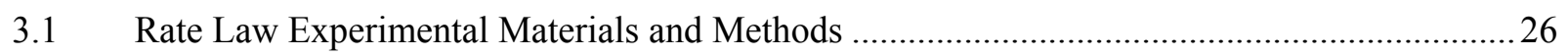

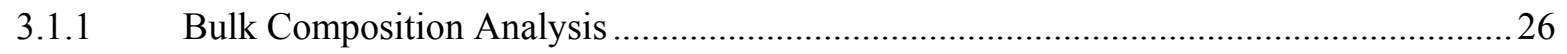

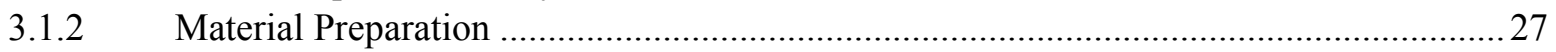

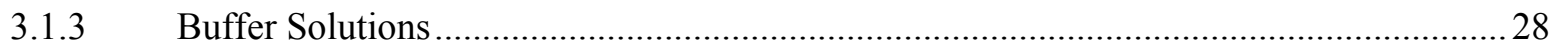

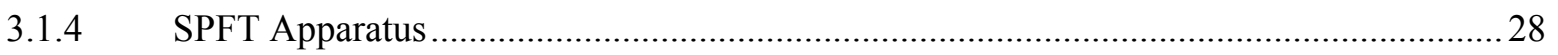

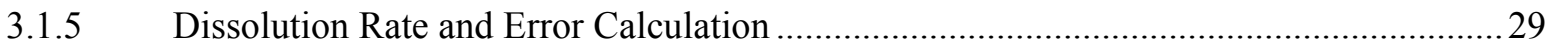

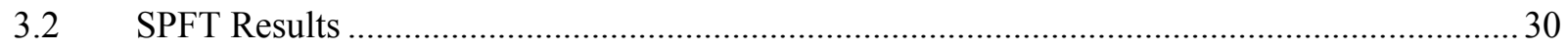

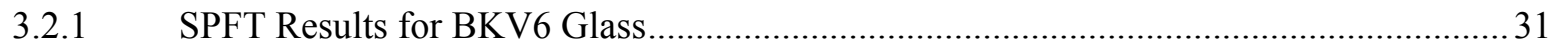

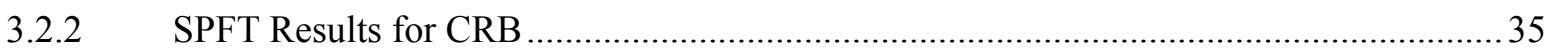

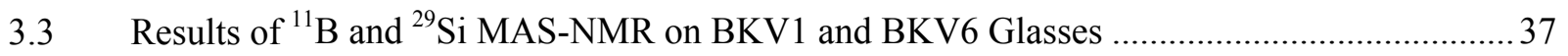

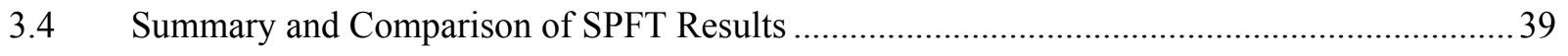

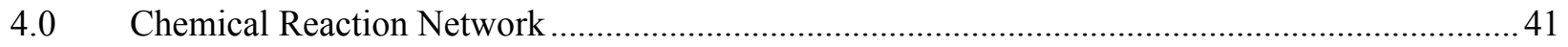

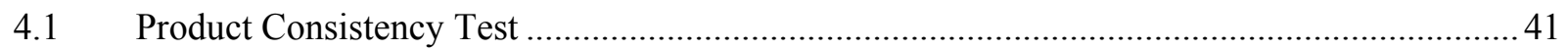

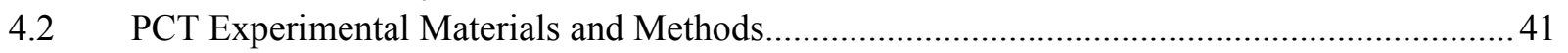

4.3 PCT Results for BKV6, BKV7, BKV8, and BKVZ Glasses ............................................ 41

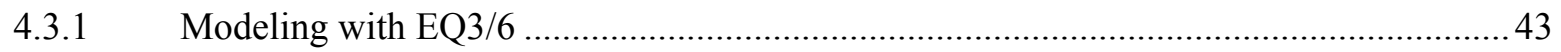

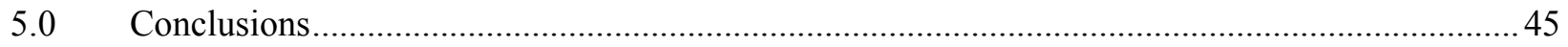

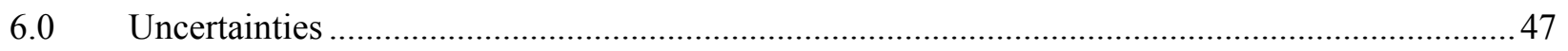

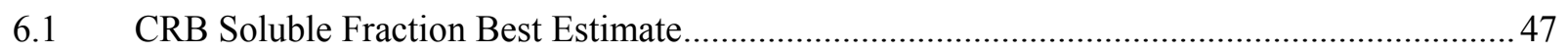

6.2 Rate Law Parameters Best Estimate and Chemical Reaction Network .................................48

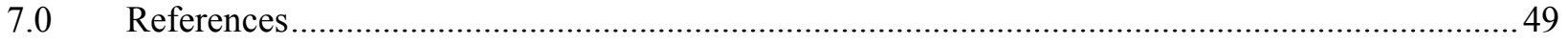

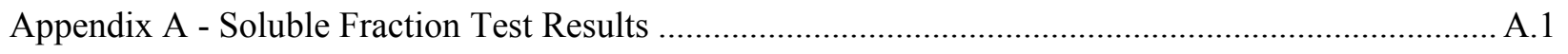

Appendix B - Single-Pass Flow-Through Test Results .................................................................. B. 1

Appendix C - Product Consistency Test Results ............................................................................. C.1 


\section{Figures}

1. Picture of Froth Layer Sample Removed From an FY03 Engineering-Scale Test.............................. 2

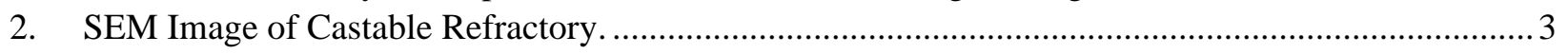

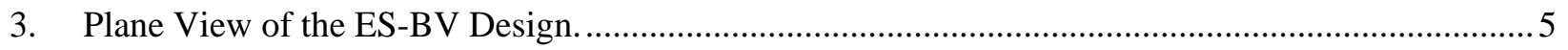

4. Schematic of the BV CRB Sampling Plan. All values shown in inches.......................................... 6

5. Photo of a Refractory Sample from ES-31A BV Waste Package .................................................. 8

6. Re Distribution as a Function of Depth for Sample EST-04-01. ...................................................... 8

7. Re Distribution as a Function of Depth for Thin Sections from ES-31B. ....................................... 12

8. Grey-Stone Tiles Applied to CRB Used for ES-31E Test. ........................................................... 15

9. Upper Portions of CRB with Partial Tile Removal................................................................... 18

10. Corner Section of Tiled CRB with Base at the Bottom of the Photograph....................................... 19

11. Schematic of the Single Pass Flow-Through (SPFT) Apparatus....................................................29

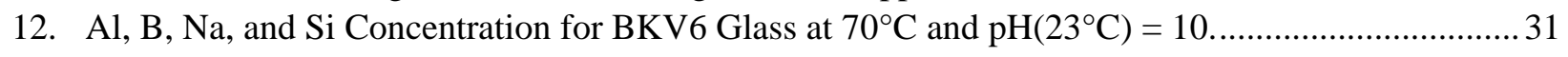

13. Dissolution Rate as a Function of Time for BKV6 Glass at $70^{\circ} \mathrm{C}$ and $\mathrm{pH}\left(23^{\circ} \mathrm{C}\right)=10 \ldots \ldots \ldots \ldots \ldots . . . . . . .31$

14. Na Dissolution Rate as a Function of pH and Temperature for BKV6 Glass.................................. 32

15. Na-IEX Rate Versus Reciprocal of Temperature for BKV6 Glass.................................................. 33

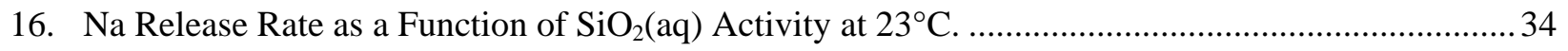

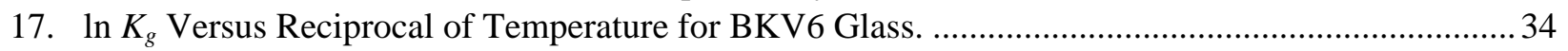

18. SEM of the Glass/CRB Interface, Sample Taken from ES-31A. .................................................... 35

19. XRD Results of the Castable Refractory Block............................................................................ 35

20. Normalized Si Dissolution Rate as a Function of $\mathrm{pH}$ and Temperature for

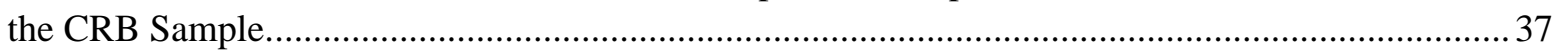

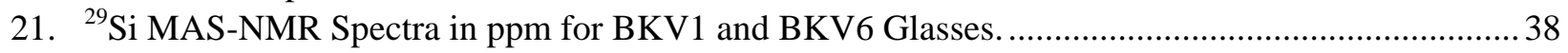

22. ${ }^{11}$ B MAS-NMR Spectra in ppm for BKV1 and BKV6 Glasses.................................................... 38

23. Comparison of the Normalized Release Rates as a Function of $\mathrm{pH}$ and Temperature for BKV6 Glass and the FY03 Glass Samples Tested. ............................................. 39

24. Comparison of $\ln K_{g}$ as a Function of Temperature for BKV6 Glass and

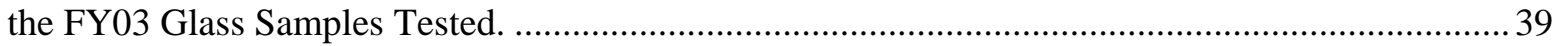

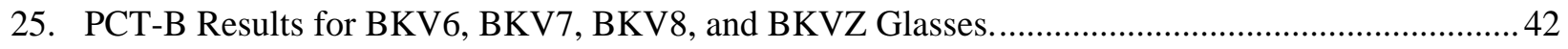

26. SEM Results of the Reacted BKV6 Glass After $100 \mathrm{~d}$ PCT Test in Comparison to BKV1 Glass After 398 Days of Testing.

27. Comparison of Solution Concentration Data with the Solution Composition Calculated with the EQ3/6 Code .

28. Predicted Paragenetic Sequence of Alteration Phases Formed During Reaction of BKV6 Glass in Deionized Water. 


\section{Tables}

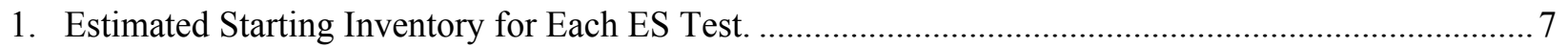

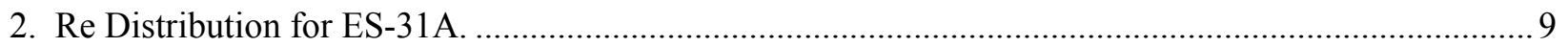

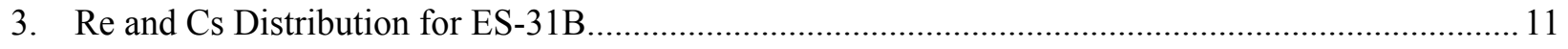

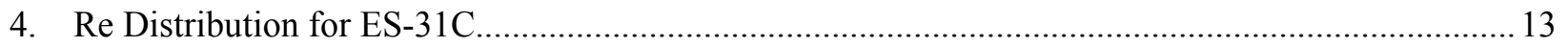

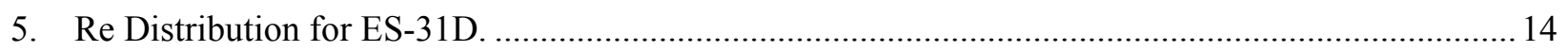

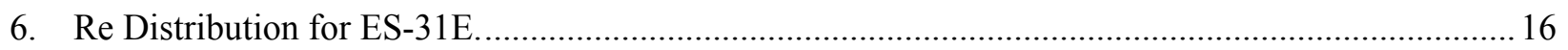

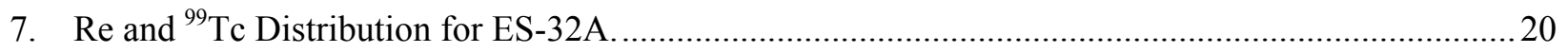

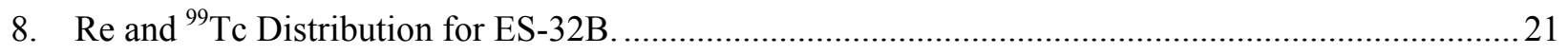

9. Summary of ES Soluble Fraction Test Results and the Estimated ${ }^{99} \mathrm{Tc} / \mathrm{Re}$ Volatilization Ratio.........23

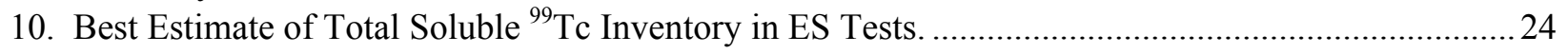

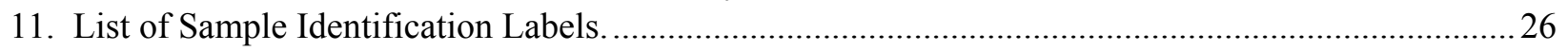

12. Calculated Thermal Cool-Down Schedule for Crucible Melt Samples BKV6 and BKV1.................26

13. Normalized Chemical Composition of Bulk Vitrified Glass Samples..............................................27

14. Solution Composition of Solutions Used in SPFT Experiments ......................................................28

15. Estimate of the Pseudo-Equilibrium Constants for BKV6 Glass as a Function of Temperature......... 34

16. Thermodynamic Data Used for Calculating the Mullite CRB Solubility Product at $15^{\circ} \mathrm{C}$................. 36

17. Summary of Best Estimate Rate Law Parameters for BV Glasses at $15^{\circ} \mathrm{C}$......................................40

18. Secondary Phase Reaction Network for BKV6 Glass. ............................................................... 44

19. Summary of Best Estimate Rate Law Parameters for BV Glasses, Castable Refractory,

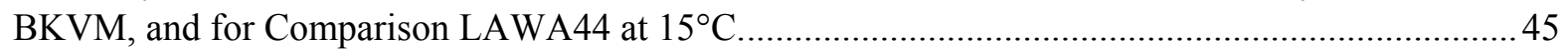

20. Summary Table of the Soluble Fraction Results for each ES Test. .................................................46

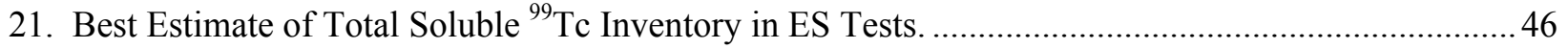




\subsection{Introduction}

The purpose of this report is to document the results from laboratory testing of the bulk vitrified (BV) waste form that was conducted in support of the 2005 integrated disposal facility (IDF) performance assessment (PA). Laboratory testing provides a majority of the key input data required to assess the longterm performance of the BV waste package with the STORM code. Test data from three principal methods, as described by McGrail et al. (2000a; 2003a), are discussed in this testing report including the single-pass flow-through test (SPFT) and product consistency test (PCT). Each of these test methods focuses on different aspects of the glass corrosion process. See McGrail et al. (2000a; 2003a) for additional details regarding these test methods and their use in evaluating long-term glass performance. In addition to evaluating the long-term glass performance, this report discusses the results and methods used to provided a recommended best estimate of the soluble fraction of ${ }^{99} \mathrm{Tc}$ that can be leached from the engineering-scale BV waste package. These laboratory tests are part of a continuum of testing that is aimed at improving the performance of the BV waste package.

The data contained in this report is discussed in three different sections. Section 1.0 of the report discusses the results of the soluble fraction of Re from five non-radioactive ES tests (ES-31A, ES-31B, ES-

31C, ES-31D, and ES-31E), one test using a ${ }^{99}$ Tc spike (ES-32A), and one test using actual Hanford tank waste (ES-32B). Soluble ${ }^{99}$ Tc was determined for ES-32A and ES-32B and soluble Cs was determined for ES-31B. Results obtained from these ES tests were used to develop a recommended best estimate of the soluble fraction of ${ }^{99} \mathrm{Tc}$ contained in the engineering-scale BV waste packages. Section 1.0 discusses data related to 1) kinetic rate law parameters for glass and refractory dissolution, 2) alkali ( $\left.\mathrm{Na}^{+}\right)$-hydrogen $\left(\mathrm{H}^{+}\right)$ion exchange rate for glass, and 3) pseudo-equilibrium constant for glass. Product consistency tests results for several BV glass formulations are discussed in Section 4.0. These data were used to develop a chemical reaction network of secondary phases that form. A majority of the thermodynamic data used in this report were extracted from the thermodynamic database package shipped with the geochemical code EQ3/6, version 8.0 (Wolery 1992a).

\subsection{Background}

The accelerated cleanup mission at Hanford is a strategic initiative for acceleration of tank waste treatment by increasing the capacity of the Waste Treatment Plant (WTP) and using supplemental technologies for waste treatment and immobilization of as much as $70 \%$ of the low-activity waste (LAW) (DOE 2002). Three supplemental treatment technology options (bulk vitrification [BV], steam reformation [SR], and cementation or cast stone [CS]) were evaluated in 2003 for the immobilization of lowactivity tank waste. Detailed discussions of the preliminary risk assessment (RA) results are included in Mann et al. (2003). Upon completion of the 2003 RA, a decision was made to pursue a pilot-scale test and demonstration facility for BV treatment of selected Hanford low-activity waste (LAW). The test and demonstration facility is planned to be operational late in 2005, and will provide data to support a final decision on tank waste treatment. In support of the pilot-scale facility design and additional process demonstration, engineering-scale BV testing continued through 2004. The two main goals for BV testing in 2004 were to determine methods to 1) evaluate the deposition of soluble technetium $\left({ }^{99} \mathrm{Tc}\right)$ salts in the refractory portions of the BV waste package, and 2) test BV using tank waste at a scale deemed appropriate to demonstrate performance. 
Work in FY03 on engineering- and large-scale tests of the BV process suggested that approximately $0.3 \mathrm{wt} \%$ of the ${ }^{99} \mathrm{Tc}$ inventory in the waste stream would end up in a soluble form deposited in a vesicular glass layer located at the top of the BV melt. ${ }^{(a)}$ Additional analysis and extrapolation of the FY03 engineering- and large-scale test indicate that as much as $3 \mathrm{wt} \%$ of the ${ }^{99} \mathrm{Tc}$ inventory waste stream may have ended up in the sand insulation layer after vitrification. ${ }^{(\mathrm{b})}$ The FY03 RA results suggest that soluble Tc salt contained in the BV waste packages may create an initial ${ }^{99} \mathrm{Tc}$ concentration peak in the groundwater extracted from a 100-m down-gradient well (Mann et al. 2003) ${ }^{(\mathrm{c})}$. This peak is less than the regulatory limit but greater than the presently predicted baseline WTP glass performance, which shows an asymptotic rise to a constant release rate. Because of the desire by regulatory agencies to achieve essentially equivalent performance to WTP glass with supplemental treatment technologies, the BV process was modified in FY04 with the goal of reducing deposits of soluble ${ }^{99} \mathrm{Tc}$ salts in the waste package. These modifications included the addition of a mullite castable refractory block (Vibrocast 60 PC) (CRB) in place of a portion of the refractory sand layer and the use of a bottom-up melting technique which has eliminated the vesicular glass layer at the top. For additional details on the overall BV process, as well as the FY04 design changes see Thompson et al. (2004).

Technetium $\left({ }^{99} \mathrm{Tc}\right)$ and its chemical analog rhenium ( $\mathrm{Re})$ are volatile elements when in the +7 oxidation state and exposed to high temperatures, such as during vitrification processes (Darab and Smith 1996). Although glass temperatures in the $\mathrm{BV}$ process have not been measured, temperatures as high as $1500^{\circ} \mathrm{C}$ may be experienced in some portions of the melt. These high process temperatures are thought to drive volatilization of Tc-bearing salts from the glass melt and also from radiative heating of the waste feed prior to physical incorporation in the glass. The volatilized salts are subject to vaporphase condensation when they contact cooler surfaces. Characterization results on the vesicular glass layer found in FY03 test specimens,

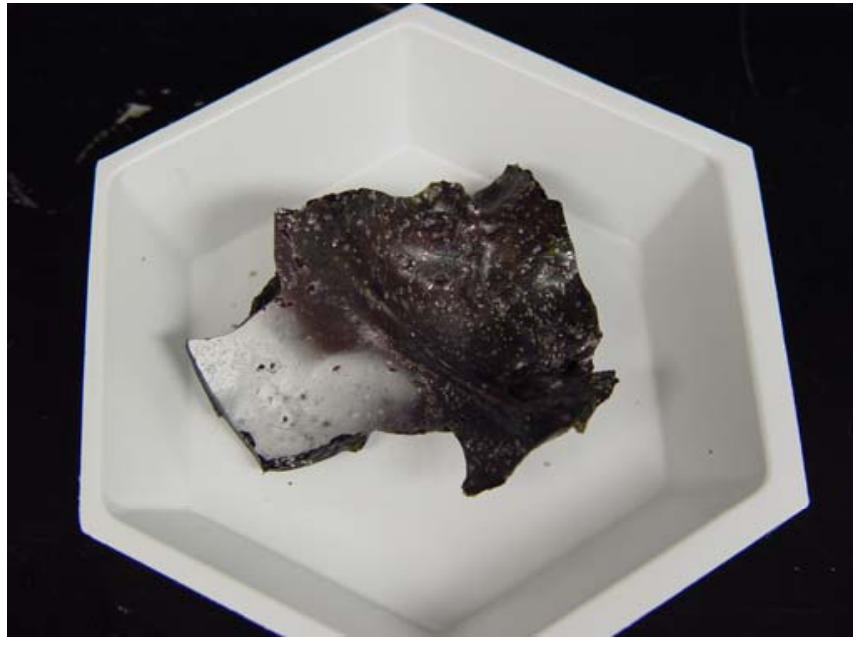

Figure 1. Froth Layer Sample Removed from an FY03 Engineering-Scale Test prior to altering the $\mathrm{BV}$ waste immobilization process, identified a white coating that is partially made up of $\mathrm{KReO}_{4}$ (see Figure 1). Although changing to a CRB from quartz sand in the new BV process significantly reduced the overall porosity and permeability of the insulation layer, the CRB is still porous and also has a much higher relative surface area (see Figure 2) as compared with quartz sand where volatilized rhenium (Re) and technetium $\left({ }^{99} \mathrm{Tc}\right.$ ) bearing soluble salts can condense. Although ${ }^{99} \mathrm{Tc}$ is assumed to volatilize, migrate, and condense in an analogous manner in the CRB forming a soluble $\mathrm{KTcO}_{4} \mathrm{salt}_{\text {, }}$ $\mathrm{KTcO}_{4}$ has not been positively identified as a discrete phase in the $\mathrm{BV}$ process.

(a) The lower value of $0.3 \mathrm{wt} \%$ of the waste stream ${ }^{99} \mathrm{Tc}$ was calculated from the mass of soluble rhenium (Re, chemical analogue for ${ }^{99} \mathrm{Tc}$ ) found in the vesicular glass layer from a non-radioactive large-scale BV test, adjusted for a measured volatilization ratio between ${ }^{99} \mathrm{Tc}$ and Re from engineering-scale testing (McGrail et al., $2003 \mathrm{~b}$ ).

(b) The higher value of $3 \mathrm{wt} \%$ is extrapolated from engineering-scale data where soluble ${ }^{99} \mathrm{Tc}$ and Re were measured in the refractory sand. Actual data for soluble Re in the refractory sand of the non-radioactive large-scale BV test were not available.

(c) The FY03 risk assessment used $0.3 \mathrm{wt} \%$ of the waste stream ${ }^{99} \mathrm{Tc}$. 


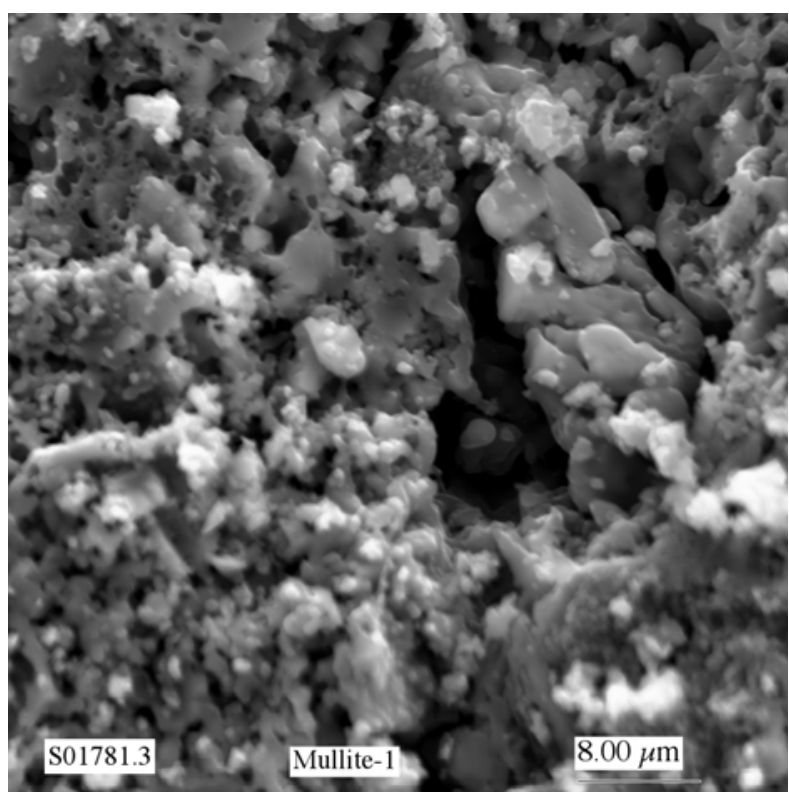

Figure 2. SEM Image of Castable Refractory. 


\subsection{Bulk Vitrification Soluble Fraction}

Bulk vitrification [AMEC Earth \& Environmental, Inc. (AMEC)] is a modification of the in-situ vitrification (ISV) process developed for remediation of buried wastes and contaminant plumes in soil (Luey and Seiler 1995; Tixier 1991). An in-container vitrification (ICV) process has been designed in which low-activity waste, soil, and glass-forming chemicals are mixed, dried, and then melted at approximately $1500^{\circ} \mathrm{C}$ by electrical resistance (Kim et al. 2003). Graphite flakes are added to the mix to form a conductive path for melt initiation. Electrical current is supplied by two graphite electrodes imbedded in the batch. After melt initiation, waste is gradually loaded in increments until the box is filled with waste glass. The current full-scale BV design uses steel containers that are 8 - $\mathrm{ft}$ (tall) $\times 8$-ft (high) $\times 24$ - $\mathrm{ft}$ (long), which is considerably larger than the engineering-scale (ES) design. Refractory material is used to insulate the steel container walls from the high-temperature glass melt. Starting at the glass/castable refractory block (CRB) interface and moving toward the outer wall of the steel container, the layers include a 15.2-cm (6-in.) cast refractory, 10.2-cm (4-in.) of quartz sand and a 5.1-cm (2-in.) layer of duraboard insulation. For a more detailed description see Sederburg and Thompson (2004).

To gather information on the full-scale BV configuration, $1 / 6^{\text {th }}$ linear scale ES tests were conducted. In these tests, the high-temperature glass melt was kept insulated from the steel container by lining the container walls with a 10.2-cm (4-in.) CRB, $5.1-\mathrm{cm}$ (2-in.) of quartz sand, and a 5.1-cm (2-in.) layer of duraboard insulation. The temperature condition for each test was monitored using thermocouples (T/C) that were distributed throughout the glass, cast refractory block, and sand portions of the BV waste package. Figure 3 is a schematic plan view of the engineered scale BV waste package configuration. The current technique of loading waste incrementally over time has eliminated the vesicular glass layer observed in previous BV waste package designs (McGrail et al. 2003b). Although the vesicular glass layer has been eliminated, the waste package cannot be represented by a single set of physical and chemical properties. The package is heterogeneous with complex interfaces. Therefore, the BV product is divided into four distinct components: 1) bulk glass, 2) mullite cast refractory, 3) sand layer, and 4) ICV box lid. Additional divisions could be assigned, but these four components are believed to adequately represent the most significant features of the final BV product. Sampling and analysis of condensed salts on the box lid was conducted by AMEC and is discussed in AMEC (2005a) and Kim et al. (2004).

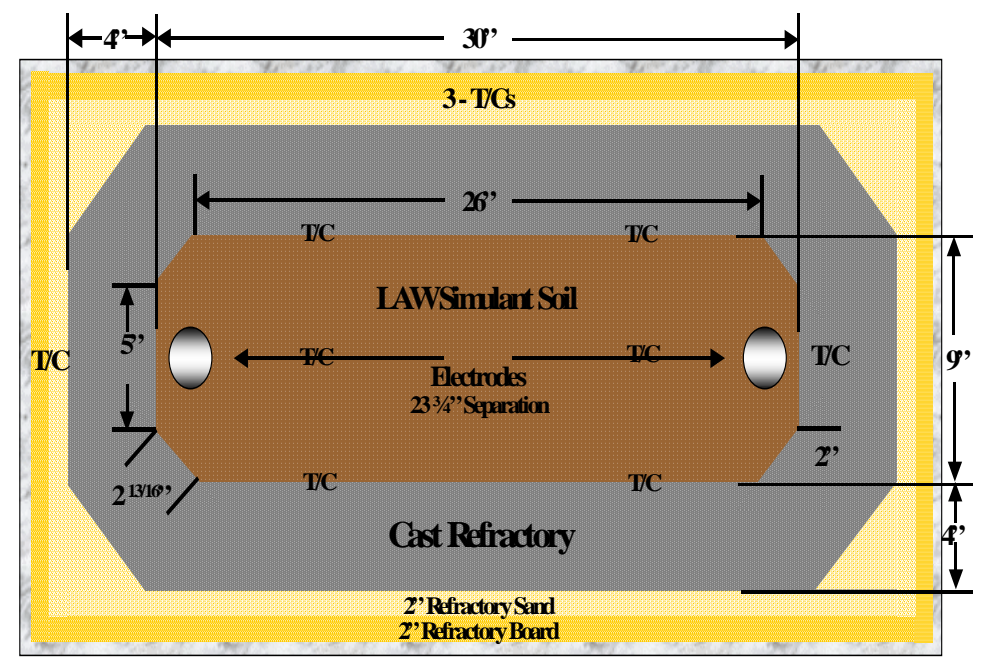

Figure 3. Plan View of the ES-BV Design (Sederburg and Thompson 2004). 


\subsection{Soluble Fraction Experimental Materials and Methods}

The techniques and procedures used to sample, analyze, calculate, and estimate the relative uncertainty associated with the soluble fraction of $\mathrm{Cs}$, Re, and ${ }^{99} \mathrm{Tc}$ contained in the CRB are described in Pierce et al. (2004a). To limit duplication, only a brief summary of these techniques are provided here. Note the sampling and analysis plan discussed below and in Pierce et al. (2004a) was not statistically designed. A grab sampling approach was used to remove representative samples of the five vertical depths, which were used to estimate the soluble fraction of Cs, Re, and ${ }^{99} \mathrm{Tc}$ in the CRB for each ES test.

Several samples of cast refractory were removed using an electric jackhammer and broken into the appropriate size for the equipment used in the extraction. The approximate sampling locations are illustrated in Figure 4. Each sample had an approximate height of $2 \mathrm{in}$. and penetrated through the full 4-in. thickness of the refractory wall. Figure 4 also illustrates that cast refractory was sampled at six points and five vertical depths ranging between 3 and 5 inches for a total of 30 samples. Note the six points represent the sample locations for each of the five vertical depths. In addition to these 30 samples, at least one additional sample was taken from the bottom of each engineeringscale (ES) test castable refractory block. Due to time and resource constraints, approximately 5 to 10 of the 31 samples were used in the extraction set.

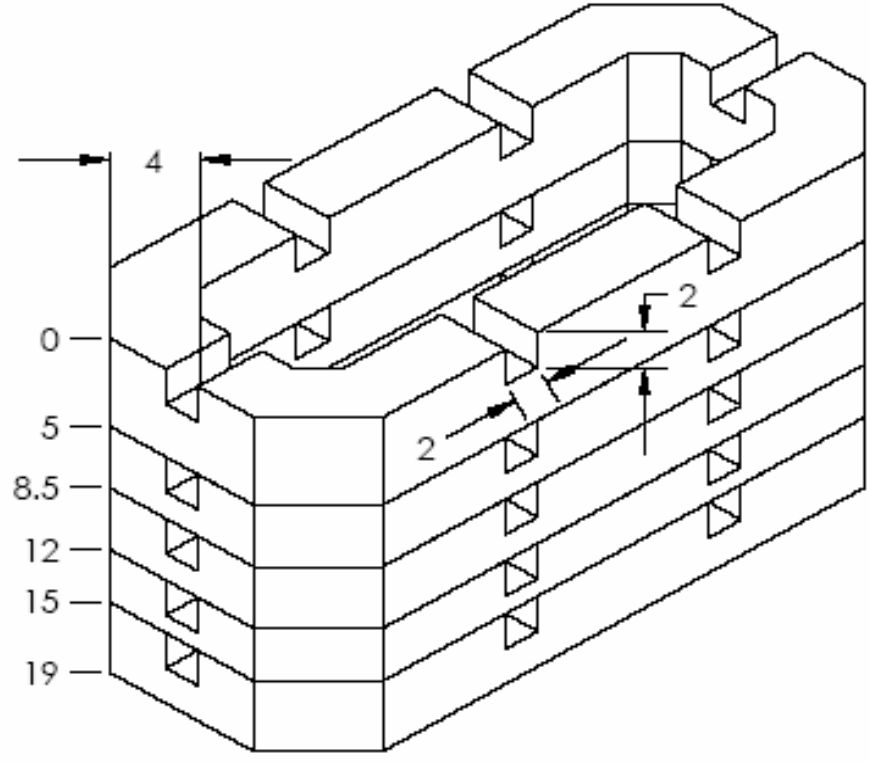

Figure 4. Schematic of the BV CRB Sampling Plan. All values shown in inches.

In general, each fragment of dry refractory material was weighed, placed into a known volume of leaching solution, and vacuum saturated at a pressure of $84.6-\mathrm{kPa}\left(12.3-\mathrm{lb} \mathrm{in} .^{-2}\right)$ for no less than four hours. Deionized water (DIW) was used as the leaching solution for ES-31 A and 0.001 M nitric acid $\left(\mathrm{HNO}_{3}\right)$ as an extraction solution for all other ES tests. After saturating each sample, an aliquot of the saturation solution was removed for analysis. The sample fragment was lifted out of the saturation solution and allowed to drip dry so there was no free liquid. As part of the second step in the extraction, the refractory sample was spun between 2000 and 5000 revolutions per minute (rpm) in a centrifuge for one hour to release non-gravity drainable pore liquid. A sample of the centrifuge-extracted liquid was collected for each fragment. The two-part extraction process (saturation and centrifugation) was repeated until the majority of the soluble $\mathrm{Cs}, \mathrm{Re}$, and/or ${ }^{99} \mathrm{Tc}$ was leached from each sample, typically accomplished with five consecutive two part extractions. ${ }^{\text {(a) }}$ The solution composition from each extract was determined by analyzing for $\mathrm{Cs}, \mathrm{Re}$, and ${ }^{99} \mathrm{Tc}$ via inductively-coupled plasma-mass spectrometry (ICP-MS).

(a) Unpublished results from a scoping test using a $50 \mathrm{ppb}$ Re stock solution showed that $>80 \%$ of the total extractable Re was removed after three consecutive extractions. 


\subsection{Soluble Fraction Results and Discussion}

Seven engineering-scale tests were conducted in late FY04 and early FY05. The objective of three of the tests: ES-31A, $-31 \mathrm{~B}$, and $-32 \mathrm{~A}$, was to determine whether modifications to the BV process minimized the leachable fraction of $\mathrm{Cs}, \mathrm{Re}$, and/or ${ }^{99} \mathrm{Tc}$ contained in the BV waste package compared to FY03. In addition to evaluating these process modifications, ES-31A, $-31 \mathrm{~B}$, and $32 \mathrm{~A}$ were also used to evaluate refractory glaze, a calcium-fluoride glass mixture (RX-14), to minimize Re and/or ${ }^{99} \mathrm{Tc}$ penetration into the CRB. Therefore, RX-14 refractory glaze was placed on the inner surfaces of the CRB. Although these tests illustrated a reduction in the soluble fraction of Re and/or ${ }^{99} \mathrm{Tc}$ compared to results from FY03, it was clear that further improvements were possible. Therefore, three additional tests; ES-31C, $-31 \mathrm{D}$, and $-31 \mathrm{E}$, were conducted to evaluate alternative approaches to minimizing the amount of soluble Re in the BV waste package. These alternative approaches included the use of refractory glazes (Ferro-Frit 3225 and sodium silicate), a simulated denitrated feed that contained reduced $\operatorname{Re}$ (e.g., $\operatorname{Re}(\mathrm{IV})$ instead of $\mathrm{Re}(\mathrm{VII})$ oxidation state), and refractory tiles. One additional engineering-scale test, ES-32B (ES-13) was conducted to evaluate the performance of the BV process using actual Hanford tank waste.

Before presenting these results, it is important to note the starting inventory and background concentration for each contaminant of concern (Cs, Re [chemical analogue for ${ }^{99} \mathrm{Tc}$ ], and ${ }^{99} \mathrm{Tc}$ ). The estimated total inventories for each ES tests are provided in Table 1.

For additional information on the simulant and spike concentrations see Kim et al. (2004) for ES31A, -31B, and -32A, Bagaasen et al. (2004) for ES-32B, and AMEC (AMEC 2005b) for ES-31C, -31D, and -31E. The background concentration of soluble Re present in the CRB prior to being used in the BV process was determined using the extraction technique discussed in Pierce et al. (2004a). The measured concentration was $1.7 \pm 0.1 \times 10^{-10}$ gram of Re per gram of refractory, based on one sample of untreated refractory. Assuming a 300-kg mass of refractory, the mass of soluble Re in the CRB is estimated to be $5.0 \times 10^{-5} \mathrm{~g}$, which is less than $0.02 \%$ of the lowest Re spike level, indicating that background corrections were not necessary. Four additional refractory samples from an AMEC starter path test that contained no Re-spike also were extracted. These samples had Re concentrations that were one to two orders of magnitude higher, on a gram-per-gram basis, than the background concentration measured on the untreated refractory. The discrepancy in background concentration could be the result of residual Re present in the

Table 1. Estimated Starting Inventory for Each ES Test.

\begin{tabular}{|c|c|c|c|c|c|}
\hline \multirow[b]{2}{*}{ AMEC ID } & \multirow[b]{2}{*}{ PNNL ID } & \multirow[b]{2}{*}{ Test ID } & \multicolumn{3}{|c|}{$\begin{array}{c}\text { Estimated Starting } \\
\text { Inventory (g) }\end{array}$} \\
\hline & & & $\operatorname{Re}$ & Cs & ${ }^{99} \mathrm{Tc}$ \\
\hline ES-10 & ${ }^{\mathrm{a}} \mathrm{ES}-31 \mathrm{~A}$ & EST-04 thru 06 & 7.7151 & - & - \\
\hline ES-11 & ${ }^{\mathrm{a}} \mathrm{ES}-31 \mathrm{~B}$ & EST-07 thru -09 & 0.4126 & 0.2600 & \\
\hline \multirow[t]{4}{*}{ ES-12 } & ${ }^{\mathrm{a}} \mathrm{ES}-32 \mathrm{~A}$ & EST-10 & 7.5103 & - & 0.3816 \\
\hline & ${ }^{\mathrm{b}} \mathrm{ES}-31 \mathrm{C}$ & EST-11 and -12 & 0.7956 & - & - \\
\hline & ${ }^{\mathrm{b}} \mathrm{ES}-31 \mathrm{D}$ & EST-13 and -14 & 0.7909 & - & - \\
\hline & ${ }^{\mathrm{b}} \mathrm{ES}-31 \mathrm{E}$ & EST-17 and -18 & 0.7632 & - & - \\
\hline ES-13 & ${ }^{\mathrm{c}} \mathrm{ES}-32 \mathrm{~B}$ & ES-15 and -16 & 0.7093 & - & 0.4295 \\
\hline $\begin{array}{l}{ }^{\mathrm{a}} \mathrm{Kim} \text { et al. (2 } \\
\text { b. } \\
{ }^{\mathrm{b}} \text { AMEC (200 } \\
{ }^{\circ} \text { Bagaasen et }\end{array}$ & $\begin{array}{l}504) \\
\text { b) } \\
\text { al. (2004) }\end{array}$ & & & & \\
\hline
\end{tabular}


equipment used for previous Re-spiked ES BV tests or starter path material, although more samples are needed for confirmation. Unlike Re, $\mathrm{Cs}$ and ${ }^{99} \mathrm{Tc}$ were determined to be below the detection threshold. The detection threshold of any element is defined here as the lowest calibration standard that can be determined reproducibly during an analytical run within $10 \%$ multiplied by the sample dilution factor.

Based on the Re results from the untreated refractory and the potential uncertainty associated with samples from the starter path test, a conservative approach was adopted and no background corrections were made to the data presented in this report. Results from each ES test are discussed in the following sections, starting with the ES-31 series and concluding with the ES-32 series.

\subsubsection{ES-31A Soluble Fraction Results}

Fourteen samples of the cast refractory from the ES-31A test were used to determine the percentage of spiked Re that deposits in a water-soluble form in the refractory block. Each sample was fractured into fragments: water saturated, and extracted using the techniques described in Pierce et al. (2004a).

Figure 5 shows a photo of an ES-31A sample, EST-04-01, collected from the back quarter of the refractory near the box lid exhaust and electrode. This sample was broken into five individual fragments, corresponding to the entire $4 \mathrm{in}$. thickness of the refractory block from the glass-refractory interface to the sand-refractory interface. A plot of the specific mass of Re extracted from each fragment illustrates the Re concentration decreases by several orders of magnitude with increasing distance away from the glass melt (Figure 6). These results suggest that the majority of Re is depositing within the first inch of depth beyond the mullite/glass interface.

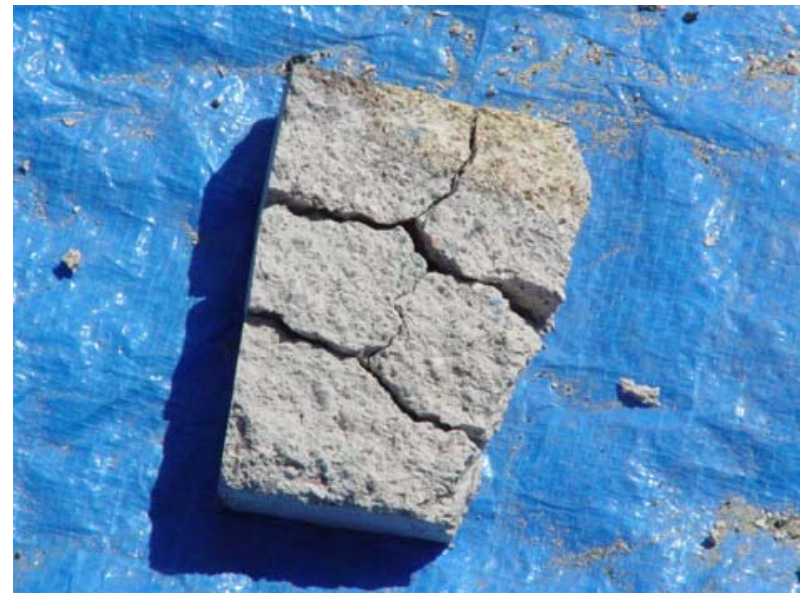

Figure 5. Refractory Sample from ES-31A BV

Waste Package. Glass/refractory interface is at the top.

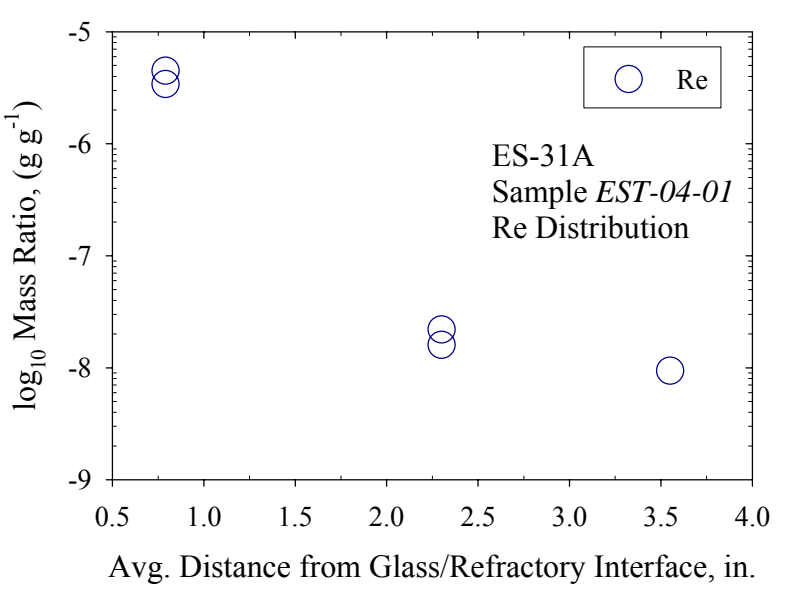

Figure 6. Re Distribution as a Function of Depth for Sample EST-04-01.

The extracted Re mass for each fragment was summed and then divided by the total mass of the refractory sample to determine the mass fraction of soluble Re in the entire refractory sample. Table 2 shows the percent of the total Re in the test system that was extractable from each of the five sections in the ES-31A refractory block. Table 2 also shows individual sample locations in X, Y, Z space taken from the $k^{\text {th }}$ section, depth of each $k^{\text {th }}$ section $\left(\mathrm{H}_{\mathrm{k}}\right)$, and leachable concentration in gram of Re per gram of refractory for the individual samples $\left(\beta_{\mathrm{i}, \mathrm{k}, \mathrm{p}}\right)$ and the average of all the samples taken at a given height $\left(\beta_{\mathrm{i}, \mathrm{k}}\right)$. 
Table 2. Re Distribution for ES-31A.

\begin{tabular}{|c|c|c|c|c|c|c|c|}
\hline \multicolumn{5}{|c|}{ Section \#1, 0 to 5 in. from the top } & \multicolumn{3}{|c|}{$\mathbf{R e}$} \\
\hline Sample ID & $\mathrm{X}$, in & $\mathrm{Y}$, in & $\mathrm{Z}$, in & $\mathrm{H}_{\mathrm{k}}$, in. & ${ }^{\mathrm{a}} \beta_{\mathrm{i} \_\mathrm{k} p}$ & & \\
\hline EST-04-01 & 8 & 2 & 0 & 5 & $1.87 \mathrm{E}-06$ & & \\
\hline EST-05-01 & 8 & 15 & 0 & 5 & $3.23 \mathrm{E}-07$ & & \\
\hline \multirow[t]{3}{*}{ EST-06-04 } & 28 & 15 & 0 & 5 & $1.25 \mathrm{E}-07$ & & \\
\hline & & & & & ${ }^{\mathrm{a}} \beta_{-} \mathrm{i}_{\mathrm{k}} \mathrm{k}$ & ${ }^{\mathrm{b}} f_{-\mathrm{i} \_\mathrm{k}}$ & ${ }^{\mathrm{b}} \sigma_{f_{-} \_\_}$ \\
\hline & & & & & $7.73 \mathrm{E}-07$ & $0.838 \%$ & $\pm 0.130 \%$ \\
\hline \multicolumn{5}{|c|}{ Section \#2, 5 to 8.5 in. from the top } & \multicolumn{3}{|c|}{$\mathbf{R e}$} \\
\hline Sample ID & $\mathrm{X}$, in & $\mathrm{Y}$, in & $\mathrm{Z}$, in & $\mathrm{H}_{\mathrm{k}}$, in. & $\beta_{i \_k \_p}$ & & \\
\hline EST-04-02 & 8 & 2 & 5 & 3.5 & $1.09 \mathrm{E}-06$ & & \\
\hline \multirow[t]{3}{*}{ EST-05-02 } & 8 & 15 & 5 & 3.5 & 6.99E-08 & & \\
\hline & & & & & $\bar{\beta} \beta_{\mathrm{i} i \mathrm{k}}$ & $\overline{f f_{\mathrm{i} i \mathrm{k}}}$ & 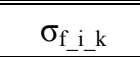 \\
\hline & & & & & $5.78 \mathrm{E}-07$ & $0.439 \%$ & $\pm 0.073 \%$ \\
\hline \multicolumn{5}{|c|}{ Section \#3, 8.5 to 12 in. from the top } & \multicolumn{3}{|c|}{$\overline{\operatorname{Re}}$} \\
\hline Sample ID & $\mathrm{X}$, in & $\mathrm{Y}$, in & $\mathrm{Z}$, in & $\mathrm{H}_{\mathrm{k}}$, in. & $\beta_{\mathrm{i} \_\mathrm{k} \_\mathrm{p}}$ & & \\
\hline EST-04-05 & 8 & 2 & 9 & 3.5 & $1.81 \mathrm{E}-07$ & & \\
\hline EST-04-09 & 0 & 2 & 9 & 3.5 & $1.06 \mathrm{E}-07$ & & \\
\hline EST-04-10 & 19 & 2 & 9 & 3.5 & $1.37 \mathrm{E}-07$ & & \\
\hline \multirow[t]{3}{*}{ EST-06-03 } & 28 & 2 & 9 & 3.5 & $2.42 \mathrm{E}-07$ & & \\
\hline & & & & & $\beta_{\text {i } \_\mathrm{k}}$ & $f_{\mathrm{i}_{\mathrm{i}} \mathrm{k}}$ & $\overline{\sigma_{\mathrm{f}} \mathrm{i} \_\mathrm{k}}$ \\
\hline & & & & & $1.67 \mathrm{E}-07$ & $0.126 \%$ & $\pm 0.020 \%$ \\
\hline \multicolumn{5}{|c|}{ Section \#4, 12 to 15 in. from the top } & \multicolumn{3}{|c|}{$\mathbf{R e}$} \\
\hline Sample ID & $\mathrm{X}$, in & $\mathrm{Y}$, in & $\mathrm{Z}$, in & $\mathrm{H}_{\mathrm{k}}$, in. & $\beta_{-} i_{-} k_{-} \mathrm{p}$ & & \\
\hline EST-04-06 & 8 & 2 & 12 & 3 & $2.16 \mathrm{E}-07$ & & \\
\hline EST-05-03 & 8 & 15 & 14 & 3 & $1.02 \mathrm{E}-07$ & & \\
\hline \multirow[t]{3}{*}{ EST-06-02 } & 28 & 2 & 15 & 3 & $1.77 \mathrm{E}-07$ & & \\
\hline & & & & & $\beta_{\_} \mathrm{i} \_\mathrm{k}$ & $f_{-\mathrm{i} \_\mathrm{k}}$ & $\sigma_{f_{-}{ }_{i} k}$ \\
\hline & & & & & $1.65 \mathrm{E}-07$ & $0.107 \%$ & $\pm 0.017 \%$ \\
\hline \multicolumn{5}{|c|}{ Section \#5, Refractory Base } & \multicolumn{3}{|c|}{$\mathbf{R e}$} \\
\hline Sample ID & $\mathrm{X}$, in & $\mathrm{Y}$, in & $Z$, in & $\mathrm{H}_{\mathrm{k}}$, in. & $\beta_{-} i_{-} \_p$ & & \\
\hline EST-04-07 & 8 & 2 & 17 & 4 & $1.95 \mathrm{E}-09$ & & \\
\hline \multirow[t]{4}{*}{ EST-06-01 } & 28 & 2 & 17 & 4 & $1.20 \mathrm{E}-08$ & & \\
\hline & & & & & $\beta_{-} i_{i} \mathrm{k}$ & $f_{A_{i} \mathrm{k}}$ & $\sigma_{f_{-}{ }_{i} k}$ \\
\hline & & & & & $6.98 \mathrm{E}-09$ & $0.005 \%$ & $\pm 0.001 \%$ \\
\hline & & & & & Total & $1.514 \%$ & $\pm 0.538 \%$ \\
\hline
\end{tabular}

The $\mathrm{X}$ dimension is the length along the long refractory wall with the origin located at the exhaust side of the box lid. The $\mathrm{Y}$ dimension is the length along the short refractory wall with the origin located at the front of the CRB. The $\mathrm{Z}$ dimension is the length down the refractory wall with the origin located at the top of the CRB. Applying the soluble fraction and error calculations as described in Pierce et al., (2004a) and using a total Re test inventory of $7.72 \mathrm{~g}$, the soluble Re fraction $\left(f_{i, k}\right)$ present at each height is reported and added over the entire $\mathrm{CRB}$ to give a total soluble $\mathrm{Re}$ fraction of $1.51 \pm 0.54 \%$. Additional chemical analysis of the extraction solutions, using inductively coupled plasma optical emission spectroscopy (ICP-OES), illustrates that the major dissolved components were $\mathrm{Al}, \mathrm{Ca}, \mathrm{Na}$, and $\mathrm{S}$, with lesser 
amounts of B, Li, K, and $\mathrm{Si}$. The results shown in Table 2 indicate that approximately $84 \%$ of the soluble Re is contained in the upper two sections of the refractory block. This combined with the results shown in Figure 6 and the ICP-OES analysis of the extraction solutions suggest that Re transport occurs from vaporization/condensation of a salt.

To determine the soluble Re contained in the refractory sand from ES-31A, approximately $50 \%$ of the sand was removed, placed into a 55-gallon drum, mixed with deionized water (DIW), and leached for several days. At the end of the leaching time, a sample of the leachate solution was removed, filtered, and analyzed for Re using ICP-MS. The results show that the soluble fraction of Re contained in the sand for this test was $0.0032 \pm 0.0005 \%$ of the total Re in the test. Engineering-scale tests ES-32A and $-32 \mathrm{~B}$ sand extractions and analyses were conducted by AMEC and are discussed in AMEC (2005a) and Kim et al. (2004).

\subsubsection{ES-31B Soluble Fraction Results}

The main objective for the ES-31B test was to obtain data on processing a simulated waste composition for tank S-109 (Mahoney and Rassat 2003) which will be used as the waste feed for Demonstration Bulk Vitrification System (DBVS) operations. Therefore, early data at engineering-scale was necessary to help ensure the characteristics of tank S-109 waste did not result in unforeseen processing concerns. Additional details are provided in Sederburg and Thompson (2004). In comparison, the total Re inventory in this test was approximately 18 times less than the inventory for ES-31A and -32A (Table 1). Twenty-four refractory samples were used to determine the soluble fraction of $\mathrm{Re}$ and Cs.

The results in Table 3 show that the soluble fraction of Re in ES-31B was a factor of two lower than in ES-31A. Using the techniques described in Pierce et al., (2004a), the soluble fractions of Re and Cs were determined to be $0.77 \pm 0.27 \%$ and $0.084 \pm 0.029 \%$, respectively. The results also suggest that $\operatorname{Re}$ is more evenly distributed along refractory wall sections, with a decrease in the Re concentration at the base that is different than the distribution seen in ES-31A. Although it is unclear, process differences that occurred during ES-31A and ES-31B melts such as the loss of electrodes, feed rate differences, gas bubbles, and soil caps, could contribute to differences in the results. It should also be noted that Re distribution in these tests is estimated using samples that comprised less than $2.8 \%$ of the refractory mass.

One additional sample in the ES-31B test was used to assess the Re penetration depth. This sample was sectioned (without water cooling) along the y-axis into five individual pieces ( 0.7 -in. thick) using a miter saw with a 0.1 -in. thick diamond tip cutting blade. The extraction results are shown in Figure 6. These results are similar to those shown in Figure 5 for ES-31A. The dilute nitric acid-leachable Re concentration decreases by more than an order of magnitude with increasing distance away from the glass melt (Figure 6). No results were obtained for the outermost sample because extractions of that sample did not produce enough extract for analysis. 
Table 3. Re and Cs Distribution for ES-31B.

\begin{tabular}{|c|c|c|c|c|c|c|c|c|c|c|}
\hline \multicolumn{5}{|c|}{ Section \#1, 0 to 4 in. from the top } & \multicolumn{3}{|c|}{$\mathbf{R e}$} & \multicolumn{3}{|c|}{ Cs } \\
\hline Sample ID & $\mathrm{X}$, in & $\mathrm{Y}$, in & $\mathrm{Z}$, in & $\mathrm{H}_{\mathrm{k}}$, in. & ${ }^{\mathrm{a}} \beta_{-} \mathrm{i}_{\mathrm{k} \_p}$ & & & $\beta_{\_} \mathrm{i} \_\_p$ & & \\
\hline EST-07-01 & 8 & 2 & 2 & 4 & $1.34 \mathrm{E}-08$ & & & 4.76E-10 & & \\
\hline EST-08-01 & 8 & 15 & 2 & 4 & $1.11 \mathrm{E}-08$ & & & $8.66 \mathrm{E}-10$ & & \\
\hline EST-07-05-1 & 2 & 5 & 2 & 4 & $1.77 \mathrm{E}-08$ & & & $1.65 \mathrm{E}-09$ & & \\
\hline EST-07-05-3 & 2 & 6 & 2 & 4 & 7.31E-09 & & & 4.32E-10 & & \\
\hline EST-08-05 & 2 & 12 & 2 & 4 & $2.13 \mathrm{E}-08$ & & & $5.60 \mathrm{E}-10$ & & \\
\hline \multirow[t]{3}{*}{ EST-09-01 } & 28 & 2 & 2 & 4 & 8.83E-09 & & & $1.94 \mathrm{E}-10$ & & \\
\hline & & & & & ${ }^{\mathrm{a}} \beta_{\_} \mathrm{i}$ k & 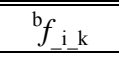 & ${ }^{\mathrm{b}} \mathrm{\sigma}_{\mathrm{f} \_\mathrm{i} \_\mathrm{k}}$ & $\beta_{\text {_i } k}$ & 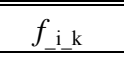 & $\overline{\sigma_{\mathrm{f} \_\mathrm{i} \_\mathrm{k}}}$ \\
\hline & & & & & $1.33 \mathrm{E}-08$ & $0.215 \%$ & $\pm 0.033 \%$ & $6.96 \mathrm{E}-10$ & $0.018 \%$ & $\pm 0.003 \%$ \\
\hline \multicolumn{5}{|c|}{ Section \#2, 4 to 8 in. from the top } & \multicolumn{3}{|c|}{$\mathbf{R e}$} & \multicolumn{3}{|c|}{ Cs } \\
\hline Sample ID & $\mathrm{X}$, in & $Y$, in & $\mathrm{Z}$, in & $\mathrm{H}_{\mathrm{k}}$, in. & 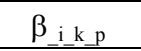 & & & $\beta_{\text {i } \_\_p}$ & & \\
\hline EST-07-02 & 8 & 2 & 6 & 4 & 7.11E-09 & & & $1.93 \mathrm{E}-10$ & & \\
\hline EST-08-02 & 8 & 15 & 6 & 4 & $1.02 \mathrm{E}-08$ & & & $1.26 \mathrm{E}-10$ & & \\
\hline EST-07-06 & 2 & 5 & 6 & 4 & $1.19 \mathrm{E}-08$ & & & $2.75 \mathrm{E}-10$ & & \\
\hline EST-08-06-01 & 2 & 12 & 6 & 4 & $1.07 \mathrm{E}-08$ & & & $2.52 \mathrm{E}-10$ & & \\
\hline EST-08-06-02 & 4 & 13 & 6 & 4 & 5.89E-09 & & & $7.81 \mathrm{E}-11$ & & \\
\hline \multirow[t]{3}{*}{ EST-09-02 } & 28 & 2 & 6 & 4 & $8.82 \mathrm{E}-09$ & & & $6.24 \mathrm{E}-10$ & & \\
\hline & & & & & $\beta_{\mathrm{i} i \mathrm{k}}$ & $f_{\text {i } \mathrm{i} k}$ & $\sigma_{\mathrm{f}_{\mathrm{f} i \mathrm{k}}}$ & $\beta_{\mathrm{i} i \mathrm{k}}$ & $f_{\text {i } i k}$ & $\sigma_{f_{\text {fi }} k}$ \\
\hline & & & & & $9.10 \mathrm{E}-09$ & $0.147 \%$ & $\pm 0.023 \%$ & $2.58 \mathrm{E}-10$ & $0.007 \%$ & $\pm 0.001 \%$ \\
\hline \multicolumn{5}{|c|}{ Section \#3, 8 to 13 in. from the top } & \multicolumn{3}{|c|}{$\mathbf{R e}$} & \multicolumn{3}{|c|}{ Cs } \\
\hline Sample ID & $\mathrm{X}$, in & $\mathrm{Y}$, in & $Z$, in & $\mathrm{H}_{\mathrm{k}}$, in. & $\beta_{\text {i_k_p }}$ & & & $\beta_{\text {i_k_p }}$ & & \\
\hline EST-07-03 & 8 & 2 & 10.5 & 5 & $1.17 \mathrm{E}-08$ & & & $9.00 \mathrm{E}-10$ & & \\
\hline EST-08-03 & 8 & 15 & 10.5 & 5 & $1.82 \mathrm{E}-08$ & & & 1.17E-09 & & \\
\hline EST-08-07 & 2 & 12 & 10.5 & 5 & $1.95 \mathrm{E}-08$ & & & $1.48 \mathrm{E}-10$ & & \\
\hline \multirow[t]{3}{*}{ EST-09-03 } & 28 & 2 & 10.5 & 5 & $9.67 \mathrm{E}-09$ & & & $9.69 \mathrm{E}-10$ & & \\
\hline & & & & & $\bar{\beta} \beta_{\mathrm{i} i \mathrm{k}}$ & $f_{\mathrm{i} i \mathrm{k}}$ & 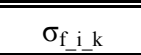 & $\bar{\beta} \beta_{\mathrm{i} i \mathrm{k}}$ & 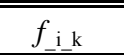 & 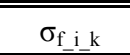 \\
\hline & & & & & $1.48 \mathrm{E}-08$ & $0.300 \%$ & $\pm 0.046 \%$ & $7.98 \mathrm{E}-10$ & $0.026 \%$ & $\pm 0.004 \%$ \\
\hline \multicolumn{5}{|c|}{ Section $\# 4,13$ to 15 in. from the top } & \multicolumn{3}{|c|}{$\mathbf{R e}$} & \multicolumn{3}{|c|}{ Cs } \\
\hline Sample ID & $\mathrm{X}$, in & $\mathrm{Y}$, in & $Z$, in & $\mathrm{H}_{\mathrm{k}}$, in & $\beta_{i \text { ik } p p}$ & & & $\beta_{\text {i k } \_p}$ & & \\
\hline EST-07-04 & 8 & 2 & 14 & 2 & $8.41 \mathrm{E}-09$ & & & $7.14 \mathrm{E}-10$ & & \\
\hline EST-07-08 & 2 & 5 & 14 & 2 & $9.41 \mathrm{E}-09$ & & & $9.17 \mathrm{E}-10$ & & \\
\hline EST-08-04 & 8 & 15 & 14 & 2 & $3.37 \mathrm{E}-09$ & & & $8.83 \mathrm{E}-10$ & & \\
\hline EST-08-08 & 2 & 12 & 14 & 2 & 2.52E-08 & & & $2.85 \mathrm{E}-10$ & & \\
\hline \multirow[t]{3}{*}{ EST-09-04 } & 28 & 2 & 14 & 2 & $6.65 \mathrm{E}-09$ & & & $8.12 \mathrm{E}-10$ & & \\
\hline & & & & & $\beta_{i} i_{-} k$ & $f_{-i \_k}$ & $\sigma_{\mathrm{f} \_\mathrm{i} \_\mathrm{k}}$ & $\beta_{\text {_ i } k}$ & $f_{\mathrm{i} \_\mathrm{k}}$ & $\sigma_{\mathrm{f} \_\mathrm{i} \_}$ \\
\hline & & & & & $1.06 \mathrm{E}-08$ & $0.086 \%$ & $\pm 0.013 \%$ & $7.22 \mathrm{E}-10$ & $0.009 \%$ & $\pm 0.001 \%$ \\
\hline \multicolumn{5}{|c|}{ Section \#5, Refractory Base } & \multicolumn{3}{|c|}{$\mathbf{R e}$} & \multicolumn{3}{|c|}{ Cs } \\
\hline Sample ID & $\mathrm{X}$, in & $\mathrm{Y}$, in & $\mathrm{Z}$, in & $\mathrm{H}_{\mathrm{k}}$, in & $\beta_{i \mathrm{i} k \mathrm{p}}$ & & & $\beta_{\text {i } \_\_p}$ & & \\
\hline EST-07-09 & 8 & 2 & 17 & 4 & $3.50 \mathrm{E}-09$ & & & $1.35 \mathrm{E}-09$ & & \\
\hline EST-08-09 & 8 & 15 & 17 & 4 & $1.50 \mathrm{E}-09$ & & & $1.11 \mathrm{E}-09$ & & \\
\hline \multirow[t]{3}{*}{ EST-09-05 } & 28 & 2 & 17 & 4 & $7.17 \mathrm{E}-10$ & & & $1.38 \mathrm{E}-09$ & & \\
\hline & & & & & $\beta_{\text {- } \beta_{\text {i_k }}}$ & 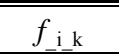 & $\overline{\sigma_{\mathrm{f} \_\mathrm{i} k}}$ & $\beta_{\text {i }{ }_{-} \mathrm{k}}$ & 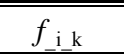 & 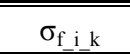 \\
\hline & & & & & $1.90 \mathrm{E}-09$ & $0.023 \%$ & $\pm 0.004 \%$ & $1.28 \mathrm{E}-09$ & $0.025 \%$ & $\pm 0.004 \%$ \\
\hline & & & & & Total & $0.771 \%$ & $\pm 0.268 \%$ & Total & $0.084 \%$ & $\pm 0.029 \%$ \\
\hline
\end{tabular}




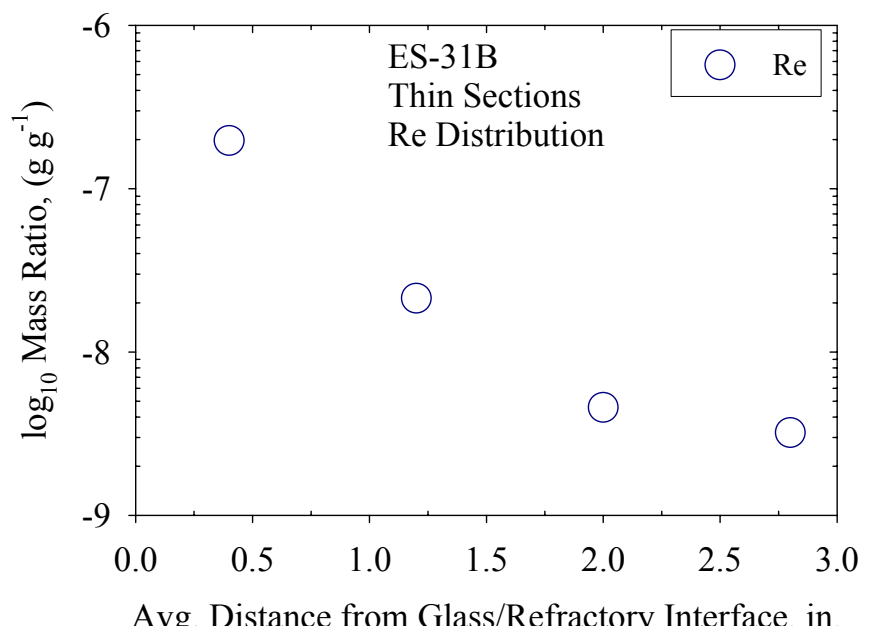

Figure 7. Re Distribution as a Function of Depth for Thin Sections from ES-31B.

\subsubsection{ES-31C Soluble Fraction Results}

ES-31C was conducted to test the effectiveness of two refractory glazes for reducing the Re salt deposition in the CRB. Previous ES tests; ES-31A, -31B, and -32A, using RX-14 (RX Chemical Company, Inc.) glaze suggested this glaze does not prevent penetration of Re or ${ }^{99} \mathrm{Tc}$ into the $\mathrm{CRB}$. Therefore, two additional refractory glazes, Ferro-Frit 3225-3 (Ferro Corporation) and Sodium Silicate (PQ Corporation), that have different melting points were applied to separate sections of the interior walls of the CRB. One glaze was applied to each half of the CRB at room temperature and then separately kiln-fired for two hours before testing. The half of the CRB that contained the high-temperature Ferro-Frit 3225-3 glaze was kiln-fired at $1050^{\circ} \mathrm{C}$ and placed on the air-intake side of BV ES box. The other half of the CRB that was coated with the lower temperature sodium silicate glaze was fired at $100^{\circ} \mathrm{C}$ and placed on the exhaust side of the BV ES box. For additional details on the test objectives and process information for ES-31C see AMEC (2005b). Five CRB samples from each half were removed and tested for soluble Re using the extraction technique discussed in Pierce et al. (2004a).

Results for ES-31C are provided in Table 4. Samples with the identification number EST-11 refer to the CRB half coated with the Sodium Silicate glaze and EST-12 refers to the half coated with the FerroFrit glaze (see Table 4). Using the five EST-12 or five EST-11 samples, an estimate of the soluble fraction of Re was determined assuming the entire refractory was coated with a single glaze. These results suggest that if the entire CRB was coated with the Sodium Silicate or Ferro-Frit glaze, the leachable fraction of Re for this test would be $6.11 \pm 1.94 \%$ and $3.52 \pm 1.12 \%$, respectively. Previous tests, ES-31A and ES-31B, have illustrated that samples removed from the CRB half located on the exhaust side of the BV ES box typically have a higher concentration of soluble Re in comparison to samples removed from the CRB half placed on the air-inlet side of the ICV box. This asymmetry in the soluble Re concentration between the exhaust and air-inlet side of the refractory and the experimental uncertainty associated with the final numbers makes it difficult to conclusively determine whether or not the Ferro-Frit glaze outperformed the Sodium Silicate glaze.

Combining the extraction results from these 10 samples the estimated fraction of soluble Re in the CRB for ES-31C was $4.82 \pm 1.51 \%$. This is significantly higher than the estimates observed in other ES tests. Section 0 discusses the factors that may contribute to these differences. 
Table 4. Re Distribution for ES-31C.

\begin{tabular}{|c|c|c|c|c|c|c|c|}
\hline \multicolumn{5}{|c|}{ Section \#1, 2 to 6 in. from the top } & \multicolumn{3}{|c|}{$\mathbf{R e}$} \\
\hline Sample ID & $X$, in & $\mathrm{Y}$, in & $\mathrm{Z}$, in & $\mathrm{H}_{\mathrm{k}}$, in & ${ }^{\mathrm{a}} \beta_{\mathrm{i} i \mathrm{k} \_\mathrm{p}}$ & & \\
\hline EST-11-01a & 8 & 15 & 4.0 & 4 & $2.13 \mathrm{E}-07$ & & \\
\hline \multirow[t]{3}{*}{ EST-12-01a } & 28 & 15 & 4.0 & 4 & $5.74 \mathrm{E}-08$ & & \\
\hline & & & & & ${ }^{\mathrm{a}} \beta_{-\mathrm{i} \_\mathrm{k}}$ & ${ }^{\mathrm{b}} f_{-}{ }_{-} \mathrm{k}$ & ${ }^{\mathrm{b}} \sigma_{\mathrm{f}_{-} \mathrm{i}-\mathrm{k}}$ \\
\hline & & & & & $1.35 \mathrm{E}-07$ & $1.138 \%$ & $\pm 0.178 \%$ \\
\hline \multicolumn{5}{|c|}{ Section \#2, 6 to 9 in. from the top } & \multicolumn{3}{|c|}{$\mathbf{R e}$} \\
\hline Sample ID & $\mathrm{X}$, in & $\mathrm{Y}$, in & $\mathrm{Z}$, in & $\mathrm{H}_{\mathrm{k}}$, in & $\beta_{-i \_k} \_p$ & & \\
\hline EST-11-01b & 8 & 15 & 7.5 & 3 & $8.98 \mathrm{E}-08$ & & \\
\hline \multirow[t]{3}{*}{ EST-12-01b } & 28 & 15 & 7.5 & 3 & $4.24 \mathrm{E}-08$ & & \\
\hline & & & & & $\beta_{-} \mathrm{i} k_{\mathrm{k}}$ & $f_{-} \mathrm{i}_{\mathrm{k}}$ & $\sigma_{f_{-}{ }_{i} k}$ \\
\hline & & & & & $6.61 \mathrm{E}-08$ & $0.417 \%$ & $\pm 0.065 \%$ \\
\hline \multicolumn{5}{|c|}{ Section \#3, 9 to 12 in. from the top } & \multicolumn{3}{|c|}{$\mathbf{R e}$} \\
\hline Sample ID & $X$, in & $\mathrm{Y}$, in & $\mathrm{Z}$, in & $\mathrm{H}_{\mathrm{k}}$, in & $\beta_{-i \_} \_p$ & & \\
\hline EST-11-02 & 8 & 15 & 10.5 & 3 & $3.73 \mathrm{E}-07$ & & \\
\hline \multirow[t]{3}{*}{ EST-12-02a } & 28 & 15 & 10.5 & 3 & $2.51 \mathrm{E}-07$ & & \\
\hline & & & & & $\beta_{-i \mathrm{i} k}$ & $f_{-} \mathrm{i}_{\mathrm{i} k}$ & $\sigma_{\mathrm{f} \_\mathrm{i} \_\mathrm{k}}$ \\
\hline & & & & & $3.12 \mathrm{E}-07$ & $1.968 \%$ & $\pm 0.306 \%$ \\
\hline \multicolumn{5}{|c|}{ Section \#4, 12 to 15 in. from the top } & \multicolumn{3}{|c|}{$\mathbf{R e}$} \\
\hline Sample ID & $X$, in & $\mathrm{Y}$, in & $\mathrm{Z}$, in & $\mathrm{H}_{\mathrm{k}}$, in & $\beta_{-i \_k p}$ & & \\
\hline EST-11-03 & 8 & 15 & 13.5 & 3 & $2.22 \mathrm{E}-07$ & & \\
\hline \multirow[t]{3}{*}{ EST-12-02b } & 28 & 15 & 13.5 & 3 & $1.89 \mathrm{E}-07$ & & \\
\hline & & & & & $\beta_{-\mathrm{i} \_\mathrm{k}}$ & $\overline{f_{-} \mathrm{i}_{\mathrm{k}} \mathrm{k}}$ & $\overline{\sigma_{\mathrm{f}} \mathrm{i} \_\mathrm{k}}$ \\
\hline & & & & & $2.05 \mathrm{E}-07$ & $1.293 \%$ & $\pm 0.204 \%$ \\
\hline \multicolumn{5}{|c|}{ Section \#5, Refractory Base } & \multicolumn{3}{|c|}{$\mathbf{R e}$} \\
\hline Sample ID & $\mathrm{X}$, in & $\mathrm{Y}$, in & $Z$, in & $\mathrm{H}_{\mathrm{k}}$, in & $\beta_{-i \_k p}$ & & \\
\hline EST-11-04a & 7.5 & 15 & 17.0 & 4 & $2.94 \mathrm{E}-08$ & & \\
\hline EST-11-04b & 8.5 & 15 & 17.0 & 4 & $2.48 \mathrm{E}-07$ & & \\
\hline EST-12-03a & 28 & 15 & 17.0 & 4 & $1.66 \mathrm{E}-07$ & & \\
\hline \multirow[t]{4}{*}{ EST-12-03b } & 28 & 15 & 17.0 & 4 & $1.49 \mathrm{E}-07$ & & \\
\hline & & & & & $\beta_{-} \mathrm{i}_{-} \mathrm{k}$ & $f_{-} \mathrm{i}_{\mathrm{K}} \mathrm{n}$ & $\sigma_{\mathrm{f} \_ \text {i_k }}$ \\
\hline & & & & & $1.48 \mathrm{E}-07$ & $0.925 \%$ & $\pm 0.142 \%$ \\
\hline & & & & & Total & $4.815 \%$ & $\pm 1.506 \%$ \\
\hline
\end{tabular}

\subsubsection{ES-31D Soluble Fraction Results}

Unlike the other ES tests, ES-31D was conducted in an attempt to decrease the volatilization of Re by using a denitrated feed spiked with $\operatorname{Re}(\mathrm{IV})$ instead of $\operatorname{Re}(\mathrm{VII})$. Rhenium volatilization decreases when the oxidation state is reduced from $\operatorname{Re}(\mathrm{VII})$ to $\operatorname{Re}(\mathrm{IV})$ (Darab and Smith 1996). The feed for this test was spiked with $\operatorname{Re}(\mathrm{IV})$ instead of $\operatorname{Re}(\mathrm{VII})$ to see if $\mathrm{Re}$ would remain as $\operatorname{Re}(\mathrm{IV})$ and reduce the amount of $\operatorname{Re}$ being volatilized during the BV process. A denitrated feed was used to simulate a potential pre- or earlymelting denitration step in the BV process that was thought to be necessary to maintain Re in the +4 oxi- 
dation state. For additional details on the test objectives and process information for ES-31D see AMEC (2005b). Ten CRB samples from the exhaust half of the CRB were removed and tested for soluble Re using the extraction technique discussed in Pierce et al. (2004a).

The extraction results from the $10 \mathrm{CRB}$ samples are provided in Table 5. Applying the estimation technique described in Pierce et al. (2004a) the soluble fraction of Re was determined to be $0.22 \pm 0.07 \%$. This value is 3.6 to 21 times lower than the other ES tests and suggests that methods to reduce the oxidation state of $\operatorname{Re}$ (and potentially ${ }^{99} \mathrm{Tc}$ ) and/or the early destruction of nitrate salts could decrease the soluble fraction of these materials in the refractory.

Table 5. Re Distribution for ES-31D.

\begin{tabular}{|c|c|c|c|c|c|c|c|}
\hline \multicolumn{5}{|c|}{ Section \#1, 0 to 4 in. from the top wall } & \multicolumn{3}{|c|}{$\mathbf{R e}$} \\
\hline Sample ID & $\mathrm{X}$, in & $\mathrm{Y}$, in & $\mathrm{Z}$, in & $\mathrm{H}_{\mathrm{k}}$, in. & ${ }^{\mathrm{a}} \beta_{\_}{ }_{i} \mathrm{k} \_\mathrm{p}$ & & \\
\hline EST-13-01 & 8 & 2 & 2.0 & 4 & $1.30 \mathrm{E}-08$ & & \\
\hline \multirow[t]{3}{*}{ EST-14-01 } & 8 & 15 & 2.0 & 4 & $3.13 \mathrm{E}-08$ & & \\
\hline & & & & & ${ }^{\mathrm{a}} \beta_{\mathrm{i} i \mathrm{k}}$ & 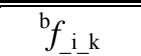 & $\bar{~}{ }^{\mathrm{b}} \sigma_{\mathrm{f}_{\mathrm{i} i \mathrm{k}}}$ \\
\hline & & & & & $2.21 \mathrm{E}-08$ & $0.187 \%$ & $0.030 \%$ \\
\hline \multicolumn{5}{|c|}{ Section \#2, 4 to 8 in. from the top } & \multicolumn{3}{|c|}{$\mathbf{R e}$} \\
\hline Sample ID & $\mathrm{X}$, in & $\mathrm{Y}$, in & $Z$, in & $\mathrm{H}_{\mathrm{k}}$, in. & 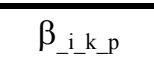 & & \\
\hline EST-13-02 & 8 & 2 & 6.0 & 4 & $3.48 \mathrm{E}-09$ & & \\
\hline \multirow[t]{3}{*}{ EST-14-02 } & 8 & 15 & 6.0 & 4 & $2.77 \mathrm{E}-09$ & & \\
\hline & & & & & $\beta_{\beta_{i} \mathrm{k}}$ & $f_{-\mathrm{i} \_\mathrm{k}}$ & $\overline{\sigma_{\mathrm{f}} \mathrm{i} \text { k }}$ \\
\hline & & & & & $3.13 \mathrm{E}-09$ & $0.026 \%$ & $0.004 \%$ \\
\hline \multicolumn{5}{|c|}{ Section \#3, 8 to 12 in. from the top } & \multicolumn{3}{|c|}{$\overline{\operatorname{Re}}$} \\
\hline Sample ID & $X$, in & $\mathrm{Y}$, in & $Z$, in & $\mathrm{H}_{\mathrm{k}}$, in. & $\overline{\beta_{i} \_k p p}$ & & \\
\hline EST-13-03 & 8 & 2 & 10.0 & 4 & $6.89 \mathrm{E}-10$ & & \\
\hline \multirow[t]{3}{*}{ EST-14-03 } & 8 & 15 & 10.0 & 4 & $4.07 \mathrm{E}-10$ & & \\
\hline & & & & & 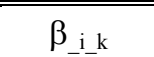 & 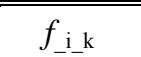 & 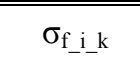 \\
\hline & & & & & $5.48 \mathrm{E}-10$ & $0.005 \%$ & $\pm 0.001 \%$ \\
\hline \multicolumn{5}{|c|}{ Section \#4, 12 to 15 in. from the top } & \multicolumn{3}{|c|}{$\mathbf{R e}$} \\
\hline Sample ID & $\mathrm{X}$, in & $\mathrm{Y}$, in & $\mathrm{Z}$, in & $\mathrm{H}_{\mathrm{k}}$, in. & $\bar{\beta} \beta_{i} \_$k $p$ & & \\
\hline EST-13-04 & 8 & 2 & 13.5 & 3 & $8.04 \mathrm{E}-10$ & & \\
\hline \multirow[t]{3}{*}{ EST-14-04 } & 8 & 15 & 13.5 & 3 & $6.93 \mathrm{E}-10$ & & \\
\hline & & & & & $\overline{\beta_{-i} \mathrm{k}}$ & $\overline{f f_{\mathrm{i} i \mathrm{k}}}$ & $\overline{\sigma_{\mathrm{f}} \mathrm{i} \_\mathrm{k}}$ \\
\hline & & & & & $7.48 \mathrm{E}-10$ & $0.005 \%$ & $\pm 0.001 \%$ \\
\hline \multicolumn{5}{|c|}{ Section \#5, Refractory Base } & \multicolumn{3}{|c|}{$\mathbf{R e}$} \\
\hline Sample ID & $\mathrm{X}$, in & $\mathrm{Y}$, in & $\mathrm{Z}$, in & $\mathrm{H}_{\mathrm{k}}$, in. & $\overline{\beta_{i} \_k \_p}$ & & \\
\hline EST-13-05 & 8 & 2 & 17.0 & 4 & $4.64 \mathrm{E}-09$ & & \\
\hline \multirow[t]{4}{*}{ EST-14-05 } & 8 & 15 & 17.0 & 4 & $1.14 \mathrm{E}-09$ & & \\
\hline & & & & & $\beta_{\text {i }-k}$ & $f_{\text {i } \mathrm{i} k \mathrm{k}}$ & $\overline{\sigma_{\mathrm{f}} \mathrm{i} \_\mathrm{k}}$ \\
\hline & & & & & $2.89 \mathrm{E}-09$ & $0.018 \%$ & $\pm 0.003 \%$ \\
\hline & & & & & Total & $0.223 \%$ & $\pm 0.070 \%$ \\
\hline
\end{tabular}




\subsubsection{ES-31E Soluble Fraction Results}

ES-31E was conducted to evaluate the effectiveness of refractory tile on minimizing $\mathrm{Re}$ salt penetration into the CRB. For this test, a 0.25-in. thick aluminum-silicate grey-stone tile $^{\mathrm{a}}$ was used to line $75 \%$ of the inner surfaces of the CRB by fully tiling one-half of the CRB and applying tiles to $50 \%$ of the area in the other half of the CRB. The untiled $25 \%$ of the CRB served as a control to evaluate the performance of the tiles. The fully tiled half of the CRB is shown in Figure 8. Note that approximately 0.25 -in. "grout lines" were left between the tiles to aid in tile bonding. These grout lines were filled with Vibrocast 60 PC as part of the CRB casting process. The grey-

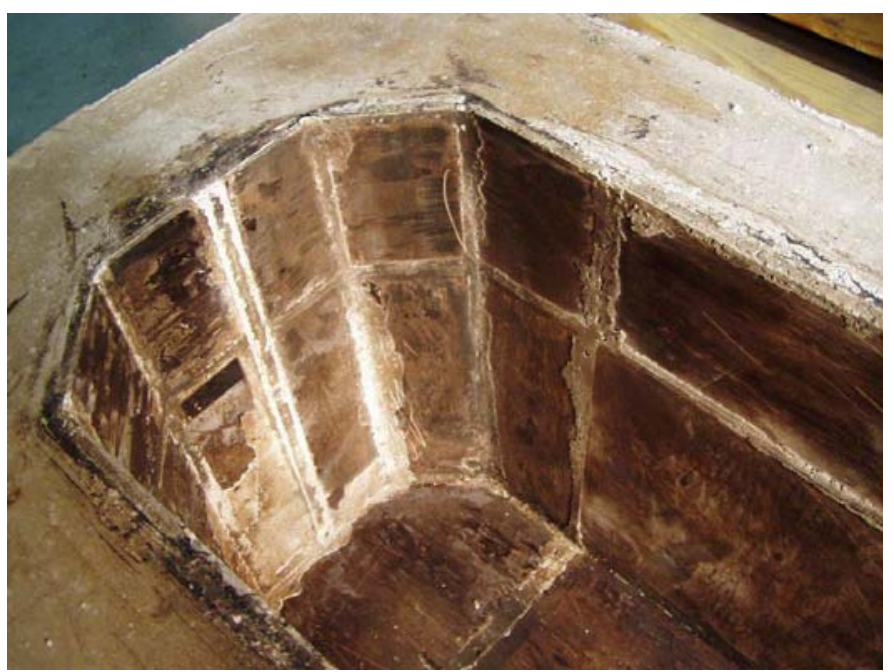

Figure 8. Grey-Stone Tiles Applied to CRB Used for ES-31E Test. stone tile was chosen because it was corrosion resistant, had a composition similar to the CRB, bonded well to the $\mathrm{CRB}$, and had a low air-permeability relative to the CRB before and after heating to temperatures greater than $800^{\circ} \mathrm{C}$. Additional details are provided in Sederburg and Thompson (2004).

Results from six refractory samples removed from the untiled portion of the CRB located on the exhaust side of the BV waste package were used to estimate the performance of the untiled CRB in this test using the extraction technique discussed in Pierce et al. (2004a). Untiled samples taken from the exhaust end of the CRB, referred to as EST-18-03 thru -07, were adjacent to the set of refractory samples with well bonded tiles discussed below. Table 6 displays the untiled results, which suggest an even distribution of Re along the wall with a significant drop in the base sample. Similar trends have been observed in several other ES tests. Applying the soluble fraction calculations, as described by Pierce et al. (2004a), and using a total Re test inventory of $0.7632 \mathrm{~g}$, an estimate of the leachable fraction of Re was determined assuming the entire refractory was untiled. These results suggest that if the entire CRB was untiled, the leachable fraction of Re would be $1.96 \pm 0.69 \%$. This value is within the experimental uncertainty of the values reported for tests ES-31A, ES-31B, ES-32A, and ES-32B.

The results from the tiled portions of the refractory are also shown in Table 6. After the test, the tiles near the CRB joint had clearly separated from the CRB and glass had flowed between the tile and CRB (Figure 9). Many of the refractory tiles were loosely bonded after the test but appeared to have prevented any glass flow behind the tile. Other tiles near the ends of the refractory blocks appeared to have remained bonded. A series of CRB samples with well bonded tiles (EST-17-03 thru-07) were taken from the exhaust end of the CRB adjacent to the untiled samples discussed above. The refractory portions of each of these samples were analyzed separately from the tile. The tiles cleanly separated from the refractory at tile/refractory interface as the refractory samples were chipped from the CRB. The extraction technique discussed in Pierce et al. (2004a) was used to analyze the refractory samples while multiple leaches were used on the tile segments since there was essentially no open porosity in the tile material. The analyses of these samples showed that soluble Re was present in all the CRB samples and all the tile

(a) Gray wonderstone unfired (grey) alumina silicate machinable ceramic, manufactured by Graphtek LLC, available at Graphitestore.com 
Table 6. Re Distribution for ES-31E.

\begin{tabular}{|c|c|c|c|c|c|c|c|c|c|c|c|c|c|c|}
\hline \multicolumn{4}{|c|}{$\begin{array}{c}\text { Section \#1, } 0 \text { to } 3 \text { in. from } \\
\text { the top of the wall }\end{array}$} & \multicolumn{5}{|c|}{ Untiled Refractory Re Data } & \multicolumn{3}{|c|}{ Tiled Refractory Re Data } & \multicolumn{3}{|c|}{ Tile Re Data } \\
\hline $\mathrm{X}$, in & $\mathrm{Y}$, in & $Z$, in & $\mathrm{H}_{\mathrm{k}}$, in. & Sample ID & ${ }^{b} \beta_{i k p p}$ & $\sigma_{\beta \_ \text {i k p }}$ & & & Sample ID & $\beta_{i, k p}$ & $\sigma_{\beta \_ \text {i_kp }}$ & Sample ID & $\overline{\beta_{i} k p}$ & $\overline{\sigma_{\beta} i \mathrm{k} p}$ \\
\hline 18 & 2 & 1.5 & 3 & EST-18-01 & $1.21 \mathrm{E}-07$ & $\pm 5.45 \mathrm{E}-09$ & & & & & & & & \\
\hline 18 & 15 & 1.5 & 3 & & & & & & EST-17-01 & $8.12 \mathrm{E}-09$ & $9 \pm 3.61 \mathrm{E}-10$ & EST-17-01T & $8.78 \mathrm{E}-07$ & $\pm 5.20 \mathrm{E}-08$ \\
\hline 18 & 15 & 2.5 & 3 & & & & & & EST-17-02 & $7.54 \mathrm{E}-08$ & $8 \pm 2.77 \mathrm{E}-09$ & & & \\
\hline 2 & 8 & 1.5 & 3 & EST-18-03 & $7.20 \mathrm{E}-08$ & $\pm 3.90 \mathrm{E}-09$ & & & & & & & & \\
\hline 2 & 10 & 1.5 & 3 & & & & & & EST-17-03 & $31.81 \mathrm{E}-08$ & $8 \pm 1.04 \mathrm{E}-09$ & EST-17-03T & $5.30 \mathrm{E}-07$ & $\pm 2.91 \mathrm{E}-08$ \\
\hline \multirow[t]{3}{*}{24} & 15 & 1.5 & 3 & & & & & & EST-21-05 & $2.08 \mathrm{E}-08$ & $8 \pm 7.91 \mathrm{E}-10$ & & & \\
\hline & & & & & $\beta_{\text {_i } k}$ & $\sigma_{\beta \_\mathrm{i} \_\mathrm{k}}$ & ${ }^{\mathrm{c}} f_{-} i_{-} k$ & $\sigma_{f_{-} \_k}$ & & 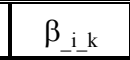 & $\sigma_{\beta \_\_ \text {i }}$ & & $\beta_{-\mathrm{i} \_\mathrm{k}}$ & $\sigma_{\beta \_ \text {i_k }}$ \\
\hline & & & & & $9.65 \mathrm{E}-08$ & $\pm 3.35 \mathrm{E}-09$ & $0.634 \%$ & $\pm 0.099 \%$ & & $3.06 \mathrm{E}-08$ & $\pm 7.72 \mathrm{E}-10$ & & $7.04 \mathrm{E}-07$ & $\pm 2.98 \mathrm{E}-08$ \\
\hline \multicolumn{4}{|c|}{$\begin{array}{c}\text { Section } \# 2,4 \text { to } 7 \text { in. from } \\
\text { the top of the wall }\end{array}$} & \multicolumn{5}{|c|}{ Untiled Refractory Re Data } & \multicolumn{3}{|c|}{ Tiled Refractory Re Data } & \multicolumn{3}{|c|}{ Tile Re Data } \\
\hline $\mathrm{X}$, in & $\mathrm{Y}$, in & $Z$, in & $\mathrm{H}_{\mathrm{k}}$, in. & Sample ID & $\beta_{-} \mathrm{i} k \__{\mathrm{p}}$ & $\sigma_{\beta \_\_ \text {i } k p p}$ & & & Sample ID & $\beta_{-i \_k p p}$ & $\sigma_{\beta \_ \text {i } \_\_p}$ & Sample ID & $\beta_{-i \_k p}$ & $\sigma_{\beta \_ \text {i } \_\_p}$ \\
\hline 2 & 8 & 5 & 4 & EST-18-04 & $4.03 \mathrm{E}-08$ & $\pm 1.66 \mathrm{E}-09$ & & & & & & & & \\
\hline \multirow[t]{3}{*}{2} & 10 & 5 & 4 & & & & & & EST-17-04 & $46.04 \mathrm{E}-08$ & $\pm 2.67 \mathrm{E}-09$ & EST-17-04T & $1.12 \mathrm{E}-08$ & $\pm 6.72 \mathrm{E}-10$ \\
\hline & & & & & $\beta_{\text {i_k }}$ & $\sigma_{\beta \_\mathrm{i} \_\mathrm{k}}$ & $f_{-i \_k}$ & $\sigma_{f_{-} \_k}$ & & $\beta_{\text {i_k }}$ & $\sigma_{\beta \_\mathrm{i} \_\mathrm{k}}$ & & $\beta_{-\mathrm{i} i \mathrm{k}}$ & $\sigma_{\beta \_ \text {i_k }}$ \\
\hline & & & & & $4.03 \mathrm{E}-08$ & $\pm 1.66 \mathrm{E}-09$ & $0.353 \%$ & $\pm 0.056 \%$ & & $6.04 \mathrm{E}-08$ & $\pm 2.67 \mathrm{E}-09$ & & $1.12 \mathrm{E}-08$ & $\pm 6.72 \mathrm{E}-10$ \\
\hline
\end{tabular}


Table 6. Continued

\begin{tabular}{|c|c|c|c|c|c|c|c|c|c|c|c|c|c|c|}
\hline \multicolumn{4}{|c|}{$\begin{array}{c}\text { Section \#3, } 7 \text { to } 11 \text { in. from } \\
\text { the top of the wall }\end{array}$} & \multicolumn{5}{|c|}{ Untiled Refractory Re Data } & \multicolumn{3}{|c|}{ Tiled Refractory Re Data } & \multicolumn{3}{|c|}{ Tile Re Data } \\
\hline$X$, in & $\mathrm{Y}$, in & $Z$, in & $\mathrm{H}_{\mathrm{k}}$, in. & Sample ID & $\beta_{-i \_ \text {_ } \_p}$ & $\sigma_{\beta \_ \text {i } \_\_p}$ & & & Sample ID & $\beta \_\mathrm{i} \_\mathrm{k} \_\mathrm{p}$ & $\sigma \beta \_\mathrm{i} \_\mathrm{k} \_\mathrm{p}$ & Sample ID & $\beta_{-i \_ \text {_ } \_p}$ & $\sigma_{\beta \_ \text {i } \_\_p}$ \\
\hline 2 & 8 & 9 & 4 & EST-18-05 & 7.63E-08 & $\pm 3.45 \mathrm{E}-09$ & & & & & & & & \\
\hline 2 & 10 & 9 & 4 & & & & & & EST-17-05 & $3.36 \mathrm{E}-08$ & $\pm 1.40 \mathrm{E}-09$ & EST-17-05T & $8.43 \mathrm{E}-09$ & $\pm 4.90 \mathrm{E}-10$ \\
\hline 30 & 2 & 9 & 4 & & & & & & EST-21-01 & 4.23E-09 & $\pm 1.73 \mathrm{E}-10$ & & & \\
\hline 28 & 2 & 9 & 4 & & & & & & EST-21-02 & $8.78 \mathrm{E}-09$ & $\pm 3.52 \mathrm{E}-10$ & & & \\
\hline 26 & 2 & 9 & 4 & & & & & & EST-21-03 & $6.48 \mathrm{E}-09$ & $\pm 2.28 \mathrm{E}-10$ & & & \\
\hline \multirow[t]{3}{*}{30} & 15 & 9 & 4 & & & & & & EST-21-04 & $3.59 \mathrm{E}-08$ & $\pm 1.41 \mathrm{E}-09$ & & & \\
\hline & & & & & $\beta_{-i \mathrm{k}}$ & $\sigma_{\beta \_ \text {i_k }}$ & $f_{-i-k}$ & $\sigma_{f-i, k}$ & & $\beta_{-i \mathrm{k}}$ & $\sigma_{\beta \_i k}$ & & $\beta_{-i \ldots k}$ & $\sigma_{\beta-1, k}$ \\
\hline & & & & & 7.63E-08 & $\pm 3.45 \mathrm{E}-09$ & $0.668 \%$ & $\pm 0.107 \%$ & & $1.78 \mathrm{E}-08$ & $\pm 4.07 \mathrm{E}-10$ & & 8.43E-09 & $\pm 4.90 \mathrm{E}-10$ \\
\hline \multicolumn{4}{|c|}{$\begin{array}{c}\text { Section \#4, } 11 \text { to } 15 \text { in. from } \\
\text { top of the wall }\end{array}$} & \multicolumn{5}{|c|}{ Untiled Refractory Re Data } & \multicolumn{3}{|c|}{ Tiled Refractory Re Data } & \multicolumn{3}{|c|}{ Tile Re Data } \\
\hline$X$, in & $\mathrm{Y}$, in & $Z$, in & $\mathrm{H}_{\mathrm{k}}$, in. & Sample ID & $\beta_{-i \_\_p}$ & $\sigma_{\beta \_ \text {i_k_p }}$ & & & Sample ID & $\beta_{-i \_\_p}$ & $\sigma_{\beta \_\_ \text {_k } \_p}$ & Sample ID & $\beta_{\text {i_k_p }}$ & $\sigma_{\beta \_i \_k \_p}$ \\
\hline 2 & 8 & 13 & 4 & EST-18-06 & $3.37 \mathrm{E}-08$ & $\pm 1.38 \mathrm{E}-09$ & & & & & & & & \\
\hline \multirow[t]{3}{*}{2} & 10 & 13 & 4 & & & & & & EST-17-06 & $2.82 \mathrm{E}-08$ & $\pm 1.23 \mathrm{E}-09$ & EST-17-06T & $2.50 \mathrm{E}-08$ & $\pm 1.43 \mathrm{E}-09$ \\
\hline & & & & & $\beta_{-i \_k}$ & $\sigma_{\beta \_\_k}$ & $f_{-i \_k}$ & $\sigma_{f-i, k}$ & & $\beta_{-i \text { i }}$ & $\sigma_{\beta} \_$i_k & & $\beta_{-i \_k}$ & $\sigma_{\beta} \_$i_k \\
\hline & & & & & $3.37 \mathrm{E}-08$ & $\pm 1.38 \mathrm{E}-09$ & $0.295 \%$ & $\pm 0.047 \%$ & & $2.82 \mathrm{E}-08$ & $\pm 1.23 \mathrm{E}-09$ & & $2.50 \mathrm{E}-08$ & $\pm 1.43 \mathrm{E}-09$ \\
\hline \multicolumn{4}{|c|}{ Section \#5, Refractory. Base } & \multicolumn{5}{|c|}{ Untiled Refractory Re Data } & \multicolumn{3}{|c|}{ Tiled Refractory Re Data } & \multicolumn{3}{|c|}{ Tile Re Data } \\
\hline$X$, in & $\mathrm{Y}$, in & $Z$, in & $\mathrm{H}_{\mathrm{k}}$, in. & Sample ID & $\beta_{\mathrm{i} k \mathrm{k} p}$ & $\sigma_{\beta i \mathrm{ik} p}$ & & & Sample ID & $\beta_{\mathrm{i} k \mathrm{k} p}$ & $\sigma_{\beta \text { i k p }}$ & Sample ID & $\beta_{\mathrm{i} k \mathrm{k} p}$ & $\sigma_{\beta}{ }_{i j k \_p}$ \\
\hline 8 & 8 & 17 & 4 & EST-18-07 & $1.41 \mathrm{E}-09$ & $\pm 6.98 \mathrm{E}-11$ & & & & & & & & \\
\hline \multirow[t]{4}{*}{8} & 10 & 17 & 4 & & & & & & EST-17-07 & $1.30 \mathrm{E}-09$ & $\pm 5.64 \mathrm{E}-11$ & EST-17-07T & 5.88E-09 & $\pm 3.35 \mathrm{E}-10$ \\
\hline & & & & & $\beta_{\text {_i_k }}$ & $\sigma_{\beta} \sigma_{\beta_{-} \mathrm{i} k}$ & $f_{-i \_k}$ & $\sigma_{f_{-} \_k}$ & & $\beta_{\text {_i_k }}$ & $\overline{\sigma_{\beta} \sigma_{\text {i } \_k}}$ & & $\beta_{\text {_i_k }}$ & 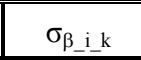 \\
\hline & & & & & $1.41 \mathrm{E}-09$ & $\pm 6.98 \mathrm{E}-11$ & $0.009 \%$ & $\pm 0.001 \%$ & & $1.30 \mathrm{E}-09$ & $\pm 5.64 \mathrm{E}-11$ & & 5.88E-09 & $\pm 3.35 \mathrm{E}-10$ \\
\hline & & & & Total & & & $1.960 \%$ & $\pm 0.694 \%$ & & & & & & \\
\hline
\end{tabular}




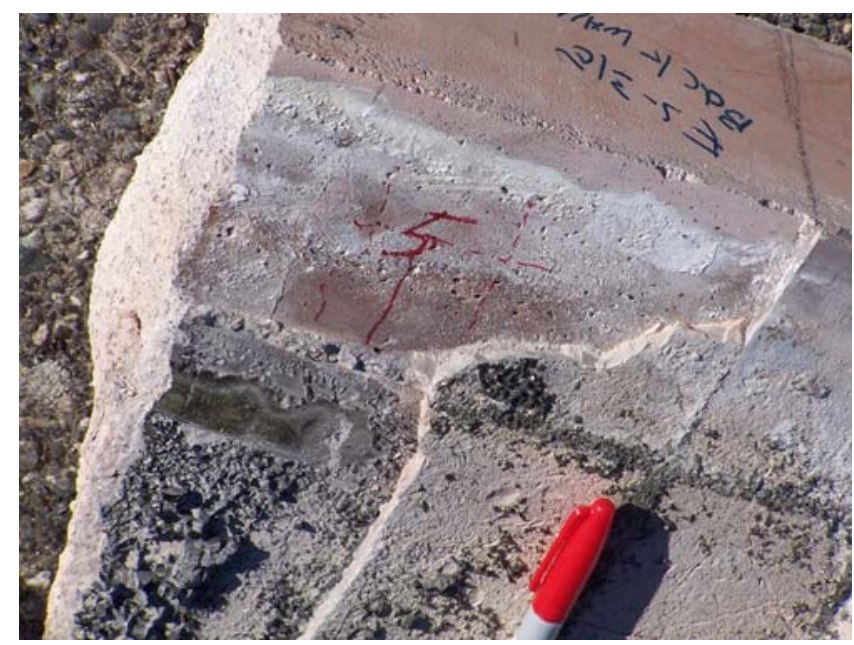

Figure 9. Upper Portions of CRB with Partial Tile Removal. Note Glass Penetration Behind Tile in Lower Left Hand Corner of Photograph. The "5" Indicates Where CRB Sample EST-21-05 Was Taken.

samples. In the lowest section of the refractory (section 4) and the base of the refractory (section 5), the tiles did little to reduce the concentration of Re in the CRB relative to the untiled sections. Section 2 also showed no reduction. There was some indication that the tile reduced the Re concentrations in the CRB in Sections 1 and 3 but the high concentrations of soluble Re on the section 1 tile sample negated much of the potential benefit. For example, in Section 1, the untiled CRB sample (EST-18-03) had a soluble Re mass fraction of $7.20 \pm 0.40 \times 10^{-8}$ while the tiled CRB sample (EST-17-03) had a soluble Re mass fraction of $1.81 \pm 0.10 \times 10^{-8}$ indicating a $75 \%$ reduction. However, this reduction is significantly negated when you consider the total Re deposition within the $\mathrm{CRB}$ and on the corresponding tile. The tile sample (EST-17-03T), which made up $1 / 16^{\text {th }}$ of the wall ( 0.25 in. of a 4 in thick refractory wall), had a soluble Re mass fraction of $5.30 \pm 0.30 \times 10^{-7}$. Assuming that the density of the tile is roughly equal to the Vibrocast $60 \mathrm{PC}$, the average soluble Re mass fraction is $5.00 \pm 0.21 \times 10^{-8}$ or a $30 \%$ reduction relative to the untiled sample.

Although the tiles on the CRB samples (EST-17-03 thru -07) appeared to be well bonded, there were concerns that edge effects may have resulted in the poor performance of the tiles in this area of the CRB due to vapor or liquid penetration migrating from the adjacent untiled area. Additional samples, EST-21, were taken to test this concern. A series of three CRB samples; EST-21-01, -02, and -03, were taken from the front wall on the inlet side in section 3. The EST-21-01 sample was taken from behind the middle of the largest tile (approximately $9 \times 9$ in.) used in the CRB. This sample was the furthest away from any tile edges. The EST-21-02 sample was taken from behind the same tile but nearer to the edge of the tile. The EST-21-03 sample was taken from a well bonded tile right next to the large tile. The EST-21-04 sample was in the same position as sample EST-21-03 but from the back wall. The EST-21-01, -02, and -03 sample locations are shown in Figure 10. A fifth sample, EST-21-05, was taken from behind the middle of a large tile located on the back wall on the inlet side in Section 1. The location of this sample is shown in Figure 9. The EST-21-01, -02, and -03 samples all had soluble Re mass fractions that were significantly less than the EST-17-05 sample indicating that edge effects may have reduced tile effectiveness. However, the EST-21-04 sample had essentially the same soluble Re mass as the EST-17-05 sample and the EST-21-05 sample had essentially the same soluble Re mass as the EST-17-03 sample. The results from EST-21-04 and EST-21-05 indicate that edge effects were not significant. 


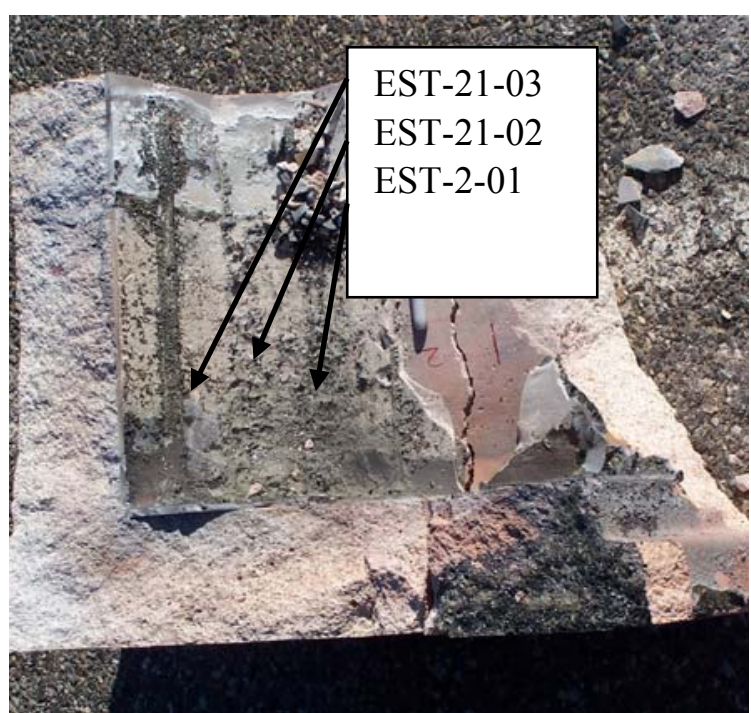

Figure 10. Corner Section of Tiled CRB with Base at the Bottom of the Photograph. Tiles have been removed from the Area Below and to the Right of the Pen. Note Large Crack Between the \#1 and \#2 was an Artifact of the Sampling Process.

The results from ES-31E did not conclusively confirm or refute the effectiveness of tiles to reduce the soluble fraction of Re in the refractory. All CRB samples tested showed that soluble Re was present in refractory behind tiles and, in many areas of the CRB, the concentration was similar to that found in untiled areas. However, selected refractory areas that were covered with well bonded tiles and/or were significant distance from a tile edge showed soluble Re concentration reductions of up to an order of magnitude relative to similar untiled areas. Controlled experiments that simulate the conditions that tiles experience at different times in the bulk vitrification process are necessary to understand how Re penetrates behind the tiles and into the refractory. This information will help determine if better tiles and/or bonding/fabrication techniques might be used to reduce soluble ${ }^{99} \mathrm{Tc}$ in the CRB.

\subsubsection{ES-32A Soluble Fraction Results}

ES-32A was conducted using a waste simulant composition that contained both Re, and ${ }^{99} \mathrm{Tc}$ spikes. For a detailed discussion of this test see Sederburg and Thompson (2004). In general, the objective of this test was to compare these results to a similar test conducted in FY03 that contained ${ }^{99} \mathrm{Tc}$ in the waste simulant. ES-32A was used to determine the soluble fraction of Re and ${ }^{99} \mathrm{Tc}$ as well as the Re to ${ }^{99} \mathrm{Tc}$ volatilization ratio. One cast refractory sample from each horizontal slice (see Figure 47), obtained from the back wall near the exhaust port, was removed and extracted to determine the soluble fraction of Re and ${ }^{99} \mathrm{Tc}$.

Table 7 shows the dilute nitric acid soluble fraction for each of the five sections in ES-32A. Using the technique outlined in Pierce et al. (2004a), the soluble fraction of Re and ${ }^{99} \mathrm{Tc}$ was determined to be $1.55 \pm 0.56$ and $0.37 \pm 0.13 \%$, respectively. The distribution of Re and ${ }^{99} \mathrm{Tc}$ in the different sections appears to be relatively uniform.

The ${ }^{99} \mathrm{Tc} / \mathrm{Re}$ volatilization ratio $\alpha_{k}$ was determined for each $k^{\text {th }}$ section using Equation (1). 


$$
\alpha_{k}=\frac{\left(m_{T c, k} / m_{\text {total }, T c}\right)}{\left(m_{R e, k} / m_{\text {total }, R e}\right)}
$$

The volatilization ratio differed for each $k^{\text {th }}$ section, $0.14 \pm 0.03,0.21 \pm 0.05,0.41 \pm 0.09,0.93 \pm 0.22$, and $0.11 \pm 0.03$, for sections $1,2,3,4$, and 5, respectively. Each $k^{\text {th }}$ section refers to a horizontal section illustrated in Figure 4 with the depth $\left(\mathrm{H}_{\mathrm{k}}\right)$ of each section provided in Table 7 . The average ${ }^{99} \mathrm{Tc} / \mathrm{Re}$ volatilization ratio for ES-32A was $0.22 \pm 0.03$, excluding section 4 which was considered an outlier because it was $>5 \sigma$ away from the average. This average volatilization ratio determined from levels in the CRB is higher than the 0.06 value determined from FY03 scoria layer samples (McGrail et al. 2003b), but is similar to the 0.23 value determined from FY03 sand layer samples (Thompson 2003).

Table 7. Re and ${ }^{99} \mathrm{Tc}$ Distribution for ES-32A.

\begin{tabular}{|c|c|c|c|c|c|c|c|c|c|c|}
\hline \multicolumn{5}{|c|}{ Section \#1, 0 to 4 in. from the top } & \multicolumn{3}{|c|}{$\mathbf{R e}$} & \multicolumn{3}{|c|}{${ }^{99} \mathrm{Tc}$} \\
\hline Sample ID & $\mathrm{X}$, in & $\mathrm{Y}$, in & $Z$, in & $\mathrm{H}_{\mathrm{k}}$, in. & ${ }^{\mathrm{a}} \beta_{\_} \mathrm{i} \_\mathrm{k} \_\mathrm{p}$ & ${ }^{\mathrm{b}} f_{-\mathrm{i} \_\mathrm{k}}$ & ${ }^{\mathrm{b}} \sigma_{f_{-} \_k}$ & ${ }^{\mathrm{a}} \beta_{-} \mathrm{i} \_\mathrm{k} \_\mathrm{p}$ & ${ }^{\mathrm{b}} f_{-\mathrm{i} \_\mathrm{k}}$ & ${ }^{\mathrm{b}} \sigma_{f_{-} \_ \text {_k }}$ \\
\hline EST-10-1A & 8 & 2 & 2 & 4 & 4.65E-07 & $0.414 \%$ & $\pm 0.068 \%$ & 3.29E-09 & $0.058 \%$ & $\pm 0.009 \%$ \\
\hline \multicolumn{5}{|c|}{ Section \#2, 4 to 8 in. from the top } & \multicolumn{3}{|c|}{$\overline{\operatorname{Re}}$} & \multicolumn{3}{|c|}{ 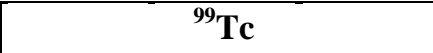 } \\
\hline Sample ID & $X$, in & $\mathrm{Y}$, in & $\mathrm{Z}$, in & $\mathrm{H}_{\mathrm{k}}$, in. & $\beta_{i} \_k \_p$ & $f_{\mathrm{i}_{-} \mathrm{k}}$ & $\sigma_{f_{-}{ }_{i} k}$ & $\beta_{i \_k \_p}$ & $f_{-\mathrm{i}-\mathrm{k}}$ & $\sigma_{f_{-} i k}$ \\
\hline EST-10-1B & 8 & 2 & 6 & 4 & $3.38 \mathrm{E}-07$ & $0.301 \%$ & $\pm 0.049 \%$ & $3.54 \mathrm{E}-09$ & $0.062 \%$ & $\pm 0.010 \%$ \\
\hline \multicolumn{5}{|c|}{ Section \#3, 8 to 12 in. from the top } & \multicolumn{3}{|c|}{ Re } & \multicolumn{3}{|c|}{ 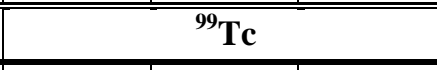 } \\
\hline Sample ID & $\mathrm{X}$, in & $\mathrm{Y}$, in & $Z$, in & $\mathrm{H}_{\mathrm{k}}$, in. & $\beta_{i} i_{k} \_p$ & $f_{f_{\mathrm{i}} \mathrm{k}}$ & $\overline{\sigma_{\mathrm{f} \_\mathrm{i}} \mathrm{k}}$ & $\beta_{-i \_k p}$ & $\overline{f_{-\mathrm{i} \_\mathrm{k}}}$ & $\overline{\sigma_{\mathrm{f} \_\mathrm{i}} \mathrm{k}}$ \\
\hline EST-10-02 & 8 & 2 & 10 & 4 & $3.59 \mathrm{E}-07$ & $0.319 \%$ & $\pm 0.050 \%$ & $7.53 \mathrm{E}-09$ & $0.132 \%$ & $\pm 0.021 \%$ \\
\hline \multicolumn{5}{|c|}{ Section \#4, 12 to 15 in. from the top } & \multicolumn{3}{|c|}{ Re } & \multicolumn{3}{|c|}{ 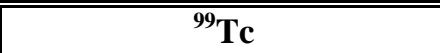 } \\
\hline Sample ID & $\mathrm{X}$, in & $\mathrm{Y}$, in & $\mathrm{Z}$, in & $\mathrm{H}_{\mathrm{k}}$, in. & $\beta_{-i \_} \_p$ & $\overline{f_{-} \mathrm{i}_{\mathrm{k}} \mathrm{k}}$ & $\overline{\sigma_{\mathrm{f} \_\mathrm{i}} \mathrm{k}}$ & $\overline{\beta_{-i} k_{k} \_\mathrm{p}}$ & $\overline{f_{-} \mathrm{i}_{\mathrm{k}} \mathrm{k}}$ & $\overline{\sigma_{\mathrm{f} \_\mathrm{i}} \mathrm{k}}$ \\
\hline EST-10-03 & 8 & 2 & 13.5 & 3 & $1.04 \mathrm{E}-07$ & $0.069 \%$ & $\pm 0.011 \%$ & $4.89 \mathrm{E}-09$ & $0.064 \%$ & $\pm 0.011 \%$ \\
\hline \multicolumn{5}{|c|}{ Section \#5, Refractory Base } & \multicolumn{3}{|c|}{ Re } & \multicolumn{3}{|c|}{${ }^{99} \mathrm{Tc}$} \\
\hline Sample ID & $\mathrm{X}$, in & $\mathrm{Y}$, in & $Z$, in & $\mathrm{H}_{\mathrm{k}}$, in. & $\beta_{-i k \_p}$ & $f_{\text {i } \_k}$ & $\sigma_{f_{-} i k}$ & $\beta_{-i k} \_p$ & $f_{-\mathrm{i} \_\mathrm{k}}$ & $\sigma_{\mathrm{f} i \mathrm{i} k}$ \\
\hline \multirow[t]{2}{*}{ EST-10-04 } & 8 & 2 & 17 & 4 & $6.74 \mathrm{E}-07$ & $0.446 \%$ & $\pm 0.072 \%$ & $3.92 \mathrm{E}-09$ & $0.051 \%$ & $\pm 0.008 \%$ \\
\hline & & & & & Total & $1.550 \%$ & $\pm 0.559 \%$ & Total & $0.367 \%$ & $\pm 0.134 \%$ \\
\hline
\end{tabular}

\subsubsection{ES-32B (ES-13) Soluble Fraction Results}

Test ES-32B was conducted using a waste feed that was made up of Hanford tank waste $(6.9 \mathrm{~L})$ and waste simulant (123.1 L) (Mahoney 2004). In a similar fashion to test ES-31A, -31B, and -32A a refractory glaze, RX-14, was applied to the back inner half of the CRB. This glaze was applied to verify earlier results that suggested that applying a refractory glaze did not reduce deposition of Re and ${ }^{99} \mathrm{Tc}$ into the CRB. Nine samples were removed and tested for soluble Re and ${ }^{99} \mathrm{Tc}$ using the extraction technique discussed in Pierce et al. (2004a). Six of the nine samples were taken from different heights on the unglazed segment; three of the nine samples were taken from the glazed segment. 
Table 8 shows the dilute nitric acid soluble fraction for each of the five sections in ES-32B. These results indicate the concentrations of Re and ${ }^{99} \mathrm{Tc}$ are generally low and that 10 to 20 times more deposition occurred in the upper regions of the refractory than the lower regions. Applying the calculation technique outlined in Pierce et al. (2004a) to these results, the soluble fraction of Re and ${ }^{99} \mathrm{Tc}$ was determined to be $1.13 \pm 0.41 \%$ and $0.17 \pm 0.06 \%$, respectively. These values are within the experimental error of the values reported for ES-32A, $\operatorname{Re}=1.55 \pm 0.56 \%$ and ${ }^{99} \mathrm{Tc}=0.37 \pm 0.13 \%$

Table 8. Re and ${ }^{99} \mathrm{Tc}$ Distribution for ES-32B.

\begin{tabular}{|c|c|c|c|c|c|c|c|c|c|c|}
\hline \multicolumn{5}{|c|}{ Section \#1, 0 to 3 in. from the top of the wall, Above } & \multicolumn{3}{|c|}{ Re } & \multicolumn{3}{|c|}{${ }^{99} \mathrm{Tc}$} \\
\hline Sample ID & $\mathrm{X}$, in & $\mathrm{Y}$, in & $\mathrm{Z}$, in & $\mathrm{H}_{\mathrm{k}}$, in. & $\beta_{i k p}$ & & & $\beta_{i k p}$ & & \\
\hline EST-16-04 & 8 & 2 & 1.5 & 3 & 7.2E-08 & & & $6.8 \mathrm{E}-09$ & & \\
\hline \multirow[t]{3}{*}{ EST-16-05 } & 10 & 2 & 1.5 & 3 & $9.7 \mathrm{E}-08$ & & & $1.1 \mathrm{E}-08$ & & \\
\hline & & & & & $\beta_{\mathrm{ik}}$ & $f_{\mathrm{ik}}$ & $\overline{\sigma_{\mathrm{fik}}}$ & $\beta_{\mathrm{ik}}$ & $f_{\mathrm{ik}}$ & $\overline{\sigma_{\mathrm{fik}}}$ \\
\hline & & & & & $8.4 \mathrm{E}-08$ & $0.597 \%$ & $\pm 0.094 \%$ & $8.7 \mathrm{E}-09$ & $0.102 \%$ & $\pm 0.016 \%$ \\
\hline \multicolumn{5}{|c|}{ Section \#2, 3 to 7 in. from the top of the wall } & \multicolumn{3}{|c|}{$\overline{\operatorname{Re}}$} & \multicolumn{3}{|c|}{${ }^{99} \mathrm{Tc}$} \\
\hline Sample ID & $\mathrm{X}$, in & $\mathrm{Y}$, in & $\mathrm{Z}$, in & $\mathrm{H}_{\mathrm{k}}$, in. & $\beta_{\mathrm{ikp}}$ & & & $\beta_{i k p}$ & & \\
\hline EST-16-03 & 8 & 2 & 5 & 4 & $5.2 \mathrm{E}-08$ & & & $3.5 \mathrm{E}-09$ & & \\
\hline \multirow[t]{3}{*}{ EST-15-03 } & 8 & 15 & 5 & 4 & $1.5 \mathrm{E}-08$ & & & $2.3 \mathrm{E}-09$ & & \\
\hline & & & & & $\overline{\beta_{i k}}$ & $f_{\mathrm{ik}}$ & $\overline{\sigma_{\mathrm{fik}}}$ & $\beta_{i k}$ & $f_{\mathrm{ik}}$ & $\overline{\sigma_{\mathrm{f} \mathrm{ik}}}$ \\
\hline & & & & & $3.32 \mathrm{E}-08$ & $0.313 \%$ & $\pm 0.049 \%$ & 2.93E-09 & $0.046 \%$ & $\pm 0.007 \%$ \\
\hline \multicolumn{4}{|c|}{ Section \#3, 7 to 11 in. from the top of the } & & \multicolumn{3}{|c|}{$\mathbf{R e}$} & \multicolumn{3}{|c|}{${ }^{99} \mathbf{T c}$} \\
\hline Sample ID & $\mathrm{X}$, in & $\mathrm{Y}$, in & $\mathrm{Z}$, in & $\mathrm{H}_{\mathrm{k}}$, in. & $\beta_{\mathrm{ikp}}$ & & & $\beta_{i k p}$ & & \\
\hline EST-16-02 & 8 & 2 & 9 & 4 & $1.3 \mathrm{E}-08$ & & & $1.3 \mathrm{E}-09$ & & \\
\hline \multirow[t]{3}{*}{ EST-15-02 } & 8 & 15 & 9 & 4 & 8.7E-09 & & & $9.7 \mathrm{E}-10$ & & \\
\hline & & & & & $\overline{\beta_{i k}}$ & 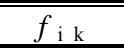 & $\sigma_{\mathrm{f} \mathrm{ik}_{\mathrm{k}}}$ & $\overline{\beta_{i k}}$ & $\overline{f f_{\mathrm{ik}}}$ & $\sigma_{\mathrm{fik}}$ \\
\hline & & & & & $1.1 \mathrm{E}-08$ & $0.104 \%$ & $\pm 0.017 \%$ & $1.1 \mathrm{E}-09$ & $0.017 \%$ & $\pm 0.003 \%$ \\
\hline \multicolumn{4}{|c|}{ Section $\# 4,11$ to 15 in. from the top of the } & & \multicolumn{3}{|c|}{ Re } & \multicolumn{3}{|c|}{${ }^{99} \mathrm{Tc}$} \\
\hline Sample ID & $X$, in & $Y$, in & $\mathrm{Z}$, in & $\mathrm{H}_{\mathrm{k}}$, in. & $\beta_{\mathrm{ikp}}$ & & & $\beta_{i k p}$ & & \\
\hline EST-16-01 & 8 & 2 & 13 & 4 & $3.2 \mathrm{E}-09$ & & & $2.8 \mathrm{E}-10$ & & \\
\hline \multirow[t]{3}{*}{ EST-15-01 } & 8 & 15 & 13 & 4 & $1.3 \mathrm{E}-08$ & & & $4.4 \mathrm{E}-10$ & & \\
\hline & & & & & $\overline{\beta_{i k}}$ & $\bar{~} f_{\mathrm{ik}}$ & $\sigma_{f_{\text {fik }}}$ & $\overline{\beta_{i k}}$ & $\overline{f_{\mathrm{ik}}}$ & $\sigma_{f_{\text {fik }}}$ \\
\hline & & & & & 7.9E-09 & $0.075 \%$ & $\pm 0.012 \%$ & $3.6 \mathrm{E}-10$ & $0.006 \%$ & $\pm 0.001 \%$ \\
\hline \multicolumn{3}{|c|}{ Section \#5, Refractory Base } & & & \multicolumn{3}{|c|}{$\mathbf{R e}$} & \multicolumn{3}{|c|}{${ }^{99} \mathrm{Tc}$} \\
\hline Sample ID & $X$, in & $\mathrm{Y}$, in & $Z$, in & $\mathrm{H}_{\mathrm{k}}$, in. & $\beta_{\mathrm{ikp}}$ & & & $\beta_{i k p}$ & & \\
\hline \multirow[t]{4}{*}{ EST-16-06 } & 10 & 8.5 & 17 & 4 & $5.9 \mathrm{E}-09$ & & & $1.7 \mathrm{E}-11$ & & \\
\hline & & & & & $\beta_{\mathrm{ik}}$ & $\overline{f f_{\mathrm{ik}}}$ & 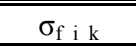 & $\beta_{i k}$ & $\overline{f f_{\mathrm{ik}}}$ & $\overline{\sigma_{\mathrm{f} \mathrm{i} \mathrm{k}}}$ \\
\hline & & & & & $5.9 \mathrm{E}-09$ & $0.041 \%$ & $0.007 \%$ & $1.7 \mathrm{E}-11$ & $0.0002 \%$ & $\pm 0.00003 \%$ \\
\hline & & & & & Total & $1.130 \%$ & $\pm 0.405 \%$ & Total & $0.171 \%$ & $\pm 0.063 \%$ \\
\hline${ }_{k}$ and $\sigma_{f, i}$ & the & 10 & per & 10 & & & & & & \\
\hline
\end{tabular}

The results listed in Table 8 can also be used to compare the leachable fraction of Re and ${ }^{99} \mathrm{Tc}$ from unglazed and glazed refractory. Samples with the identification numbers EST-16 refers to the unglazed portion of the CRB; EST-15 refers to the glazed portion of the CRB (see Table 8). An evaluation of these results suggests that there is no significant difference between the soluble fraction of Re and ${ }^{99} \mathrm{Tc}$ deposited on the glazed and unglazed portions of the CRB. 
Finally, using Eq. (1) and the results listed in Table 8, the ${ }^{99} \mathrm{Tc} / \mathrm{Re}$ volatilization ratio for each $k^{\text {th }}$ section was determined to be; $0.17 \pm 0.04,0.15 \pm 0.03,0.17 \pm 0.04,0.07 \pm 0.02$, and $0.005 \pm 0.001$ for sections $1-5$, respectively. The average ${ }^{99} \mathrm{Tc} / \mathrm{Re}$ volatilization ratio was $0.11 \pm 0.01$, which is approximately two times lower than the values reported for ES-32A and the FY03 sand layer samples (Thompson 2003).

\subsection{Summary of ES Soluble Fraction Test Results}

A large amount of process and extraction information has been acquired from seven ES tests. This section summarizes the available information and provides a best estimate of the leachable fraction of ${ }^{99} \mathrm{Tc}$ within the CRB from ES tests using the current BV process configuration.

In these dynamic ES tests, several factors contribute to the deposition of Re and/or ${ }^{99} \mathrm{Tc}$ on the CRB and box lid. These factors include: 1) horizontal and vertical temperature gradients in the CRB, 2) airflow, 3) physical and chemical changes in the CRB, and 4) mineralogical phase changes the CRB undergoes during the BV process (AMEC 2005a, b; Kim et al. 2004). Results from laboratory tests suggest that two mechanisms affect the deposition of these soluble salts: 1) vapor phase transport, and 2) molten salt intrusion. ${ }^{\text {(a) }}$ Although it is currently unclear which mechanism is dominant in these ES tests, each of the above factors affects the deposition of Re and/or ${ }^{99} \mathrm{Tc}$ into the CRB. Because of these process variations, the amount of leachable Re in each ES test, excluding the results from ES-31D (denitrated feed), ranged from a high of $4.82 \pm 1.51 \%$ to a low of $0.77 \pm 0.27 \%$ with an average value of $1.96 \pm 0.32 \%$. These results were combined with the ${ }^{99} \mathrm{Tc}$ results obtained from ES-32A and $-32 \mathrm{~B}$ to estimate the amount of ${ }^{99} \mathrm{Tc}$ that would be present as a soluble salt in the BV CRB.

As previously stated, Re was used as a chemical analogue for ${ }^{99} \mathrm{Tc}$ in non-radioactive ES tests. Previous studies of high-temperature vitrification processes clearly show that ${ }^{99} \mathrm{Tc}$ is significantly less volatile than Re (Darab and Smith 1996). To account for the difference in volatilization, an average ${ }^{99} \mathrm{Tc} / \mathrm{Re}$ volatilization ratio $(\bar{\alpha})$ of $0.17 \pm 0.02$ was calculated using the results from ES-32A and -32B. Section 4 from ES-32A was considered to be an outlier and therefore, excluded from the calculation. Using the total $\mathrm{Re}$ soluble fraction from each non-radioactive ES test: ES-31A, $-31 \mathrm{~B},-31 \mathrm{C}$, and $-31 \mathrm{E}$, an estimated soluble fraction of ${ }^{99} \mathrm{Tc}$ was calculated for each test using

$$
f_{\text {total }, \mathrm{Tc}}=f_{\text {total }, \mathrm{Re}} \bar{\alpha}
$$

where $f_{\text {total }}$ is the Re and ${ }^{99} \mathrm{Tc}$ extractable fraction. The resulting ${ }^{99} \mathrm{Tc}$ values for each non-radioactive ES test are displayed in Table 9 with the results from ES-32A and -32B for comparison.

The average best estimate of the ${ }^{99} \mathrm{Tc}$ inventory that would be leachable from the CRB in these ES tests is $0.34 \pm 0.06 \%$. This value is significantly lower than the FY03 ES tests that indicated that $2 \mathrm{wt} \%$ of the ${ }^{99} \mathrm{Tc}$ inventory waste stream ended up in the sand insulation and scoria layer after vitrification (Thompson 2003). The $0.34 \%$ estimate is only for the CRB and does not include other areas of the ES waste package that collect small amounts of soluble ${ }^{99}$ Tc deposits, as discussed in the following section.

(a) Personal communication with Pavel Hrma. These results will be provided in the report "Hrma et al. (2005). Bulk Vitrification Castable Refractory Block Protection Study. Draft Report, PNNL, Richland, WA." 
Table 9. Summary of ES Soluble Fraction Test Results and the Estimated ${ }^{99} \mathrm{Tc} / \mathrm{Re}$ Volatilization Ratio.

\begin{tabular}{|c|c|c|c|c|}
\hline AMEC ID & PNNL ID & $f_{\text {total, Re }}$ & $f_{\text {total, } T c}$ & $\alpha^{\mathrm{c}}$ \\
\hline ES-10 & ${ }^{\mathrm{a}} \mathrm{ES}-31 \mathrm{~A}$ & $1.51 \pm 0.54 \%$ & $0.25 \pm 0.09 \%$ & \\
\hline ES-11 & ${ }^{\mathrm{a}} \mathrm{ES}-31 \mathrm{~B}$ & $0.77 \pm 0.27 \%$ & $0.12 \pm 0.05 \%$ & \\
\hline ES-12 & ES-32A & $1.55 \pm 0.56 \%$ & $0.37 \pm 0.13 \%$ & $0.22 \pm 0.03^{\mathrm{b}}$ \\
\hline \multirow[t]{4}{*}{ ES-13 } & ES-32B & $1.13 \pm 0.41 \%$ & $0.17 \pm 0.06 \%$ & $0.11 \pm 0.01$ \\
\hline & ${ }^{\mathrm{a}} \mathrm{ES}-31 \mathrm{C}$ & $4.82 \pm 1.51 \%$ & $0.80 \pm 0.26 \%$ & \\
\hline & ${ }^{\mathrm{a}, \mathrm{d}} \mathrm{ES}-31 \mathrm{D}$ & $0.22 \pm 0.07 \%$ & $0.04 \pm 0.01 \%$ & \\
\hline & ${ }^{\mathrm{a}} \mathrm{ES}-31 \mathrm{E}$ & $1.96 \pm 0.69$ & $0.32 \pm 0.12 \%$ & \\
\hline \multicolumn{5}{|c|}{$\begin{array}{l}\text { 'N Nonradioactive ES tests } \\
\text { bection \#4 from ES-32A is not included in the volatilization ratio calculation } \\
{ }^{\mathrm{c}} \text { Average volatilization ratio, } \bar{\alpha}=0.17 \pm 0.05 \text {, calculated using results from ES-32A and }-32 B \\
\text { dDenitrated Feed and } \operatorname{Re}(\mathrm{IV}) \text { Spike Test }\end{array}$} \\
\hline
\end{tabular}

\subsection{Total Soluble ${ }^{99}$ Tc Fraction}

Although the CRB is the major source of soluble ${ }^{99} \mathrm{Tc}$ in the ES waste packages, other areas also contain smaller quantities of soluble ${ }^{99} \mathrm{Tc}$. These other areas include the surface of the glass block where small amounts of non-glassy materials collect, the refractory sand liner, and the ICV box lid that acts as a cover during the melting process but also serves as the disposal lid. Estimates of the amounts of soluble ${ }^{99} \mathrm{Tc}$ in these areas for ES-32A and ES-32B are reported in Kim et al. (2004) and AMEC (2005a). The results of these estimates are shown in Table 10 along with the values for the CRB. Table 10 also shows the best estimate values for each area and describes the basis for each estimate. The best estimate of the total soluble ${ }^{99} \mathrm{Tc}$ fraction from all areas in the ES tests is $0.45 \pm 0.07 \%$.

The total soluble ${ }^{99} \mathrm{Tc}$ fraction in the full-scale (FS) box is expected to be different than that determined from the ES tests. Several factors that are different between ES and FS, such as the lower surface area to volume ratio and the lower power requirements per mass of feed melted, indicate that the soluble 99Tc fraction in the large box may be significantly less. However, until FS Re-spiked tests are available to determine an appropriate scale-up factor that can be used to extrapolate the 99Tc data collected at the ES to the FS BV waste package, the best estimate soluble 99Tc fraction from the ES tests can be used as a conservative estimate for the full size system. 
Table 10. Best Estimate of Total Soluble ${ }^{99}$ Tc Inventory in ES Tests.

\begin{tabular}{|c|c|c|c|c|}
\hline Waste Package Area & ES-32A ${ }^{a}$ & ES-32B ${ }^{a}$ & Best Estimate $^{\mathrm{a}}$ & Basis of Best Estimate \\
\hline Castable Refractory Block & $0.37 \pm 0.13$ & $0.17 \pm 0.06$ & $0.34 \pm 0.06$ & See Section 0 \\
\hline Surface Glass Wash & $0.015^{\mathrm{b}}$ & $0.026 \pm 0.008$ & $0.026 \pm 0.008$ & $\begin{array}{c}\text { Maximum of two measured } \\
\text { values }\end{array}$ \\
\hline Refractory Sand Liner & $\mathrm{BRL}^{\mathrm{c}}$ & $\begin{array}{c}0.0001 \\
+0.0002 /-0.0001\end{array}$ & $\begin{array}{c}0.0001 \\
+0.0002 /-0.0001\end{array}$ & $\begin{array}{l}\text { Only Measured }{ }^{99} \mathrm{Tc} \text { value } \\
\text { above reporting limit }\end{array}$ \\
\hline Box Lid & $0.053^{\mathrm{b}, \mathrm{d}}$ & $0.112 \pm 0.042$ & $0.083 \pm 0.031^{\mathrm{e}}$ & $\begin{array}{c}\text { Average of two measured } \\
\text { lid values }\end{array}$ \\
\hline \multicolumn{3}{|c|}{ Total } & $0.45 \pm 0.07 \%{ }^{f}$ & \\
\hline \multicolumn{5}{|c|}{$\begin{array}{l}{ }^{2} \text { All values reported in units of \% relative to amount of }{ }^{99} \text { Tc spike added. } \\
{ }^{b} \text { No uncertainty reported. } \\
\text { cBelow reportable limit. } \\
{ }^{d} \text { Summation of overall hood value and exhaust side value taken from Kim et al. (2004). } \\
\text { eSame relative uncertainty from ES-32B applied to best estimate value. } \\
\text { f Uncertainty estimated by addition in quadrature. }\end{array}$} \\
\hline
\end{tabular}




\subsection{Kinetic Rate Law}

To predict the long-term fate of glass in the subsurface over the period of regulatory concern, a mathematical model that describes glass reactivity is needed. Over the last few decades, a general rate equation has been fashioned to describe the dissolution of glass (and more ordered materials) into aqueous solution. As described below, the equation is based on the Transition State Theory (TST) of chemical kinetics, in which the overall reaction rate is governed by the slowest elementary reaction. Elementary reactions have simple stoichiometry and can be combined as an overall reaction. In many cases, the elementary reactions can only be inferred. As an example of an elementary reaction, consider the dissolution of $\mathrm{SiO}_{2}$ polymorphs to form silicic acid:

$$
\mathrm{SiO}_{2} \text { (solid) }+2 \mathrm{H}_{2} \mathrm{O} \leftrightarrow \mathrm{SiO}_{2} \cdot 2 \mathrm{H}_{2} \mathrm{O}^{\ddagger} \rightarrow \mathrm{H}_{4} \mathrm{SiO}_{4} \text { (aqueous) }
$$

in which $\mathrm{SiO}_{2} \cdot 2 \mathrm{H}_{2} \mathrm{O}^{\ddagger}$ represents an activated complex of unknown stoichiometry. Note that the reactants and the activated complex in Equation (3) are linked by a double-headed arrow symbolizing a reversible reaction. Equation (3) also illustrates that the TST formulation assumes the decay of the activated complex is an irreversible reaction.

With these assumptions, a general equation describing the rate of reaction as a function of $\mathrm{pH}$, temperature, saturation state of the system, and the activities of rate enhancing or inhibiting species (Aagaard and Helgeson 1982) has been proposed

$$
r=\vec{k} v_{i} a_{\mathrm{H}^{+}}^{ \pm \eta} \exp \left(\frac{-E_{a}}{R T}\right)\left[1-\frac{Q}{K_{g}}\right]^{\sigma} \prod_{j} a_{j}^{\eta_{i}}, i=1,2, \ldots N
$$

where $r$ is the dissolution rate in $\mathrm{g} \mathrm{m}^{-2} \mathrm{~d}^{-1}, \vec{k}$ is the intrinsic rate constant in $\mathrm{g} \mathrm{m}^{-2} \mathrm{~d}^{-1}, v_{i}$ is the mass fraction of element $i, a_{H^{+}}$is the hydrogen ion activity, $a_{j}$ is the activity of the $j^{\text {th }}$ aqueous species that acts as an inhibitor or catalyst, $E_{a}$ is the activation energy in $\mathrm{kJ} \mathrm{mol}^{-1}, R$ is the gas constant in $\mathrm{kJ} \mathrm{mol}^{-1} \mathrm{~K}^{-1}, T$ is the temperature in $\mathrm{K}, Q$ is the ion activity product, $K_{g}$ is the pseudo-equilibrium constant for glass, $\eta$ is the power law coefficient, and $\sigma$ is the Temkin coefficient. Although there are a number of issues regarding the applicability of Equation (4) for modeling glass dissolution, McGrail et al. (2000a) concluded that this rate law currently "... best describes the majority of the experimental data that has been gathered after over 35 years of studying the glass/water reaction processes." Consequently, parameterization of this equation is required to conduct source-term calculations with the STORM code (Bacon et al. 2004). Because the disposal system temperature is a known constant, the determination of five parameters: $\vec{k}, E_{a}$, $\eta$, $\sigma$, and $K_{g}$, is required for each glass formulation (neglecting the $\prod_{j} a_{j}^{\eta_{i}}$ term). The ion activity product $(Q)$ is a variable and must be computed with STORM as a function of time and space for the disposal system. Lasaga (1995) convincingly argues that $\sigma=1$ in the above equation because any value where $\sigma \neq$ 1 is inconsistent with transition state theory. Consequently, $\sigma=1$ is assumed for this work, thus eliminating $\sigma$ as an unknown parameter in the rate law. 


\subsection{Rate Law Experimental Materials and Methods}

This section discusses techniques and procedures used to prepare each glass sample, buffer solutions, SPFT test, and calculate the dissolution rate and associated uncertainty.

\subsubsection{Bulk Composition Analysis}

Two samples from an engineering-scale test (BKV7 and BKV8), one simulated glass/refractory interface crucible melt sample (BKVZ), and a sample of untreated cast refractory (BKVM) were selected for testing. For ease of discussion, the labels used in the SPFT experiments, listed in Table 11, will be

Table 11. List of Sample Identification Labels.

\begin{tabular}{|c|c|c|}
\hline Sample I.D. & PNNL I.D. & $\begin{array}{c}\text { SPFT } \\
\text { Exp. I.D. }\end{array}$ \\
\hline ASCM-01-CCC & Six Tank Comp. & BKV1 \\
\hline AMP1-01a-B & S-109 Simulant & BKV6 \\
\hline AMP1-01a-SC & Mullite/Glass Interface & BKVZ \\
\hline ES-10 (ES-31A) & ES-10-Centerline & BKV7 \\
\hline ES-10 (ES-31A) & ES-10-Interface & BKV8 \\
\hline Untreated Refractory & Mullite Refractory & BKVM \\
\hline \multicolumn{3}{|c|}{$\begin{array}{l}\text { Exp. I.D. - Experiment identification. } \\
\text { BKV1 - FY03 crucible melt glass sample. } \\
\text { FY04 glass samples are BKV6, BKV7, BKV8, and BKVZ. } \\
\text { BKV6 - FY04 crucible melt glass sample. } \\
\text { BKV7 and BKV8 are ES glass samples. }\end{array}$} \\
\hline
\end{tabular}
used when referring to individual experiments and the Pacific Northwest National Laboratory (PNNL) identification will be used when referring to a group of experiments on one glass sample. Samples from ES-10 were taken from the middle and glass/mullite interface, BKV7 and BKV8, respectively. Another crucible melt sample, BKV6, that had been heat-treated according to the expected centerline cooling curve (CCC), shown in Table 12 was also tested.

Table 12. Calculated Thermal Cool-Down Schedule for Crucible Melt Samples BKV6 and BKV1.

\begin{tabular}{|c|c|c|c|c|c|}
\hline \multicolumn{3}{|c|}{ BKV1 } & \multicolumn{3}{|c|}{ BKV6 } \\
\hline $\begin{array}{c}\text { Time } \\
(\mathbf{h r})\end{array}$ & $\begin{array}{c}\text { Crucible } \\
\text { Melt }\left({ }^{\circ} \mathbf{C}\right) \\
\text { C.D.S }\end{array}$ & $\begin{array}{c}\Delta \mathbf{T} / \Delta \mathbf{t} \\
\left({ }^{\circ} \mathbf{C} / \mathbf{h r}\right)\end{array}$ & Time (hr) & $\begin{array}{c}\text { Crucible } \\
\text { Melt }\left({ }^{\circ} \mathbf{C}\right) \\
\text { C.D.S }\end{array}$ & $\begin{array}{c}\Delta \mathbf{T} / \Delta \mathbf{t} \\
\left({ }^{\circ} \mathbf{C} / \mathbf{h r}\right)\end{array}$ \\
\hline $0-14$ & $1300-1080$ & -15.71 & $0-13.4$ & $1270-1200$ & -5.22 \\
\hline $14-38$ & $1080-880$ & -8.33 & $13.4-34.3$ & $1200-1100$ & -4.78 \\
\hline $38-62$ & $880-720$ & -6.67 & $34.3-60.9$ & $1100-1000$ & -2.50 \\
\hline $62-86$ & $720-600$ & -5.00 & $60.9-88.4$ & $1000-900$ & -2.07 \\
\hline $86-110$ & $600-500$ & -4.17 & $88.4-120.1$ & $900-800$ & -1.39 \\
\hline & & & $120.1-157.3$ & $800-700$ & -1.17 \\
\hline & & & $157.3-197.5$ & $700-600$ & -0.89 \\
\hline & & & $197.5-248.5$ & $600-500$ & -0.73 \\
\hline
\end{tabular}

The compositions of each bulk vitrified glass formulation and cast refractory are displayed in Table 13. A low-activity waste (LAW) glass formulation, LAWA44, and the FY03 crucible melt glass formulation, BKV1, are shown for comparison. Although these BV glass formulations contain $\sim 4 \%$ less boron $\left(\mathrm{B}_{2} \mathrm{O}_{3}\right.$ in Table 13) in comparison to a typical WTP Envelope A glass, LAWA44, the overall compositions are similar. The composition of each glass sample was determined by analyzing sodium peroxide $\left(\mathrm{Na}_{2} \mathrm{O}_{2}\right)$ and lithium borate $\left(\mathrm{LiBO}_{2}\right)$ fusions via inductively coupled optical emission mass spectroscopy (ICP-OES) and/or inductively coupled mass spectrometry (ICP-MS). For a more detailed description of the techniques used see McGrail et al. (2001a). 
Table 13. Normalized Chemical Composition of Bulk Vitrified Glass Samples.

\begin{tabular}{|c|c|c|c|c|c|c|c|c|}
\hline Oxide & ${ }^{\mathrm{a}}$ Target & ${ }^{\mathrm{b}} \mathrm{BKV1}$ & $\begin{array}{c}{ }^{\mathrm{c}} \mathrm{BKV6} \\
\end{array}$ & $\begin{array}{c}{ }^{\mathrm{c}} \mathrm{BKV7} \\
\end{array}$ & $\begin{array}{l}{ }^{\mathrm{c}} \mathrm{BKV} 8 \\
\end{array}$ & $\bar{c}$ cBKVM & $\begin{array}{l}{ }^{\mathrm{c}} \mathrm{BKVZ} \\
\end{array}$ & ${ }^{\mathrm{b}}$ LAWA44 \\
\hline$\overline{\mathrm{Al}_{2} \mathrm{O}_{3}}$ & 9.12 & 8.69 & 10.02 & 10.29 & 10.475 & 59.56 & 9.13 & 6.2 \\
\hline $\mathrm{B}_{2} \mathrm{O}_{3}$ & 4.65 & 5.99 & 4.19 & 6.076 & 6.033 & 0.951 & 5.00 & 8.9 \\
\hline $\mathrm{CaO}$ & 2.62 & 2.71 & 3.36 & 3.663 & 3.797 & 2.133 & 2.78 & 1.99 \\
\hline $\mathrm{Cl}$ & 0.18 & 0.03 & ND & ND & ND & ND & 0.03 & 0.65 \\
\hline $\mathrm{Cr}_{2} \mathrm{O}_{3}$ & 0.1 & 0.09 & 0.58 & 0.092 & 0.096 & 0.375 & 0.130 & 0.02 \\
\hline $\mathrm{Fe}_{2} \mathrm{O}_{3}$ & 4.01 & 3.69 & 4.75 & 4.582 & 4.35 & 0.805 & 4.34 & 6.98 \\
\hline $\mathrm{K}_{2} \mathrm{O}$ & 1.78 & 1.65 & 1.14 & 1.684 & 1.554 & 0.139 & 1.51 & 0.5 \\
\hline $\mathrm{MgO}$ & 1.19 & 1.23 & 1.54 & 1.62 & 1.527 & 0.081 & 1.35 & 1.99 \\
\hline $\mathrm{MnO}$ & ND & ND & 0.09 & 0.077 & 0.073 & 0.005 & 0.07 & ND \\
\hline $\mathrm{MoO}_{2}$ & ND & ND & 0.01 & 0.009 & 0.009 & 0.006 & ND & 0.01 \\
\hline $\mathrm{Na}_{2} \mathrm{O}$ & 21.37 & 22.19 & 19.83 & 18.86 & 18.02 & 0.63 & 20.00 & 20 \\
\hline $\mathrm{NiO}$ & ND & ND & 0.01 & 0.011 & 0.011 & 0.008 & ND & ND \\
\hline $\mathrm{P}_{2} \mathrm{O}_{5}$ & 0.49 & 0.42 & 0.46 & 0.386 & 0.35 & 0.307 & 0.60 & 0.03 \\
\hline $\mathrm{ReO}_{2}$ & 0.09 & 0.001 & ND & ND & ND & ND & ND & 0.09 \\
\hline $\mathrm{SO}_{3}$ & 0.52 & 0.67 & 0.07 & 0.209 & 0.578 & 0.062 & 0.340 & 0.1 \\
\hline $\mathrm{SiO}_{2}$ & 46.79 & 45.2 & 47.23 & 45.28 & 46.62 & 33.09 & 46.83 & 44.55 \\
\hline $\mathrm{SrO}$ & ND & ND & 0.04 & 0.037 & 0.037 & 0.029 & 0.03 & ND \\
\hline $\mathrm{TiO}_{2}$ & 0.65 & 0.63 & 0.88 & 0.902 & 0.892 & 1.621 & 0.80 & 1.99 \\
\hline $\mathrm{ZnO}$ & ND & ND & 0.03 & 0.026 & 0.04 & 0.044 & ND & 2.96 \\
\hline $\mathrm{ZrO}_{2}$ & 6.09 & 6.82 & 5.79 & 6.2 & 5.543 & 0.154 & 7.00 & 2.99 \\
\hline Total & 100 & 100 & 100 & 100 & 100 & 100 & 100 & 100 \\
\hline \multicolumn{9}{|c|}{$\begin{array}{l}\text { ND - Not Determined. } \\
{ }^{\mathrm{a}} \text { Target compositions were used in rate law parameter calculations for BKV6. } \\
\text { b Composition determined using XRF and analytical chemistry analysis of fusions via ICP-OES } \\
\text { and ICP-MS. } \\
\text { c } \text { Composition determined using analytical chemistry analysis of fusions via ICP-OES. }\end{array}$} \\
\hline
\end{tabular}

\subsubsection{Material Preparation}

The samples used in this study were prepared by crushing a sub-sample of glass in a ceramic ball mill. The crushed glass was then sieved into $-100+200$ mesh (149 to $75 \mu \mathrm{m}$ diameter) size fractions, washed in deionized water (DIW), sonicated in DIW, rinsed in ethanol, and dried in a $90^{\circ} \mathrm{C}$ oven. The specific surface area for the glass samples BKV6, BKV7, and BKV8 was calculated using a geometric formula (McGrail et al. 1997). The geometric formula assumes that the particles are spherical, size distributions of the grains are normally distributed, and that surface pits, cracks, and other forms of surface roughness do not affect the surface area. Although all three assumptions may not be valid, results from LAW glass experiments using glass coupons, with a calculated and measured surface area, have shown that the geometric surface area best represents the overall glass surface area (McGrail et al. 2000b). However, nitrogen adsorption BET (Brunauer et al. 1938) measurements [Micromeritics ASAP 2010 surface area analyzer (Micromeritics 1995)] were used to determine the specific surface area of the castable refractory sample BKVM. Additional details on determining the surface area of the CRB are discussed in Section 3.2.2. 


\subsubsection{Buffer Solutions}

The solutions used to control the $\mathrm{pH}$ during the SPFT experiments are summarized in Table 14 . Table 14 also contains a summary of the in-situ $\mathrm{pH}$ values computed at each test temperature using the thermodynamic software package EQ3NR (Wolery 1992b). It is important to take into account the change in $\mathrm{pH}$ that occurs at different temperatures when computing dissolution rates from SPFT data, as the in-situ $\mathrm{pH}$ can vary by as much as $1.5 \mathrm{pH}$ units over the temperature range from $23^{\circ}$ to $90^{\circ} \mathrm{C}$. These solutions were prepared by adding small amounts of the organic tris (hydroxymethyl) aminomethane (THAM) buffer to DIW and adjusting the solution to the desired $\mathrm{pH}$ value using $15.8 \mathrm{M} \mathrm{HNO}_{3}$ or $1 \mathrm{M}$ $\mathrm{LiOH}$. The THAM buffer range is between $\mathrm{pH} 7$ to 10; therefore, the alkaline solutions, $\mathrm{pH}$ range 11 and 12, were prepared by adding $\mathrm{LiOH}$ and $\mathrm{LiCl}$ to DIW and adjusting the solution to the desired $\mathrm{pH}$ value using 15.8 $\mathrm{M} \mathrm{HNO}_{3}$ or $1 \mathrm{M} \mathrm{LiOH}$.

Table 14. Solution Composition of Solutions Used in SPFT Experiments. Solution pH values above $23^{\circ} \mathrm{C}$ were calculated with EQ3NR Code V7.2b database.

\begin{tabular}{|c|c|c|c|c|c|}
\hline \multirow{2}{*}{ Solution } & \multirow{2}{*}{ Composition } & \multicolumn{4}{|c|}{ pH@ } \\
\hline & & $23^{\circ} \mathrm{C}$ & $40^{\circ} \mathrm{C}$ & $70^{\circ} \mathrm{C}$ & $90^{\circ} \mathrm{C}$ \\
\hline 1 & $0.05 \mathrm{M} \mathrm{THAM}+0.047 \mathrm{M} \mathrm{HNO}_{3}$ & 7.01 & 6.57 & 5.91 & 5.55 \\
\hline 2 & $0.05 \mathrm{M}$ THAM $+0.02 \mathrm{M} \mathrm{HNO}_{3}$ & 8.32 & 7.90 & 7.25 & 6.89 \\
\hline 3 & $0.05 \mathrm{M} \mathrm{THAM}+0.0041 \mathrm{M} \mathrm{HNO}_{3}$ & 8.99 & 8.67 & 8.08 & 7.72 \\
\hline 4 & $0.05 \mathrm{M}$ THAM + $0.003 \mathrm{M} \mathrm{LiOH}$ & 9.99 & 9.55 & 8.88 & 8.52 \\
\hline 5 & $0.0107 \mathrm{M} \mathrm{LiOH}+0.010 \mathrm{M} \mathrm{LiCl}$ & 11.00 & 10.89 & 10.43 & 10.06 \\
\hline 6 & $0.0207 \mathrm{M} \mathrm{LiOH}+0.010 \mathrm{M} \mathrm{LiCl}$ & 12.02 & 11.74 & 11.08 & 10.70 \\
\hline 7 & $0.05 \mathrm{M}$ THAM $+\mathrm{Si}^{*}$ & 9.00 & 8.83 & 8.51 & 8.27 \\
\hline
\end{tabular}

Influent silicon concentration was varied from dilute to saturated with respect to amorphous silica $\left[\mathrm{SiO}_{2}(\mathrm{am})\right]$, based on the results from calculations using EQ3NR (Wolery 1992b) for select experiments. The solubility behavior of $\mathrm{SiO}_{2}(\mathrm{am})$ changes with temperature; therefore, the target amount of $\mathrm{Si}$ added to each solution was adjusted to correspond to the experimental temperature being interrogated, resulting in Si solution concentrations that ranged from 15 to $140 \mathrm{ppm}$. These solutions were prepared by dissolving analytical grade silicic acid powder $\left(\mathrm{SiO}_{2} \bullet \mathrm{H}_{2} \mathrm{O}\right)$ in a solution of $0.05 \mathrm{M}$ THAM buffer and heating the mixture in a $90^{\circ} \mathrm{C}$ oven for no less than 3 days to facilitate complete dissolution. Upon complete dissolution, each solution was removed from the oven, allowed to cool, and $\mathrm{pH}$ adjusted (target $\mathrm{pH}=9$ ) using aliquots of $15.8 \mathrm{M} \mathrm{HNO}_{3}$ or $1 \mathrm{M} \mathrm{LiOH}$.

\subsubsection{SPFT Apparatus}

Dissolution experiments were conducted using the SPFT apparatus (Figure11). The SPFT experimental system provides a continuous flow of fresh influent solution, prevents the build-up of reaction products, maintains the bulk solution composition throughout an experiment, provides a direct measure of the dissolution rate, and allows an investigator to study the reactivity of a material over a wide range of experimental conditions. This system has been extensively described by McGrail et al. (2000a) and the references contained therein. 


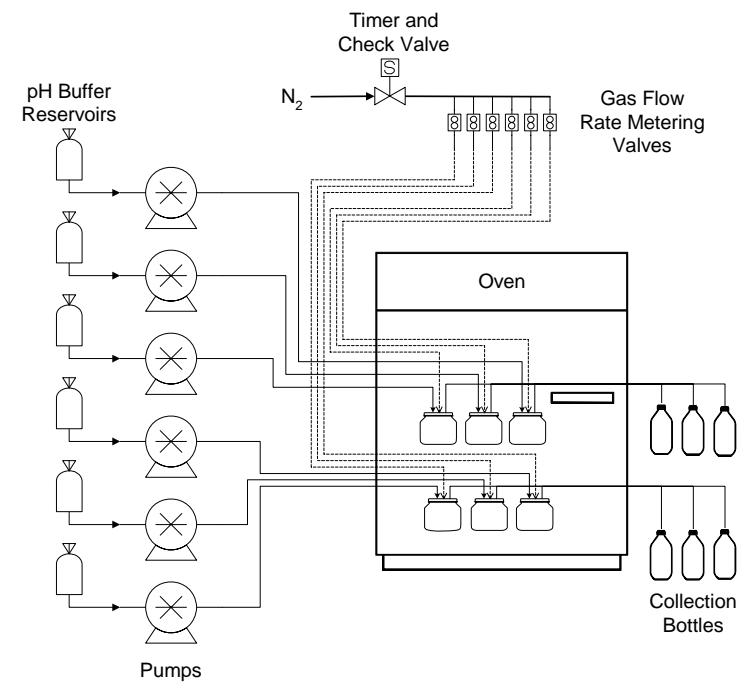

Figure 11. Schematic of the Single Pass Flow-Through (SPFT) Apparatus.

In general, solution is transferred using a Kloehn syringe pump (Model 50300) from a reservoir bottle to a Teflon reactor and finally to a sample collection vial using 1.59-mm Teflon tubing. The Teflon reactor vessels consisted of two main pieces, (e.g., a top and bottom) that threaded together to form a cylinder that was $63-\mathrm{mm}$ tall, with a $47.5-\mathrm{mm}$ outer diameter, and a total inner volume of approximately $80 \mathrm{~mL}$. The relatively large diameter of the sample holder (40.6-mm inner diameter) allows the glass particles to form a thin layer at the reactor bottom and interact with the contacting solution. The effluent solutions were monitored for four major glass components: Al, B, Na, and Si using ICP-OES.

\subsubsection{Dissolution Rate and Error Calculation}

Dissolution rates, based on steady-state concentrations of elements in the effluent, are normalized to the amount of the element present in the sample by the following formula:

$$
\text { Normalized dissolution rate, } \mathrm{g} \mathrm{m}^{-2} \mathrm{~d}^{-1}=\frac{\left(C_{i}-\bar{C}_{i, b}\right) q}{f_{i} S}
$$

where $C_{i}$ is the concentration of the element, $i$, in the effluent $\left(\mathrm{g} \mathrm{L}^{-1}\right), \bar{C}_{i, b}$ is the average background concentration of the element of interest $\left(\mathrm{g} \mathrm{L}^{-1}\right), q$ is the flow-through rate $\left(\mathrm{L} \mathrm{d}^{-1}\right), f_{i}$ is the mass fraction of the element in glass (dimensionless), and $S$ is the surface area of the sample $\left(\mathrm{m}^{2}\right)$. The value of $f_{i}$ can be calculated from the chemical composition of the sample. Flow-through rates are determined by gravimetric analysis of the fluid collected in each effluent collection vessel upon sampling. The background concentration of the element of interest is determined, as previously discussed, by analysis of the starting input solution and the three blank solutions. Typically, background concentrations of elements are below their respective detection threshold. The detection threshold of any element is defined here as the lowest calibration standard that can be determined reproducibly during an analytical run within $10 \%$ multiplied by the sample dilution factor. In cases where the analyte is below the detection threshold, the background concentration of the element is set at the value of the detection threshold. 
Determining the experimental uncertainty of the dissolution rate takes into account uncertainties of each parameter in Eq. (5). For uncorrelated random errors, the standard deviation of a function $f\left(x_{1}\right.$, $\left.x_{2}, \ldots x_{n}\right)$ is given by:

$$
\sigma_{f}=\sqrt{\sum_{i=1}^{n}\left(\frac{\partial f}{\partial x_{i}}\right)^{2} \sigma_{i}^{2}}
$$

where $\sigma_{f}$ is the standard deviation of the function $f ., x_{i}$ is the parameter $i$, and $\sigma_{i}$ is the standard deviation of parameter $i$. Substituting (5) into (6) results in

$$
\sigma_{r_{i}}=\sqrt{\left(\frac{q}{f_{i} S}\right)^{2}\left(\sigma_{C_{i}}^{2}+\sigma_{\bar{C}_{i, b}}^{2}\right)+\left(\frac{C_{i}-\bar{C}_{i, b}}{f_{i} S}\right)^{2} \sigma_{q}^{2}+\left(\frac{\left(C_{i}-\bar{C}_{i, b}\right) q}{f_{i}^{2} S}\right)^{2} \sigma_{f_{i}}^{2}+\left(\frac{\left(C_{i}-\bar{C}_{i, b}\right) q}{f_{i} S^{2}}\right)^{2} \sigma_{S}^{2}}
$$

Eq. (7) can also be expressed in terms of the relative error, $\hat{\sigma}_{r_{i}}=\sigma_{r_{i}} / r_{i}$, and is given by

$$
\hat{\sigma}_{r_{i}}=\sqrt{\frac{\left(\hat{\sigma}_{C_{i}} C_{i}\right)^{2}+\left(\hat{\sigma}_{\bar{C}_{i, b}} \bar{C}_{i, b}\right)^{2}}{\left(C_{i}-\bar{C}_{i, b}\right)^{2}}+\hat{\sigma}_{q}^{2}+\hat{\sigma}_{f_{i}}^{2}+\hat{\sigma}_{S}^{2}}
$$

Relative errors of $10 \%, 10 \%, 5 \%, 3 \%$, and $15 \%$ for $C_{i}, \bar{C}_{i, b}, q, f_{i}$, and $S$, respectively, are typical for measurements conducted at PNNL. Although the absolute error in $f_{i}$ is likely higher than $3 \%$, this error is non-systematic and so does not contribute significantly to sample-to-sample uncertainty, which is the principal error of interest here. The conservative appraisal of errors assigned to the parameters in Eq. (8), in addition to the practice of imputing detection threshold values to background concentrations, results in typical uncertainties of approximately $\pm 35 \%$ on the dissolution rate.

\subsection{SPFT Results}

Silicate waste glass dissolution depends strongly on temperature, $\mathrm{pH}$, and the solution chemistry contacting the glass (McGrail et al. 2000a; 2003a). As expected, dissolution of BV glass followed very similar patterns as has been observed for WTP glasses. A comprehensive list of the experimental conditions, temperature, solution $\mathrm{pH}$, flow-through rates $(q)$, and solution saturation state used in these experiments is given in Appendix B. To simplify the discussion, the data set has been divided into two sections. In the first section, the results of SPFT tests conducted using S-109 simulant crucible melt glass (BKV6) and the mullite castable refractory (BKVM) samples are discussed to determine rate law parameters for dissolution of the BV waste package glass and refractory. This section is followed by a summary section that compares the experimental results obtained in FY03 (McGrail et al. 2003b) to the data used to determine the rate law parameters for the STORM code. 


\subsubsection{SPFT Results for BKV6 Glass}

The majority of the reported rates are computed based on the concentration of Na. Although $\mathrm{B}$ is considered the most reliable index for matrix dissolution, $\mathrm{Na}$ was used here because of sensitivity issues encountered when analyzing for B via ICP-OES. Although $\mathrm{Na}$ is released from the glass via two separate mechanisms, matrix dissolution and alkali-hydrogen exchange, it is a more reliable measure of matrix dissolution rates than are $\mathrm{Al}$ and Si. Release of $\mathrm{Al}$ and $\mathrm{Si}$ from the glass matrix may be inhibited by the formation of alteration layers on the glass surface, thereby providing an under estimation of the overall dissolution rate. Therefore, a conservative approach was taken by using $\mathrm{Na}$ as the primary element for determining the corresponding rate law parameters for BKV6.

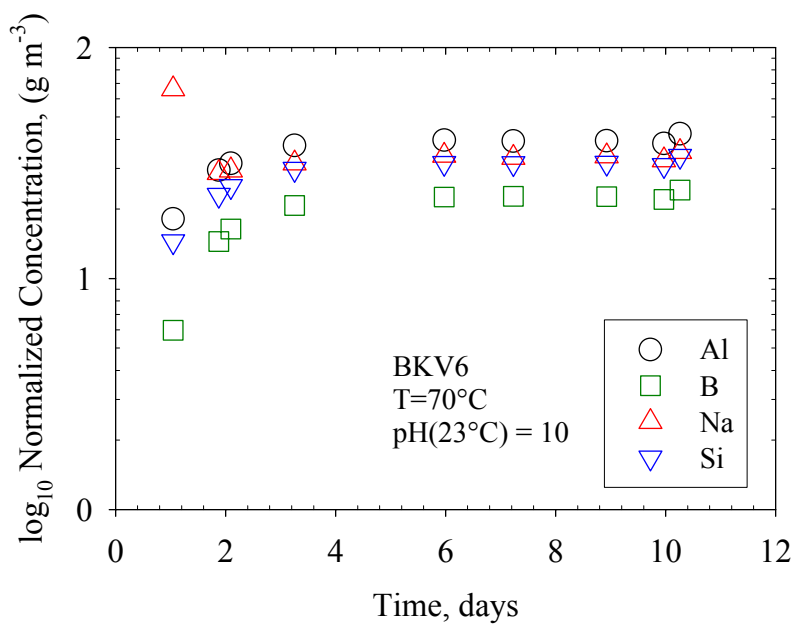

Figure 12. $\mathrm{Al}, \mathrm{B}, \mathrm{Na}$, and $\mathrm{Si}$ Concentration for BKV6 Glass at $70^{\circ} \mathrm{C}$ and $\mathrm{pH}\left(23^{\circ} \mathrm{C}\right)=10$.

\subsubsection{Achievement of Steady-State and Consistency of Results}

Obtaining valid dissolution rates depends on the glass-solution system reaching steady-state conditions. Figure 12 shows that these conditions were met for an experiment conducted at $70^{\circ} \mathrm{C}$ and $\mathrm{pH}\left(23^{\circ} \mathrm{C}\right)=10$. Concentrations of $\mathrm{Al}, \mathrm{B}, \mathrm{Na}$, and Si were invariant with respect to time after approximately seven reactor volumes in these experiments. The results shown in Figure 12 are typical of all experiments.

Figure 13 illustrates the steady-state dissolution rates for $\mathrm{Al}, \mathrm{B}, \mathrm{Na}$, and $\mathrm{Si}$ at $70^{\circ} \mathrm{C}$ and $\mathrm{pH}$ $\left(23^{\circ} \mathrm{C}\right)=10$. These results suggest each element is being released congruently from the glass matrix into solution. The results also show that ma-

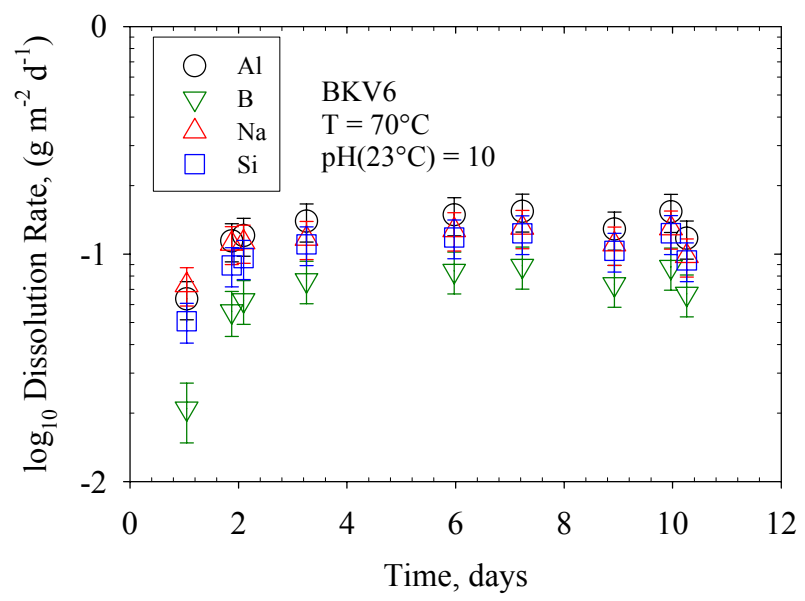

Figure 13. Dissolution Rate as a Function of Time for BKV6 Glass at $70^{\circ} \mathrm{C}$ and $\mathrm{pH}\left(23^{\circ} \mathrm{C}\right)=10$. trix dissolution is the dominant mechanism of dissolution under these conditions, suggesting that alkali-hydrogen is having little effect on the overall dissolution rate. This result is to be expected, considering that at this alkaline $\mathrm{pH}$ glass dissolution tends to occur rapidly. 


\subsubsection{Effect of pH on BKV6 Glass}

To determine the effect of $\mathrm{pH}$ on the dissolution rate, solution $\mathrm{pH}$ values were varied between 7 and 12 at temperatures of $23^{\circ}, 40^{\circ}, 70^{\circ}$, and $90^{\circ} \mathrm{C}$. The in-situ solution $\mathrm{pH}$ has been corrected for the effect of temperature using EQ3NR (Table 14). Figure 14 illustrates that as the $\mathrm{pH}$ increases from 7 to 12 , the overall glass dissolution rate also increases. This direct relationship between the dissolution rate and $\mathrm{pH}$, going from the neutral to alkaline $\mathrm{pH}$ range, is typical for LAW glasses and was also observed in test conducted on the sixtank composite glass composition, BKV1. Performing a linear regression on the data at each temperature gave a slope $\eta=0.53 \pm 0.03$ indicating that $\eta$ does not depend on temperature within

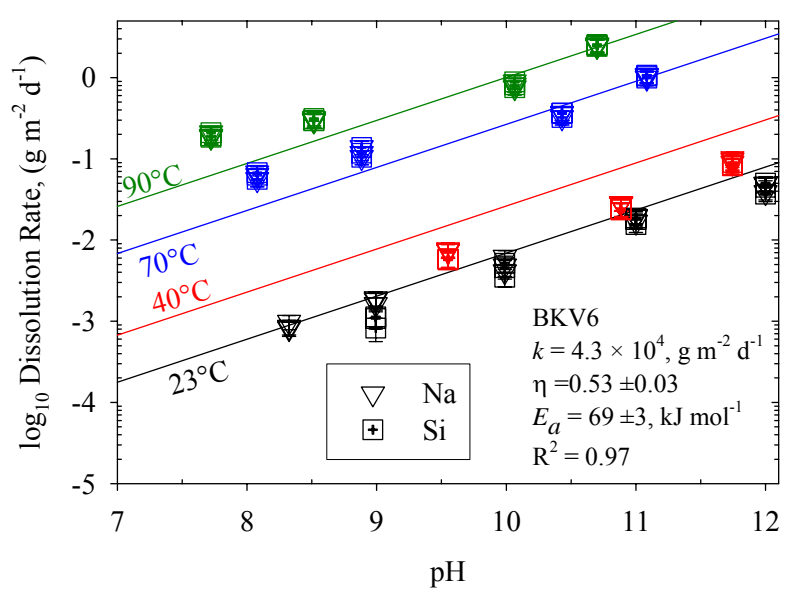

Figure 14. Na Dissolution Rate as a Function of $\mathrm{pH}$ and Temperature for BKV6 Glass.

experimental error. Using this value for $\eta$, a non-linear regression was performed on the entire data set shown in Figure 14 using the kinetic rate law:

$$
J=\vec{k}_{o} 10^{\eta p H} \exp \left(\frac{-E_{a}}{R T}\right)
$$

where $J$ is the normalized release rate, $\vec{k}_{o}$ is the intrinsic rate constant in $\mathrm{g} \mathrm{m}^{-2} \mathrm{~d}^{-1}, \eta$ is the power law coefficient, $E_{a}$ is the activation energy in $\mathrm{kJ} \mathrm{mol}^{-1}, R$ is the ideal gas constant in $\mathrm{kJ} \mathrm{K} \mathrm{mol}^{-1}$ and $T$ is the temperature in $\mathrm{K}$. The resulting regression coefficients are $\vec{k}_{o}=4.3 \times 10^{4} \mathrm{~g} \mathrm{~m}^{-2} \mathrm{~d}^{-1}, E_{a}=69 \pm 3 \mathrm{~kJ} \mathrm{~mol}^{-1}$ with a correlation coefficient $\left(\mathrm{R}^{2}\right)$ of 0.97 . The value of $\eta$ is within the experimental error of values reported for LAW glass formulation, LAWA44, $0.49 \pm 0.08$ (Pierce et al. 2004b), but higher than the values reported in FY03 for BKV1, $\eta=0.42 \pm 0.02$ (McGrail et al. 2003b), and LAWABP1, $\eta=0.35 \pm 0.03$ (McGrail et al. 2001a).

Figure 14 also illustrates that temperature has a strong effect on the dissolution rates. The apparent activation energy determined $\left(E_{a}=69 \pm 3 \mathrm{~kJ} \mathrm{~mol}^{-1}\right)$ corresponds to a surface controlled reaction process, 41.8 to $83.7 \mathrm{~kJ} \mathrm{~mol}^{-1}$ (Lasaga 1981). This value is in good agreement with the values reported for BKV1, other LAW glass formulations, and several $\mathrm{SiO}_{2}$ polymorphs $\left[\mathrm{BKV} 1=77 \pm 3 \mathrm{~kJ} \mathrm{~mol}^{-1}\right.$ ( $\mathrm{McGrail}^{\mathrm{et}}$ al. 2003b), LAWA44 = $60 \pm 7 \mathrm{~kJ} \mathrm{~mol}^{-1}$ (Pierce et al. 2004b), LAWC22 $64 \pm 2 \mathrm{~kJ} \mathrm{~mol}^{-1}$ (Pierce et al. 2004b),

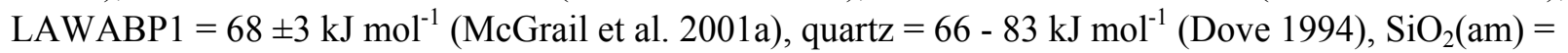
$74.5 \mathrm{~kJ} \mathrm{~mol}^{-1}$ (Icenhower and Dove 2000), and cristobalite $=69 \mathrm{~kJ} \mathrm{~mol}^{-1}$ (Renders 1995)], suggesting that the rupture of the $\mathrm{Si}-\mathrm{O}$ bond is the rate-limiting step in dissolution. The Na release rates at $40^{\circ} \mathrm{C}$ suggest that alkali-hydrogen ion exchange, "a secondary reaction mechanism" may be affecting these results, evident by the release rates being lower than predicted. This process affects glass dissolution at lower temperature and lower $\mathrm{pH}$. 
Another factor affecting glass dissolution that is observed when evaluating the dissolution rate as a function of $\mathrm{pH}$ and temperature is alkali-hydrogen ion exchange (IEX). Ion exchange is a process by which $\mathrm{H}^{+}$, contained in solution, exchanges for the ions contained in the glass matrix. The addition of this mechanism may affect $\mathrm{BV}$ glass performance because of the significant $\mathrm{Na}_{2} \mathrm{O}$ content. The process and method used to quantify the Na ion-exchange rate for the BKV6 glass is discussed below.

\subsubsection{Effect of Sodium-Hydrogen Exchange on BKV6 Glass}

The exchange of alkalis contained in the glass for hydrogen contained in solution is a widely recognized process in the initial stages of the glass-water interactions. The process of IEX eventually causes the breakdown of the glass network and dissolution into the aqueous phase. In general, the overall chemical reaction describing this process can be written as

$$
\equiv \mathrm{Si} \cdots \mathrm{O} \cdots \mathrm{Na}+\mathrm{H}^{+} \rightarrow \equiv \mathrm{Si} \cdots \mathrm{OH}+\mathrm{Na}^{+}
$$

Loss of $\mathrm{H}^{+}$from the aqueous phase raises the local $\mathrm{pH}$, effectively generating $\mathrm{OH}^{-}$ions that can directly attack the glass matrix (McGrail et al. 2001b). IEX occurs in parallel with matrix dissolution. To distinguish between these two competing mechanisms, the rate of IEX was computed by subtracting the rate of matrix dissolution, indexed by boron, from the Na release rate and converting the resulting value to moles of $\mathrm{Na}$ per square meter per second.

Figure 15 shows the natural logarithm of the IEX rate versus computed ion exchange rate at $\mathrm{pH}\left(23^{\circ} \mathrm{C}\right)=9$ and $a\left[\mathrm{SiO}_{2}(\mathrm{aq})\right]$ from 0.9 to 5.4 $\mathrm{mg} \mathrm{L}^{-1}$. Typically, an IEX rate can be computed at each $\mathrm{SiO}_{2}(\mathrm{aq})$ activity, but due to $\mathrm{B}$ detection limit problems, the rate could only be computed for one $\mathrm{SiO}_{2}(\mathrm{aq})$ activity. Conducting a linear regression on the data and using these regressed coefficients, the Na-IEX rate at $15^{\circ} \mathrm{C}$ was computed, $r_{x}=2.77 \times 10^{-10} \mathrm{~mol} \mathrm{~m} \mathrm{~m}^{-2}$, with a correlation coefficient $\left(\mathrm{R}^{2}\right)$ of 0.95 . ${ }^{(\mathrm{a})}$ Using the slope, the activation energy is $E_{x}=44 \pm 2 \mathrm{~kJ}$ $\mathrm{mol}^{-1}$.

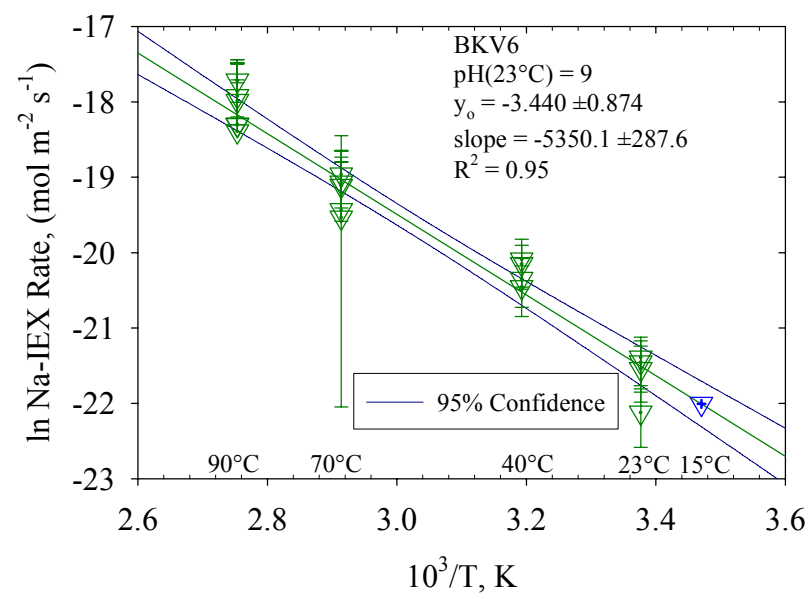

Figure 15. Na-IEX Rate Versus Reciprocal of Temperature for BKV6 Glass.

(a) IEX data points from experiments conducted at $40^{\circ} \mathrm{C}$ became available after initial STORM modeling had been completed. As a result, slightly different regression coefficients were calculated and used in the initial STORM simulations. These were $r_{x}=2.29 \times 10^{-10} \mathrm{~mol} \mathrm{~m}^{-2} \mathrm{~s}^{-1}, E_{x}=47 \pm 2 \mathrm{~kJ} \mathrm{~mol}^{-1}$ with a correlation coefficient $\left(\mathrm{R}^{2}\right)$ of 0.97 . 


\subsubsection{Effect of Solution Saturation State}

Experiments with input solutions doped with Si (ranging from 2 to $140 \mathrm{mg} \mathrm{L}^{-1}$ ) were conducted as a function of temperature at $\mathrm{pH}\left(23^{\circ} \mathrm{C}\right)=9$. Before discussing these results, it is important to determine the aqueous Si speciation at each temperature to correctly account for the change in Si speciation with temperature in the analysis. Therefore, the solution speciation of dissolved $\mathrm{Si}$ species was computed with the aid of the geochemical code EQ3NR (Wolery 1992b). Results of this computation shows that $\mathrm{SiO}_{2}$ (aq) was the dominant solution species in the buffer solution from 23 to $90^{\circ} \mathrm{C}$, ranging from $90 \%$, at $23^{\circ} \mathrm{C}$, to $87 \%$, at $90^{\circ} \mathrm{C}$. The remaining 10 and $13 \%$, at 23 and $90^{\circ} \mathrm{C}$ respectively, correspond to the solution species $\mathrm{HSiO}_{3}{ }^{-}$.

Normalized release rates for $\mathrm{Na}$ as a function of $a\left[\mathrm{SiO}_{2}(\mathrm{aq})\right]$ at $23^{\circ} \mathrm{C}$ are shown in Figure6. The trend, a decrease in the dissolution rate with increasing $\mathrm{SiO}_{2}$ (aq) activity, is similar to those obtained for several LAW glass formulations (McGrail et al. 2001a; Pierce et al. 2004b). As the activity $\mathrm{SiO}_{2}$ (aq) increases, Figure 16 also shows the $\mathrm{Na}$ release rate becomes steady, approximately $0.001 \mathrm{~g} \mathrm{~m}^{-2} \mathrm{~d}^{-1}$, at $a\left[\mathrm{SiO}_{2}(\mathrm{aq})\right]=0.4 \mathrm{mmol} \mathrm{L}^{-1}$. This steady release of $\mathrm{Na}$ is caused by the secondary reaction Na-IEX becoming the dominant mechanism of glass dissolution. This trend is expected and typical for LAW glass formulations as well as previous BV glass formulations tested in FY03. Applying a linear fit to the normalized $\mathrm{Na}$ release rates as they approached steady release for the data shown in Figure 16, the x-intercept was determined at each temperature, which is equivalent to the pseudo-equilibrium constant $\left(K_{g}\right)$. The estimated $K_{g}$ values are given in Table 15 and also plotted versus inverse temperature in Figure 17, along with the temperature-dependent solubility products for quartz and $\mathrm{SiO}_{2}(\mathrm{am})$. The results show the $K_{g}$ for BKV6 glass is intermediate between quartz and amorphous silica. The slope of a line regressed through the data also provides a crude estimate of the enthalpy of reaction, $\Delta \mathrm{H}_{\mathrm{r}}=$

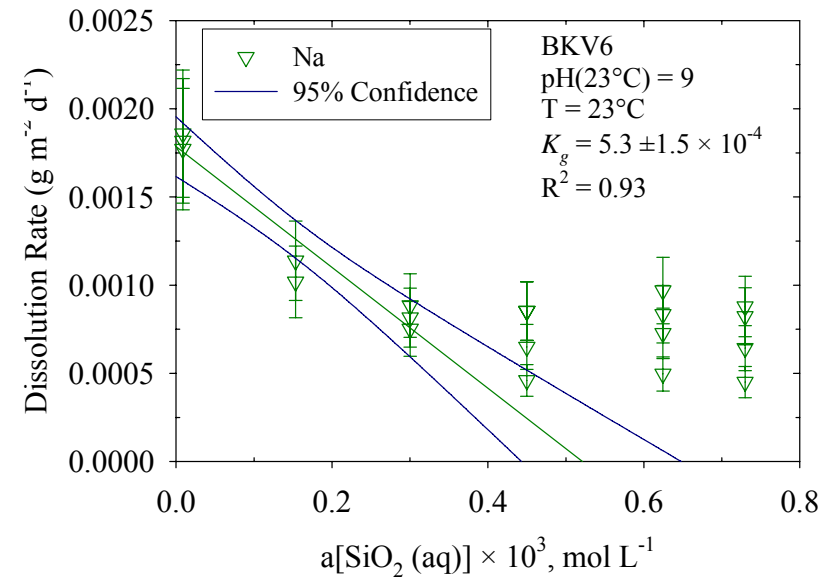

Figure 16. Na Release Rate as a Function of $\mathrm{SiO}_{2}$ (aq) Activity at $23^{\circ} \mathrm{C}$.

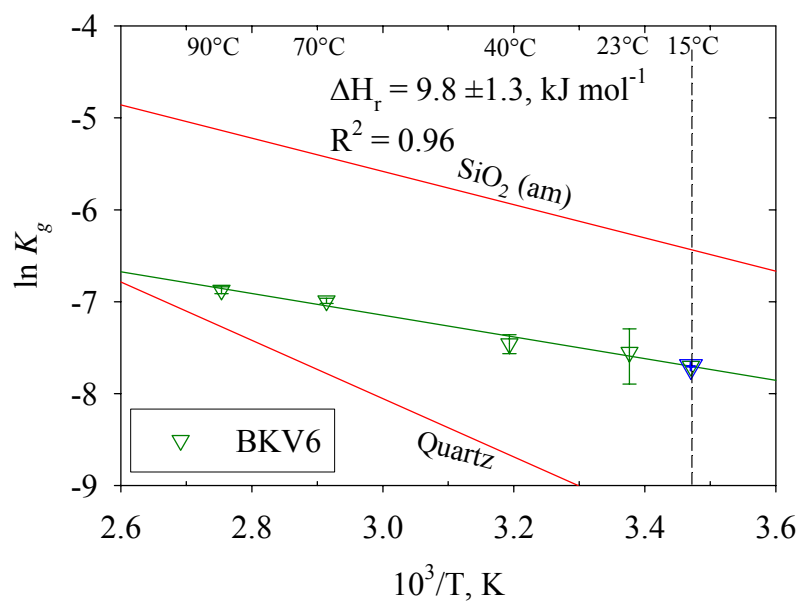

Figure 17. $\ln K_{g}$ Versus Reciprocal of Temperature for BKV6 Glass.

Table 15. Estimate of the Pseudo-equilibrium Constants $\left(K_{g}\right)$ for BKV6 Glass as a Function of Temperature.

\begin{tabular}{c|c|c|c}
\hline $\mathbf{T}\left({ }^{\mathbf{}} \mathbf{C}\right)$ & $\boldsymbol{K}_{\boldsymbol{g}}$ & Error & $\mathbf{R}^{2}$ \\
\hline 15 & $4.51 \mathrm{E}-04$ & - & 0.96 \\
23 & $5.26 \mathrm{E}-04$ & $\pm 1.54 \mathrm{E}-04$ & 0.93 \\
40 & $5.77 \mathrm{E}-04$ & $\pm 5.99 \mathrm{E}-05$ & 0.88 \\
70 & $9.21 \mathrm{E}-03$ & $\pm 2.58 \mathrm{E}-05$ & 0.89 \\
90 & $1.03 \mathrm{E}-03$ & $\pm 3.87 \mathrm{E}-05$ & 0.78 \\
\hline
\end{tabular}


$11 \pm 2 \mathrm{~kJ} \mathrm{~mol}^{-1}$. Using the regression line shown in Figure 17, the value for $K_{g}$ at the disposal system temperature of $15^{\circ} \mathrm{C}$ was calculated and is provided in Table 15 .

\subsubsection{SPFT Results for CRB}

A castable refractory block (CRB) was added to the BV configuration in FY04 in place of a portion of the refractory sand layer. The addition of a CRB created a distinct interface within the BV waste package between the glass and $\mathrm{CRB}$, as shown in Figure 18. Unlike glass, which is homogenous, the CRB is a heterogeneous material composed of several different mineral phases. These include mullite $\left(\mathrm{Al}_{6} \mathrm{Si}_{2} \mathrm{O}_{13}\right)$, corundum $\left(\mathrm{Al}_{2} \mathrm{O}_{3}\right)$, kyanite $\left(\mathrm{Al}_{2} \mathrm{SiO}_{5}\right)$, quartz $\left(\mathrm{SiO}_{2}\right)$, andalusite $\left(\mathrm{Al}_{2}\left[\mathrm{SiO}_{4}\right] \mathrm{O}\right)$, biotite $\left(\mathrm{KMg}_{3} \mathrm{AlSi}_{3} \mathrm{O}_{10} \mathrm{OH}\right)$, and pyrophillite

$\left(\mathrm{Al}_{2} \mathrm{Si}_{4} \mathrm{O}_{10}[\mathrm{OH}]_{2}\right)$ (Figure 19). This mixture of mineral phases makes it somewhat difficult to determine kinetic rate law parameters for the CRB.

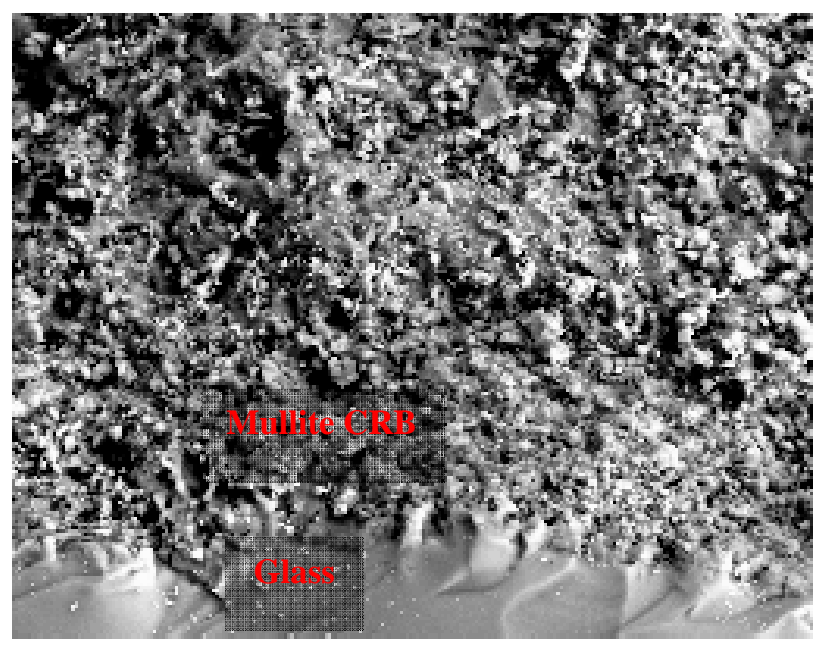

Figure 18. SEM of the Glass/CRB Interface, Sample Taken from ES-31A. Therefore, semi-quantitative XRD was conducted to determine the relative amount of each mineral phase.

Results from this analysis suggest the CRB is composed of approximately 25 to $30 \%$ mullite; 15 to $20 \%$ corundum; 10 to $15 \%$ quartz, kyanite, and graphite; $5 \%$ or less andalusite; and less than $2 \%$, biotite and pyrophyllite. Based on these results, we have assumed that mullite contributes the majority of the dissolved Si measured in SPFT tests conducted with the CRB. Therefore, the steady-state $\mathrm{Si}$ concentration was used to compute the rates reported in Appendix B.

The same kinetic rate equation used for modeling glass dissolution, discussed in Section 1.0, was used for modeling the dissolution kinetics of the mullite CRB. Consequently, the parameters $\vec{k}, E_{a}$, $\eta$, and $K$ were determined for the mullite CRB.

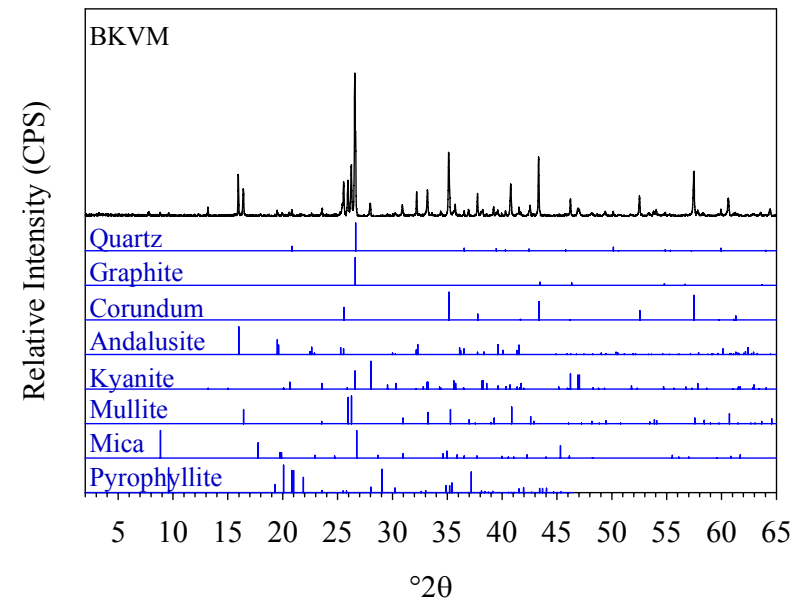

Figure 19. XRD Results of the Castable Refractory Block.

The $\vec{k}, E_{a}$, and $\eta$ were determined using SPFT tests with untreated CRB, whereas the $\log K$ at $15^{\circ} \mathrm{C}$ for mullite was computed using thermodynamic values obtained from Robbie and Hemingway (1995) and Wagman et al. (1982) (Table 16). The technique used to estimate the $\log \mathrm{K}$ for the mullite $\mathrm{CRB}$ at $15^{\circ} \mathrm{C}$ is discussed in the next section. 
Table 16. Thermodynamic Data Used for Calculating the Mullite CRB Solubility Product at $15^{\circ} \mathrm{C}$.

\begin{tabular}{|c|c|c|}
\hline Species & $\begin{array}{c}\Delta G_{f}^{o} \\
\mathrm{~kJ} \mathrm{~mol}^{-1}\end{array}$ & $\begin{array}{c}\Delta H_{f}^{o} \\
\mathrm{~kJ} \mathrm{~mol}^{-1}\end{array}$ \\
\hline $\mathrm{Al}_{6} \mathrm{Si}_{2} \mathrm{O}_{13}$ (mullite CRB) $^{\mathrm{a}}$ & $-6431.3^{\mathrm{a}}$ & $-6819.2^{\mathrm{a}}$ \\
\hline $\mathrm{Al}^{3+}(\mathrm{aq})^{\mathrm{a}}$ & -489.4 & -538.4 \\
\hline $\mathrm{H}_{4} \mathrm{SiO}_{4}^{\mathrm{o}}(\mathrm{aq})^{\mathrm{b}}$ & -1308.0 & -1460.0 \\
\hline $\mathrm{H}_{2} \mathrm{O}(\mathrm{liq})^{\mathrm{b}}$ & $-237.1^{\mathrm{b}}$ & $-285.8^{\mathrm{b}}$ \\
\hline $\begin{array}{l}{ }^{\mathrm{a}} \text { Robbie and Hemingway (1995) } \\
{ }^{\mathrm{b}} \text { Wagman et al. (1982) }\end{array}$ \\
\hline
\end{tabular}

\subsubsection{Mullite CRB Solubility Product}

The dissolution/precipitation reaction for mullite is expressed in the form:

$$
\mathrm{Al}_{6} \mathrm{Si}_{2} \mathrm{O}_{13}+18 \mathrm{H}^{+} \rightarrow 6 \mathrm{Al}^{3+}+2 \mathrm{H}_{4} \mathrm{SiO}_{4}^{\circ}(\mathrm{aq})+5 \mathrm{H}_{2} \mathrm{O}
$$

Using the $\Delta G_{f}^{o}$ constants listed in Table 16 for the species in Eq. (11), and determining the Gibbs free energy of reaction $\left(\Delta G_{r}^{o}=-306.6 \mathrm{~kJ} \mathrm{~mol}^{-1}\right)$, a $\log K$ at $25^{\circ} \mathrm{C}$ of 53.7 for the mullite $\mathrm{CRB}$ was calculated. Because the temperature of the disposal system is expected to be $15^{\circ} \mathrm{C}$, the solubility product must be temperature corrected to conduct STORM calculations. The integrated van't Hoff equation

$$
\log \frac{K_{2}}{K_{1}}=\frac{\Delta H_{r}^{\circ}}{2.303 R}\left[\frac{1}{T_{1}}-\frac{1}{T_{2}}\right]
$$

where $K$ is the solubility product for mullite at temperature $T(\mathrm{~K}), \Delta H_{r}^{o}$ is the enthalpy of reaction ( $\mathrm{J} \mathrm{mol}^{-}$ ${ }^{1}$ ), and $R$ is the gas constant $\left(\mathrm{J} \mathrm{mol}^{-1} \mathrm{~K}^{-1}\right)$, was used to calculate the $\log K$ at $15^{\circ} \mathrm{C}$ using the enthalpy of formation constants $\left(\Delta H_{f}^{o}\right)$ listed in Table 16. The calculated enthalpy of reaction $\left(\Delta H_{r}^{o}\right)$ and resulting $\log \mathrm{K}$ at $15^{\circ} \mathrm{C}$ was determined to be $-760.2 \mathrm{~kJ} \mathrm{~mol}^{-1}$ and 58.3 , respectively.

\subsubsection{Determination of CRB Surface Area}

Surface area has been recognized as an important factor in quantifying mineral dissolution rates. The proper handling of surface area is one of, if not the most problematic variable, and has been the subject of numerous studies (Brantley and Mellott 2000). A large degree of uncertainty is associated with measurements of bulk BET surface area, and the contribution of actual reactive surface area is not always known. For glasses, it has been shown that the geometric surface area best represents the overall glass surface area but no such case currently exists for the CRB (McGrail et al. 1997). Therefore, two methods were employed to determine the surface area of the CRB, calculated geometric (McGrail et al. 1997) and $\mathrm{N}_{2}$-adsorption BET (Brunauer et al. 1938). The BET specific surface area for the mullite CRB samples 
used in SPFT tests was determined to be $1.3 \mathrm{~m}^{2} \mathrm{~g}^{-1}$. In contrast, geometric surface area was determined to be $0.017 \mathrm{~m}^{2} \mathrm{~g}^{-1}$, using the geometric equation from McGrail et al. (1997) and a density of $3.12 \mathrm{~g} \mathrm{~cm}^{-3}$ (measured using a Accupyc $1330 \mathrm{He}$ pycnometer). This value is 77 times less than the measured value via $\mathrm{N}_{2}$-adsorption $\mathrm{BET}$. As previously discussed, the CRB contains a large amount of microporosity that increases the reactive surface area (Figure8), an artifact not observed in glasses. Anbeek et al. (1994) illustrated that feldspar and quartz dissolution rates varied as a function of grain size when using the geometric surface area. They attributed this observation to an increase in the dissolution reactive sites as a result of micropores/mesopores (diameter $\leq 50 \mathrm{~nm}$ ) being present in the larger grain sizes. However, Brantley and Mellott (2000) point out that surface area measured by gas adsorption may not be appropriate for extrapolation of interface-limited dissolution of many silicates if the accessible internal surfaces are substantially less reactive than the external surfaces. Although use of the BET surface area may overestimate the true reactive surface area, the obvious microporosity indicates that use of the geometric surface area will underestimate the true dissolution rate. Therefore, a conservative approach was taken by normalizing the dissolution rates using the BET surface area. The true reactive surface area is probably less than the BET value, but also probably significantly higher than the geometric value. Additional work will be required to better constrain the reactive surface area of the mullite CRB.

\subsubsection{Effect of $\mathrm{pH}$ on the $\mathrm{CRB}$}

Figure 20 illustrates the experimental results for BKVM as a function of $\mathrm{pH}$ and temperature. Results from BKVM illustrate a trend typical of most silicate minerals, where the dissolution rate increases with an increase in $\mathrm{pH}$ and temperature. Therefore, the same process, as discussed in subsection 3.2.1.2, was used to evaluate the data and extract the corresponding kinetic rate law parameters.

Results from the linear regression at each temperature gave a slope $\eta=0.34 \pm 0.06$ indicating that $\eta$ does not depend on temperature within experimental error. Using the same non-linear regression technique as described in subsection 3.2.1.2 the resulting regression coefficients are

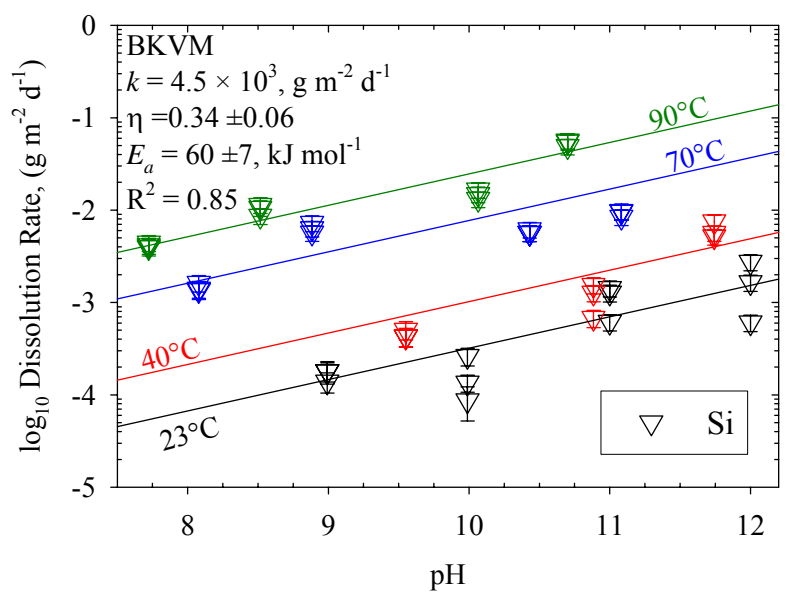

Figure 20. Normalized Si Dissolution Rate as a Function of $\mathrm{pH}$ and Temperature for CRB Sample. $\vec{k}=4.5 \times 10^{3} \mathrm{~g} \mathrm{~m}^{-2} \mathrm{~d}^{-1}, E_{a}=60 \pm 7 \mathrm{~kJ} \mathrm{~mol}^{-1}$ with a correlation coefficient $\left(\mathrm{R}^{2}\right)$ of 0.85 .

\subsection{Results of ${ }^{11} \mathrm{~B}$ and ${ }^{29}$ Si MAS-NMR on BKV1 and BKV6 Glasses}

To gain a more detailed understanding of the relationship between the local coordination geometry around silicon and boron atoms and the effect these network former elements have on glass dissolution, magic angle spinning nuclear magnetic resonance (MAS-NMR) spectroscopy was collected for the FY03, BKV1, and FY04, BKV6, crucible melt glass formulations that were investigated. 
The local coordination geometry around boron and silicon atoms within the glass structure was investigated at room temperature for each glass formulation, BKV1 and BKV6, using ${ }^{29} \mathrm{Si}$ and ${ }^{11} \mathrm{~B}$ MAS-NMR. The ${ }^{29}$ Si spectra were obtained under MAS conditions at a magnetic field strength of $100 \mathrm{MHz}$ frequency (e.g., 2.3T) using a Chemagnetics spectrometer. Each sample was analyzed with a spin speed of $4 \mathrm{kHz}$ using a Chemagentics 2-channnel MAS probe. A high magnetic field strength, $800 \mathrm{MHz}$ frequency (e.g., $18.4 \mathrm{~T}$ ), was required to evaluate the local ${ }^{11} \mathrm{~B}$ coordination geometry. The ${ }^{11} \mathrm{~B}$ spectrum for each sample was collected at PNNL's Environmental Molecular Sciences Laboratory (EMSL) using a Chemagnetics spectrometer, a spin speed of 4 $\mathrm{kHz}$, and Chemagentics 2-channel MAS probe.

Figure 2121 shows the ${ }^{29} \mathrm{Si}$ MAS-NMR spectra for each glass formulation. The observed chemical shifts were referenced against an internal standard Tetrakis (trimethylsilyl) silane (TMS), which gives sharp peaks at 0.0 and -126 ppm. Broad ${ }^{29} \mathrm{Si}$ peaks were observed, which is typical for these complex Fe bearing borosilicate glasses. Previous MAS-NMR results show that octahedrally coordinated $\mathrm{Si}\left(\mathrm{Si}^{\mathrm{VI}}\right)$ has chemical shifts between -180 and -221 ppm (Grimmer et al. 1986), whereas tetrahedrally coordinated $\mathrm{Si}\left(\mathrm{Si}^{\mathrm{IV}}\right)$ has chemical shifts between -60 and -126 ppm (Kirkpatrick 1988). The ${ }^{29} \mathrm{Si}$ chemical shifts for BKV1, -76.1 ppm, and BKV6, 74.3 ppm, confirm

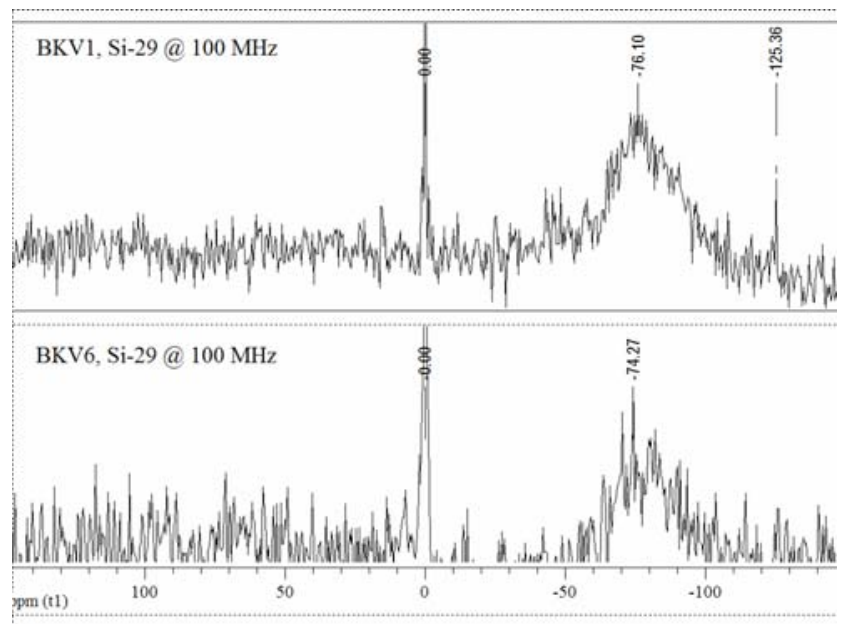

Figure 21. ${ }^{29} \mathrm{Si}$ MAS-NMR Spectra in ppm for BKV1 and BKV6 Glasses.

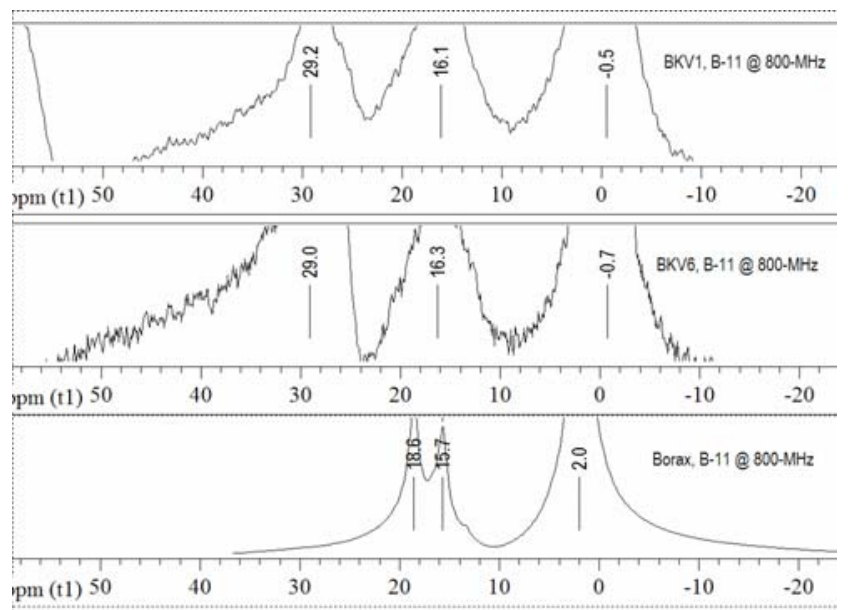

Figure 22. ${ }^{11} \mathrm{~B}$ MAS-NMR Spectra in ppm for BKV1 and BKV6 Glasses. four-fold coordinated $\mathrm{Si}$ as the dominant local structure for these glasses.

The observed isotropic chemical shifts for ${ }^{11} \mathrm{~B}$ were referenced against borax $\left.\left[\mathrm{Na}_{2} \mathrm{~B}_{4} \mathrm{O}_{5} \mathrm{OH}\right)_{4} \bullet 8 \mathrm{H}_{2} \mathrm{O}\right]$, which has three sharp peaks at 1.99, 15.66, and $18.57 \mathrm{ppm}$ (Figure 22). Previous results have shown that isotropic chemical shifts that are between 12 and $19 \mathrm{ppm}$ correspond to trigonally-coordinated boron $\left(\mathrm{B}^{\mathrm{III}}\right)$, where as tetrahedrally-coordinated boron $\left(\mathrm{B}^{\mathrm{IV}}\right)$ has chemical shifts from -4 to $2 \mathrm{ppm}$, respectively (Kirkpatrick 1988). The ${ }^{11} \mathrm{~B}$ isotropic chemical shifts for BKV1, 16.1 and -0.5, and BKV6, 16.3 and -0.7, confirm the presence of $\mathrm{B}^{\mathrm{III}}$ and $\mathrm{B}^{\mathrm{IV}}$ coordination for $\mathrm{B}$ in these glasses. Although we cannot fully explain the additional peak observed at 29.18 and 29.03 for BKV1 and BKV6, respectively, at this time, we believe that these peaks are associated with trigonally coordinated $\mathrm{B}$ but additional data is needed. The relative percentage of $\mathrm{B}^{\mathrm{IV}}$ and $\mathrm{B}^{\mathrm{III}}$ for $\mathrm{BKV} 1$ and $\mathrm{BKV} 6$ is $71 \%$ and $29 \%$, respectively. The boron local coordination is a very important factor that affects glass durability because the glass structure is polymerized by $\mathrm{B}^{\mathrm{IV}}$ which serves as a network former; whereas the presence of $\mathrm{B}^{\mathrm{III}}$ results in network depolymerization, caused by the formation of non-bridging oxygen (NBO) sites, and decreases glass durability. 
Given the high soda content of these glass formulations, $\sim 20 \mathrm{wt} \% \mathrm{Na}_{2} \mathrm{O}$, a percentage of the total $\mathrm{B}$ is expected to be trigonally coordinated and is also observed in the ${ }^{11} \mathrm{~B}$ spectra of the mineral borax (Figure 22) as well as WTP glasses; LAWA44, LAWB45, and LAWC22, not shown here.

\subsection{Summary and Comparison of SPFT Results}

In FY03, a crucible melt sample was used to develop the kinetic rate law parameters used in the preliminary RA (Mann et al. 2003). These results were compared to SPFT test results using glass samples taken from engineered and large-scale test, EST-01 and LST-02, to ensure the use of a crucible melt sample could serve as a simulant to the vitrified product expected from the BV process. For additional details on the test conditions and compositions of the samples tested in FY03 see McGrail et al. (2003b). In a similar fashion to FY03, a crucible melt sample was used to develop the kinetic rate law parameters required for STORM calculations. Therefore, we compared the results obtained from testing the FY04 crucible melt sample, BKV6, to the FY03 results for one crucible melt sample, BKV1, and two centerline samples taken from the first ES test and the second large-scale test, BKVX and BKV4, respectively. An evaluation of the dissolution rates as a function of $\mathrm{pH}$ and temperature illustrates the BKV6 results are within the experimental error of the results obtained for BKV1, BKVX, and BKV4 (Figure 23).

Figure 24 compares the pseudo-equilibrium constant $\left(K_{\mathrm{g}}\right)$ as a function of temperature, which illustrates the line slope for BKV1 and BKVX glasses is slightly lower than for BKV6, suggesting that BKV1 and BKVX glasses are slightly more durable than BKV6 glass.

Single-pass flow through test data are provided in this section on a prototypic simulant BV glass: BKV6 and the castable refractory, BKVM. Results from these experiments were used to derive the input parameters necessary to conduct long-term performance assessment (PA) calculations with the STORM reactive transport computer code. A summary of the recommended best estimate rate law parameters is provided in Table 17 and compared to the BKV1 results used in the FY03 RA (Mann et al. 2003).

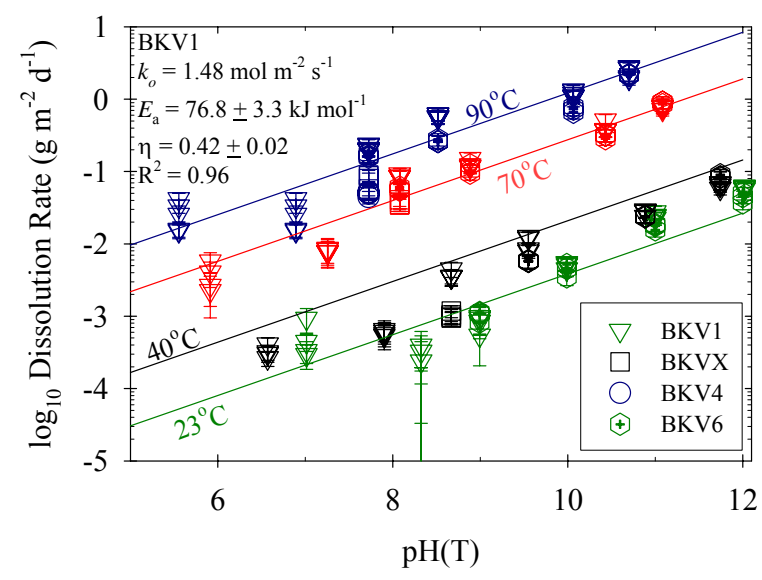

Figure 23. Comparison of the Normalized Release Rates as a Function of $\mathrm{pH}$ and Temperature for BKV6 Glass and the FY03 Glass Samples Tested.

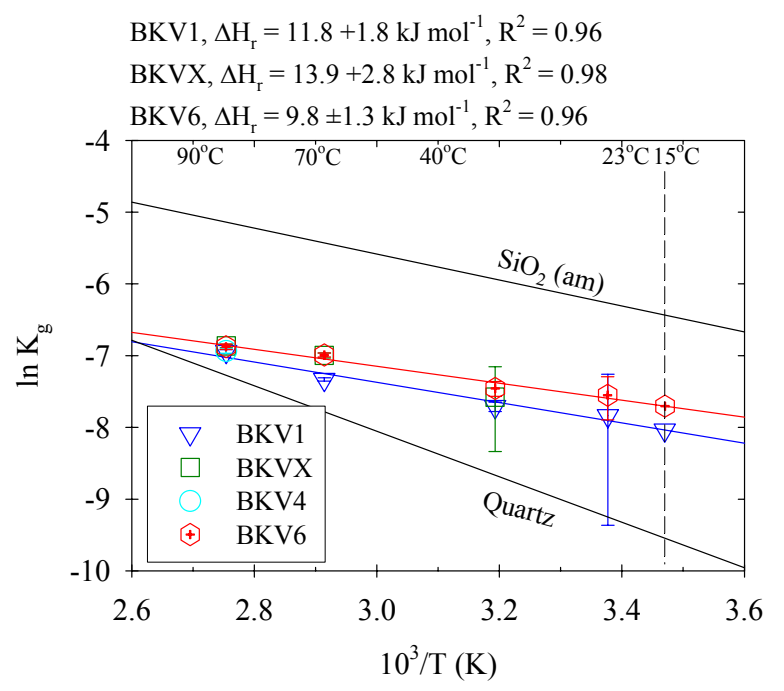

Figure 24. Comparison of $\ln K_{g}$ as a Function of Temperature for BKV6 Glass and the FY03 Glass Samples Tested. 
Table 17. Summary of Best Estimate Rate Law Parameters for BV Glasses, BKV1 and BKV6, and the Castable Refractory, BKVM, at $15^{\circ} \mathrm{C}$.

\begin{tabular}{|c|l|c|c|c|c|}
\hline Parameter & \multicolumn{1}{|c|}{ Meaning } & BKV1 & BKV6 & BKVM & Comments \\
\hline$\vec{k}$ & $\begin{array}{l}\text { forward rate } \\
\text { constant }\left(\mathrm{g} \mathrm{m}^{-2} \mathrm{~d}^{-1}\right)\end{array}$ & $8.6 \times 10^{6}$ & $4.3 \times 10^{4}$ & $4.5 \times 10^{3}$ & \\
\hline$K_{g}$ & $\begin{array}{l}\text { apparent equilibrium } \\
\text { constant for glass } \\
\text { based on activity } \\
\text { product } a\left[\mathrm{SiO}_{2}(\mathrm{aq})\right]\end{array}$ & $3.2 \times 10^{-4}$ & $4.5 \times 10^{-4}$ & 58.3 & $\begin{array}{l}\text { log } K \text { Calculated } \\
\text { for the dissolution } \\
\text { of BKVM at } 15^{\circ} \mathrm{C}\end{array}$ \\
\hline$\eta$ & $\begin{array}{l}\text { pH power law } \\
\text { coefficient }\end{array}$ & $0.42 \pm 0.02$ & $0.53 \pm 0.03$ & $0.34 \pm 0.06$ & \\
\hline$E_{a}$ & $\left.\begin{array}{l}\text { activation energy of } \\
\text { glass dissolution } \\
\text { reaction }(\mathrm{kJ} \text { mol }\end{array}{ }^{-1}\right)$ & $77 \pm 3$ & $69 \pm 3$ & $60 \pm 7$ & 1 \\
\hline$\sigma$ & Temkin coefficient & 1 & 1 & $\begin{array}{l}\text { Assigned } \\
\text { constant }\end{array}$ \\
\hline$r_{x}$ & $\begin{array}{l}\text { Na ion-exchange rate } \\
\left(\text { mol } \mathrm{m}^{-2} \mathrm{~s}^{-1}\right)\end{array}$ & $2.1 \times 10^{-10}$ & $2.8 \times 10^{-10}$ & $\begin{array}{l}\text { Not measurable } \\
\text { for BKVM }\end{array}$ \\
\hline
\end{tabular}




\subsection{Chemical Reaction Network}

Low-activity waste (LAW) performance assessment models must account for the long-term corrosion rate of each BV glass formulation. This corrosion rate is a key parameter affecting the overall performance of the integrated disposal facility (IDF). Therefore, having determined the kinetic rate law parameters for BKV6 samples, as described in Section 3.2, the next set of required data to conduct source-term calculations with the STORM code is 1) a set of secondary phases that form from the long-term corrosion of this glass in the disposal system environment, and 2) the precipitation-dissolution rate and/or solubility product for each of these phases. Although the suite of weathering products that will form as a consequence of the glass-water reactions cannot be determined a priori at this time, as discussed by McGrail et al. (2000a), laboratory tests can be used to simulate and accelerate the weathering process. To address these and other issues, product consistency tests (PCT) were conducted to evaluate the corrosion rate on each BV glass formulation: BKV6, BKV7, BKV8, and BKVZ.

\subsection{Product Consistency Test}

The PCT has been standardized as an American Society for Testing and Materials (ASTM) standard procedure (ASTM 1994). The ASTM standard includes two methods: PCT Method A was developed specifically for verifying process control during production of vitrified high-level waste (HLW) forms and is conducted with specific values of test parameters; PCT Method B does not specify the values of test parameters. Because the PCT Method B encompasses commonly used variations of test parameters, PCT Method B was used in this work.

\subsection{PCT Experimental Materials and Methods}

Each glass sample used in PCT tests was sieved and washed using the same procedure as described in Section 3.1.2. The PCTs were conducted by placing a fixed amount of crushed glass with DIW in a Teflon reaction vessel at $90^{\circ} \mathrm{C}$. Two glass surface-area-to-solution volume ratios (S/V) were used: 1$) 1 \mathrm{~g}$ of glass per $10 \mathrm{~mL}$ of DIW to give an S/V of $2000 \mathrm{~m}^{-1}$, and 2) $1 \mathrm{~g}$ of glass per $1 \mathrm{~mL}$ of DIW to give an S/V of $20,000 \mathrm{~m}^{-1}$. To limit water loss for long-duration experiments, Teflon PFA (perfluoro alkoxy alkane) reactors were sealed inside a stainless steel Parr reactor. At the end of the test, the solution was analyzed for $\mathrm{pH}$ and concentrations of dissolved glass components. The reacted glass surface also was analyzed to help characterize any alteration phases formed during the test.

\subsection{PCT Results for BKV6, BKV7, BKV8, and BKVZ Glasses}

Figure 25 summarizes the available PCT data on BKV6, BKV7, BKV8, and BKVZ glasses to date for the experiments with $\mathrm{S} / \mathrm{V}$ ratios of 2,000 and $20,000 \mathrm{~m}^{-1}$. These results suggest that glass dissolution behavior is entirely normal with no indication of reaction rate acceleration due to secondary phase formation. Figure 26 suggests minimal secondary phase formation, which confirms that reaction rate acceleration is not occurring at this point in PCT tests with BKV6 glass. Images of BKV1 glass after 398 days of testing are provided for comparison. The scanning electron microscopy (SEM) images of reacted glass removed from PCT tests with BKV7, BKV8, and BKVZ glasses were not complete at the time this report was written. The normalized mass losses for BKV7 glass are slightly higher than BKV6 glass, but it is 

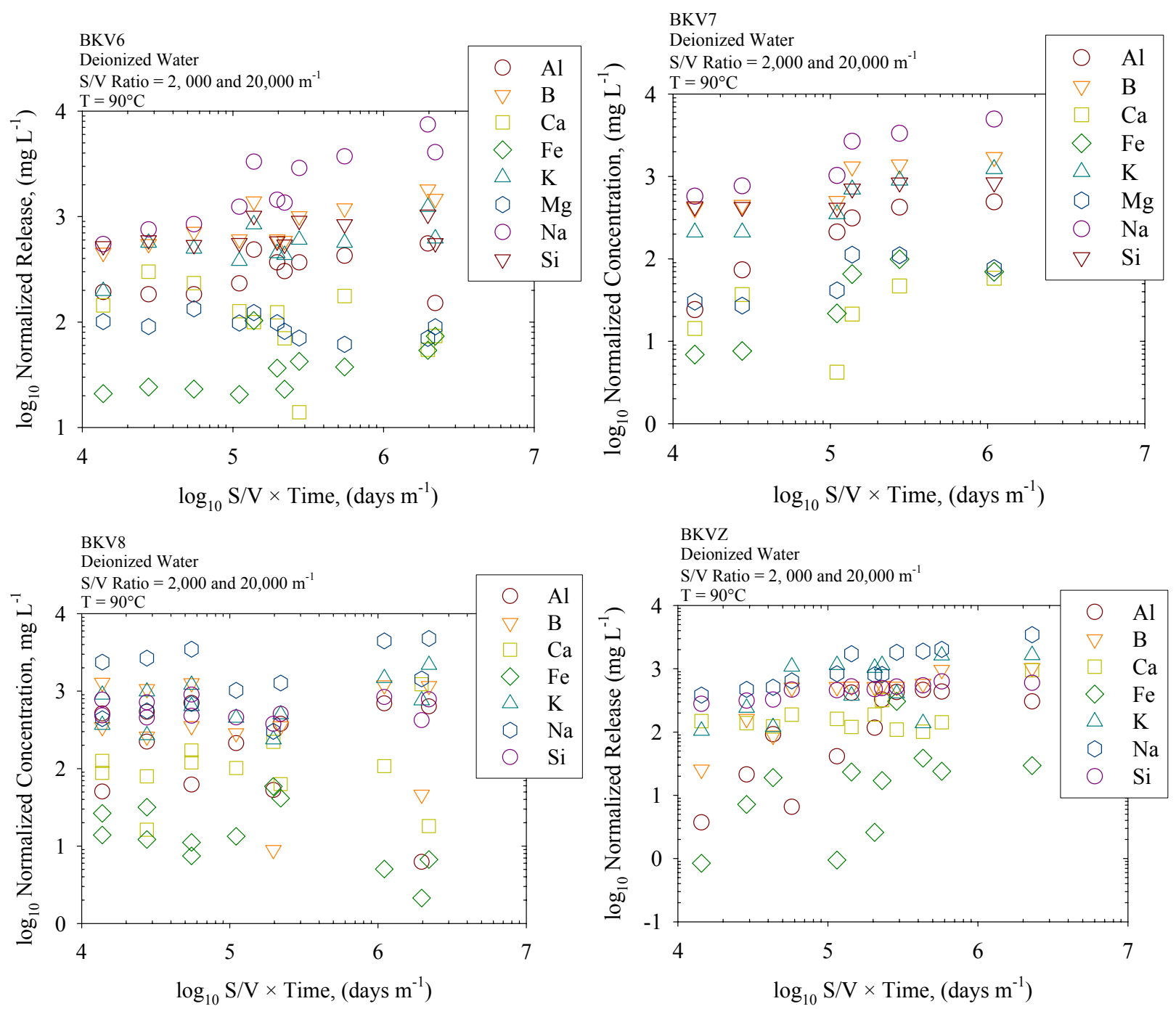

Figure 25. PCT-B Results for BKV6, BKV7, BKV8, and BKVZ Glasses.

still early in this test ( $<60$ days). Note the concentrations of $\mathrm{Ca}, \mathrm{Fe}, \mathrm{K}$, and $\mathrm{Mg}$ shown in Figure 25 are below the detection threshold and should be used only as a reference. Reaction path modeling of the solution composition data was only conducted for the experiments with BKV6 glass. 

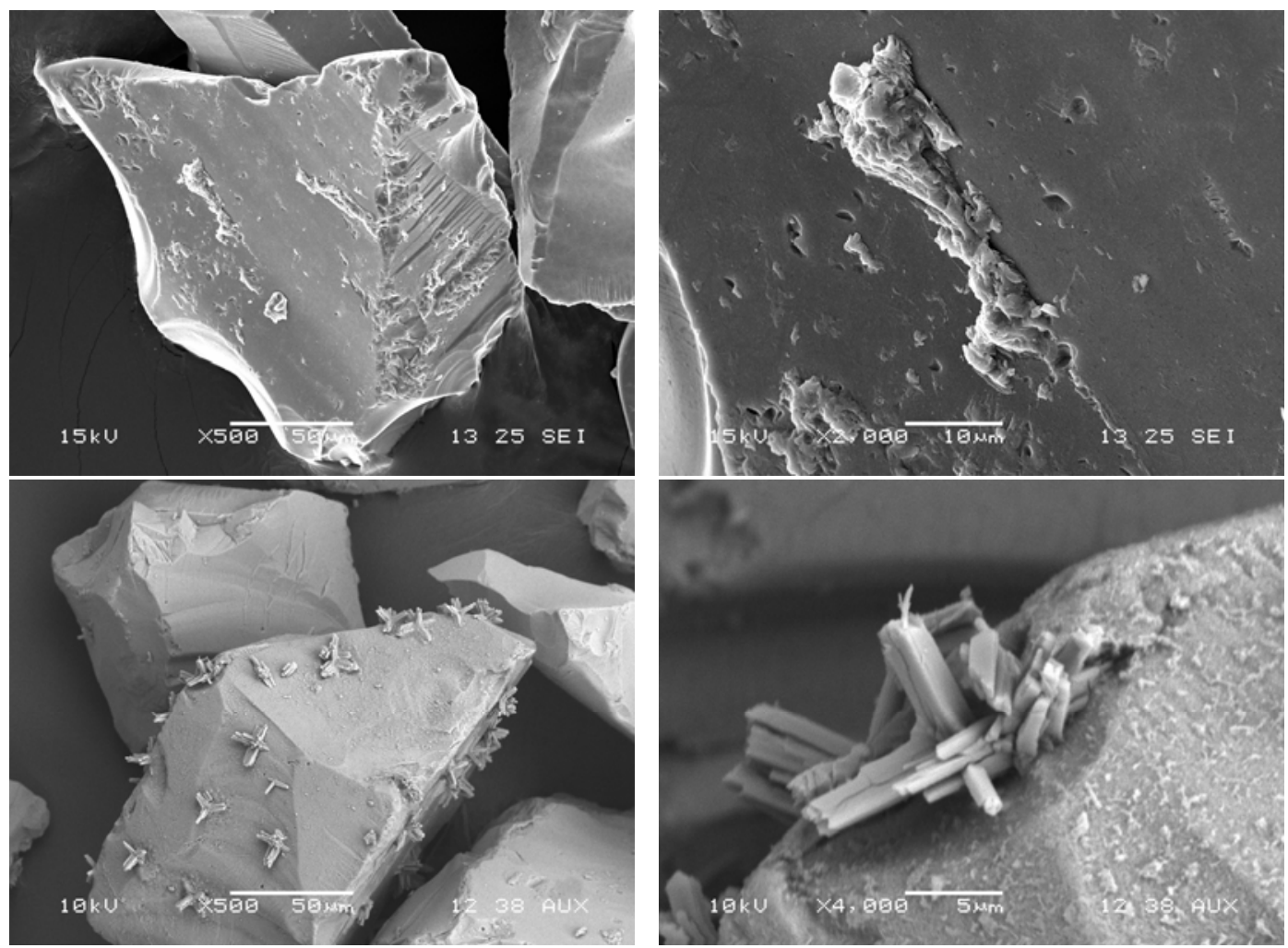

Figure 26. SEM Results of the Reacted BKV6 Glass (Top Two Images) After $100 \mathrm{~d}$ PCT Test in Comparison to BKV1 (Bottom Two Images) Glass After 398 Days of Testing.

\subsubsection{Modeling with EQ3/6}

Using the boron release data from the PCT experiments with BKV6 glass, a reaction progress value was calculated as a function of test duration. Reaction progress is simply the moles of glass dissolved in $1 \mathrm{~kg}$ of water. The results are shown in Figure 27. Also shown on the figure is the predicted elemental solution concentration from the EQ3/6 version 8.0 code. Agreement with the experimental data is good, except for sodium. More sodium is present than can be accounted for by simple dissolution, indicating that Na-IEX may be occurring.

The predicted secondary phase paragenesis is provided in Figure 28. To adequately reproduce the PCT data, it was necessary to adjust the $\log K$ upward for several of the phases. This is a consequence of the fact that amorphous solids rather than their crystalline analogs often form in laboratory experiments with waste glasses. The amorphous solids are typically much more soluble and this is reflected in the equilibrium constant. The $\log K$ values for each of the phases used in the simulations are provided in Table 18 , although values are shown at the subsurface disposal facility temperature of $15^{\circ} \mathrm{C}$. 


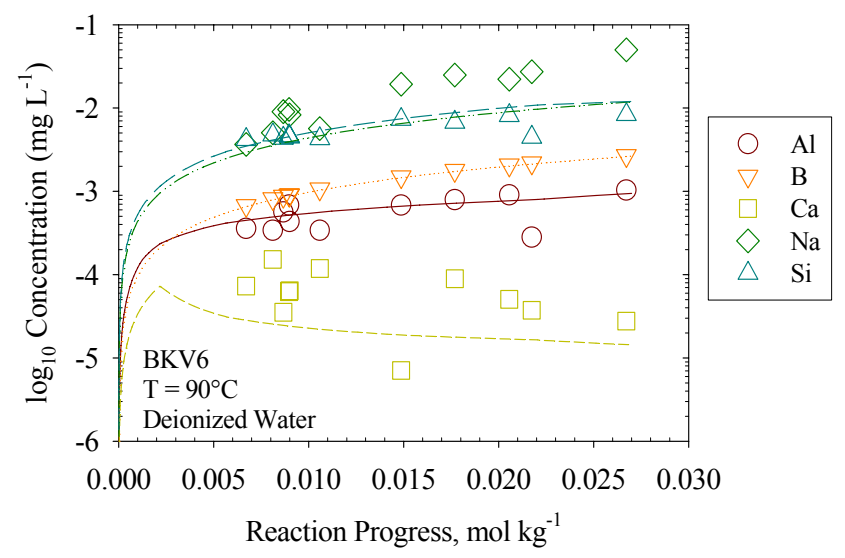

Figure 27. Comparison of Solution Concentration Data (Symbols) with the Solution Composition Calculated with the EQ3/6 Code (Lines).

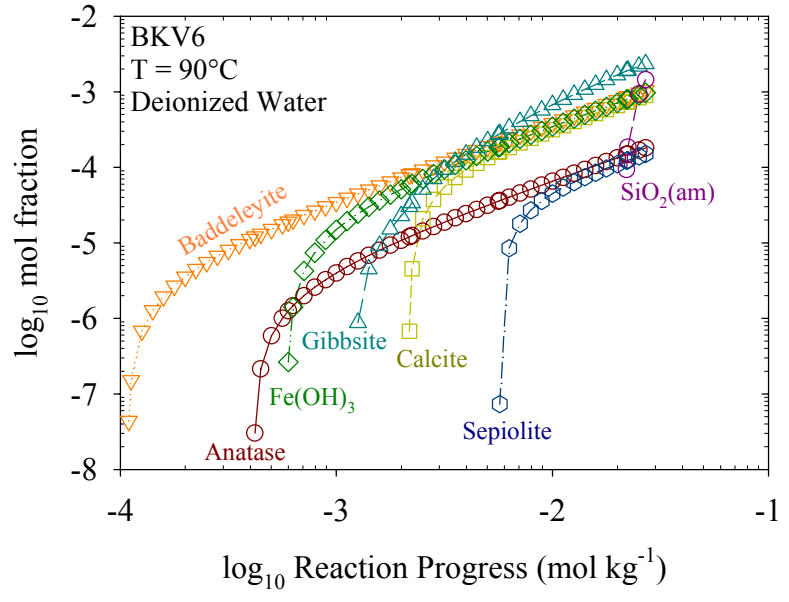

Figure 28. Predicted Paragenetic Sequence of Alteration Phases Formed During Reaction of BKV6 Glass in Deionized Water.

Table 18. Secondary Phase Reaction Network for BKV6 Glass.

\begin{tabular}{|c|c|c|}
\hline Phase & Reaction & $\log K @ 15^{\circ} \mathrm{C}$ \\
\hline $\begin{array}{c}\text { Anatase } \\
\mathrm{TiO}_{2}\end{array}$ & Anatase $+2 \mathrm{H}_{2} \mathrm{O}=\mathrm{Ti}(\mathrm{OH})_{4}(\mathrm{aq})$ & -5.56 \\
\hline $\begin{array}{c}\text { Baddeleyite } \\
\mathrm{ZrO}\end{array}$ & Baddeleyite $+2 \mathrm{H}_{2} \mathrm{O}=\mathrm{Zr}(\mathrm{OH})_{4}(\mathrm{aq})$ & -5.73 \\
\hline $\begin{array}{c}\text { Calcite } \\
\mathrm{CaCO}\end{array}$ & Calcite $+\mathrm{H}^{+}=\mathrm{Ca}^{2+}+\mathrm{HCO}_{3}{ }^{-}$ & 2.00 \\
\hline $\begin{array}{c}\text { Amorphous Silica } \\
\mathrm{SiO}_{2}(\text { am })\end{array}$ & $\mathrm{SiO}_{2}(\mathrm{am})=\mathrm{SiO}_{2}(\mathrm{aq})$ & -2.85 \\
\hline $\begin{array}{c}\mathrm{Iron} \mathrm{Hydroxide} \\
\mathrm{Fe}(\mathrm{OH})_{3}\end{array}$ & $\mathrm{Fe}(\mathrm{OH})_{3}=\mathrm{Fe}(\mathrm{OH})_{3}(\mathrm{aq})$ & -1.53 \\
\hline $\begin{array}{c}\mathrm{Gibbsite} \\
\mathrm{Al}(\mathrm{OH})_{3}\end{array}$ & $\mathrm{Gibbsite}=\mathrm{AlO}_{2}{ }^{-}+\mathrm{H}^{+}+\mathrm{H}_{2} \mathrm{O}$ & -14.90 \\
\hline $\begin{array}{c}\mathrm{Sepiolite} \\
\mathrm{Mg}_{4} \mathrm{Si}_{6} \mathrm{O}_{15}(\mathrm{OH})_{2} \cdot 6 \mathrm{H}_{2} \mathrm{O}\end{array}$ & Sepiolite $+8 \mathrm{H}^{+}=4 \mathrm{Mg}^{2+}+6 \mathrm{SiO}_{2}(\mathrm{aq})+11 \mathrm{H}_{2} \mathrm{O}$ & 31.29 \\
\hline
\end{tabular}




\subsection{Conclusions}

This report presents a large body of data on the corrosion behavior of one prototypic simulant glass for BV: BKV6. In addition to this simulated glass composition, PCT test results on three additional glasses; BKV7, BKV8, and BKVZ are discussed. Two test methods, SPFT and PCT, were used in combination to examine the corrosion behavior of glass over a wide range of conditions. Results from these experiments were used to develop the parameters necessary to conduct long-term PA calculations using the STORM reactive transport code. Table 19 provides the recommended parameters for BKV6, plus BKV1 for comparison (McGrail et al. 2003b). Single-pass flow-through data also were used to calculate a bounding release rate for the mullite CRB. The presence of multiple mineral phases in and the uncertainty regarding the true reactive surface area of the $\mathrm{CRB}$ may have a significant effect on the reported rates. Therefore, we recommend that rate law parameters be developed for the pure mineral phases identified in the CRB. These results should be combined with literature values to develop a scientifically defensible conclusion regarding the dissolution of the mullite $\mathrm{CRB}$ and the potential impact the CRB may have on BV waste package performance. Although additional testing is needed, currently available experimental data suggest that rate law parameters derived for BV glasses are comparable to those determined for WTP glass formulations (Pierce et al. 2004b).

Table 19. Summary of Best Estimate Rate Law Parameters for BV Glasses, BKV1 and BKV6, the Castable Refractory, BKVM, and for Comparison LAWA44 at $15^{\circ} \mathrm{C}$.

\begin{tabular}{|c|c|c|c|c|c|c|}
\hline Parameter & Meaning & $\overline{B K V 1}$ & BKV6 & $\overline{B K V M}$ & LAWA44 & Comments \\
\hline$\vec{k}$ & $\begin{array}{l}\text { forward rate constant } \\
\left(\mathrm{g} \mathrm{m}^{-2} \mathrm{~d}^{-1}\right)\end{array}$ & $8.6 \times 10^{6}$ & $4.3 \times 10^{4}$ & $4.5 \times 10^{3}$ & $1.3 \times 10^{4}$ & \\
\hline$K_{g}$ & $\begin{array}{l}\text { apparent equilibrium constant } \\
\text { for glass based on activity } \\
\text { product } a\left[\mathrm{SiO}_{2}(\mathrm{aq})\right]\end{array}$ & $3.2 \times 10^{-4}$ & $4.5 \times 10^{-4}$ & 58.3 & $5.45 \times 10^{-4}$ & $\begin{array}{l}\log K \text { calculated } \\
\text { for dissolution of } \\
\mathrm{BKVM} \text { at } 15^{\circ} \mathrm{C} \\
\end{array}$ \\
\hline$\eta$ & pH power law coefficient & $0.42 \pm 0.02$ & $0.53 \pm 0.03$ & $0.34 \pm 0.06$ & $0.49 \pm 0.08$ & \\
\hline$E_{a}$ & $\begin{array}{l}\text { activation energy of glass } \\
\text { dissolution reaction } \\
\left(\mathrm{kJ} \mathrm{mol}^{-1}\right)\end{array}$ & $77 \pm 3$ & $69 \pm 3$ & $60 \pm 7$ & $60 \pm 7$ & \\
\hline$\sigma$ & Temkin coefficient & 1 & 1 & 1 & 1 & Assigned constant \\
\hline$r_{x}$ & $\begin{array}{l}\text { Na ion-exchange rate } \\
\left(\mathrm{mol} \mathrm{m}^{-2} \mathrm{~s}^{-1}\right)\end{array}$ & $2.1 \times 10^{-10}$ & $2.8 \times 10^{-10}$ & & $5.3 \times 10^{-11}$ & $\begin{array}{l}\text { Not measurable } \\
\text { for BKVM }\end{array}$ \\
\hline
\end{tabular}

Results from seven individual ES tests were used to determine an average recommended best estimate of the soluble ${ }^{99} \mathrm{Tc}$ inventory that is leachable from the CRB based on these ES tests (Table 20). The individual ES tests suggest the following with regard to ${ }^{99} \mathrm{Tc}$ deposition into the pores of the $\mathrm{CRB}$ :

- Deposition into the pores of the CRB is occurring by vapor phase transport and molten salt intrusion, although the rate-limiting mechanism is not clear.

- The results from multiple sections in ES-32A and ES-32B indicate that an average ${ }^{99} \mathrm{Tc} / \mathrm{Re}$ volatilization ratio of 0.17 should be used to estimate the ${ }^{99} \mathrm{Tc} C \mathrm{CRB}$ results from Re-spiked tests.

- The combined ES scale results for the FY04 BV design indicate that a best estimate of the soluble fraction of ${ }^{99} \mathrm{Tc}$ in the ES CRB is $0.34 \pm 0.06 \%$. 
Table 20. Summary Table of the Soluble Fraction Results for each ES Test.

\begin{tabular}{|c|c|c|c|c|}
\hline \multirow{2}{*}{ Test I.D. } & \multicolumn{3}{|c|}{ Soluble Fraction $\left(f_{\text {total }}\right), \%$} & \multirow{2}{*}{$\begin{array}{c}\text { Volatilization } \\
\text { Ratio ( } \alpha) \\
{ }^{99} \mathbf{T c} / \mathbf{R e}\end{array}$} \\
\hline & $\mathbf{R e}$ & Cs & ${ }^{99} \mathrm{Tc}$ & \\
\hline ES-31A $(E S-10)^{a}$ & $1.51 \pm 0.54 \%$ & & $0.25 \pm 0.09 \%$ & \\
\hline ES-31B (ES-11) ${ }^{\mathrm{a}}$ & $0.77 \pm 0.27 \%$ & $0.08 \pm 0.03 \%$ & $0.13 \pm 0.05 \%$ & \\
\hline$E S-31 C^{a}$ & $4.82 \pm 1.51 \%$ & & $0.80 \pm 0.26 \%$ & \\
\hline ES-31D ${ }^{\mathrm{a}, \mathrm{c}}$ & $0.23 \pm 0.07 \%$ & & $0.04 \pm 0.01 \%$ & \\
\hline$E S-31 E^{a}$ & $1.96 \pm 0.69 \%$ & & $0.32 \pm 0.12 \%$ & \\
\hline ES-32A (ES-12) & $1.55 \pm 0.56 \%$ & & $0.37 \pm 0.13 \%$ & $0.22 \pm 0.02^{\mathrm{b}}$ \\
\hline ES-32B (ES-13) & $1.13 \pm 0.41 \%$ & & $0.17 \pm 0.06 \%$ & $0.11 \pm 0.01$ \\
\hline Average & $1.96 \pm 0.32 \%$ & & $0.34 \pm 0.06 \%$ & $0.17 \pm 0.02$ \\
\hline
\end{tabular}

- The $0.34 \pm 0.06 \%$ value for the CRB in the FY04 BV design is significantly lower than the FY03 design in which tests indicated that $2 \mathrm{wt} \%$ of the ${ }^{99} \mathrm{Tc}$ inventory waste stream ended up in the sand insulation and scoria layer after vitrification.

- The refractory glazes tested did not reduce the amount of soluble Re or ${ }^{99} \mathrm{Tc}$ in the CRB.

- Use of a denitrated feed spiked with Re(IV) decreased Re deposition into the refractory pores by an order of magnitude. However, a practical technique that can produce a denitrated feed and/or maintain $\mathrm{Re}$ in the +4 oxidation state has not been developed.

Although the CRB is the major source of soluble ${ }^{99} \mathrm{Tc}$ in the ES waste packages, other areas contain smaller quantities of soluble ${ }^{99} \mathrm{Tc}$., e.g., the surface of the glass block where small amounts of non-glassy materials collect, the refractory sand liner, and the ICV box lid that acts as a cover during the melting process but also serves as the disposal lid (Table 21). The best estimate of the total soluble ${ }^{99} \mathrm{Tc}$ fraction from all areas in the ES tests is $0.45 \pm 0.07 \%$. Additional analysis is underway to estimate the soluble fraction in full-scale BV waste packages.

Table 21. Best Estimate of Total Soluble ${ }^{99}$ Tc Inventory in ES Tests.

\begin{tabular}{|c|c|c|c|c|}
\hline Waste Package Area & $\mathrm{ES}-32 \mathrm{~A}^{\mathrm{a}}$ & ES-32B ${ }^{a}$ & Best Estimate $^{a}$ & Basis of Best Estimate \\
\hline Castable Refractory Block & $0.37 \pm 0.13$ & $0.17 \pm 0.06$ & $0.34 \pm 0.06$ & See Section 2.3 \\
\hline Surface Glass Wash & $0.015^{\mathrm{b}}$ & $0.026 \pm 0.008$ & $0.026 \pm 0.008$ & Maximum of 2 measured values \\
\hline Refractory Sand Liner & $\mathrm{BRL}^{\mathrm{c}}$ & $\begin{array}{c}0.0001 \\
+0.0002 /-0.0001 \\
\end{array}$ & $\begin{array}{c}0.0001 \\
+0.0002 /-0.0001 \\
\end{array}$ & $\begin{array}{c}\text { Only Measured }{ }^{99} \mathrm{Tc} \text { value } \\
\text { above reporting limit }\end{array}$ \\
\hline Box Lid & $0.053^{\mathrm{b}, \mathrm{d}}$ & $0.112 \pm 0.042$ & $0.083 \pm 0.031^{\mathrm{e}}$ & $\begin{array}{c}\text { Average of two measured lid } \\
\text { values }\end{array}$ \\
\hline \multicolumn{3}{|c|}{ Total } & $0.45 \pm 0.07^{f}$ & \\
\hline \multicolumn{5}{|c|}{ 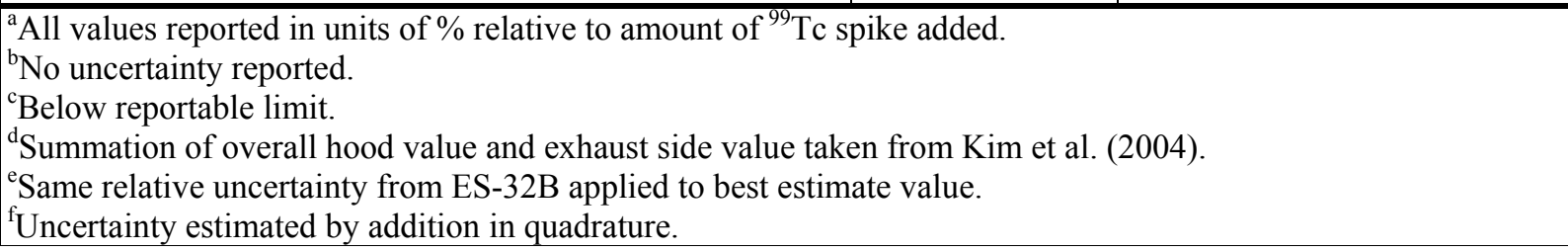 } \\
\hline
\end{tabular}




\subsection{Uncertainties}

Like all scientific studies there are limitations associated with the experimental and analytical methods, understanding of the fundamental processes, and assumptions made to allow for best estimates and conclusions to be drawn from limited data. The analyses and results provided in the preceding sections of this report are presented as though all the uncertainty is quantitatively reflected in the experimental and analytical uncertainty. Given the state of information and the complexity of the mechanisms involved, this representation of the overall uncertainty is incomplete. This section discusses, the limitations, key issues, and any assumptions that were made to reach the reported conclusions.

\subsection{CRB Soluble Fraction Best Estimate}

The initial purpose for determining the soluble fraction contained in the CRB was to identify whether or not a soluble salt of Cs, Re, and/or ${ }^{99} \mathrm{Tc}$ was being deposited within the pore-spaces of the CRB as a result of the BV process. A primary objective was to ensure that the extraction and analysis procedure resulted in a low enough detection limit to demonstrate that Re and ${ }^{99} \mathrm{Tc}$ were below desired limits. Once sample extractions from ES-31A determined that Re was being deposited in the CRB, additional extractions were conducted to attempt to quantify the total amount of soluble Re present. In other words, the initial purpose was simply to detect the presence of Re, but the procedure evolved into a methodology to estimate the fraction of soluble salt contained within the entire CRB. The following assumptions were necessary to extrapolate the analytical results to obtain a soluble fraction estimate:

Spatial Variability: An assumption was used that the average concentration, in grams per gram, of Cs, $\mathrm{Re}$, or ${ }^{99} \mathrm{Tc}$ is evenly distributed throughout a horizontal section. In other words, any sample removed from a horizontal section is representative of the entire section. This assumption was based on the distributions observed in several ES tests, including ES-31A, which suggest greater horizontal than vertical symmetry. Although the horizontal symmetry was better, results from these ES tests indicate variability between individual samples taken from a given horizontal section as well as asymmetry between the airinlet and exhaust ends of the BV waste package. The variability in the deposition of Cs, Re, and/or ${ }^{99} \mathrm{Tc}$ is thought to result from two possible mechanisms: molten salt penetration and volatilization/ condensation of soluble salts. These two mechanisms along with the variability in test conditions contribute to the variability in both the vertical and horizontal distributions between tests. Testing and sampling of fullscale melts is planned and will determine if the spatial variability is as prominent at full-scale.

Process Variability: The current set of ES tests represent a limited range of process variability on the total soluble fraction in the CRB. Process variability includes 1) power level variations, 2) feed rate variations, 3) variation in melting durations, 4) horizontal and vertical temperature gradients in the CRB, 5) air-flow variations, and 6) physical and chemical changes in the CRB before and during the BV process. ES tests conducted to date represent a range of process conditions, but may not provide upper and lower boundaries for the full range of process conditions to be considered. Significant differences in salt deposition processes may occur at larger scales and these effects, if any, cannot be quantified from ES tests. Therefore, the range of expected process variability will need to be evaluated from analyses of up to 50 full-scale boxes planned for the demonstration bulk vitrification system. 
Extraction Methods: The extraction technique used in this study does not recover $100 \%$ of the accessible soluble analytes. Moreover, differences in the recovery efficiency from sample to sample have not been evaluated. A scoping study using a $50 \mathrm{ppb}$ stock solution demonstrated that $>80 \%$ of the starting concentration was recovered after three consecutive extractions. However, the remaining contaminant is thought to be trapped in the smaller pores spaces which are not drained during the centrifugation step, which gives a small low bias in the results. The amount of pores that are not drained may vary from sample to sample based on the thermal history of different portions of the CRB and also likely contributes to some of the variability seen in the refractory results.

Scale Differences: The extent that ES test results are representative of the general trends expected in the full-scale BV waste package are presently unknown. The ES and full-scale waste packages showed similar trends for the top-down melting configuration used in FY03 testing. However, no data from full scale bottom-up melts is currently available. The best estimate of the soluble fraction provided in this report is based on ES test results. This estimate does not account for the differences in scale between the ES and full-scale BV waste package that may affect the soluble fraction. For example, engineering-scale $\mathrm{BV}$ waste package has a $\mathrm{CRB} /$ glass weight ratio of 3 , where the full-scale package has a CRB/glass weight ratio of about 0.35 . The CRB thermal profiles of the ES and full scale packages may be very different and influence Re and ${ }^{99} \mathrm{Tc}$ deposition within the CRB. The surface area to volume ratio is also roughly $1 / 6$ lower in the full-scale system and may reduce the relative amount of material that migrates to the refractory/glass interface and deposits in the CRB. Full-scale testing results will be used to assess the scale-up relationship.

\subsection{Rate Law Parameters Best Estimate and Chemical Reaction Network}

In addition to the limitations and assumptions made to estimate the soluble fraction, limitations are also associated with the best estimate rate law parameters and chemical reaction network for the BV glass. These limitations and assumptions are:

- Mullite was the dominant mineral phase in the CRB, and the additional mineral phases, identified by XRD, were assumed to not affect the measured dissolution rates of the CRB material.

- The BET surface area was assumed to be a conservatively high measure of the true surface area for the CRB

Kinetic rate law parameter measurements were conducted using crucible melt glasses made from waste simulants. These samples do not contain any of the metal inclusions observed in some ES glass melts. Therefore, the potential effect that metal inclusions may have on contaminant release rate from BV glass has not been included in this analysis.

Chemical reaction network measurements were made using both crucible melt and ES test glass samples. However, the effect of metal inclusions on the durability of these glasses was not addressed. The kinetic rate law parameters and chemical reaction network results provided in this report were derived from two expected BV glass compositions. The results do not account for any changes in the glass composition as a result of expected changes in the waste feed envelope that will occur over the operating life of a BV system. Ongoing laboratory-, engineering-, and full-scale waste form qualification tests are specifically targeted to supply the required information to evaluate the impacts of this source of uncertainty. 


\subsection{References}

Aagaard P. and H. C. Helgeson. (1982). Thermodynamic and Kinetic Constraints on Reaction Rates among Minerals and Aqueous Solutions. I. Theoretical Considerations. American Journal of Science 282, 237-285.

AMEC. 2005a. Engineering-Scale Quantitative Test Report, Test ES-32B Final Report. 35004-RT-0001, Rev. 0, AMEC Earth \& Environmental, Inc., GeoMelt ${ }^{\mathrm{TM}}$ Division, Richland, WA.

AMEC. 2005b. Engineering-Scale Quantitative Test Report; Tests ES-31C, -31D, and -31E Final Report. 35004-RT-0002, Rev. 0, AMEC Earth \& Environmental, Inc., GeoMelt ${ }^{\mathrm{TM}}$ Division, Richland, WA.

Anbeek C., N. van Breemen, E. L. Meijer, and L. Van Der Plas. (1994). The Dissolution of Naturally Weathered Feldspar and Quartz. Geochimica Cosmochimica Acta 58(21), 4601-4613.

ASTM. 1994. Standard Test Methods for Determining Chemical Durability of Nuclear Waste Glasses: The Product Consistency Test (PCT). ASTM C1285, American Society for Testing and Materials, Philadelphia, PA.

Bacon D. H., M. D. White, and B. P. McGrail. 2004. Subsurface Transport Over Reactive Multiphases (STORM): A Parallel, Coupled, Nonisothermal Multiphase Flow, Reactive Transport, and Porous Medium Alteration Simulator, Version 3.0. PNNL-14783, Pacific Northwest National Laboratory, Richland, WA.

Bagaasen L. M., E. M. Pierce, B. P. McGrail, T. M. Brouns, D. S. Kim, M. J. Schweiger, G. J. Sevigny, and M. L. Elliott. 2004. Initial Results of Bulk Vitrification Engineering-Scale Test ES-13. ST05.006, Pacific Northwest National Laboratory, Richland, WA.

Brantley S. L. and N. P. Mellott. (2000). Surface area and Porosity of Primary Silicate Minerals. American Mineralogist 85, 1767-1783.

Brunauer S., P. H. Emmett, and E. Teller. (1938). Adsorption of Gases in Multimolecular Layers. Journal of the American Chemical Society 60, 309-319.

Darab J. G. and P. A. Smith. (1996). Chemistry of Technetium and Rhenium Species During Low-Level Radioactive Waste Vitrification. Chem. Mater. 8, 1004-1021.

DOE. 2002. Performance Management Plan for the Accelerated Cleanup of the Hanford Site. DOE/RL2002-47, U.S. Department of Energy, Richland, WA.

Dove P. M. (1994). The Dissolution Kinetics of Amorphous Silica Into Sodium Chloride Solutions: Effects of Temperature and Ionic Strength. American Journal of Science 294, 665-712.

Grimmer A. R., F. Vonlampe, and M. Magi. (1986). Solid-State High-Resolution ${ }^{29}$ Si MAS NMR of Silicates with Six-fold Coordinated Silicon. Chemical Physics Letters 132(6), 549-553.

Icenhower J. P. and P. M. Dove. (2000). The Dissolution Kinetics of Amorphous Silica in Sodium Chloride Solutions: Effects of Temperature and Ionic Strength. Geochimica et Cosmochimica Acta 64(24), 4193-4203.

Kim D. S., M. J. Schweiger, R. W. Shimskey, J. V. Crum, G. J. Sevigny, and M. L. Elliott. 2004. Letter Report: Soluble Fraction of Re and Tc in Engineering-Scale 31A, 31B, and 32A Tests, Rev. 0 (DVBS Activity ID: 32A515). Pacific Northwest National Laboratory, Richland, WA.

Kim D. S., J. D. Vienna, P. R. Hrma, M. J. Schweiger, J. Matyas, J. V. Crum, D. E. Smith, G. J. Sevigny, W. C. Buchmiller, J. S. Tixier, V. J. Yeager, and K. B. Belew. 2003. Development and Testing of ICV Glasses for Hanford LAW. PNNL-14351, Pacific Northwest National Laboratory, Richland, WA. 
Kirkpatrick R. J. (1988) MAS NMR-Spectroscopy of Minerals and Glasses. In Spectroscopic Methods in Mineralogy and Geology, Vol. 18 (ed. F. C. Hawthorne), pp. 341-403. Mineralogical Society of America.

Lasaga A. C. (1981) Transition State Theory. In Reviews in Mineralogy, Vol. 8 (ed. P. H. Ribbe).

Lasaga A. C. (1995) Fundamental Approaches in Describing Mineral Dissolution and Precipitation Rates. In Chemical Weathering Rates of Silicate Minerals, Vol. 31 (ed. A. F. White and S. L. Brantley), pp. 23-86. Mineralogical Society of America.

Luey J. and D. K. Seiler. 1995. Application of In Situ Vitrification in the Soil Subsurface: EngineeringScale Testing. PNL-10485, Pacific Northwest Laboratory, Richland, WA.

Mahoney L. A. 2004. Waste Simulant Formulation for ES-13 Bulk Vitrification Test. PNNL-14822, Rev. 1, Pacific Northwest National Laboratory, Richland, WA.

Mahoney L. A. and S. D. Rassat. 2003. Tank 241-S-109 Cold Saltcake Simulant Formulation. Letter Report ST04.007, Pacific Northwest National Laboratory, Richland, WA.

Mann F. M., B. P. McGrail, D. H. Bacon, R. J. Serne, K. M. Krupka, R. J. Puigh, R. Khaleel, and S. Finfock. 2003. Risk Assessment Supporting the Decision on the Initial Selection of Supplemental ILAW Technologies. RPP-17675, Rev. 0, CH2MHILL Hanford Group Inc., Richland, WA.

McGrail B. P., D. H. Bacon, W. L. Ebert, and K. P. Saripalli. 2000a. A Strategy to Conduct an Analysis of the Long-Term Performance of Low-Activity Waste Glass in a Shallow Subsurface Disposal System at Hanford. PNNL-11834 Rev.1, Pacific Northwest National Laboratory, Richland, WA.

McGrail B. P., D. H. Bacon, R. J. Serne, and E. M. Pierce. 2003a. A Strategy to Assess Performance of Selected Low-Activity Waste Forms in an Integrated Disposal Facility. PNNL-14362, Pacific Northwest National Laboratory, Richland, WA.

McGrail B. P., W. L. Ebert, A. J. Bakel, and D. K. Peeler. (1997). Measurement of kinetic rate law parameters on a Na-Ca-Al borosilicate glass for low-activity waste. Journal of Nuclear Materials 249, 175-189.

McGrail B. P., J. P. Icenhower, P. F. Martin, D. R. Rector, H. T. Schaef, E. A. Rodriguez, and J. L. Steele. 2000b. Low-Activity Waste Glass Studies: FY2000 Summary Report. PNNL-13381, Pacific Northwest National Laboratory, Richland, WA.

McGrail B. P., J. P. Icenhower, P. F. Martin, H. T. Schaef, M. J. O'Hara, E. A. Rodriguez, and J. L. Steele. 2001a. Waste Form Release Data Package for the 2001 Immobilized Low-Activity Waste Performance Assessment. PNNL-13043, Rev.2, Pacific Northwest National Laboratory, Richland, WA.

McGrail B. P., J. P. Icenhower, D. K. Shuh, P. Liu, J. G. Darab, D. R. Baer, S. Thevuthasan, V. Shutthanandan, M. H. Engelhard, C. H. Booth, and P. Nachimuthu. (2001b). The structure of $\mathrm{Na}_{2} \mathrm{O}-\mathrm{Al}_{2} \mathrm{O}_{3}-$ $\mathrm{SiO}_{2}$ glass: impact on sodium ion exchange in $\mathrm{H}_{2} \mathrm{O}$ and $\mathrm{D}_{2} \mathrm{O}$. Journal of Non-Crystalline Solids 296, 10-26.

McGrail B. P., E. M. Pierce, H. T. Schaef, E. A. Rodriguez, J. L. Steele, A. T. Owen, and D. W. Wellman. 2003b. Laboratory Testing of Bulk Vitrified and Steam Reformed Low-Activity Waste Forms to Support A Preliminary Risk Assessment for an Integrated Disposal Facility. PNNL14414, Pacific Northwest National Laboratory, Richland, WA.

Micromeritics. (1995) ASAP 2010, Accelerated Surface Area and Porsometry System Operator's Manual. Micromeritics Corp.

Pierce E. M., B. P. McGrail, L. M. Bagaasen, D. W. Wellman, J. V. Crum, K. N. Geiszler, and S. R. Baum. 2004a. Progress Report on the Laboratory Testing of Bulk Vitrification Cast Refractory. PNNL-14935, Pacific Northwest National Laboratory, Richland, WA. 
Pierce E. M., B. P. McGrail, E. A. Rodriguez, H. T. Schaef, K. P. Saripalli, R. J. Serne, K. M. Krupka, P. F. Martin, S. R. Baum, K. N. Geiszler, L. R. Reed, and W. J. Shaw. 2004b. Waste Form Release Data Package for the 2005 Integrated Disposal Facility Performance Assessment. PNNL-14805, Pacific Northwest National Laboratory, Richland, WA.

Renders P. J. N. G., C.H.; and Barnes, H.L. (1995). Precipitation and Dissolution Rate Constants for Cristobalite From 150 to $300^{\circ} \mathrm{C}$. Geochimica et Cosmochimica Acta 59, 77-85.

Robie R. A. and B. S. Hemingway. (1995) Thermodynamic Properties of Minerals and Related Substances at 298.15 and 1 Bar (10 $0^{5}$ Pascals) Pressure and at Higher Temperatures. U. S. Geological Survey Bulletin.

Sederburg P. and L. Thompson. 2004. Quantitative Engineering Scale Testing Plan. 17902-ES-RT1, Rev.1, AMEC Earth and Environmental, Inc. GeoMelt Division, Richland, WA.

Thompson L. 2003. Bulk Vitrification Project \#17902 Engineering-Scale In-Container Vitrification Test Results - Final Report. AMEC Earth and Environmental, Inc. - GeoMelt Division, Richland, WA.

Thompson L. 2004. Bulk Vitrification Project \#17902 Task 6 Process Improvements Testing Results. AMEC Earth and Environmental, Inc. - GeoMelt Division, Richland, WA.

Tixier J. S., J. A. Stottlemyre, and M. T. Murphy. (1991). Vitrified Underground Barriers. Waste Management 91, 603-611.

Wagman D. D., W. H. Evans, V. B. Parker, R. H. Schumm, I. Halow, S. M. Bailey, K. L. Churney, and R. L. Nuttall. (1982). The NBS Tables of Chemical Thermodynamic Properties, Select Values for Inorganic and C1 and C2 Organic Substances in SI Units. Journal Physical and Chemical Reference Data 11(Supplement No. 2), 1-392.

Wolery T. J. 1992a. EQ3/6, A Software Package for Geochemical Modeling of Aqueous Systems: Package Overview and Installation Guide (Version 7.0). UCRL-MA-110662 PT I, Lawrence Livermore National Laboratory, Livermore, CA.

Wolery T. J. 1992b. EQ3NR, A Computer Program for Geochemical Aqueous Speciation-Solubility Calculations: Theoretical Manual, User's Guide, and Related Documentation (Version 7.0). UCRLMA-110662 PT III, Lawrence Livermore National Laboratory, Livermore, CA. 
Appendix A

Soluble Fraction Test Results 
Table A1. Extraction Results for ES-31A.

\begin{tabular}{|c|c|c|c|c|c|c|c|c|c|c|}
\hline $\begin{array}{c}\text { Dry Sample } \\
\text { Mass (g) } \\
\text { ES-31A }\end{array}$ & $\begin{array}{l}\text { Extraction } \\
\text { Step \# }\end{array}$ & $\begin{array}{l}\text { Soln. } \\
\text { Type: }\end{array}$ & $\begin{array}{l}\text { Vol. of Soln. } \\
\text { Added for } \\
\text { Sat. (mL) }\end{array}$ & \begin{tabular}{|c|} 
Pre-Sat. \\
Sample \\
Mass (g)
\end{tabular} & $\begin{array}{l}\text { Post-Sat. \& } \\
\text { Draining Free } \\
\text { Liq. Sample } \\
\text { Mass (g) }\end{array}$ & $\begin{array}{l}\text { Post-Cent. } \\
\text { Sample } \\
\text { Mass (g) }\end{array}$ & Sat. Sample \# & \begin{tabular}{|c} 
Liq. [Re] \\
(Sat.) \\
$(\mu \mathrm{g} / \mathrm{L})$
\end{tabular} & Cent. Sample \# & $\begin{array}{c}\text { Liq. [Re] (Cent.) } \\
(\mu \mathrm{g} / \mathrm{L})\end{array}$ \\
\hline EST-04-01 & & & & & & & & & & \\
\hline Fragment \#1 & & & & & & & & & & \\
\hline $1.20 \mathrm{E}+02$ & 1 & \begin{tabular}{|l|} 
DIW \\
\end{tabular} & $7.69 \mathrm{E}+01$ & $1.20 \mathrm{E}+02$ & $1.26 \mathrm{E}+02$ & $1.23 \mathrm{E}+02$ & EST-04-01-1-1 & $1.03 \mathrm{E}+03$ & EST-04-01-1-2 & $2.04 \mathrm{E}+04$ \\
\hline $1.20 \mathrm{E}+02$ & 2 & DIW & $1.18 \mathrm{E}+02$ & $1.23 \mathrm{E}+02$ & $1.26 \mathrm{E}+02$ & $1.22 \mathrm{E}+02$ & EST-04-01-1-3 & $2.42 \mathrm{E}+02$ & EST-04-01-1-4 & $2.28 \mathrm{E}+04$ \\
\hline $1.20 \mathrm{E}+02$ & 3 & DIW & $1.20 \mathrm{E}+02$ & $1.22 \mathrm{E}+02$ & $1.26 \mathrm{E}+02$ & $1.22 \mathrm{E}+02$ & EST-04-01-1-5 & $1.48 \mathrm{E}+02$ & EST-04-01-1-6 & $1.16 \mathrm{E}+04$ \\
\hline $1.20 \mathrm{E}+02$ & 4 & DIW & $7.21 \mathrm{E}+01$ & $1.22 \mathrm{E}+02$ & $1.26 \mathrm{E}+02$ & $1.22 \mathrm{E}+02$ & EST-04-01-1-7 & $2.42 \mathrm{E}+02$ & EST-04-01-1-8 & $7.21 \mathrm{E}+03$ \\
\hline $1.20 \mathrm{E}+02$ & 5 & DIW & $7.06 \mathrm{E}+01$ & $1.22 \mathrm{E}+02$ & $1.26 \mathrm{E}+02$ & $1.22 \mathrm{E}+02$ & EST-04-01-1-9 & $5.61 \mathrm{E}+01$ & EST-04-01-1-10 & $2.38 \mathrm{E}+03$ \\
\hline $1.20 \mathrm{E}+02$ & 6 & DIW & $7.12 \mathrm{E}+01$ & $1.22 \mathrm{E}+02$ & $1.26 \mathrm{E}+02$ & $1.22 \mathrm{E}+02$ & EST-04-01-1-11 & $4.55 \mathrm{E}+01$ & EST-04-01-1-12 & $1.80 \mathrm{E}+03$ \\
\hline $1.20 \mathrm{E}+02$ & 7 & DIW & $1.04 \mathrm{E}+02$ & \begin{tabular}{|l|}
$1.22 \mathrm{E}+02$ \\
\end{tabular} & $1.25 \mathrm{E}+02$ & $1.22 \mathrm{E}+02$ & EST-04-01-1-13 & $6.02 \mathrm{E}+01$ & EST-04-01-1-14 & $1.78 \mathrm{E}+03$ \\
\hline Fragment \#2 & & & & & & & & & & \\
\hline $9.56 \mathrm{E}+01$ & 1 & DIW & $5.71 \mathrm{E}+01$ & \begin{tabular}{|l|}
$9.56 \mathrm{E}+01$ \\
\end{tabular} & $9.99 \mathrm{E}+01$ & $9.69 \mathrm{E}+01$ & EST-04-01-2-1 & $2.08 \mathrm{E}+03$ & $\begin{array}{l}\text { EST-04-01-2-2 } \\
\end{array}$ & $5.13 \mathrm{E}+04$ \\
\hline $9.56 \mathrm{E}+01$ & 2 & DIW & $1.24 \mathrm{E}+02$ & $9.69 \mathrm{E}+01$ & $1.00 \mathrm{E}+02$ & $9.67 \mathrm{E}+01$ & EST-04-01-2-3 & $3.04 \mathrm{E}+02$ & EST-04-01-2-4 & $1.50 \mathrm{E}+04$ \\
\hline $9.56 \mathrm{E}+01$ & 3 & DIW & $1.28 \mathrm{E}+02$ & \begin{tabular}{|l|}
$9.67 \mathrm{E}+01$ \\
\end{tabular} & $9.95 \mathrm{E}+01$ & $9.61 \mathrm{E}+01$ & EST-04-01-2-5 & $5.27 \mathrm{E}+01$ & EST-04-01-2-6 & $6.32 \mathrm{E}+03$ \\
\hline $9.56 \mathrm{E}+01$ & 4 & \begin{tabular}{|l|} 
DIW \\
\end{tabular} & $1.24 \mathrm{E}+02$ & $9.61 \mathrm{E}+01$ & $9.96 \mathrm{E}+01$ & $9.50 \mathrm{E}+01$ & $\begin{array}{l}\text { EST-04-01-2-7 } \\
\end{array}$ & $7.01 \mathrm{E}+01$ & EST-04-01-2-8 & \\
\hline $9.56 \mathrm{E}+01$ & 5 & DIW & $8.33 \mathrm{E}+01$ & \begin{tabular}{|l|}
$9.50 \mathrm{E}+01$ \\
\end{tabular} & $9.92 \mathrm{E}+01$ & $9.56 \mathrm{E}+01$ & EST-04-01-2-9 & $3.22 \mathrm{E}+01$ & EST-04-01-2-10 & $1.45 \mathrm{E}+03$ \\
\hline $9.56 \mathrm{E}+01$ & 6 & \begin{tabular}{|l|} 
DIW \\
\end{tabular} & $8.22 \mathrm{E}+01$ & \begin{tabular}{|l|}
$9.56 \mathrm{E}+01$ \\
\end{tabular} & $9.89 \mathrm{E}+01$ & $9.58 \mathrm{E}+01$ & EST-04-01-2-11 & $4.82 \mathrm{E}+01$ & EST-04-01-2-12 & $2.71 \mathrm{E}+03$ \\
\hline $9.56 \mathrm{E}+01$ & 7 & DIW & $8.16 \mathrm{E}+01$ & \begin{tabular}{|l|}
$9.58 \mathrm{E}+01$ \\
\end{tabular} & & & EST-04-01-2-13 & $7.83 \mathrm{E}+01$ & EST-04-01-2-14 & $3.17 \mathrm{E}+03$ \\
\hline Fragment \#3 & & & & & & & & & & \\
\hline $5.85 \mathrm{E}+01$ & 1 & \begin{tabular}{|l|} 
DIW \\
\end{tabular} & $5.86 \mathrm{E}+01$ & \begin{tabular}{|l|}
$5.85 \mathrm{E}+01$ \\
\end{tabular} & $6.20 \mathrm{E}+01$ & $6.02 \mathrm{E}+01$ & EST-04-01-3-1 & $9.78 \mathrm{E}+00$ & EST-04-01-3-2 & $1.12 \mathrm{E}+02$ \\
\hline $5.85 \mathrm{E}+01$ & 2 & \begin{tabular}{|l|} 
DIW \\
\end{tabular} & $8.21 \mathrm{E}+01$ & \begin{tabular}{|l|}
$6.02 \mathrm{E}+01$ \\
\end{tabular} & $6.39 \mathrm{E}+01$ & $6.17 \mathrm{E}+01$ & EST-04-01-3-3 & $1.78 \mathrm{E}+00$ & EST-04-01-3-4 & $5.64 \mathrm{E}+00$ \\
\hline Fragment \#4 & & & & & & & & & & \\
\hline $6.00 \mathrm{E}+01$ & 1 & \begin{tabular}{|l|} 
DIW \\
\end{tabular} & $5.04 \mathrm{E}+01$ & \begin{tabular}{|l|}
$6.00 \mathrm{E}+01$ \\
\end{tabular} & $6.39 \mathrm{E}+01$ & $6.17 \mathrm{E}+01$ & EST-04-01-4-1 & $1.49 \mathrm{E}+01$ & EST-04-01-4-2 & $1.68 \mathrm{E}+02$ \\
\hline $6.00 \mathrm{E}+01$ & 2 & DIW & $7.34 \mathrm{E}+01$ & \begin{tabular}{|l|}
$6.17 \mathrm{E}+01$ \\
\end{tabular} & $6.36 \mathrm{E}+01$ & $6.17 \mathrm{E}+01$ & EST-04-01-4-3 & $2.60 \mathrm{E}+00$ & EST-04-01-4-4 & $4.60 \mathrm{E}+00$ \\
\hline Fragment \#5 & & & & & & & & & & \\
\hline $1.16 \mathrm{E}+02$ & 1 & DIW & $1.00 \mathrm{E}+02$ & \begin{tabular}{|l|}
$1.16 \mathrm{E}+02$ \\
\end{tabular} & $1.22 \mathrm{E}+02$ & $1.20 \mathrm{E}+02$ & EST-04-01-5-1 & $3.76 \mathrm{E}+00$ & EST-04-01-5-2 & $4.14 \mathrm{E}+01$ \\
\hline $1.16 \mathrm{E}+02$ & 2 & DIW & $1.61 \mathrm{E}+02$ & $1.20 \mathrm{E}+02$ & $1.22 \mathrm{E}+02$ & $1.20 \mathrm{E}+02$ & EST-04-01-5-3 & $3.31 \mathrm{E}-01$ & EST-04-01-5-4 & $3.67 \mathrm{E}+01$ \\
\hline $1.16 \mathrm{E}+02$ & 3 & DIW & $1.50 \mathrm{E}+02$ & \begin{tabular}{|l|}
$1.20 \mathrm{E}+02$ \\
\end{tabular} & $1.23 \mathrm{E}+02$ & $1.19 \mathrm{E}+02$ & EST-04-01-5-5 & 5.91E-01 & EST-04-01-5-6 & $3.37 \mathrm{E}+01$ \\
\hline $1.16 \mathrm{E}+02$ & 4 & DIW & $1.73 \mathrm{E}+02$ & \begin{tabular}{|l|}
$1.19 \mathrm{E}+02$ \\
\end{tabular} & $1.22 \mathrm{E}+02$ & $1.20 \mathrm{E}+02$ & EST-04-01-5-7 & $1.85 \mathrm{E}-01$ & EST-04-01-5-8 & $7.35 \mathrm{E}+01$ \\
\hline $1.16 \mathrm{E}+02$ & 5 & DIW & $1.70 \mathrm{E}+02$ & $1.20 \mathrm{E}+02$ & $1.22 \mathrm{E}+02$ & $1.20 \mathrm{E}+02$ & EST-04-01-5-9 & 7.25E-02 & EST-04-01-5-10 & $1.26 \mathrm{E}+01$ \\
\hline & & & & & & & & & & \\
\hline & & & & & & & & & & \\
\hline
\end{tabular}


Table A1. Extraction Results for ES-31A.

\begin{tabular}{|c|c|c|c|c|c|c|c|c|c|c|}
\hline $\begin{array}{c}\text { Dry Sample } \\
\text { Mass (g) } \\
\text { ES-31A }\end{array}$ & $\begin{array}{c}\text { Extraction } \\
\text { Step \# }\end{array}$ & \begin{tabular}{|l} 
Soln. \\
Type¥
\end{tabular} & $\begin{array}{l}\text { Vol. of Soln. } \\
\text { Added for } \\
\text { Sat. (mL) }\end{array}$ & \begin{tabular}{|c|} 
Pre-Sat. \\
Sample \\
Mass (g)
\end{tabular} & $\begin{array}{c}\text { Post-Sat. \& } \\
\text { Draining Free } \\
\text { Liq. Sample } \\
\text { Mass (g) }\end{array}$ & $\begin{array}{c}\text { Post-Cent. } \\
\text { Sample } \\
\text { Mass (g) }\end{array}$ & Sat. Sample \# & \begin{tabular}{|c} 
Liq. [Re] \\
(Sat.) \\
$(\mu \mathrm{g} / \mathrm{L})$
\end{tabular} & Cent. Sample \# & $\begin{array}{c}\text { Liq. [Re] (Cent.) } \\
(\mathbf{g g} / \mathbf{L})\end{array}$ \\
\hline EST-04-02 & & & & & & & & & & \\
\hline Fragment \#1 & & & & & & & & & & \\
\hline $1.49 \mathrm{E}+02$ & 1 & DIW & $1.22 \mathrm{E}+02$ & $1.49 \mathrm{E}+02$ & $1.55 \mathrm{E}+02$ & $1.51 \mathrm{E}+02$ & EST-04-02-1-1 & $6.70 \mathrm{E}+02$ & EST-04-02-1-2 & $4.32 \mathrm{E}+04$ \\
\hline $1.49 \mathrm{E}+02$ & 2 & DIW & $1.09 \mathrm{E}+02$ & - & - & - & EST-04-02-1-3 & $3.02 \mathrm{E}+02$ & & \\
\hline $1.49 \mathrm{E}+02$ & 3 & DIW & $1.22 \mathrm{E}+02$ & - & - & - & EST-04-02-1-5 & - & & \\
\hline $1.49 \mathrm{E}+02$ & 4 & DIW & $1.38 \mathrm{E}+02$ & - & - & - & EST-04-02-1-7 & $9.33 \mathrm{E}+01$ & & \\
\hline $1.49 \mathrm{E}+02$ & 5 & DIW & $9.09 \mathrm{E}+01$ & - & - & - & EST-04-02-1-9 & $5.43 \mathrm{E}+01$ & & \\
\hline Fragment \#2 & & & & & & & & & & \\
\hline $1.46 \mathrm{E}+02$ & 1 & DIW & $8.97 \mathrm{E}+01$ & \begin{tabular}{|l|}
$1.46 \mathrm{E}+02$ \\
\end{tabular} & $1.54 \mathrm{E}+02$ & $1.50 \mathrm{E}+02$ & EST-04-02-2-1 & $3.06 \mathrm{E}+00$ & EST-04-02-2-2 & $5.45 \mathrm{E}+01$ \\
\hline $1.46 \mathrm{E}+02$ & 2 & DIW & $1.10 \mathrm{E}+02$ & \begin{tabular}{|l|}
$1.50 \mathrm{E}+02$ \\
\end{tabular} & $1.53 \mathrm{E}+02$ & $1.49 \mathrm{E}+02$ & $\begin{array}{l}\text { EST-04-02-2-3 } \\
\end{array}$ & 9.29E-01 & EST-04-02-2-4 & $8.49 \mathrm{E}+01$ \\
\hline $1.46 \mathrm{E}+02$ & 3 & DIW & $8.82 \mathrm{E}+01$ & \begin{tabular}{|l|}
$1.49 \mathrm{E}+02$ \\
\end{tabular} & $1.54 \mathrm{E}+02$ & $1.52 \mathrm{E}+02$ & EST-04-02-2-5 & - & EST-04-02-2-6 & $6.10 \mathrm{E}+00$ \\
\hline $1.46 \mathrm{E}+02$ & 4 & DIW & $1.04 \mathrm{E}+02$ & $1.52 \mathrm{E}+02$ & $1.54 \mathrm{E}+02$ & $1.53 \mathrm{E}+02$ & EST-04-02-2-7 & $2.73 \mathrm{E}-01$ & EST-04-02-2-8 & $0.00 \mathrm{E}+00$ \\
\hline $1.46 \mathrm{E}+02$ & 5 & DIW & $1.42 \mathrm{E}+02$ & \begin{tabular}{|l|}
$1.53 \mathrm{E}+02$ \\
\end{tabular} & $1.54 \mathrm{E}+02$ & $1.52 \mathrm{E}+02$ & EST-04-02-2-9 & $0.00 \mathrm{E}+00$ & EST-04-02-2-10 & $0.00 \mathrm{E}+00$ \\
\hline & & & & & & & & & & \\
\hline $\begin{array}{l}\text { EST-04-05 } \\
\end{array}$ & & & & & & & & & & \\
\hline Fragment \#1 & & & & & & & & & & \\
\hline $8.31 \mathrm{E}+01$ & 1 & DIW & $8.97 \mathrm{E}+01$ & \begin{tabular}{|l|}
$8.31 \mathrm{E}+01$ \\
\end{tabular} & $8.76 \mathrm{E}+01$ & $8.61 \mathrm{E}+01$ & EST-04-05-2-1 & $1.93 \mathrm{E}+02$ & EST-04-05-2-2 & $1.64 \mathrm{E}+03$ \\
\hline $8.31 \mathrm{E}+01$ & 2 & DIW & $4.78 \mathrm{E}+01$ & \begin{tabular}{|l|}
$8.61 \mathrm{E}+01$ \\
\end{tabular} & $8.75 \mathrm{E}+01$ & $8.54 \mathrm{E}+01$ & EST-04-05-2-3 & $2.89 \mathrm{E}+01$ & EST-04-05-2-4 & $1.35 \mathrm{E}+03$ \\
\hline $8.31 \mathrm{E}+01$ & 3 & DIW & $5.04 \mathrm{E}+01$ & $8.54 \mathrm{E}+01$ & $8.74 \mathrm{E}+01$ & $8.53 \mathrm{E}+01$ & EST-04-05-2-5 & $2.02 \mathrm{E}+01$ & EST-04-05-2-6 & $7.13 \mathrm{E}+02$ \\
\hline $8.31 \mathrm{E}+01$ & 4 & DIW & $5.02 \mathrm{E}+01$ & $8.53 \mathrm{E}+01$ & $8.74 \mathrm{E}+01$ & $8.56 \mathrm{E}+01$ & EST-04-05-2-7 & $1.03 \mathrm{E}+01$ & EST-04-05-2-8 & $3.19 \mathrm{E}+02$ \\
\hline Fragment \#2 & & & & & & & & & & \\
\hline $6.48 \mathrm{E}+01$ & 1 & DIW & $6.57 \mathrm{E}+01$ & \begin{tabular}{|l|}
$6.48 \mathrm{E}+01$ \\
\end{tabular} & $6.93 \mathrm{E}+01$ & $6.81 \mathrm{E}+01$ & EST-04-05-3-1 & $6.44 \mathrm{E}+01$ & EST-04-05-3-2 & $3.89 \mathrm{E}+02$ \\
\hline $6.48 \mathrm{E}+01$ & 2 & DIW & $5.87 \mathrm{E}+01$ & \begin{tabular}{|l|}
$6.81 \mathrm{E}+01$ \\
\end{tabular} & $6.92 \mathrm{E}+01$ & $6.80 \mathrm{E}+01$ & EST-04-05-3-3 & $7.36 \mathrm{E}+00$ & EST-04-05-3-4 & $2.16 \mathrm{E}+02$ \\
\hline $6.48 \mathrm{E}+01$ & 3 & DIW & $1.30 \mathrm{E}+02$ & \begin{tabular}{|l|}
$6.80 \mathrm{E}+01$ \\
\end{tabular} & $6.93 \mathrm{E}+01$ & $6.80 \mathrm{E}+01$ & EST-04-05-3-5 & $6.39 \mathrm{E}+00$ & EST-04-05-3-6 & $1.14 \mathrm{E}+02$ \\
\hline $6.48 \mathrm{E}+01$ & 4 & DIW & $5.84 \mathrm{E}+01$ & \begin{tabular}{|c|}
$6.80 \mathrm{E}+01$ \\
\end{tabular} & $6.93 \mathrm{E}+01$ & $6.80 \mathrm{E}+01$ & EST-04-05-3-7 & $2.67 \mathrm{E}+00$ & EST-04-05-3-8 & $6.75 \mathrm{E}+01$ \\
\hline Fragment \#3 & & & & & & & & & & \\
\hline $4.50 \mathrm{E}+01$ & 1 & DIW & $5.08 \mathrm{E}+01$ & \begin{tabular}{|l|}
$4.50 \mathrm{E}+01$ \\
\end{tabular} & $4.79 \mathrm{E}+01$ & $4.69 \mathrm{E}+01$ & EST-04-05-4-1 & $8.67 \mathrm{E}+00$ & EST-04-05-4-2 & $2.08 \mathrm{E}+01$ \\
\hline $4.50 \mathrm{E}+01$ & 2 & DIW & $7.01 \mathrm{E}+01$ & $4.69 \mathrm{E}+01$ & $4.74 \mathrm{E}+01$ & $4.66 \mathrm{E}+01$ & EST-04-05-4-3 & $2.64 \mathrm{E}+00$ & EST-04-05-4-4 & $1.39 \mathrm{E}+01$ \\
\hline $4.50 \mathrm{E}+01$ & 3 & DIW & $6.26 \mathrm{E}+01$ & $4.66 \mathrm{E}+01$ & $4.75 \mathrm{E}+01$ & $4.68 \mathrm{E}+01$ & EST-04-05-4-5 & $1.60 \mathrm{E}+00$ & EST-04-05-4-6 & $8.56 \mathrm{E}+00$ \\
\hline $4.50 \mathrm{E}+01$ & 4 & DIW & $5.80 \mathrm{E}+01$ & \begin{tabular}{|l|}
$4.68 \mathrm{E}+01$ \\
\end{tabular} & $4.75 \mathrm{E}+01$ & $4.66 \mathrm{E}+01$ & EST-04-05-4-7 & $3.81 \mathrm{E}-01$ & EST-04-05-4-8 & $5.49 \mathrm{E}+00$ \\
\hline
\end{tabular}


Table A1. Extraction Results for ES-31A.

\begin{tabular}{|c|c|c|c|c|c|c|c|c|c|c|}
\hline $\begin{array}{c}\text { Dry Sample } \\
\text { Mass (g) } \\
\text { ES-31A }\end{array}$ & $\begin{array}{l}\text { Extraction } \\
\text { Step \# }\end{array}$ & $\begin{array}{l}\text { Soln. } \\
\text { Type\# }\end{array}$ & $\begin{array}{l}\text { Vol. of Soln. } \\
\text { Added for } \\
\text { Sat. (mL) }\end{array}$ & $\begin{array}{c}\text { Pre-Sat. } \\
\text { Sample } \\
\text { Mass (g) }\end{array}$ & $\begin{array}{l}\text { Post-Sat. \& } \\
\text { Draining Free } \\
\text { Liq. Sample } \\
\text { Mass (g) }\end{array}$ & $\begin{array}{l}\text { Post-Cent. } \\
\text { Sample } \\
\text { Mass (g) }\end{array}$ & Sat. Sample \# & $\begin{array}{c}\text { Liq. [Re] } \\
\text { (Sat.) } \\
(\mu \mathrm{g} / \mathrm{L})\end{array}$ & Cent. Sample \# & $\begin{array}{c}\text { Liq. [Re] (Cent.) } \\
(\mu \mathrm{g} / \mathrm{L})\end{array}$ \\
\hline $\begin{array}{l}\text { EST-04-06 } \\
\end{array}$ & & & & & & & & & & \\
\hline Fragment \#1 & & & & & & & & & & \\
\hline $1.18 \mathrm{E}+02$ & 1 & DIW & $8.35 \mathrm{E}+01$ & $1.18 \mathrm{E}+02$ & $1.25 \mathrm{E}+02$ & $1.19 \mathrm{E}+02$ & EST-04-06-1-1 & $4.27 \mathrm{E}+02$ & EST-04-06-1-2 & $1.13 \mathrm{E}+03$ \\
\hline $1.18 \mathrm{E}+02$ & 2 & DIW & $8.29 \mathrm{E}+01$ & $1.19 \mathrm{E}+02$ & $1.24 \mathrm{E}+02$ & $1.18 \mathrm{E}+02$ & EST-04-06-1-3 & $2.55 \mathrm{E}+01$ & EST-04-06-1-4 & $3.65 \mathrm{E}+02$ \\
\hline $1.18 \mathrm{E}+02$ & 3 & DIW & $1.05 \mathrm{E}+02$ & $1.18 \mathrm{E}+02$ & $1.23 \mathrm{E}+02$ & $1.20 \mathrm{E}+02$ & EST-04-06-1-5 & $2.77 \mathrm{E}+01$ & EST-04-06-1-6 & $5.37 \mathrm{E}+01$ \\
\hline $1.18 \mathrm{E}+02$ & 4 & DIW & $1.06 \mathrm{E}+02$ & $1.20 \mathrm{E}+02$ & $1.24 \mathrm{E}+02$ & $1.20 \mathrm{E}+02$ & EST-04-06-1-7 & $1.51 \mathrm{E}+00$ & EST-04-06-1-8 & $1.97 \mathrm{E}+01$ \\
\hline $1.18 \mathrm{E}+02$ & 5 & \begin{tabular}{|l|} 
DIW \\
\end{tabular} & $1.18 \mathrm{E}+02$ & & & & $\begin{array}{l}\text { EST-04-06-1-9 } \\
\end{array}$ & \begin{tabular}{|l|}
$3.11 \mathrm{E}-01$ \\
\end{tabular} & EST-04-06-1-10 & $4.42 \mathrm{E}+01$ \\
\hline Fragment \#2 & & & & & & & & & & \\
\hline $8.00 \mathrm{E}+01$ & 1 & DIW & $6.95 \mathrm{E}+01$ & $8.00 \mathrm{E}+01$ & $8.47 \mathrm{E}+01$ & $8.06 \mathrm{E}+01$ & $\begin{array}{l}\text { EST-04-06-2-1 } \\
\end{array}$ & $2.88 \mathrm{E}+01$ & $\begin{array}{l}\text { EST-04-06-2-2 } \\
\end{array}$ & $2.88 \mathrm{E}+02$ \\
\hline $8.00 \mathrm{E}+01$ & 2 & DIW & $9.05 \mathrm{E}+01$ & $8.06 \mathrm{E}+01$ & $8.45 \mathrm{E}+01$ & $8.01 \mathrm{E}+01$ & EST-04-06-2-3 & $1.86 \mathrm{E}+00$ & EST-04-06-2-4 & $3.55 \mathrm{E}+01$ \\
\hline $8.00 \mathrm{E}+01$ & 3 & DIW & $1.35 \mathrm{E}+02$ & $8.01 \mathrm{E}+01$ & $8.42 \mathrm{E}+01$ & $8.22 \mathrm{E}+01$ & EST-04-06-2-5 & $1.35 \mathrm{E}+00$ & EST-04-06-2-6 & $5.20 \mathrm{E}+00$ \\
\hline $8.00 \mathrm{E}+01$ & 4 & DIW & $1.01 \mathrm{E}+02$ & $8.22 \mathrm{E}+01$ & $8.41 \mathrm{E}+01$ & $8.24 \mathrm{E}+01$ & EST-04-06-2-7 & \begin{tabular}{|l|}
$5.07 \mathrm{E}-01$ \\
\end{tabular} & EST-04-06-2-8 & $0.00 \mathrm{E}+00$ \\
\hline $8.00 \mathrm{E}+01$ & 5 & DIW & $1.07 \mathrm{E}+02$ & $8.24 \mathrm{E}+01$ & $8.40 \mathrm{E}+01$ & $8.01 \mathrm{E}+01$ & EST-04-06-2-9 & $0.00 \mathrm{E}+00$ & EST-04-06-2-10 & $0.00 \mathrm{E}+00$ \\
\hline \begin{tabular}{|l|} 
Fragment \#3 \\
\end{tabular} & & & & & & & & & & \\
\hline $5.08 \mathrm{E}+01$ & 1 & DIW & $5.36 \mathrm{E}+01$ & $5.08 \mathrm{E}+01$ & $5.41 \mathrm{E}+01$ & $5.28 \mathrm{E}+01$ & EST-04-06-3-1 & \begin{tabular}{|l|}
$6.18 \mathrm{E}-01$ \\
\end{tabular} & EST-04-06-3-2 & $4.14 \mathrm{E}+00$ \\
\hline $5.08 \mathrm{E}+01$ & 2 & DIW & $5.82 \mathrm{E}+01$ & $5.28 \mathrm{E}+01$ & $5.39 \mathrm{E}+01$ & $5.27 \mathrm{E}+01$ & EST-04-06-3-3 & $0.00 \mathrm{E}+00$ & EST-04-06-3-4 & $2.73 \mathrm{E}+00$ \\
\hline $5.08 \mathrm{E}+01$ & 3 & DIW & $9.50 \mathrm{E}+01$ & $5.27 \mathrm{E}+01$ & $5.39 \mathrm{E}+01$ & $5.28 \mathrm{E}+01$ & EST-04-06-3-5 & $0.00 \mathrm{E}+00$ & EST-04-06-3-6 & - \\
\hline $5.08 \mathrm{E}+01$ & 4 & DIW & $5.66 \mathrm{E}+01$ & $5.28 \mathrm{E}+01$ & $5.34 \mathrm{E}+01$ & $5.29 \mathrm{E}+01$ & EST-04-06-3-7 & $0.00 \mathrm{E}+00$ & EST-04-06-3-8 & $1.70 \mathrm{E}+00$ \\
\hline $5.08 \mathrm{E}+01$ & 5 & DIW & $5.33 \mathrm{E}+01$ & $5.29 \mathrm{E}+01$ & $5.37 \mathrm{E}+01$ & $5.29 \mathrm{E}+01$ & EST-04-06-3-9 & \begin{tabular}{|l|}
$0.00 \mathrm{E}+00$ \\
\end{tabular} & EST-04-06-3-10 & $0.00 \mathrm{E}+00$ \\
\hline & & & & & & & & & & \\
\hline EST-04-07 & & & & & & & & & & \\
\hline Fragment \#1 & & & & & & & & & & \\
\hline \begin{tabular}{|l|}
$7.43 \mathrm{E}+01$ \\
\end{tabular} & 1 & DIW & $1.77 \mathrm{E}+02$ & $7.43 \mathrm{E}+01$ & $7.90 \mathrm{E}+01$ & $7.63 \mathrm{E}+01$ & EST-04-07-1-1 & \begin{tabular}{|l|}
$8.33 \mathrm{E}-01$ \\
\end{tabular} & EST-04-07-1-2 & $4.71 \mathrm{E}+01$ \\
\hline $7.43 \mathrm{E}+01$ & 2 & DIW & $1.73 \mathrm{E}+02$ & $7.63 \mathrm{E}+01$ & $7.91 \mathrm{E}+01$ & $7.60 \mathrm{E}+01$ & EST-04-07-1-3 & $2.07 \mathrm{E}+00$ & EST-04-07-1-4 & $5.03 \mathrm{E}+00$ \\
\hline $7.43 \mathrm{E}+01$ & 3 & DIW & $7.91 \mathrm{E}+01$ & & & & EST-04-07-1-5 & $0.00 \mathrm{E}+00$ & & \\
\hline $7.43 \mathrm{E}+01$ & 4 & DIW & $1.23 \mathrm{E}+02$ & & & & EST-04-07-1-7 & $0.00 \mathrm{E}+00$ & & \\
\hline Fragment \#2 & & & & & & & & & & \\
\hline $5.47 \mathrm{E}+01$ & 1 & DIW & $4.79 \mathrm{E}+01$ & $5.47 \mathrm{E}+01$ & $5.79 \mathrm{E}+01$ & $5.62 \mathrm{E}+01$ & EST-04-07-2-1 & $3.17 \mathrm{E}+00$ & EST-04-07-2-2 & $1.28 \mathrm{E}+01$ \\
\hline $5.47 \mathrm{E}+01$ & 2 & DIW & $4.90 \mathrm{E}+01$ & $5.62 \mathrm{E}+01$ & $5.73 \mathrm{E}+01$ & $5.52 \mathrm{E}+01$ & EST-04-07-2-3 & $0.00 \mathrm{E}+00$ & EST-04-07-2-4 & $0.00 \mathrm{E}+00$ \\
\hline $5.47 \mathrm{E}+01$ & 3 & DIW & $4.30 \mathrm{E}+01$ & $5.52 \mathrm{E}+01$ & $5.73 \mathrm{E}+01$ & $5.62 \mathrm{E}+01$ & EST-04-07-2-5 & $0.00 \mathrm{E}+00$ & EST-04-07-2-6 & $3.87 \mathrm{E}+01$ \\
\hline $5.47 \mathrm{E}+01$ & 4 & DIW & $4.97 \mathrm{E}+01$ & $5.62 \mathrm{E}+01$ & $5.71 \mathrm{E}+01$ & $5.65 \mathrm{E}+01$ & EST-04-07-2-7 & $0.00 \mathrm{E}+00$ & EST-04-07-2-8 & $5.80 \mathrm{E}+00$ \\
\hline
\end{tabular}


Table A1. Extraction Results for ES-31A.

\begin{tabular}{|c|c|c|c|c|c|c|c|c|c|c|}
\hline $\begin{array}{c}\text { Dry Sample } \\
\text { Mass (g) } \\
\text { ES-31A }\end{array}$ & $\begin{array}{l}\text { Extraction } \\
\text { Step \# }\end{array}$ & $\begin{array}{l}\text { Soln. } \\
\text { Type: }\end{array}$ & $\begin{array}{l}\text { Vol. of Soln. } \\
\text { Added for } \\
\text { Sat. (mL) }\end{array}$ & $\begin{array}{l}\text { Pre-Sat. } \\
\text { Sample } \\
\text { Mass (g) }\end{array}$ & $\begin{array}{l}\text { Post-Sat. \& } \\
\text { Draining Free } \\
\text { Liq. Sample } \\
\text { Mass (g) }\end{array}$ & $\begin{array}{l}\text { Post-Cent. } \\
\text { Sample } \\
\text { Mass (g) }\end{array}$ & Sat. Sample \# & $\begin{array}{c}\text { Liq. [Re] } \\
\text { (Sat.) } \\
(\mu \mathrm{g} / \mathrm{L})\end{array}$ & Cent. Sample \# & $\begin{array}{c}\text { Liq. [Re] (Cent.) } \\
(\mu \mathrm{g} / \mathrm{L})\end{array}$ \\
\hline $5.47 \mathrm{E}+01$ & 5 & DIW & $4.77 \mathrm{E}+01$ & $5.65 \mathrm{E}+01$ & $5.74 \mathrm{E}+01$ & $5.65 \mathrm{E}+01$ & EST-04-07-2-9 & $0.00 \mathrm{E}+00$ & EST-04-07-2-10 & $7.37 \mathrm{E}+00$ \\
\hline $5.47 \mathrm{E}+01$ & 6 & DIW & $5.37 \mathrm{E}+01$ & $5.65 \mathrm{E}+01$ & $5.74 \mathrm{E}+01$ & $5.66 \mathrm{E}+01$ & EST-04-07-2-11 & $0.00 \mathrm{E}+00$ & EST-04-07-2-12 & $2.44 \mathrm{E}+00$ \\
\hline Fragment \#3 & & & & & & & & & & \\
\hline $6.85 \mathrm{E}+01$ & 1 & DIW & $5.62 \mathrm{E}+01$ & $6.86 \mathrm{E}+01$ & $7.23 \mathrm{E}+01$ & $7.13 \mathrm{E}+01$ & EST-04-07-3-1 & $3.26 \mathrm{E}+00$ & EST-04-07-3-2 & $1.70 \mathrm{E}+01$ \\
\hline $6.85 \mathrm{E}+01$ & 2 & DIW & $5.47 \mathrm{E}+01$ & $7.13 \mathrm{E}+01$ & $7.21 \mathrm{E}+01$ & $6.99 \mathrm{E}+01$ & EST-04-07-3-3 & $0.00 \mathrm{E}+00$ & EST-04-07-3-4 & $3.72 \mathrm{E}+01$ \\
\hline $6.85 \mathrm{E}+01$ & 3 & DIW & $5.11 \mathrm{E}+01$ & $6.99 \mathrm{E}+01$ & $7.20 \mathrm{E}+01$ & $7.00 \mathrm{E}+01$ & EST-04-07-3-5 & $0.00 \mathrm{E}+00$ & EST-04-07-3-6 & $1.39 \mathrm{E}+01$ \\
\hline $6.85 \mathrm{E}+01$ & 4 & DIW & $5.29 \mathrm{E}+01$ & $7.00 \mathrm{E}+01$ & $7.18 \mathrm{E}+01$ & $7.09 \mathrm{E}+01$ & EST-04-07-3-7 & $0.00 \mathrm{E}+00$ & EST-04-07-3-8 & $3.93 \mathrm{E}+00$ \\
\hline $6.85 \mathrm{E}+01$ & 5 & DIW & $5.36 \mathrm{E}+01$ & $7.09 \mathrm{E}+01$ & $7.20 \mathrm{E}+01$ & $7.10 \mathrm{E}+01$ & EST-04-07-3-9 & $0.00 \mathrm{E}+00$ & EST-04-07-3-10 & $2.47 \mathrm{E}+00$ \\
\hline $6.85 \mathrm{E}+01$ & 6 & DIW & $5.27 \mathrm{E}+01$ & $7.10 \mathrm{E}+01$ & $7.19 \mathrm{E}+01$ & $7.07 \mathrm{E}+01$ & EST-04-07-3-11 & $0.00 \mathrm{E}+00$ & EST-04-07-3-12 & $3.08 \mathrm{E}+00$ \\
\hline Fragment \#4 & & & & & & & & & & \\
\hline $8.03 \mathrm{E}+01$ & 1 & DIW & $5.92 \mathrm{E}+01$ & $8.03 \mathrm{E}+01$ & $8.50 \mathrm{E}+01$ & $8.33 \mathrm{E}+01$ & EST-04-07-4-1 & $2.23 \mathrm{E}+00$ & EST-04-07-4-2 & $1.01 \mathrm{E}+01$ \\
\hline $8.03 \mathrm{E}+01$ & 2 & \begin{tabular}{|l|} 
DIW \\
\end{tabular} & $5.61 \mathrm{E}+01$ & $8.33 \mathrm{E}+01$ & $8.48 \mathrm{E}+01$ & $8.19 \mathrm{E}+01$ & $\begin{array}{l}\text { EST-04-07-4-3 } \\
\end{array}$ & $0.00 \mathrm{E}+00$ & EST-04-07-4-4 & $2.40 \mathrm{E}+01$ \\
\hline $8.03 \mathrm{E}+01$ & 3 & DIW & $5.71 \mathrm{E}+01$ & $8.19 \mathrm{E}+01$ & $8.49 \mathrm{E}+01$ & $8.33 \mathrm{E}+01$ & EST-04-07-4-5 & $0.00 \mathrm{E}+00$ & EST-04-07-4-6 & $5.80 \mathrm{E}+00$ \\
\hline $8.03 \mathrm{E}+01$ & 4 & DIW & $6.19 \mathrm{E}+01$ & $8.33 \mathrm{E}+01$ & $8.45 \mathrm{E}+01$ & $8.38 \mathrm{E}+01$ & EST-04-07-4-7 & $0.00 \mathrm{E}+00$ & EST-04-07-4-8 & $1.08 \mathrm{E}+00$ \\
\hline $8.03 \mathrm{E}+01$ & 5 & DIW & $5.87 \mathrm{E}+01$ & $8.38 \mathrm{E}+01$ & $8.49 \mathrm{E}+01$ & $8.38 \mathrm{E}+01$ & EST-04-07-4-9 & $0.00 \mathrm{E}+00$ & EST-04-07-4-10 & $9.39 \mathrm{E}+00$ \\
\hline $8.03 \mathrm{E}+01$ & 6 & \begin{tabular}{|l|} 
DIW \\
\end{tabular} & $5.92 \mathrm{E}+01$ & $8.38 \mathrm{E}+01$ & $8.49 \mathrm{E}+01$ & $8.36 \mathrm{E}+01$ & EST-04-07-4-11 & $0.00 \mathrm{E}+00$ & EST-04-07-4-12 & $2.08 \mathrm{E}+00$ \\
\hline Fragment \#5 & & & & & & & & & & \\
\hline $6.53 \mathrm{E}+01$ & 1 & \begin{tabular}{|l|} 
DIW \\
\end{tabular} & $5.60 \mathrm{E}+01$ & $6.53 \mathrm{E}+01$ & $6.93 \mathrm{E}+01$ & $6.75 \mathrm{E}+01$ & EST-04-07-5-1 & $3.58 \mathrm{E}+00$ & EST-04-07-5-2 & $1.76 \mathrm{E}+01$ \\
\hline $6.53 \mathrm{E}+01$ & 2 & \begin{tabular}{|l|} 
DIW \\
\end{tabular} & $6.18 \mathrm{E}+01$ & $6.75 \mathrm{E}+01$ & $6.94 \mathrm{E}+01$ & $6.68 \mathrm{E}+01$ & EST-04-07-5-3 & $0.00 \mathrm{E}+00$ & EST-04-07-5-4 & $1.49 \mathrm{E}+01$ \\
\hline $6.53 \mathrm{E}+01$ & 3 & \begin{tabular}{|l|} 
DIW \\
\end{tabular} & $6.01 \mathrm{E}+01$ & $6.68 \mathrm{E}+01$ & $6.92 \mathrm{E}+01$ & $6.73 \mathrm{E}+01$ & EST-04-07-5-5 & $2.68 \mathrm{E}-01$ & EST-04-07-5-6 & $8.99 \mathrm{E}+00$ \\
\hline $6.53 \mathrm{E}+01$ & 4 & DIW & $6.22 \mathrm{E}+01$ & $6.73 \mathrm{E}+01$ & $6.88 \mathrm{E}+01$ & $6.79 \mathrm{E}+01$ & EST-04-07-5-7 & 5.45E-02 & EST-04-07-5-8 & $1.34 \mathrm{E}+00$ \\
\hline $6.53 \mathrm{E}+01$ & 5 & DIW & $5.95 \mathrm{E}+01$ & $6.79 \mathrm{E}+01$ & $6.92 \mathrm{E}+01$ & $6.79 \mathrm{E}+01$ & EST-04-07-5-9 & $0.00 \mathrm{E}+00$ & EST-04-07-5-10 & $1.04 \mathrm{E}+00$ \\
\hline $6.53 \mathrm{E}+01$ & 6 & DIW & $5.75 \mathrm{E}+01$ & $6.79 \mathrm{E}+01$ & $6.91 \mathrm{E}+01$ & $6.79 \mathrm{E}+01$ & EST-04-07-5-11 & $0.00 \mathrm{E}+00$ & EST-04-07-5-12 & 7.92E-01 \\
\hline & & & & & & & & & & \\
\hline EST-04-09 & & & & & & & & & & \\
\hline Fragment \#1 & & & & & & & & & & \\
\hline $7.38 \mathrm{E}+01$ & 1 & DIW & $7.30 \mathrm{E}+01$ & $7.38 \mathrm{E}+01$ & $7.81 \mathrm{E}+01$ & $7.69 \mathrm{E}+01$ & EST-04-09-1-1 & $1.05 \mathrm{E}+02$ & EST-04-09-1-2 & $1.83 \mathrm{E}+03$ \\
\hline $7.38 \mathrm{E}+01$ & 2 & DIW & $6.34 \mathrm{E}+01$ & $7.69 \mathrm{E}+01$ & $7.78 \mathrm{E}+01$ & $7.61 \mathrm{E}+01$ & EST-04-09-1-3 & $4.50 \mathrm{E}+01$ & EST-04-09-1-4 & $8.64 \mathrm{E}+02$ \\
\hline $7.38 \mathrm{E}+01$ & 3 & DIW & $6.99 \mathrm{E}+01$ & $7.62 \mathrm{E}+01$ & $7.77 \mathrm{E}+01$ & $7.65 \mathrm{E}+01$ & EST-04-09-1-5 & $9.53 \mathrm{E}+00$ & EST-04-09-1-6 & $5.92 \mathrm{E}+02$ \\
\hline $7.38 \mathrm{E}+01$ & 4 & \begin{tabular}{|l|} 
DIW \\
\end{tabular} & $6.36 \mathrm{E}+01$ & $7.65 \mathrm{E}+01$ & $7.79 \mathrm{E}+01$ & $7.60 \mathrm{E}+01$ & EST-04-09-1-7 & $7.20 \mathrm{E}+00$ & EST-04-09-1-8 & $3.01 \mathrm{E}+02$ \\
\hline $7.38 \mathrm{E}+01$ & 5 & DIW & $6.15 \mathrm{E}+01$ & $7.60 \mathrm{E}+01$ & $7.74 \mathrm{E}+01$ & $7.62 \mathrm{E}+01$ & EST-04-09-1-9 & $9.94 \mathrm{E}+00$ & EST-04-09-1-10 & $2.13 \mathrm{E}+02$ \\
\hline
\end{tabular}


Table A1. Extraction Results for ES-31A.

\begin{tabular}{|c|c|c|c|c|c|c|c|c|c|c|}
\hline $\begin{array}{c}\text { Dry Sample } \\
\text { Mass (g) } \\
\text { ES-31A }\end{array}$ & $\begin{array}{l}\text { Extraction } \\
\text { Step \# }\end{array}$ & \begin{tabular}{|c|} 
Soln. \\
Type\#
\end{tabular} & $\begin{array}{l}\text { Vol. of Soln. } \\
\text { Added for } \\
\text { Sat. (mL) }\end{array}$ & $\begin{array}{l}\text { Pre-Sat. } \\
\text { Sample } \\
\text { Mass (g) }\end{array}$ & $\begin{array}{l}\text { Post-Sat. \& } \\
\text { Draining Free } \\
\text { Liq. Sample } \\
\text { Mass (g) }\end{array}$ & $\begin{array}{l}\text { Post-Cent. } \\
\text { Sample } \\
\text { Mass (g) }\end{array}$ & Sat. Sample \# & \begin{tabular}{|c} 
Liq. [Re] \\
(Sat.) \\
$(\mu \mathrm{g} / \mathrm{L})$
\end{tabular} & Cent. Sample \# & $\begin{array}{c}\text { Liq. [Re] (Cent.) } \\
(\mu \mathrm{g} / \mathrm{L})\end{array}$ \\
\hline Fragment \#2 & & & & & & & & & & \\
\hline $5.67 \mathrm{E}+01$ & 1 & DIW & $7.02 \mathrm{E}+01$ & $5.67 \mathrm{E}+01$ & $6.01 \mathrm{E}+01$ & $5.93 \mathrm{E}+01$ & EST-04-09-2-1 & $3.44 \mathrm{E}+00$ & EST-04-09-2-2 & $2.21 \mathrm{E}+01$ \\
\hline $5.67 \mathrm{E}+01$ & 2 & DIW & $5.70 \mathrm{E}+01$ & $5.93 \mathrm{E}+01$ & $5.98 \mathrm{E}+01$ & $5.84 \mathrm{E}+01$ & EST-04-09-2-3 & $1.27 \mathrm{E}+00$ & EST-04-09-2-4 & $1.82 \mathrm{E}+01$ \\
\hline $5.67 \mathrm{E}+01$ & 3 & DIW & $6.20 \mathrm{E}+01$ & $5.84 \mathrm{E}+01$ & $5.94 \mathrm{E}+01$ & $5.85 \mathrm{E}+01$ & EST-04-09-2-5 & 3.51E-01 & EST-04-09-2-6 & $1.34 \mathrm{E}+01$ \\
\hline $5.67 \mathrm{E}+01$ & 4 & DIW & $6.94 \mathrm{E}+01$ & $5.85 \mathrm{E}+01$ & $5.93 \mathrm{E}+01$ & $5.86 \mathrm{E}+01$ & EST-04-09-2-7 & $0.00 \mathrm{E}+00$ & EST-04-09-2-8 & $7.21 \mathrm{E}+00$ \\
\hline $5.67 \mathrm{E}+01$ & 5 & DIW & $7.10 \mathrm{E}+01$ & $5.86 \mathrm{E}+01$ & $5.97 \mathrm{E}+01$ & $5.86 \mathrm{E}+01$ & EST-04-09-2-9 & $0.00 \mathrm{E}+00$ & EST-04-09-2-10 & $3.34 \mathrm{E}+00$ \\
\hline Fragment \#3 & & & & & & & & & & \\
\hline $6.65 \mathrm{E}+01$ & 1 & DIW & $1.12 \mathrm{E}+02$ & $6.65 \mathrm{E}+01$ & $7.06 \mathrm{E}+01$ & $6.96 \mathrm{E}+01$ & EST-04-09-3-1 & $3.23 \mathrm{E}+01$ & EST-04-09-3-2 & $1.56 \mathrm{E}+02$ \\
\hline $6.65 \mathrm{E}+01$ & 2 & \begin{tabular}{|l|} 
DIW \\
\end{tabular} & $1.18 \mathrm{E}+02$ & $6.96 \mathrm{E}+01$ & $7.07 \mathrm{E}+01$ & $6.78 \mathrm{E}+01$ & $\begin{array}{l}\text { EST-04-09-3-3 } \\
\end{array}$ & $1.04 \mathrm{E}+01$ & EST-04-09-3-4 & $3.78 \mathrm{E}+01$ \\
\hline $6.65 \mathrm{E}+01$ & 3 & \begin{tabular}{|l|} 
DIW \\
\end{tabular} & $1.08 \mathrm{E}+02$ & $6.78 \mathrm{E}+01$ & $7.01 \mathrm{E}+01$ & $6.73 \mathrm{E}+01$ & $\begin{array}{l}\text { EST-04-09-3-5 } \\
\end{array}$ & 5.24E-01 & EST-04-09-3-6 & $3.64 \mathrm{E}+01$ \\
\hline $6.65 \mathrm{E}+01$ & 4 & DIW & $1.23 \mathrm{E}+02$ & - & - & - & $\begin{array}{l}\text { EST-04-09-3-7 } \\
\end{array}$ & $1.54 \mathrm{E}+00$ & EST-04-09-3-8 & $0.00 \mathrm{E}+00$ \\
\hline Fragment \#4 & & & & & & & & & & \\
\hline $2.23 \mathrm{E}+01$ & 1 & DIW & $3.78 \mathrm{E}+01$ & $2.23 \mathrm{E}+01$ & $2.37 \mathrm{E}+01$ & $2.32 \mathrm{E}+01$ & EST-04-09-4-1 & $2.04 \mathrm{E}+00$ & EST-04-09-4-2 & $0.00 \mathrm{E}+00$ \\
\hline $2.23 \mathrm{E}+01$ & 2 & DIW & $6.50 \mathrm{E}+01$ & $2.22 \mathrm{E}+01$ & $2.37 \mathrm{E}+01$ & $2.22 \mathrm{E}+01$ & EST-04-09-4-3 & 4.47E-01 & EST-04-09-4-4 & $1.15 \mathrm{E}+01$ \\
\hline $2.23 \mathrm{E}+01$ & 3 & DIW & $4.86 \mathrm{E}+01$ & - & - & - & EST-04-09-4-5 & $0.00 \mathrm{E}+00$ & & \\
\hline $2.23 \mathrm{E}+01$ & 4 & \begin{tabular}{|l|} 
DIW \\
\end{tabular} & $3.58 \mathrm{E}+01$ & - & - & - & EST-04-09-4-7 & $0.00 \mathrm{E}+00$ & & \\
\hline $2.23 \mathrm{E}+01$ & 5 & DIW & $4.21 \mathrm{E}+01$ & - & - & - & EST-04-09-4-9 & $0.00 \mathrm{E}+00$ & & \\
\hline & & & & & & & & & & \\
\hline EST-04-10 & & & & & & & & & & \\
\hline Fragment \#1 & & & & & & & & & & \\
\hline $1.97 \mathrm{E}+02$ & 1 & $\mathrm{~N}$ & $1.78 \mathrm{E}+02$ & $1.97 \mathrm{E}+02$ & $2.08 \mathrm{E}+02$ & $2.05 \mathrm{E}+02$ & EST-04-10-1-1 & $4.39 \mathrm{E}+01$ & EST-04-10-1-2 & $1.56 \mathrm{E}+03$ \\
\hline $1.97 \mathrm{E}+02$ & 2 & $\mathrm{~N}$ & $1.44 \mathrm{E}+02$ & $2.05 \mathrm{E}+02$ & $2.07 \mathrm{E}+02$ & $2.06 \mathrm{E}+02$ & EST-04-10-1-3 & $3.17 \mathrm{E}+01$ & EST-04-10-1-4 & $9.91 \mathrm{E}+02$ \\
\hline $1.97 \mathrm{E}+02$ & 3 & $\mathrm{~N}$ & $0.00 \mathrm{E}+00$ & $2.06 \mathrm{E}+02$ & $2.07 \mathrm{E}+02$ & $2.05 \mathrm{E}+02$ & EST-04-10-1-5 & $1.81 \mathrm{E}+01$ & EST-04-10-1-6 & $4.55 \mathrm{E}+02$ \\
\hline $1.97 \mathrm{E}+02$ & 4 & $\bar{A}$ & $1.76 \mathrm{E}+02$ & $2.05 \mathrm{E}+02$ & $2.08 \mathrm{E}+02$ & $2.06 \mathrm{E}+02$ & EST-04-10-1-7 & $1.98 \mathrm{E}+01$ & EST-04-10-1-8 & $2.67 \mathrm{E}+02$ \\
\hline $1.97 \mathrm{E}+02$ & 5 & $\bar{A}$ & $1.45 \mathrm{E}+02$ & $2.06 \mathrm{E}+02$ & $2.08 \mathrm{E}+02$ & $2.06 \mathrm{E}+02$ & EST-04-10-1-9 & $2.50 \mathrm{E}+01$ & EST-04-10-1-10 & $5.51 \mathrm{E}+02$ \\
\hline Fragment \#2 & & & & & & & & & & \\
\hline $1.58 \mathrm{E}+02$ & 1 & $\mathrm{~N}$ & $1.37 \mathrm{E}+02$ & $1.58 \mathrm{E}+02$ & $1.66 \mathrm{E}+02$ & $1.64 \mathrm{E}+02$ & EST-04-10-2-1 & $1.83 \mathrm{E}+01$ & EST-04-10-2-2 & $9.82 \mathrm{E}+02$ \\
\hline $1.58 \mathrm{E}+02$ & 2 & $\mathrm{~N}$ & $1.48 \mathrm{E}+02$ & $1.64 \mathrm{E}+02$ & $1.66 \mathrm{E}+02$ & $1.65 \mathrm{E}+02$ & EST-04-10-2-3 & $2.66 \mathrm{E}+01$ & EST-04-10-2-4 & $1.17 \mathrm{E}+03$ \\
\hline $1.58 \mathrm{E}+02$ & 3 & $\mathrm{~N}$ & $1.39 \mathrm{E}+02$ & $1.65 \mathrm{E}+02$ & $1.66 \mathrm{E}+02$ & $1.64 \mathrm{E}+02$ & EST-04-10-2-5 & $3.60 \mathrm{E}+01$ & EST-04-10-2-6 & $7.81 \mathrm{E}+02$ \\
\hline $1.58 \mathrm{E}+02$ & 4 & $\bar{A}$ & $1.37 \mathrm{E}+02$ & $1.64 \mathrm{E}+02$ & $1.66 \mathrm{E}+02$ & $1.64 \mathrm{E}+02$ & EST-04-10-2-7 & $2.00 \mathrm{E}+01$ & EST-04-10-2-8 & $2.44 \mathrm{E}+02$ \\
\hline $1.58 \mathrm{E}+02$ & 5 & $\overline{\mathrm{A}}$ & $1.35 \mathrm{E}+02$ & $1.64 \mathrm{E}+02$ & $1.66 \mathrm{E}+02$ & $1.65 \mathrm{E}+02$ & EST-04-10-2-9 & $9.56 \mathrm{E}+00$ & EST-04-10-2-10 & $1.31 \mathrm{E}+02$ \\
\hline
\end{tabular}


Table A1. Extraction Results for ES-31A.

\begin{tabular}{|c|c|c|c|c|c|c|c|c|c|c|}
\hline $\begin{array}{c}\text { Dry Sample } \\
\text { Mass (g) } \\
\text { ES-31A }\end{array}$ & $\begin{array}{l}\text { Extraction } \\
\text { Step \# }\end{array}$ & \begin{tabular}{|l} 
Soln. \\
Type¥
\end{tabular} & $\begin{array}{l}\text { Vol. of Soln. } \\
\text { Added for } \\
\text { Sat. (mL) }\end{array}$ & \begin{tabular}{|c|} 
Pre-Sat. \\
Sample \\
Mass (g)
\end{tabular} & $\begin{array}{l}\text { Post-Sat. \& } \\
\text { Draining Free } \\
\text { Liq. Sample } \\
\text { Mass (g) }\end{array}$ & $\begin{array}{l}\text { Post-Cent. } \\
\text { Sample } \\
\text { Mass (g) }\end{array}$ & Sat. Sample \# & $\begin{array}{c}\text { Liq. [Re] } \\
\text { (Sat.) } \\
\text { ( } \mu \mathrm{g} / \mathrm{L})\end{array}$ & Cent. Sample \# & $\begin{array}{c}\text { Liq. [Re] (Cent.) } \\
(\mu \mathrm{g} / \mathbf{L})\end{array}$ \\
\hline EST-05-01 & & & & & & & & & & \\
\hline Fragment \#1 & & & & & & & & & & \\
\hline $3.60 \mathrm{E}+02$ & 1 & $\mathrm{~N}$ & $2.24 \mathrm{E}+02$ & $3.60 \mathrm{E}+02$ & $3.73 \mathrm{E}+02$ & $3.69 \mathrm{E}+02$ & EST-05-01-1-1 & $7.68 \mathrm{E}+01$ & EST-05-01-1-2 & $5.79 \mathrm{E}+03$ \\
\hline $3.60 \mathrm{E}+02$ & 2 & $\mathrm{~N}$ & $2.10 \mathrm{E}+02$ & $3.69 \mathrm{E}+02$ & $3.72 \mathrm{E}+02$ & $3.69 \mathrm{E}+02$ & EST-05-01-1-3 & $5.94 \mathrm{E}+01$ & EST-05-01-1-4 & $4.90 \mathrm{E}+02$ \\
\hline $3.60 \mathrm{E}+02$ & 3 & $\mathrm{~N}$ & $2.17 \mathrm{E}+02$ & $3.69 \mathrm{E}+02$ & $3.72 \mathrm{E}+02$ & $3.69 \mathrm{E}+02$ & EST-05-01-1-5 & $2.02 \mathrm{E}+01$ & EST-05-01-1-6 & $2.09 \mathrm{E}+03$ \\
\hline $3.60 \mathrm{E}+02$ & 4 & $\bar{A}$ & $2.18 \mathrm{E}+02$ & $3.69 \mathrm{E}+02$ & $3.74 \mathrm{E}+02$ & $3.68 \mathrm{E}+02$ & EST-05-01-1-7 & $3.56 \mathrm{E}+01$ & EST-05-01-1-8 & $8.69 \mathrm{E}+02$ \\
\hline $3.60 \mathrm{E}+02$ & 5 & $\overline{\mathrm{A}}$ & $2.20 \mathrm{E}+02$ & $3.68 \mathrm{E}+02$ & $3.73 \mathrm{E}+02$ & $3.70 \mathrm{E}+02$ & EST-05-01-1-9 & $4.18 \mathrm{E}+01$ & EST-05-01-1-10 & $1.43 \mathrm{E}+02$ \\
\hline Fragment \#2 & & & & & & & & & & \\
\hline $2.48 \mathrm{E}+02$ & 1 & $\mathrm{~N}$ & $1.44 \mathrm{E}+02$ & \begin{tabular}{|l|}
$2.48 \mathrm{E}+02$ \\
\end{tabular} & $2.56 \mathrm{E}+02$ & $2.53 \mathrm{E}+02$ & $\begin{array}{l}\text { EST-05-01-2-1 } \\
\end{array}$ & $1.56 \mathrm{E}+02$ & EST-05-01-2-2 & $1.32 \mathrm{E}+04$ \\
\hline $2.48 \mathrm{E}+02$ & 2 & $\mathrm{~N}$ & $1.56 \mathrm{E}+02$ & \begin{tabular}{|l|}
$2.53 \mathrm{E}+02$ \\
\end{tabular} & $2.55 \mathrm{E}+02$ & $2.53 \mathrm{E}+02$ & $\begin{array}{l}\text { EST-05-01-2-3 } \\
\end{array}$ & $1.14 \mathrm{E}+02$ & EST-05-01-2-4 & $5.53 \mathrm{E}+03$ \\
\hline $2.48 \mathrm{E}+02$ & 3 & $\mathrm{~N}$ & $1.54 \mathrm{E}+02$ & \begin{tabular}{|l|}
$2.53 \mathrm{E}+02$ \\
\end{tabular} & $2.51 \mathrm{E}+02$ & $2.50 \mathrm{E}+02$ & EST-05-01-2-5 & \begin{tabular}{|l|}
$8.73 E+01$ \\
\end{tabular} & EST-05-01-2-6 & $1.04 \mathrm{E}+03$ \\
\hline $2.48 \mathrm{E}+02$ & 4 & $\mathrm{~A}$ & $1.40 \mathrm{E}+02$ & $2.50 \mathrm{E}+02$ & $2.51 \mathrm{E}+02$ & $2.50 \mathrm{E}+02$ & EST-05-01-2-7 & \begin{tabular}{|l|}
$4.79 \mathrm{E}+01$ \\
\end{tabular} & EST-05-01-2-8 & $2.80 \mathrm{E}+02$ \\
\hline $2.48 \mathrm{E}+02$ & 5 & $\bar{A}$ & $1.39 \mathrm{E}+02$ & \begin{tabular}{|l|}
$2.50 \mathrm{E}+02$ \\
\end{tabular} & $2.52 \mathrm{E}+02$ & $2.50 \mathrm{E}+02$ & EST-05-01-2-9 & $1.39 \mathrm{E}+01$ & EST-05-01-2-10 & $1.68 \mathrm{E}+02$ \\
\hline & & & & & & & & & & \\
\hline EST-05-02 & & & & & & & & & & \\
\hline Fragment \#1 & & & & & & & & & & \\
\hline $1.18 \mathrm{E}+02$ & 1 & $\mathrm{~N}$ & $9.91 \mathrm{E}+01$ & \begin{tabular}{|l|}
$1.18 \mathrm{E}+02$ \\
\end{tabular} & $1.23 \mathrm{E}+02$ & $1.22 \mathrm{E}+02$ & EST-05-02-1-1 & \begin{tabular}{|l|}
$4.68 \mathrm{E}+01$ \\
\end{tabular} & EST-05-02-1-2 & $5.44 \mathrm{E}+02$ \\
\hline $1.18 \mathrm{E}+02$ & 2 & $\mathrm{~N}$ & - & \begin{tabular}{|l|}
$1.21 \mathrm{E}+02$ \\
\end{tabular} & $1.21 \mathrm{E}+02$ & $1.20 \mathrm{E}+02$ & EST-05-02-1-3 & \begin{tabular}{|l|}
$2.46 \mathrm{E}+01$ \\
\end{tabular} & EST-05-02-1-4 & $4.23 \mathrm{E}+02$ \\
\hline $1.18 \mathrm{E}+02$ & 3 & $\mathrm{~N}$ & $1.12 \mathrm{E}+02$ & \begin{tabular}{|l|}
$1.20 \mathrm{E}+02$ \\
\end{tabular} & $1.21 \mathrm{E}+02$ & $1.21 \mathrm{E}+02$ & EST-05-02-1-5 & \begin{tabular}{|l|}
$1.38 \mathrm{E}+01$ \\
\end{tabular} & EST-05-02-1-6 & $1.82 \mathrm{E}+02$ \\
\hline $1.18 \mathrm{E}+02$ & 4 & $\bar{A}$ & $1.21 \mathrm{E}+02$ & \begin{tabular}{|l|}
$1.21 \mathrm{E}+02$ \\
\end{tabular} & $1.21 \mathrm{E}+02$ & $1.21 \mathrm{E}+02$ & EST-05-02-1-7 & \begin{tabular}{|l|}
$2.86 \mathrm{E}+01$ \\
\end{tabular} & EST-05-02-1-8 & $1.03 \mathrm{E}+02$ \\
\hline $1.18 \mathrm{E}+02$ & 5 & $\bar{A}$ & $1.00 \mathrm{E}+02$ & \begin{tabular}{|l|}
$1.21 \mathrm{E}+02$ \\
\end{tabular} & $1.21 \mathrm{E}+02$ & $1.20 \mathrm{E}+02$ & EST-05-02-1-9 & \begin{tabular}{|l|}
$1.43 \mathrm{E}+01$ \\
\end{tabular} & EST-05-02-1-10 & $9.42 \mathrm{E}+01$ \\
\hline Fragment \#2 & & & & & & & & & & \\
\hline $2.81 \mathrm{E}+02$ & 1 & $\mathrm{~N}$ & $1.44 \mathrm{E}+02$ & \begin{tabular}{|l|}
$2.81 \mathrm{E}+02$ \\
\end{tabular} & $2.94 \mathrm{E}+02$ & $2.84 \mathrm{E}+02$ & EST-05-02-2-1 & $3.06 \mathrm{E}+01$ & EST-05-02-2-2 & $4.67 \mathrm{E}+02$ \\
\hline $2.81 \mathrm{E}+02$ & 2 & $\mathrm{~N}$ & $0.00 \mathrm{E}+00$ & $2.84 \mathrm{E}+02$ & $2.91 \mathrm{E}+02$ & $2.84 \mathrm{E}+02$ & EST-05-02-2-3 & $2.41 \mathrm{E}+01$ & EST-05-02-2-4 & $3.77 \mathrm{E}+02$ \\
\hline $2.81 \mathrm{E}+02$ & 3 & $\mathrm{~N}$ & $1.62 \mathrm{E}+02$ & - & - & - & EST-05-02-2-5 & $1.27 \mathrm{E}+01$ & EST-05-02-2-6 & $1.53 \mathrm{E}+02$ \\
\hline $2.81 \mathrm{E}+02$ & 4 & $\overline{\mathrm{A}}$ & $1.59 \mathrm{E}+02$ & - & - & - & EST-05-02-2-7 & $7.28 \mathrm{E}+00$ & EST-05-02-2-8 & $1.07 \mathrm{E}+02$ \\
\hline $2.81 \mathrm{E}+02$ & 5 & $\overline{\mathrm{A}}$ & $1.59 \mathrm{E}+02$ & - & - & - & EST-05-02-2-9 & $1.33 \mathrm{E}+00$ & EST-05-02-2-10 & $6.72 \mathrm{E}+01$ \\
\hline & & & & & & & & & & \\
\hline & & & & & & & & & & \\
\hline & & & & & & & & & & \\
\hline & & & & & & & & & & \\
\hline
\end{tabular}


Table A1. Extraction Results for ES-31A.

\begin{tabular}{|c|c|c|c|c|c|c|c|c|c|c|}
\hline $\begin{array}{c}\text { Dry Sample } \\
\text { Mass (g) } \\
\text { ES-31A }\end{array}$ & $\begin{array}{l}\text { Extraction } \\
\text { Step \# }\end{array}$ & $\begin{array}{c}\text { Soln. } \\
\text { Type\# }\end{array}$ & $\begin{array}{l}\text { Vol. of Soln. } \\
\text { Added for } \\
\text { Sat. (mL) }\end{array}$ & $\begin{array}{l}\text { Pre-Sat. } \\
\text { Sample } \\
\text { Mass (g) }\end{array}$ & $\begin{array}{l}\text { Post-Sat. \& } \\
\text { Draining Free } \\
\text { Liq. Sample } \\
\text { Mass (g) }\end{array}$ & $\begin{array}{l}\text { Post-Cent. } \\
\text { Sample } \\
\text { Mass (g) }\end{array}$ & Sat. Sample \# & \begin{tabular}{|c} 
Liq. [Re] \\
(Sat.) \\
$(\mu \mathrm{g} / \mathrm{L})$
\end{tabular} & Cent. Sample \# & $\begin{array}{c}\text { Liq. [Re] (Cent.) } \\
(\mu \mathrm{g} / \mathrm{L})\end{array}$ \\
\hline EST-05-03 & & & & & & & & & & \\
\hline Fragment \#1 & & & & & & & & & & \\
\hline $2.54 \mathrm{E}+02$ & 1 & $\mathrm{~N}$ & $2.53 \mathrm{E}+02$ & $2.54 \mathrm{E}+02$ & $2.64 \mathrm{E}+02$ & $2.58 \mathrm{E}+02$ & EST-05-03-1-1 & $1.77 \mathrm{E}+01$ & EST-05-03-1-2 & $1.77 \mathrm{E}+03$ \\
\hline $2.54 \mathrm{E}+02$ & 2 & $\mathrm{~N}$ & $1.85 \mathrm{E}+02$ & $2.58 \mathrm{E}+02$ & $2.63 \mathrm{E}+02$ & $2.60 \mathrm{E}+02$ & EST-05-03-1-3 & $2.45 \mathrm{E}+01$ & EST-05-03-1-4 & $4.99 \mathrm{E}+02$ \\
\hline $2.54 \mathrm{E}+02$ & 3 & $\mathrm{~N}$ & $2.13 \mathrm{E}+02$ & $2.60 \mathrm{E}+02$ & $2.63 \mathrm{E}+02$ & $2.61 \mathrm{E}+02$ & EST-05-03-1-5 & $1.59 \mathrm{E}+01$ & EST-05-03-1-6 & $7.26 \mathrm{E}+02$ \\
\hline $2.54 \mathrm{E}+02$ & 4 & $\bar{A}$ & $2.29 \mathrm{E}+02$ & $2.61 \mathrm{E}+02$ & $2.63 \mathrm{E}+02$ & $2.61 \mathrm{E}+02$ & EST-05-03-1-7 & $4.57 \mathrm{E}+01$ & EST-05-03-1-8 & $8.25 \mathrm{E}+02$ \\
\hline $2.54 \mathrm{E}+02$ & 5 & $\overline{\mathrm{A}}$ & $1.85 \mathrm{E}+02$ & $2.61 \mathrm{E}+02$ & $2.63 \mathrm{E}+02$ & $2.62 \mathrm{E}+02$ & EST-05-03-1-9 & $1.59 \mathrm{E}+01$ & EST-05-03-1-10 & $8.19 \mathrm{E}+02$ \\
\hline Fragment \#2 & & & & & & & & & & \\
\hline $3.67 \mathrm{E}+02$ & 1 & $\mathrm{~N}$ & $1.19 \mathrm{E}+02$ & $3.67 \mathrm{E}+02$ & $3.83 \mathrm{E}+02$ & $3.80 \mathrm{E}+02$ & $\begin{array}{l}\text { EST-05-03-2-1 } \\
\end{array}$ & $5.53 \mathrm{E}+01$ & EST-05-03-2-2 & $1.28 \mathrm{E}+03$ \\
\hline $3.67 \mathrm{E}+02$ & 2 & $\mathrm{~N}$ & - & $3.80 \mathrm{E}+02$ & $3.83 \mathrm{E}+02$ & $3.78 \mathrm{E}+02$ & $\begin{array}{l}\text { EST-05-03-2-3 } \\
\end{array}$ & $4.58 \mathrm{E}+01$ & EST-05-03-2-4 & $8.39 \mathrm{E}+02$ \\
\hline $3.67 \mathrm{E}+02$ & 3 & $\mathrm{~N}$ & $1.17 \mathrm{E}+02$ & $3.78 \mathrm{E}+02$ & $3.83 \mathrm{E}+02$ & $3.80 \mathrm{E}+02$ & EST-05-03-2-5 & $3.25 \mathrm{E}+01$ & EST-05-03-2-6 & $2.00 \mathrm{E}+02$ \\
\hline $3.67 \mathrm{E}+02$ & 4 & $\bar{A}$ & $1.14 \mathrm{E}+02$ & $3.80 \mathrm{E}+02$ & $3.83 \mathrm{E}+02$ & $3.80 \mathrm{E}+02$ & EST-05-03-2-7 & $2.19 \mathrm{E}+01$ & EST-05-03-2-8 & $2.42 \mathrm{E}+02$ \\
\hline $3.67 \mathrm{E}+02$ & 5 & $\bar{A}$ & $1.20 \mathrm{E}+02$ & $3.80 \mathrm{E}+02$ & $3.83 \mathrm{E}+02$ & $3.82 \mathrm{E}+02$ & EST-05-03-2-9 & $3.56 \mathrm{E}+00$ & EST-05-03-2-10 & $2.71 \mathrm{E}+02$ \\
\hline & & & & & & & & & & \\
\hline EST-06-01 & & & & & & & & & & \\
\hline Fragment \#1 & & & & & & & & & & \\
\hline $3.75 \mathrm{E}+02$ & 1 & $\mathrm{~N}$ & $2.18 \mathrm{E}+02$ & $3.75 \mathrm{E}+02$ & $3.95 \mathrm{E}+02$ & $3.90 \mathrm{E}+02$ & EST-06-01-1-1 & $2.00 \mathrm{E}+00$ & EST-06-01-1-2 & $2.80 \mathrm{E}+02$ \\
\hline $3.75 \mathrm{E}+02$ & 2 & $\mathrm{~N}$ & $2.33 \mathrm{E}+02$ & $3.90 \mathrm{E}+02$ & $3.96 \mathrm{E}+02$ & $3.91 \mathrm{E}+02$ & EST-06-01-1-3 & $4.85 \mathrm{E}+00$ & EST-06-01-1-4 & $1.47 \mathrm{E}+02$ \\
\hline $3.75 \mathrm{E}+02$ & 3 & $\mathrm{~N}$ & $1.61 \mathrm{E}+02$ & $3.91 \mathrm{E}+02$ & $3.94 \mathrm{E}+02$ & $3.87 \mathrm{E}+02$ & EST-06-01-1-5 & $2.44 \mathrm{E}+00$ & EST-06-01-1-6 & $1.09 \mathrm{E}+02$ \\
\hline $3.75 \mathrm{E}+02$ & 4 & $\bar{A}$ & $1.62 \mathrm{E}+02$ & $3.87 \mathrm{E}+02$ & $3.95 \mathrm{E}+02$ & $3.91 \mathrm{E}+02$ & EST-06-01-1-7 & $2.39 \mathrm{E}+00$ & EST-06-01-1-8 & $5.25 \mathrm{E}+01$ \\
\hline $3.75 \mathrm{E}+02$ & 5 & $\bar{A}$ & $1.73 \mathrm{E}+02$ & $3.91 \mathrm{E}+02$ & $3.95 \mathrm{E}+02$ & $3.89 \mathrm{E}+02$ & EST-06-01-1-9 & $1.54 \mathrm{E}+00$ & EST-06-01-1-10 & $2.79 \mathrm{E}+01$ \\
\hline Fragment \#2 & & & & & & & & & & \\
\hline $1.74 \mathrm{E}+02$ & 1 & $\mathrm{~N}$ & $1.58 \mathrm{E}+02$ & $1.74 \mathrm{E}+02$ & $1.84 \mathrm{E}+02$ & $1.81 \mathrm{E}+02$ & EST-06-01-2-1 & 7.17E-01 & EST-06-01-2-2 & $2.45 \mathrm{E}+01$ \\
\hline $1.74 \mathrm{E}+02$ & 2 & $\mathrm{~N}$ & $1.49 \mathrm{E}+02$ & $1.81 \mathrm{E}+02$ & $1.84 \mathrm{E}+02$ & $1.81 \mathrm{E}+02$ & EST-06-01-2-3 & 8.79E-01 & EST-06-01-2-4 & $1.81 \mathrm{E}+01$ \\
\hline $1.74 \mathrm{E}+02$ & 3 & $\mathrm{~N}$ & $1.67 \mathrm{E}+02$ & $1.81 \mathrm{E}+02$ & $1.83 \mathrm{E}+02$ & $1.81 \mathrm{E}+02$ & EST-06-01-2-5 & $2.25 \mathrm{E}-01$ & EST-06-01-2-6 & $1.41 \mathrm{E}+01$ \\
\hline $1.74 \mathrm{E}+02$ & 4 & $\overline{\mathrm{A}}$ & $1.46 \mathrm{E}+02$ & $1.81 \mathrm{E}+02$ & $1.83 \mathrm{E}+02$ & $1.81 \mathrm{E}+02$ & EST-06-01-2-7 & $4.71 \mathrm{E}-01$ & EST-06-01-2-8 & $5.25 \mathrm{E}+00$ \\
\hline $1.74 \mathrm{E}+02$ & 5 & $\overline{\mathrm{A}}$ & $1.56 \mathrm{E}+02$ & $1.81 \mathrm{E}+02$ & $1.83 \mathrm{E}+02$ & $1.79 \mathrm{E}+02$ & EST-06-01-2-9 & 1.75E-01 & EST-06-01-2-10 & $0.00 \mathrm{E}+00$ \\
\hline & & & & & & & & & & \\
\hline & & & & & & & & & & \\
\hline & & & & & & & & & & \\
\hline & & & & & & & & & & \\
\hline
\end{tabular}


Table A1. Extraction Results for ES-31A.

\begin{tabular}{|c|c|c|c|c|c|c|c|c|c|c|}
\hline $\begin{array}{c}\text { Dry Sample } \\
\text { Mass (g) } \\
\text { ES-31A }\end{array}$ & $\begin{array}{l}\text { Extraction } \\
\text { Step \# }\end{array}$ & $\begin{array}{c}\text { Soln. } \\
\text { Type\# }\end{array}$ & $\begin{array}{l}\text { Vol. of Soln. } \\
\text { Added for } \\
\text { Sat. (mL) }\end{array}$ & \begin{tabular}{|c|} 
Pre-Sat. \\
Sample \\
Mass (g)
\end{tabular} & $\begin{array}{l}\text { Post-Sat. \& } \\
\text { Draining Free } \\
\text { Liq. Sample } \\
\text { Mass (g) }\end{array}$ & $\begin{array}{l}\text { Post-Cent. } \\
\text { Sample } \\
\text { Mass (g) }\end{array}$ & Sat. Sample \# & $\begin{array}{c}\text { Liq. [Re] } \\
\text { (Sat.) } \\
\text { ( } \mu \mathrm{g} / \mathrm{L})\end{array}$ & Cent. Sample \# & $\begin{array}{c}\text { Liq. [Re] (Cent.) } \\
(\mu \mathrm{g} / \mathbf{L})\end{array}$ \\
\hline EST-06-02 & & & & & & & & & & \\
\hline Fragment \#1 & & & & & & & & & & \\
\hline $2.98 \mathrm{E}+02$ & 1 & $\mathrm{~N}$ & $1.31 \mathrm{E}+02$ & $2.98 \mathrm{E}+02$ & $3.14 \mathrm{E}+02$ & $3.10 \mathrm{E}+02$ & $\begin{array}{l}\text { EST-06-02-1-1 } \\
\text { EST }\end{array}$ & $5.89 \mathrm{E}+01$ & EST-06-02-1-2 & $3.59 \mathrm{E}+03$ \\
\hline $2.98 \mathrm{E}+02$ & 2 & $\mathrm{~N}$ & $1.26 \mathrm{E}+02$ & $3.10 \mathrm{E}+02$ & $3.14 \mathrm{E}+02$ & $3.10 \mathrm{E}+02$ & EST-06-02-1-3 & $9.64 \mathrm{E}+01$ & EST-06-02-1-4 & $2.50 \mathrm{E}+03$ \\
\hline $2.98 \mathrm{E}+02$ & 3 & $\mathrm{~N}$ & $1.10 \mathrm{E}+02$ & $3.10 \mathrm{E}+02$ & $3.12 \mathrm{E}+02$ & $3.10 \mathrm{E}+02$ & EST-06-02-1-5 & $4.49 \mathrm{E}+01$ & EST-06-02-1-6 & $1.96 \mathrm{E}+03$ \\
\hline $2.98 \mathrm{E}+02$ & 4 & $\bar{A}$ & $1.14 \mathrm{E}+02$ & $3.10 \mathrm{E}+02$ & $3.13 \mathrm{E}+02$ & $3.10 \mathrm{E}+02$ & EST-06-02-1-7 & $7.64 \mathrm{E}+01$ & EST-06-02-1-8 & $1.07 \mathrm{E}+03$ \\
\hline $2.98 \mathrm{E}+02$ & 5 & $\overline{\mathrm{A}}$ & $1.08 \mathrm{E}+02$ & $3.10 \mathrm{E}+02$ & $3.13 \mathrm{E}+02$ & $3.09 \mathrm{E}+02$ & EST-06-02-1-9 & $4.27 \mathrm{E}+01$ & EST-06-02-1-10 & $5.61 \mathrm{E}+02$ \\
\hline Fragment \#2 & & & & & & & & & & \\
\hline $2.72 \mathrm{E}+02$ & 1 & $\mathrm{~N}$ & $1.50 \mathrm{E}+02$ & \begin{tabular}{|l|}
$2.72 \mathrm{E}+02$ \\
\end{tabular} & $2.87 \mathrm{E}+02$ & $2.84 \mathrm{E}+02$ & $\begin{array}{l}\text { EST-06-02-2-1 } \\
\end{array}$ & \begin{tabular}{|l|}
$2.01 \mathrm{E}+01$ \\
\end{tabular} & EST-06-02-2-2 & $1.36 \mathrm{E}+03$ \\
\hline $2.72 \mathrm{E}+02$ & 2 & $\mathrm{~N}$ & $1.38 \mathrm{E}+02$ & \begin{tabular}{|l|}
$2.84 \mathrm{E}+02$ \\
\end{tabular} & $2.87 \mathrm{E}+02$ & $2.84 \mathrm{E}+02$ & $\begin{array}{l}\text { EST-06-02-2-3 } \\
\end{array}$ & $4.93 \mathrm{E}+01$ & EST-06-02-2-4 & $1.06 \mathrm{E}+03$ \\
\hline $2.72 \mathrm{E}+02$ & 3 & $\mathrm{~N}$ & $1.49 \mathrm{E}+02$ & \begin{tabular}{|l|}
$2.84 \mathrm{E}+02$ \\
\end{tabular} & $2.85 \mathrm{E}+02$ & $2.83 \mathrm{E}+02$ & EST-06-02-2-5 & \begin{tabular}{|l|}
$1.63 E+01$ \\
\end{tabular} & EST-06-02-2-6 & $7.63 \mathrm{E}+02$ \\
\hline $2.72 \mathrm{E}+02$ & 4 & $\mathrm{~A}$ & $1.53 \mathrm{E}+02$ & \begin{tabular}{|l|}
$2.83 \mathrm{E}+02$ \\
\end{tabular} & $2.86 \mathrm{E}+02$ & $2.84 \mathrm{E}+02$ & EST-06-02-2-7 & \begin{tabular}{|l|}
$2.77 \mathrm{E}+01$ \\
\end{tabular} & EST-06-02-2-8 & $4.85 \mathrm{E}+02$ \\
\hline $2.72 \mathrm{E}+02$ & 5 & $\bar{A}$ & $1.47 \mathrm{E}+02$ & \begin{tabular}{|l|}
$2.84 \mathrm{E}+02$ \\
\end{tabular} & $2.86 \mathrm{E}+02$ & $2.82 \mathrm{E}+02$ & EST-06-02-2-9 & $1.71 \mathrm{E}+01$ & EST-06-02-2-10 & $1.87 \mathrm{E}+02$ \\
\hline & & & & & & & & & & \\
\hline EST-06-03 & & & & & & & & & & \\
\hline Fragment \#1 & & & & & & & & & & \\
\hline $2.53 \mathrm{E}+02$ & 1 & $\mathrm{~N}$ & $1.45 \mathrm{E}+02$ & \begin{tabular}{|l|}
$2.53 \mathrm{E}+02$ \\
\end{tabular} & $2.67 \mathrm{E}+02$ & $2.64 \mathrm{E}+02$ & EST-06-03-1-1 & \begin{tabular}{|l|}
$8.87 \mathrm{E}+01$ \\
\end{tabular} & EST-06-03-1-2 & $1.11 \mathrm{E}+04$ \\
\hline $2.53 \mathrm{E}+02$ & 2 & $\mathrm{~N}$ & - & \begin{tabular}{|l|}
$2.64 \mathrm{E}+02$ \\
\end{tabular} & $2.66 \mathrm{E}+02$ & $2.63 \mathrm{E}+02$ & EST-06-03-1-3 & \begin{tabular}{|l|}
$2.38 \mathrm{E}+02$ \\
\end{tabular} & EST-06-03-1-4 & $7.95 \mathrm{E}+03$ \\
\hline $2.53 \mathrm{E}+02$ & 3 & $\mathrm{~N}$ & $1.33 \mathrm{E}+02$ & \begin{tabular}{|l|}
$2.63 \mathrm{E}+02$ \\
\end{tabular} & $2.66 \mathrm{E}+02$ & $2.61 \mathrm{E}+02$ & EST-06-03-1-5 & \begin{tabular}{|l|}
$8.22 \mathrm{E}+01$ \\
\end{tabular} & EST-06-03-1-6 & $1.63 \mathrm{E}+03$ \\
\hline $2.53 \mathrm{E}+02$ & 4 & $\bar{A}$ & $1.29 \mathrm{E}+02$ & \begin{tabular}{|l|}
$2.61 \mathrm{E}+02$ \\
\end{tabular} & $2.65 \mathrm{E}+02$ & $2.60 \mathrm{E}+02$ & EST-06-03-1-7 & \begin{tabular}{|l|}
$3.03 \mathrm{E}+01$ \\
\end{tabular} & EST-06-03-1-8 & $1.54 \mathrm{E}+03$ \\
\hline $2.53 \mathrm{E}+02$ & 5 & $\bar{A}$ & $1.31 \mathrm{E}+02$ & \begin{tabular}{|l|}
$2.60 \mathrm{E}+02$ \\
\end{tabular} & $2.65 \mathrm{E}+02$ & $2.64 \mathrm{E}+02$ & EST-06-03-1-9 & $3.86 \mathrm{E}+01$ & EST-06-03-1-10 & $7.49 \mathrm{E}+02$ \\
\hline Fragment \#2 & & & & & & & & & & \\
\hline $2.36 \mathrm{E}+02$ & 1 & $\mathrm{~N}$ & $1.47 \mathrm{E}+02$ & \begin{tabular}{|l|}
$2.36 \mathrm{E}+02$ \\
\end{tabular} & $2.49 \mathrm{E}+02$ & $2.47 \mathrm{E}+02$ & EST-06-03-2-1 & $9.67 \mathrm{E}+00$ & EST-06-03-2-2 & $3.74 \mathrm{E}+02$ \\
\hline $2.36 \mathrm{E}+02$ & 2 & $\mathrm{~N}$ & $1.44 \mathrm{E}+02$ & $2.47 \mathrm{E}+02$ & $2.49 \mathrm{E}+02$ & $2.46 \mathrm{E}+02$ & EST-06-03-2-3 & $1.36 \mathrm{E}+01$ & EST-06-03-2-4 & $4.08 \mathrm{E}+02$ \\
\hline $2.36 \mathrm{E}+02$ & 3 & $\mathrm{~N}$ & $1.40 \mathrm{E}+02$ & $2.46 \mathrm{E}+02$ & $2.49 \mathrm{E}+02$ & $2.47 \mathrm{E}+02$ & EST-06-03-2-5 & $8.64 \mathrm{E}+00$ & EST-06-03-2-6 & $2.74 \mathrm{E}+02$ \\
\hline $2.36 \mathrm{E}+02$ & 4 & $\overline{\mathrm{A}}$ & $1.08 \mathrm{E}+02$ & \begin{tabular}{|l|}
$2.47 \mathrm{E}+02$ \\
\end{tabular} & $2.48 \mathrm{E}+02$ & $2.46 \mathrm{E}+02$ & EST-06-03-2-7 & \begin{tabular}{|l|}
$6.38 \mathrm{E}+00$ \\
\end{tabular} & EST-06-03-2-8 & $2.29 \mathrm{E}+02$ \\
\hline $2.36 \mathrm{E}+02$ & 5 & $\mathrm{~A}$ & $1.22 \mathrm{E}+02$ & \begin{tabular}{|l|}
$2.46 \mathrm{E}+02$ \\
\end{tabular} & $2.48 \mathrm{E}+02$ & $2.47 \mathrm{E}+02$ & EST-06-03-2-9 & $3.93 \mathrm{E}+00$ & EST-06-03-2-10 & $1.71 \mathrm{E}+02$ \\
\hline & & & & & & & & & & \\
\hline & & & & & & & & & & \\
\hline & & & & & & & & & & \\
\hline & & & & & & & & & & \\
\hline
\end{tabular}


Table A1. Extraction Results for ES-31A.

\begin{tabular}{|c|c|c|c|c|c|c|c|c|c|c|}
\hline $\begin{array}{l}\text { Dry Sample } \\
\text { Mass (g) } \\
\text { ES-31A }\end{array}$ & $\begin{array}{c}\text { Extraction } \\
\text { Step \# }\end{array}$ & $\begin{array}{c}\text { Soln. } \\
\text { Type\# }\end{array}$ & $\begin{array}{l}\text { Vol. of Soln. } \\
\text { Added for } \\
\text { Sat. (mL) }\end{array}$ & $\begin{array}{c}\text { Pre-Sat. } \\
\text { Sample } \\
\text { Mass (g) }\end{array}$ & $\begin{array}{c}\text { Post-Sat. \& } \\
\text { Draining Free } \\
\text { Liq. Sample } \\
\text { Mass (g) }\end{array}$ & $\begin{array}{l}\text { Post-Cent. } \\
\text { Sample } \\
\text { Mass (g) }\end{array}$ & Sat. Sample \# & $\begin{array}{c}\text { Liq. [Re] } \\
\text { (Sat.) } \\
(\mu \mathrm{g} / \mathrm{L})\end{array}$ & Cent. Sample \# & $\begin{array}{c}\text { Liq. [Re] (Cent.) } \\
(\mu \mathrm{g} / \mathrm{L})\end{array}$ \\
\hline \multicolumn{11}{|l|}{ EST-06-04 } \\
\hline \multicolumn{11}{|l|}{\begin{tabular}{|l|} 
Fragment \#1 \\
\end{tabular}} \\
\hline $2.78 \mathrm{E}+02$ & 1 & $\mathrm{~N}$ & $2.60 \mathrm{E}+02$ & $2.78 \mathrm{E}+02$ & $2.93 \mathrm{E}+02$ & $2.89 \mathrm{E}+02$ & $\begin{array}{l}\text { EST-06-04-1-1 } \\
\end{array}$ & $1.12 \mathrm{E}+02$ & EST-06-04-1-2 & $3.90 \mathrm{E}+03$ \\
\hline $2.78 \mathrm{E}+02$ & 2 & $\mathrm{~N}$ & - & - & - & - & $\begin{array}{l}\text { EST-06-04-1-3 } \\
\end{array}$ & $5.70 \mathrm{E}+01$ & EST-06-04-1-4 & $3.24 \mathrm{E}+03$ \\
\hline $2.78 \mathrm{E}+02$ & 3 & $\mathrm{~N}$ & $2.06 \mathrm{E}+02$ & - & - & - & EST-06-04-1-5 & $1.07 \mathrm{E}+01$ & EST-06-04-1-6 & $1.66 \mathrm{E}+03$ \\
\hline $2.78 \mathrm{E}+02$ & 4 & $\mathrm{~A}$ & $2.32 \mathrm{E}+02$ & - & - & - & EST-06-04-1-7 & $1.54 \mathrm{E}+01$ & EST-06-04-1-8 & $1.74 \mathrm{E}+02$ \\
\hline $2.78 \mathrm{E}+02$ & 5 & $\mathrm{~A}$ & $2.17 \mathrm{E}+02$ & - & - & - & EST-06-04-1-9 & $3.55 \mathrm{E}+01$ & EST-06-04-1-10 & $1.30 \mathrm{E}+02$ \\
\hline \multicolumn{11}{|l|}{\begin{tabular}{|l} 
Fragment \#2 \\
\end{tabular}} \\
\hline $3.11 \mathrm{E}+02$ & 1 & $\mathrm{~N}$ & $3.12 \mathrm{E}+02$ & $3.11 \mathrm{E}+02$ & $3.28 \mathrm{E}+02$ & $3.23 \mathrm{E}+02$ & EST-06-04-2-1 & $3.34 \mathrm{E}+01$ & EST-06-04-2-2 & $1.25 \mathrm{E}+02$ \\
\hline $3.11 \mathrm{E}+02$ & 2 & $\mathrm{~N}$ & $2.19 \mathrm{E}+02$ & $3.23 \mathrm{E}+02$ & $3.28 \mathrm{E}+02$ & $3.24 \mathrm{E}+02$ & EST-06-04-2-3 & $1.69 \mathrm{E}+01$ & EST-06-04-2-4 & $5.39 \mathrm{E}+01$ \\
\hline $3.11 \mathrm{E}+02$ & 3 & $\mathrm{~N}$ & $2.40 \mathrm{E}+02$ & $3.24 \mathrm{E}+02$ & $3.26 \mathrm{E}+02$ & $3.24 \mathrm{E}+02$ & EST-06-04-2-5 & $4.25 \mathrm{E}+00$ & EST-06-04-2-6 & $3.26 \mathrm{E}+01$ \\
\hline $3.11 \mathrm{E}+02$ & 4 & $\mathrm{~A}$ & $3.29 \mathrm{E}+02$ & $3.24 \mathrm{E}+02$ & $3.25 \mathrm{E}+02$ & $3.24 \mathrm{E}+02$ & EST-06-04-2-7 & $3.36 \mathrm{E}-01$ & EST-06-04-2-8 & $4.37 \mathrm{E}+01$ \\
\hline $3.11 \mathrm{E}+02$ & 5 & $\mathrm{~A}$ & $2.46 \mathrm{E}+02$ & $3.24 \mathrm{E}+02$ & $3.25 \mathrm{E}+02$ & $3.24 \mathrm{E}+02$ & EST-06-04-2-9 & $1.45 \mathrm{E}+00$ & EST-06-04-2-10 & $0.00 \mathrm{E}+00$ \\
\hline \multicolumn{11}{|c|}{\begin{tabular}{|l|} 
Soln - Solution \\
Vol. - Volume \\
Sat - Saturation \\
Liq. - Liquid \\
Cent. - Centrifugation \\
[Re] - Rhenium Concentration \\
\end{tabular}} \\
\hline
\end{tabular}


Table A2. Extraction Results for ES-31B.

\begin{tabular}{|c|c|c|c|c|c|c|c|c|c|c|c|c|}
\hline $\begin{array}{c}\text { Dry Sample } \\
\text { Mass (g) } \\
\text { ES-31B }\end{array}$ & $\begin{array}{c}\text { Extraction } \\
\text { Step \# }\end{array}$ & $\begin{array}{l}\text { Soln. } \\
\text { Type¥ }\end{array}$ & $\begin{array}{l}\text { Vol. of Soln. } \\
\text { Added for } \\
\text { Sat. (mL) }\end{array}$ & $\begin{array}{c}\text { Pre-Sat. } \\
\text { Sample } \\
\text { Mass (g) }\end{array}$ & $\begin{array}{c}\text { Post-Sat. \& } \\
\text { Draining Free Liq. } \\
\text { Sample Mass (g) }\end{array}$ & $\begin{array}{l}\text { Post-Cent. } \\
\text { Sample } \\
\text { Mass (g) }\end{array}$ & Sat. Sample \# & $\begin{array}{l}\text { Liq. [Re] } \\
\text { (Sat.) } \\
(\mu \mathrm{g} / \mathrm{L})\end{array}$ & $\begin{array}{c}\text { Liq. [Cs] } \\
\text { (Sat.) } \\
(\mu \mathrm{g} / \mathrm{L})\end{array}$ & Cent. Sample \# & $\begin{array}{l}\text { Liq. [Re] } \\
\text { (Cent.) } \\
\text { ( } \mu \mathrm{g} / \mathrm{L})\end{array}$ & $\begin{array}{l}\text { Liq. [Cs] } \\
\text { (Cent.) } \\
(\mu \mathrm{g} / \mathrm{L})\end{array}$ \\
\hline \multicolumn{13}{|l|}{ EST-07-01 } \\
\hline \multicolumn{13}{|l|}{ Fragment \#1 } \\
\hline $3.82 \mathrm{E}+02$ & 1 & A & $5.53 \mathrm{E}+02$ & $3.82 \mathrm{E}+02$ & $4.00 \mathrm{E}+02$ & - & EST-07-01-1-1 & $2.18 \mathrm{E}+00$ & $1.53 \mathrm{E}-01$ & EST-07-01-1-2 & - & - \\
\hline $3.82 \mathrm{E}+02$ & 2 & A & $5.56 \mathrm{E}+02$ & $4.00 \mathrm{E}+02$ & $4.01 \mathrm{E}+02$ & $3.98 \mathrm{E}+02$ & EST-07-01-1-3 & $3.27 \mathrm{E}+00$ & 1.29E-01 & EST-07-01-1-4 & $1.55 \mathrm{E}+01$ & $2.21 \mathrm{E}-01$ \\
\hline $3.82 \mathrm{E}+02$ & 3 & A & $4.77 \mathrm{E}+02$ & $3.98 \mathrm{E}+02$ & $4.00 \mathrm{E}+02$ & $3.99 \mathrm{E}+02$ & EST-07-01-1-5 & $1.17 \mathrm{E}+00$ & 4.65E-02 & EST-07-01-1-6 & - & - \\
\hline $3.82 \mathrm{E}+02$ & 4 & A & $5.30 \mathrm{E}+02$ & $3.99 \mathrm{E}+02$ & $4.01 \mathrm{E}+02$ & $3.97 \mathrm{E}+02$ & EST-07-01-1-7 & $1.34 \mathrm{E}+00$ & $0.00 \mathrm{E}+00$ & EST-07-01-1-8 & $2.49 \mathrm{E}+01$ & $3.26 \mathrm{E}-01$ \\
\hline $3.82 \mathrm{E}+02$ & 5 & A & $3.38 \mathrm{E}+02$ & $3.97 \mathrm{E}+02$ & $3.98 \mathrm{E}+02$ & $3.96 \mathrm{E}+02$ & EST-07-01-1-9 & $5.14 \mathrm{E}-01$ & $0.00 \mathrm{E}+00$ & \begin{tabular}{|l|} 
EST-07-01-1-10 \\
\end{tabular} & $1.52 \mathrm{E}+01$ & $2.66 \mathrm{E}-01$ \\
\hline $3.82 \mathrm{E}+02$ & 6 & A & $4.11 \mathrm{E}+02$ & $3.96 \mathrm{E}+02$ & $3.98 \mathrm{E}+02$ & $3.95 \mathrm{E}+02$ & EST-07-01-1-11 & $1.01 \mathrm{E}+00$ & $0.00 \mathrm{E}+00$ & EST-07-01-1-12 & $1.82 \mathrm{E}+01$ & $2.12 \mathrm{E}-01$ \\
\hline \multicolumn{13}{|l|}{ EST-07-02 } \\
\hline \multicolumn{13}{|l|}{ Fragment \#1 } \\
\hline $2.09 \mathrm{E}+02$ & 1 & A & $3.50 \mathrm{E}+02$ & $2.08 \mathrm{E}+02$ & $2.20 \mathrm{E}+02$ & - & EST-07-02-1-1 & $1.25 \mathrm{E}+00$ & $1.11 \mathrm{E}-01$ & EST-07-02-1-2 & - & - \\
\hline $2.09 \mathrm{E}+02$ & 2 & A & $3.22 \mathrm{E}+02$ & $2.20 \mathrm{E}+02$ & $2.21 \mathrm{E}+02$ & $2.18 \mathrm{E}+02$ & EST-07-02-1-3 & $1.66 \mathrm{E}+00$ & $0.00 \mathrm{E}+00$ & EST-07-02-1-4 & $1.29 \mathrm{E}+01$ & $6.89 \mathrm{E}-02$ \\
\hline $2.09 \mathrm{E}+02$ & 3 & A & $4.27 \mathrm{E}+02$ & $2.18 \mathrm{E}+02$ & $2.21 \mathrm{E}+02$ & $2.18 \mathrm{E}+02$ & EST-07-02-1-5 & $8.11 \mathrm{E}-01$ & $0.00 \mathrm{E}+00$ & EST-07-02-1-6 & $7.04 \mathrm{E}+00$ & $1.18 \mathrm{E}-01$ \\
\hline $2.09 \mathrm{E}+02$ & 4 & A & $3.64 \mathrm{E}+02$ & $2.18 \mathrm{E}+02$ & $2.20 \mathrm{E}+02$ & $2.17 \mathrm{E}+02$ & EST-07-02-1-7 & $8.76 \mathrm{E}-02$ & $0.00 \mathrm{E}+00$ & EST-07-02-1-8 & $5.46 \mathrm{E}+00$ & $2.11 \mathrm{E}-01$ \\
\hline $2.09 \mathrm{E}+02$ & 5 & A & $3.58 \mathrm{E}+02$ & $2.17 \mathrm{E}+02$ & $2.19 \mathrm{E}+02$ & $2.17 \mathrm{E}+02$ & EST-07-02-1-9 & $9.80 \mathrm{E}-02$ & $0.00 \mathrm{E}+00$ & \begin{tabular}{|l|} 
EST-07-02-1-10 \\
\end{tabular} & $3.48 \mathrm{E}+00$ & $6.77 \mathrm{E}-02$ \\
\hline $2.09 \mathrm{E}+02$ & 6 & A & $3.61 \mathrm{E}+02$ & $2.17 \mathrm{E}+02$ & $2.19 \mathrm{E}+02$ & - & EST-07-02-1-11 & $4.14 \mathrm{E}-02$ & $0.00 \mathrm{E}+00$ & & & \\
\hline & & & & & & & & & & & & \\
\hline \multicolumn{13}{|l|}{ EST-07-03 } \\
\hline \multicolumn{13}{|l|}{ Fragment \#1 } \\
\hline $4.26 \mathrm{E}+02$ & 1 & A & $4.76 \mathrm{E}+02$ & $4.26 \mathrm{E}+02$ & $4.50 \mathrm{E}+02$ & $4.50 \mathrm{E}+02$ & EST-07-03-1-1 & $2.68 \mathrm{E}+00$ & $3.52 \mathrm{E}-01$ & EST-07-03-1-2 & - & - \\
\hline $4.26 \mathrm{E}+02$ & 2 & A & $4.59 \mathrm{E}+02$ & $4.50 \mathrm{E}+02$ & $4.51 \mathrm{E}+02$ & $4.45 \mathrm{E}+02$ & EST-07-03-1-3 & $1.46 \mathrm{E}+00$ & $1.24 \mathrm{E}-01$ & EST-07-03-1-4 & $8.47 \mathrm{E}+01$ & $1.13 \mathrm{E}+00$ \\
\hline $4.26 \mathrm{E}+02$ & 3 & A & $4.14 \mathrm{E}+02$ & $4.45 \mathrm{E}+02$ & $4.51 \mathrm{E}+02$ & $4.44 \mathrm{E}+02$ & \begin{tabular}{|l|} 
EST-07-03-1-5 \\
\end{tabular} & $1.30 \mathrm{E}+00$ & $9.08 \mathrm{E}-02$ & EST-07-03-1-6 & $7.13 \mathrm{E}+01$ & $1.74 \mathrm{E}+00$ \\
\hline $4.26 \mathrm{E}+02$ & 4 & A & $4.22 \mathrm{E}+02$ & $4.44 \mathrm{E}+02$ & $4.50 \mathrm{E}+02$ & $4.44 \mathrm{E}+02$ & \begin{tabular}{|l|} 
EST-07-03-1-7 \\
\end{tabular} & $1.40 \mathrm{E}+00$ & $7.67 \mathrm{E}-02$ & EST-07-03-1-8 & $2.92 \mathrm{E}+01$ & $3.34 \mathrm{E}-01$ \\
\hline $4.26 \mathrm{E}+02$ & 5 & $\mathrm{~A}$ & $4.29 \mathrm{E}+02$ & $4.44 \mathrm{E}+02$ & $4.49 \mathrm{E}+02$ & $4.38 \mathrm{E}+02$ & \begin{tabular}{|l|} 
EST-07-03-1-9 \\
\end{tabular} & $1.41 \mathrm{E}+00$ & $6.55 \mathrm{E}-02$ & \begin{tabular}{|l|} 
EST-07-03-1-10 \\
\end{tabular} & $2.37 \mathrm{E}+01$ & $9.63 \mathrm{E}-01$ \\
\hline $4.26 \mathrm{E}+02$ & 6 & $\mathrm{~A}$ & $4.49 \mathrm{E}+02$ & \begin{tabular}{|l|}
$4.38 \mathrm{E}+02$ \\
\end{tabular} & $4.48 \mathrm{E}+02$ & $4.39 \mathrm{E}+02$ & \begin{tabular}{|l|} 
EST-07-03-1-11 \\
\end{tabular} & 4.34E-01 & 5.68E-02 & \begin{tabular}{|l|} 
EST-07-03-1-12 \\
\end{tabular} & $3.35 \mathrm{E}+01$ & 5.96E-01 \\
\hline \multicolumn{13}{|l|}{ EST-07-04 } \\
\hline \multicolumn{13}{|l|}{ Fragment \#1 } \\
\hline $4.26 \mathrm{E}+02$ & 1 & $\overline{\mathrm{A}}$ & $4.76 \mathrm{E}+02$ & \begin{tabular}{|l|}
$4.26 \mathrm{E}+02$ \\
\end{tabular} & $4.50 \mathrm{E}+02$ & $4.50 \mathrm{E}+02$ & \begin{tabular}{|l|} 
EST-07-04-1-1 \\
\end{tabular} & $1.42 \mathrm{E}+00$ & 2.05E-01 & EST-07-04-1-2 & - & - \\
\hline $4.26 \mathrm{E}+02$ & 2 & $\bar{A}$ & $4.59 \mathrm{E}+02$ & \begin{tabular}{|l|}
$4.50 \mathrm{E}+02$ \\
\end{tabular} & $4.51 \mathrm{E}+02$ & $4.45 \mathrm{E}+02$ & \begin{tabular}{|l|} 
EST-07-04-1-3 \\
\end{tabular} & $1.24 \mathrm{E}+00$ & 1.33E-01 & \begin{tabular}{|l|} 
EST-07-04-1-4 \\
\end{tabular} & $7.38 \mathrm{E}+01$ & $4.09 \mathrm{E}+00$ \\
\hline
\end{tabular}


Table A2. Extraction Results for ES-31B.

\begin{tabular}{|c|c|c|c|c|c|c|c|c|c|c|c|c|}
\hline $\begin{array}{c}\text { Dry Sample } \\
\text { Mass (g) } \\
\text { ES-31B }\end{array}$ & $\begin{array}{c}\text { Extraction } \\
\text { Step \# }\end{array}$ & $\begin{array}{c}\text { Soln. } \\
\text { Type¥ }\end{array}$ & $\begin{array}{l}\text { Vol. of Soln. } \\
\text { Added for } \\
\text { Sat. (mL) }\end{array}$ & $\begin{array}{c}\text { Pre-Sat. } \\
\text { Sample } \\
\text { Mass (g) }\end{array}$ & \begin{tabular}{|c|} 
Post-Sat. \& \\
Draining Free Liq. \\
Sample Mass (g)
\end{tabular} & $\begin{array}{l}\text { Post-Cent. } \\
\text { Sample } \\
\text { Mass (g) }\end{array}$ & Sat. Sample \# & $\begin{array}{c}\text { Liq. [Re] } \\
\text { (Sat.) } \\
\text { ( } \mu \mathrm{g} / \mathrm{L})\end{array}$ & $\begin{array}{c}\text { Liq. [Cs] } \\
\text { (Sat.) } \\
(\mu \mathrm{g} / \mathrm{L})\end{array}$ & Cent. Sample \# & $\begin{array}{c}\text { Liq. [Re] } \\
\text { (Cent.) } \\
\text { ( } \mu \mathrm{g} / \mathrm{L})\end{array}$ & $\begin{array}{c}\text { Liq. [Cs] } \\
\text { (Cent.) } \\
(\mu \mathrm{\mu} / \mathrm{L})\end{array}$ \\
\hline $4.26 \mathrm{E}+02$ & 3 & $\bar{A}$ & $4.14 \mathrm{E}+02$ & $4.45 \mathrm{E}+02$ & $4.51 \mathrm{E}+02$ & $4.44 \mathrm{E}+02$ & \begin{tabular}{|l|} 
EST-07-04-1-5 \\
\end{tabular} & 8.03E-01 & $9.41 \mathrm{E}-02$ & \begin{tabular}{|l|} 
EST-07-04-1-6 \\
\end{tabular} & $4.34 \mathrm{E}+01$ & $2.25 \mathrm{E}+0 \mathrm{c}$ \\
\hline $4.26 \mathrm{E}+02$ & 4 & $\overline{\mathrm{A}}$ & $4.22 \mathrm{E}+02$ & $4.44 \mathrm{E}+02$ & $4.50 \mathrm{E}+02$ & $4.44 \mathrm{E}+02$ & \begin{tabular}{|l|} 
EST-07-04-1-7 \\
\end{tabular} & \begin{tabular}{|c|}
$6.55 \mathrm{E}-01$ \\
\end{tabular} & $6.58 \mathrm{E}-02$ & \begin{tabular}{|c|} 
EST-07-04-1-8 \\
\end{tabular} & $3.89 \mathrm{E}+01$ & $1.58 \mathrm{E}+0 \mathrm{c}$ \\
\hline $4.26 \mathrm{E}+02$ & 5 & $\overline{\mathrm{A}}$ & $4.29 \mathrm{E}+02$ & $4.44 \mathrm{E}+02$ & $4.49 \mathrm{E}+02$ & $4.42 \mathrm{E}+02$ & \begin{tabular}{|l|} 
EST-07-04-1-9 \\
\end{tabular} & \begin{tabular}{|l|}
$8.06 \mathrm{E}-01$ \\
\end{tabular} & $6.63 \mathrm{E}-02$ & \begin{tabular}{|l} 
EST-07-04-1-10 \\
\end{tabular} & $2.24 \mathrm{E}+01$ & $1.50 \mathrm{E}-01$ \\
\hline $4.26 \mathrm{E}+02$ & 6 & $\mathrm{~A}$ & $4.45 \mathrm{E}+02$ & $4.42 \mathrm{E}+02$ & $4.48 \mathrm{E}+02$ & $4.42 \mathrm{E}+02$ & \begin{tabular}{|l|} 
EST-07-04-1-11 \\
\end{tabular} & 3.33E-01 & $0.00 \mathrm{E}+00$ & \begin{tabular}{|l|} 
EST-07-04-1-12 \\
\end{tabular} & $1.94 \mathrm{E}+01$ & 6.87E-02 \\
\hline \multicolumn{13}{|l|}{ EST-07-05-1 } \\
\hline \multicolumn{13}{|l|}{ Fragment \#1 } \\
\hline $1.62 \mathrm{E}+02$ & 1 & $\bar{A}$ & $3.72 \mathrm{E}+02$ & $1.62 \mathrm{E}+02$ & $1.70 \mathrm{E}+02$ & $1.68 \mathrm{E}+02$ & \begin{tabular}{|c|} 
EST-07-05-1-1 \\
\end{tabular} & $1.30 \mathrm{E}+00$ & 1.83E-01 & \begin{tabular}{|c|} 
EST-07-05-1-2 \\
\end{tabular} & $5.90 \mathrm{E}+01$ & $2.69 \mathrm{E}+0 \mathrm{c}$ \\
\hline $1.62 \mathrm{E}+02$ & 2 & $\bar{A}$ & $2.99 \mathrm{E}+02$ & $1.68 \mathrm{E}+02$ & $1.69 \mathrm{E}+02$ & $1.68 \mathrm{E}+02$ & \begin{tabular}{|l|} 
EST-07-05-1-3 \\
\end{tabular} & $6.79 \mathrm{E}+00$ & 4.07E-01 & \begin{tabular}{|c|} 
EST-07-05-1-4 \\
\end{tabular} & $9.21 \mathrm{E}+00$ & $5.76 \mathrm{E}-01$ \\
\hline $1.62 \mathrm{E}+02$ & 3 & $\mathrm{~A}$ & $2.87 \mathrm{E}+02$ & $1.68 \mathrm{E}+02$ & $1.69 \mathrm{E}+02$ & $\begin{array}{l}1.67 \mathrm{E}+02 \\
\end{array}$ & EST-07-05-1-5 & $2.55 \mathrm{E}-01$ & 8.13E-02 & \begin{tabular}{|l|} 
EST-07-05-1-6 \\
\end{tabular} & $1.62 \mathrm{E}+00$ & $2.84 \mathrm{E}-01$ \\
\hline $1.62 \mathrm{E}+02$ & 4 & $\bar{A}$ & $2.98 \mathrm{E}+02$ & $1.67 \mathrm{E}+02$ & $1.68 \mathrm{E}+02$ & \begin{tabular}{|l}
$1.67 \mathrm{E}+02$ \\
\end{tabular} & EST-07-05-1-7 & $1.14 \mathrm{E}-01$ & 4.13E-02 & \begin{tabular}{|l|} 
EST-07-05-1-8 \\
\end{tabular} & $4.36 \mathrm{E}+00$ & $2.16 \mathrm{E}-01$ \\
\hline $1.62 \mathrm{E}+02$ & 5 & $\mathrm{~A}$ & $3.56 \mathrm{E}+02$ & $1.67 \mathrm{E}+02$ & $1.68 \mathrm{E}+02$ & $1.66 \mathrm{E}+02$ & EST-07-05-1-9 & $3.60 \mathrm{E}-01$ & 9.73E-02 & \begin{tabular}{|l|} 
EST-07-05-1-10 \\
\end{tabular} & $3.09 \mathrm{E}+00$ & $1.10 \mathrm{E}+0 \mathrm{C}$ \\
\hline & & & & & & & & & & & & \\
\hline \multicolumn{13}{|l|}{\begin{tabular}{|l|} 
EST-07-05-3 \\
\end{tabular}} \\
\hline \multicolumn{13}{|l|}{ Fragment \#1 } \\
\hline $1.63 \mathrm{E}+02$ & 1 & $\bar{A}$ & $3.63 \mathrm{E}+02$ & $1.63 \mathrm{E}+02$ & $1.71 \mathrm{E}+02$ & $1.69 \mathrm{E}+02$ & \begin{tabular}{|l|} 
EST-07-05-3-1 \\
\end{tabular} & $1.81 \mathrm{E}+00$ & \begin{tabular}{|l|}
$1.09 \mathrm{E}-01$ \\
\end{tabular} & \begin{tabular}{|c|} 
EST-07-05-3-2 \\
\end{tabular} & - & - \\
\hline $1.63 \mathrm{E}+02$ & 2 & $\bar{A}$ & $3.55 \mathrm{E}+02$ & $1.69 \mathrm{E}+02$ & $1.69 \mathrm{E}+02$ & $1.67 \mathrm{E}+02$ & \begin{tabular}{|l|} 
EST-07-05-3-3 \\
\end{tabular} & $1.50 \mathrm{E}+00$ & \begin{tabular}{|l|}
$6.30 \mathrm{E}-02$ \\
\end{tabular} & \begin{tabular}{|c|} 
EST-07-05-3-4 \\
\end{tabular} & $2.43 \mathrm{E}+00$ & $1.10 \mathrm{E}-01$ \\
\hline $1.63 \mathrm{E}+02$ & 3 & $\bar{A}$ & $3.14 \mathrm{E}+02$ & $1.67 \mathrm{E}+02$ & $1.69 \mathrm{E}+02$ & \begin{tabular}{|l}
$1.67 \mathrm{E}+02$ \\
\end{tabular} & EST-07-05-3-5 & $0.00 \mathrm{E}+00$ & $0.00 \mathrm{E}+00$ & \begin{tabular}{|l|} 
EST-07-05-3-6 \\
\end{tabular} & $5.29 \mathrm{E}-01$ & $5.68 \mathrm{E}-02$ \\
\hline $1.63 \mathrm{E}+02$ & 4 & $\bar{A}$ & $3.76 \mathrm{E}+02$ & $1.67 \mathrm{E}+02$ & $1.68 \mathrm{E}+02$ & $1.67 \mathrm{E}+02$ & EST-07-05-3-7 & $0.00 \mathrm{E}+00$ & $0.00 \mathrm{E}+00$ & \begin{tabular}{|l|} 
EST-07-05-3-8 \\
\end{tabular} & $2.95 \mathrm{E}+00$ & $0.00 \mathrm{E}+0 \mathrm{c}$ \\
\hline $1.63 \mathrm{E}+02$ & 5 & $\mathrm{~A}$ & $4.09 \mathrm{E}+02$ & $1.67 \mathrm{E}+02$ & $1.68 \mathrm{E}+02$ & \begin{tabular}{|c|}
$1.67 \mathrm{E}+02$ \\
\end{tabular} & EST-07-05-3-9 & $0.00 \mathrm{E}+00$ & 1.99E-02 & EST-07-05-3-10 & 6.79E-01 & $1.18 \mathrm{E}-01$ \\
\hline & & & & & & & & & & & & \\
\hline \multicolumn{13}{|l|}{ EST-07-06 } \\
\hline $2.46 \mathrm{E}+02$ & 1 & $\overline{\mathrm{A}}$ & $4.41 \mathrm{E}+02$ & $2.46 \mathrm{E}+02$ & $2.60 \mathrm{E}+02$ & $2.58 \mathrm{E}+02$ & \begin{tabular}{|l|} 
EST-07-06-1-1 \\
\end{tabular} & $1.03 \mathrm{E}+00$ & $7.45 \mathrm{E}-02$ & \begin{tabular}{|c|} 
EST-07-06-1-2 \\
\end{tabular} & $2.88 \mathrm{E}+00$ & $6.35 \mathrm{E}-02$ \\
\hline $2.46 \mathrm{E}+02$ & 2 & $\overline{\mathrm{A}}$ & $4.14 \mathrm{E}+02$ & $2.58 \mathrm{E}+02$ & $2.60 \mathrm{E}+02$ & $2.54 \mathrm{E}+02$ & EST-07-06-1-3 & $1.13 \mathrm{E}+00$ & $0.00 \mathrm{E}+00$ & EST-07-06-1-4 & $1.05 \mathrm{E}+02$ & $1.89 \mathrm{E}-01$ \\
\hline $2.46 \mathrm{E}+02$ & 3 & $\overline{\mathrm{A}}$ & $4.48 \mathrm{E}+02$ & $2.54 \mathrm{E}+02$ & $2.61 \mathrm{E}+02$ & $2.54 \mathrm{E}+02$ & EST-07-06-1-5 & 3.19E-01 & 6.04E-02 & \begin{tabular}{|l|} 
EST-07-06-1-6 \\
\end{tabular} & $7.67 \mathrm{E}+01$ & - \\
\hline $2.46 \mathrm{E}+02$ & 4 & $\bar{A}$ & $4.55 \mathrm{E}+02$ & $2.54 \mathrm{E}+02$ & $2.60 \mathrm{E}+02$ & $2.54 \mathrm{E}+02$ & \begin{tabular}{|l|} 
EST-07-06-1-7 \\
\end{tabular} & $2.72 \mathrm{E}-01$ & $0.00 \mathrm{E}+00$ & \begin{tabular}{|l|} 
EST-07-06-1-8 \\
\end{tabular} & $2.08 \mathrm{E}+01$ & $1.06 \mathrm{E}+0 \mathrm{c}$ \\
\hline $2.46 \mathrm{E}+02$ & 5 & $\overline{\mathrm{A}}$ & $4.24 \mathrm{E}+02$ & $2.54 \mathrm{E}+02$ & $2.58 \mathrm{E}+02$ & $2.53 \mathrm{E}+02$ & \begin{tabular}{|l|} 
EST-07-06-1-9 \\
\end{tabular} & $3.29 \mathrm{E}-01$ & $0.00 \mathrm{E}+00$ & \begin{tabular}{|l|} 
EST-07-06-1-10 \\
\end{tabular} & $1.67 \mathrm{E}+01$ & $0.00 \mathrm{E}+0 \mathrm{c}$ \\
\hline $2.46 \mathrm{E}+02$ & 6 & $\bar{A}$ & $4.61 \mathrm{E}+02$ & $2.53 \mathrm{E}+02$ & $2.59 \mathrm{E}+02$ & $2.53 \mathrm{E}+02$ & \begin{tabular}{|l|} 
EST-07-06-1-11 \\
\end{tabular} & \begin{tabular}{|c|}
$3.06 \mathrm{E}-01$ \\
\end{tabular} & $0.00 \mathrm{E}+00$ & \begin{tabular}{|l|} 
EST-07-06-1-12 \\
\end{tabular} & $7.67 \mathrm{E}+00$ & - \\
\hline \multicolumn{13}{|l|}{$\begin{array}{l}\text { EST-07-08 } \\
\end{array}$} \\
\hline \multicolumn{13}{|l|}{ Fragment \#1 } \\
\hline $5.61 \mathrm{E}+02$ & 1 & $\bar{A}$ & $4.41 \mathrm{E}+02$ & $5.61 \mathrm{E}+02$ & $5.66 \mathrm{E}+02$ & $5.66 \mathrm{E}+02$ & \begin{tabular}{|c|} 
EST-07-08-1-1 \\
\end{tabular} & $3.99 \mathrm{E}+00$ & 4.87E-01 & EST-07-08-1-2 & - & - \\
\hline $5.61 \mathrm{E}+02$ & 2 & $\bar{A}$ & $5.26 \mathrm{E}+02$ & $5.66 \mathrm{E}+02$ & $5.67 \mathrm{E}+02$ & $5.59 \mathrm{E}+02$ & \begin{tabular}{|l|} 
EST-07-08-1-3 \\
\end{tabular} & $1.58 \mathrm{E}+00$ & 1.15E-01 & \begin{tabular}{|c|} 
EST-07-08-1-4 \\
\end{tabular} & $4.26 \mathrm{E}+01$ & $9.35 \mathrm{E}-01$ \\
\hline
\end{tabular}


Table A2. Extraction Results for ES-31B.

\begin{tabular}{|c|c|c|c|c|c|c|c|c|c|c|c|c|}
\hline $\begin{array}{c}\text { Dry Sample } \\
\text { Mass (g) } \\
\text { ES-31B }\end{array}$ & $\begin{array}{c}\text { Extraction } \\
\text { Step \# }\end{array}$ & $\begin{array}{c}\text { Soln. } \\
\text { Type¥ }\end{array}$ & \begin{tabular}{|c|} 
Vol. of Soln. \\
Added for \\
Sat. (mL)
\end{tabular} & $\begin{array}{c}\text { Pre-Sat. } \\
\text { Sample } \\
\text { Mass (g) }\end{array}$ & $\begin{array}{c}\text { Post-Sat. \& } \\
\text { Draining Free Liq. } \\
\text { Sample Mass (g) }\end{array}$ & $\begin{array}{l}\text { Post-Cent. } \\
\text { Sample } \\
\text { Mass (g) }\end{array}$ & Sat. Sample \# & $\begin{array}{c}\text { Liq. [Re] } \\
\text { (Sat.) } \\
\text { ( } \mu \mathrm{g} / \mathrm{L})\end{array}$ & $\begin{array}{c}\text { Liq. [Cs] } \\
\text { (Sat.) } \\
(\mu \mathrm{g} / \mathrm{L})\end{array}$ & Cent. Sample \# & $\begin{array}{c}\text { Liq. [Re] } \\
\text { (Cent.) } \\
\text { ( } \mu \mathrm{g} / \mathrm{L})\end{array}$ & $\begin{array}{c}\text { Liq. [Cs] } \\
\text { (Cent.) } \\
\text { ( } \mu \mathrm{g} / \mathbf{L})\end{array}$ \\
\hline $5.61 \mathrm{E}+02$ & 3 & A & $4.85 \mathrm{E}+02$ & $5.59 \mathrm{E}+02$ & $5.64 \mathrm{E}+02$ & $5.60 \mathrm{E}+02$ & \begin{tabular}{|l|} 
EST-07-08-1-5 \\
\end{tabular} & $1.78 \mathrm{E}+00$ & $1.27 \mathrm{E}-01$ & \begin{tabular}{|l|} 
EST-07-08-1-6 \\
\end{tabular} & $4.07 \mathrm{E}+01$ & $9.47 \mathrm{E}-01$ \\
\hline $5.61 \mathrm{E}+02$ & 4 & $\bar{A}$ & $4.99 \mathrm{E}+02$ & - & - & - & \begin{tabular}{|l|} 
EST-07-08-1-7 \\
\end{tabular} & $1.45 \mathrm{E}+00$ & $6.95 \mathrm{E}-02$ & \begin{tabular}{|c|} 
EST-07-08-1-8 \\
\end{tabular} & - & - \\
\hline $5.61 \mathrm{E}+02$ & 5 & $\bar{A}$ & $4.30 \mathrm{E}+02$ & - & - & - & \begin{tabular}{|l|} 
EST-07-08-1-9 \\
\end{tabular} & $1.10 \mathrm{E}+00$ & 1.97E-01 & \begin{tabular}{|l} 
EST-07-08-1-10 \\
\end{tabular} & - & - \\
\hline $5.61 \mathrm{E}+02$ & 6 & $\bar{A}$ & $4.49 \mathrm{E}+02$ & - & - & - & \begin{tabular}{|l} 
EST-07-08-1-11 \\
\end{tabular} & 2.72E-01 & 1.03E-01 & \begin{tabular}{|l|} 
EST-07-08-1-12 \\
\end{tabular} & - & - \\
\hline & & & & & & & & & & & & \\
\hline \multicolumn{13}{|l|}{$\begin{array}{l}\text { EST-07-09 } \\
\end{array}$} \\
\hline \multicolumn{13}{|l|}{ Fragment \#1 } \\
\hline $4.32 \mathrm{E}+02$ & 1 & $\bar{A}$ & $4.98 \mathrm{E}+02$ & $4.32 \mathrm{E}+02$ & $4.55 \mathrm{E}+02$ & $4.55 \mathrm{E}+02$ & \begin{tabular}{|l|} 
EST-07-09-1-1 \\
\end{tabular} & $\begin{array}{l}1.46 \mathrm{E}-01 \\
\end{array}$ & 3.16E-01 & \begin{tabular}{|c|} 
EST-07-09-1-2 \\
\end{tabular} & - & - \\
\hline $4.32 \mathrm{E}+02$ & 2 & $\bar{A}$ & $4.62 \mathrm{E}+02$ & $4.55 \mathrm{E}+02$ & $4.55 \mathrm{E}+02$ & $4.49 \mathrm{E}+02$ & \begin{tabular}{|l|} 
EST-07-09-1-3 \\
\end{tabular} & $1.69 \mathrm{E}-01$ & $2.46 \mathrm{E}-01$ & \begin{tabular}{|c|} 
EST-07-09-1-4 \\
\end{tabular} & $7.62 \mathrm{E}+00$ & $2.91 \mathrm{E}+00$ \\
\hline $4.32 \mathrm{E}+02$ & 3 & $\bar{A}$ & $4.95 \mathrm{E}+02$ & $4.49 \mathrm{E}+02$ & $4.58 \mathrm{E}+02$ & $4.48 \mathrm{E}+02$ & \begin{tabular}{|l|} 
EST-07-09-1-5 \\
\end{tabular} & $4.58 \mathrm{E}-01$ & $2.45 \mathrm{E}-01$ & \begin{tabular}{|l|} 
EST-07-09-1-6 \\
\end{tabular} & $4.13 \mathrm{E}+00$ & $3.62 \mathrm{E}+00$ \\
\hline $4.32 \mathrm{E}+02$ & 4 & $\bar{A}$ & $4.80 \mathrm{E}+02$ & $4.48 \mathrm{E}+02$ & $4.56 \mathrm{E}+02$ & $4.46 \mathrm{E}+02$ & \begin{tabular}{|l|} 
EST-07-09-1-7 \\
\end{tabular} & $2.05 \mathrm{E}+00$ & $5.50 \mathrm{E}-02$ & \begin{tabular}{|l|} 
EST-07-09-1-8 \\
\end{tabular} & $2.19 \mathrm{E}+00$ & $2.31 \mathrm{E}+00$ \\
\hline $4.32 \mathrm{E}+02$ & 5 & $\bar{A}$ & $4.89 \mathrm{E}+02$ & $4.46 \mathrm{E}+02$ & $4.54 \mathrm{E}+02$ & $4.47 \mathrm{E}+02$ & \begin{tabular}{|l|} 
EST-07-09-1-9 \\
\end{tabular} & $0.00 \mathrm{E}+00$ & $6.44 \mathrm{E}-02$ & \begin{tabular}{|l|} 
EST-07-09-1-10 \\
\end{tabular} & $1.08 \mathrm{E}+00$ & $1.42 \mathrm{E}+00$ \\
\hline $4.32 \mathrm{E}+02$ & 6 & $\mathrm{~A}$ & $5.05 E+02$ & $4.47 \mathrm{E}+02$ & $4.56 \mathrm{E}+02$ & \begin{tabular}{|l|}
$4.49 \mathrm{E}+02$ \\
\end{tabular} & EST-07-09-1-11 & 7.77E-02 & 1.01E-01 & EST-07-09-1-12 & $2.12 \mathrm{E}-01$ & $8.19 \mathrm{E}-02$ \\
\hline & & & & & & & & & & & & \\
\hline \multicolumn{13}{|l|}{ EST-08-01 } \\
\hline \multicolumn{13}{|l|}{ Fragment \#1 } \\
\hline $4.98 \mathrm{E}+02$ & 1 & $\bar{A}$ & $4.52 \mathrm{E}+02$ & $4.98 \mathrm{E}+02$ & $5.24 \mathrm{E}+02$ & $5.20 \mathrm{E}+02$ & \begin{tabular}{|l|} 
EST-08-01-1-1 \\
\end{tabular} & $4.22 \mathrm{E}+00$ & $4.58 \mathrm{E}-01$ & \begin{tabular}{|c|} 
EST-08-01-1-2 \\
\end{tabular} & $6.64 \mathrm{E}+01$ & $3.54 \mathrm{E}+00$ \\
\hline $4.98 \mathrm{E}+02$ & 2 & $\mathrm{~A}$ & $5.31 \mathrm{E}+02$ & $5.20 \mathrm{E}+02$ & $5.28 \mathrm{E}+02$ & $5.19 \mathrm{E}+02$ & EST-08-01-1-3 & $2.97 \mathrm{E}+00$ & 1.90E-01 & EST-08-01-1-4 & $1.95 \mathrm{E}+01$ & 9.19E-01 \\
\hline $4.98 \mathrm{E}+02$ & 3 & $\mathrm{~A}$ & $4.58 \mathrm{E}+02$ & $5.19 \mathrm{E}+02$ & $5.22 \mathrm{E}+02$ & $5.18 \mathrm{E}+02$ & EST-08-01-1-5 & $1.98 \mathrm{E}+00$ & 8.55E-02 & EST-08-01-1-6 & $1.50 \mathrm{E}+01$ & 4.55E-01 \\
\hline $4.98 \mathrm{E}+02$ & 4 & $\mathrm{~A}$ & $4.33 \mathrm{E}+02$ & $5.18 \mathrm{E}+02$ & $5.22 \mathrm{E}+02$ & $5.18 \mathrm{E}+02$ & EST-08-01-1-7 & 7.07E-01 & 7.39E-02 & EST-08-01-1-8 & $1.23 \mathrm{E}+01$ & 4.33E-01 \\
\hline $4.98 \mathrm{E}+02$ & 5 & $\mathrm{~A}$ & $4.78 \mathrm{E}+02$ & $5.18 \mathrm{E}+02$ & $5.17 \mathrm{E}+02$ & - & EST-08-01-1-9 & $6.13 \mathrm{E}-01$ & 5.78E-02 & EST-08-01-1-10 & - & - \\
\hline & & & & & & & & & & & & \\
\hline \multicolumn{13}{|l|}{\begin{tabular}{|l} 
EST-08-02 \\
\end{tabular}} \\
\hline \multicolumn{13}{|l|}{ Fragment \#1 } \\
\hline $3.83 \mathrm{E}+02$ & 1 & $\overline{\mathrm{A}}$ & $4.72 \mathrm{E}+02$ & $3.83 \mathrm{E}+02$ & $4.04 \mathrm{E}+02$ & $3.99 \mathrm{E}+02$ & \begin{tabular}{|l|} 
EST-08-02-1-1 \\
\end{tabular} & $3.87 \mathrm{E}+00$ & $8.82 \mathrm{E}-02$ & \begin{tabular}{|c|} 
EST-08-02-1-2 \\
\end{tabular} & $4.74 \mathrm{E}+01$ & $7.12 \mathrm{E}-01$ \\
\hline $3.83 \mathrm{E}+02$ & 2 & $\overline{\mathrm{A}}$ & $4.55 \mathrm{E}+02$ & $3.99 \mathrm{E}+02$ & $4.03 \mathrm{E}+02$ & - & \begin{tabular}{|l|} 
EST-08-02-1-3 \\
\end{tabular} & \begin{tabular}{|l|}
$7.75 \mathrm{E}-01$ \\
\end{tabular} & $0.00 \mathrm{E}+00$ & \begin{tabular}{|c|} 
EST-08-02-1-4 \\
\end{tabular} & - & - \\
\hline $3.83 \mathrm{E}+02$ & 3 & $\bar{A}$ & $4.50 \mathrm{E}+02$ & $4.03 \mathrm{E}+02$ & $4.06 \mathrm{E}+02$ & $3.98 \mathrm{E}+02$ & \begin{tabular}{|l|} 
EST-08-02-1-5 \\
\end{tabular} & $1.34 \mathrm{E}+00$ & $0.00 \mathrm{E}+00$ & \begin{tabular}{|c|} 
EST-08-02-1-6 \\
\end{tabular} & $3.49 \mathrm{E}+01$ & $2.93 \mathrm{E}-01$ \\
\hline $3.83 \mathrm{E}+02$ & 4 & $\mathrm{~A}$ & $6.97 \mathrm{E}+02$ & $3.98 \mathrm{E}+02$ & $4.01 \mathrm{E}+02$ & $3.94 \mathrm{E}+02$ & EST-08-02-1-7 & $2.56 \mathrm{E}-01$ & $0.00 \mathrm{E}+00$ & EST-08-02-1-8 & $2.56 \mathrm{E}+01$ & 1.24E-01 \\
\hline $3.83 \mathrm{E}+02$ & 5 & A & $5.92 \mathrm{E}+02$ & $3.94 \mathrm{E}+02$ & $4.01 \mathrm{E}+02$ & $3.94 \mathrm{E}+02$ & \begin{tabular}{|l|} 
EST-08-02-1-9 \\
\end{tabular} & 2.22E-01 & $0.00 \mathrm{E}+00$ & EST-08-02-1-10 & $1.70 \mathrm{E}+01$ & 5.82E-02 \\
\hline $3.83 \mathrm{E}+02$ & 6 & $\mathrm{~A}$ & $5.53 \mathrm{E}+02$ & $3.94 \mathrm{E}+02$ & $4.01 \mathrm{E}+02$ & - & EST-08-02-1-11 & 8.89E-02 & $0.00 \mathrm{E}+00$ & EST-08-02-1-12 & - & - \\
\hline & & & & & & & & & & & & \\
\hline EST-08-03 & & & & & & & & & & & & \\
\hline
\end{tabular}


Table A2. Extraction Results for ES-31B.

\begin{tabular}{|c|c|c|c|c|c|c|c|c|c|c|c|c|}
\hline $\begin{array}{c}\text { Dry Sample } \\
\text { Mass (g) } \\
\text { ES-31B }\end{array}$ & \begin{tabular}{|c|} 
Extraction \\
Step \#
\end{tabular} & $\begin{array}{l}\text { Soln. } \\
\text { Type¥ }\end{array}$ & \begin{tabular}{|c|} 
Vol. of Soln. \\
Added for \\
Sat. (mL)
\end{tabular} & $\begin{array}{c}\text { Pre-Sat. } \\
\text { Sample } \\
\text { Mass (g) }\end{array}$ & \begin{tabular}{|c} 
Post-Sat. \& \\
Draining Free Liq. \\
Sample Mass (g)
\end{tabular} & $\begin{array}{l}\text { Post-Cent. } \\
\text { Sample } \\
\text { Mass (g) }\end{array}$ & Sat. Sample \# & $\begin{array}{c}\text { Liq. [Re] } \\
\text { (Sat.) } \\
\text { ( } \mu \mathrm{g} / \mathrm{L})\end{array}$ & $\begin{array}{c}\text { Liq. [Cs] } \\
\text { (Sat.) } \\
(\mu \mathrm{g} / \mathrm{L})\end{array}$ & Cent. Sample \# & $\begin{array}{c}\text { Liq. [Re] } \\
\text { (Cent.) } \\
\text { ( } \mu \mathrm{g} / \mathrm{L})\end{array}$ & $\begin{array}{c}\text { Liq. [Cs] } \\
\text { (Cent.) } \\
(\mu \mathrm{\mu g} / \mathrm{L})\end{array}$ \\
\hline \multicolumn{13}{|l|}{ Fragment \#1 } \\
\hline $3.90 \mathrm{E}+02$ & 1 & $\mathrm{~A}$ & $4.71 \mathrm{E}+02$ & $3.90 \mathrm{E}+02$ & $4.12 \mathrm{E}+02$ & $4.07 \mathrm{E}+02$ & EST-08-03-1-1 & $6.39 \mathrm{E}+00$ & 4.81E-01 & \begin{tabular}{|c|} 
EST-08-03-1-2 \\
\end{tabular} & $7.51 \mathrm{E}+01$ & $1.94 \mathrm{E}+0 \mathrm{c}$ \\
\hline $3.90 \mathrm{E}+02$ & 2 & $\bar{A}$ & $4.91 \mathrm{E}+02$ & $4.07 \mathrm{E}+02$ & $4.12 \mathrm{E}+02$ & $4.09 \mathrm{E}+02$ & EST-08-03-1-3 & $1.76 \mathrm{E}+00$ & $1.47 \mathrm{E}-01$ & \begin{tabular}{|c|} 
EST-08-03-1-4 \\
\end{tabular} & - & - \\
\hline $3.90 \mathrm{E}+02$ & 3 & $\overline{\mathrm{A}}$ & $4.41 \mathrm{E}+02$ & $4.09 \mathrm{E}+02$ & $4.15 \mathrm{E}+02$ & $4.04 \mathrm{E}+02$ & \begin{tabular}{|l|} 
EST-08-03-1-5 \\
\end{tabular} & $2.40 \mathrm{E}+00$ & $1.44 \mathrm{E}-01$ & \begin{tabular}{|c|} 
EST-08-03-1-6 \\
\end{tabular} & $5.75 \mathrm{E}+01$ & \begin{tabular}{|l|}
$7.63 \mathrm{E}-01$ \\
\end{tabular} \\
\hline $3.90 \mathrm{E}+02$ & 4 & $\overline{\mathrm{A}}$ & $5.01 \mathrm{E}+02$ & $4.04 \mathrm{E}+02$ & $4.10 \mathrm{E}+02$ & \begin{tabular}{|c|}
$3.98 \mathrm{E}+02$ \\
\end{tabular} & \begin{tabular}{|l|} 
EST-08-03-1-7 \\
\end{tabular} & 4.69E-01 & $6.84 \mathrm{E}-02$ & \begin{tabular}{|c|} 
EST-08-03-1-8 \\
\end{tabular} & $2.84 \mathrm{E}+01$ & \begin{tabular}{|c|}
$6.66 \mathrm{E}-01$ \\
\end{tabular} \\
\hline $3.90 \mathrm{E}+02$ & 5 & $\bar{A}$ & $4.92 \mathrm{E}+02$ & $3.98 \mathrm{E}+02$ & $4.03 \mathrm{E}+02$ & $3.92 \mathrm{E}+02$ & EST-08-03-1-9 & 3.84E-01 & 5.56E-02 & \begin{tabular}{|l} 
EST-08-03-1-10 \\
\end{tabular} & $2.44 \mathrm{E}+01$ & $5.25 \mathrm{E}-01$ \\
\hline $3.90 \mathrm{E}+02$ & 6 & $\bar{A}$ & $4.48 \mathrm{E}+02$ & $3.92 \mathrm{E}+02$ & $4.02 \mathrm{E}+02$ & - & EST-08-03-1-11 & $1.86 \mathrm{E}-01$ & $0.00 \mathrm{E}+00$ & EST-08-03-1-12 & - & - \\
\hline & & & & & & & & & & & & \\
\hline \multicolumn{13}{|l|}{ EST-08-04 } \\
\hline \multicolumn{13}{|l|}{ Fragment \#1 } \\
\hline $4.25 \mathrm{E}+02$ & 1 & $\mathrm{~A}$ & $4.90 \mathrm{E}+02$ & $4.25 \mathrm{E}+02$ & $4.49 \mathrm{E}+02$ & $4.44 \mathrm{E}+02$ & EST-08-04-1-1 & $1.08 \mathrm{E}+00$ & 3.46E-01 & EST-08-04-1-2 & $1.72 \mathrm{E}+01$ & $1.37 \mathrm{E}+0 \mathrm{C}$ \\
\hline $4.25 \mathrm{E}+02$ & 2 & $\bar{A}$ & $5.47 \mathrm{E}+02$ & $4.44 \mathrm{E}+02$ & $4.49 \mathrm{E}+02$ & \begin{tabular}{|l}
$4.39 \mathrm{E}+02$ \\
\end{tabular} & EST-08-04-1-3 & 7.37E-01 & $1.71 \mathrm{E}-01$ & \begin{tabular}{|l|} 
EST-08-04-1-4 \\
\end{tabular} & $1.29 \mathrm{E}+01$ & $8.01 \mathrm{E}-01$ \\
\hline $4.25 \mathrm{E}+02$ & 3 & $\bar{A}$ & $5.06 \mathrm{E}+02$ & $4.39 \mathrm{E}+02$ & $4.47 \mathrm{E}+02$ & \begin{tabular}{|l}
$4.34 \mathrm{E}+02$ \\
\end{tabular} & EST-08-04-1-5 & 7.87E-02 & 6.01E-02 & \begin{tabular}{|l|} 
EST-08-04-1-6 \\
\end{tabular} & $6.60 \mathrm{E}+00$ & $6.68 \mathrm{E}-01$ \\
\hline $4.25 \mathrm{E}+02$ & 4 & $\mathrm{~A}$ & $3.89 \mathrm{E}+02$ & $4.34 \mathrm{E}+02$ & $4.42 \mathrm{E}+02$ & $4.33 \mathrm{E}+02$ & EST-08-04-1-7 & $9.00 \mathrm{E}-02$ & 6.84E-02 & \begin{tabular}{|l|} 
EST-08-04-1-8 \\
\end{tabular} & $3.34 \mathrm{E}+00$ & $1.76 \mathrm{E}-01$ \\
\hline $4.25 \mathrm{E}+02$ & 5 & $\bar{A}$ & $5.01 \mathrm{E}+02$ & $4.33 \mathrm{E}+02$ & $4.43 \mathrm{E}+02$ & $4.35 \mathrm{E}+02$ & EST-08-04-1-9 & $1.57 \mathrm{E}-01$ & 5.36E-02 & \begin{tabular}{|l|} 
EST-08-04-1-10 \\
\end{tabular} & $4.80 \mathrm{E}-01$ & $2.71 \mathrm{E}-01$ \\
\hline & & & & & & & & & & & & \\
\hline \multicolumn{13}{|l|}{\begin{tabular}{|l|} 
EST-08-05-1 \\
\end{tabular}} \\
\hline \multicolumn{13}{|l|}{ Fragment \#1 } \\
\hline $4.45 \mathrm{E}+02$ & 1 & $\bar{A}$ & $4.76 \mathrm{E}+02$ & $4.45 \mathrm{E}+02$ & $4.68 \mathrm{E}+02$ & $4.65 \mathrm{E}+02$ & \begin{tabular}{|l} 
EST-08-05-1-1 \\
\end{tabular} & $1.33 \mathrm{E}+01$ & 2.35E-01 & \begin{tabular}{|c|} 
EST-08-05-1-2 \\
\end{tabular} & $4.34 \mathrm{E}+01$ & $5.51 \mathrm{E}-01$ \\
\hline $4.45 \mathrm{E}+02$ & 2 & $\bar{A}$ & $4.78 \mathrm{E}+02$ & $4.65 \mathrm{E}+02$ & $4.68 \mathrm{E}+02$ & \begin{tabular}{|l}
$4.65 E+02$ \\
\end{tabular} & EST-08-05-1-3 & $6.25 \mathrm{E}-01$ & 6.51E-02 & \begin{tabular}{|l|} 
EST-08-05-1-4 \\
\end{tabular} & $2.34 \mathrm{E}+01$ & $2.66 \mathrm{E}-01$ \\
\hline $4.45 \mathrm{E}+02$ & 3 & $\bar{A}$ & $4.82 \mathrm{E}+02$ & $4.65 E+02$ & $4.67 \mathrm{E}+02$ & \begin{tabular}{|l}
$4.65 \mathrm{E}+02$ \\
\end{tabular} & EST-08-05-1-5 & $2.10 \mathrm{E}-01$ & 3.96E-02 & \begin{tabular}{|l|} 
EST-08-05-1-6 \\
\end{tabular} & $3.06 \mathrm{E}+01$ & $8.04 \mathrm{E}-01$ \\
\hline $4.45 \mathrm{E}+02$ & 4 & A & $4.98 \mathrm{E}+02$ & $4.65 \mathrm{E}+02$ & $4.67 \mathrm{E}+02$ & \begin{tabular}{|l}
$4.64 \mathrm{E}+02$ \\
\end{tabular} & EST-08-05-1-7 & $8.24 \mathrm{E}-01$ & 6.29E-02 & \begin{tabular}{|l|} 
EST-08-05-1-8 \\
\end{tabular} & $1.37 \mathrm{E}+01$ & $2.35 \mathrm{E}-01$ \\
\hline $4.45 \mathrm{E}+02$ & 5 & $\mathrm{~A}$ & $4.95 \mathrm{E}+02$ & $4.64 \mathrm{E}+02$ & $4.66 \mathrm{E}+02$ & \begin{tabular}{|l}
$4.64 \mathrm{E}+02$ \\
\end{tabular} & EST-08-05-1-9 & $6.60 \mathrm{E}-01$ & 7.00E-02 & \begin{tabular}{|l|} 
EST-08-05-1-10 \\
\end{tabular} & $2.07 \mathrm{E}+01$ & 1.93E-01 \\
\hline & & & & & & & & & & & & \\
\hline \multicolumn{13}{|l|}{\begin{tabular}{|l|} 
EST-08-06-1 \\
\end{tabular}} \\
\hline \multicolumn{13}{|l|}{ Fragment \#1 } \\
\hline $3.63 \mathrm{E}+02$ & 1 & $\mathrm{~A}$ & $3.16 \mathrm{E}+02$ & $3.63 \mathrm{E}+02$ & $3.82 \mathrm{E}+02$ & $3.80 \mathrm{E}+02$ & EST-08-06-01-1 & $1.17 \mathrm{E}+00$ & $8.94 \mathrm{E}-02$ & \begin{tabular}{|l|} 
EST-08-06-01-2 \\
\end{tabular} & $7.59 \mathrm{E}+00$ & $1.99 \mathrm{E}+0 \mathrm{c}$ \\
\hline $3.63 \mathrm{E}+02$ & 2 & $\bar{A}$ & $3.27 \mathrm{E}+02$ & $3.80 \mathrm{E}+02$ & $3.82 \mathrm{E}+02$ & $3.78 \mathrm{E}+02$ & EST-08-06-01-3 & $1.35 \mathrm{E}+00$ & $6.20 \mathrm{E}-02$ & \begin{tabular}{|l|} 
EST-08-06-01-4 \\
\end{tabular} & $1.23 \mathrm{E}+02$ & $3.50 \mathrm{E}+0 \mathrm{c}$ \\
\hline $3.63 \mathrm{E}+02$ & 3 & $\bar{A}$ & $3.45 \mathrm{E}+02$ & $3.78 \mathrm{E}+02$ & $3.82 \mathrm{E}+02$ & \begin{tabular}{|c|}
$3.77 \mathrm{E}+02$ \\
\end{tabular} & EST-08-06-01-5 & $7.28 \mathrm{E}-01$ & $0.00 \mathrm{E}+00$ & \begin{tabular}{|l|} 
EST-08-06-01-6 \\
\end{tabular} & $1.14 \mathrm{E}+02$ & $2.05 \mathrm{E}+0 \mathrm{C}$ \\
\hline $3.63 \mathrm{E}+02$ & 4 & $\bar{A}$ & $3.44 \mathrm{E}+02$ & $3.77 \mathrm{E}+02$ & $3.82 \mathrm{E}+02$ & \begin{tabular}{|c|}
$3.76 \mathrm{E}+02$ \\
\end{tabular} & EST-08-06-01-7 & $6.44 \mathrm{E}-01$ & $0.00 \mathrm{E}+00$ & \begin{tabular}{|l|} 
EST-08-06-01-8 \\
\end{tabular} & $1.00 \mathrm{E}+02$ & $1.53 \mathrm{E}+0 \mathrm{c}$ \\
\hline $3.63 \mathrm{E}+02$ & 5 & $\bar{A}$ & $3.06 \mathrm{E}+02$ & $3.76 \mathrm{E}+02$ & $3.82 \mathrm{E}+02$ & \begin{tabular}{|l|}
$3.77 \mathrm{E}+02$ \\
\end{tabular} & EST-08-06-01-9 & $7.04 \mathrm{E}-01$ & $0.00 \mathrm{E}+00$ & EST-08-06-01-10 & $6.39 \mathrm{E}+01$ & $8.75 \mathrm{E}-01$ \\
\hline $3.63 \mathrm{E}+02$ & 6 & $\mathrm{~A}$ & $3.23 \mathrm{E}+02$ & $3.77 \mathrm{E}+02$ & $3.83 \mathrm{E}+02$ & $3.76 \mathrm{E}+02$ & \begin{tabular}{|c} 
EST-08-06-01- \\
11
\end{tabular} & $6.83 \mathrm{E}-01$ & $0.00 \mathrm{E}+00$ & \begin{tabular}{|l} 
EST-08-06-01-12 \\
\end{tabular} & $3.34 \mathrm{E}+01$ & $5.50 \mathrm{E}-01$ \\
\hline
\end{tabular}


Table A2. Extraction Results for ES-31B.

\begin{tabular}{|c|c|c|c|c|c|c|c|c|c|c|c|c|}
\hline $\begin{array}{c}\begin{array}{c}\text { Dry Sample } \\
\text { Mass (g) }\end{array} \\
\text { ES-31B }\end{array}$ & \begin{tabular}{|c|} 
Extraction \\
Step \#
\end{tabular} & $\begin{array}{l}\text { Soln. } \\
\text { Type¥ }\end{array}$ & $\begin{array}{l}\text { Vol. of Soln. } \\
\text { Added for } \\
\text { Sat. (mL) }\end{array}$ & \begin{tabular}{|c|} 
Pre-Sat. \\
Sample \\
Mass (g)
\end{tabular} & \begin{tabular}{|c|} 
Post-Sat. \& \\
Draining Free Liq. \\
Sample Mass (g)
\end{tabular} & \begin{tabular}{|l} 
Post-Cent. \\
Sample \\
Mass (g)
\end{tabular} & Sat. Sample \# & $\begin{array}{l}\text { Liq. [Re] } \\
\text { (Sat.) } \\
\text { ( } \mathrm{\mu g} / \mathrm{L})\end{array}$ & \begin{tabular}{|c|} 
Liq. $[\mathrm{Cs}]$ \\
(Sat.) \\
$(\mu \mathrm{g} / \mathrm{L})$
\end{tabular} & Cent. Sample \# & $\begin{array}{c}\text { Liq. [Re] } \\
\text { (Cent.) } \\
(\mu g / L)\end{array}$ & $\begin{array}{c}\text { Liq. [Cs] } \\
\text { (Cent.) } \\
(\mu g / L)\end{array}$ \\
\hline \multirow{2}{*}{\multicolumn{13}{|c|}{ EST-08-06-2 }} \\
\hline & & & & & & & & & & & & \\
\hline \multicolumn{13}{|l|}{ Fragment \#1 } \\
\hline $2.03 \mathrm{E}+02$ & 1 & A & $2.47 \mathrm{E}+02$ & $2.03 \mathrm{E}+02$ & $2.14 \mathrm{E}+02$ & $2.12 \mathrm{E}+02$ & EST-08-06-02-1 & $1.08 \mathrm{E}+00$ & 5.22E-02 & EST-08-06-02-2 & $4.19 \mathrm{E}+00$ & $8.00 \mathrm{E}-02$ \\
\hline $2.03 \mathrm{E}+02$ & 2 & $\mathrm{~A}$ & $3.49 \mathrm{E}+02$ & $2.12 \mathrm{E}+02$ & $2.13 \mathrm{E}+02$ & $2.11 \mathrm{E}+02$ & \begin{tabular}{|l|} 
EST-08-06-02-3 \\
\end{tabular} & 5.66E-01 & $0.00 \mathrm{E}+00$ & \begin{tabular}{|l|} 
EST-08-06-02-4 \\
\end{tabular} & $4.56 \mathrm{E}+01$ & $1.90 \mathrm{E}-01$ \\
\hline $2.03 \mathrm{E}+02$ & 3 & $\bar{A}$ & $2.60 \mathrm{E}+02$ & $2.11 \mathrm{E}+02$ & $2.13 \mathrm{E}+02$ & $2.11 \mathrm{E}+02$ & EST-08-06-02-5 & $2.87 \mathrm{E}-01$ & $0.00 \mathrm{E}+00$ & EST-08-06-02-6 & $3.07 \mathrm{E}+01$ & $4.09 \mathrm{E}-01$ \\
\hline $2.03 \mathrm{E}+02$ & 4 & $\overline{\mathrm{A}}$ & $2.69 \mathrm{E}+02$ & $2.11 \mathrm{E}+02$ & $2.12 \mathrm{E}+02$ & $2.10 \mathrm{E}+02$ & EST-08-06-02-7 & $3.40 \mathrm{E}-01$ & $0.00 \mathrm{E}+00$ & EST-08-06-02-8 & $3.50 \mathrm{E}+01$ & $3.93 \mathrm{E}-01$ \\
\hline $2.03 \mathrm{E}+02$ & 5 & $\bar{A}$ & $2.52 \mathrm{E}+02$ & $2.10 \mathrm{E}+02$ & $2.13 \mathrm{E}+02$ & $2.10 \mathrm{E}+02$ & EST-08-06-02-9 & $4.12 \mathrm{E}-01$ & $0.00 \mathrm{E}+00$ & EST-08-06-02-10 & $3.15 \mathrm{E}+01$ & $2.78 \mathrm{E}-01$ \\
\hline $2.03 \mathrm{E}+02$ & 6 & $\mathrm{~A}$ & $2.61 \mathrm{E}+02$ & $2.10 \mathrm{E}+02$ & $2.12 \mathrm{E}+02$ & $2.09 \mathrm{E}+02$ & \begin{tabular}{|c|} 
EST-08-06-02- \\
11
\end{tabular} & $4.84 \mathrm{E}-01$ & $0.00 \mathrm{E}+00$ & EST-08-06-02-12 & - & - \\
\hline & & & & & & & & & & & & \\
\hline \multicolumn{13}{|l|}{ EST-08-07 } \\
\hline \multicolumn{13}{|l|}{ Fragment \#1 } \\
\hline $3.53 \mathrm{E}+02$ & 1 & $\bar{A}$ & $4.59 \mathrm{E}+02$ & $3.53 E+02$ & $3.71 \mathrm{E}+02$ & $3.70 \mathrm{E}+02$ & \begin{tabular}{|l|} 
EST-08-07-1-1 \\
\end{tabular} & $1.27 \mathrm{E}+00$ & 6.00E-02 & EST-08-07-1-2 & $4.30 \mathrm{E}+00$ & $1.02 \mathrm{E}-01$ \\
\hline $3.53 \mathrm{E}+02$ & 2 & $\bar{A}$ & $4.51 \mathrm{E}+02$ & $3.70 \mathrm{E}+02$ & $3.72 \mathrm{E}+02$ & $3.65 \mathrm{E}+02$ & EST-08-07-1-3 & $1.91 \mathrm{E}+00$ & 4.58E-02 & EST-08-07-1-4 & $1.51 \mathrm{E}+02$ & $1.78 \mathrm{E}-01$ \\
\hline $3.53 \mathrm{E}+02$ & 3 & $\bar{A}$ & $4.61 \mathrm{E}+02$ & $3.65 \mathrm{E}+02$ & $3.72 \mathrm{E}+02$ & $3.64 \mathrm{E}+02$ & EST-08-07-1-5 & 5.79E-01 & $0.00 \mathrm{E}+00$ & EST-08-07-1-6 & $1.64 \mathrm{E}+02$ & $1.02 \mathrm{E}-01$ \\
\hline $3.53 \mathrm{E}+02$ & 4 & $\overline{\mathrm{A}}$ & $4.39 \mathrm{E}+02$ & $3.64 \mathrm{E}+02$ & $3.72 \mathrm{E}+02$ & $3.64 \mathrm{E}+02$ & EST-08-07-1-7 & $8.50 \mathrm{E}-01$ & $0.00 \mathrm{E}+00$ & EST-08-07-1-8 & $1.50 \mathrm{E}+02$ & $1.11 \mathrm{E}-01$ \\
\hline $3.53 \mathrm{E}+02$ & 5 & $\mathrm{~A}$ & $4.53 \mathrm{E}+02$ & $3.64 \mathrm{E}+02$ & $3.72 \mathrm{E}+02$ & $3.65 \mathrm{E}+02$ & \begin{tabular}{|l|} 
EST-08-07-1-9 \\
\end{tabular} & $9.19 \mathrm{E}-01$ & $0.00 \mathrm{E}+00$ & \begin{tabular}{|l|} 
EST-08-07-1-10 \\
\end{tabular} & $6.47 \mathrm{E}+01$ & $6.02 \mathrm{E}-02$ \\
\hline $3.53 \mathrm{E}+02$ & 6 & $\mathrm{~A}$ & $4.44 \mathrm{E}+02$ & $3.65 \mathrm{E}+02$ & $3.72 \mathrm{E}+02$ & $3.64 \mathrm{E}+02$ & EST-08-07-1-11 & $6.96 \mathrm{E}-01$ & $0.00 \mathrm{E}+00$ & \begin{tabular}{|l|} 
EST-08-07-1-12 \\
\end{tabular} & $2.29 \mathrm{E}+01$ & $4.91 \mathrm{E}-02$ \\
\hline & & & & & & & & & & & & \\
\hline \multicolumn{13}{|l|}{ EST-08-08 } \\
\hline \multicolumn{13}{|l|}{ Fragment \#1 } \\
\hline $3.80 \mathrm{E}+02$ & 1 & $\mathrm{~A}$ & $5.23 \mathrm{E}+02$ & $3.80 \mathrm{E}+02$ & $5.07 \mathrm{E}+02$ & $4.99 \mathrm{E}+02$ & EST-08-08-1-1 & $5.84 \mathrm{E}+00$ & 1.32E-01 & EST-08-08-1-2 & $3.85 \mathrm{E}+01$ & $1.19 \mathrm{E}-01$ \\
\hline $3.80 \mathrm{E}+02$ & 2 & $\bar{A}$ & $4.80 \mathrm{E}+02$ & $4.99 \mathrm{E}+02$ & $5.05 \mathrm{E}+02$ & $5.05 \mathrm{E}+02$ & EST-08-08-1-3 & $3.58 \mathrm{E}+00$ & 5.15E-02 & EST-08-08-1-4 & - & - \\
\hline $3.80 \mathrm{E}+02$ & 3 & $\bar{A}$ & $4.77 \mathrm{E}+02$ & $5.05 \mathrm{E}+02$ & $5.06 \mathrm{E}+02$ & $5.01 \mathrm{E}+02$ & EST-08-08-1-5 & $3.56 \mathrm{E}+00$ & $0.00 \mathrm{E}+00$ & EST-08-08-1-6 & $1.77 \mathrm{E}+02$ & $1.47 \mathrm{E}+00$ \\
\hline $3.80 \mathrm{E}+02$ & 4 & $\bar{A}$ & $4.83 \mathrm{E}+02$ & $5.01 \mathrm{E}+02$ & $5.05 \mathrm{E}+02$ & $5.00 \mathrm{E}+02$ & EST-08-08-1-7 & $9.59 \mathrm{E}-01$ & $0.00 \mathrm{E}+00$ & EST-08-08-1-8 & $1.19 \mathrm{E}+02$ & $8.38 \mathrm{E}-01$ \\
\hline $3.80 \mathrm{E}+02$ & 5 & $\overline{\mathrm{A}}$ & $5.24 \mathrm{E}+02$ & $5.00 \mathrm{E}+02$ & $5.04 \mathrm{E}+02$ & $4.95 \mathrm{E}+02$ & EST-08-08-1-9 & $8.07 \mathrm{E}-01$ & $0.00 \mathrm{E}+00$ & \begin{tabular}{|l|} 
EST-08-08-1-10 \\
\end{tabular} & $2.44 \mathrm{E}+01$ & $0.00 \mathrm{E}+00$ \\
\hline & & & & & & & & & & & & \\
\hline & & & & & & & & & & & & \\
\hline \multicolumn{13}{|l|}{ EST-08-09 } \\
\hline \multicolumn{13}{|l|}{ Fragment \#1 } \\
\hline $5.97 \mathrm{E}+02$ & 1 & $\mathrm{~A}$ & $4.64 \mathrm{E}+02$ & $5.97 \mathrm{E}+02$ & $6.30 \mathrm{E}+02$ & $6.19 \mathrm{E}+02$ & EST-08-09-1-1 & 5.27E-01 & 5.49E-01 & EST-08-09-1-2 & $4.12 \mathrm{E}+00$ & $3.48 \mathrm{E}+00$ \\
\hline $5.97 \mathrm{E}+02$ & 2 & $\overline{\mathrm{A}}$ & $4.47 \mathrm{E}+02$ & $6.19 \mathrm{E}+02$ & $6.28 \mathrm{E}+02$ & $6.20 \mathrm{E}+02$ & EST-08-09-1-3 & 2.52E-01 & 2.64E-01 & EST-08-09-1-4 & $4.72 \mathrm{E}+00$ & $2.59 \mathrm{E}+00$ \\
\hline
\end{tabular}


Table A2. Extraction Results for ES-31B.

\begin{tabular}{|c|c|c|c|c|c|c|c|c|c|c|c|c|}
\hline $\begin{array}{c}\text { Dry Sample } \\
\text { Mass (g) } \\
\text { ES-31B }\end{array}$ & $\begin{array}{c}\text { Extraction } \\
\text { Step \# }\end{array}$ & $\begin{array}{c}\text { Soln. } \\
\text { Type¥ }\end{array}$ & $\begin{array}{l}\text { Vol. of Soln. } \\
\text { Added for } \\
\text { Sat. (mL) }\end{array}$ & $\begin{array}{c}\text { Pre-Sat. } \\
\text { Sample } \\
\text { Mass (g) }\end{array}$ & \begin{tabular}{|c} 
Post-Sat. \& \\
Draining Free Liq. \\
Sample Mass (g)
\end{tabular} & $\begin{array}{l}\text { Post-Cent. } \\
\text { Sample } \\
\text { Mass (g) }\end{array}$ & Sat. Sample \# & $\begin{array}{c}\text { Liq. [Re] } \\
\text { (Sat.) } \\
\text { ( } \mu \mathrm{g} / \mathrm{L})\end{array}$ & $\begin{array}{c}\text { Liq. [Cs] } \\
\text { (Sat.) } \\
(\mu \mathrm{g} / \mathrm{L})\end{array}$ & Cent. Sample \# & $\begin{array}{c}\text { Liq. [Re] } \\
\text { (Cent.) } \\
\text { ( } \mu \mathrm{g} / \mathrm{L})\end{array}$ & $\begin{array}{c}\text { Liq. [Cs] } \\
\text { (Cent.) } \\
\text { ( } \mu \mathrm{g} / \mathbf{L})\end{array}$ \\
\hline $5.97 \mathrm{E}+02$ & 3 & A & $4.78 \mathrm{E}+02$ & $6.20 \mathrm{E}+02$ & $6.29 \mathrm{E}+02$ & $6.17 \mathrm{E}+02$ & EST-08-09-1-5 & 3.65E-01 & $2.60 \mathrm{E}-01$ & \begin{tabular}{|l|} 
EST-08-09-1-6 \\
\end{tabular} & $2.39 \mathrm{E}+00$ & $1.78 \mathrm{E}+00$ \\
\hline $5.97 \mathrm{E}+02$ & 4 & $\mathrm{~A}$ & $4.91 \mathrm{E}+02$ & $6.17 \mathrm{E}+02$ & $6.27 \mathrm{E}+02$ & \begin{tabular}{|l|}
$6.18 \mathrm{E}+02$ \\
\end{tabular} & $\begin{array}{l}\text { EST-08-09-1-7 } \\
\end{array}$ & 2.11E-01 & $1.36 \mathrm{E}-01$ & \begin{tabular}{|c|} 
EST-08-09-1-8 \\
\end{tabular} & $3.98 \mathrm{E}+00$ & $1.23 \mathrm{E}+00$ \\
\hline $5.97 \mathrm{E}+02$ & 5 & A & $4.89 \mathrm{E}+02$ & $6.18 \mathrm{E}+02$ & $6.28 \mathrm{E}+02$ & $6.17 \mathrm{E}+02$ & EST-08-09-1-9 & $1.09 \mathrm{E}-01$ & $0.00 \mathrm{E}+00$ & EST-08-09-1-10 & $6.13 \mathrm{E}+00$ & $1.04 \mathrm{E}+00$ \\
\hline EST-08-10 & & & & & & & & & & & & \\
\hline \multicolumn{13}{|l|}{ Fragment \#1 } \\
\hline $4.46 \mathrm{E}+02$ & 1 & A & $5.11 \mathrm{E}+02$ & $4.46 \mathrm{E}+02$ & $4.71 \mathrm{E}+02$ & $4.62 \mathrm{E}+02$ & EST-08-10-1-1 & $1.84 \mathrm{E}-01$ & $1.35 \mathrm{E}-01$ & EST-08-10-1-2 & $2.52 \mathrm{E}+01$ & $1.92 \mathrm{E}+00$ \\
\hline $4.46 \mathrm{E}+02$ & 2 & $\mathrm{~A}$ & $5.11 \mathrm{E}+02$ & $4.62 \mathrm{E}+02$ & $4.72 \mathrm{E}+02$ & $4.60 \mathrm{E}+02$ & EST-08-10-1-3 & $1.44 \mathrm{E}+00$ & $2.41 \mathrm{E}-01$ & EST-08-10-1-4 & $3.41 \mathrm{E}+00$ & $1.75 \mathrm{E}-01$ \\
\hline $4.46 \mathrm{E}+02$ & 3 & A & $4.96 \mathrm{E}+02$ & $4.60 \mathrm{E}+02$ & $4.70 \mathrm{E}+02$ & $4.63 \mathrm{E}+02$ & EST-08-10-1-5 & $0.00 \mathrm{E}+00$ & $2.15 \mathrm{E}-02$ & \begin{tabular}{|c|} 
EST-08-10-1-6 \\
\end{tabular} & $2.53 \mathrm{E}+00$ & $7.26 \mathrm{E}-02$ \\
\hline $4.46 \mathrm{E}+02$ & 4 & $\bar{A}$ & $4.83 \mathrm{E}+02$ & $4.63 \mathrm{E}+02$ & $4.69 \mathrm{E}+02$ & $4.61 \mathrm{E}+02$ & EST-08-10-1-7 & $0.00 \mathrm{E}+00$ & $2.63 \mathrm{E}-02$ & \begin{tabular}{|l|} 
EST-08-10-1-8 \\
\end{tabular} & $1.31 \mathrm{E}+00$ & $6.28 \mathrm{E}-02$ \\
\hline $4.46 \mathrm{E}+02$ & 5 & A & $4.89 \mathrm{E}+02$ & $4.61 \mathrm{E}+02$ & $4.70 \mathrm{E}+02$ & $4.65 \mathrm{E}+02$ & EST-08-10-1-9 & $0.00 \mathrm{E}+00$ & 6.97E-02 & EST-08-10-1-10 & $0.00 \mathrm{E}+00$ & 4.05E-02 \\
\hline & & & & & & & & & & & & \\
\hline \multicolumn{13}{|l|}{ EST-09-01 } \\
\hline \multicolumn{13}{|l|}{ Fragment \#1 } \\
\hline $4.28 \mathrm{E}+02$ & 1 & A & $4.84 \mathrm{E}+02$ & $4.28 \mathrm{E}+02$ & $4.48 \mathrm{E}+02$ & $4.46 \mathrm{E}+02$ & EST-09-01-1-1 & $2.76 \mathrm{E}+00$ & 6.78E-02 & \begin{tabular}{|l|} 
EST-09-01-1-2 \\
\end{tabular} & $9.91 \mathrm{E}+01$ & $1.21 \mathrm{E}+00$ \\
\hline $4.28 \mathrm{E}+02$ & 2 & $\mathrm{~A}$ & $4.78 \mathrm{E}+02$ & $4.46 \mathrm{E}+02$ & $4.47 \mathrm{E}+02$ & $4.46 \mathrm{E}+02$ & EST-09-01-1-3 & $1.59 \mathrm{E}-01$ & $0.00 \mathrm{E}+00$ & \begin{tabular}{|l|} 
EST-09-01-1-4 \\
\end{tabular} & $7.07 \mathrm{E}+01$ & $1.60 \mathrm{E}-01$ \\
\hline $4.28 \mathrm{E}+02$ & 3 & $\bar{A}$ & $4.90 \mathrm{E}+02$ & $4.46 \mathrm{E}+02$ & $4.47 \mathrm{E}+02$ & $4.46 \mathrm{E}+02$ & EST-09-01-1-5 & $4.52 \mathrm{E}-01$ & $1.71 \mathrm{E}-02$ & \begin{tabular}{|l|} 
EST-09-01-1-6 \\
\end{tabular} & $6.10 \mathrm{E}+01$ & $1.30 \mathrm{E}-01$ \\
\hline $4.28 \mathrm{E}+02$ & 4 & $\mathrm{~A}$ & $4.67 \mathrm{E}+02$ & $4.46 \mathrm{E}+02$ & $4.49 \mathrm{E}+02$ & $4.46 \mathrm{E}+02$ & EST-09-01-1-7 & $2.72 \mathrm{E}+00$ & $4.84 \mathrm{E}-02$ & \begin{tabular}{|l|} 
EST-09-01-1-8 \\
\end{tabular} & $1.49 \mathrm{E}+01$ & $7.98 \mathrm{E}-02$ \\
\hline $4.28 \mathrm{E}+02$ & 5 & A & $4.85 \mathrm{E}+02$ & $4.46 \mathrm{E}+02$ & $4.47 \mathrm{E}+02$ & $4.46 \mathrm{E}+02$ & EST-09-01-1-9 & 7.07E-01 & $3.11 \mathrm{E}-02$ & \begin{tabular}{|l|} 
EST-09-01-1-10 \\
\end{tabular} & $3.57 \mathrm{E}+01$ & $1.25 \mathrm{E}-01$ \\
\hline \multicolumn{13}{|l|}{ EST-09-02 } \\
\hline \multicolumn{13}{|l|}{ Fragment \#1 } \\
\hline $3.02 \mathrm{E}+02$ & 1 & $\bar{A}$ & $5.31 \mathrm{E}+02$ & $3.02 \mathrm{E}+02$ & $3.18 \mathrm{E}+02$ & $3.13 \mathrm{E}+02$ & \begin{tabular}{|l} 
EST-09-02-1-1 \\
EST
\end{tabular} & $1.36 \mathrm{E}+00$ & $7.21 \mathrm{E}-02$ & \begin{tabular}{|c|} 
EST-09-02-1-2 \\
\end{tabular} & $7.31 \mathrm{E}+01$ & $7.90 \mathrm{E}+00$ \\
\hline $3.02 \mathrm{E}+02$ & 2 & $\bar{A}$ & $5.32 \mathrm{E}+02$ & $3.13 \mathrm{E}+02$ & $3.18 \mathrm{E}+02$ & $3.15 \mathrm{E}+02$ & EST-09-02-1-3 & $\begin{array}{l}3.16 \mathrm{E}-01 \\
\end{array}$ & $3.82 \mathrm{E}-02$ & EST-09-02-1-4 & $6.30 \mathrm{E}+01$ & $7.20 \mathrm{E}+00$ \\
\hline $3.02 \mathrm{E}+02$ & 3 & $\mathrm{~A}$ & $5.13 \mathrm{E}+02$ & $3.15 \mathrm{E}+02$ & $3.17 \mathrm{E}+02$ & \begin{tabular}{|l|}
$3.13 \mathrm{E}+02$ \\
\end{tabular} & \begin{tabular}{|l} 
EST-09-02-1-5 \\
\end{tabular} & $1.64 \mathrm{E}-01$ & 2.09E-02 & \begin{tabular}{|l|} 
EST-09-02-1-6 \\
\end{tabular} & $6.56 \mathrm{E}+01$ & $4.67 \mathrm{E}+00$ \\
\hline $3.02 \mathrm{E}+02$ & 4 & $\mathrm{~A}$ & $5.03 \mathrm{E}+02$ & $3.13 \mathrm{E}+02$ & $3.17 \mathrm{E}+02$ & $3.16 \mathrm{E}+02$ & EST-09-02-1-7 & $1.52 \mathrm{E}+00$ & $5.35 \mathrm{E}-02$ & EST-09-02-1-8 & $3.15 \mathrm{E}+01$ & $2.99 \mathrm{E}+00$ \\
\hline $3.02 \mathrm{E}+02$ & 5 & A & - & $3.16 \mathrm{E}+02$ & $3.19 \mathrm{E}+02$ & $3.15 \mathrm{E}+02$ & EST-09-02-1-9 & 1.76E-01 & 3.93E-02 & EST-09-02-1-10 & $1.43 \mathrm{E}+01$ & $1.49 \mathrm{E}+00$ \\
\hline \multirow{2}{*}{\multicolumn{13}{|c|}{ EST-09-03 }} \\
\hline & & & & & & & & & & & & \\
\hline \multicolumn{13}{|l|}{ Fragment \#1 } \\
\hline $3.09 \mathrm{E}+02$ & 1 & A & $5.57 \mathrm{E}+02$ & $3.09 \mathrm{E}+02$ & $3.24 \mathrm{E}+02$ & $3.18 \mathrm{E}+02$ & EST-09-03-1-1 & 8.01E-01 & $1.26 \mathrm{E}-01$ & \begin{tabular}{|l|} 
EST-09-03-1-2 \\
\end{tabular} & $9.12 \mathrm{E}+01$ & $2.13 \mathrm{E}-01$ \\
\hline $3.09 \mathrm{E}+02$ & 2 & A & $5.16 \mathrm{E}+02$ & $3.18 \mathrm{E}+02$ & $3.26 \mathrm{E}+02$ & $3.19 \mathrm{E}+02$ & EST-09-03-1-3 & $1.34 \mathrm{E}+00$ & $1.65 \mathrm{E}-01$ & \begin{tabular}{|l|} 
EST-09-03-1-4 \\
\end{tabular} & $3.69 \mathrm{E}+01$ & $1.44 \mathrm{E}-01$ \\
\hline
\end{tabular}


Table A2. Extraction Results for ES-31B.

\begin{tabular}{|c|c|c|c|c|c|c|c|c|c|c|c|c|}
\hline $\begin{array}{c}\text { Dry Sample } \\
\text { Mass (g) } \\
\text { ES-31B }\end{array}$ & $\begin{array}{c}\text { Extraction } \\
\text { Step \# }\end{array}$ & $\begin{array}{l}\text { Soln. } \\
\text { Type¥ }\end{array}$ & $\begin{array}{l}\text { Vol. of Soln. } \\
\text { Added for } \\
\text { Sat. (mL) }\end{array}$ & \begin{tabular}{|c|} 
Pre-Sat. \\
Sample \\
Mass (g)
\end{tabular} & \begin{tabular}{|c|} 
Post-Sat. \& \\
Draining Free Liq. \\
Sample Mass (g)
\end{tabular} & \begin{tabular}{|l} 
Post-Cent. \\
Sample \\
Mass (g)
\end{tabular} & Sat. Sample \# & $\begin{array}{c}\text { Liq. [Re] } \\
\text { (Sat.) } \\
\text { ( } \mu \mathrm{g} / \mathrm{L})\end{array}$ & \begin{tabular}{|c|} 
Liq. $[\mathrm{Cs}]$ \\
(Sat.) \\
$(\mu \mathrm{g} / \mathrm{L})$
\end{tabular} & Cent. Sample \# & $\begin{array}{c}\text { Liq. [Re] } \\
\text { (Cent.) } \\
\text { ( } \mu \mathrm{g} / \mathrm{L})\end{array}$ & $\begin{array}{c}\text { Liq. [Cs] } \\
\text { (Cent.) } \\
(\mu \mathrm{g} / \mathrm{L})\end{array}$ \\
\hline $3.09 \mathrm{E}+02$ & 3 & A & $5.36 \mathrm{E}+02$ & $3.19 \mathrm{E}+02$ & $3.25 \mathrm{E}+02$ & $3.21 \mathrm{E}+02$ & EST-09-03-1-5 & $0.00 \mathrm{E}+00$ & $7.11 \mathrm{E}-02$ & \begin{tabular}{|l|} 
EST-09-03-1-6 \\
\end{tabular} & $2.38 \mathrm{E}+01$ & $1.30 \mathrm{E}-01$ \\
\hline $3.09 \mathrm{E}+02$ & 4 & $\bar{A}$ & $5.46 \mathrm{E}+02$ & $3.21 \mathrm{E}+02$ & $3.23 \mathrm{E}+02$ & $3.18 \mathrm{E}+02$ & $\begin{array}{l}\text { EST-09-03-1-7 } \\
\end{array}$ & $2.10 \mathrm{E}-01$ & $2.72 \mathrm{E}-02$ & \begin{tabular}{|c|} 
EST-09-03-1-8 \\
\end{tabular} & $2.27 \mathrm{E}+01$ & $9.06 \mathrm{E}-02$ \\
\hline $3.09 \mathrm{E}+02$ & 5 & $\bar{A}$ & $5.65 \mathrm{E}+02$ & $3.18 \mathrm{E}+02$ & $3.25 \mathrm{E}+02$ & $3.20 \mathrm{E}+02$ & $\begin{array}{l}\text { EST-09-03-1-9 } \\
\end{array}$ & $1.32 \mathrm{E}+00$ & $1.55 \mathrm{E}-01$ & \begin{tabular}{|l} 
EST-09-03-1-10 \\
\end{tabular} & $8.64 \mathrm{E}+00$ & \begin{tabular}{|l}
$8.60 \mathrm{E}-02$ \\
\end{tabular} \\
\hline EST-09-04 & & & & & & & & & & & & \\
\hline \multicolumn{13}{|l|}{ Fragment \#1 } \\
\hline $2.58 \mathrm{E}+02$ & 1 & $\overline{\mathrm{A}}$ & $5.34 \mathrm{E}+02$ & $2.58 \mathrm{E}+02$ & $2.72 \mathrm{E}+02$ & $2.67 \mathrm{E}+02$ & \begin{tabular}{|l|} 
EST-09-04-1-1 \\
\end{tabular} & 4.35E-01 & $7.58 \mathrm{E}-02$ & \begin{tabular}{|l|} 
EST-09-04-1-2 \\
\end{tabular} & $8.42 \mathrm{E}+01$ & $7.45 \mathrm{E}+0 \mathrm{c}$ \\
\hline $2.58 \mathrm{E}+02$ & 2 & $\bar{A}$ & $4.92 \mathrm{E}+02$ & $2.67 \mathrm{E}+02$ & $2.74 \mathrm{E}+02$ & $2.67 \mathrm{E}+02$ & EST-09-04-1-3 & $6.49 \mathrm{E}-01$ & 9.41E-02 & \begin{tabular}{|l|} 
EST-09-04-1-4 \\
\end{tabular} & $2.92 \mathrm{E}+01$ & $2.74 \mathrm{E}+0 \mathrm{C}$ \\
\hline $2.58 \mathrm{E}+02$ & 3 & $\bar{A}$ & $5.04 \mathrm{E}+02$ & $2.67 \mathrm{E}+02$ & $2.73 \mathrm{E}+02$ & $2.69 \mathrm{E}+02$ & EST-09-04-1-5 & $1.26 \mathrm{E}-01$ & $2.61 \mathrm{E}-02$ & \begin{tabular}{|l|} 
EST-09-04-1-6 \\
\end{tabular} & $1.72 \mathrm{E}+01$ & $1.80 \mathrm{E}+0 \mathrm{C}$ \\
\hline $2.58 \mathrm{E}+02$ & 4 & $\bar{A}$ & $4.86 \mathrm{E}+02$ & $2.69 \mathrm{E}+02$ & $2.72 \mathrm{E}+02$ & $2.67 \mathrm{E}+02$ & EST-09-04-1-7 & $8.69 \mathrm{E}-02$ & 1.87E-02 & \begin{tabular}{|l|} 
EST-09-04-1-8 \\
\end{tabular} & $1.26 \mathrm{E}+01$ & $1.38 \mathrm{E}+0 c$ \\
\hline $2.58 \mathrm{E}+02$ & 5 & $\bar{A}$ & $5.56 \mathrm{E}+02$ & $2.67 \mathrm{E}+02$ & $2.74 \mathrm{E}+02$ & $2.68 \mathrm{E}+02$ & EST-09-04-1-9 & 4.15E-01 & $4.22 \mathrm{E}-02$ & EST-09-04-1-10 & $4.22 \mathrm{E}+00$ & \begin{tabular}{|l}
$4.68 \mathrm{E}-01$ \\
\end{tabular} \\
\hline & & & & & & & & & & & & \\
\hline \multicolumn{13}{|l|}{ EST-09-05 } \\
\hline \multicolumn{13}{|l|}{ Fragment \#1 } \\
\hline $3.88 \mathrm{E}+02$ & 1 & $\bar{A}$ & $5.10 \mathrm{E}+02$ & $3.88 \mathrm{E}+02$ & $4.11 \mathrm{E}+02$ & $4.00 \mathrm{E}+02$ & $\begin{array}{l}\text { EST-09-05-1-1 } \\
\end{array}$ & 1.17E-01 & 4.48E-01 & \begin{tabular}{|c|} 
EST-09-05-1-2 \\
\end{tabular} & $4.01 \mathrm{E}+00$ & $4.72 \mathrm{E}+0 \mathrm{C}$ \\
\hline $3.88 \mathrm{E}+02$ & 2 & $\bar{A}$ & $5.20 \mathrm{E}+02$ & $4.00 \mathrm{E}+02$ & $4.10 \mathrm{E}+02$ & $4.04 \mathrm{E}+02$ & EST-09-05-1-3 & $2.24 \mathrm{E}-01$ & $3.22 \mathrm{E}-02$ & \begin{tabular}{|c|} 
EST-09-05-1-4 \\
\end{tabular} & $4.36 \mathrm{E}+00$ & $3.43 \mathrm{E}+0 \mathrm{c}$ \\
\hline $3.88 \mathrm{E}+02$ & 3 & $\bar{A}$ & $5.10 \mathrm{E}+02$ & $4.04 \mathrm{E}+02$ & $4.08 \mathrm{E}+02$ & $4.00 \mathrm{E}+02$ & EST-09-05-1-5 & $0.00 \mathrm{E}+00$ & 5.95E-02 & \begin{tabular}{|c|} 
EST-09-05-1-6 \\
\end{tabular} & $3.36 \mathrm{E}+00$ & $2.97 \mathrm{E}+0 \mathrm{c}$ \\
\hline $3.88 \mathrm{E}+02$ & 4 & $\bar{A}$ & $5.37 \mathrm{E}+02$ & $4.00 \mathrm{E}+02$ & $4.10 \mathrm{E}+02$ & $4.00 \mathrm{E}+02$ & EST-09-05-1-7 & $0.00 \mathrm{E}+00$ & $2.70 \mathrm{E}-01$ & \begin{tabular}{|l|} 
EST-09-05-1-8 \\
\end{tabular} & $7.66 \mathrm{E}-01$ & 7.95E-01 \\
\hline $3.88 \mathrm{E}+02$ & 5 & $\mathrm{~A}$ & $5.25 \mathrm{E}+02$ & $4.00 \mathrm{E}+02$ & $4.08 \mathrm{E}+02$ & \begin{tabular}{|l}
$4.05 \mathrm{E}+02$ \\
\end{tabular} & EST-09-05-1-9 & $0.00 \mathrm{E}+00$ & \begin{tabular}{|l|}
$2.04 \mathrm{E}-02$ \\
\end{tabular} & \begin{tabular}{|l|} 
EST-09-05-1-10 \\
\end{tabular} & $0.00 \mathrm{E}+00$ & 7.90E-01 \\
\hline & & & & & & & & & & & & \\
\hline \multicolumn{13}{|l|}{$\begin{array}{c}\text { Thin Section } \\
\text { Samples } \\
\end{array}$} \\
\hline \multicolumn{13}{|l|}{ 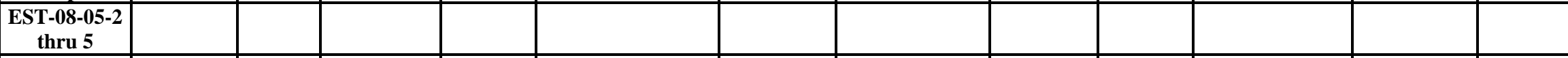 } \\
\hline \multicolumn{13}{|l|}{ EST-08-05-2 } \\
\hline \multicolumn{13}{|l|}{ Fragment \#1 } \\
\hline $6.84 \mathrm{E}+01$ & 1 & $\bar{A}$ & $1.46 \mathrm{E}+02$ & $6.84 \mathrm{E}+01$ & $7.25 \mathrm{E}+01$ & $7.15 \mathrm{E}+01$ & $\begin{array}{l}\text { EST-08-05-2-1 } \\
\end{array}$ & $6.49 \mathrm{E}+01$ & $7.29 \mathrm{E}-01$ & \begin{tabular}{|l|} 
EST-08-05-2-2 \\
\end{tabular} & - & - \\
\hline $6.84 \mathrm{E}+01$ & 2 & $\bar{A}$ & $9.08 \mathrm{E}+01$ & $7.15 \mathrm{E}+01$ & $7.19 \mathrm{E}+01$ & $7.17 \mathrm{E}+01$ & $\begin{array}{l}\text { EST-08-05-2-3 } \\
\end{array}$ & $8.77 \mathrm{E}+00$ & $1.18 \mathrm{E}-01$ & \begin{tabular}{|l|} 
EST-08-05-2-4 \\
\end{tabular} & $4.66 \mathrm{E}+02$ & - \\
\hline $6.84 \mathrm{E}+01$ & 3 & $\bar{A}$ & $1.01 \mathrm{E}+02$ & $7.17 \mathrm{E}+01$ & $7.25 \mathrm{E}+01$ & $7.17 \mathrm{E}+01$ & $\begin{array}{l}\text { EST-08-05-2-5 } \\
\end{array}$ & $2.58 \mathrm{E}+01$ & $2.94 \mathrm{E}-01$ & \begin{tabular}{|c|} 
EST-08-05-2-6 \\
\end{tabular} & $8.36 \mathrm{E}+01$ & $2.56 \mathrm{E}+0 \mathrm{c}$ \\
\hline $6.84 \mathrm{E}+01$ & 4 & $\bar{A}$ & $7.40 \mathrm{E}+01$ & $7.17 \mathrm{E}+01$ & $7.24 \mathrm{E}+01$ & $7.13 \mathrm{E}+01$ & EST-08-05-2-7 & $3.23 \mathrm{E}+00$ & 1.49E-01 & EST-08-05-2-8 & $3.79 \mathrm{E}+01$ & $9.86 \mathrm{E}-01$ \\
\hline $6.84 \mathrm{E}+01$ & 5 & $\mathrm{~A}$ & $1.04 \mathrm{E}+02$ & $7.13 \mathrm{E}+01$ & $7.21 \mathrm{E}+01$ & \begin{tabular}{|l|}
$7.13 \mathrm{E}+01$ \\
\end{tabular} & EST-08-05-2-9 & 7.31E-01 & 7.58E-02 & EST-08-05-2-10 & $3.26 \mathrm{E}+01$ & $7.85 \mathrm{E}-01$ \\
\hline & & & & & & & & & & & & \\
\hline EST-08-05-3 & & & & & & & & & & & & \\
\hline
\end{tabular}


Table A2. Extraction Results for ES-31B.

\begin{tabular}{|c|c|c|c|c|c|c|c|c|c|c|c|c|}
\hline $\begin{array}{c}\text { Dry Sample } \\
\text { Mass (g) } \\
\text { ES-31B }\end{array}$ & $\begin{array}{c}\text { Extraction } \\
\text { Step \# }\end{array}$ & $\begin{array}{l}\text { Soln. } \\
\text { Type\# }\end{array}$ & $\begin{array}{l}\text { Vol. of Soln. } \\
\text { Added for } \\
\text { Sat. (mL) }\end{array}$ & $\begin{array}{c}\text { Pre-Sat. } \\
\text { Sample } \\
\text { Mass (g) }\end{array}$ & \begin{tabular}{|c} 
Post-Sat. \& \\
Draining Free Liq. \\
Sample Mass (g)
\end{tabular} & $\begin{array}{l}\text { Post-Cent. } \\
\text { Sample } \\
\text { Mass (g) }\end{array}$ & Sat. Sample \# & $\begin{array}{c}\text { Liq. [Re] } \\
\text { (Sat.) } \\
\text { ( } \mu \mathrm{g} / \mathrm{L})\end{array}$ & $\begin{array}{c}\text { Liq. [Cs] } \\
\text { (Sat.) } \\
(\mu \mathrm{g} / \mathrm{L})\end{array}$ & Cent. Sample \# & $\begin{array}{c}\text { Liq. [Re] } \\
\text { (Cent.) } \\
\text { ( } \mu \mathrm{g} / \mathrm{L})\end{array}$ & $\begin{array}{c}\text { Liq. [Cs] } \\
\text { (Cent.) } \\
\text { ( } \mu \mathrm{g} / \mathrm{L})\end{array}$ \\
\hline \multicolumn{13}{|l|}{ Fragment \#1 } \\
\hline $3.85 \mathrm{E}+01$ & 1 & $\mathrm{~A}$ & $1.08 \mathrm{E}+02$ & $3.85 \mathrm{E}+01$ & $4.08 \mathrm{E}+01$ & $4.02 \mathrm{E}+01$ & EST-08-05-3-1 & $4.98 \mathrm{E}+00$ & 9.17E-02 & \begin{tabular}{|l|} 
EST-08-05-3-2 \\
\end{tabular} & - & - \\
\hline $3.85 \mathrm{E}+01$ & 2 & $\overline{\mathrm{A}}$ & $5.76 \mathrm{E}+01$ & $4.02 \mathrm{E}+01$ & $4.04 \mathrm{E}+01$ & $4.02 \mathrm{E}+01$ & \begin{tabular}{|l} 
EST-08-05-3-3 \\
\end{tabular} & $1.11 \mathrm{E}+00$ & $3.01 \mathrm{E}-02$ & \begin{tabular}{|c|} 
EST-08-05-3-4 \\
\end{tabular} & $2.17 \mathrm{E}+01$ & - \\
\hline $3.85 \mathrm{E}+01$ & 3 & $\overline{\mathrm{A}}$ & $6.56 \mathrm{E}+01$ & $4.02 \mathrm{E}+01$ & $4.07 \mathrm{E}+01$ & $4.03 \mathrm{E}+01$ & $\begin{array}{l}\text { EST-08-05-3-5 } \\
\end{array}$ & $3.05 \mathrm{E}+00$ & $7.41 \mathrm{E}-02$ & \begin{tabular}{|c|} 
EST-08-05-3-6 \\
\end{tabular} & $7.09 \mathrm{E}+00$ & - \\
\hline $3.85 \mathrm{E}+01$ & 4 & $\overline{\mathrm{A}}$ & $1.01 \mathrm{E}+02$ & $4.03 \mathrm{E}+01$ & $4.08 \mathrm{E}+01$ & $4.03 \mathrm{E}+01$ & \begin{tabular}{|l|} 
EST-08-05-3-7 \\
\end{tabular} & $\begin{array}{l}8.47 \mathrm{E}-02 \\
\end{array}$ & $3.04 \mathrm{E}-02$ & \begin{tabular}{|c|} 
EST-08-05-3-8 \\
\end{tabular} & $2.13 \mathrm{E}+00$ & $4.89 \mathrm{E}-01$ \\
\hline $3.85 \mathrm{E}+01$ & 5 & $\bar{A}$ & $5.39 \mathrm{E}+01$ & $4.03 \mathrm{E}+01$ & $4.07 \mathrm{E}+01$ & $4.03 \mathrm{E}+01$ & EST-08-05-3-9 & $0.00 \mathrm{E}+00$ & 3.18E-02 & EST-08-05-3-10 & $1.81 \mathrm{E}+00$ & - \\
\hline \multicolumn{13}{|l|}{\begin{tabular}{|l|} 
EST-08-05-4 \\
\end{tabular}} \\
\hline \multicolumn{13}{|l|}{ Fragment \#1 } \\
\hline $2.98 \mathrm{E}+01$ & 1 & $\bar{A}$ & $7.98 \mathrm{E}+01$ & $2.98 \mathrm{E}+01$ & $3.16 \mathrm{E}+01$ & $\begin{array}{l}3.13 \mathrm{E}+01 \\
\end{array}$ & EST-08-05-4-1 & $1.55 \mathrm{E}+00$ & 5.93E-02 & \begin{tabular}{|c|} 
EST-08-05-4-2 \\
\end{tabular} & - & - \\
\hline $2.98 \mathrm{E}+01$ & 2 & $\mathrm{~A}$ & $8.84 \mathrm{E}+01$ & $3.13 \mathrm{E}+01$ & $3.14 \mathrm{E}+01$ & $3.12 \mathrm{E}+01$ & $\begin{array}{l}\text { EST-08-05-4-3 } \\
\end{array}$ & $1.40 \mathrm{E}-01$ & \begin{tabular}{|l|}
$1.76 \mathrm{E}-02$ \\
\end{tabular} & \begin{tabular}{|c|} 
EST-08-05-4-4 \\
\end{tabular} & 5.89E-01 & $4.23 \mathrm{E}-02$ \\
\hline $2.98 \mathrm{E}+01$ & 3 & $\bar{A}$ & $0.00 \mathrm{E}+00$ & $3.12 \mathrm{E}+01$ & $3.17 \mathrm{E}+01$ & $3.12 \mathrm{E}+01$ & $\begin{array}{l}\text { EST-08-05-4-5 } \\
\end{array}$ & 7.06E-01 & \begin{tabular}{|l|}
$4.68 \mathrm{E}-02$ \\
\end{tabular} & \begin{tabular}{|c|} 
EST-08-05-4-6 \\
\end{tabular} & $1.06 \mathrm{E}+00$ & \begin{tabular}{|l|}
$1.58 \mathrm{E}-01$ \\
\end{tabular} \\
\hline $2.98 \mathrm{E}+01$ & 4 & $\mathrm{~A}$ & $4.52 \mathrm{E}+01$ & $3.12 \mathrm{E}+01$ & $3.17 \mathrm{E}+01$ & $3.12 \mathrm{E}+01$ & $\begin{array}{l}\text { EST-08-05-4-7 } \\
\end{array}$ & $0.00 \mathrm{E}+00$ & 2.29E-02 & \begin{tabular}{|c|} 
EST-08-05-4-8 \\
\end{tabular} & $0.00 \mathrm{E}+00$ & \begin{tabular}{|l|}
$1.36 \mathrm{E}-01$ \\
\end{tabular} \\
\hline $2.98 \mathrm{E}+01$ & 5 & $\mathrm{~A}$ & $6.57 \mathrm{E}+01$ & $3.12 \mathrm{E}+01$ & $3.18 \mathrm{E}+01$ & $3.14 \mathrm{E}+01$ & EST-08-05-4-9 & $0.00 \mathrm{E}+00$ & 1.69E-02 & \begin{tabular}{|l|} 
EST-08-05-4-10 \\
\end{tabular} & $0.00 \mathrm{E}+00$ & $1.13 \mathrm{E}-01$ \\
\hline & & & & & & & & & & & & \\
\hline \multicolumn{13}{|l|}{\begin{tabular}{|l|} 
EST-08-05-5 \\
\end{tabular}} \\
\hline \multicolumn{13}{|l|}{ Fragment \#1 } \\
\hline $4.75 \mathrm{E}+01$ & 1 & $\bar{A}$ & $1.25 \mathrm{E}+02$ & $4.75 \mathrm{E}+01$ & $5.02 \mathrm{E}+01$ & $4.97 \mathrm{E}+01$ & EST-08-05-5-1 & 9.73E-01 & \begin{tabular}{|l|}
$4.75 \mathrm{E}-02$ \\
\end{tabular} & \begin{tabular}{|c|} 
EST-08-05-5-2 \\
\end{tabular} & - & - \\
\hline $4.75 \mathrm{E}+01$ & 2 & $\bar{A}$ & $7.45 \mathrm{E}+01$ & $4.97 \mathrm{E}+01$ & $4.98 \mathrm{E}+01$ & $4.97 \mathrm{E}+01$ & EST-08-05-5-3 & $2.58 \mathrm{E}-01$ & 1.70E-02 & \begin{tabular}{|l|} 
EST-08-05-5-4 \\
\end{tabular} & $1.33 \mathrm{E}+00$ & $3.22 \mathrm{E}-02$ \\
\hline $4.75 \mathrm{E}+01$ & 3 & $\bar{A}$ & - & $4.97 \mathrm{E}+01$ & $5.00 \mathrm{E}+01$ & $4.96 \mathrm{E}+01$ & EST-08-05-5-5 & 9.97E-01 & \begin{tabular}{|l|}
$3.38 \mathrm{E}-02$ \\
\end{tabular} & \begin{tabular}{|l|} 
EST-08-05-5-6 \\
\end{tabular} & $6.68 \mathrm{E}+00$ & 3.53E-01 \\
\hline $4.75 \mathrm{E}+01$ & 4 & $\bar{A}$ & $8.68 \mathrm{E}+01$ & $4.96 \mathrm{E}+01$ & $5.01 \mathrm{E}+01$ & $4.97 \mathrm{E}+01$ & EST-08-05-5-7 & $6.84 \mathrm{E}-02$ & \begin{tabular}{|l|}
$2.80 \mathrm{E}-02$ \\
\end{tabular} & \begin{tabular}{|l|} 
EST-08-05-5-8 \\
\end{tabular} & $2.97 \mathrm{E}+00$ & 2.78E-01 \\
\hline $4.75 \mathrm{E}+01$ & 5 & $\mathrm{~A}$ & $8.59 \mathrm{E}+01$ & $4.97 \mathrm{E}+01$ & $5.01 \mathrm{E}+01$ & $4.97 \mathrm{E}+01$ & EST-08-05-5-9 & $0.00 \mathrm{E}+00$ & $0.00 \mathrm{E}+00$ & \begin{tabular}{|l|} 
EST-08-05-5-10 \\
\end{tabular} & $2.80 \mathrm{E}+00$ & 7.72E-01 \\
\hline $\begin{array}{l}\text { Soln - Solutio } \\
\text { Vol. - Volume } \\
\text { Sat - Saturatio } \\
\text { Liq. - Liquid } \\
\text { Cent. - Centrif } \\
\text { [Re] and [Cs] }\end{array}$ & tion & 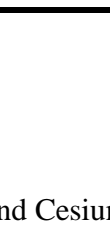 & 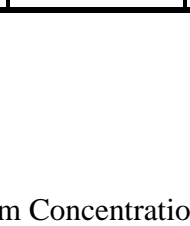 & & & & & & & & & \\
\hline
\end{tabular}


Table A3. Extraction Results for ES-31C.

\begin{tabular}{|c|c|c|c|c|c|c|c|c|c|c|}
\hline $\begin{array}{c}\text { Dry Sample } \\
\text { Mass (g) } \\
\text { ES-31C } \\
\end{array}$ & $\begin{array}{c}\text { Extraction } \\
\text { Step \# }\end{array}$ & $\begin{array}{l}\text { Soln. } \\
\text { Type }\end{array}$ & $\begin{array}{l}\text { Vol. of Soln. } \\
\text { Added for } \\
\text { Sat. (mL) }\end{array}$ & $\begin{array}{c}\text { Pre-Sat. } \\
\text { Sample } \\
\text { Mass (g) }\end{array}$ & \begin{tabular}{|} 
Post-Sat. \& Draining \\
Free Liq. Sample \\
Mass (g)
\end{tabular} & $\begin{array}{l}\text { Post-Cent. } \\
\text { Sample } \\
\text { Mass (g) }\end{array}$ & Sat. Sample \# & $\begin{array}{l}\text { Liq. [Re] } \\
\text { (Sat.) } \\
(\mu \mathrm{g} / \mathrm{L})\end{array}$ & Cent. Sample \# & $\begin{array}{c}\text { Liq. [Re] } \\
\text { (Cent.) } \\
(\mu \mathrm{g} / \mathrm{L})\end{array}$ \\
\hline EST-11-01A & & & & & & & & & & \\
\hline Fragment \#1 & & & & & & & & & & \\
\hline $3.78 \mathrm{E}+02$ & 1 & $\mathrm{~A}$ & $5.11 \mathrm{E}+02$ & $3.78 \mathrm{E}+02$ & $3.99 \mathrm{E}+02$ & $3.91 \mathrm{E}+02$ & EST-11-01A-1 & $1.34 \mathrm{E}+01$ & EST-11-01A-2 & $4.21 \mathrm{E}+02$ \\
\hline $3.78 \mathrm{E}+02$ & 2 & A & $5.06 \mathrm{E}+02$ & $3.91 \mathrm{E}+02$ & $3.99 \mathrm{E}+02$ & $3.91 \mathrm{E}+02$ & EST-11-01A-3 & $4.85 \mathrm{E}+00$ & EST-11-01A-4 & $1.50 \mathrm{E}+03$ \\
\hline $3.78 \mathrm{E}+02$ & 3 & $\mathrm{~A}$ & $4.88 \mathrm{E}+02$ & $3.91 \mathrm{E}+02$ & $3.99 \mathrm{E}+02$ & $3.91 \mathrm{E}+02$ & EST-11-01A-5 & $1.97 \mathrm{E}+01$ & EST-11-01A-6 & $1.85 \mathrm{E}+03$ \\
\hline $3.78 \mathrm{E}+02$ & 4 & $\mathrm{~A}$ & $5.10 \mathrm{E}+02$ & $3.91 \mathrm{E}+02$ & $3.99 \mathrm{E}+02$ & $3.91 \mathrm{E}+02$ & EST-11-01A-7 & $4.75 \mathrm{E}+00$ & EST-11-01A-8 & $1.91 \mathrm{E}+03$ \\
\hline $3.78 \mathrm{E}+02$ & 5 & $\mathrm{~A}$ & $5.64 \mathrm{E}+02$ & $3.91 \mathrm{E}+02$ & $3.99 \mathrm{E}+02$ & $3.90 \mathrm{E}+02$ & EST-11-01A-9 & $3.86 \mathrm{E}+00$ & EST-11-01A-10 & $1.47 \mathrm{E}+03$ \\
\hline & & & & & & & & & & \\
\hline EST-11-01B & & & & & & & & & & \\
\hline Fragment \#1 & & & & & & & & & & \\
\hline $4.34 \mathrm{E}+02$ & 1 & $\mathrm{~A}$ & - & $4.34 \mathrm{E}+02$ & $4.58 \mathrm{E}+02$ & $4.51 \mathrm{E}+02$ & EST-11-01B-1 & $7.35 \mathrm{E}+00$ & EST-11-01B-2 & $2.40 \mathrm{E}+02$ \\
\hline $4.34 \mathrm{E}+02$ & 2 & A & - & $4.51 \mathrm{E}+02$ & $4.58 \mathrm{E}+02$ & $4.51 \mathrm{E}+02$ & EST-11-01B-3 & $2.52 \mathrm{E}+00$ & EST-11-01B-4 & $3.97 \mathrm{E}+02$ \\
\hline $4.34 \mathrm{E}+02$ & 3 & $\mathrm{~A}$ & - & $4.51 \mathrm{E}+02$ & $4.58 \mathrm{E}+02$ & $4.50 \mathrm{E}+02$ & EST-11-01B-5 & $2.08 \mathrm{E}+00$ & EST-11-01B-6 & $1.05 \mathrm{E}+03$ \\
\hline $4.34 \mathrm{E}+02$ & 4 & $\mathrm{~A}$ & - & $4.50 \mathrm{E}+02$ & $4.58 \mathrm{E}+02$ & $4.51 \mathrm{E}+02$ & EST-11-01B-7 & $1.05 \mathrm{E}+01$ & EST-11-01B-8 & $1.39 \mathrm{E}+03$ \\
\hline $4.34 \mathrm{E}+02$ & 5 & $\mathrm{~A}$ & - & $4.51 \mathrm{E}+02$ & $4.58 \mathrm{E}+02$ & \begin{tabular}{|l|}
$4.55 \mathrm{E}+02$ \\
\end{tabular} & EST-11-01B-9 & $4.13 \mathrm{E}+00$ & \begin{tabular}{|l|} 
EST-11-01B-10 \\
\end{tabular} & $1.16 \mathrm{E}+03$ \\
\hline & & & & & & & & & & \\
\hline EST-11-02 & & & & & & & & & & \\
\hline Fragment \#1 & & & & & & & & & & \\
\hline $3.81 \mathrm{E}+02$ & 1 & $\mathrm{~A}$ & $3.29 \mathrm{E}+02$ & $3.81 \mathrm{E}+02$ & $4.02 \mathrm{E}+02$ & $3.96 \mathrm{E}+02$ & EST-11-02-1 & $4.39 \mathrm{E}+01$ & EST-11-02-2 & $4.35 \mathrm{E}+03$ \\
\hline $3.81 \mathrm{E}+02$ & 2 & $\mathrm{~A}$ & $3.36 \mathrm{E}+02$ & $3.96 \mathrm{E}+02$ & $4.02 \mathrm{E}+02$ & $3.96 \mathrm{E}+02$ & EST-11-02-3 & $2.86 \mathrm{E}+01$ & EST-11-02-4 & $5.18 \mathrm{E}+03$ \\
\hline $3.81 \mathrm{E}+02$ & 3 & $\mathrm{~A}$ & $5.21 \mathrm{E}+02$ & $3.96 \mathrm{E}+02$ & $4.01 \mathrm{E}+02$ & \begin{tabular}{|l|}
$3.94 \mathrm{E}+02$ \\
\end{tabular} & EST-11-02-5 & $3.98 \mathrm{E}+01$ & EST-11-02-6 & $2.17 \mathrm{E}+03$ \\
\hline $3.81 \mathrm{E}+02$ & 4 & $\mathrm{~A}$ & $3.71 \mathrm{E}+02$ & $3.94 \mathrm{E}+02$ & $4.00 \mathrm{E}+02$ & $3.93 \mathrm{E}+02$ & EST-11-02-7 & $9.11 \mathrm{E}+00$ & EST-11-02-8 & $1.78 \mathrm{E}+03$ \\
\hline $3.81 \mathrm{E}+02$ & 5 & $\mathrm{~A}$ & $2.52 \mathrm{E}+02$ & $3.93 \mathrm{E}+02$ & $4.00 \mathrm{E}+02$ & $3.93 \mathrm{E}+02$ & EST-11-02-9 & $9.37 \mathrm{E}+00$ & EST-11-02-10 & $9.30 \mathrm{E}+02$ \\
\hline & & & & & & & & & & \\
\hline EST-11-03 & & & & & & & & & & \\
\hline Fragment \#1 & & & & & & & & & & \\
\hline $2.39 \mathrm{E}+02$ & 1 & $\mathrm{~A}$ & $6.36 \mathrm{E}+02$ & $2.39 \mathrm{E}+02$ & $2.52 \mathrm{E}+02$ & $2.50 \mathrm{E}+02$ & EST-11-03-1 & $9.59 \mathrm{E}+00$ & EST-11-03-2 & $8.72 \mathrm{E}+03$ \\
\hline $2.39 \mathrm{E}+02$ & 2 & $\mathrm{~A}$ & $6.17 \mathrm{E}+02$ & $2.50 \mathrm{E}+02$ & $2.52 \mathrm{E}+02$ & \begin{tabular}{|l|}
$2.49 \mathrm{E}+02$ \\
\end{tabular} & EST-11-03-3 & $8.73 \mathrm{E}+00$ & EST-11-03-4 & $3.53 \mathrm{E}+03$ \\
\hline $2.39 \mathrm{E}+02$ & 3 & $\mathrm{~A}$ & $6.14 \mathrm{E}+02$ & $2.49 \mathrm{E}+02$ & $2.51 \mathrm{E}+02$ & $2.48 \mathrm{E}+02$ & EST-11-03-5 & $3.89 \mathrm{E}+00$ & EST-11-03-6 & $1.39 \mathrm{E}+03$ \\
\hline
\end{tabular}


Table A3. Extraction Results for ES-31C.

\begin{tabular}{|c|c|c|c|c|c|c|c|c|c|c|}
\hline $\begin{array}{c}\text { Dry Sample } \\
\text { Mass (g) } \\
\text { ES-31C } \\
\end{array}$ & $\begin{array}{c}\text { Extraction } \\
\text { Step \# }\end{array}$ & $\begin{array}{c}\text { Soln. } \\
\text { Type¥ }\end{array}$ & $\begin{array}{l}\text { Vol. of Soln. } \\
\text { Added for } \\
\text { Sat. (mL) }\end{array}$ & $\begin{array}{c}\text { Pre-Sat. } \\
\text { Sample } \\
\text { Mass (g) }\end{array}$ & $\begin{array}{c}\text { Post-Sat. \& Draining } \\
\text { Free Liq. Sample } \\
\text { Mass (g) }\end{array}$ & $\begin{array}{l}\text { Post-Cent. } \\
\text { Sample } \\
\text { Mass (g) }\end{array}$ & Sat. Sample \# & $\begin{array}{l}\text { Liq. [Re] } \\
\text { (Sat.) } \\
(\mu \mathrm{g} / \mathrm{L})\end{array}$ & Cent. Sample \# & $\begin{array}{c}\text { Liq. [Re] } \\
\text { (Cent.) } \\
(\mu \mathrm{g} / \mathrm{L})\end{array}$ \\
\hline $2.39 \mathrm{E}+02$ & 4 & A & $5.99 \mathrm{E}+02$ & $2.48 \mathrm{E}+02$ & $2.51 \mathrm{E}+02$ & $2.49 \mathrm{E}+02$ & EST-11-03-7 & $3.81 \mathrm{E}+00$ & EST-11-03-8 & $2.68 \mathrm{E}+02$ \\
\hline $2.39 \mathrm{E}+02$ & 5 & A & $5.95 \mathrm{E}+02$ & $2.49 \mathrm{E}+02$ & $2.51 \mathrm{E}+02$ & $2.48 \mathrm{E}+02$ & EST-11-03-9 & 2.95E-01 & EST-11-03-10 & $1.20 \mathrm{E}+02$ \\
\hline & & & & & & & & & & \\
\hline EST-11-04A & & & & & & & & & & \\
\hline Fragment \#1 & & & & & & & & & & \\
\hline $4.91 \mathrm{E}+02$ & 1 & A & $4.14 \mathrm{E}+02$ & $4.91 \mathrm{E}+02$ & $5.19 \mathrm{E}+02$ & $5.13 \mathrm{E}+02$ & EST-11-04A-1 & $4.46 \mathrm{E}+00$ & EST-11-04A-2 & $3.19 \mathrm{E}+02$ \\
\hline $4.91 \mathrm{E}+02$ & 2 & A & $4.35 \mathrm{E}+02$ & $5.13 \mathrm{E}+02$ & $5.20 \mathrm{E}+02$ & $5.11 \mathrm{E}+02$ & EST-11-04A-3 & $2.91 \mathrm{E}+00$ & EST-11-04A-4 & $3.81 \mathrm{E}+02$ \\
\hline $4.91 \mathrm{E}+02$ & 3 & A & $4.02 \mathrm{E}+02$ & $5.11 \mathrm{E}+02$ & $5.20 \mathrm{E}+02$ & $5.09 \mathrm{E}+02$ & EST-11-04A-5 & $4.86 \mathrm{E}+00$ & EST-11-04A-6 & $1.85 \mathrm{E}+02$ \\
\hline $4.91 \mathrm{E}+02$ & 4 & A & $4.07 \mathrm{E}+02$ & $5.09 \mathrm{E}+02$ & $5.19 \mathrm{E}+02$ & $5.09 \mathrm{E}+02$ & EST-11-04A-7 & $1.16 \mathrm{E}+00$ & EST-11-04A-8 & $7.68 \mathrm{E}+01$ \\
\hline $4.91 \mathrm{E}+02$ & 5 & A & $4.24 \mathrm{E}+02$ & $5.09 \mathrm{E}+02$ & $5.19 \mathrm{E}+02$ & $5.10 \mathrm{E}+02$ & EST-11-04A-9 & 7.32E-01 & EST-11-04A-10 & $1.96 \mathrm{E}+01$ \\
\hline & & & & & & & & & & \\
\hline EST-11-04B & & & & & & & & & & \\
\hline Fragment \#1 & & & & & & & & & & \\
\hline $2.95 \mathrm{E}+02$ & 1 & $\mathrm{~A}$ & $4.36 \mathrm{E}+02$ & $2.95 \mathrm{E}+02$ & $3.12 \mathrm{E}+02$ & $2.95 \mathrm{E}+02$ & EST-11-04B-1 & $2.39 \mathrm{E}+01$ & EST-11-04B-2 & $1.34 \mathrm{E}+03$ \\
\hline $2.95 \mathrm{E}+02$ & 2 & $\mathrm{~A}$ & $3.77 \mathrm{E}+02$ & $3.09 \mathrm{E}+02$ & $3.13 \mathrm{E}+02$ & $3.09 \mathrm{E}+02$ & EST-11-04B-3 & $1.70 \mathrm{E}+01$ & EST-11-04B-4 & $2.17 \mathrm{E}+03$ \\
\hline $2.95 \mathrm{E}+02$ & 3 & $\mathrm{~A}$ & $3.93 \mathrm{E}+02$ & $3.09 \mathrm{E}+02$ & $3.13 \mathrm{E}+02$ & $3.09 \mathrm{E}+02$ & EST-11-04B-5 & $2.80 \mathrm{E}+01$ & EST-11-04B-6 & $1.21 \mathrm{E}+03$ \\
\hline $2.95 \mathrm{E}+02$ & 4 & $\mathrm{~A}$ & $3.99 \mathrm{E}+02$ & $3.06 \mathrm{E}+02$ & $3.12 \mathrm{E}+02$ & $3.06 \mathrm{E}+02$ & EST-11-04B-7 & $3.94 \mathrm{E}+00$ & EST-11-04B-8 & $8.66 \mathrm{E}+02$ \\
\hline $2.95 \mathrm{E}+02$ & 5 & A & $4.04 \mathrm{E}+02$ & $3.04 \mathrm{E}+02$ & $3.12 \mathrm{E}+02$ & $3.07 \mathrm{E}+02$ & EST-11-04B-9 & $3.54 \mathrm{E}+00$ & EST-11-04B-10 & $2.41 \mathrm{E}+02$ \\
\hline & & & & & & & & & & \\
\hline EST-12-01A & & & & & & & & & & \\
\hline Fragment \#1 & & & & & & & & & & \\
\hline $3.01 \mathrm{E}+02$ & 1 & $\mathrm{~A}$ & $4.50 \mathrm{E}+02$ & $3.01 \mathrm{E}+02$ & $3.16 \mathrm{E}+02$ & $3.13 \mathrm{E}+02$ & EST-12-01A-1 & $3.79 \mathrm{E}+00$ & EST-12-01A-2 & $6.62 \mathrm{E}+02$ \\
\hline $3.01 \mathrm{E}+02$ & 2 & $\mathrm{~A}$ & $3.55 \mathrm{E}+02$ & $3.13 \mathrm{E}+02$ & $3.17 \mathrm{E}+02$ & $3.14 \mathrm{E}+02$ & EST-12-01A-3 & $6.19 \mathrm{E}+00$ & EST-12-01A-4 & $4.34 \mathrm{E}+02$ \\
\hline $3.01 \mathrm{E}+02$ & 3 & $\mathrm{~A}$ & $4.54 \mathrm{E}+02$ & $3.14 \mathrm{E}+02$ & $3.17 \mathrm{E}+02$ & $3.13 \mathrm{E}+02$ & EST-12-01A-5 & $1.08 \mathrm{E}+01$ & EST-12-01A-6 & $4.46 \mathrm{E}+02$ \\
\hline $3.01 \mathrm{E}+02$ & 4 & $\mathrm{~A}$ & $4.55 \mathrm{E}+02$ & $3.13 \mathrm{E}+02$ & $3.17 \mathrm{E}+02$ & $3.12 \mathrm{E}+02$ & EST-12-01A-7 & $1.48 \mathrm{E}+00$ & EST-12-01A-8 & - \\
\hline $3.01 \mathrm{E}+02$ & 5 & $\mathrm{~A}$ & $4.14 \mathrm{E}+02$ & $3.12 \mathrm{E}+02$ & $3.16 \mathrm{E}+02$ & $3.13 \mathrm{E}+02$ & EST-12-01A-9 & $5.06 \mathrm{E}+00$ & EST-12-01A-10 & $1.12 \mathrm{E}+02$ \\
\hline & & & & & & & & & & \\
\hline & & & & & & & & & & \\
\hline & & & & & & & & & & \\
\hline & & & & & & & & & & \\
\hline
\end{tabular}


Table A3. Extraction Results for ES-31C.

\begin{tabular}{|c|c|c|c|c|c|c|c|c|c|c|}
\hline $\begin{array}{c}\text { Dry Sample } \\
\text { Mass (g) } \\
\text { ES-31C }\end{array}$ & $\begin{array}{c}\text { Extraction } \\
\text { Step \# }\end{array}$ & \begin{tabular}{|} 
Soln. \\
Type¥
\end{tabular} & $\begin{array}{l}\text { Vol. of Soln. } \\
\text { Added for } \\
\text { Sat. (mL) }\end{array}$ & $\begin{array}{l}\text { Pre-Sat. } \\
\text { Sample } \\
\text { Mass (g) }\end{array}$ & \begin{tabular}{|c} 
Post-Sat. \& Draining \\
Free Liq. Sample \\
Mass (g)
\end{tabular} & $\begin{array}{l}\text { Post-Cent. } \\
\text { Sample } \\
\text { Mass (g) }\end{array}$ & Sat. Sample \# & $\begin{array}{c}\text { Liq. [Re] } \\
\text { (Sat.) } \\
(\mu \mathrm{g} / \mathrm{L})\end{array}$ & Cent. Sample \# & $\begin{array}{c}\text { Liq. [Re] } \\
\text { (Cent.) } \\
(\mu \mathrm{g} / \mathrm{L})\end{array}$ \\
\hline \multicolumn{11}{|l|}{ EST-12-01B } \\
\hline \multicolumn{11}{|l|}{ Fragment \#1 } \\
\hline $3.54 \mathrm{E}+02$ & 1 & A & $3.35 \mathrm{E}+02$ & $3.54 \mathrm{E}+02$ & $3.71 \mathrm{E}+02$ & $3.66 \mathrm{E}+02$ & EST-12-01B-1 & $5.60 \mathrm{E}+00$ & EST-12-01B-2 & $4.99 \mathrm{E}+02$ \\
\hline $3.54 \mathrm{E}+02$ & 2 & $\mathrm{~A}$ & $4.25 \mathrm{E}+02$ & $3.66 \mathrm{E}+02$ & $3.71 \mathrm{E}+02$ & $3.67 \mathrm{E}+02$ & EST-12-01B-3 & $4.17 \mathrm{E}+00$ & EST-12-01B-4 & $3.42 \mathrm{E}+02$ \\
\hline $3.54 \mathrm{E}+02$ & 3 & $\mathrm{~A}$ & $3.90 \mathrm{E}+02$ & $3.67 \mathrm{E}+02$ & $3.72 E+02$ & $3.67 \mathrm{E}+02$ & EST-12-01B-5 & $8.90 \mathrm{E}+00$ & EST-12-01B-6 & $2.30 \mathrm{E}+02$ \\
\hline $3.54 \mathrm{E}+02$ & 4 & $\mathrm{~A}$ & $3.05 \mathrm{E}+02$ & $3.67 \mathrm{E}+02$ & $3.72 \mathrm{E}+02$ & $3.66 \mathrm{E}+02$ & EST-12-01B-7 & $2.28 \mathrm{E}+00$ & EST-12-01B-8 & $1.48 \mathrm{E}+02$ \\
\hline $3.54 \mathrm{E}+02$ & 5 & A & $3.96 \mathrm{E}+02$ & $3.66 \mathrm{E}+02$ & $3.71 \mathrm{E}+02$ & $3.66 \mathrm{E}+02$ & EST-12-01B-9 & $1.21 \mathrm{E}+00$ & EST-12-01B-10 & $1.03 \mathrm{E}+02$ \\
\hline \multicolumn{11}{|l|}{\begin{tabular}{|l|} 
EST-12-02A \\
\end{tabular}} \\
\hline \multicolumn{11}{|l|}{ Fragment \#1 } \\
\hline $3.49 \mathrm{E}+02$ & 1 & $\mathrm{~A}$ & $5.33 \mathrm{E}+02$ & $3.49 \mathrm{E}+02$ & $3.68 \mathrm{E}+02$ & $3.62 \mathrm{E}+02$ & \begin{tabular}{|l} 
EST-12-02A-1 \\
\end{tabular} & $2.04 \mathrm{E}+01$ & EST-12-02A-2 & $1.21 \mathrm{E}+03$ \\
\hline $3.49 \mathrm{E}+02$ & 2 & $\mathrm{~A}$ & $5.34 \mathrm{E}+02$ & $3.62 \mathrm{E}+02$ & $3.68 \mathrm{E}+02$ & $3.61 \mathrm{E}+02$ & \begin{tabular}{|l} 
EST-12-02A-3 \\
\end{tabular} & $9.16 \mathrm{E}+00$ & EST-12-02A-4 & $2.94 \mathrm{E}+03$ \\
\hline $3.49 \mathrm{E}+02$ & 3 & $\mathrm{~A}$ & $5.08 \mathrm{E}+02$ & $3.61 \mathrm{E}+02$ & $3.68 \mathrm{E}+02$ & $3.62 \mathrm{E}+02$ & EST-12-02A-5 & $2.95 \mathrm{E}+01$ & EST-12-02A-6 & $2.29 \mathrm{E}+03$ \\
\hline $3.49 \mathrm{E}+02$ & 4 & $\mathrm{~A}$ & $5.19 \mathrm{E}+02$ & $3.62 \mathrm{E}+02$ & $3.69 \mathrm{E}+02$ & \begin{tabular}{|l|}
$3.63 \mathrm{E}+02$ \\
\end{tabular} & \begin{tabular}{|l|} 
EST-12-02A-7 \\
\end{tabular} & $5.93 \mathrm{E}+00$ & EST-12-02A-8 & $1.23 \mathrm{E}+03$ \\
\hline $3.49 \mathrm{E}+02$ & 5 & A & $5.09 \mathrm{E}+02$ & $3.63 E+02$ & $3.68 \mathrm{E}+02$ & $3.63 \mathrm{E}+02$ & EST-12-02A-9 & $4.17 \mathrm{E}+00$ & EST-12-02A-10 & $6.06 \mathrm{E}+02$ \\
\hline \multicolumn{11}{|l|}{ EST-12-02B } \\
\hline \multicolumn{11}{|l|}{ Fragment \#1 } \\
\hline $4.93 E+02$ & 1 & A & $4.79 \mathrm{E}+02$ & $4.93 E+02$ & $5.20 \mathrm{E}+02$ & $5.09 \mathrm{E}+02$ & EST-12-02B-1 & $6.56 \mathrm{E}+00$ & EST-12-02B-2 & $4.41 \mathrm{E}+03$ \\
\hline $4.93 E+02$ & 2 & A & $4.78 \mathrm{E}+02$ & $5.09 \mathrm{E}+02$ & $5.20 \mathrm{E}+02$ & $5.09 \mathrm{E}+02$ & EST-12-02B-3 & $9.31 \mathrm{E}+00$ & EST-12-02B-4 & $2.02 \mathrm{E}+03$ \\
\hline $4.93 \mathrm{E}+02$ & 3 & $\mathrm{~A}$ & $4.94 \mathrm{E}+02$ & $5.09 \mathrm{E}+02$ & $5.19 \mathrm{E}+02$ & $5.09 \mathrm{E}+02$ & EST-12-02B-5 & $4.40 \mathrm{E}+00$ & EST-12-02B-6 & $7.51 \mathrm{E}+02$ \\
\hline $4.93 \mathrm{E}+02$ & 4 & A & $4.83 \mathrm{E}+02$ & $5.09 \mathrm{E}+02$ & $5.20 \mathrm{E}+02$ & $5.10 \mathrm{E}+02$ & EST-12-02B-7 & $4.97 \mathrm{E}+00$ & EST-12-02B-8 & $2.20 \mathrm{E}+02$ \\
\hline $4.93 \mathrm{E}+02$ & 5 & $\mathrm{~A}$ & $4.95 \mathrm{E}+02$ & $5.10 \mathrm{E}+02$ & $5.19 \mathrm{E}+02$ & $5.14 \mathrm{E}+02$ & \begin{tabular}{|l} 
EST-12-02B-9 \\
\end{tabular} & 5.80E-01 & EST-12-02B-10 & $9.79 \mathrm{E}+01$ \\
\hline \multicolumn{11}{|l|}{ EST-12-03A } \\
\hline \multicolumn{11}{|l|}{ Fragment \#1 } \\
\hline $3.71 \mathrm{E}+02$ & 1 & $\mathrm{~A}$ & $5.85 \mathrm{E}+02$ & $3.71 \mathrm{E}+02$ & $3.90 \mathrm{E}+02$ & $3.82 \mathrm{E}+02$ & EST-12-03A-1 & $3.54 \mathrm{E}+00$ & EST-12-03A-2 & $4.61 \mathrm{E}+03$ \\
\hline $3.71 \mathrm{E}+02$ & 2 & $\mathrm{~A}$ & $5.05 \mathrm{E}+02$ & $3.82 \mathrm{E}+02$ & $3.91 \mathrm{E}+02$ & $3.82 \mathrm{E}+02$ & EST-12-03A-3 & $5.00 \mathrm{E}+00$ & EST-12-03A-4 & $1.57 \mathrm{E}+03$ \\
\hline $3.71 \mathrm{E}+02$ & 3 & $\mathrm{~A}$ & $5.09 \mathrm{E}+02$ & $3.82 \mathrm{E}+02$ & $3.91 \mathrm{E}+02$ & $3.84 \mathrm{E}+02$ & EST-12-03A-5 & $1.64 \mathrm{E}+00$ & EST-12-03A-6 & $2.46 \mathrm{E}+02$ \\
\hline $3.71 \mathrm{E}+02$ & 4 & A & $5.04 \mathrm{E}+02$ & $3.84 \mathrm{E}+02$ & $3.91 \mathrm{E}+02$ & $3.82 \mathrm{E}+02$ & EST-12-03A-7 & 4.68E-01 & EST-12-03A-8 & $9.78 \mathrm{E}+01$ \\
\hline
\end{tabular}


Table A3. Extraction Results for ES-31C.

\begin{tabular}{|c|c|c|c|c|c|c|c|c|c|c|}
\hline \begin{tabular}{|c} 
Dry Sample \\
Mass (g) \\
ES-31C \\
\end{tabular} & $\begin{array}{c}\text { Extraction } \\
\text { Step \# }\end{array}$ & \begin{tabular}{|c|} 
Soln. \\
Type\#
\end{tabular} & $\begin{array}{l}\text { Vol. of Soln. } \\
\text { Added for } \\
\text { Sat. (mL) }\end{array}$ & $\begin{array}{l}\text { Pre-Sat. } \\
\text { Sample } \\
\text { Mass (g) }\end{array}$ & \begin{tabular}{|} 
Post-Sat. \& Draining \\
Free Liq. Sample \\
Mass (g)
\end{tabular} & $\begin{array}{l}\text { Post-Cent. } \\
\text { Sample } \\
\text { Mass (g) }\end{array}$ & Sat. Sample \# & $\begin{array}{l}\text { Liq. [Re] } \\
\text { (Sat.) } \\
(\boldsymbol{\mu g} / \mathbf{L})\end{array}$ & Cent. Sample \# & $\begin{array}{c}\text { Liq. [Re] } \\
\text { (Cent.) } \\
(\mu \mathrm{g} / \mathrm{L})\end{array}$ \\
\hline $3.71 \mathrm{E}+02$ & 5 & A & $5.13 \mathrm{E}+02$ & $3.82 \mathrm{E}+02$ & $3.91 E+02$ & $3.82 \mathrm{E}+02$ & EST-12-03A-9 & 1.55E-01 & EST-12-03A-10 & $2.37 \mathrm{E}+01$ \\
\hline & & & & & & & & & & \\
\hline \multicolumn{11}{|l|}{ EST-12-03B } \\
\hline \multicolumn{11}{|l|}{ Fragment \#1 } \\
\hline $4.94 \mathrm{E}+02$ & 1 & A & $5.21 \mathrm{E}+02$ & $4.94 \mathrm{E}+02$ & $5.20 \mathrm{E}+02$ & $5.14 \mathrm{E}+02$ & EST-12-03B-1 & $2.71 \mathrm{E}+00$ & EST-12-03B-2 & $3.67 \mathrm{E}+03$ \\
\hline $4.94 \mathrm{E}+02$ & 2 & $\mathrm{~A}$ & $5.28 \mathrm{E}+02$ & $5.14 \mathrm{E}+02$ & $5.21 \mathrm{E}+02$ & $5.13 \mathrm{E}+02$ & EST-12-03B-3 & $1.05 \mathrm{E}+01$ & EST-12-03B-4 & $2.36 \mathrm{E}+03$ \\
\hline $4.94 \mathrm{E}+02$ & 3 & $\mathrm{~A}$ & $5.06 \mathrm{E}+02$ & $5.13 \mathrm{E}+02$ & $5.21 \mathrm{E}+02$ & $5.11 \mathrm{E}+02$ & EST-12-03B-5 & $1.48 \mathrm{E}+01$ & EST-12-03B-6 & $1.17 \mathrm{E}+03$ \\
\hline $4.94 \mathrm{E}+02$ & 4 & $\mathrm{~A}$ & $5.00 \mathrm{E}+02$ & $5.11 \mathrm{E}+02$ & $5.21 \mathrm{E}+02$ & $5.11 \mathrm{E}+02$ & EST-12-03B-7 & $3.15 \mathrm{E}+00$ & EST-12-03B-8 & $4.16 \mathrm{E}+02$ \\
\hline $4.94 \mathrm{E}+02$ & 5 & $\mathrm{~A}$ & $5.11 \mathrm{E}+02$ & $5.11 \mathrm{E}+02$ & $5.21 \mathrm{E}+02$ & $5.12 \mathrm{E}+02$ & EST-12-03B-9 & $2.07 \mathrm{E}+00$ & EST-12-03B-10 & $1.13 \mathrm{E}+02$ \\
\hline \multicolumn{11}{|c|}{$\begin{array}{l}\text { Soln - Solution } \\
\text { Vol. - Volume } \\
\text { Sat - Saturation } \\
\text { Liq. - Liquid } \\
\text { Cent. - Centrifugation } \\
\text { [Re] - Rhenium Concentration }\end{array}$} \\
\hline
\end{tabular}


Table A4. Extraction Results for ES-31D.

\begin{tabular}{|c|c|c|c|c|c|c|c|c|c|c|}
\hline $\begin{array}{c}\text { Dry Sample } \\
\text { Mass (g) } \\
\text { ES-31D } \\
\end{array}$ & $\begin{array}{c}\text { Extraction } \\
\text { Step \# }\end{array}$ & $\begin{array}{l}\text { Soln. } \\
\text { Type¥ }\end{array}$ & $\begin{array}{l}\text { Vol. of Soln. } \\
\text { Added for } \\
\text { Sat. (mL) }\end{array}$ & $\begin{array}{l}\text { Pre-Sat. } \\
\text { Sample } \\
\text { Mass (g) }\end{array}$ & $\begin{array}{c}\text { Post-Sat. \& Draining } \\
\text { Free Liq. Sample } \\
\text { Mass (g) }\end{array}$ & $\begin{array}{l}\text { Post-Cent. } \\
\text { Sample } \\
\text { Mass (g) }\end{array}$ & Sat. Sample \# & $\begin{array}{c}\text { Liq. [Re] } \\
\text { (Sat.) } \\
(\mu \mathrm{g} / \mathrm{L})\end{array}$ & Cent. Sample \# & \begin{tabular}{|c} 
Liq. [Re] \\
$($ Cent.) \\
$(\mu \mathrm{g} / \mathbf{L})$
\end{tabular} \\
\hline \multicolumn{11}{|l|}{ EST-13-01 } \\
\hline \multicolumn{11}{|l|}{ Fragment \#1 } \\
\hline $2.95 \mathrm{E}+02$ & 1 & A & $3.63 \mathrm{E}+02$ & $2.95 \mathrm{E}+02$ & $3.11 \mathrm{E}+02$ & $3.09 \mathrm{E}+02$ & EST-13-01-1 & 7.80E-01 & EST-13-01-2 & $1.50 \mathrm{E}+02$ \\
\hline $2.95 \mathrm{E}+02$ & 2 & A & $3.14 \mathrm{E}+02$ & - & - & - & EST-13-01-3 & $1.02 \mathrm{E}+00$ & EST-13-01-4 & $1.73 \mathrm{E}+02$ \\
\hline $2.95 \mathrm{E}+02$ & 3 & A & $3.18 \mathrm{E}+02$ & $3.09 \mathrm{E}+02$ & $3.12 \mathrm{E}+02$ & $3.10 \mathrm{E}+02$ & EST-13-01-5 & $7.37 \mathrm{E}+00$ & EST-13-01-6 & $6.92 \mathrm{E}+01$ \\
\hline $2.95 \mathrm{E}+02$ & 4 & A & $3.13 \mathrm{E}+02$ & $3.10 \mathrm{E}+02$ & $3.12 \mathrm{E}+02$ & $3.10 \mathrm{E}+02$ & EST-13-01-7 & 3.25E-01 & EST-13-01-8 & $6.18 \mathrm{E}+01$ \\
\hline $2.95 \mathrm{E}+02$ & 5 & A & $3.27 \mathrm{E}+02$ & $3.10 \mathrm{E}+02$ & $3.13 \mathrm{E}+02$ & $3.12 \mathrm{E}+02$ & EST-13-01-9 & 2.89E-01 & EST-13-01-10 & $4.91 \mathrm{E}+01$ \\
\hline \multicolumn{11}{|l|}{\begin{tabular}{|l|} 
EST-13-02 \\
\end{tabular}} \\
\hline \multicolumn{11}{|l|}{ Fragment \#1 } \\
\hline $3.44 \mathrm{E}+02$ & 1 & A & $5.00 \mathrm{E}+02$ & $3.44 \mathrm{E}+02$ & $3.64 \mathrm{E}+02$ & $3.61 \mathrm{E}+02$ & EST-13-02-1 & 1.47E-01 & EST-13-02-2 & $5.07 \mathrm{E}+01$ \\
\hline $3.44 \mathrm{E}+02$ & 2 & A & $5.04 \mathrm{E}+02$ & - & - & - & EST-13-02-3 & 2.16E-01 & EST-13-02-4 & $4.73 E+01$ \\
\hline $3.44 \mathrm{E}+02$ & 3 & $\mathrm{~A}$ & $5.17 \mathrm{E}+02$ & $3.61 \mathrm{E}+02$ & $3.65 \mathrm{E}+02$ & $3.61 \mathrm{E}+02$ & EST-13-02-5 & $1.34 \mathrm{E}+00$ & EST-13-02-6 & $1.47 \mathrm{E}+01$ \\
\hline $3.44 \mathrm{E}+02$ & 4 & A & $5.26 \mathrm{E}+02$ & $3.61 \mathrm{E}+02$ & $3.64 \mathrm{E}+02$ & $3.62 \mathrm{E}+02$ & EST-13-02-7 & 3.76E-02 & EST-13-02-8 & $1.18 \mathrm{E}+01$ \\
\hline $3.44 \mathrm{E}+02$ & 5 & A & $4.96 \mathrm{E}+02$ & $3.62 \mathrm{E}+02$ & $3.64 \mathrm{E}+02$ & $3.62 \mathrm{E}+02$ & EST-13-02-9 & $4.81 \mathrm{E}-02$ & EST-13-02-10 & $8.48 \mathrm{E}+00$ \\
\hline \multirow{2}{*}{\multicolumn{11}{|c|}{\begin{tabular}{|l|} 
EST-13-03 \\
\end{tabular}}} \\
\hline & & & & & & & & & & \\
\hline \multicolumn{11}{|l|}{ Fragment \#1 } \\
\hline $5.10 \mathrm{E}+02$ & 1 & $\mathrm{~A}$ & $4.52 \mathrm{E}+02$ & $5.10 \mathrm{E}+02$ & $5.37 \mathrm{E}+02$ & $5.32 \mathrm{E}+02$ & EST-13-03-1 & 2.03E-01 & EST-13-03-2 & $8.39 \mathrm{E}+00$ \\
\hline $5.10 \mathrm{E}+02$ & 2 & $\mathrm{~A}$ & $4.40 \mathrm{E}+02$ & $5.32 \mathrm{E}+02$ & $5.38 \mathrm{E}+02$ & $5.34 \mathrm{E}+02$ & EST-13-03-3 & 4.48E-02 & EST-13-03-4 & $6.48 \mathrm{E}+00$ \\
\hline $5.10 \mathrm{E}+02$ & 3 & A & $4.43 \mathrm{E}+02$ & $5.34 \mathrm{E}+02$ & $5.38 \mathrm{E}+02$ & $5.33 \mathrm{E}+02$ & EST-13-03-5 & 3.18E-02 & EST-13-03-6 & $5.93 \mathrm{E}+00$ \\
\hline $5.10 \mathrm{E}+02$ & 4 & A & 4.37E+02 & $5.33 \mathrm{E}+02$ & $5.39 \mathrm{E}+02$ & $5.34 \mathrm{E}+02$ & EST-13-03-7 & 1.83E-01 & EST-13-03-8 & $5.01 \mathrm{E}+00$ \\
\hline $5.10 \mathrm{E}+02$ & 5 & A & $4.42 \mathrm{E}+02$ & $5.34 \mathrm{E}+02$ & $5.39 \mathrm{E}+02$ & $5.34 \mathrm{E}+02$ & EST-13-03-9 & $1.94 \mathrm{E}-02$ & EST-13-03-10 & $3.01 \mathrm{E}+00$ \\
\hline \multicolumn{11}{|l|}{ EST-13-04 } \\
\hline \multicolumn{11}{|l|}{ Fragment \#1 } \\
\hline $4.46 \mathrm{E}+02$ & 1 & A & $3.88 \mathrm{E}+02$ & $4.46 \mathrm{E}+02$ & $4.70 \mathrm{E}+02$ & $4.64 \mathrm{E}+02$ & EST-13-04-1 & 9.18E-02 & EST-13-04-2 & $1.17 \mathrm{E}+01$ \\
\hline $4.46 \mathrm{E}+02$ & 2 & A & $6.41 \mathrm{E}+02$ & $4.64 \mathrm{E}+02$ & $4.72 \mathrm{E}+02$ & $4.63 E+02$ & EST-13-04-3 & $1.11 \mathrm{E}-01$ & EST-13-04-4 & $6.47 \mathrm{E}+00$ \\
\hline $4.46 \mathrm{E}+02$ & 3 & A & $4.20 \mathrm{E}+02$ & $4.63 \mathrm{E}+02$ & $4.71 \mathrm{E}+02$ & $4.62 \mathrm{E}+02$ & EST-13-04-5 & 2.18E-02 & EST-13-04-6 & $4.57 \mathrm{E}+00$ \\
\hline
\end{tabular}


Table A4. Extraction Results for ES-31D.

\begin{tabular}{|c|c|c|c|c|c|c|c|c|c|c|}
\hline $\begin{array}{c}\text { Dry Sample } \\
\text { Mass (g) } \\
\text { ES-31D }\end{array}$ & $\begin{array}{c}\text { Extraction } \\
\text { Step \# }\end{array}$ & \begin{tabular}{|c|} 
Soln. \\
Type¥
\end{tabular} & $\begin{array}{l}\text { Vol. of Soln. } \\
\text { Added for } \\
\text { Sat. (mL) }\end{array}$ & \begin{tabular}{|c|} 
Pre-Sat. \\
Sample \\
Mass (g)
\end{tabular} & \begin{tabular}{|c} 
Post-Sat. \& Draining \\
Free Liq. Sample \\
Mass (g)
\end{tabular} & $\begin{array}{l}\text { Post-Cent. } \\
\text { Sample } \\
\text { Mass (g) }\end{array}$ & Sat. Sample \# & \begin{tabular}{|c|} 
Liq. $[\mathrm{Re}]$ \\
(Sat.) \\
$(\mu \mathrm{g} / \mathrm{L})$
\end{tabular} & Cent. Sample \# & $\begin{array}{c}\text { Liq. [Re] } \\
\text { (Cent.) } \\
(\mu \mathrm{gg} / \mathrm{L})\end{array}$ \\
\hline $4.46 \mathrm{E}+02$ & 4 & A & $3.78 \mathrm{E}+02$ & $4.62 \mathrm{E}+02$ & $4.71 E+02$ & $4.61 \mathrm{E}+02$ & EST-13-04-7 & 1.98E-02 & EST-13-04-8 & $3.11 \mathrm{E}+00$ \\
\hline $4.46 \mathrm{E}+02$ & 5 & A & $3.23 \mathrm{E}+02$ & $4.61 \mathrm{E}+02$ & $4.71 \mathrm{E}+02$ & $4.63 \mathrm{E}+02$ & EST-13-04-9 & $2.18 \mathrm{E}-02$ & EST-13-04-10 & $1.90 \mathrm{E}+00$ \\
\hline \multicolumn{11}{|l|}{\begin{tabular}{|l|} 
EST-13-05 \\
\end{tabular}} \\
\hline \multicolumn{11}{|l|}{ Fragment \#1 } \\
\hline $4.87 \mathrm{E}+02$ & 1 & $\mathrm{~A}$ & $3.35 \mathrm{E}+02$ & $4.87 \mathrm{E}+02$ & $5.17 \mathrm{E}+02$ & $5.05 \mathrm{E}+02$ & EST-13-05-1 & 4.31E-01 & EST-13-05-2 & $7.35 \mathrm{E}+01$ \\
\hline $4.87 \mathrm{E}+02$ & 2 & A & $5.49 \mathrm{E}+02$ & $5.05 \mathrm{E}+02$ & $5.18 \mathrm{E}+02$ & $5.06 \mathrm{E}+02$ & EST-13-05-3 & 4.36E-01 & EST-13-05-4 & $4.09 \mathrm{E}+01$ \\
\hline $4.87 \mathrm{E}+02$ & 3 & $\mathrm{~A}$ & $3.18 \mathrm{E}+02$ & $5.06 \mathrm{E}+02$ & $5.17 \mathrm{E}+02$ & $5.03 \mathrm{E}+02$ & EST-13-05-5 & 1.24E-01 & EST-13-05-6 & $2.56 \mathrm{E}+01$ \\
\hline $4.87 \mathrm{E}+02$ & 4 & $\mathrm{~A}$ & $3.04 \mathrm{E}+02$ & $5.03 E+02$ & $5.17 \mathrm{E}+02$ & $5.04 \mathrm{E}+02$ & EST-13-05-7 & 9.37E-02 & EST-13-05-8 & $7.29 \mathrm{E}+00$ \\
\hline $4.87 \mathrm{E}+02$ & 5 & $\mathrm{~A}$ & $3.82 \mathrm{E}+02$ & $5.04 \mathrm{E}+02$ & $5.17 \mathrm{E}+02$ & $5.05 \mathrm{E}+02$ & EST-13-05-9 & 3.18E-02 & EST-13-05-10 & $2.93 \mathrm{E}+00$ \\
\hline \multicolumn{11}{|l|}{ EST-14-01 } \\
\hline \multicolumn{11}{|l|}{ Fragment \#1 } \\
\hline $2.63 E+02$ & 1 & $\mathrm{~A}$ & $4.94 \mathrm{E}+02$ & $2.63 \mathrm{E}+02$ & $2.78 \mathrm{E}+02$ & $2.77 \mathrm{E}+02$ & EST-14-01-1 & $1.73 \mathrm{E}+00$ & EST-14-01-2 & $3.02 \mathrm{E}+02$ \\
\hline $2.63 \mathrm{E}+02$ & 2 & A & $4.89 \mathrm{E}+02$ & $2.77 \mathrm{E}+02$ & $2.79 \mathrm{E}+02$ & $2.77 \mathrm{E}+02$ & EST-14-01-3 & $2.25 \mathrm{E}+00$ & EST-14-01-4 & $2.16 \mathrm{E}+02$ \\
\hline $2.63 \mathrm{E}+02$ & 3 & $\mathrm{~A}$ & $5.21 \mathrm{E}+02$ & $2.77 \mathrm{E}+02$ & $2.79 \mathrm{E}+02$ & $2.77 \mathrm{E}+02$ & EST-14-01-5 & 9.58E-01 & EST-14-01-6 & $1.70 \mathrm{E}+02$ \\
\hline $2.63 \mathrm{E}+02$ & 4 & $\mathrm{~A}$ & $4.95 \mathrm{E}+02$ & $2.77 \mathrm{E}+02$ & $2.79 \mathrm{E}+02$ & $2.77 \mathrm{E}+02$ & EST-14-01-7 & $8.55 \mathrm{E}+00$ & EST-14-01-8 & $5.01 \mathrm{E}+01$ \\
\hline $2.63 \mathrm{E}+02$ & 5 & $\mathrm{~A}$ & $4.90 \mathrm{E}+02$ & $2.77 \mathrm{E}+02$ & $2.79 \mathrm{E}+02$ & $2.77 \mathrm{E}+02$ & EST-14-01-9 & 3.13E-01 & EST-14-01-10 & $4.42 \mathrm{E}+01$ \\
\hline \multicolumn{11}{|l|}{ EST-14-02 } \\
\hline \multicolumn{11}{|l|}{ Fragment \#1 } \\
\hline $2.63 \mathrm{E}+02$ & 1 & $\mathrm{~A}$ & $4.49 \mathrm{E}+02$ & $2.63 \mathrm{E}+02$ & $2.77 \mathrm{E}+02$ & $2.75 \mathrm{E}+02$ & EST-14-02-1 & 1.41E-01 & EST-14-02-2 & $4.01 \mathrm{E}+01$ \\
\hline $2.63 \mathrm{E}+02$ & 2 & $\mathrm{~A}$ & $5.55 \mathrm{E}+02$ & $2.75 \mathrm{E}+02$ & $2.77 \mathrm{E}+02$ & $2.76 \mathrm{E}+02$ & EST-14-02-3 & 9.32E-02 & EST-14-02-4 & $3.11 \mathrm{E}+01$ \\
\hline $2.63 \mathrm{E}+02$ & 3 & $\mathrm{~A}$ & $5.57 \mathrm{E}+02$ & $2.76 \mathrm{E}+02$ & $2.77 \mathrm{E}+02$ & $2.74 \mathrm{E}+02$ & EST-14-02-5 & \begin{tabular}{|l|}
$8.48 \mathrm{E}-02$ \\
\end{tabular} & EST-14-02-6 & $2.60 \mathrm{E}+01$ \\
\hline $2.63 \mathrm{E}+02$ & 4 & $\mathrm{~A}$ & $5.42 \mathrm{E}+02$ & $2.74 \mathrm{E}+02$ & $2.78 \mathrm{E}+02$ & $2.76 \mathrm{E}+02$ & EST-14-02-7 & 4.82E-01 & EST-14-02-8 & $6.12 \mathrm{E}+00$ \\
\hline $2.63 \mathrm{E}+02$ & 5 & $\mathrm{~A}$ & $5.27 \mathrm{E}+02$ & $2.76 \mathrm{E}+02$ & $2.78 \mathrm{E}+02$ & $2.74 \mathrm{E}+02$ & EST-14-02-9 & 6.94E-02 & EST-14-02-10 & $4.85 \mathrm{E}+00$ \\
\hline & & & & & & & & & & \\
\hline & & & & & & & & & & \\
\hline & & & & & & & & & & \\
\hline & & & & & & & & & & \\
\hline
\end{tabular}


Table A4. Extraction Results for ES-31D.

\begin{tabular}{|c|c|c|c|c|c|c|c|c|c|c|}
\hline $\begin{array}{c}\text { Dry Sample } \\
\text { Mass (g) } \\
\text { ES-31D }\end{array}$ & $\begin{array}{c}\text { Extraction } \\
\text { Step \# }\end{array}$ & \begin{tabular}{|c|} 
Soln. \\
Typeः
\end{tabular} & $\begin{array}{l}\text { Vol. of Soln. } \\
\text { Added for } \\
\text { Sat. (mL) }\end{array}$ & $\begin{array}{l}\text { Pre-Sat. } \\
\text { Sample } \\
\text { Mass (g) }\end{array}$ & $\begin{array}{c}\text { Post-Sat. \& Draining } \\
\text { Free Liq. Sample } \\
\text { Mass (g) }\end{array}$ & $\begin{array}{l}\text { Post-Cent. } \\
\text { Sample } \\
\text { Mass (g) }\end{array}$ & Sat. Sample \# & \begin{tabular}{|c} 
Liq. [Re] \\
(Sat.) \\
$(\boldsymbol{\mu g} / \mathbf{L})$
\end{tabular} & Cent. Sample \# & $\begin{array}{c}\text { Liq. [Re] } \\
\text { (Cent.) } \\
(\mu \mathrm{g} / \mathrm{L})\end{array}$ \\
\hline \multicolumn{11}{|l|}{ EST-14-03 } \\
\hline \multicolumn{11}{|l|}{\begin{tabular}{|l|} 
Fragment \#1 \\
\end{tabular}} \\
\hline $4.90 \mathrm{E}+02$ & 1 & A & $4.20 \mathrm{E}+02$ & $4.90 \mathrm{E}+02$ & $5.15 E+02$ & $5.08 \mathrm{E}+02$ & EST-14-03-1 & 6.87E-02 & EST-14-03-2 & $8.20 \mathrm{E}+00$ \\
\hline $4.90 \mathrm{E}+02$ & 2 & A & $4.11 \mathrm{E}+02$ & $5.08 \mathrm{E}+02$ & $5.15 \mathrm{E}+02$ & $5.10 \mathrm{E}+02$ & EST-14-03-3 & 4.31E-02 & EST-14-03-4 & $5.21 \mathrm{E}+00$ \\
\hline $4.90 \mathrm{E}+02$ & 3 & A & $4.23 \mathrm{E}+02$ & $5.10 \mathrm{E}+02$ & $5.15 \mathrm{E}+02$ & $5.10 \mathrm{E}+02$ & EST-14-03-5 & 2.79E-02 & EST-14-03-6 & $3.28 \mathrm{E}+00$ \\
\hline $4.90 \mathrm{E}+02$ & 4 & $\mathrm{~A}$ & $4.50 \mathrm{E}+02$ & $5.10 \mathrm{E}+02$ & $5.16 \mathrm{E}+02$ & $5.11 \mathrm{E}+02$ & EST-14-03-7 & 7.83E-02 & EST-14-03-8 & 8.94E-01 \\
\hline $4.90 \mathrm{E}+02$ & 5 & A & $4.15 \mathrm{E}+02$ & $5.11 \mathrm{E}+02$ & $5.15 \mathrm{E}+02$ & $5.10 \mathrm{E}+02$ & EST-14-03-9 & $0.00 \mathrm{E}+00$ & EST-14-03-10 & 6.55E-01 \\
\hline \multicolumn{11}{|l|}{ EST-14-04 } \\
\hline \multicolumn{11}{|l|}{ Fragment \#1 } \\
\hline $3.11 \mathrm{E}+02$ & 1 & A & $4.77 \mathrm{E}+02$ & $3.11 \mathrm{E}+02$ & $3.28 \mathrm{E}+02$ & $3.24 \mathrm{E}+02$ & EST-14-04-1 & 2.55E-02 & EST-14-04-2 & $1.70 \mathrm{E}+01$ \\
\hline $3.11 \mathrm{E}+02$ & 2 & A & $4.78 \mathrm{E}+02$ & - & - & - & EST-14-04-3 & $4.01 \mathrm{E}-02$ & EST-14-04-4 & $1.28 \mathrm{E}+01$ \\
\hline $3.11 \mathrm{E}+02$ & 3 & A & $4.74 \mathrm{E}+02$ & $3.26 \mathrm{E}+02$ & $3.29 \mathrm{E}+02$ & $3.26 \mathrm{E}+02$ & EST-14-04-5 & 2.27E-01 & EST-14-04-6 & $3.58 \mathrm{E}+00$ \\
\hline $3.11 \mathrm{E}+02$ & 4 & A & $4.62 \mathrm{E}+02$ & $3.26 \mathrm{E}+02$ & $3.28 \mathrm{E}+02$ & $3.26 \mathrm{E}+02$ & EST-14-04-7 & $0.00 \mathrm{E}+00$ & EST-14-04-8 & $2.75 \mathrm{E}+00$ \\
\hline $3.11 \mathrm{E}+02$ & 5 & A & $4.76 \mathrm{E}+02$ & $3.26 \mathrm{E}+02$ & $3.28 \mathrm{E}+02$ & $3.26 \mathrm{E}+02$ & EST-14-04-9 & $0.00 \mathrm{E}+00$ & EST-14-04-10 & $2.06 \mathrm{E}+00$ \\
\hline \multicolumn{11}{|l|}{ EST-14-05 } \\
\hline \multicolumn{11}{|l|}{ Fragment \#1 } \\
\hline $3.52 \mathrm{E}+02$ & 1 & $\mathrm{~A}$ & $5.27 \mathrm{E}+02$ & $3.52 \mathrm{E}+02$ & $3.73 \mathrm{E}+02$ & $3.67 \mathrm{E}+02$ & EST-14-05-1 & \begin{tabular}{|l|}
$8.89 \mathrm{E}-02$ \\
\end{tabular} & EST-14-05-2 & $2.02 \mathrm{E}+01$ \\
\hline $3.52 \mathrm{E}+02$ & 2 & $\mathrm{~A}$ & $5.47 \mathrm{E}+02$ & - & - & - & EST-14-05-3 & 7.39E-02 & EST-14-05-4 & $1.35 \mathrm{E}+01$ \\
\hline $3.52 \mathrm{E}+02$ & 3 & A & $5.55 \mathrm{E}+02$ & $3.67 \mathrm{E}+02$ & $3.75 \mathrm{E}+02$ & $3.66 \mathrm{E}+02$ & EST-14-05-5 & 2.35E-01 & EST-14-05-6 & $2.51 \mathrm{E}+00$ \\
\hline $3.52 \mathrm{E}+02$ & 4 & $\mathrm{~A}$ & $5.36 \mathrm{E}+02$ & $3.66 \mathrm{E}+02$ & $3.73 \mathrm{E}+02$ & $3.67 \mathrm{E}+02$ & EST-14-05-7 & 1.99E-02 & EST-14-05-8 & $1.91 \mathrm{E}+00$ \\
\hline $3.52 \mathrm{E}+02$ & 5 & A & $5.49 \mathrm{E}+02$ & $3.67 \mathrm{E}+02$ & $3.74 \mathrm{E}+02$ & $3.67 \mathrm{E}+02$ & EST-14-05-9 & $0.00 \mathrm{E}+00$ & EST-14-05-10 & $1.25 \mathrm{E}+00$ \\
\hline \multicolumn{11}{|c|}{$\begin{array}{l}\text { Soln - Solution } \\
\text { Vol. - Volume } \\
\text { Sat - Saturation } \\
\text { Liq. - Liquid } \\
\text { Cent. - Centrifugation } \\
\text { [Re] - Rhenium Concentration }\end{array}$} \\
\hline
\end{tabular}


Table A5. Extraction Results for ES-31E.

\begin{tabular}{|c|c|c|c|c|c|c|c|c|c|c|}
\hline $\begin{array}{c}\text { Dry Sample Mass } \\
\text { (g) }\end{array}$ & $\begin{array}{c}\text { Extraction } \\
\text { Step \# }\end{array}$ & $\begin{array}{l}\text { Soln. } \\
\text { Type¥ }\end{array}$ & $\begin{array}{l}\text { Vol. of Soln. } \\
\text { Added for Sat. } \\
(\mathrm{mL})\end{array}$ & $\begin{array}{l}\text { Pre-Sat. } \\
\text { Sample } \\
\text { Mass (g) }\end{array}$ & $\begin{array}{c}\text { Post-Sat. \& } \\
\text { Draining Free Liq. } \\
\text { Sample Mass (g) }\end{array}$ & $\begin{array}{l}\text { Post-Cent. } \\
\text { Sample Mass } \\
\text { (g) }\end{array}$ & Sat. Sample \# & $\begin{array}{c}\text { Liq. [Re] } \\
\text { (Sat.) } \\
(\mu \mathrm{g} / \mathrm{L})\end{array}$ & $\begin{array}{c}\text { Cent. Sample } \\
\#\end{array}$ & $\begin{array}{c}\text { Liq. [Re] } \\
\text { (Cent.) } \\
(\boldsymbol{\mu g} / \mathrm{L})\end{array}$ \\
\hline ES-31E & & & & & & & & & & \\
\hline Tiled Refractory & & & & & & & & & & \\
\hline EST-17-01 & & & & & & & & & & \\
\hline Fragment \#1 & & & & & & & & & & \\
\hline $3.73 \mathrm{E}+02$ & 1 & $\mathrm{~A}$ & $3.48 \mathrm{E}+02$ & $3.73 \mathrm{E}+02$ & $3.95 \mathrm{E}+02$ & $3.94 \mathrm{E}+02$ & EST-17-01-1 & $1.20 \mathrm{E}+00$ & EST-17-01-2 & $1.02 \mathrm{E}+02$ \\
\hline $3.73 \mathrm{E}+02$ & 2 & $\mathrm{~A}$ & $3.49 \mathrm{E}+02$ & $3.94 \mathrm{E}+02$ & $3.97 \mathrm{E}+02$ & $3.93 \mathrm{E}+02$ & EST-17-01-3 & 5.86E-01 & EST-17-01-4 & $8.66 \mathrm{E}+01$ \\
\hline $3.73 \mathrm{E}+02$ & 3 & $\mathrm{~A}$ & $3.25 \mathrm{E}+02$ & $3.93 \mathrm{E}+02$ & $3.96 \mathrm{E}+02$ & $3.94 \mathrm{E}+02$ & EST-17-01-5 & 6.02E-01 & EST-17-01-6 & $6.79 \mathrm{E}+01$ \\
\hline $3.73 \mathrm{E}+02$ & 4 & $\mathrm{~A}$ & $3.58 \mathrm{E}+02$ & $3.94 \mathrm{E}+02$ & $3.88 \mathrm{E}+02$ & - & EST-17-01-7 & $3.08 \mathrm{E}+00$ & EST-17-01-8 & $2.93 \mathrm{E}+01$ \\
\hline $3.73 \mathrm{E}+02$ & 5 & A & $4.22 \mathrm{E}+02$ & - & - & - & EST-17-01-9 & $1.10 \mathrm{E}-01$ & EST-17-01-10 & $2.81 \mathrm{E}+01$ \\
\hline $3.73 \mathrm{E}+02$ & 6 & A & $3.51 \mathrm{E}+02$ & $3.92 \mathrm{E}+02$ & $3.97 \mathrm{E}+02$ & $3.92 \mathrm{E}+02$ & EST-17-01-11 & 8.83E-01 & EST-17-01-12 & $1.30 \mathrm{E}+01$ \\
\hline $3.73 \mathrm{E}+02$ & 7 & A & $3.32 \mathrm{E}+02$ & $3.92 \mathrm{E}+02$ & $3.96 \mathrm{E}+02$ & $3.89 \mathrm{E}+02$ & EST-17-01-13 & $0.00 \mathrm{E}+00$ & EST-17-01-14 & $1.19 \mathrm{E}+01$ \\
\hline EST-17-02 & & & & & & & & & & \\
\hline $5.22 \mathrm{E}+02$ & 1 & $\mathrm{~A}$ & $5.12 \mathrm{E}+02$ & $5.22 \mathrm{E}+02$ & $5.53 \mathrm{E}+02$ & $5.48 \mathrm{E}+02$ & EST-17-02-1 & $1.75 \mathrm{E}+01$ & EST-17-02-2 & $4.05 \mathrm{E}+02$ \\
\hline $5.22 \mathrm{E}+02$ & 2 & $\mathrm{~A}$ & $4.26 \mathrm{E}+02$ & $5.48 \mathrm{E}+02$ & $5.53 \mathrm{E}+02$ & $5.50 \mathrm{E}+02$ & EST-17-02-3 & $9.81 \mathrm{E}+00$ & EST-17-02-4 & $7.46 \mathrm{E}+02$ \\
\hline $5.22 \mathrm{E}+02$ & 3 & A & $4.31 \mathrm{E}+02$ & $5.50 \mathrm{E}+02$ & $5.54 \mathrm{E}+02$ & $5.48 \mathrm{E}+02$ & EST-17-02-5 & $7.97 \mathrm{E}+00$ & EST-17-02-6 & $7.62 \mathrm{E}+02$ \\
\hline $5.22 \mathrm{E}+02$ & 4 & A & $4.20 \mathrm{E}+02$ & $5.47 \mathrm{E}+02$ & $5.53 \mathrm{E}+02$ & $5.49 \mathrm{E}+02$ & EST-17-02-7 & $6.94 \mathrm{E}+00$ & EST-17-02-8 & $6.23 \mathrm{E}+02$ \\
\hline $5.22 \mathrm{E}+02$ & 5 & A & $4.39 \mathrm{E}+02$ & $5.49 \mathrm{E}+02$ & $5.54 \mathrm{E}+02$ & $5.47 \mathrm{E}+02$ & EST-17-02-9 & $8.71 \mathrm{E}+00$ & EST-17-02-10 & $7.66 \mathrm{E}+02$ \\
\hline EST-17-03 & & & & & & & & & & \\
\hline $5.39 \mathrm{E}+02$ & 1 & $\mathrm{~A}$ & $3.63 \mathrm{E}+02$ & $5.39 \mathrm{E}+02$ & $5.75 E+02$ & $5.70 \mathrm{E}+02$ & EST-17-03-1 & $1.45 \mathrm{E}+01$ & EST-17-03-2 & $1.11 \mathrm{E}+02$ \\
\hline $5.39 \mathrm{E}+02$ & 2 & A & $3.91 \mathrm{E}+02$ & $5.70 \mathrm{E}+02$ & $5.73 \mathrm{E}+02$ & $5.69 \mathrm{E}+02$ & EST-17-03-3 & $1.44 \mathrm{E}+00$ & EST-17-03-4 & $2.02 \mathrm{E}+02$ \\
\hline $5.39 \mathrm{E}+02$ & 3 & A & $3.69 \mathrm{E}+02$ & $5.69 \mathrm{E}+02$ & $5.72 \mathrm{E}+02$ & $5.69 \mathrm{E}+02$ & EST-17-03-5 & $1.27 \mathrm{E}+00$ & EST-17-03-6 & $2.50 \mathrm{E}+02$ \\
\hline $5.39 \mathrm{E}+02$ & 4 & A & $3.92 \mathrm{E}+02$ & $5.69 \mathrm{E}+02$ & $5.71 \mathrm{E}+02$ & $5.69 \mathrm{E}+02$ & EST-17-03-7 & 8.10E-01 & EST-17-03-8 & $1.64 \mathrm{E}+02$ \\
\hline $5.39 \mathrm{E}+02$ & 5 & A & $3.84 \mathrm{E}+02$ & $5.69 \mathrm{E}+02$ & $5.71 \mathrm{E}+02$ & $5.69 \mathrm{E}+02$ & EST-17-03-9 & 7.73E-01 & EST-17-03-10 & $2.21 \mathrm{E}+02$ \\
\hline EST-17-04 & & & & & & & & & & \\
\hline $4.29 \mathrm{E}+02$ & 1 & A & $3.90 \mathrm{E}+02$ & $4.29 \mathrm{E}+02$ & $4.60 \mathrm{E}+02$ & $4.49 \mathrm{E}+02$ & EST-17-04-1 & $7.20 \mathrm{E}+00$ & EST-17-04-2 & 2.19E+02 \\
\hline $4.29 \mathrm{E}+02$ & 2 & $\mathrm{~A}$ & $4.17 \mathrm{E}+02$ & $4.49 \mathrm{E}+02$ & $4.57 \mathrm{E}+02$ & $4.50 \mathrm{E}+02$ & EST-17-04-3 & 7.19E-01 & EST-17-04-4 & $6.24 \mathrm{E}+02$ \\
\hline $4.29 \mathrm{E}+02$ & 3 & A & $4.31 \mathrm{E}+02$ & $4.50 \mathrm{E}+02$ & $4.56 \mathrm{E}+02$ & $4.47 \mathrm{E}+02$ & EST-17-04-5 & $1.74 \mathrm{E}+00$ & EST-17-04-6 & $9.33 \mathrm{E}+02$ \\
\hline $4.29 \mathrm{E}+02$ & 4 & A & $4.05 \mathrm{E}+02$ & $4.47 \mathrm{E}+02$ & $4.56 \mathrm{E}+02$ & $4.48 \mathrm{E}+02$ & EST-17-04-7 & $1.45 \mathrm{E}+00$ & EST-17-04-8 & $5.51 \mathrm{E}+02$ \\
\hline $4.29 \mathrm{E}+02$ & 5 & A & $3.84 \mathrm{E}+02$ & $4.48 \mathrm{E}+02$ & $4.56 \mathrm{E}+02$ & $4.49 \mathrm{E}+02$ & EST-17-04-9 & $1.15 \mathrm{E}+00$ & EST-17-04-10 & $2.31 \mathrm{E}+02$ \\
\hline
\end{tabular}


Table A5. Extraction Results for ES-31E.

\begin{tabular}{|c|c|c|c|c|c|c|c|c|c|c|}
\hline $\begin{array}{l}\text { Dry Sample Mass } \\
\text { (g) }\end{array}$ & $\begin{array}{c}\text { Extraction } \\
\text { Step \# }\end{array}$ & \begin{tabular}{c|} 
Soln. \\
Type¥
\end{tabular} & $\begin{array}{c}\begin{array}{c}\text { Vol. of Soln. } \\
\text { Added for Sat. } \\
\text { (mL) }\end{array} \\
\end{array}$ & $\begin{array}{l}\text { Pre-Sat. } \\
\text { Sample } \\
\text { Mass (g) }\end{array}$ & $\begin{array}{c}\text { Post-Sat. \& } \\
\text { Draining Free Liq. } \\
\text { Sample Mass (g) } \\
\end{array}$ & $\begin{array}{c}\text { Post-Cent. } \\
\text { Sample Mass } \\
\text { (g) }\end{array}$ & Sat. Sample \# & $\begin{array}{c}\text { Liq. [Re] } \\
\text { (Sat.) } \\
\text { (pg/L) } \\
\end{array}$ & $\begin{array}{c}\text { Cent. Sample } \\
\#\end{array}$ & $\begin{array}{c}\text { Liq. [Re] } \\
\text { (Cent.) } \\
(\mu \mathrm{gg} / \mathbf{L}) \\
\end{array}$ \\
\hline \multicolumn{11}{|l|}{ EST-17-05 } \\
\hline $5.65 \mathrm{E}+02$ & 1 & A & $3.85 \mathrm{E}+02$ & $5.65 \mathrm{E}+02$ & $6.05 \mathrm{E}+02$ & $5.95 \mathrm{E}+02$ & EST-17-05-1 & $1.38 \mathrm{E}+01$ & EST-17-05-2 & $1.11 \mathrm{E}+02$ \\
\hline $5.65 \mathrm{E}+02$ & 2 & A & $4.62 \mathrm{E}+02$ & $5.95 \mathrm{E}+02$ & $6.04 \mathrm{E}+02$ & $5.98 \mathrm{E}+02$ & EST-17-05-3 & $1.04 \mathrm{E}+00$ & EST-17-05-4 & $2.73 \mathrm{E}+02$ \\
\hline $5.65 \mathrm{E}+02$ & 3 & A & $5.06 \mathrm{E}+02$ & $5.98 \mathrm{E}+02$ & $6.04 \mathrm{E}+02$ & $5.96 \mathrm{E}+02$ & EST-17-05-5 & $1.40 \mathrm{E}+00$ & EST-17-05-6 & $3.19 \mathrm{E}+02$ \\
\hline $5.65 \mathrm{E}+02$ & 4 & A & $4.04 \mathrm{E}+02$ & $5.96 \mathrm{E}+02$ & $6.03 \mathrm{E}+02$ & $5.94 \mathrm{E}+02$ & EST-17-05-7 & $2.01 \mathrm{E}+00$ & EST-17-05-8 & $4.02 \mathrm{E}+02$ \\
\hline $5.65 \mathrm{E}+02$ & 5 & A & $3.55 \mathrm{E}+02$ & $5.94 \mathrm{E}+02$ & $6.03 \mathrm{E}+02$ & $5.97 \mathrm{E}+02$ & EST-17-05-9 & $1.79 \mathrm{E}+00$ & EST-17-05-10 & $2.92 \mathrm{E}+02$ \\
\hline \multicolumn{11}{|l|}{ EST-17-06 } \\
\hline $5.68 \mathrm{E}+02$ & 1 & A & $3.92 \mathrm{E}+02$ & $5.68 \mathrm{E}+02$ & $6.07 \mathrm{E}+02$ & $6.00 \mathrm{E}+02$ & EST-17-06-1 & $1.37 \mathrm{E}+00$ & EST-17-06-2 & $7.91 \mathrm{E}+02$ \\
\hline $5.68 \mathrm{E}+02$ & 2 & A & $3.93 \mathrm{E}+02$ & $6.00 \mathrm{E}+02$ & $6.08 \mathrm{E}+02$ & $6.02 \mathrm{E}+02$ & EST-17-06-3 & $6.89 \mathrm{E}+00$ & EST-17-06-4 & $3.08 \mathrm{E}+02$ \\
\hline $5.68 \mathrm{E}+02$ & 3 & $\mathrm{~A}$ & $3.89 \mathrm{E}+02$ & $6.02 \mathrm{E}+02$ & $6.07 \mathrm{E}+02$ & $5.97 \mathrm{E}+02$ & EST-17-06-5 & $1.38 \mathrm{E}+00$ & EST-17-06-6 & $2.56 \mathrm{E}+02$ \\
\hline $5.68 \mathrm{E}+02$ & 4 & $\mathrm{~A}$ & $3.67 \mathrm{E}+02$ & $5.97 \mathrm{E}+02$ & $6.05 E+02$ & $5.99 \mathrm{E}+02$ & EST-17-06-7 & $1.04 \mathrm{E}+00$ & EST-17-06-8 & $1.97 \mathrm{E}+02$ \\
\hline $5.68 \mathrm{E}+02$ & 5 & A & $4.03 \mathrm{E}+02$ & $5.99 \mathrm{E}+02$ & $6.06 \mathrm{E}+02$ & $5.99 \mathrm{E}+02$ & EST-17-06-9 & 6.45E-01 & EST-17-06-10 & $1.35 \mathrm{E}+02$ \\
\hline & & & & & & & & & & \\
\hline \multicolumn{11}{|l|}{ EST-17-07 } \\
\hline $4.07 \mathrm{E}+02$ & 1 & $\mathrm{~A}$ & $4.82 \mathrm{E}+02$ & $4.07 \mathrm{E}+02$ & $4.38 \mathrm{E}+02$ & $4.26 \mathrm{E}+02$ & EST-17-07-1 & 3.11E-01 & EST-17-07-2 & $1.05 \mathrm{E}+01$ \\
\hline $4.07 \mathrm{E}+02$ & 2 & A & $5.01 \mathrm{E}+02$ & $4.26 \mathrm{E}+02$ & 4.37E+02 & $4.27 \mathrm{E}+02$ & EST-17-07-3 & 6.57E-02 & EST-17-07-4 & $7.38 \mathrm{E}+00$ \\
\hline $4.07 \mathrm{E}+02$ & 3 & $\mathrm{~A}$ & $5.10 \mathrm{E}+02$ & $4.27 \mathrm{E}+02$ & $4.34 \mathrm{E}+02$ & $4.24 \mathrm{E}+02$ & EST-17-07-5 & 4.68E-02 & EST-17-07-6 & $5.30 \mathrm{E}+00$ \\
\hline $4.07 \mathrm{E}+02$ & 4 & A & $5.00 \mathrm{E}+02$ & $4.24 \mathrm{E}+02$ & $4.33 \mathrm{E}+02$ & $4.25 \mathrm{E}+02$ & EST-17-07-7 & $3.39 \mathrm{E}-02$ & EST-17-07-8 & $3.03 \mathrm{E}+00$ \\
\hline $4.07 \mathrm{E}+02$ & 5 & A & $4.66 \mathrm{E}+02$ & $4.25 \mathrm{E}+02$ & $4.35 \mathrm{E}+02$ & $4.25 \mathrm{E}+02$ & EST-17-07-9 & $2.58 \mathrm{E}-02$ & EST-17-07-10 & $1.49 \mathrm{E}+00$ \\
\hline & & & & & & & & & & \\
\hline \multicolumn{11}{|l|}{ EST-21-01 } \\
\hline $6.25 \mathrm{E}+02$ & 1 & A & $3.92 \mathrm{E}+02$ & $6.25 \mathrm{E}+02$ & $6.56 \mathrm{E}+02$ & $6.54 \mathrm{E}+02$ & EST-21-01-1 & 3.87E-01 & EST-21-01-2 & $8.68 \mathrm{E}+01$ \\
\hline $6.25 \mathrm{E}+02$ & 2 & A & $4.05 \mathrm{E}+02$ & $6.54 \mathrm{E}+02$ & $6.58 \mathrm{E}+02$ & $6.53 \mathrm{E}+02$ & EST-21-01-3 & \begin{tabular}{|l|}
$4.15 \mathrm{E}-01$ \\
\end{tabular} & EST-21-01-4 & $9.28 \mathrm{E}+01$ \\
\hline $6.25 \mathrm{E}+02$ & 3 & A & $4.03 \mathrm{E}+02$ & $6.53 \mathrm{E}+02$ & $6.60 \mathrm{E}+02$ & $6.51 \mathrm{E}+02$ & EST-21-01-5 & $2.74 \mathrm{E}-01$ & EST-21-01-6 & $7.55 \mathrm{E}+01$ \\
\hline $6.25 \mathrm{E}+02$ & 4 & A & $3.65 \mathrm{E}+02$ & $6.51 \mathrm{E}+02$ & $6.59 \mathrm{E}+02$ & $6.53 \mathrm{E}+02$ & EST-21-01-7 & 1.83E-01 & EST-21-01-8 & $8.52 \mathrm{E}+01$ \\
\hline $6.25 \mathrm{E}+02$ & 5 & A & $3.81 \mathrm{E}+02$ & $6.53 \mathrm{E}+02$ & $6.57 \mathrm{E}+02$ & $6.54 \mathrm{E}+02$ & EST-21-01-9 & $2.60 \mathrm{E}-01$ & EST-21-01-10 & $7.78 \mathrm{E}+01$ \\
\hline & & & & & & & & & & \\
\hline & & & & & & & & & & \\
\hline & & & & & & & & & & \\
\hline & & & & & & & & & & \\
\hline
\end{tabular}


Table A5. Extraction Results for ES-31E.

\begin{tabular}{|c|c|c|c|c|c|c|c|c|c|c|}
\hline $\begin{array}{c}\text { Dry Sample Mass } \\
\text { (g) }\end{array}$ & $\begin{array}{c}\text { Extraction } \\
\text { Step \# }\end{array}$ & $\begin{array}{l}\text { Soln. } \\
\text { Type¥ }\end{array}$ & $\begin{array}{c}\begin{array}{c}\text { Vol. of Soln. } \\
\text { Added for Sat. } \\
(\mathrm{mL})\end{array} \\
\end{array}$ & $\begin{array}{l}\text { Pre-Sat. } \\
\text { Sample } \\
\text { Mass (g) }\end{array}$ & \begin{tabular}{|c|} 
Post-Sat. \& \\
Draining Free Liq. \\
Sample Mass (g)
\end{tabular} & $\begin{array}{l}\text { Post-Cent. } \\
\text { Sample Mass } \\
\text { (g) }\end{array}$ & Sat. Sample \# & $\begin{array}{c}\text { Liq. [Re] } \\
\text { (Sat.) } \\
\text { ( } \mu \mathrm{g} / \mathrm{L})\end{array}$ & $\begin{array}{c}\text { Cent. Sample } \\
\#\end{array}$ & $\begin{array}{c}\text { Liq. [Re] } \\
\text { (Cent.) } \\
(\boldsymbol{\mu g} / \mathbf{L})\end{array}$ \\
\hline & & & & & & & & & & \\
\hline & & & & & & & & & & \\
\hline \multicolumn{11}{|l|}{ EST-21-02 } \\
\hline $6.71 \mathrm{E}+02$ & 1 & A & $3.71 \mathrm{E}+02$ & $6.71 \mathrm{E}+02$ & $7.05 \mathrm{E}+02$ & $7.02 \mathrm{E}+02$ & EST-21-02-1 & 7.71E-01 & EST-21-02-2 & $1.99 \mathrm{E}+02$ \\
\hline $6.71 \mathrm{E}+02$ & 2 & $\mathrm{~A}$ & $3.56 \mathrm{E}+02$ & 7.02E+02 & $7.08 \mathrm{E}+02$ & $7.01 \mathrm{E}+02$ & EST-21-02-3 & 9.70E-01 & EST-21-02-4 & $2.23 \mathrm{E}+02$ \\
\hline $6.71 \mathrm{E}+02$ & 3 & A & $3.65 \mathrm{E}+02$ & $7.01 \mathrm{E}+02$ & $7.09 \mathrm{E}+02$ & $7.03 \mathrm{E}+02$ & EST-21-02-5 & 8.86E-01 & EST-21-02-6 & $1.58 \mathrm{E}+02$ \\
\hline $6.71 \mathrm{E}+02$ & 4 & A & $3.57 \mathrm{E}+02$ & 7.03E+02 & $7.09 \mathrm{E}+02$ & $7.04 \mathrm{E}+02$ & EST-21-02-7 & 6.67E-01 & EST-21-02-8 & $1.43 \mathrm{E}+02$ \\
\hline $6.71 \mathrm{E}+02$ & 5 & A & $4.29 \mathrm{E}+02$ & $7.04 \mathrm{E}+02$ & $7.07 \mathrm{E}+02$ & $7.03 \mathrm{E}+02$ & EST-21-02-9 & 5.77E-01 & EST-21-02-10 & $1.20 \mathrm{E}+02$ \\
\hline \multicolumn{11}{|l|}{ EST-21-03 } \\
\hline $6.52 \mathrm{E}+02$ & 1 & $\mathrm{~A}$ & $3.65 \mathrm{E}+02$ & $6.52 \mathrm{E}+02$ & $6.86 \mathrm{E}+02$ & $6.82 \mathrm{E}+02$ & EST-21-03-1 & $1.07 \mathrm{E}+00$ & EST-21-03-2 & $5.72 \mathrm{E}+01$ \\
\hline $6.52 \mathrm{E}+02$ & 2 & $\mathrm{~A}$ & $3.83 \mathrm{E}+02$ & $682 . .37$ & $6.89 \mathrm{E}+02$ & $6.83 \mathrm{E}+02$ & EST-21-03-3 & 7.60E-01 & EST-21-03-4 & $7.78 \mathrm{E}+01$ \\
\hline $6.52 \mathrm{E}+02$ & 3 & $\mathrm{~A}$ & 4.27E+02 & $6.83 \mathrm{E}+02$ & $6.90 \mathrm{E}+02$ & $6.84 \mathrm{E}+02$ & EST-21-03-5 & 9.85E-01 & EST-21-03-6 & $1.21 \mathrm{E}+02$ \\
\hline $6.52 \mathrm{E}+02$ & 4 & A & $3.52 \mathrm{E}+02$ & $6.84 \mathrm{E}+02$ & $6.90 \mathrm{E}+02$ & $6.84 \mathrm{E}+02$ & EST-21-03-7 & $1.01 \mathrm{E}+00$ & EST-21-03-8 & $9.16 \mathrm{E}+01$ \\
\hline $6.52 \mathrm{E}+02$ & 5 & A & $3.73 E+02$ & $6.84 \mathrm{E}+02$ & $6.88 \mathrm{E}+02$ & $6.84 \mathrm{E}+02$ & EST-21-03-9 & 7.02E-01 & EST-21-03-10 & $1.13 \mathrm{E}+02$ \\
\hline \multicolumn{11}{|l|}{ EST-21-04 } \\
\hline $4.63 \mathrm{E}+02$ & 1 & $\mathrm{~A}$ & $3.96 \mathrm{E}+02$ & $4.63 \mathrm{E}+02$ & $4.88 \mathrm{E}+02$ & $4.85 \mathrm{E}+02$ & EST-21-04-1 & $2.65 \mathrm{E}+00$ & EST-21-04-2 & $9.80 \mathrm{E}+02$ \\
\hline $4.63 \mathrm{E}+02$ & 2 & $\mathrm{~A}$ & $3.84 \mathrm{E}+02$ & $4.85 \mathrm{E}+02$ & $4.88 \mathrm{E}+02$ & $4.84 \mathrm{E}+02$ & EST-21-04-3 & $3.11 \mathrm{E}+00$ & EST-21-04-4 & $1.01 \mathrm{E}+03$ \\
\hline $4.63 \mathrm{E}+02$ & 3 & $\mathrm{~A}$ & $4.01 \mathrm{E}+02$ & $4.84 \mathrm{E}+02$ & $4.89 \mathrm{E}+02$ & $4.86 \mathrm{E}+02$ & EST-21-04-5 & $1.92 \mathrm{E}+00$ & EST-21-04-6 & $5.93 \mathrm{E}+02$ \\
\hline $4.63 \mathrm{E}+02$ & 4 & A & $3.78 \mathrm{E}+02$ & $4.86 \mathrm{E}+02$ & $4.89 \mathrm{E}+02$ & $4.84 \mathrm{E}+02$ & EST-21-04-7 & $2.51 \mathrm{E}+00$ & EST-21-04-8 & $4.23 \mathrm{E}+02$ \\
\hline $4.63 \mathrm{E}+02$ & 5 & A & $3.89 \mathrm{E}+02$ & $4.84 \mathrm{E}+02$ & $4.88 \mathrm{E}+02$ & $4.84 \mathrm{E}+02$ & EST-21-04-9 & $1.27 \mathrm{E}+00$ & EST-21-04-10 & $3.23 \mathrm{E}+02$ \\
\hline \multicolumn{11}{|l|}{ EST-21-05 } \\
\hline $6.73 \mathrm{E}+02$ & 1 & $\mathrm{~A}$ & $3.59 \mathrm{E}+02$ & $6.73 \mathrm{E}+02$ & $7.05 \mathrm{E}+02$ & $7.04 \mathrm{E}+02$ & EST-21-05-1 & $8.35 \mathrm{E}+00$ & EST-21-05-2 & $8.24 \mathrm{E}+02$ \\
\hline $6.73 \mathrm{E}+02$ & 2 & A & $3.46 \mathrm{E}+02$ & $7.04 \mathrm{E}+02$ & $7.08 \mathrm{E}+02$ & $7.04 \mathrm{E}+02$ & EST-21-05-3 & $2.86 \mathrm{E}+00$ & EST-21-05-4 & $6.77 \mathrm{E}+02$ \\
\hline $6.73 \mathrm{E}+02$ & 3 & $\mathrm{~A}$ & $3.41 \mathrm{E}+02$ & $7.04 \mathrm{E}+02$ & $7.09 \mathrm{E}+02$ & $7.05 \mathrm{E}+02$ & EST-21-05-5 & $2.18 \mathrm{E}+00$ & EST-21-05-6 & $5.33 \mathrm{E}+02$ \\
\hline $6.73 \mathrm{E}+02$ & 4 & $\mathrm{~A}$ & $3.37 \mathrm{E}+02$ & 7.05E+02 & $7.08 \mathrm{E}+02$ & $7.05 \mathrm{E}+02$ & EST-21-05-7 & $1.96 \mathrm{E}+00$ & EST-21-05-8 & $6.32 \mathrm{E}+02$ \\
\hline $6.73 \mathrm{E}+02$ & 5 & $\mathrm{~A}$ & $3.40 \mathrm{E}+02$ & $7.05 \mathrm{E}+02$ & $7.06 \mathrm{E}+02$ & $7.05 \mathrm{E}+02$ & EST-21-05-9 & $1.68 \mathrm{E}+00$ & EST-21-05-10 & $6.94 \mathrm{E}+02$ \\
\hline & & & & & & & & & & \\
\hline & & & & & & & & & & \\
\hline
\end{tabular}


Table A5. Extraction Results for ES-31E.

\begin{tabular}{|c|c|c|c|c|c|c|c|c|c|c|}
\hline $\begin{array}{c}\text { Dry Sample Mass } \\
\text { (g) }\end{array}$ & $\begin{array}{c}\text { Extraction } \\
\text { Step \# }\end{array}$ & $\begin{array}{l}\text { Soln. } \\
\text { Type } ¥\end{array}$ & $\begin{array}{c}\text { Vol. of Soln. } \\
\text { Added for Sat. } \\
(\mathrm{mL})\end{array}$ & $\begin{array}{c}\text { Pre-Sat. } \\
\text { Sample } \\
\text { Mass (g) }\end{array}$ & $\begin{array}{c}\text { Post-Sat. \& } \\
\text { Draining Free Liq. } \\
\text { Sample Mass (g) }\end{array}$ & $\begin{array}{l}\text { Post-Cent. } \\
\text { Sample Mass } \\
\text { (g) }\end{array}$ & Sat. Sample \# & $\begin{array}{c}\text { Liq. [Re] } \\
\text { (Sat.) } \\
(\mu \mathrm{g} / \mathrm{L})\end{array}$ & $\begin{array}{c}\text { Cent. Sample } \\
\#\end{array}$ & $\begin{array}{c}\text { Liq. [Re] } \\
\text { (Cent.) } \\
(\boldsymbol{\mu g} / \mathbf{L})\end{array}$ \\
\hline \multicolumn{11}{|l|}{ Tile Samples } \\
\hline \multicolumn{11}{|l|}{ EST-17-01T } \\
\hline $6.41 \mathrm{E}+01$ & 1 & A & $1.51 \mathrm{E}+02$ & - & - & - & EST-17T-01-1 & $2.02 \mathrm{E}+02$ & - & - \\
\hline $6.41 \mathrm{E}+01$ & 2 & A & $1.02 \mathrm{E}+02$ & - & - & - & EST-17T-01-2 & $5.54 \mathrm{E}+01$ & - & - \\
\hline $6.41 \mathrm{E}+01$ & 3 & A & $8.31 \mathrm{E}+01$ & - & - & - & EST-17T-01-3 & $1.10 \mathrm{E}+02$ & - & - \\
\hline $6.41 \mathrm{E}+01$ & 4 & A & $9.85 \mathrm{E}+01$ & - & - & - & EST-17T-01-4 & $3.49 \mathrm{E}+01$ & - & - \\
\hline $6.41 \mathrm{E}+01$ & 5 & $\mathrm{~A}$ & $1.01 \mathrm{E}+02$ & - & - & - & EST-17T-01-5 & $1.58 \mathrm{E}+01$ & - & - \\
\hline $6.41 \mathrm{E}+01$ & 6 & A & - & - & - & - & EST-17T-01-6 & $3.69 \mathrm{E}+01$ & - & - \\
\hline $6.41 \mathrm{E}+01$ & 7 & A & - & - & - & - & EST-17T-01-7 & $1.98 \mathrm{E}+02$ & - & - \\
\hline $6.41 \mathrm{E}+01$ & 8 & A & $8.42 \mathrm{E}+01$ & - & - & - & EST-17T-01-8 & $1.94 \mathrm{E}+01$ & - & - \\
\hline $6.41 \mathrm{E}+01$ & 9 & A & $1.20 \mathrm{E}+02$ & - & - & - & EST-17T-01-9 & $2.51 \mathrm{E}+01$ & - & - \\
\hline $6.41 \mathrm{E}+01$ & 10 & A & $1.00 \mathrm{E}+02$ & - & - & - & EST-17T-01-10 & $1.47 \mathrm{E}+01$ & - & - \\
\hline \multicolumn{11}{|l|}{ EST-17-03T } \\
\hline $9.12 \mathrm{E}+01$ & 1 & A & $9.12 \mathrm{E}+01$ & - & - & - & EST-17-03T-1 & $2.22 \mathrm{E}+02$ & - & - \\
\hline $9.12 \mathrm{E}+01$ & 2 & A & $9.17 \mathrm{E}+01$ & - & - & - & EST-17-03T-2 & $4.03 \mathrm{E}+01$ & - & - \\
\hline $9.12 \mathrm{E}+01$ & 3 & A & $1.04 \mathrm{E}+02$ & - & - & - & EST-17-03T-3 & $1.49 \mathrm{E}+02$ & - & - \\
\hline $9.12 \mathrm{E}+01$ & 4 & $\mathrm{~A}$ & $8.54 \mathrm{E}+01$ & - & - & - & EST-17-03T-4 & $1.16 \mathrm{E}+01$ & - & - \\
\hline $9.12 \mathrm{E}+01$ & 5 & A & $9.82 \mathrm{E}+01$ & - & - & - & EST-17-03T-5 & $1.69 \mathrm{E}+01$ & - & - \\
\hline $9.12 \mathrm{E}+01$ & 6 & A & $9.55 \mathrm{E}+01$ & - & - & - & EST-17-03T-6 & $1.23 \mathrm{E}+01$ & - & - \\
\hline $9.12 \mathrm{E}+01$ & 7 & A & $8.70 \mathrm{E}+01$ & - & - & - & EST-17-03T-7 & $8.41 \mathrm{E}+00$ & - & - \\
\hline $9.12 \mathrm{E}+01$ & 8 & $\mathrm{~A}$ & $8.85 \mathrm{E}+01$ & - & - & - & EST-17-03T-8 & $1.33 \mathrm{E}+01$ & - & - \\
\hline $9.12 \mathrm{E}+01$ & 9 & A & $8.80 \mathrm{E}+01$ & - & - & - & EST-17-03T-9 & $2.49 \mathrm{E}+01$ & - & - \\
\hline $9.12 \mathrm{E}+01$ & 10 & A & $8.99 \mathrm{E}+01$ & - & - & - & EST-17-03T-10 & $1.16 \mathrm{E}+01$ & - & - \\
\hline \multicolumn{11}{|l|}{ EST-17-04T } \\
\hline $5.06 \mathrm{E}+01$ & 1 & A & $5.06 \mathrm{E}+01$ & - & - & - & EST-17-04T-1 & $4.91 \mathrm{E}+00$ & - & - \\
\hline $5.06 \mathrm{E}+01$ & 2 & A & $5.12 \mathrm{E}+01$ & - & - & - & EST-17-04T-2 & $1.92 \mathrm{E}+00$ & - & - \\
\hline $5.06 \mathrm{E}+01$ & 3 & A & $4.88 \mathrm{E}+01$ & - & - & - & EST-17-04T-3 & $4.08 \mathrm{E}+00$ & - & - \\
\hline $5.06 \mathrm{E}+01$ & 4 & A & $3.13 \mathrm{E}+01$ & - & - & - & EST-17-04T-4 & $0.00 \mathrm{E}+00$ & - & - \\
\hline $5.06 \mathrm{E}+01$ & 5 & A & $4.58 \mathrm{E}+01$ & - & - & - & EST-17-04T-5 & $2.06 \mathrm{E}-01$ & - & - \\
\hline $5.06 \mathrm{E}+01$ & 6 & $\mathrm{~A}$ & $3.93 \mathrm{E}+01$ & - & - & - & EST-17-04T-6 & $0.00 \mathrm{E}+00$ & - & - \\
\hline
\end{tabular}


Table A5. Extraction Results for ES-31E.

\begin{tabular}{|c|c|c|c|c|c|c|c|c|c|c|}
\hline $\begin{array}{c}\text { Dry Sample Mass } \\
\text { (g) }\end{array}$ & $\begin{array}{c}\text { Extraction } \\
\text { Step \# }\end{array}$ & $\begin{array}{l}\text { Soln. } \\
\text { Type¥ }\end{array}$ & $\begin{array}{l}\text { Vol. of Soln. } \\
\text { Added for Sat. } \\
\quad(\mathrm{mL})\end{array}$ & $\begin{array}{c}\text { Pre-Sat. } \\
\text { Sample } \\
\text { Mass (g) }\end{array}$ & $\begin{array}{c}\text { Post-Sat. \& } \\
\text { Draining Free Liq. } \\
\text { Sample Mass (g) }\end{array}$ & $\begin{array}{l}\text { Post-Cent. } \\
\text { Sample Mass } \\
\text { (g) }\end{array}$ & Sat. Sample \# & $\begin{array}{c}\text { Liq. [Re] } \\
\text { (Sat.) } \\
(\mu \mathrm{g} / \mathrm{L})\end{array}$ & $\begin{array}{c}\text { Cent. Sample } \\
\#\end{array}$ & $\begin{array}{c}\text { Liq. [Re] } \\
\text { (Cent.) } \\
(\boldsymbol{\mu g} / \mathbf{L})\end{array}$ \\
\hline $5.06 \mathrm{E}+01$ & 7 & $\mathrm{~A}$ & $3.46 \mathrm{E}+01$ & - & - & - & EST-17-04T-7 & 9.73E-02 & - & - \\
\hline $5.06 \mathrm{E}+01$ & 8 & A & $4.33 \mathrm{E}+01$ & - & - & - & EST-17-04T-8 & $0.00 \mathrm{E}+00$ & - & - \\
\hline $5.06 \mathrm{E}+01$ & 9 & A & $4.96 \mathrm{E}+01$ & - & - & - & EST-17-04T-9 & \begin{tabular}{|l|}
$1.12 \mathrm{E}-01$ \\
\end{tabular} & - & - \\
\hline $5.06 \mathrm{E}+01$ & 10 & $\mathrm{~A}$ & $3.66 \mathrm{E}+01$ & - & - & - & EST-17-04T-10 & $0.00 \mathrm{E}+00$ & - & - \\
\hline \multicolumn{11}{|l|}{ EST-17-05T } \\
\hline $6.41 \mathrm{E}+01$ & 1 & A & $6.41 \mathrm{E}+01$ & - & - & - & EST-17-05T-1 & $3.29 \mathrm{E}+00$ & - & - \\
\hline $6.41 \mathrm{E}+01$ & 2 & $\mathrm{~A}$ & $7.44 \mathrm{E}+01$ & - & - & - & EST-17-05T-2 & 8.74E-01 & - & - \\
\hline $6.41 \mathrm{E}+01$ & 3 & A & $6.17 \mathrm{E}+01$ & - & - & - & EST-17-05T-3 & $3.45 \mathrm{E}+00$ & - & - \\
\hline $6.41 \mathrm{E}+01$ & 4 & A & $7.62 \mathrm{E}+01$ & - & - & - & EST-17-05T-4 & $0.00 \mathrm{E}+00$ & - & - \\
\hline $6.41 \mathrm{E}+01$ & 5 & A & $6.69 \mathrm{E}+01$ & - & - & - & EST-17-05T-5 & $3.45 \mathrm{E}-01$ & - & - \\
\hline $6.41 \mathrm{E}+01$ & 6 & A & $7.32 \mathrm{E}+01$ & - & - & - & EST-17-05T-6 & $0.00 \mathrm{E}+00$ & - & - \\
\hline $6.41 \mathrm{E}+01$ & 7 & A & $6.28 \mathrm{E}+01$ & - & - & - & EST-17-05T-7 & $1.87 \mathrm{E}-01$ & - & - \\
\hline $6.41 \mathrm{E}+01$ & 8 & A & $7.82 \mathrm{E}+01$ & - & - & - & EST-17-05T-8 & $0.00 \mathrm{E}+00$ & - & - \\
\hline $6.41 \mathrm{E}+01$ & 9 & A & $9.16 \mathrm{E}+01$ & - & - & - & EST-17-05T-9 & $1.88 \mathrm{E}-01$ & - & - \\
\hline $6.41 \mathrm{E}+01$ & 10 & A & $7.65 \mathrm{E}+01$ & - & - & - & EST-17-05T-10 & $0.00 \mathrm{E}+00$ & - & - \\
\hline \multicolumn{11}{|l|}{ EST-17-06T } \\
\hline $6.39 \mathrm{E}+01$ & 1 & $\mathrm{~A}$ & $6.39 \mathrm{E}+01$ & - & - & - & EST-17-06T-1 & $9.44 \mathrm{E}+00$ & - & - \\
\hline $6.39 \mathrm{E}+01$ & 2 & A & $6.51 \mathrm{E}+01$ & - & - & - & EST-17-06T-2 & $3.54 \mathrm{E}+00$ & - & - \\
\hline $6.39 \mathrm{E}+01$ & 3 & $\mathrm{~A}$ & $6.51 \mathrm{E}+01$ & - & - & - & EST-17-06T-3 & $9.50 \mathrm{E}+00$ & - & - \\
\hline $6.39 \mathrm{E}+01$ & 4 & A & $6.64 \mathrm{E}+01$ & - & - & - & EST-17-06T-4 & $0.00 \mathrm{E}+00$ & - & - \\
\hline $6.39 \mathrm{E}+01$ & 5 & $\mathrm{~A}$ & $6.32 \mathrm{E}+01$ & - & - & - & EST-17-06T-5 & 8.15E-01 & - & - \\
\hline $6.39 \mathrm{E}+01$ & 6 & A & $6.30 \mathrm{E}+01$ & - & - & - & EST-17-06T-6 & $0.00 \mathrm{E}+00$ & - & - \\
\hline $6.39 \mathrm{E}+01$ & 7 & $\mathrm{~A}$ & $6.57 \mathrm{E}+01$ & - & - & - & EST-17-06T-7 & 3.24E-01 & - & - \\
\hline $6.39 \mathrm{E}+01$ & 8 & $\mathrm{~A}$ & $6.22 \mathrm{E}+01$ & - & - & - & EST-17-06T-8 & 6.52E-01 & - & - \\
\hline $6.39 \mathrm{E}+01$ & 9 & A & $6.68 \mathrm{E}+01$ & - & - & - & EST-17-06T-9 & 5.12E-01 & - & - \\
\hline $6.39 \mathrm{E}+01$ & 10 & $\mathrm{~A}$ & $6.98 \mathrm{E}+01$ & - & - & - & EST-17-06T-10 & $0.00 \mathrm{E}+00$ & - & - \\
\hline & & & & & & & & & & \\
\hline & & & & & & & & & & \\
\hline & & & & & & & & & & \\
\hline
\end{tabular}


Table A5. Extraction Results for ES-31E.

\begin{tabular}{|c|c|c|c|c|c|c|c|c|c|c|}
\hline $\begin{array}{l}\text { Dry Sample Mass } \\
\text { (g) }\end{array}$ & $\begin{array}{c}\text { Extraction } \\
\text { Step \# }\end{array}$ & $\begin{array}{l}\text { Soln. } \\
\text { Type\# }\end{array}$ & $\begin{array}{l}\text { Vol. of Soln. } \\
\text { Added for Sat. } \\
\quad(\mathrm{mL})\end{array}$ & $\begin{array}{l}\text { Pre-Sat. } \\
\text { Sample } \\
\text { Mass (g) }\end{array}$ & $\begin{array}{c}\text { Post-Sat. \& } \\
\text { Draining Free Liq. } \\
\text { Sample Mass (g) }\end{array}$ & $\begin{array}{l}\text { Post-Cent. } \\
\text { Sample Mass } \\
\text { (g) }\end{array}$ & Sat. Sample \# & $\begin{array}{c}\text { Liq. [Re] } \\
\text { (Sat.) } \\
\text { ( } \mu \mathrm{g} / \mathrm{L})\end{array}$ & $\begin{array}{c}\text { Cent. Sample } \\
\#\end{array}$ & $\begin{array}{c}\text { Liq. }[\mathrm{Re}] \\
(\text { Cent.) } \\
(\mu \mathrm{g} / \mathrm{L})\end{array}$ \\
\hline \multicolumn{11}{|l|}{ EST-17-07T } \\
\hline $5.17 \mathrm{E}+01$ & 1 & A & $5.17 \mathrm{E}+01$ & - & - & - & EST-17-07T-1 & $2.73 \mathrm{E}+00$ & - & - \\
\hline $5.17 \mathrm{E}+01$ & 2 & A & $6.71 \mathrm{E}+01$ & - & - & - & EST-17-07T-2 & 7.27E-01 & - & - \\
\hline $5.17 \mathrm{E}+01$ & 3 & A & $5.62 \mathrm{E}+01$ & - & - & - & EST-17-07T-3 & $1.37 \mathrm{E}+00$ & - & - \\
\hline $5.17 \mathrm{E}+01$ & 4 & A & $5.61 \mathrm{E}+01$ & - & - & - & EST-17-07T-4 & $0.00 \mathrm{E}+00$ & - & - \\
\hline $5.17 \mathrm{E}+01$ & 5 & A & $7.66 \mathrm{E}+01$ & - & - & - & EST-17-07T-5 & 2.83E-01 & - & - \\
\hline $5.17 \mathrm{E}+01$ & 6 & A & $6.22 \mathrm{E}+01$ & - & - & - & EST-17-07T-6 & $0.00 \mathrm{E}+00$ & - & - \\
\hline $5.17 \mathrm{E}+01$ & 7 & A & $5.12 \mathrm{E}+01$ & - & - & - & EST-17-07T-7 & 1.77E-01 & - & - \\
\hline $5.17 \mathrm{E}+01$ & 8 & A & $4.50 \mathrm{E}+01$ & - & - & - & EST-17-07T-8 & $0.00 \mathrm{E}+00$ & - & - \\
\hline $5.17 \mathrm{E}+01$ & 9 & A & $4.65 \mathrm{E}+01$ & - & - & - & EST-17-07T-9 & 1.35E-01 & - & - \\
\hline $5.17 \mathrm{E}+01$ & 10 & A & $6.71 \mathrm{E}+01$ & - & - & - & EST-17-07T-10 & $0.00 \mathrm{E}+00$ & - & - \\
\hline & & & & & & & & & & \\
\hline \multicolumn{11}{|l|}{ Untiled Refractory } \\
\hline \multicolumn{11}{|l|}{ EST-18-01 } \\
\hline $6.07 \mathrm{E}+02$ & 1 & A & $3.41 \mathrm{E}+02$ & $6.07 \mathrm{E}+02$ & $6.42 \mathrm{E}+02$ & $6.39 \mathrm{E}+02$ & EST-18-01-1 & $4.24 \mathrm{E}+01$ & EST-18-01-2 & $5.02 \mathrm{E}+02$ \\
\hline $6.07 \mathrm{E}+02$ & 2 & A & $3.31 \mathrm{E}+02$ & $6.39 \mathrm{E}+02$ & $6.43 \mathrm{E}+02$ & $6.40 \mathrm{E}+02$ & EST-18-01-3 & $1.19 \mathrm{E}+01$ & EST-18-01-4 & $5.83 \mathrm{E}+02$ \\
\hline $6.07 \mathrm{E}+02$ & 3 & A & $3.54 \mathrm{E}+02$ & $6.40 \mathrm{E}+02$ & $6.42 \mathrm{E}+02$ & $6.38 \mathrm{E}+02$ & EST-18-01-5 & $9.24 \mathrm{E}+00$ & EST-18-01-6 & $5.01 \mathrm{E}+02$ \\
\hline $6.07 \mathrm{E}+02$ & 4 & A & $3.31 \mathrm{E}+02$ & $6.38 \mathrm{E}+02$ & $6.39 \mathrm{E}+02$ & - & EST-18-01-7 & $7.10 \mathrm{E}+01$ & EST-18-01-8 & $4.50 \mathrm{E}+02$ \\
\hline $6.07 \mathrm{E}+02$ & 5 & $\mathrm{~A}$ & $2.87 \mathrm{E}+02$ & - & - & - & EST-18-01-9 & $1.26 \mathrm{E}+01$ & EST-18-01-10 & $4.57 \mathrm{E}+02$ \\
\hline $6.07 \mathrm{E}+02$ & 6 & A & $2.67 \mathrm{E}+02$ & $6.37 \mathrm{E}+02$ & $6.41 \mathrm{E}+02$ & $6.35 \mathrm{E}+02$ & EST-18-01-11 & $5.45 \mathrm{E}+01$ & EST-18-01-12 & $3.66 \mathrm{E}+02$ \\
\hline $6.07 \mathrm{E}+02$ & 7 & A & $3.02 \mathrm{E}+02$ & $6.35 \mathrm{E}+02$ & $6.39 \mathrm{E}+02$ & $6.36 \mathrm{E}+02$ & EST-18-01-13 & $4.23 \mathrm{E}+00$ & EST-18-01-14 & $4.53 \mathrm{E}+02$ \\
\hline \multicolumn{11}{|l|}{ EST-18-03 } \\
\hline $5.86 \mathrm{E}+02$ & 1 & A & $4.13 \mathrm{E}+02$ & $5.86 \mathrm{E}+02$ & $6.21 \mathrm{E}+02$ & $6.18 \mathrm{E}+02$ & EST-18-03-1 & $5.01 \mathrm{E}+01$ & EST-18-03-2 & $1.23 \mathrm{E}+03$ \\
\hline $5.86 \mathrm{E}+02$ & 2 & $\mathrm{~A}$ & $4.59 \mathrm{E}+02$ & $6.18 \mathrm{E}+02$ & $6.22 \mathrm{E}+02$ & $6.18 \mathrm{E}+02$ & EST-18-03-3 & $6.62 \mathrm{E}+00$ & EST-18-03-4 & $6.29 \mathrm{E}+02$ \\
\hline $5.86 \mathrm{E}+02$ & 3 & A & $4.48 \mathrm{E}+02$ & $6.18 \mathrm{E}+02$ & $6.22 \mathrm{E}+02$ & $6.18 \mathrm{E}+02$ & EST-18-03-5 & $4.17 \mathrm{E}+00$ & EST-18-03-6 & $4.10 \mathrm{E}+02$ \\
\hline $5.86 \mathrm{E}+02$ & 4 & A & $4.42 \mathrm{E}+02$ & $6.18 \mathrm{E}+02$ & $6.22 \mathrm{E}+02$ & $6.19 \mathrm{E}+02$ & EST-18-03-7 & $1.30 \mathrm{E}+01$ & EST-18-03-8 & $4.10 \mathrm{E}+02$ \\
\hline $5.86 \mathrm{E}+02$ & 5 & $\mathrm{~A}$ & $4.03 \mathrm{E}+02$ & $6.19 \mathrm{E}+02$ & $6.21 \mathrm{E}+02$ & $6.19 \mathrm{E}+02$ & EST-18-03-9 & $2.00 \mathrm{E}+00$ & EST-18-03-10 & $3.23 \mathrm{E}+02$ \\
\hline & & & & & & & & & & \\
\hline & & & & & & & & & & \\
\hline & & & & & & & & & & \\
\hline & & & & & & & & & & \\
\hline
\end{tabular}


Table A5. Extraction Results for ES-31E.

\begin{tabular}{|c|c|c|c|c|c|c|c|c|c|c|}
\hline $\begin{array}{c}\text { Dry Sample Mass } \\
\text { (g) }\end{array}$ & $\begin{array}{c}\text { Extraction } \\
\text { Step \# }\end{array}$ & $\begin{array}{c}\text { Soln. } \\
\text { Type¥ }\end{array}$ & \begin{tabular}{|c|}
$\begin{array}{c}\text { Vol. of Soln. } \\
\text { Added for Sat. } \\
(\mathrm{mL})\end{array}$ \\
\end{tabular} & \begin{tabular}{|c|} 
Pre-Sat. \\
Sample \\
Mass (g) \\
\end{tabular} & $\begin{array}{c}\text { Post-Sat. \& } \\
\text { Draining Free Liq. } \\
\text { Sample Mass (g) } \\
\end{array}$ & $\begin{array}{c}\text { Post-Cent. } \\
\text { Sample Mass } \\
\text { (g) }\end{array}$ & Sat. Sample \# & $\begin{array}{c}\text { Liq. [Re] } \\
\text { (Sat.) } \\
\text { (pg/L) } \\
\end{array}$ & $\begin{array}{c}\text { Cent. Sample } \\
\#\end{array}$ & $\begin{array}{l}\text { Liq. [Re] } \\
\text { (Cent.) } \\
(\mu \mathrm{g} / \mathbf{L}) \\
\end{array}$ \\
\hline \multicolumn{11}{|l|}{ EST-18-04 } \\
\hline $4.38 \mathrm{E}+02$ & 1 & A & $5.28 \mathrm{E}+02$ & $4.38 \mathrm{E}+02$ & $4.68 \mathrm{E}+02$ & $4.62 \mathrm{E}+02$ & EST-18-04-1 & $1.68 \mathrm{E}+00$ & EST-18-04-2 & $2.27 \mathrm{E}+02$ \\
\hline $4.38 \mathrm{E}+02$ & 2 & A & $4.78 \mathrm{E}+02$ & $4.62 \mathrm{E}+02$ & $4.68 \mathrm{E}+02$ & $4.61 \mathrm{E}+02$ & EST-18-04-3 & $1.21 \mathrm{E}+00$ & EST-18-04-4 & $3.85 \mathrm{E}+02$ \\
\hline $4.38 \mathrm{E}+02$ & 3 & A & $4.62 \mathrm{E}+02$ & $4.61 \mathrm{E}+02$ & $4.68 \mathrm{E}+02$ & $4.60 \mathrm{E}+02$ & EST-18-04-5 & $1.29 \mathrm{E}+00$ & EST-18-04-6 & $5.94 \mathrm{E}+02$ \\
\hline $4.38 \mathrm{E}+02$ & 4 & A & $4.88 \mathrm{E}+02$ & $4.60 \mathrm{E}+02$ & $4.68 \mathrm{E}+02$ & $4.62 \mathrm{E}+02$ & EST-18-04-7 & $5.05 \mathrm{E}+00$ & EST-18-04-8 & $3.97 \mathrm{E}+02$ \\
\hline $4.38 \mathrm{E}+02$ & 5 & A & $4.69 \mathrm{E}+02$ & $4.62 \mathrm{E}+02$ & $4.67 \mathrm{E}+02$ & $4.63 \mathrm{E}+02$ & EST-18-04-9 & $1.42 \mathrm{E}+00$ & EST-18-04-10 & $2.17 \mathrm{E}+02$ \\
\hline & & & & & & & & & & \\
\hline \multicolumn{11}{|l|}{ EST-18-05 } \\
\hline $5.99 \mathrm{E}+02$ & 1 & A & $4.44 \mathrm{E}+02$ & $5.99 \mathrm{E}+02$ & $6.40 \mathrm{E}+02$ & $6.30 \mathrm{E}+02$ & EST-18-05-1 & $2.80 \mathrm{E}+00$ & EST-18-05-2 & $1.60 \mathrm{E}+02$ \\
\hline $5.99 \mathrm{E}+02$ & 2 & A & $4.15 E+02$ & $6.30 \mathrm{E}+02$ & $6.40 \mathrm{E}+02$ & $6.31 \mathrm{E}+02$ & EST-18-05-3 & $8.45 \mathrm{E}+00$ & EST-18-05-4 & $3.63 \mathrm{E}+02$ \\
\hline $5.99 \mathrm{E}+02$ & 3 & A & $4.29 \mathrm{E}+02$ & $6.31 \mathrm{E}+02$ & $6.38 \mathrm{E}+02$ & $6.27 \mathrm{E}+02$ & EST-18-05-5 & $1.46 \mathrm{E}+00$ & EST-18-05-6 & $9.75 \mathrm{E}+02$ \\
\hline $5.99 \mathrm{E}+02$ & 4 & A & $3.82 \mathrm{E}+02$ & $6.27 \mathrm{E}+02$ & $6.38 \mathrm{E}+02$ & $6.29 \mathrm{E}+02$ & EST-18-05-7 & $3.01 \mathrm{E}+00$ & EST-18-05-8 & $1.62 \mathrm{E}+03$ \\
\hline $5.99 \mathrm{E}+02$ & 5 & A & $4.08 \mathrm{E}+02$ & $6.29 \mathrm{E}+02$ & $6.37 \mathrm{E}+02$ & $6.30 \mathrm{E}+02$ & EST-18-05-9 & $4.53 \mathrm{E}+00$ & EST-18-05-10 & $1.08 \mathrm{E}+03$ \\
\hline & & & \multicolumn{2}{|c|}{ EST-18-06 } & & & & & & \\
\hline $2.99 \mathrm{E}+02$ & 1 & A & $4.48 \mathrm{E}+02$ & $2.99 \mathrm{E}+02$ & $3.20 \mathrm{E}+02$ & $3.15 \mathrm{E}+02$ & EST-18-06-1 & $2.58 \mathrm{E}+00$ & EST-18-06-2 & $2.56 \mathrm{E}+02$ \\
\hline $2.99 \mathrm{E}+02$ & 2 & $\mathrm{~A}$ & $4.45 \mathrm{E}+02$ & $3.15 E+02$ & $3.19 \mathrm{E}+02$ & $3.15 \mathrm{E}+02$ & EST-18-06-3 & $6.51 \mathrm{E}+00$ & EST-18-06-4 & $2.28 \mathrm{E}+02$ \\
\hline $2.99 \mathrm{E}+02$ & 3 & A & $4.26 \mathrm{E}+02$ & $3.15 \mathrm{E}+02$ & $3.19 \mathrm{E}+02$ & $3.12 \mathrm{E}+02$ & EST-18-06-5 & 8.18E-01 & EST-18-06-6 & $1.98 \mathrm{E}+02$ \\
\hline $2.99 \mathrm{E}+02$ & 4 & A & $4.41 \mathrm{E}+02$ & $3.12 \mathrm{E}+02$ & $3.20 \mathrm{E}+02$ & $3.14 \mathrm{E}+02$ & EST-18-06-7 & $5.10 \mathrm{E}-01$ & EST-18-06-8 & $1.52 \mathrm{E}+02$ \\
\hline $2.99 \mathrm{E}+02$ & 5 & A & $4.43 \mathrm{E}+02$ & $3.14 \mathrm{E}+02$ & $3.18 \mathrm{E}+02$ & $3.16 \mathrm{E}+02$ & EST-18-06-9 & 6.16E-01 & EST-18-06-10 & $2.75 \mathrm{E}+02$ \\
\hline & & & & & & & & & & \\
\hline \multicolumn{11}{|l|}{ EST-18-07 } \\
\hline $2.87 \mathrm{E}+02$ & 1 & A & $5.73 \mathrm{E}+02$ & $2.87 \mathrm{E}+02$ & $3.06 \mathrm{E}+02$ & $2.98 \mathrm{E}+02$ & EST-18-07-1 & 1.09E-01 & EST-18-07-2 & $1.73 \mathrm{E}+01$ \\
\hline $2.87 \mathrm{E}+02$ & 2 & A & $6.01 \mathrm{E}+02$ & $2.98 \mathrm{E}+02$ & $3.07 \mathrm{E}+02$ & $2.99 \mathrm{E}+02$ & EST-18-07-3 & 1.71E-01 & EST-18-07-4 & $6.08 \mathrm{E}+00$ \\
\hline $2.87 \mathrm{E}+02$ & 3 & $\mathrm{~A}$ & $5.97 \mathrm{E}+02$ & $2.99 \mathrm{E}+02$ & $3.07 \mathrm{E}+02$ & $2.98 \mathrm{E}+02$ & EST-18-07-5 & $0.00 \mathrm{E}+00$ & EST-18-07-6 & $3.26 \mathrm{E}+00$ \\
\hline $2.87 \mathrm{E}+02$ & 4 & A & $5.73 \mathrm{E}+02$ & $2.98 \mathrm{E}+02$ & $3.04 \mathrm{E}+02$ & $2.97 \mathrm{E}+02$ & EST-18-07-7 & $0.00 \mathrm{E}+00$ & EST-18-07-8 & $1.95 \mathrm{E}+00$ \\
\hline $2.87 \mathrm{E}+02$ & 5 & A & $5.79 \mathrm{E}+02$ & $2.97 \mathrm{E}+02$ & $3.04 \mathrm{E}+02$ & $2.98 \mathrm{E}+02$ & EST-18-07-9 & $0.00 \mathrm{E}+00$ & EST-18-07-10 & $1.26 \mathrm{E}+00$ \\
\hline \multicolumn{11}{|c|}{$\begin{array}{l}\text { Soln - Solution } \\
\text { Vol. - Volume } \\
\text { Sat - Saturation } \\
\text { Liq. - Liquid } \\
\text { Cent. - Centrifugation } \\
\text { [Re] - Rhenium Concentration } \\
\end{array}$} \\
\hline
\end{tabular}


Table A6. Extraction Results for ES-32A.

\begin{tabular}{|c|c|c|c|c|c|c|c|c|c|c|c|c|}
\hline \begin{tabular}{|c|}
$\begin{array}{c}\text { Dry Sample } \\
\text { Mass (g) }\end{array}$ \\
\\
ES-32A \\
\end{tabular} & $\begin{array}{c}\text { Extraction } \\
\text { Step \# }\end{array}$ & $\begin{array}{l}\text { Soln. } \\
\text { Typeæ }\end{array}$ & $\begin{array}{l}\text { Vol. of Soln. } \\
\text { Added for } \\
\text { Sat. (mL) }\end{array}$ & $\begin{array}{c}\text { Pre-Sat. } \\
\text { Sample } \\
\text { Mass (g) }\end{array}$ & $\begin{array}{c}\text { Post-Sat. \& } \\
\text { Draining Free } \\
\text { Liq. Sample } \\
\text { Mass (g) }\end{array}$ & $\begin{array}{c}\text { Post-Cent. } \\
\text { Sample } \\
\text { Mass (g) }\end{array}$ & Sat. Sample \# & $\begin{array}{c}\text { Liq. [Re] } \\
\text { (Sat.) } \\
\text { ( } \mu \mathrm{g} / \mathrm{L})\end{array}$ & $\begin{array}{c}\text { Liq. }\left[{ }^{99} \mathrm{Tc}\right] \\
\text { (Sat.) } \\
(\mu \mathrm{g} / \mathrm{L})\end{array}$ & Cent. Sample \# & $\begin{array}{c}\text { Liq. [Re] } \\
\text { (Cent.) } \\
\text { ( } \mu \mathrm{g} / \mathrm{L})\end{array}$ & $\begin{array}{c}\left.\text { Liq. }{ }^{99} \mathrm{Tc}\right] \\
\text { (Cent.) } \\
\text { ( } \mu \mathrm{g} / \mathrm{L})\end{array}$ \\
\hline \multicolumn{13}{|l|}{ EST-10-01A } \\
\hline \multicolumn{13}{|l|}{ Fragment \#1 } \\
\hline $5.07 \mathrm{E}+02$ & 1 & $\mathrm{~A}$ & $5.55 \mathrm{E}+02$ & $5.07 \mathrm{E}+02$ & $5.33 \mathrm{E}+02$ & $5.26 \mathrm{E}+02$ & EST-10-1A-1 & $2.22 \mathrm{E}+02$ & $1.42 \mathrm{E}+00$ & EST-10-1A-2 & $4.73 \mathrm{E}+02$ & $0.00 \mathrm{E}+00$ \\
\hline $5.07 \mathrm{E}+02$ & 2 & $\mathrm{~A}$ & $5.39 \mathrm{E}+02$ & $5.26 \mathrm{E}+02$ & $5.32 \mathrm{E}+02$ & $5.25 \mathrm{E}+02$ & EST-10-1A-3 & $2.87 \mathrm{E}+01$ & $2.23 \mathrm{E}-01$ & EST-10-1A-4 & $5.98 \mathrm{E}+02$ & $4.28 \mathrm{E}+00$ \\
\hline $5.07 \mathrm{E}+02$ & 3 & A & $5.23 \mathrm{E}+02$ & $5.25 \mathrm{E}+02$ & $5.31 \mathrm{E}+02$ & $5.25 \mathrm{E}+02$ & EST-10-1A-5 & $2.14 \mathrm{E}+01$ & $1.63 \mathrm{E}-01$ & EST-10-1A-6 & $8.59 \mathrm{E}+02$ & $5.83 \mathrm{E}+00$ \\
\hline $5.07 \mathrm{E}+02$ & 4 & $\mathrm{~A}$ & $5.57 \mathrm{E}+02$ & $5.25 \mathrm{E}+02$ & $5.32 \mathrm{E}+02$ & $5.25 \mathrm{E}+02$ & EST-10-1A-7 & $1.96 \mathrm{E}+01$ & 2.07E-01 & EST-10-1A-8 & $9.76 \mathrm{E}+02$ & $6.30 \mathrm{E}+00$ \\
\hline $5.07 \mathrm{E}+02$ & 5 & A & $5.24 \mathrm{E}+02$ & $5.25 \mathrm{E}+02$ & $5.32 \mathrm{E}+02$ & $5.25 \mathrm{E}+02$ & EST-10-1A-9 & $9.04 \mathrm{E}+01$ & $7.81 \mathrm{E}-01$ & EST-10-1A-10 & $1.28 \mathrm{E}+03$ & $6.87 \mathrm{E}+00$ \\
\hline & & & & & & & & & & & & \\
\hline \multicolumn{13}{|l|}{ EST-10-01B } \\
\hline \multicolumn{13}{|l|}{ Fragment \#1 } \\
\hline $5.08 \mathrm{E}+02$ & 1 & $\mathrm{~A}$ & $5.30 \mathrm{E}+02$ & $5.08 \mathrm{E}+02$ & $5.32 \mathrm{E}+02$ & $5.26 \mathrm{E}+02$ & EST-10-1B-1 & $1.45 \mathrm{E}+02$ & $1.72 \mathrm{E}+00$ & EST-10-1B-2 & $2.84 \mathrm{E}+02$ & $2.81 \mathrm{E}+00$ \\
\hline $5.08 \mathrm{E}+02$ & 2 & A & $5.64 \mathrm{E}+02$ & $5.26 \mathrm{E}+02$ & $5.31 \mathrm{E}+02$ & $5.26 \mathrm{E}+02$ & EST-10-1B-3 & $2.04 \mathrm{E}+01$ & $1.81 \mathrm{E}-01$ & EST-10-1B-4 & $3.69 \mathrm{E}+02$ & $3.44 \mathrm{E}+00$ \\
\hline $5.08 \mathrm{E}+02$ & 3 & $\mathrm{~A}$ & $5.21 \mathrm{E}+02$ & $5.26 \mathrm{E}+02$ & $5.31 \mathrm{E}+02$ & $5.25 \mathrm{E}+02$ & EST-10-1B-5 & $2.35 \mathrm{E}+01$ & $2.21 \mathrm{E}-01$ & EST-10-1B-6 & $5.13 E+02$ & $4.47 \mathrm{E}+00$ \\
\hline $5.08 \mathrm{E}+02$ & 4 & $\mathrm{~A}$ & $5.33 \mathrm{E}+02$ & $5.25 \mathrm{E}+02$ & $5.31 \mathrm{E}+02$ & $5.25 \mathrm{E}+02$ & EST-10-1B-7 & $1.77 \mathrm{E}+01$ & $1.54 \mathrm{E}-01$ & EST-10-1B-8 & $6.48 \mathrm{E}+02$ & $5.23 \mathrm{E}+00$ \\
\hline $5.08 \mathrm{E}+02$ & 5 & $\mathrm{~A}$ & $5.07 \mathrm{E}+02$ & $5.25 \mathrm{E}+02$ & $5.32 \mathrm{E}+02$ & $5.26 \mathrm{E}+02$ & EST-10-1B-9 & $9.26 \mathrm{E}+01$ & $9.16 \mathrm{E}-01$ & EST-10-1B-10 & $7.87 \mathrm{E}+02$ & $5.00 \mathrm{E}+00$ \\
\hline \multicolumn{13}{|l|}{\begin{tabular}{|c|} 
EST-10-02 \\
\end{tabular}} \\
\hline \\
\hline $2.64 \mathrm{E}+02$ & 1 & A & $3.61 \mathrm{E}+02$ & $2.64 \mathrm{E}+02$ & $2.77 \mathrm{E}+02$ & $2.73 \mathrm{E}+02$ & EST-10-02-1-1 & $4.24 \mathrm{E}+01$ & $4.67 \mathrm{E}+00$ & EST-10-02-1-2 & $1.12 \mathrm{E}+04$ & $1.25 \mathrm{E}+02$ \\
\hline $2.64 \mathrm{E}+02$ & 2 & $\mathrm{~A}$ & $4.33 \mathrm{E}+02$ & $2.73 \mathrm{E}+02$ & $2.77 \mathrm{E}+02$ & $2.73 \mathrm{E}+02$ & EST-10-02-1-3 & $2.42 \mathrm{E}+01$ & 4.63E-01 & EST-10-02-1-4 & $1.11 \mathrm{E}+04$ & $1.48 \mathrm{E}+02$ \\
\hline $2.64 \mathrm{E}+02$ & 3 & $\mathrm{~A}$ & $3.47 \mathrm{E}+02$ & $2.73 \mathrm{E}+02$ & $2.77 \mathrm{E}+02$ & $2.73 \mathrm{E}+02$ & EST-10-02-1-5 & $3.58 \mathrm{E}+01$ & $5.98 \mathrm{E}-01$ & EST-10-02-1-6 & $8.01 \mathrm{E}+03$ & $1.33 \mathrm{E}+02$ \\
\hline $2.64 \mathrm{E}+02$ & 4 & $\mathrm{~A}$ & $3.69 \mathrm{E}+02$ & $2.73 \mathrm{E}+02$ & $2.77 \mathrm{E}+02$ & $2.74 \mathrm{E}+02$ & EST-10-02-1-7 & $2.06 \mathrm{E}+01$ & 4.24E-01 & EST-10-02-1-8 & $3.46 \mathrm{E}+03$ & $5.12 \mathrm{E}+01$ \\
\hline $2.64 \mathrm{E}+02$ & 5 & $\mathrm{~A}$ & $3.60 \mathrm{E}+02$ & $2.74 \mathrm{E}+02$ & $2.78 \mathrm{E}+02$ & $2.73 \mathrm{E}+02$ & EST-10-02-1-9 & $2.34 \mathrm{E}+01$ & 4.73E-01 & EST-10-02-1-10 & $1.76 \mathrm{E}+03$ & $3.08 \mathrm{E}+01$ \\
\hline \multicolumn{13}{|l|}{ Fragment \#2 } \\
\hline $3.33 \mathrm{E}+02$ & 1 & A & $3.62 \mathrm{E}+02$ & $3.33 \mathrm{E}+02$ & $3.36 \mathrm{E}+02$ & $3.32 \mathrm{E}+02$ & EST-10-02-2-1 & $3.99 \mathrm{E}+00$ & $2.62 \mathrm{E}-02$ & EST-10-02-2-2 & $9.15 \mathrm{E}+02$ & $2.84 \mathrm{E}+00$ \\
\hline $3.33 \mathrm{E}+02$ & 2 & $\mathrm{~A}$ & $3.81 \mathrm{E}+02$ & $3.32 \mathrm{E}+02$ & $3.37 \mathrm{E}+02$ & $3.32 \mathrm{E}+02$ & EST-10-02-2-3 & $3.71 \mathrm{E}+00$ & $2.55 \mathrm{E}-02$ & EST-10-02-2-4 & $4.14 \mathrm{E}+02$ & $1.62 \mathrm{E}+00$ \\
\hline $3.33 E+02$ & 3 & A & $3.39 \mathrm{E}+02$ & $3.32 \mathrm{E}+02$ & $3.37 E+02$ & $3.32 \mathrm{E}+02$ & EST-10-02-2-5 & $2.18 \mathrm{E}+00$ & $0.00 \mathrm{E}+00$ & EST-10-02-2-6 & $1.94 \mathrm{E}+02$ & $9.60 \mathrm{E}-01$ \\
\hline $3.33 \mathrm{E}+02$ & 4 & A & $3.61 \mathrm{E}+02$ & $3.32 \mathrm{E}+02$ & $3.38 \mathrm{E}+02$ & $3.32 \mathrm{E}+02$ & EST-10-02-2-7 & 9.07E-01 & $0.00 \mathrm{E}+00$ & EST-10-02-2-8 & $1.04 \mathrm{E}+02$ & 5.95E-01 \\
\hline $3.33 \mathrm{E}+02$ & 5 & A & $2.82 \mathrm{E}+02$ & $3.32 \mathrm{E}+02$ & $3.37 \mathrm{E}+02$ & $3.31 \mathrm{E}+02$ & EST-10-02-2-9 & $1.44 \mathrm{E}+00$ & $0.00 \mathrm{E}+00$ & EST-10-02-2-10 & $6.62 \mathrm{E}+01$ & 3.57E-01 \\
\hline
\end{tabular}


Table A6. Extraction Results for ES-32A.

\begin{tabular}{|c|c|c|c|c|c|c|c|c|c|c|c|c|}
\hline $\begin{array}{c}\text { Dry Sample } \\
\text { Mass (g) } \\
\text { ES-32A }\end{array}$ & $\begin{array}{c}\text { Extraction } \\
\text { Step \# }\end{array}$ & \begin{tabular}{|l} 
Soln. \\
Type\#
\end{tabular} & $\begin{array}{l}\text { Vol. of Soln. } \\
\text { Added for } \\
\text { Sat. (mL) }\end{array}$ & $\begin{array}{c}\text { Pre-Sat. } \\
\text { Sample } \\
\text { Mass (g) }\end{array}$ & $\begin{array}{c}\text { Post-Sat. \& } \\
\text { Draining Free } \\
\text { Liq. Sample } \\
\text { Mass (g) }\end{array}$ & $\begin{array}{l}\text { Post-Cent. } \\
\text { Sample } \\
\text { Mass (g) }\end{array}$ & Sat. Sample \# & $\begin{array}{c}\text { Liq. [Re] } \\
\text { (Sat.) } \\
(\mu \mathrm{g} / \mathrm{L})\end{array}$ & $\begin{array}{c}\text { Liq. }\left[{ }^{99} \mathrm{Tc}\right] \\
\text { (Sat.) } \\
(\mu \mathrm{g} / \mathrm{L})\end{array}$ & Cent. Sample \# & $\begin{array}{c}\text { Liq. [Re] } \\
\text { (Cent.) } \\
(\mu \mathrm{g} / \mathrm{L})\end{array}$ & $\begin{array}{c}\left.\text { Liq. } .^{99} \mathrm{Tc}\right] \\
\text { (Cent.) } \\
(\mu \mathrm{g} / \mathrm{L})\end{array}$ \\
\hline \multicolumn{13}{|l|}{ ST-10-03 } \\
\hline \multicolumn{13}{|l|}{ Fragment \#1 } \\
\hline $4.60 \mathrm{E}+02$ & 1 & $\mathrm{~A}$ & $5.67 \mathrm{E}+02$ & $4.60 \mathrm{E}+02$ & $4.86 \mathrm{E}+02$ & $4.72 \mathrm{E}+02$ & EST-10-03-1 & $3.06 \mathrm{E}+01$ & $2.48 \mathrm{E}+00$ & EST-10-03-2 & $4.69 \mathrm{E}+02$ & $7.56 \mathrm{E}+00$ \\
\hline $4.60 \mathrm{E}+02$ & 2 & $\mathrm{~A}$ & $4.88 \mathrm{E}+02$ & $4.72 \mathrm{E}+02$ & $4.83 \mathrm{E}+02$ & $4.74 \mathrm{E}+02$ & EST-10-03-3 & $2.42 \mathrm{E}+01$ & $8.17 \mathrm{E}-01$ & EST-10-03-4 & $3.29 \mathrm{E}+02$ & $6.56 \mathrm{E}+00$ \\
\hline $4.60 \mathrm{E}+02$ & 3 & A & $4.17 \mathrm{E}+02$ & $4.74 \mathrm{E}+02$ & $4.83 \mathrm{E}+02$ & $4.74 \mathrm{E}+02$ & EST-10-03-5 & $3.19 \mathrm{E}+00$ & $1.04 \mathrm{E}-01$ & EST-10-03-6 & $2.78 \mathrm{E}+02$ & $7.03 \mathrm{E}+00$ \\
\hline $4.60 \mathrm{E}+02$ & 4 & A & $4.64 \mathrm{E}+02$ & $4.74 \mathrm{E}+02$ & $4.82 \mathrm{E}+02$ & $4.74 \mathrm{E}+02$ & EST-10-03-7 & $3.03 \mathrm{E}+00$ & 1.09E-01 & EST-10-03-8 & $1.56 \mathrm{E}+02$ & $5.47 \mathrm{E}+00$ \\
\hline $4.60 \mathrm{E}+02$ & 5 & $\mathrm{~A}$ & $4.20 \mathrm{E}+02$ & $4.74 \mathrm{E}+02$ & $4.82 \mathrm{E}+02$ & $4.73 \mathrm{E}+02$ & EST-10-03-9 & $3.01 \mathrm{E}+00$ & $9.88 \mathrm{E}-02$ & EST-10-03-10 & $1.50 \mathrm{E}+02$ & $4.44 \mathrm{E}+00$ \\
\hline & & & & & & & & & & & & \\
\hline \multicolumn{13}{|l|}{ EST-10-04 } \\
\hline \multicolumn{13}{|l|}{ Fragment \#1 } \\
\hline $2.47 \mathrm{E}+02$ & 1 & $\mathrm{~A}$ & $5.15 \mathrm{E}+02$ & $2.47 \mathrm{E}+02$ & $2.60 \mathrm{E}+02$ & $2.55 \mathrm{E}+02$ & EST-10-04-1 & $1.43 \mathrm{E}+01$ & 4.19E-01 & EST-10-04-2 & $1.57 \mathrm{E}+04$ & $8.39 \mathrm{E}+01$ \\
\hline $2.47 \mathrm{E}+02$ & 2 & $\mathrm{~A}$ & $5.55 \mathrm{E}+02$ & $2.55 \mathrm{E}+02$ & $2.60 \mathrm{E}+02$ & $2.54 \mathrm{E}+02$ & EST-10-04-3 & $3.57 \mathrm{E}+01$ & 1.99E-01 & EST-10-04-4 & $5.02 \mathrm{E}+03$ & $1.56 \mathrm{E}+01$ \\
\hline $2.47 \mathrm{E}+02$ & 3 & A & $5.36 \mathrm{E}+02$ & $2.54 \mathrm{E}+02$ & $2.60 \mathrm{E}+02$ & $2.55 \mathrm{E}+02$ & EST-10-04-5 & $9.10 \mathrm{E}+00$ & $4.16 \mathrm{E}-02$ & EST-10-04-6 & $1.99 \mathrm{E}+03$ & $6.37 \mathrm{E}+00$ \\
\hline $2.47 \mathrm{E}+02$ & 4 & $\mathrm{~A}$ & $5.71 \mathrm{E}+02$ & $2.55 \mathrm{E}+02$ & $2.61 \mathrm{E}+02$ & $2.55 \mathrm{E}+02$ & EST-10-04-7 & $5.28 \mathrm{E}+00$ & $2.09 \mathrm{E}-02$ & EST-10-04-8 & $8.90 \mathrm{E}+02$ & $3.55 \mathrm{E}+00$ \\
\hline $2.47 \mathrm{E}+02$ & 5 & $\mathrm{~A}$ & $6.01 \mathrm{E}+02$ & $2.55 \mathrm{E}+02$ & $2.60 \mathrm{E}+02$ & $2.56 \mathrm{E}+02$ & EST-10-04-9 & $1.95 \mathrm{E}+00$ & $0.00 \mathrm{E}+00$ & EST-10-04-10 & $5.48 \mathrm{E}+02$ & $2.63 \mathrm{E}+00$ \\
\hline \multicolumn{13}{|c|}{$\begin{array}{l}\text { Soln }- \text { Solution } \\
\text { Vol. - Volume } \\
\text { Sat - Saturation } \\
\text { Liq. - Liquid } \\
\text { Cent. - Centrifugation } \\
\left.\text { [Re] and }{ }^{99} \mathrm{Tc}\right] \text { - Rhenium and Technetium Concentrations } \\
\end{array}$} \\
\hline
\end{tabular}


Table A7. Extraction Results for ES-32B.

\begin{tabular}{|c|c|c|c|c|c|c|c|c|c|c|c|c|}
\hline $\begin{array}{l}\text { Dry Sample } \\
\text { Mass (g) }\end{array}$ & $\begin{array}{c}\text { Extraction } \\
\text { Step \# }\end{array}$ & $\begin{array}{l}\text { Soln. } \\
\text { Type } \\
¥\end{array}$ & $\begin{array}{l}\text { Vol. of Soln. } \\
\text { Added for } \\
\text { Sat. (mL) }\end{array}$ & $\begin{array}{c}\text { Pre-Sat. } \\
\text { Sample Mass } \\
\text { (g) }\end{array}$ & \begin{tabular}{|c|} 
Post-Sat. \& \\
Draining \\
Free Liq. \\
Sample Mass \\
(g)
\end{tabular} & \begin{tabular}{|} 
Post-Cent. \\
Sample Mass \\
(g)
\end{tabular} & Sat. Sample \# & $\begin{array}{c}\text { Liq. [Re] } \\
\text { (Sat.) } \\
\text { ( } \mathrm{gg} / \mathrm{L})\end{array}$ & $\begin{array}{c}\text { Liq. }\left[{ }^{99} \mathrm{Tc}\right] \\
\text { (Sat.) } \\
\text { ( } \mathrm{gg} / \mathrm{L})\end{array}$ & Cent. Sample \# & $\begin{array}{c}\text { Liq. [Re] } \\
\text { (Cent.) } \\
(\mu \mathrm{g} / \mathrm{L})\end{array}$ & $\mid \begin{array}{c}\text { Liq. }\left[{ }^{99} \mathbf{T c}\right] \\
\text { (Cent.) } \\
(\mu \mathrm{g} / \mathrm{L})\end{array}$ \\
\hline \multicolumn{13}{|l|}{ ES-32B } \\
\hline \multicolumn{13}{|l|}{ EST-15-01 } \\
\hline \multicolumn{13}{|l|}{ Fragment \#1 } \\
\hline $3.76 \mathrm{E}+02$ & 1 & $\bar{A}$ & $5.45 \mathrm{E}+02$ & $3.76 \mathrm{E}+02$ & $3.95 \mathrm{E}+02$ & $3.88 \mathrm{E}+02$ & \begin{tabular}{|l|} 
EST-15-01-1 \\
\end{tabular} & $6.09 \mathrm{E}+00$ & 2.53E-01 & EST-15-01-2 & $2.53 \mathrm{E}+01$ & 3.03E-01 \\
\hline $3.76 \mathrm{E}+02$ & 3 & A & $5.34 \mathrm{E}+02$ & $3.89 \mathrm{E}+02$ & $3.94 \mathrm{E}+02$ & $3.90 \mathrm{E}+02$ & \begin{tabular}{|l|} 
EST-15-01-5 \\
\end{tabular} & $0.00 \mathrm{E}+00$ & $0.00 \mathrm{E}+00$ & EST-15-01-6 & $2.82 \mathrm{E}+01$ & $1.46 \mathrm{E}+00$ \\
\hline $3.76 \mathrm{E}+02$ & 4 & A & $5.34 \mathrm{E}+02$ & $3.90 \mathrm{E}+02$ & $3.94 \mathrm{E}+02$ & $3.87 \mathrm{E}+02$ & \begin{tabular}{|l|} 
EST-15-01-7 \\
\end{tabular} & $9.76 \mathrm{E}-01$ & $0.00 \mathrm{E}+00$ & EST-15-01-8 & $1.70 \mathrm{E}+01$ & $1.44 \mathrm{E}+00$ \\
\hline $3.76 \mathrm{E}+02$ & 5 & A & $5.21 \mathrm{E}+02$ & $3.87 \mathrm{E}+02$ & $3.95 \mathrm{E}+02$ & $3.88 \mathrm{E}+02$ & \begin{tabular}{|l|} 
EST-15-01-9 \\
\end{tabular} & $0.00 \mathrm{E}+00$ & $0.00 \mathrm{E}+00$ & EST-15-01-10 & $5.54 \mathrm{E}+00$ & 9.76E-01 \\
\hline \multicolumn{13}{|l|}{ EST-15-02 } \\
\hline \multicolumn{13}{|l|}{ Fragment \#1 } \\
\hline $4.28 \mathrm{E}+02$ & 1 & A & $3.97 \mathrm{E}+02$ & $4.28 \mathrm{E}+02$ & $4.50 \mathrm{E}+02$ & $4.44 \mathrm{E}+02$ & \begin{tabular}{|l|} 
EST-15-02-1 \\
\end{tabular} & $5.32 \mathrm{E}+00$ & 5.79E-01 & EST-15-02-2 & $6.05 \mathrm{E}+01$ & \begin{tabular}{|l|}
$7.76 \mathrm{E}-01$ \\
\end{tabular} \\
\hline $4.28 \mathrm{E}+02$ & 2 & A & $3.53 \mathrm{E}+02$ & $4.44 \mathrm{E}+02$ & $4.50 \mathrm{E}+02$ & $4.44 \mathrm{E}+02$ & \begin{tabular}{|l|} 
EST-15-02-3 \\
\end{tabular} & 6.02E-01 & 5.02E-02 & EST-15-02-4 & $5.01 \mathrm{E}+01$ & $2.18 \mathrm{E}+00$ \\
\hline $4.28 \mathrm{E}+02$ & 3 & A & $4.28 \mathrm{E}+02$ & $4.44 \mathrm{E}+02$ & $4.49 \mathrm{E}+02$ & $4.45 \mathrm{E}+02$ & \begin{tabular}{|l|} 
EST-15-02-5 \\
\end{tabular} & $0.00 \mathrm{E}+00$ & $0.00 \mathrm{E}+00$ & EST-15-02-6 & $4.14 \mathrm{E}+01$ & $5.86 \mathrm{E}+00$ \\
\hline $4.28 \mathrm{E}+02$ & 4 & A & $3.66 \mathrm{E}+02$ & $4.45 \mathrm{E}+02$ & $4.49 \mathrm{E}+02$ & $4.41 \mathrm{E}+02$ & \begin{tabular}{|l|} 
EST-15-02-7 \\
\end{tabular} & $2.57 \mathrm{E}-01$ & 4.12E-02 & EST-15-02-8 & $2.85 \mathrm{E}+01$ & $5.81 \mathrm{E}+00$ \\
\hline $4.28 \mathrm{E}+02$ & 5 & $\bar{A}$ & $3.20 \mathrm{E}+02$ & $4.41 \mathrm{E}+02$ & $4.50 \mathrm{E}+02$ & $4.43 \mathrm{E}+02$ & \begin{tabular}{|l|} 
EST-15-02-9 \\
\end{tabular} & $4.68 \mathrm{E}-01$ & 9.05E-02 & $\begin{array}{l}\text { EST-15-02-10 } \\
\end{array}$ & \begin{tabular}{|l|}
$1.56 \mathrm{E}+01$ \\
\end{tabular} & $4.89 \mathrm{E}+00$ \\
\hline & & & & & & & & & & & & \\
\hline \multicolumn{13}{|l|}{ EST-15-03 } \\
\hline \multicolumn{13}{|l|}{ Fragment \#1 } \\
\hline $5.05 \mathrm{E}+02$ & 1 & $\bar{A}$ & $4.78 \mathrm{E}+02$ & $5.05 \mathrm{E}+02$ & $5.31 \mathrm{E}+02$ & $5.23 \mathrm{E}+02$ & \begin{tabular}{|l|} 
EST-15-03-1 \\
\end{tabular} & $9.26 \mathrm{E}+00$ & $1.74 \mathrm{E}+00$ & EST-15-03-2 & $9.89 \mathrm{E}+01$ & $1.77 \mathrm{E}+01$ \\
\hline $5.05 \mathrm{E}+02$ & 2 & $\mathrm{~A}$ & $4.82 \mathrm{E}+02$ & $5.23 \mathrm{E}+02$ & $5.30 \mathrm{E}+02$ & $5.22 \mathrm{E}+02$ & \begin{tabular}{|l|} 
EST-15-03-3 \\
\end{tabular} & 7.09E-01 & 6.58E-02 & EST-15-03-4 & $6.85 \mathrm{E}+01$ & $6.41 \mathrm{E}+00$ \\
\hline $5.05 \mathrm{E}+02$ & 3 & $\bar{A}$ & $4.87 \mathrm{E}+02$ & $5.22 \mathrm{E}+02$ & $5.31 \mathrm{E}+02$ & $5.24 \mathrm{E}+02$ & \begin{tabular}{|l|} 
EST-15-03-5 \\
\end{tabular} & 8.11E-01 & 6.83E-02 & EST-15-03-6 & $3.90 \mathrm{E}+01$ & $2.47 \mathrm{E}+00$ \\
\hline $5.05 E+02$ & 4 & $\bar{A}$ & $4.97 \mathrm{E}+02$ & $5.24 \mathrm{E}+02$ & $5.30 \mathrm{E}+02$ & $5.24 \mathrm{E}+02$ & \begin{tabular}{|l|} 
EST-15-03-7 \\
\end{tabular} & $0.00 \mathrm{E}+00$ & $0.00 \mathrm{E}+00$ & EST-15-03-8 & \begin{tabular}{|l|}
$2.23 \mathrm{E}+01$ \\
\end{tabular} & $1.48 \mathrm{E}+00$ \\
\hline $5.05 \mathrm{E}+02$ & 5 & $\overline{\mathrm{A}}$ & $4.91 \mathrm{E}+02$ & $5.24 \mathrm{E}+02$ & $5.32 \mathrm{E}+02$ & $5.26 \mathrm{E}+02$ & \begin{tabular}{|l|} 
EST-15-03-9 \\
\end{tabular} & $8.15 \mathrm{E}-01$ & \begin{tabular}{|c|}
$1.02 \mathrm{E}-01$ \\
\end{tabular} & \begin{tabular}{|l|} 
EST-15-03-10 \\
\end{tabular} & \begin{tabular}{|l|}
$7.83 \mathrm{E}+00$ \\
\end{tabular} & \begin{tabular}{|c|}
$9.07 \mathrm{E}-01$ \\
\end{tabular} \\
\hline & & & & & & & & & & & & \\
\hline \multicolumn{13}{|l|}{ EST-16-01 } \\
\hline \multicolumn{13}{|l|}{ Fragment \#1 } \\
\hline $3.98 \mathrm{E}+02$ & 1 & $\bar{A}$ & $4.92 \mathrm{E}+02$ & $3.98 \mathrm{E}+02$ & $4.22 \mathrm{E}+02$ & $4.16 \mathrm{E}+02$ & \begin{tabular}{|l|} 
EST-16-01-1 \\
\end{tabular} & $2.02 \mathrm{E}+00$ & 2.23E-01 & EST-16-01-2 & \begin{tabular}{|l|}
$1.59 \mathrm{E}+01$ \\
\end{tabular} & 2.97E-01 \\
\hline $3.98 \mathrm{E}+02$ & 2 & $\bar{A}$ & $4.74 \mathrm{E}+02$ & $4.16 \mathrm{E}+02$ & $4.22 \mathrm{E}+02$ & $4.20 \mathrm{E}+02$ & \begin{tabular}{|l|} 
EST-16-01-3 \\
\end{tabular} & $0.00 \mathrm{E}+00$ & $0.00 \mathrm{E}+00$ & EST-16-01-4 & \begin{tabular}{|l|}
$1.36 \mathrm{E}+01$ \\
\end{tabular} & 1.76E-01 \\
\hline $3.98 \mathrm{E}+02$ & 3 & $\bar{A}$ & $4.64 \mathrm{E}+02$ & $4.20 \mathrm{E}+02$ & $4.21 \mathrm{E}+02$ & $4.17 \mathrm{E}+02$ & \begin{tabular}{|l|l} 
EST-16-01-5 \\
\end{tabular} & $0.00 \mathrm{E}+00$ & $0.00 \mathrm{E}+00$ & EST-16-01-6 & \begin{tabular}{|l|}
$1.23 \mathrm{E}+01$ \\
\end{tabular} & 1.64E-01 \\
\hline $3.98 \mathrm{E}+02$ & 4 & A & $5.00 \mathrm{E}+02$ & $4.17 \mathrm{E}+02$ & $4.24 \mathrm{E}+02$ & $4.15 \mathrm{E}+02$ & \begin{tabular}{|l|} 
EST-16-01-7 \\
\end{tabular} & $0.00 \mathrm{E}+00$ & $0.00 \mathrm{E}+00$ & EST-16-01-8 & $5.81 \mathrm{E}+00$ & $0.00 \mathrm{E}+00$ \\
\hline $3.98 \mathrm{E}+02$ & 5 & $\bar{A}$ & $4.84 \mathrm{E}+02$ & $4.15 \mathrm{E}+02$ & $4.20 \mathrm{E}+02$ & $4.14 \mathrm{E}+02$ & \begin{tabular}{|l|} 
EST-16-01-9 \\
\end{tabular} & $0.00 \mathrm{E}+00$ & $0.00 \mathrm{E}+00$ & \begin{tabular}{|l|} 
EST-16-01-10 \\
\end{tabular} & $4.18 \mathrm{E}+00$ & $0.00 \mathrm{E}+00$ \\
\hline
\end{tabular}


Table A7. Extraction Results for ES-32B.

\begin{tabular}{|c|c|c|c|c|c|c|c|c|c|c|c|c|}
\hline $\begin{array}{l}\text { Dry Sample } \\
\text { Mass (g) }\end{array}$ & $\begin{array}{c}\text { Extraction } \\
\text { Step \# }\end{array}$ & $\begin{array}{l}\text { Soln. } \\
\text { Type } \\
¥\end{array}$ & $\begin{array}{l}\text { Vol. of Soln. } \\
\text { Added for } \\
\text { Sat. (mL) }\end{array}$ & $\begin{array}{c}\text { Pre-Sat. } \\
\text { Sample Mass } \\
\text { (g) }\end{array}$ & \begin{tabular}{|c} 
Post-Sat. \& \\
Draining \\
Free Liq. \\
Sample Mass \\
(g)
\end{tabular} & \begin{tabular}{|} 
Post-Cent. \\
Sample Mass \\
(g)
\end{tabular} & Sat. Sample \# & $\begin{array}{c}\text { Liq. [Re] } \\
\text { (Sat.) } \\
(\mu \mathrm{g} / \mathrm{L})\end{array}$ & $\begin{array}{c}\left.\text { Liq. } \text { [ }^{99} \mathrm{Tc}\right] \\
\text { (Sat.) } \\
(\mu \mathrm{g} / \mathrm{L})\end{array}$ & Cent. Sample \# & $\begin{array}{c}\text { Liq. [Re] } \\
\text { (Cent.) } \\
(\boldsymbol{\mu g} / \mathbf{L})\end{array}$ & $\mid \begin{array}{c}\text { Liq. }\left[{ }^{99} \mathbf{T c}\right] \\
\text { (Cent.) } \\
(\mu \mathrm{g} / \mathrm{L})\end{array}$ \\
\hline \multicolumn{13}{|l|}{ ES-32B } \\
\hline & & & & & & & & & & & & \\
\hline \multicolumn{13}{|l|}{ EST-16-02 } \\
\hline \multicolumn{13}{|l|}{ Fragment \#1 } \\
\hline $6.64 \mathrm{E}+02$ & 1 & $\bar{A}$ & $3.98 \mathrm{E}+02$ & $6.64 \mathrm{E}+02$ & $6.99 \mathrm{E}+02$ & $6.93 \mathrm{E}+02$ & \begin{tabular}{|l|} 
EST-16-02-1 \\
\end{tabular} & \begin{tabular}{|l|}
$1.70 \mathrm{E}+01$ \\
\end{tabular} & $1.87 \mathrm{E}+00$ & EST-16-02-2 & $6.78 \mathrm{E}+01$ & $1.86 \mathrm{E}+00$ \\
\hline $6.64 \mathrm{E}+02$ & 2 & A & $4.34 \mathrm{E}+02$ & $6.93 \mathrm{E}+02$ & $6.99 \mathrm{E}+02$ & $6.89 \mathrm{E}+02$ & \begin{tabular}{|l|} 
EST-16-02-3 \\
\end{tabular} & $8.28 \mathrm{E}-01$ & 6.64E-02 & EST-16-02-4 & $4.86 \mathrm{E}+01$ & $1.19 \mathrm{E}+00$ \\
\hline $6.64 \mathrm{E}+02$ & 3 & A & $4.05 \mathrm{E}+02$ & $6.89 \mathrm{E}+02$ & $6.99 \mathrm{E}+02$ & $6.93 \mathrm{E}+02$ & \begin{tabular}{|l|} 
EST-16-02-5 \\
\end{tabular} & $0.00 \mathrm{E}+00$ & $0.00 \mathrm{E}+00$ & EST-16-02-6 & $3.40 \mathrm{E}+01$ & 9.28E-01 \\
\hline $6.64 \mathrm{E}+02$ & 4 & A & $4.22 \mathrm{E}+02$ & $6.93 \mathrm{E}+02$ & $7.00 \mathrm{E}+02$ & $6.94 \mathrm{E}+02$ & \begin{tabular}{|l|} 
EST-16-02-7 \\
\end{tabular} & $8.84 \mathrm{E}-01$ & 7.69E-02 & EST-16-02-8 & $2.07 \mathrm{E}+01$ & 5.92E-01 \\
\hline $6.64 \mathrm{E}+02$ & 5 & A & $4.18 \mathrm{E}+02$ & $6.94 \mathrm{E}+02$ & $6.99 \mathrm{E}+02$ & $6.90 \mathrm{E}+02$ & \begin{tabular}{|l|} 
EST-16-02-9 \\
\end{tabular} & $0.00 \mathrm{E}+00$ & $0.00 \mathrm{E}+00$ & $\begin{array}{l}\text { EST-16-02-10 } \\
\end{array}$ & $1.55 \mathrm{E}+01$ & 4.45E-01 \\
\hline & & & & & & & & & & & & \\
\hline \multicolumn{13}{|l|}{ EST-16-03 } \\
\hline \multicolumn{13}{|l|}{ Fragment \#1 } \\
\hline $5.70 \mathrm{E}+02$ & 1 & A & $4.56 \mathrm{E}+02$ & $5.70 \mathrm{E}+02$ & $6.01 \mathrm{E}+02$ & $5.92 \mathrm{E}+02$ & EST-16-03-1 & $7.96 \mathrm{E}+00$ & \begin{tabular}{|l|}
$2.00 \mathrm{E}+00$ \\
\end{tabular} & EST-16-03-2 & $4.49 \mathrm{E}+02$ & $2.50 \mathrm{E}+00$ \\
\hline $5.70 \mathrm{E}+02$ & 2 & A & $4.58 \mathrm{E}+02$ & $5.92 \mathrm{E}+02$ & $6.01 \mathrm{E}+02$ & $5.92 \mathrm{E}+02$ & EST-16-03-3 & $8.62 \mathrm{E}+00$ & $9.48 \mathrm{E}-01$ & EST-16-03-4 & $4.38 \mathrm{E}+02$ & $2.25 \mathrm{E}+00$ \\
\hline $5.70 \mathrm{E}+02$ & 3 & A & $4.53 \mathrm{E}+02$ & $5.92 \mathrm{E}+02$ & $6.01 \mathrm{E}+02$ & $5.93 \mathrm{E}+02$ & EST-16-03-5 & $1.76 \mathrm{E}+00$ & $5.52 \mathrm{E}-02$ & EST-16-03-6 & $4.40 \mathrm{E}+02$ & $2.92 \mathrm{E}+00$ \\
\hline $5.70 \mathrm{E}+02$ & 4 & A & $4.61 \mathrm{E}+02$ & $5.93 \mathrm{E}+02$ & $6.03 \mathrm{E}+02$ & $5.95 \mathrm{E}+02$ & EST-16-03-7 & $1.61 \mathrm{E}+01$ & $1.05 \mathrm{E}+00$ & EST-16-03-8 & $1.01 \mathrm{E}+02$ & $3.31 \mathrm{E}+00$ \\
\hline $5.70 \mathrm{E}+02$ & 5 & A & $4.53 \mathrm{E}+02$ & $5.95 \mathrm{E}+02$ & $6.03 \mathrm{E}+02$ & $5.93 \mathrm{E}+02$ & EST-16-03-9 & 8.60E-01 & $5.22 \mathrm{E}-02$ & EST-16-03-10 & $7.85 \mathrm{E}+01$ & $4.28 \mathrm{E}+00$ \\
\hline & & & & & & & & & & & & \\
\hline \multicolumn{13}{|l|}{ EST-16-04 } \\
\hline \multicolumn{13}{|l|}{ Fragment \#1 } \\
\hline $6.06 \mathrm{E}+02$ & 1 & A & $4.22 \mathrm{E}+02$ & $6.06 \mathrm{E}+02$ & $6.35 \mathrm{E}+02$ & $6.33 \mathrm{E}+02$ & EST-16-04-1 & $2.62 \mathrm{E}+01$ & $1.77 \mathrm{E}+00$ & EST-16-04-2 & $3.08 \mathrm{E}+02$ & $1.88 \mathrm{E}+00$ \\
\hline $6.06 \mathrm{E}+02$ & 2 & $\bar{A}$ & $4.57 \mathrm{E}+02$ & $6.33 \mathrm{E}+02$ & $6.37 \mathrm{E}+02$ & $6.34 \mathrm{E}+02$ & EST-16-04-3 & $1.98 \mathrm{E}+01$ & $2.25 \mathrm{E}+00$ & EST-16-04-4 & $1.65 \mathrm{E}+02$ & \begin{tabular}{|l|}
$3.29 \mathrm{E}+00$ \\
\end{tabular} \\
\hline $6.06 \mathrm{E}+02$ & 3 & A & $4.09 \mathrm{E}+02$ & $6.34 \mathrm{E}+02$ & $6.37 \mathrm{E}+02$ & $6.34 \mathrm{E}+02$ & EST-16-04-5 & $4.84 \mathrm{E}+00$ & 2.41E-01 & EST-16-04-6 & $1.67 \mathrm{E}+02$ & $3.82 \mathrm{E}+00$ \\
\hline $6.06 \mathrm{E}+02$ & 4 & A & $4.16 \mathrm{E}+02$ & $6.34 \mathrm{E}+02$ & $6.38 \mathrm{E}+02$ & $6.36 \mathrm{E}+02$ & EST-16-04-7 & $4.57 \mathrm{E}+01$ & $5.06 \mathrm{E}+00$ & EST-16-04-8 & $1.03 \mathrm{E}+02$ & $5.74 \mathrm{E}+00$ \\
\hline $6.06 \mathrm{E}+02$ & 5 & A & $4.45 \mathrm{E}+02$ & $6.36 \mathrm{E}+02$ & $6.37 \mathrm{E}+02$ & $6.36 \mathrm{E}+02$ & EST-16-04-9 & $1.86 \mathrm{E}+00$ & 1.71E-01 & EST-16-04-10 & $5.29 \mathrm{E}+01$ & $1.87 \mathrm{E}+00$ \\
\hline & & & & & & & & & & & & \\
\hline & & & & & & & & & & & & \\
\hline & & & & & & & & & & & & \\
\hline & & & & & & & & & & & & \\
\hline & & & & & & & & & & & & \\
\hline & & & & & & & & & & & & \\
\hline & & & & & & & & & & & & \\
\hline
\end{tabular}


Table A7. Extraction Results for ES-32B.

\begin{tabular}{|c|c|c|c|c|c|c|c|c|c|c|c|c|}
\hline $\begin{array}{c}\text { Dry Sample } \\
\text { Mass (g) }\end{array}$ & $\begin{array}{c}\text { Extraction } \\
\text { Step \# }\end{array}$ & $\begin{array}{c}\text { Soln. } \\
\text { Type } \\
\text { ¥ }\end{array}$ & \begin{tabular}{|} 
Vol. of Soln. \\
Added for \\
Sat. (mL)
\end{tabular} & $\begin{array}{c}\text { Pre-Sat. } \\
\text { Sample Mass } \\
\text { (g) }\end{array}$ & \begin{tabular}{|c|} 
Post-Sat. \& \\
Draining \\
Free Liq. \\
Sample Mass \\
(g)
\end{tabular} & $\begin{array}{c}\text { Post-Cent. } \\
\text { Sample Mass } \\
\text { (g) }\end{array}$ & Sat. Sample \# & $\begin{array}{c}\text { Liq. [Re] } \\
\text { (Sat.) } \\
(\boldsymbol{\mu g} / \mathbf{L})\end{array}$ & $\begin{array}{c}\left.\text { Liq. }{ }^{99} \mathrm{Tc}\right] \\
\text { (Sat.) } \\
(\mu \mathrm{g} / \mathrm{L})\end{array}$ & Cent. Sample \# & \begin{tabular}{|c} 
Liq. [Re] \\
(Cent.) \\
$(\mu \mathrm{g} / \mathrm{L})$
\end{tabular} & $\begin{array}{c}\text { Liq. }\left[{ }^{99} \mathrm{Tc}\right] \\
\text { (Cent.) } \\
(\mu \mathrm{g} / \mathrm{L})\end{array}$ \\
\hline \multicolumn{13}{|l|}{ ES-32B } \\
\hline & & & & & & & & & & & & \\
\hline & & & & & & & & & & & & \\
\hline \multicolumn{13}{|l|}{ EST-16-05 } \\
\hline \multicolumn{13}{|l|}{ Fragment \#1 } \\
\hline $5.03 \mathrm{E}+02$ & 1 & $\mathrm{~A}$ & $4.79 \mathrm{E}+02$ & $5.03 \mathrm{E}+02$ & $5.26 \mathrm{E}+02$ & $5.25 \mathrm{E}+02$ & EST-16-05-1 & $1.53 \mathrm{E}+01$ & $9.64 \mathrm{E}-01$ & EST-16-05-2 & $2.38 \mathrm{E}+02$ & $1.64 \mathrm{E}+00$ \\
\hline $5.03 \mathrm{E}+02$ & 2 & A & $4.85 \mathrm{E}+02$ & $5.25 \mathrm{E}+02$ & $5.27 \mathrm{E}+02$ & $5.25 \mathrm{E}+02$ & EST-16-05-3 & $5.15 \mathrm{E}+00$ & 3.50E-01 & EST-16-05-4 & $4.56 \mathrm{E}+03$ & $6.13 \mathrm{E}+02$ \\
\hline $5.03 \mathrm{E}+02$ & 3 & $\mathrm{~A}$ & $4.76 \mathrm{E}+02$ & $5.25 \mathrm{E}+02$ & $5.28 \mathrm{E}+02$ & $5.27 \mathrm{E}+02$ & EST-16-05-5 & $2.35 \mathrm{E}+01$ & $2.66 \mathrm{E}+00$ & EST-16-05-6 & $2.39 \mathrm{E}+03$ & $2.34 \mathrm{E}+02$ \\
\hline $5.03 \mathrm{E}+02$ & 4 & $\mathrm{~A}$ & $4.91 \mathrm{E}+02$ & $5.27 \mathrm{E}+02$ & $5.27 \mathrm{E}+02$ & $5.26 \mathrm{E}+02$ & EST-16-05-7 & $3.57 \mathrm{E}+00$ & $3.44 \mathrm{E}-01$ & EST-16-05-8 & $2.13 \mathrm{E}+03$ & $2.42 \mathrm{E}+02$ \\
\hline $5.03 \mathrm{E}+02$ & 5 & $\mathrm{~A}$ & $4.87 \mathrm{E}+02$ & $5.26 \mathrm{E}+02$ & $5.30 \mathrm{E}+02$ & $5.28 \mathrm{E}+02$ & EST-16-05-9 & $2.66 \mathrm{E}+01$ & $3.63 \mathrm{E}+00$ & EST-16-05-10 & $2.06 \mathrm{E}+02$ & $2.98 \mathrm{E}+01$ \\
\hline \multicolumn{13}{|c|}{\begin{tabular}{|l} 
Soln - Solution \\
Vol. - Volume \\
Sat - Saturation \\
Liq. - Liquid \\
Cent. - Centrifugation \\
{$\left[\right.$ Re] and [ $\left.{ }^{99} \mathrm{Tc}\right]$ - Rhenium and Technetium Concentrations }
\end{tabular}} \\
\hline
\end{tabular}


Table A8. Extraction Results for ES-Blanks.

\begin{tabular}{|c|c|c|c|c|c|c|c|c|c|c|}
\hline $\begin{array}{c}\text { Dry Sample Mass (g) } \\
\text { ES-Blank }\end{array}$ & $\begin{array}{c}\text { Extraction } \\
\text { Step \# }\end{array}$ & \begin{tabular}{|c|} 
Soln. \\
Type¥
\end{tabular} & $\begin{array}{l}\text { Vol. of Soln. } \\
\text { Added for } \\
\text { Sat. (mL) }\end{array}$ & \begin{tabular}{|} 
Pre-Sat. \\
Sample \\
Mass (g)
\end{tabular} & $\begin{array}{c}\text { Post-Sat. \& } \\
\text { Draining Free Liq. } \\
\text { Sample Mass (g) }\end{array}$ & $\begin{array}{l}\text { Post-Cent. } \\
\text { Sample } \\
\text { Mass (g) }\end{array}$ & Sat. Sample \# & $\begin{array}{c}\text { Liq. }[\mathrm{Re}] \\
\text { (Sat.) } \\
(\mu \mathrm{g} / \mathrm{L})\end{array}$ & Cent. Sample \# & $\begin{array}{c}\text { Liq. [Re] } \\
\text { (Cent.) } \\
(\mu \mathrm{g} / \mathrm{L})\end{array}$ \\
\hline \multicolumn{11}{|l|}{ Untreated Refractory Blank } \\
\hline \multicolumn{11}{|l|}{ EST-Blank-1 } \\
\hline \multicolumn{11}{|l|}{ Fragment \#1 } \\
\hline $3.31 \mathrm{E}+02$ & 1 & $\mathrm{~A}$ & $3.17 \mathrm{E}+02$ & $3.31 \mathrm{E}+02$ & $3.41 \mathrm{E}+02$ & $3.41 \mathrm{E}+02$ & EST-Blank-1.1 & $6.48 \mathrm{E}-02$ & EST-Blank-1.2 & - \\
\hline $3.31 \mathrm{E}+02$ & 2 & A & $3.62 \mathrm{E}+02$ & $3.41 \mathrm{E}+02$ & $3.45 \mathrm{E}+02$ & $3.44 \mathrm{E}+02$ & EST-Blank-1.3 & $2.24 \mathrm{E}-02$ & EST-Blank-1.4 & $4.81 \mathrm{E}-01$ \\
\hline $3.31 \mathrm{E}+02$ & 3 & A & $3.27 \mathrm{E}+02$ & $3.44 \mathrm{E}+02$ & $3.46 \mathrm{E}+02$ & $3.44 \mathrm{E}+02$ & EST-Blank-1.5 & 2.28E-02 & EST-Blank-1.6 & 5.53E-01 \\
\hline $3.31 \mathrm{E}+02$ & 4 & $\mathrm{~A}$ & $3.08 \mathrm{E}+02$ & $3.44 \mathrm{E}+02$ & $3.46 \mathrm{E}+02$ & $3.44 \mathrm{E}+02$ & EST-Blank-1.7 & 3.23E-02 & EST-Blank-1.8 & $5.40 \mathrm{E}-01$ \\
\hline $3.31 \mathrm{E}+02$ & 5 & $\mathrm{~A}$ & $3.07 \mathrm{E}+02$ & $3.44 \mathrm{E}+02$ & $3.46 \mathrm{E}+02$ & $3.44 \mathrm{E}+02$ & EST-Blank-1.9 & 1.97E-02 & EST-Blank-1.10 & 4.86E-01 \\
\hline \multicolumn{11}{|l|}{ Starter Path Blanks } \\
\hline \multicolumn{11}{|l|}{ EST-Blank-2 } \\
\hline \multicolumn{11}{|l|}{ Fragment \#1 } \\
\hline $3.01 \mathrm{E}+02$ & 1 & $\mathrm{~A}$ & $4.23 \mathrm{E}+02$ & $3.01 \mathrm{E}+02$ & $3.27 \mathrm{E}+02$ & $3.24 \mathrm{E}+02$ & EST-Blank-2.1 & 9.01E-01 & EST-Blank-2.2 & $3.01 \mathrm{E}+01$ \\
\hline $3.01 \mathrm{E}+02$ & 2 & $\mathrm{~A}$ & $3.40 \mathrm{E}+02$ & $3.24 \mathrm{E}+02$ & $3.26 \mathrm{E}+02$ & $3.23 \mathrm{E}+02$ & EST-Blank-2.3 & 6.51E-01 & EST-Blank-2.4 & $1.87 \mathrm{E}+02$ \\
\hline $3.01 \mathrm{E}+02$ & 3 & $\mathrm{~A}$ & $3.48 \mathrm{E}+02$ & $3.23 \mathrm{E}+02$ & $3.24 \mathrm{E}+02$ & $3.20 \mathrm{E}+02$ & EST-Blank-2.5 & $1.20 \mathrm{E}+00$ & EST-Blank-2.6 & $2.76 \mathrm{E}+01$ \\
\hline $3.01 \mathrm{E}+02$ & 4 & A & $3.59 \mathrm{E}+02$ & $3.20 \mathrm{E}+02$ & $3.23 \mathrm{E}+02$ & $3.21 \mathrm{E}+02$ & EST-Blank-2.7 & 5.15E-01 & EST-Blank-2.8 & $2.62 \mathrm{E}+01$ \\
\hline $3.01 \mathrm{E}+02$ & 5 & $\mathrm{~A}$ & $3.98 \mathrm{E}+02$ & $3.21 \mathrm{E}+02$ & $3.23 \mathrm{E}+02$ & $3.20 \mathrm{E}+02$ & EST-Blank-2.9 & 9.68E-01 & EST-Blank-2.10 & $2.71 \mathrm{E}+01$ \\
\hline \multicolumn{11}{|l|}{ EST-Blank-3 } \\
\hline \multicolumn{11}{|l|}{ Fragment \#1 } \\
\hline $3.76 \mathrm{E}+02$ & 1 & $\mathrm{~A}$ & $3.40 \mathrm{E}+02$ & $3.76 \mathrm{E}+02$ & $4.07 \mathrm{E}+02$ & $4.04 \mathrm{E}+02$ & EST-Blank-3.1 & $3.48 \mathrm{E}+00$ & EST-Blank-3.2 & $1.99 \mathrm{E}+02$ \\
\hline $3.76 \mathrm{E}+02$ & 2 & $\mathrm{~A}$ & $3.33 \mathrm{E}+02$ & $4.04 \mathrm{E}+02$ & $4.06 \mathrm{E}+02$ & $4.03 \mathrm{E}+02$ & EST-Blank-3.3 & $4.42 \mathrm{E}+00$ & EST-Blank-3.4 & $3.03 \mathrm{E}+01$ \\
\hline $3.76 \mathrm{E}+02$ & 3 & $\mathrm{~A}$ & $3.34 \mathrm{E}+02$ & $4.03 \mathrm{E}+02$ & $4.06 \mathrm{E}+02$ & $4.02 \mathrm{E}+02$ & EST-Blank-3.5 & $5.35 \mathrm{E}+00$ & EST-Blank-3.6 & $2.04 \mathrm{E}+02$ \\
\hline $3.76 \mathrm{E}+02$ & 4 & $\mathrm{~A}$ & $3.06 \mathrm{E}+02$ & $4.02 \mathrm{E}+02$ & $4.05 \mathrm{E}+02$ & $4.02 \mathrm{E}+02$ & EST-Blank-3.7 & $2.93 \mathrm{E}+00$ & EST-Blank-3.8 & $1.70 \mathrm{E}+02$ \\
\hline $3.76 \mathrm{E}+02$ & 5 & $\mathrm{~A}$ & $3.19 \mathrm{E}+02$ & $4.02 \mathrm{E}+02$ & $4.04 \mathrm{E}+02$ & $4.01 \mathrm{E}+02$ & EST-Blank-3.9 & $4.25 \mathrm{E}+00$ & EST-Blank-3.10 & $1.48 \mathrm{E}+02$ \\
\hline \multicolumn{11}{|l|}{ EST-Blank-4 } \\
\hline \multicolumn{11}{|l|}{ Fragment \#1 } \\
\hline $3.25 \mathrm{E}+02$ & 1 & A & $3.75 \mathrm{E}+02$ & $3.25 \mathrm{E}+02$ & $3.51 \mathrm{E}+02$ & $3.49 \mathrm{E}+02$ & EST-Blank-4.1 & $3.19 \mathrm{E}+00$ & EST-Blank-4.2 & $2.17 \mathrm{E}+02$ \\
\hline $3.25 \mathrm{E}+02$ & 2 & A & $2.89 \mathrm{E}+02$ & $3.49 \mathrm{E}+02$ & $3.51 \mathrm{E}+02$ & $3.48 \mathrm{E}+02$ & EST-Blank-4.3 & $4.80 \mathrm{E}+00$ & EST-Blank-4.4 & $8.73 \mathrm{E}+01$ \\
\hline
\end{tabular}


Table A8. Extraction Results for ES-Blanks.

\begin{tabular}{|c|c|c|c|c|c|c|c|c|c|c|}
\hline $\begin{array}{c}\text { Dry Sample Mass (g) } \\
\text { ES-Blank }\end{array}$ & $\begin{array}{c}\text { Extraction } \\
\text { Step \# }\end{array}$ & $\begin{array}{c}\text { Soln. } \\
\text { Type¥ }\end{array}$ & $\begin{array}{l}\text { Vol. of Soln. } \\
\text { Added for } \\
\text { Sat. (mL) }\end{array}$ & $\begin{array}{l}\text { Pre-Sat. } \\
\text { Sample } \\
\text { Mass (g) }\end{array}$ & $\begin{array}{c}\text { Post-Sat. \& } \\
\text { Draining Free Liq. } \\
\text { Sample Mass (g) }\end{array}$ & $\begin{array}{l}\text { Post-Cent. } \\
\text { Sample } \\
\text { Mass (g) }\end{array}$ & Sat. Sample \# & $\begin{array}{c}\text { Liq. [Re] } \\
\text { (Sat.) } \\
(\mu \mathrm{g} / \mathrm{L})\end{array}$ & Cent. Sample \# & $\begin{array}{c}\text { Liq. [Re] } \\
\text { (Cent.) } \\
(\mu \mathrm{g} / \mathrm{L})\end{array}$ \\
\hline $3.25 \mathrm{E}+02$ & 3 & $\mathrm{~A}$ & $3.27 \mathrm{E}+02$ & $3.48 \mathrm{E}+02$ & $3.51 \mathrm{E}+02$ & $3.48 \mathrm{E}+02$ & EST-Blank-4.5 & $8.97 \mathrm{E}+00$ & EST-Blank-4.6 & $4.73 \mathrm{E}+02$ \\
\hline $3.25 \mathrm{E}+02$ & 4 & $\mathrm{~A}$ & $2.50 \mathrm{E}+02$ & $3.48 \mathrm{E}+02$ & $3.50 \mathrm{E}+02$ & $3.47 \mathrm{E}+02$ & EST-Blank-4.7 & $5.80 \mathrm{E}+00$ & EST-Blank-4.8 & $3.72 \mathrm{E}+02$ \\
\hline $3.25 \mathrm{E}+02$ & 5 & A & $2.87 \mathrm{E}+02$ & $3.47 \mathrm{E}+02$ & $3.49 \mathrm{E}+02$ & $3.47 \mathrm{E}+02$ & EST-Blank-4.9 & $9.26 \mathrm{E}+00$ & EST-Blank-4.10 & $3.29 \mathrm{E}+02$ \\
\hline $\begin{array}{l}\text { Soln - Solution } \\
\text { Vol. - Volume } \\
\text { Sat - Saturation } \\
\text { Liq. - Liquid } \\
\text { Cent. - Centrifugation } \\
\text { [Re] - Rhenium Concentrati }\end{array}$ & & & & & & & & & & \\
\hline
\end{tabular}


Appendix B

Single-Pass Flow-Through Test Results 
Table B1. SPFT Results for BKV6 Glass.

\begin{tabular}{|c|c|c|c|c|c|c|c|c|c|c|c|c|c|c|c|c|}
\hline Sample ID & $\begin{array}{c}\text { Influent } \\
\text { [Si] }\end{array}$ & $\mathrm{T}\left({ }^{\circ} \mathrm{C}\right)$ & $\begin{array}{c}\text { Flow Rate } \\
\left(\mathbf{m}^{3} / \mathbf{d}\right)\end{array}$ & Time, days & $\mathrm{pH}\left(23^{\circ} \mathrm{C}\right)$ & $\begin{array}{c}\text { Glass } \\
\text { Mass (g) }\end{array}$ & $\mathrm{SA}\left(\mathbf{m}^{2}\right)$ & [B] & B Rate & [Al] & Al Rate & {$[\mathrm{Na}]$} & Na Rate & [Si] & Si Rate & IEX Rate \\
\hline \multicolumn{17}{|l|}{ BKV6 } \\
\hline \multicolumn{17}{|l|}{$\underline{\operatorname{Exp} \# 1}$} \\
\hline BKV6-1.A & $<500$ & 23 & - & - & 9.00 & - & - & $<25$ & - & 30 & - & $<50$ & - & $<500$ & - & - \\
\hline BKV6-1.1 & $<500$ & 23 & $2.3 \mathrm{E}-05$ & 1.75 & 9.00 & 1.100 & 2.17E-02 & 30 & $1.54 \mathrm{E}-04$ & 146 & 1.09E-03 & 1,750 & 4.85E-03 & 534 & 7.05E-05 & $1.88 \mathrm{E}-09$ \\
\hline BKV6-1.3 & $<500$ & 23 & $2.3 \mathrm{E}-05$ & 6.78 & 9.00 & 1.100 & 2.17E-02 & 56 & $9.76 \mathrm{E}-04$ & 275 & $2.28 \mathrm{E}-03$ & 1,566 & 4.29E-03 & 1,094 & $1.22 \mathrm{E}-03$ & 1.32E-09 \\
\hline BKV6-1.7 & $<500$ & 23 & $2.3 \mathrm{E}-05$ & 15.96 & 9.00 & 1.100 & $2.16 \mathrm{E}-02$ & 63 & $1.16 \mathrm{E}-03$ & 263 & 2.13E-03 & 1,089 & $2.90 \mathrm{E}-03$ & 1,199 & $1.41 \mathrm{E}-03$ & $6.92 \mathrm{E}-10$ \\
\hline BKV6-1.10 & $<500$ & 23 & $2.3 \mathrm{E}-05$ & 18.03 & 9.00 & 1.100 & $2.16 \mathrm{E}-02$ & 60 & $1.07 \mathrm{E}-03$ & 244 & $1.97 \mathrm{E}-03$ & 933 & $2.48 \mathrm{E}-03$ & 1,160 & $1.34 \mathrm{E}-03$ & $5.63 \mathrm{E}-10$ \\
\hline BKV6-1.14 & $<500$ & 23 & $2.3 \mathrm{E}-05$ & 34.11 & 9.00 & 1.100 & 2.16E-02 & 50 & 7.58E-04 & 223 & $1.78 \mathrm{E}-03$ & 711 & $1.85 \mathrm{E}-03$ & 919 & 8.51E-04 & 4.36E-10 \\
\hline BKV6-1.15 & $<500$ & 23 & $2.3 \mathrm{E}-05$ & 40.18 & 9.00 & 1.099 & $2.16 \mathrm{E}-02$ & 45 & $6.17 \mathrm{E}-04$ & 202 & $1.59 \mathrm{E}-03$ & 668 & $1.74 \mathrm{E}-03$ & 851 & $7.16 \mathrm{E}-04$ & $4.48 \mathrm{E}-10$ \\
\hline BKV6-1.16 & $<500$ & 23 & $2.3 \mathrm{E}-05$ & 45.97 & 9.00 & 1.099 & $2.16 \mathrm{E}-02$ & 48 & 7.19E-04 & 209 & $1.64 \mathrm{E}-03$ & 642 & $1.66 \mathrm{E}-03$ & 993 & $1.00 \mathrm{E}-03$ & $3.75 \mathrm{E}-10$ \\
\hline BKV6-1.17 & $<500$ & 23 & $2.3 \mathrm{E}-05$ & 53.06 & 9.00 & 1.099 & $2.16 \mathrm{E}-02$ & 52 & $4.45 \mathrm{E}-04$ & 231 & $1.01 \mathrm{E}-03$ & 684 & 9.67E-04 & 986 & $5.38 \mathrm{E}-04$ & $2.08 \mathrm{E}-10$ \\
\hline BKV6-1.18 & $<500$ & 23 & $2.3 \mathrm{E}-05$ & 59.00 & 9.00 & 1.099 & $2.16 \mathrm{E}-02$ & 47 & $6.58 \mathrm{E}-04$ & 211 & 1.63E-03 & 672 & $1.70 \mathrm{E}-03$ & 885 & 7.63E-04 & 4.17E-10 \\
\hline \multicolumn{17}{|l|}{ Exp \#2 } \\
\hline BKV6-2.A & 17,808 & 23 & - & - & 9.00 & - & - & $<25$ & - & 25 & - & $<50$ & - & 17,808 & - & - \\
\hline BKV6-2.1 & 17,808 & 23 & $1.0 \mathrm{E}-05$ & 1.75 & 9.00 & 1.007 & 1.98E-02 & 24 & - & 96 & 7.34E-04 & 1,742 & 5.38E-03 & 15,765 & - & 2.17E-09 \\
\hline BKV6-2.3 & 17,808 & 23 & $9.4 \mathrm{E}-06$ & 6.78 & 9.00 & 1.007 & $1.98 \mathrm{E}-02$ & 23 & - & 111 & $8.46 \mathrm{E}-04$ & 1,453 & $4.20 \mathrm{E}-03$ & 15,659 & - & $1.70 \mathrm{E}-09$ \\
\hline BKV6-2.7 & 17,808 & 23 & $9.2 \mathrm{E}-06$ & 15.96 & 9.00 & 1.007 & $1.98 \mathrm{E}-02$ & 20 & - & 88 & $6.05 \mathrm{E}-04$ & 769 & $2.11 \mathrm{E}-03$ & 15,654 & - & $9.07 \mathrm{E}-10$ \\
\hline BKV6-2.10 & 17,808 & 23 & $9.5 \mathrm{E}-06$ & 23.94 & 9.00 & 1.007 & $1.98 \mathrm{E}-02$ & 20 & - & 84 & 5.82E-04 & 630 & $1.76 \mathrm{E}-03$ & 14,566 & - & $7.66 \mathrm{E}-10$ \\
\hline BKV6-2.14 & 17,808 & 23 & $9.3 \mathrm{E}-06$ & 40.02 & 9.00 & 1.007 & $1.98 \mathrm{E}-02$ & 17 & - & 57 & $3.05 \mathrm{E}-04$ & 428 & $1.12 \mathrm{E}-03$ & 17,871 & - & $5.58 \mathrm{E}-10$ \\
\hline BKV6-2.15 & 17,808 & 23 & $9.3 \mathrm{E}-06$ & 46.08 & 9.00 & 1.007 & $1.98 \mathrm{E}-02$ & 15 & - & 57 & $3.15 \mathrm{E}-04$ & 408 & $1.07 \mathrm{E}-03$ & 17,265 & - & $5.56 \mathrm{E}-10$ \\
\hline BKV6-2.16 & 17,808 & 23 & $9.3 \mathrm{E}-06$ & 51.88 & 9.00 & 1.007 & $1.98 \mathrm{E}-02$ & 17 & - & 72 & $4.51 \mathrm{E}-04$ & 350 & 8.87E-04 & 16,406 & - & $4.62 \mathrm{E}-10$ \\
\hline BKV6-2.17 & 17,808 & 23 & 5.5E-06 & 58.97 & 9.00 & 1.007 & $1.98 \mathrm{E}-02$ & 20 & - & 84 & $3.38 \mathrm{E}-04$ & 385 & 5.86E-04 & 16,308 & - & $2.74 \mathrm{E}-10$ \\
\hline BKV6-2.18 & 17,808 & 23 & 9.6E-06 & 64.91 & 9.00 & 1.006 & $1.98 \mathrm{E}-02$ & 19 & - & 104 & 7.94E-04 & 361 & 9.53E-04 & 16,574 & - & $4.66 \mathrm{E}-10$ \\
\hline \multicolumn{17}{|l|}{ Exp \#3 } \\
\hline BKV6-3.A & 31,462 & 23 & - & - & 9.00 & - & - & $<25$ & - & 21 & - & 60 & - & 31,462 & - & - \\
\hline BKV6-3.1 & 31,462 & 23 & $9.9 \mathrm{E}-06$ & 1.75 & 9.00 & 0.998 & $1.96 \mathrm{E}-02$ & 25 & - & 91 & 7.26E-04 & 1,975 & $6.06 \mathrm{E}-03$ & 33,462 & $4.59 \mathrm{E}-03$ & 2.42E-09 \\
\hline BKV6-3.3 & 31,462 & 23 & $9.8 \mathrm{E}-06$ & 6.78 & 9.00 & 0.998 & 1.96E-02 & 17 & - & 80 & $6.06 \mathrm{E}-04$ & 1,229 & 3.67E-03 & 31,137 & - & 1.57E-09 \\
\hline BKV6-3.7 & 31,462 & 23 & $9.8 \mathrm{E}-06$ & 15.96 & 9.00 & 0.998 & $1.96 \mathrm{E}-02$ & 13 & - & 62 & $4.20 \mathrm{E}-04$ & 658 & $1.88 \mathrm{E}-03$ & 33,386 & $4.39 \mathrm{E}-03$ & $9.23 \mathrm{E}-10$ \\
\hline BKV6-3.10 & 31,462 & 23 & 9.9E-06 & 23.94 & 9.00 & 0.998 & $1.96 \mathrm{E}-02$ & 12 & - & 57 & 3.74E-04 & 458 & $1.27 \mathrm{E}-03$ & 24,701 & - & $6.81 \mathrm{E}-10$ \\
\hline BKV6-3.14 & 31,462 & 23 & $9.8 \mathrm{E}-06$ & 40.02 & 9.00 & 0.998 & $1.96 \mathrm{E}-02$ & 8 & - & 39 & $1.82 \mathrm{E}-04$ & 346 & 8.99E-04 & 37,632 & $1.41 \mathrm{E}-02$ & $5.90 \mathrm{E}-10$ \\
\hline BKV6-3.15 & \begin{tabular}{|l|}
31,462 \\
\end{tabular} & 23 & $9.8 \mathrm{E}-06$ & 46.08 & 9.00 & 0.998 & $1.96 \mathrm{E}-02$ & 7 & - & 29 & 7.77E-05 & 322 & $8.27 \mathrm{E}-04$ & 37,257 & $1.32 \mathrm{E}-02$ & $5.80 \mathrm{E}-10$ \\
\hline BKV6-3.16 & \begin{tabular}{|l|}
31,462 \\
\end{tabular} & 23 & 9.7E-06 & 51.88 & 9.00 & 0.998 & $1.96 \mathrm{E}-02$ & 8 & - & 31 & $1.03 \mathrm{E}-04$ & 303 & 7.63E-04 & 32,660 & $2.72 \mathrm{E}-03$ & $5.39 \mathrm{E}-10$ \\
\hline BKV6-3.17 & \begin{tabular}{|l|}
31,462 \\
\end{tabular} & 23 & 5.7E-06 & 58.97 & 9.00 & 0.998 & $1.96 \mathrm{E}-02$ & 9 & - & 39 & $1.04 \mathrm{E}-04$ & 306 & 4.52E-04 & 32,166 & 9.35E-04 & $3.10 \mathrm{E}-10$ \\
\hline BKV6-3.18 & \begin{tabular}{|l|}
31,462 \\
\end{tabular} & 23 & $9.6 \mathrm{E}-06$ & 64.91 & 9.00 & 0.998 & $1.96 \mathrm{E}-02$ & 9 & - & 40 & 1.83E-04 & 288 & 7.04E-04 & 31,657 & $4.34 \mathrm{E}-04$ & $4.98 \mathrm{E}-10$ \\
\hline & & & & & & & & & & & & & & & & \\
\hline & & & & & & & & & & & & & & & & \\
\hline
\end{tabular}


Table B1. SPFT Results for BKV6 Glass.

\begin{tabular}{|c|c|c|c|c|c|c|c|c|c|c|c|c|c|c|c|c|}
\hline Sample ID & \begin{tabular}{|c|}
$\begin{array}{c}\text { Influent } \\
\text { [Si] }\end{array}$ \\
\end{tabular} & $\mathrm{T}\left({ }^{\circ} \mathrm{C}\right)$ & \begin{tabular}{|c}
$\begin{array}{c}\text { Flow Rate } \\
\left(\mathrm{m}^{3} / \mathrm{d}\right)\end{array}$ \\
\end{tabular} & Time, days & $\mathrm{pH}\left(23^{\circ} \mathrm{C}\right)$ & \begin{tabular}{|c|} 
Glass \\
Mass (g)
\end{tabular} & $\mathrm{SA}\left(\mathrm{m}^{2}\right)$ & [B] & B Rate & [Al] & Al Rate & [Na] & Na Rate & [Si] & Si Rate & IEX Rate \\
\hline \multicolumn{17}{|l|}{ Exp \#4 } \\
\hline BKV6-4.A & 53,051 & 23 & - & - & 9.00 & - & - & $<25$ & - & 19 & - & $<50$ & - & 53,051 & - & - \\
\hline BKV6-4.1 & 53,051 & 23 & $1.0 \mathrm{E}-05$ & 1.75 & 9.00 & 2.007 & $3.95 \mathrm{E}-02$ & 37 & $2.05 \mathrm{E}-04$ & 112 & $4.93 \mathrm{E}-04$ & 3,374 & $5.36 \mathrm{E}-03$ & 57,588 & $5.31 \mathrm{E}-03$ & 2.06E-09 \\
\hline BKV6-4.3 & 53,051 & 23 & $9.8 \mathrm{E}-06$ & 6.78 & 9.00 & 2.007 & 3.95E-02 & 22 & - & 91 & $3.70 \mathrm{E}-04$ & 2,215 & 3.39E-03 & 46,843 & - & 1.37E-09 \\
\hline BKV6-4.7 & 53,051 & 23 & $1.4 \mathrm{E}-05$ & 15.96 & 9.00 & 2.007 & 3.95E-02 & 13 & - & 64 & $3.24 \mathrm{E}-04$ & 1,141 & $2.38 \mathrm{E}-03$ & 49,602 & - & 1.07E-09 \\
\hline BKV6-4.10 & 53,051 & 23 & $9.7 \mathrm{E}-06$ & 23.94 & 9.00 & 2.007 & 3.95E-02 & 11 & - & 48 & $1.50 \mathrm{E}-04$ & 754 & $1.09 \mathrm{E}-03$ & 32,633 & - & $5.30 \mathrm{E}-10$ \\
\hline BKV6-4.14 & 53,051 & 23 & $9.3 \mathrm{E}-06$ & 40.02 & 9.00 & 2.007 & $3.95 \mathrm{E}-02$ & 9 & - & 61 & $2.04 \mathrm{E}-04$ & 632 & 8.67E-04 & 58,267 & $5.63 \mathrm{E}-03$ & 4.53E-10 \\
\hline BKV6-4.15 & 53,051 & 23 & $9.1 \mathrm{E}-06$ & 46.08 & 9.00 & 2.007 & 3.95E-02 & 6 & - & 26 & $3.41 \mathrm{E}-05$ & 602 & 7.99E-04 & 53,725 & 7.07E-04 & $4.41 \mathrm{E}-10$ \\
\hline BKV6-4.16 & 53,051 & 23 & $9.4 \mathrm{E}-06$ & 51.88 & 9.00 & 2.007 & 3.95E-02 & 6 & - & 27 & 3.84E-05 & 582 & 7.98E-04 & 48,665 & - & $4.45 \mathrm{E}-10$ \\
\hline BKV6-4.17 & 53,051 & 23 & $5.7 \mathrm{E}-06$ & 58.97 & 9.00 & 2.007 & $3.95 \mathrm{E}-02$ & 6 & - & 33 & $4.14 \mathrm{E}-05$ & 523 & $4.30 \mathrm{E}-04$ & 48,169 & - & $2.47 \mathrm{E}-10$ \\
\hline BKV6-4.18 & 53,051 & 23 & $9.6 \mathrm{E}-06$ & 64.91 & 9.00 & 2.007 & 3.95E-02 & 6 & - & 31 & $6.15 \mathrm{E}-05$ & 448 & $6.08 \mathrm{E}-04$ & 47,684 & - & $3.68 \mathrm{E}-10$ \\
\hline \multicolumn{17}{|l|}{ Exp \#5 } \\
\hline BKV6-5.A & 80,823 & 23 & - & - & 9.00 & - & - & $<25$ & - & 19 & - & $<50$ & - & 80,823 & - & - \\
\hline BKV6-5.1 & 80,823 & 23 & $1.3 \mathrm{E}-05$ & 1.75 & 9.00 & 2.004 & $3.94 \mathrm{E}-02$ & 77 & $1.19 \mathrm{E}-03$ & 307 & $1.96 \mathrm{E}-03$ & 3,503 & $7.17 \mathrm{E}-03$ & 79,673 & - & 2.39E-09 \\
\hline BKV6-5.3 & 80,823 & 23 & $9.8 \mathrm{E}-06$ & 6.78 & 9.00 & 2.004 & 3.94E-02 & 20 & - & 58 & $2.03 \mathrm{E}-04$ & 2,137 & $3.28 \mathrm{E}-03$ & 61,890 & - & 1.35E-09 \\
\hline BKV6-5.7 & 80,823 & 23 & $9.9 \mathrm{E}-06$ & 15.96 & 9.00 & 2.004 & $3.94 \mathrm{E}-02$ & 9 & - & 38 & $9.54 \mathrm{E}-05$ & 1,221 & $1.85 \mathrm{E}-03$ & 74,157 & - & $8.51 \mathrm{E}-10$ \\
\hline BKV6-5.10 & 80,823 & 23 & 9.9E-06 & 23.94 & 9.00 & 2.004 & 3.94E-02 & 6 & - & 103 & 4.37E-04 & 804 & $1.19 \mathrm{E}-03$ & 59,539 & - & 6.07E-10 \\
\hline BKV6-5.14 & 80,823 & 23 & $9.8 \mathrm{E}-06$ & 40.02 & 9.00 & 2.004 & $3.94 \mathrm{E}-02$ & 5 & - & 23 & $2.19 \mathrm{E}-05$ & 499 & $7.05 \mathrm{E}-04$ & 67,628 & - & 4.17E-10 \\
\hline BKV6-5.15 & 80,823 & 23 & $9.8 \mathrm{E}-06$ & 46.08 & 9.00 & 2.004 & $3.94 \mathrm{E}-02$ & 2 & - & 16 & - & 548 & $7.81 \mathrm{E}-04$ & 66,129 & - & $4.68 \mathrm{E}-10$ \\
\hline BKV6-5.16 & 80,823 & 23 & $9.8 \mathrm{E}-06$ & 51.88 & 9.00 & 2.004 & 3.94E-02 & 3 & - & 19 & - & 628 & 9.07E-04 & 62,894 & - & $5.16 \mathrm{E}-10$ \\
\hline BKV6-5.17 & 80,823 & 23 & $5.8 \mathrm{E}-06$ & 58.97 & 9.00 & 2.004 & 3.94E-02 & 3 & - & 21 & $4.25 \mathrm{E}-06$ & 555 & 4.65E-04 & 71,453 & - & $2.75 \mathrm{E}-10$ \\
\hline BKV6-5.18 & 80,823 & 23 & $9.8 \mathrm{E}-06$ & 64.91 & 9.00 & 2.004 & 3.94E-02 & 2 & - & 21 & $9.69 \mathrm{E}-06$ & 483 & $6.80 \mathrm{E}-04$ & 66,305 & - & $4.31 \mathrm{E}-10$ \\
\hline \multicolumn{17}{|l|}{$\underline{\operatorname{Exp} \# 6}$} \\
\hline BKV6-6.A & 62,744 & 23 & - & - & 9.00 & - & - & $<25$ & - & $<10$ & - & 55 & - & 62,744 & - & - \\
\hline BKV6-6.1 & 62,744 & 23 & 9.963 & 1.75 & 9.00 & 2.001 & $3.94 \mathrm{E}-02$ & 45 & $3.56 \mathrm{E}-04$ & 166 & $8.19 \mathrm{E}-04$ & 3,078 & $4.82 \mathrm{E}-03$ & 60,938 & - & $1.78 \mathrm{E}-09$ \\
\hline BKV6-6.3 & 62,744 & 23 & 9.856 & 6.78 & 9.00 & 2.001 & $3.94 \mathrm{E}-02$ & 20 & - & 84 & $3.85 \mathrm{E}-04$ & 2,166 & $3.33 \mathrm{E}-03$ & 65,108 & $2.70 \mathrm{E}-03$ & 1.37E-09 \\
\hline BKV6-6.7 & 62,744 & 23 & 9.809 & 15.96 & 9.00 & 2.001 & $3.94 \mathrm{E}-02$ & 7 & - & 32 & $1.15 \mathrm{E}-04$ & 1,104 & $1.65 \mathrm{E}-03$ & 84,697 & $2.50 \mathrm{E}-02$ & $7.80 \mathrm{E}-10$ \\
\hline BKV6-6.10 & 62,744 & 23 & 9.959 & 23.94 & 9.00 & 2.001 & $3.94 \mathrm{E}-02$ & 5 & - & 22 & $6.24 \mathrm{E}-05$ & 787 & $1.17 \mathrm{E}-03$ & 67,920 & $5.98 \mathrm{E}-03$ & $6.03 \mathrm{E}-10$ \\
\hline BKV6-6.14 & 62,744 & 23 & 9.736 & 40.02 & 9.00 & 2.001 & 3.94E-02 & 3 & - & 13 & $1.59 \mathrm{E}-05$ & 473 & 6.52E-04 & 72,940 & $1.15 \mathrm{E}-02$ & $4.10 \mathrm{E}-10$ \\
\hline BKV6-6.15 & 62,744 & 23 & 9.815 & 46.08 & 9.00 & 2.001 & $3.94 \mathrm{E}-02$ & 3 & - & 19 & 4.89E-05 & 545 & 7.70E-04 & 72,687 & $1.13 \mathrm{E}-02$ & $4.59 \mathrm{E}-10$ \\
\hline BKV6-6.16 & 62,744 & 23 & 9.785 & 51.88 & 9.00 & 2.001 & 3.94E-02 & 2 & - & 23 & $6.83 \mathrm{E}-05$ & 579 & $8.22 \mathrm{E}-04$ & 72,623 & $1.12 \mathrm{E}-02$ & $4.86 \mathrm{E}-10$ \\
\hline BKV6-6.17 & 62,744 & 23 & 5.699 & 58.97 & 9.00 & 2.001 & $3.94 \mathrm{E}-02$ & 2 & - & 16 & $1.66 \mathrm{E}-05$ & 516 & $4.21 \mathrm{E}-04$ & 79,185 & $1.09 \mathrm{E}-02$ & $2.60 \mathrm{E}-10$ \\
\hline BKV6-6.18 & 62,744 & 23 & 9.459 & 64.91 & 9.00 & 2.001 & 3.94E-02 & 1 & - & 15 & $2.27 \mathrm{E}-05$ & 452 & 6.02E-04 & 82,688 & $2.19 \mathrm{E}-02$ & $3.98 \mathrm{E}-10$ \\
\hline & & & & & & & & & & & & & & & & \\
\hline & & & & & & & & & & & & & & & & \\
\hline & & & & & & & & & & & & & & & & \\
\hline & & & & & & & & & & & & & & & & \\
\hline & & & & & & & & & & & & & & & & \\
\hline
\end{tabular}


Table B1. SPFT Results for BKV6 Glass.

\begin{tabular}{|c|c|c|c|c|c|c|c|c|c|c|c|c|c|c|c|c|}
\hline Sample ID & \begin{tabular}{|c|}
$\begin{array}{c}\text { Influent } \\
\text { [Si] }\end{array}$ \\
\end{tabular} & $\mathrm{T}\left({ }^{\circ} \mathrm{C}\right)$ & \begin{tabular}{|c}
$\begin{array}{c}\text { Flow Rate } \\
\left(\mathrm{m}^{3} / \mathrm{d}\right)\end{array}$ \\
\end{tabular} & Time, days & $\mathrm{pH}\left(23^{\circ} \mathrm{C}\right)$ & \begin{tabular}{|c|} 
Glass \\
Mass (g)
\end{tabular} & $\mathrm{SA}\left(\mathrm{m}^{2}\right)$ & [B] & B Rate & [Al] & Al Rate & [Na] & Na Rate & [Si] & Si Rate & IEX Rate \\
\hline \multicolumn{17}{|l|}{ Exp \#7 } \\
\hline BKV6-7.A & 0 & 23 & - & - & 7.00 & - & - & $<100$ & - & 34 & - & 65 & - & $<500$ & - & - \\
\hline BKV6-7.1 & 0 & 23 & $1.0 \mathrm{E}-05$ & 1.86 & 7.00 & 1.003 & $1.97 \mathrm{E}-02$ & $<100$ & - & 45 & $1.19 \mathrm{E}-04$ & 3,158 & $1.02 \mathrm{E}-02$ & - & - & $4.08 \mathrm{E}-09$ \\
\hline BKV6-7.3 & 0 & 23 & $8.8 \mathrm{E}-06$ & 6.82 & 7.00 & 1.003 & $1.97 \mathrm{E}-02$ & $<100$ & - & - & - & 2,151 & $5.89 \mathrm{E}-03$ & - & - & 2.35E-09 \\
\hline BKV6-7.7 & 0 & 23 & $8.5 \mathrm{E}-06$ & 15.98 & 7.00 & 1.002 & 1.97E-02 & $<100$ & - & - & - & 884 & $2.23 \mathrm{E}-03$ & - & - & $8.92 \mathrm{E}-10$ \\
\hline BKV6-7.10 & 0 & 23 & $9.6 \mathrm{E}-06$ & 22.98 & 7.00 & 1.002 & 1.97E-02 & $<100$ & - & - & - & 774 & $2.18 \mathrm{E}-03$ & - & - & $8.70 \mathrm{E}-10$ \\
\hline BKV6-7.14 & 0 & 23 & $1.0 \mathrm{E}-05$ & 38.95 & 7.00 & 1.002 & $1.97 \mathrm{E}-02$ & $<100$ & - & - & - & 391 & $1.06 \mathrm{E}-03$ & - & - & 4.23E-10 \\
\hline BKV6-7.15 & 0 & 23 & $9.4 \mathrm{E}-06$ & 45.13 & 7.00 & 1.002 & $1.97 \mathrm{E}-02$ & $<100$ & - & - & - & 398 & 9.97E-04 & - & - & $3.98 \mathrm{E}-10$ \\
\hline BKV6-7.16 & 0 & 23 & 9.2E-06 & 50.86 & 7.00 & 1.001 & 1.97E-02 & $<100$ & - & - & - & 351 & $8.46 \mathrm{E}-04$ & - & - & $3.38 \mathrm{E}-10$ \\
\hline BKV6-7.17 & 0 & 23 & 7.4E-06 & 58.02 & 7.00 & 1.000 & $1.97 \mathrm{E}-02$ & $<100$ & - & - & - & 346 & $6.66 \mathrm{E}-04$ & - & - & $2.66 \mathrm{E}-10$ \\
\hline BKV6-7.18 & 0 & 23 & $8.1 \mathrm{E}-06$ & 63.95 & 7.00 & 1.000 & $1.97 \mathrm{E}-02$ & $<100$ & - & - & - & 350 & 7.43E-04 & - & - & $2.97 \mathrm{E}-10$ \\
\hline \multicolumn{17}{|l|}{ Exp \#8 } \\
\hline BKV6-8.A & 0 & 23 & - & - & 8.00 & - & - & $<100$ & - & $<25$ & - & $<50$ & - & $<500$ & - & - \\
\hline BKV6-8.1 & 0 & 23 & $1.0 \mathrm{E}-05$ & 1.86 & 8.00 & 1.004 & $1.98 \mathrm{E}-02$ & $<100$ & - & 160 & $1.45 \mathrm{E}-03$ & 2,734 & $8.76 \mathrm{E}-03$ & - & - & $3.50 \mathrm{E}-09$ \\
\hline BKV6-8.3 & 0 & 23 & $9.7 \mathrm{E}-06$ & 6.82 & 8.00 & 1.004 & $1.98 \mathrm{E}-02$ & $<100$ & - & 75 & 5.06E-04 & 1,691 & 5.07E-03 & - & - & 2.02E-09 \\
\hline BKV6-8.7 & 0 & 23 & $9.7 \mathrm{E}-06$ & 15.98 & 8.00 & 1.003 & $1.97 \mathrm{E}-02$ & $<100$ & - & 60 & 3.56E-04 & 697 & $2.00 \mathrm{E}-03$ & - & - & $7.98 \mathrm{E}-10$ \\
\hline BKV6-8.10 & 0 & 23 & $9.2 \mathrm{E}-06$ & 22.98 & 8.00 & 1.003 & 1.97E-02 & $<100$ & - & 63 & 3.65E-04 & 528 & $1.41 \mathrm{E}-03$ & - & - & 5.61E-10 \\
\hline BKV6-8.14 & 0 & 23 & $1.1 \mathrm{E}-05$ & 38.95 & 8.00 & 1.003 & $1.97 \mathrm{E}-02$ & $<100$ & - & 35 & 1.14E-04 & 346 & $1.05 \mathrm{E}-03$ & - & - & $4.18 \mathrm{E}-10$ \\
\hline BKV6-8.15 & 0 & 23 & $1.0 \mathrm{E}-05$ & 45.13 & 8.00 & 1.002 & $1.97 \mathrm{E}-02$ & $<100$ & - & 38 & 1.37E-04 & 324 & 8.74E-04 & - & - & 3.49E-10 \\
\hline BKV6-8.16 & 0 & 23 & $9.8 \mathrm{E}-06$ & 50.86 & 8.00 & 1.002 & 1.97E-02 & $<100$ & - & 43 & 1.87E-04 & 343 & 9.19E-04 & - & - & $3.67 \mathrm{E}-10$ \\
\hline BKV6-8.17 & 0 & 23 & $8.2 \mathrm{E}-06$ & 58.02 & 8.00 & 1.001 & 1.97E-02 & $<100$ & - & 42 & 1.43E-04 & 342 & 7.65E-04 & - & - & 3.06E-10 \\
\hline BKV6-8.18 & 0 & 23 & $9.8 \mathrm{E}-06$ & 63.95 & 8.00 & 1.001 & 1.97E-02 & $<100$ & - & 38 & 1.30E-04 & 305 & 7.99E-04 & - & - & 3.19E-10 \\
\hline \multicolumn{17}{|l|}{$\underline{\operatorname{Exp} \# 9}$} \\
\hline BKV6-9.A & 0 & 23 & - & - & 9.00 & - & - & $<100$ & - & $<25$ & - & $<50$ & - & $<500$ & - & - \\
\hline BKV6-9.1 & 0 & 23 & $1.0 \mathrm{E}-05$ & 1.86 & 9.00 & 1.002 & $1.97 \mathrm{E}-02$ & $<100$ & - & 136 & $1.18 \mathrm{E}-03$ & 1,692 & $5.34 \mathrm{E}-03$ & 523 & $5.51 \mathrm{E}-05$ & 2.13E-09 \\
\hline BKV6-9.3 & 0 & 23 & 9.6E-06 & 6.82 & 9.00 & 1.002 & $1.97 \mathrm{E}-02$ & $<100$ & - & 252 & $2.29 \mathrm{E}-03$ & 1,485 & $4.41 \mathrm{E}-03$ & 998 & $1.11 \mathrm{E}-03$ & $1.76 \mathrm{E}-09$ \\
\hline BKV6-9.7 & 0 & 23 & $9.6 \mathrm{E}-06$ & 15.98 & 9.00 & 1.001 & $1.97 \mathrm{E}-02$ & $<100$ & - & 268 & $2.44 \mathrm{E}-03$ & 1,098 & $3.21 \mathrm{E}-03$ & 1,093 & $1.32 \mathrm{E}-03$ & $1.28 \mathrm{E}-09$ \\
\hline BKV6-9.10 & 0 & 23 & $9.8 \mathrm{E}-06$ & 22.98 & 9.00 & 1.001 & $1.97 \mathrm{E}-02$ & $<100$ & - & 224 & $2.05 E-03$ & 873 & $2.59 \mathrm{E}-03$ & 1,003 & $1.15 \mathrm{E}-03$ & 1.03E-09 \\
\hline BKV6-9.14 & 0 & 23 & $1.1 \mathrm{E}-05$ & 38.95 & 9.00 & 1.001 & 1.97E-02 & $<100$ & - & 203 & $2.10 \mathrm{E}-03$ & 662 & $2.20 \mathrm{E}-03$ & 833 & 8.67E-04 & $8.77 \mathrm{E}-10$ \\
\hline BKV6-9.15 & 0 & 23 & $9.8 \mathrm{E}-06$ & 45.13 & 9.00 & 1.000 & 1.97E-02 & $<100$ & - & 193 & $1.74 \mathrm{E}-03$ & 613 & $1.77 \mathrm{E}-03$ & 822 & 7.34E-04 & 7.06E-10 \\
\hline BKV6-9.16 & 0 & 23 & $9.7 \mathrm{E}-06$ & 50.86 & 9.00 & 1.000 & 1.97E-02 & $<100$ & - & 235 & $2.15 \mathrm{E}-03$ & 603 & $1.72 \mathrm{E}-03$ & 996 & 1.12E-03 & $6.88 \mathrm{E}-10$ \\
\hline BKV6-9.17 & 0 & 23 & $8.1 \mathrm{E}-06$ & 58.02 & 9.00 & 0.999 & 1.97E-02 & $<100$ & - & 255 & $1.97 \mathrm{E}-03$ & 633 & $1.52 \mathrm{E}-03$ & 1,068 & $1.07 \mathrm{E}-03$ & $6.07 \mathrm{E}-10$ \\
\hline BKV6-9.18 & 0 & 23 & 9.7E-06 & 63.95 & 9.00 & 0.999 & 1.97E-02 & $<100$ & - & 233 & 2.13E-03 & 625 & $1.80 \mathrm{E}-03$ & 862 & 8.19E-04 & 7.17E-10 \\
\hline & & & & & & & & & & & & & & & & \\
\hline & & & & & & & & & & & & & & & & \\
\hline & & & & & & & & & & & & & & & & \\
\hline & & & & & & & & & & & & & & & & \\
\hline & & & & & & & & & & & & & & & & \\
\hline
\end{tabular}


Table B1. SPFT Results for BKV6 Glass.

\begin{tabular}{|c|c|c|c|c|c|c|c|c|c|c|c|c|c|c|c|c|}
\hline Sample ID & \begin{tabular}{|c|}
$\begin{array}{c}\text { Influent } \\
\text { [Si] }\end{array}$ \\
\end{tabular} & $\mathbf{T}\left({ }^{\circ} \mathbf{C}\right)$ & $\begin{array}{c}\text { Flow Rate } \\
\left(\mathrm{m}^{3} / \mathrm{d}\right)\end{array}$ & Time, days & $\mathrm{pH}\left(23^{\circ} \mathrm{C}\right)$ & $\begin{array}{c}\text { Glass } \\
\text { Mass (g) } \\
\end{array}$ & $\mathrm{SA}\left(\mathrm{m}^{2}\right)$ & {$[\mathrm{B}]$} & B Rate & [Al] & Al Rate & [Na] & Na Rate & [Si] & Si Rate & IEX Rate \\
\hline \multicolumn{17}{|l|}{$\underline{\operatorname{Exp} \# 10}$} \\
\hline BKV6-10.A & 0 & 23 & - & - & 10.00 & - & - & $<100$ & - & 27 & - & $<50$ & - & $<500$ & - & - \\
\hline BKV6-10.1 & 0 & 23 & $1.1 \mathrm{E}-05$ & 1.86 & 10.00 & 0.500 & 9.84E-03 & 213 & 8.58E-03 & 779 & $1.71 \mathrm{E}-02$ & 2,488 & 1.69E-02 & 3,687 & $1.60 \mathrm{E}-02$ & 3.30E-09 \\
\hline BKV6-10.3 & 0 & 23 & $9.9 \mathrm{E}-06$ & 6.82 & 10.00 & 0.499 & 9.83E-03 & 108 & 5.72E-04 & 399 & 7.72E-03 & 1,251 & 7.60E-03 & 1,857 & 6.22E-03 & $2.80 \mathrm{E}-09$ \\
\hline BKV6-10.7 & 0 & 23 & $9.8 \mathrm{E}-06$ & 15.98 & 10.00 & 0.499 & $9.82 \mathrm{E}-03$ & 102 & $1.60 \mathrm{E}-04$ & 410 & 7.92E-03 & 1,221 & 7.37E-03 & 1,866 & $6.23 \mathrm{E}-03$ & $2.88 \mathrm{E}-09$ \\
\hline BKV6-10.10 & 0 & 23 & $9.9 \mathrm{E}-06$ & 22.98 & 10.00 & 0.499 & 9.82E-03 & $<100$ & - & 359 & 6.93E-03 & 972 & $5.87 \mathrm{E}-03$ & 1,578 & 4.97E-03 & $2.34 \mathrm{E}-09$ \\
\hline BKV6-10.14 & 0 & 23 & $1.1 \mathrm{E}-05$ & 38.95 & 10.00 & 0.499 & $9.81 \mathrm{E}-03$ & $<100$ & - & 246 & $5.28 \mathrm{E}-03$ & 752 & 5.16E-03 & 1,035 & $2.85 \mathrm{E}-03$ & $2.06 \mathrm{E}-09$ \\
\hline BKV6-10.15 & 0 & 23 & 9.7E-06 & 45.13 & 10.00 & 0.498 & $9.81 \mathrm{E}-03$ & $<100$ & - & 206 & 3.67E-03 & 644 & $3.70 \mathrm{E}-03$ & 881 & $1.72 \mathrm{E}-03$ & $1.48 \mathrm{E}-09$ \\
\hline BKV6-10.16 & 0 & 23 & 9.7E-06 & 50.86 & 10.00 & 0.498 & $9.80 \mathrm{E}-03$ & $<100$ & - & 286 & 5.34E-03 & 663 & $3.84 \mathrm{E}-03$ & 1,262 & $3.46 \mathrm{E}-03$ & 1.53E-09 \\
\hline BKV6-10.17 & 0 & 23 & $8.1 \mathrm{E}-06$ & 58.02 & 10.00 & 0.497 & $9.78 \mathrm{E}-03$ & $<100$ & - & 379 & 6.03E-03 & 919 & 4.53E-03 & 1,699 & $4.53 \mathrm{E}-03$ & $1.81 \mathrm{E}-09$ \\
\hline BKV6-10.18 & 0 & 23 & $9.8 \mathrm{E}-06$ & 63.95 & 10.00 & 0.496 & $9.77 \mathrm{E}-03$ & $<100$ & - & 363 & 7.01E-03 & 962 & 5.79E-03 & 1,617 & 5.14E-03 & $2.31 \mathrm{E}-09$ \\
\hline \multicolumn{17}{|l|}{ Exp \#11 } \\
\hline BKV6-11.A & 0 & 23 & - & - & 11.00 & - & - & $<100$ & - & 39 & - & 79 & - & 947 & - & - \\
\hline BKV6-11.1 & 0 & 23 & $1.0 \mathrm{E}-05$ & 1.86 & 11.00 & 0.500 & $9.84 \mathrm{E}-03$ & 200 & $7.21 \mathrm{E}-03$ & 470 & $9.24 \mathrm{E}-03$ & 1,729 & $1.08 \mathrm{E}-02$ & 3,058 & $1.00 \mathrm{E}-02$ & $1.43 \mathrm{E}-09$ \\
\hline BKV6-11.3 & 0 & 23 & $9.8 \mathrm{E}-06$ & 6.82 & 11.00 & 0.499 & 9.83E-03 & 294 & 1.34E-02 & 1,090 & $2.17 \mathrm{E}-02$ & 3,175 & 1.95E-02 & 4,995 & 1.84E-02 & $2.43 \mathrm{E}-09$ \\
\hline BKV6-11.7 & 0 & 23 & $9.8 \mathrm{E}-06$ & 15.98 & 11.00 & 0.498 & $9.81 \mathrm{E}-03$ & 299 & $1.37 \mathrm{E}-02$ & 1,182 & $2.36 \mathrm{E}-02$ & 3,270 & $2.00 \mathrm{E}-02$ & 5,187 & $1.93 \mathrm{E}-02$ & $2.52 \mathrm{E}-09$ \\
\hline BKV6-11.10 & 0 & 23 & $9.9 \mathrm{E}-06$ & 22.98 & 11.00 & 0.498 & $9.80 \mathrm{E}-03$ & 279 & $1.26 \mathrm{E}-02$ & 1,115 & $2.26 \mathrm{E}-02$ & 3,025 & $1.88 \mathrm{E}-02$ & 4,838 & $1.80 \mathrm{E}-02$ & $2.50 \mathrm{E}-09$ \\
\hline BKV6-11.14 & 0 & 23 & $1.1 \mathrm{E}-05$ & 38.95 & 11.00 & 0.497 & 9.79E-03 & 279 & $1.45 \mathrm{E}-02$ & 1,136 & $2.65 \mathrm{E}-02$ & 3,048 & $2.18 \mathrm{E}-02$ & 4,901 & $2.11 \mathrm{E}-02$ & 2.93E-09 \\
\hline BKV6-11.15 & 0 & 23 & $9.4 \mathrm{E}-06$ & 45.13 & 11.00 & 0.496 & 9.77E-03 & 251 & 1.00E-02 & 1,065 & $2.04 \mathrm{E}-02$ & 2,882 & 1.70E-02 & 4,475 & $1.55 \mathrm{E}-02$ & $2.78 \mathrm{E}-09$ \\
\hline BKV6-11.16 & 0 & 23 & 9.7E-06 & 50.86 & 11.00 & 0.494 & $9.74 \mathrm{E}-03$ & 269 & $1.16 \mathrm{E}-02$ & 1,134 & $2.26 \mathrm{E}-02$ & 3,002 & $1.84 \mathrm{E}-02$ & 4,826 & $1.77 \mathrm{E}-02$ & $2.69 \mathrm{E}-09$ \\
\hline BKV6-11.17 & 0 & 23 & $7.9 \mathrm{E}-06$ & 58.02 & 11.00 & 0.493 & $9.71 \mathrm{E}-03$ & 290 & $1.08 \mathrm{E}-02$ & 1,179 & $1.93 \mathrm{E}-02$ & 3,113 & $1.57 \mathrm{E}-02$ & 5,066 & $1.54 \mathrm{E}-02$ & $1.96 \mathrm{E}-09$ \\
\hline BKV6-11.18 & 0 & 23 & $9.8 \mathrm{E}-06$ & 63.95 & 11.00 & 0.491 & $9.67 \mathrm{E}-03$ & 283 & $1.28 \mathrm{E}-02$ & 1,059 & 2.13E-02 & 2,911 & $1.80 \mathrm{E}-02$ & 4,962 & $1.85 \mathrm{E}-02$ & $2.10 \mathrm{E}-09$ \\
\hline \multicolumn{17}{|l|}{$\underline{\operatorname{Exp} \# 12}$} \\
\hline BKV6-12.A & 0 & 23 & - & - & 12.00 & - & - & 101 & - & 61 & - & 113 & - & 1,232 & - & - \\
\hline BKV6-12.1 & 0 & 23 & $9.9 \mathrm{E}-06$ & 1.86 & 12.00 & 0.510 & $1.00 \mathrm{E}-02$ & 356 & $1.75 \mathrm{E}-02$ & 967 & $1.86 \mathrm{E}-02$ & 2,782 & $1.67 \mathrm{E}-02$ & 5,502 & $1.93 \mathrm{E}-02$ & $-3.45 \mathrm{E}-10$ \\
\hline BKV6-12.3 & 0 & 23 & $9.9 \mathrm{E}-06$ & 6.82 & 12.00 & 0.508 & $1.00 \mathrm{E}-02$ & 612 & $3.51 \mathrm{E}-02$ & 2,554 & $5.11 \mathrm{E}-02$ & 6,876 & $4.22 \mathrm{E}-02$ & 10,829 & 4.34E-02 & $2.86 \mathrm{E}-09$ \\
\hline BKV6-12.7 & 0 & 23 & $9.9 \mathrm{E}-06$ & 15.98 & 12.00 & 0.506 & $9.98 \mathrm{E}-03$ & 696 & $4.08 \mathrm{E}-02$ & 3,010 & $6.04 \mathrm{E}-02$ & 7,997 & 4.92E-02 & 12,644 & $5.16 \mathrm{E}-02$ & 3.35E-09 \\
\hline BKV6-12.10 & 0 & 23 & $9.9 \mathrm{E}-06$ & 22.98 & 12.00 & 0.505 & $9.95 \mathrm{E}-03$ & 651 & $3.79 \mathrm{E}-02$ & 2,796 & $5.63 \mathrm{E}-02$ & 7,480 & $4.62 \mathrm{E}-02$ & 11,906 & $4.85 \mathrm{E}-02$ & 3.33E-09 \\
\hline BKV6-12.14 & 0 & 23 & $1.1 \mathrm{E}-05$ & 38.95 & 12.00 & 0.504 & 9.92E-03 & 590 & 3.92E-02 & 2,532 & 5.93E-02 & 6,764 & $4.86 \mathrm{E}-02$ & 10,703 & 5.01E-02 & 3.73E-09 \\
\hline BKV6-12.15 & 0 & 23 & $8.4 \mathrm{E}-06$ & 45.13 & 12.00 & 0.501 & $9.88 \mathrm{E}-03$ & 606 & $2.97 \mathrm{E}-02$ & 2,712 & 4.66E-02 & 7,220 & $3.81 \mathrm{E}-02$ & 10,958 & 3.77E-02 & 3.34E-09 \\
\hline BKV6-12.16 & 0 & 23 & $9.8 \mathrm{E}-06$ & 50.86 & 12.00 & 0.497 & $9.81 \mathrm{E}-03$ & 608 & $3.49 \mathrm{E}-02$ & 2,737 & 5.51E-02 & 7,369 & $4.55 \mathrm{E}-02$ & 11,018 & $4.45 \mathrm{E}-02$ & 4.23E-09 \\
\hline BKV6-12.17 & 0 & 23 & $7.5 \mathrm{E}-06$ & 58.02 & 12.00 & 0.494 & $9.74 \mathrm{E}-03$ & 646 & $2.91 \mathrm{E}-02$ & 2,778 & 4.35E-02 & 7,535 & $3.62 \mathrm{E}-02$ & 11,584 & 3.66E-02 & $2.80 \mathrm{E}-09$ \\
\hline BKV6-12.18 & 0 & 23 & $9.8 \mathrm{E}-06$ & 63.95 & 12.00 & 0.490 & $9.67 \mathrm{E}-03$ & 641 & $3.81 \mathrm{E}-02$ & 2,710 & 5.59E-02 & 7,304 & 4.62E-02 & 11,979 & $5.00 \mathrm{E}-02$ & 3.23E-09 \\
\hline & & & & & & & & & & & & & & & & \\
\hline & & & & & & & & & & & & & & & & \\
\hline & & & & & & & & & & & & & & & & \\
\hline & & & & & & & & & & & & & & & & \\
\hline & & & & & & & & & & & & & & & & \\
\hline
\end{tabular}


Table B1. SPFT Results for BKV6 Glass.

\begin{tabular}{|c|c|c|c|c|c|c|c|c|c|c|c|c|c|c|c|c|}
\hline Sample ID & \begin{tabular}{|c|}
$\begin{array}{c}\text { Influent } \\
\text { [Si] }\end{array}$ \\
\end{tabular} & $\mathrm{T}\left({ }^{\circ} \mathrm{C}\right)$ & \begin{tabular}{|c}
$\begin{array}{c}\text { Flow Rate } \\
\left(\mathrm{m}^{3} / \mathrm{d}\right)\end{array}$ \\
\end{tabular} & Time, days & $\mathrm{pH}\left(23^{\circ} \mathrm{C}\right)$ & \begin{tabular}{|c|} 
Glass \\
Mass (g)
\end{tabular} & $\mathrm{SA}\left(\mathrm{m}^{2}\right)$ & [B] & B Rate & [Al] & Al Rate & [Na] & Na Rate & [Si] & Si Rate & IEX Rate \\
\hline \multicolumn{17}{|l|}{ Exp\#13 } \\
\hline BKV6-13.A & $<500$ & 40 & - & - & 9.00 & - & - & $<50$ & - & 19 & - & $<100$ & - & $<500$ & - & - \\
\hline BKV6-13.1 & $<500$ & 40 & $8.6 \mathrm{E}-06$ & 3.14 & 9.00 & 0.509 & $1.00 \mathrm{E}-02$ & - & - & 190 & $3.03 \mathrm{E}-03$ & 1,411 & 7.07E-03 & 816 & $1.24 \mathrm{E}-03$ & 3.07E-09 \\
\hline BKV6-13.2 & $<500$ & 40 & 9.5E-06 & 7.02 & 9.00 & 0.509 & $1.00 \mathrm{E}-02$ & 72 & $1.42 \mathrm{E}-03$ & 314 & 5.79E-03 & 1,592 & 8.89E-03 & 1,342 & $3.64 \mathrm{E}-03$ & $2.98 \mathrm{E}-09$ \\
\hline BKV6-13.5 & $<500$ & 40 & $9.4 \mathrm{E}-06$ & 21.22 & 9.00 & 0.508 & $1.00 \mathrm{E}-02$ & 82 & $2.12 \mathrm{E}-03$ & 335 & $6.16 \mathrm{E}-03$ & 1,106 & $5.97 \mathrm{E}-03$ & 1,605 & $4.75 \mathrm{E}-03$ & 1.54E-09 \\
\hline BKV6-13.6 & $<500$ & 40 & 9.3E-06 & 24.92 & 9.00 & 0.508 & $1.00 \mathrm{E}-02$ & 84 & $2.18 \mathrm{E}-03$ & 340 & $6.22 \mathrm{E}-03$ & 1,130 & $6.07 \mathrm{E}-03$ & 1,612 & $4.75 \mathrm{E}-03$ & 1.55E-09 \\
\hline BKV6-13.8 & $<500$ & 40 & $8.9 \mathrm{E}-06$ & 32.96 & 9.00 & 0.508 & $9.99 \mathrm{E}-03$ & 83 & $2.05 \mathrm{E}-03$ & 354 & $6.16 \mathrm{E}-03$ & 1,095 & 5.56E-03 & 1,570 & $4.34 \mathrm{E}-03$ & 1.40E-09 \\
\hline BKV6-13.9 & $<500$ & 40 & 7.9E-06 & 39.18 & 9.00 & 0.507 & $9.99 \mathrm{E}-03$ & 80 & $1.64 \mathrm{E}-03$ & 342 & $5.28 \mathrm{E}-03$ & 1,072 & $4.84 \mathrm{E}-03$ & 1,490 & $3.57 \mathrm{E}-03$ & $1.28 \mathrm{E}-09$ \\
\hline BKV6-13.12 & $<500$ & 40 & $7.0 \mathrm{E}-06$ & 49.21 & 9.00 & 0.507 & $9.98 \mathrm{E}-03$ & 83 & $1.61 \mathrm{E}-03$ & 354 & $4.89 \mathrm{E}-03$ & 1,106 & $4.46 \mathrm{E}-03$ & 1,560 & $3.41 \mathrm{E}-03$ & 1.14E-09 \\
\hline BKV6-13.13 & $<500$ & 40 & $1.0 \mathrm{E}-05$ & 54.07 & 9.00 & 0.507 & $9.98 \mathrm{E}-03$ & 78 & $1.98 \mathrm{E}-03$ & 332 & $6.64 \mathrm{E}-03$ & 1,051 & $6.14 \mathrm{E}-03$ & 1,477 & $4.57 \mathrm{E}-03$ & 1.66E-09 \\
\hline BKV6-13.14 & $<500$ & 40 & $9.4 \mathrm{E}-06$ & 59.27 & 9.00 & 0.506 & 9.97E-03 & 72 & $1.41 \mathrm{E}-03$ & 296 & $5.43 \mathrm{E}-03$ & 1,004 & $5.38 \mathrm{E}-03$ & 1,323 & $3.55 \mathrm{E}-03$ & 1.59E-09 \\
\hline \multicolumn{17}{|l|}{ Exp \#14 } \\
\hline BKV6-14.A & 17,483 & 40 & - & - & 9.00 & - & - & $<50$ & - & 14 & - & $<100$ & - & 17,483 & - & - \\
\hline BKV6-14.1 & 17,483 & 40 & $8.7 \mathrm{E}-06$ & 3.14 & 9.00 & 0.502 & $9.88 \mathrm{E}-03$ & $<50$ & - & 122 & 1.97E-03 & 1,361 & $7.01 \mathrm{E}-03$ & 18,222 & $2.98 \mathrm{E}-03$ & $2.80 \mathrm{E}-09$ \\
\hline BKV6-14.2 & 17,483 & 40 & $9.1 \mathrm{E}-06$ & 7.02 & 9.00 & 0.502 & $9.88 \mathrm{E}-03$ & $<50$ & - & 184 & $3.25 \mathrm{E}-03$ & 1,545 & 8.39E-03 & 18,515 & 4.35E-03 & 3.35E-09 \\
\hline BKV6-14.5 & 17,483 & 40 & $9.5 \mathrm{E}-06$ & 21.22 & 9.00 & 0.502 & 9.87E-03 & $<50$ & - & 204 & $3.78 \mathrm{E}-03$ & 855 & $4.56 \mathrm{E}-03$ & 18,826 & $5.88 \mathrm{E}-03$ & 1.82E-09 \\
\hline BKV6-14.6 & 17,483 & 40 & $9.5 \mathrm{E}-06$ & 24.92 & 9.00 & 0.501 & $9.87 \mathrm{E}-03$ & $<50$ & - & 201 & 3.72E-03 & 800 & $4.24 \mathrm{E}-03$ & 18,896 & $6.21 \mathrm{E}-03$ & 1.69E-09 \\
\hline BKV6-14.8 & 17,483 & 40 & $8.9 \mathrm{E}-06$ & 32.96 & 9.00 & 0.501 & $9.86 \mathrm{E}-03$ & $<50$ & - & 202 & 3.52E-03 & 756 & 3.74E-03 & 18,940 & 6.03E-03 & 1.49E-09 \\
\hline BKV6-14.9 & 17,483 & 40 & 9.3E-06 & 39.18 & 9.00 & 0.501 & $9.86 \mathrm{E}-03$ & $<50$ & - & 177 & $3.18 \mathrm{E}-03$ & 723 & $3.71 \mathrm{E}-03$ & 18,884 & $6.04 \mathrm{E}-03$ & $1.48 \mathrm{E}-09$ \\
\hline BKV6-14.12 & 17,483 & 40 & 9.3E-06 & 49.21 & 9.00 & 0.501 & $9.85 \mathrm{E}-03$ & $<50$ & - & 179 & $3.23 \mathrm{E}-03$ & 684 & $3.49 \mathrm{E}-03$ & 19,001 & $6.58 \mathrm{E}-03$ & 1.39E-09 \\
\hline BKV6-14.13 & 17,483 & 40 & $9.4 \mathrm{E}-06$ & 54.07 & 9.00 & 0.500 & 9.85E-03 & $<50$ & - & 161 & $2.89 \mathrm{E}-03$ & 629 & 3.18E-03 & 19,470 & $8.64 \mathrm{E}-03$ & 1.27E-09 \\
\hline BKV6-14.14 & 17,483 & 40 & 9.3E-06 & 59.27 & 9.00 & 0.500 & $9.85 \mathrm{E}-03$ & $<50$ & - & 152 & $2.68 \mathrm{E}-03$ & 596 & $2.94 \mathrm{E}-03$ & 19,715 & $9.60 \mathrm{E}-03$ & 1.18E-09 \\
\hline \multicolumn{17}{|l|}{ Exp \#15 } \\
\hline BKV6-15.A & 35,134 & 40 & - & - & 9.00 & - & - & $<50$ & - & $<10$ & - & $<100$ & - & 35,134 & - & - \\
\hline BKV6-15.1 & 35,134 & 40 & $6.1 \mathrm{E}-06$ & 3.14 & 9.00 & 0.503 & $9.90 \mathrm{E}-03$ & $<50$ & - & 95 & $1.08 \mathrm{E}-03$ & 1,309 & 4.67E-03 & 35,842 & $1.98 \mathrm{E}-03$ & 1.86E-09 \\
\hline BKV6-15.2 & 35,134 & 40 & $9.6 \mathrm{E}-06$ & 7.02 & 9.00 & 0.503 & $9.90 \mathrm{E}-03$ & $<50$ & - & 147 & $2.76 \mathrm{E}-03$ & 1,676 & $9.68 \mathrm{E}-03$ & 36,173 & $4.63 \mathrm{E}-03$ & 3.86E-09 \\
\hline BKV6-15.5 & 35,134 & 40 & $9.5 \mathrm{E}-06$ & 21.22 & 9.00 & 0.503 & $9.89 \mathrm{E}-03$ & $<50$ & - & 124 & $2.26 \mathrm{E}-03$ & 754 & 3.96E-03 & 36,543 & $6.19 \mathrm{E}-03$ & $1.58 \mathrm{E}-09$ \\
\hline BKV6-15.6 & 35,134 & 40 & $9.2 \mathrm{E}-06$ & 24.92 & 9.00 & 0.502 & $9.89 \mathrm{E}-03$ & $<50$ & - & 124 & $2.20 \mathrm{E}-03$ & 716 & $3.62 \mathrm{E}-03$ & 36,724 & $6.76 \mathrm{E}-03$ & $1.44 \mathrm{E}-09$ \\
\hline BKV6-15.8 & 35,134 & 40 & $9.5 \mathrm{E}-06$ & 32.96 & 9.00 & 0.502 & $9.88 \mathrm{E}-03$ & $<50$ & - & 122 & $2.24 \mathrm{E}-03$ & 638 & $3.27 \mathrm{E}-03$ & 36,776 & $7.22 \mathrm{E}-03$ & 1.30E-09 \\
\hline BKV6-15.9 & 35,134 & 40 & 7.3E-06 & 39.18 & 9.00 & 0.502 & $9.88 \mathrm{E}-03$ & $<50$ & - & 124 & $1.74 \mathrm{E}-03$ & 616 & $2.39 \mathrm{E}-03$ & 36,811 & $5.64 \mathrm{E}-03$ & $9.56 \mathrm{E}-10$ \\
\hline BKV6-15.12 & 35,134 & 40 & $8.6 \mathrm{E}-06$ & 49.21 & 9.00 & 0.502 & $9.88 \mathrm{E}-03$ & $<50$ & - & 105 & $1.72 \mathrm{E}-03$ & 531 & $2.38 \mathrm{E}-03$ & 37,354 & 8.87E-03 & $9.49 \mathrm{E}-10$ \\
\hline BKV6-15.13 & 35,134 & 40 & $9.1 \mathrm{E}-06$ & 54.07 & 9.00 & 0.502 & 9.87E-03 & $<50$ & - & 100 & $1.73 \mathrm{E}-03$ & 466 & $2.13 \mathrm{E}-03$ & 36,864 & $7.32 \mathrm{E}-03$ & $8.52 \mathrm{E}-10$ \\
\hline BKV6-15.14 & 35,134 & 40 & $9.8 \mathrm{E}-06$ & 59.27 & 9.00 & 0.501 & 9.87E-03 & $<50$ & - & 98 & $1.81 \mathrm{E}-03$ & 435 & $2.10 \mathrm{E}-03$ & 36,526 & $6.33 \mathrm{E}-03$ & $8.40 \mathrm{E}-10$ \\
\hline & & & & & & & & & & & & & & & & \\
\hline & & & & & & & & & & & & & & & & \\
\hline & & & & & & & & & & & & & & & & \\
\hline & & & & & & & & & & & & & & & & \\
\hline & & & & & & & & & & & & & & & & \\
\hline
\end{tabular}


Table B1. SPFT Results for BKV6 Glass.

\begin{tabular}{|c|c|c|c|c|c|c|c|c|c|c|c|c|c|c|c|c|}
\hline Sample ID & \begin{tabular}{|c|}
$\begin{array}{c}\text { Influent } \\
\text { [Si] }\end{array}$ \\
\end{tabular} & $\mathbf{T}\left({ }^{\circ} \mathbf{C}\right)$ & $\begin{array}{c}\text { Flow Rate } \\
\left(\mathrm{m}^{3} / \mathrm{d}\right)\end{array}$ & Time, days & $\mathrm{pH}\left(23^{\circ} \mathrm{C}\right)$ & $\begin{array}{c}\text { Glass } \\
\text { Mass (g) } \\
\end{array}$ & $\mathrm{SA}\left(\mathrm{m}^{2}\right)$ & [B] & B Rate & [Al] & Al Rate & [Na] & Na Rate & [Si] & Si Rate & IEX Rate \\
\hline \multicolumn{17}{|l|}{ Exp\#16 } \\
\hline BKV6-16.A & 48,131 & 40 & - & - & 9.00 & - & - & $<50$ & - & 22 & - & 102 & - & 48,131 & - & - \\
\hline BKV6-16.1 & 48,131 & 40 & $8.9 \mathrm{E}-06$ & 3.14 & 9.00 & 1.009 & $1.99 \mathrm{E}-02$ & $<50$ & - & 123 & $9.39 \mathrm{E}-04$ & 2,484 & $6.71 \mathrm{E}-03$ & 50,408 & $4.65 \mathrm{E}-03$ & $2.68 \mathrm{E}-09$ \\
\hline BKV6-16.2 & 48,131 & 40 & $9.6 \mathrm{E}-06$ & 7.02 & 9.00 & 1.009 & 1.99E-02 & $<50$ & - & 138 & $1.17 \mathrm{E}-03$ & 2,396 & $7.02 \mathrm{E}-03$ & 54,141 & $1.33 \mathrm{E}-02$ & $2.80 \mathrm{E}-09$ \\
\hline BKV6-16.5 & 48,131 & 40 & $9.6 \mathrm{E}-06$ & 21.22 & 9.00 & 1.009 & $1.98 \mathrm{E}-02$ & $<50$ & - & 94 & $7.23 \mathrm{E}-04$ & 1,201 & $3.36 \mathrm{E}-03$ & 60,235 & $2.68 \mathrm{E}-02$ & $1.34 \mathrm{E}-09$ \\
\hline BKV6-16.6 & 48,131 & 40 & $9.4 \mathrm{E}-06$ & 24.92 & 9.00 & 1.008 & $1.98 \mathrm{E}-02$ & $<50$ & - & 85 & $6.21 \mathrm{E}-04$ & 1,118 & $3.02 \mathrm{E}-03$ & 60,346 & 2.63E-02 & $1.21 \mathrm{E}-09$ \\
\hline BKV6-16.8 & 48,131 & 40 & 8.9E-06 & 32.96 & 9.00 & 1.008 & $1.98 \mathrm{E}-02$ & $<50$ & - & 78 & $5.20 \mathrm{E}-04$ & 913 & $2.29 \mathrm{E}-03$ & 60,599 & $2.55 \mathrm{E}-02$ & $9.14 \mathrm{E}-10$ \\
\hline BKV6-16.9 & 48,131 & 40 & $9.0 \mathrm{E}-06$ & 39.18 & 9.00 & 1.008 & $1.98 \mathrm{E}-02$ & $<50$ & - & 74 & 4.91E-04 & 839 & $2.10 \mathrm{E}-03$ & 61,069 & $2.67 \mathrm{E}-02$ & $8.38 \mathrm{E}-10$ \\
\hline BKV6-16.12 & 48,131 & 40 & $8.0 \mathrm{E}-06$ & 49.21 & 9.00 & 1.008 & $1.98 \mathrm{E}-02$ & $<50$ & - & 63 & $3.52 \mathrm{E}-04$ & 750 & $1.66 \mathrm{E}-03$ & 61,898 & $2.55 \mathrm{E}-02$ & $6.61 \mathrm{E}-10$ \\
\hline BKV6-16.13 & 48,131 & 40 & $9.4 \mathrm{E}-06$ & 54.07 & 9.00 & 1.007 & $1.98 \mathrm{E}-02$ & $<50$ & - & 63 & $4.11 \mathrm{E}-04$ & 673 & $1.72 \mathrm{E}-03$ & 56,673 & $1.86 \mathrm{E}-02$ & $6.85 \mathrm{E}-10$ \\
\hline BKV6-16.14 & 48,131 & 40 & $9.1 \mathrm{E}-06$ & 59.27 & 9.00 & 1.007 & $1.98 \mathrm{E}-02$ & $<50$ & - & 78 & 5.37E-04 & 575 & $1.37 \mathrm{E}-03$ & 48,394 & 5.52E-04 & $5.48 \mathrm{E}-10$ \\
\hline \multicolumn{17}{|l|}{ Exp \#17 } \\
\hline BKV6-17.A & 60,741 & 40 & - & - & 9.00 & - & - & $<50$ & - & $<10$ & - & $<100$ & - & 60,741 & - & - \\
\hline BKV6-17.1 & 60,741 & 40 & $9.2 \mathrm{E}-06$ & 3.14 & 9.00 & 1.004 & $1.98 \mathrm{E}-02$ & $<50$ & - & 102 & $8.83 \mathrm{E}-04$ & 2,550 & $7.17 \mathrm{E}-03$ & 63,785 & $6.46 \mathrm{E}-03$ & $2.86 \mathrm{E}-09$ \\
\hline BKV6-17.2 & 60,741 & 40 & $9.5 \mathrm{E}-06$ & 7.02 & 9.00 & 1.004 & $1.98 \mathrm{E}-02$ & $<50$ & - & 108 & 9.83E-04 & 2,442 & $7.13 \mathrm{E}-03$ & 68,726 & $1.76 \mathrm{E}-02$ & $2.85 \mathrm{E}-09$ \\
\hline BKV6-17.5 & 60,741 & 40 & $9.1 \mathrm{E}-06$ & 21.22 & 9.00 & 1.004 & $1.98 \mathrm{E}-02$ & $<50$ & - & 56 & $4.43 \mathrm{E}-04$ & 1,153 & $3.06 \mathrm{E}-03$ & 80,976 & $4.27 \mathrm{E}-02$ & $1.22 \mathrm{E}-09$ \\
\hline BKV6-17.6 & 60,741 & 40 & $9.4 \mathrm{E}-06$ & 24.92 & 9.00 & 1.003 & $1.97 \mathrm{E}-02$ & $<50$ & - & 39 & $2.92 \mathrm{E}-04$ & 1,033 & $2.81 \mathrm{E}-03$ & 82,564 & 4.77E-02 & $1.12 \mathrm{E}-09$ \\
\hline BKV6-17.8 & 60,741 & 40 & $9.4 \mathrm{E}-06$ & 32.96 & 9.00 & 1.003 & $1.97 \mathrm{E}-02$ & $<50$ & - & 33 & $2.24 \mathrm{E}-04$ & 825 & $2.18 \mathrm{E}-03$ & 83,680 & $5.01 \mathrm{E}-02$ & $8.72 \mathrm{E}-10$ \\
\hline BKV6-17.9 & 60,741 & 40 & 8.3E-06 & 39.18 & 9.00 & 1.003 & 1.97E-02 & $<50$ & - & 29 & 1.64E-04 & 789 & $1.83 \mathrm{E}-03$ & 84,630 & $4.60 \mathrm{E}-02$ & $7.31 \mathrm{E}-10$ \\
\hline BKV6-17.12 & 60,741 & 40 & $8.1 \mathrm{E}-06$ & 49.21 & 9.00 & 1.003 & $1.97 \mathrm{E}-02$ & $<50$ & - & 25 & $1.31 \mathrm{E}-04$ & 648 & $1.42 \mathrm{E}-03$ & 86,252 & $4.80 \mathrm{E}-02$ & $5.68 \mathrm{E}-10$ \\
\hline BKV6-17.13 & 60,741 & 40 & $9.5 \mathrm{E}-06$ & 54.07 & 9.00 & 1.002 & $1.97 \mathrm{E}-02$ & $<50$ & - & 24 & $1.42 \mathrm{E}-04$ & 569 & $1.42 \mathrm{E}-03$ & 77,127 & $3.60 \mathrm{E}-02$ & $5.67 \mathrm{E}-10$ \\
\hline BKV6-17.14 & 60,741 & 40 & $9.4 \mathrm{E}-06$ & 59.27 & 9.00 & 1.002 & 1.97E-02 & $<50$ & - & 30 & 1.93E-04 & 529 & $1.28 \mathrm{E}-03$ & 66,660 & $1.28 \mathrm{E}-02$ & 5.13E-10 \\
\hline \multicolumn{17}{|l|}{$\underline{\operatorname{Exp} \# 18}$} \\
\hline BKV6-18.A & 80,684 & 40 & - & - & 9.00 & - & - & $<50$ & - & $<10$ & - & $<100$ & - & 80,684 & - & - \\
\hline BKV6-18.1 & 80,684 & 40 & $9.1 \mathrm{E}-06$ & 3.14 & 9.00 & 1.008 & $1.98 \mathrm{E}-02$ & $<50$ & - & 83 & $6.96 \mathrm{E}-04$ & 2,365 & $6.54 \mathrm{E}-03$ & 83,655 & $6.22 \mathrm{E}-03$ & $2.61 \mathrm{E}-09$ \\
\hline BKV6-18.2 & 80,684 & 40 & $9.6 \mathrm{E}-06$ & 7.02 & 9.00 & 1.008 & $1.98 \mathrm{E}-02$ & $<50$ & - & 78 & $6.85 \mathrm{E}-04$ & 2,404 & $7.03 \mathrm{E}-03$ & 86,789 & $1.35 \mathrm{E}-02$ & $2.81 \mathrm{E}-09$ \\
\hline BKV6-18.5 & 80,684 & 40 & $9.2 \mathrm{E}-06$ & 21.22 & 9.00 & 1.008 & $1.98 \mathrm{E}-02$ & $<50$ & - & 38 & $2.67 \mathrm{E}-04$ & 1,172 & $3.14 \mathrm{E}-03$ & 95,268 & $3.10 \mathrm{E}-02$ & $1.25 \mathrm{E}-09$ \\
\hline BKV6-18.6 & 80,684 & 40 & $9.5 \mathrm{E}-06$ & 24.92 & 9.00 & 1.007 & $1.98 \mathrm{E}-02$ & $<50$ & - & 33 & $2.31 \mathrm{E}-04$ & 1,014 & $2.76 \mathrm{E}-03$ & 96,808 & 3.53E-02 & $1.10 \mathrm{E}-09$ \\
\hline BKV6-18.8 & 80,684 & 40 & $9.3 \mathrm{E}-06$ & 32.96 & 9.00 & 1.007 & $1.98 \mathrm{E}-02$ & $<50$ & - & 25 & $1.49 \mathrm{E}-04$ & 825 & $2.14 \mathrm{E}-03$ & 97,786 & $3.67 \mathrm{E}-02$ & $8.56 \mathrm{E}-10$ \\
\hline BKV6-18.9 & 80,684 & 40 & $9.3 \mathrm{E}-06$ & 39.18 & 9.00 & 1.007 & $1.98 \mathrm{E}-02$ & $<50$ & - & 19 & $8.98 \mathrm{E}-05$ & 733 & $1.88 \mathrm{E}-03$ & 97,459 & $3.60 \mathrm{E}-02$ & $7.50 \mathrm{E}-10$ \\
\hline BKV6-18.12 & 80,684 & 40 & $8.1 \mathrm{E}-06$ & 49.21 & 9.00 & 1.007 & $1.98 \mathrm{E}-02$ & $<50$ & - & 16 & 4.83E-05 & 764 & $1.70 \mathrm{E}-03$ & 100,490 & $3.68 \mathrm{E}-02$ & $6.79 \mathrm{E}-10$ \\
\hline BKV6-18.13 & 80,684 & 40 & $9.2 \mathrm{E}-06$ & 54.07 & 9.00 & 1.006 & $1.98 \mathrm{E}-02$ & $<50$ & - & 15 & $5.00 \mathrm{E}-05$ & 615 & $1.50 \mathrm{E}-03$ & 88,111 & $1.57 \mathrm{E}-02$ & $6.00 \mathrm{E}-10$ \\
\hline BKV6-18.14 & 80,684 & 40 & $9.4 \mathrm{E}-06$ & 59.27 & 9.00 & 1.006 & $1.98 \mathrm{E}-02$ & $<50$ & - & 20 & $1.02 \mathrm{E}-04$ & 451 & $1.05 \mathrm{E}-03$ & 74,243 & - & $4.18 \mathrm{E}-10$ \\
\hline & & & & & & & & & & & & & & & & \\
\hline & & & & & & & & & & & & & & & & \\
\hline & & & & & & & & & & & & & & & & \\
\hline & & & & & & & & & & & & & & & & \\
\hline & & & & & & & & & & & & & & & & \\
\hline
\end{tabular}


Table B1. SPFT Results for BKV6 Glass.

\begin{tabular}{|c|c|c|c|c|c|c|c|c|c|c|c|c|c|c|c|c|}
\hline Sample ID & \begin{tabular}{|c|}
$\begin{array}{c}\text { Influent } \\
\text { [Si] }\end{array}$ \\
\end{tabular} & $\mathrm{T}\left({ }^{\circ} \mathrm{C}\right)$ & \begin{tabular}{|c}
$\begin{array}{c}\text { Flow Rate } \\
\left(\mathrm{m}^{3} / \mathrm{d}\right)\end{array}$ \\
\end{tabular} & Time, days & $\mathrm{pH}\left(23^{\circ} \mathrm{C}\right)$ & \begin{tabular}{|c|} 
Glass \\
Mass (g)
\end{tabular} & $\mathrm{SA}\left(\mathrm{m}^{2}\right)$ & [B] & B Rate & [Al] & Al Rate & [Na] & Na Rate & [Si] & Si Rate & IEX Rate \\
\hline \multicolumn{17}{|l|}{ Exp\#19 } \\
\hline BKV6-19.A & 0 & 40 & - & - & 7.00 & - & - & $<100$ & - & $<25$ & - & $<50$ & - & $<500$ & - & - \\
\hline BKV6-19.2 & 0 & 40 & $9.4 \mathrm{E}-06$ & 4.08 & 7.00 & 0.500 & $9.84 \mathrm{E}-03$ & $<100$ & - & - & - & 2,951 & $1.75 \mathrm{E}-02$ & - & - & 6.97E-09 \\
\hline BKV6-19.3 & 0 & 40 & 9.5E-06 & 7.08 & 7.00 & 0.499 & $9.83 \mathrm{E}-03$ & $<100$ & - & - & - & 2,062 & $1.23 \mathrm{E}-02$ & - & - & 4.92E-09 \\
\hline BKV6-19.6 & 0 & 40 & $9.0 \mathrm{E}-06$ & 10.18 & 7.00 & 0.499 & 9.82E-03 & $<100$ & - & - & - & 968 & $5.28 \mathrm{E}-03$ & - & - & $2.11 \mathrm{E}-09$ \\
\hline BKV6-19.8 & 0 & 40 & $9.6 \mathrm{E}-06$ & 15.03 & 7.00 & 0.499 & $9.82 \mathrm{E}-03$ & $<100$ & - & - & - & 737 & $4.22 \mathrm{E}-03$ & - & - & 1.69E-09 \\
\hline BKV6-19.12 & 0 & 40 & $9.5 \mathrm{E}-06$ & 19.14 & 7.00 & 0.498 & $9.81 \mathrm{E}-03$ & $<100$ & - & - & - & 574 & $3.21 \mathrm{E}-03$ & - & - & 1.28E-09 \\
\hline BKV6-19.13 & 0 & 40 & $9.5 \mathrm{E}-06$ & 22.08 & 7.00 & 0.498 & $9.80 \mathrm{E}-03$ & $<100$ & - & - & - & 517 & $2.87 \mathrm{E}-03$ & - & - & 1.14E-09 \\
\hline BKV6-19.14 & 0 & 40 & $9.4 \mathrm{E}-06$ & 25.90 & 7.00 & 0.498 & $9.80 \mathrm{E}-03$ & $<100$ & - & - & - & 515 & $2.80 \mathrm{E}-03$ & - & - & 1.12E-09 \\
\hline BKV6-19.15 & 0 & 40 & $9.1 \mathrm{E}-06$ & 28.87 & 7.00 & 0.497 & 9.79E-03 & $<100$ & - & - & - & 480 & $2.53 \mathrm{E}-03$ & - & - & 1.01E-09 \\
\hline BKV6-19.16 & 0 & 40 & $9.5 \mathrm{E}-06$ & 32.07 & 7.00 & 0.497 & $9.78 \mathrm{E}-03$ & $<100$ & - & 26 & $2.51 \mathrm{E}-05$ & 469 & $2.56 \mathrm{E}-03$ & - & - & 1.02E-09 \\
\hline \multicolumn{17}{|l|}{ Exp \#20 } \\
\hline BKV6-20.A & 0 & 40 & - & - & 8.00 & - & - & $<100$ & - & $<25$ & - & $<50$ & - & $<500$ & - & - \\
\hline BKV6-20.2 & 0 & 40 & $9.4 \mathrm{E}-06$ & 4.08 & 8.00 & 0.499 & $9.82 \mathrm{E}-03$ & $<100$ & - & 84 & $1.17 \mathrm{E}-03$ & 2,683 & $1.59 \mathrm{E}-02$ & - & - & $6.34 \mathrm{E}-09$ \\
\hline BKV6-20.3 & 0 & 40 & 9.5E-06 & 7.08 & 8.00 & 0.498 & $9.81 \mathrm{E}-03$ & $<100$ & - & 84 & $1.18 \mathrm{E}-03$ & 1,962 & $1.17 \mathrm{E}-02$ & - & - & 4.67E-09 \\
\hline BKV6-20.6 & 0 & 40 & 9.3E-06 & 10.18 & 8.00 & 0.498 & $9.81 \mathrm{E}-03$ & $<100$ & - & 81 & $1.10 \mathrm{E}-03$ & 1,043 & 5.95E-03 & - & - & $2.38 \mathrm{E}-09$ \\
\hline BKV6-20.8 & 0 & 40 & 9.3E-06 & 15.03 & 8.00 & 0.498 & $9.80 \mathrm{E}-03$ & $<100$ & - & 72 & 9.32E-04 & 852 & $4.80 \mathrm{E}-03$ & - & - & 1.92E-09 \\
\hline BKV6-20.12 & 0 & 40 & $9.4 \mathrm{E}-06$ & 19.14 & 8.00 & 0.497 & $9.79 \mathrm{E}-03$ & $<100$ & - & 79 & $1.08 \mathrm{E}-03$ & 636 & $3.55 \mathrm{E}-03$ & - & - & 1.42E-09 \\
\hline BKV6-20.13 & 0 & 40 & $8.8 \mathrm{E}-06$ & 22.08 & 8.00 & 0.497 & $9.78 \mathrm{E}-03$ & $<100$ & - & 91 & $1.24 \mathrm{E}-03$ & 646 & $3.38 \mathrm{E}-03$ & - & - & 1.35E-09 \\
\hline BKV6-20.14 & 0 & 40 & 9.3E-06 & 25.90 & 8.00 & 0.497 & $9.78 \mathrm{E}-03$ & $<100$ & - & 73 & $9.41 \mathrm{E}-04$ & 589 & $3.25 \mathrm{E}-03$ & - & - & 1.30E-09 \\
\hline BKV6-20.15 & 0 & 40 & 9.3E-06 & 28.87 & 8.00 & 0.496 & 9.77E-03 & $<100$ & - & 79 & 1.06E-03 & 553 & 3.02E-03 & - & - & 1.20E-09 \\
\hline BKV6-20.16 & 0 & 40 & $9.4 \mathrm{E}-06$ & 32.07 & 8.00 & 0.496 & $9.76 \mathrm{E}-03$ & $<100$ & - & 82 & 1.13E-03 & 558 & 3.09E-03 & - & - & 1.23E-09 \\
\hline \multicolumn{17}{|l|}{ Exp \#21 } \\
\hline BKV6-21.A & 0 & 40 & - & - & 9.00 & - & - & $<100$ & - & $<25$ & - & $<50$ & - & $<500$ & - & - \\
\hline BKV6-21.2 & 0 & 40 & $9.4 \mathrm{E}-06$ & 4.08 & 9.00 & 0.500 & $9.84 \mathrm{E}-03$ & $<100$ & - & 201 & $3.50 \mathrm{E}-03$ & 2,334 & $1.38 \mathrm{E}-02$ & 751 & $1.10 \mathrm{E}-03$ & 5.51E-09 \\
\hline BKV6-21.3 & 0 & 40 & 9.5E-06 & 7.08 & 9.00 & 0.499 & $9.83 \mathrm{E}-03$ & $<100$ & - & 225 & 4.03E-03 & 1,785 & $1.06 \mathrm{E}-02$ & 901 & $1.78 \mathrm{E}-03$ & 4.24E-09 \\
\hline BKV6-21.6 & 0 & 40 & $8.7 \mathrm{E}-06$ & 10.18 & 9.00 & 0.499 & 9.82E-03 & $<100$ & - & 235 & 3.85E-03 & 1,078 & 5.73E-03 & 947 & $1.81 \mathrm{E}-03$ & 2.29E-09 \\
\hline BKV6-21.8 & 0 & 40 & $9.6 \mathrm{E}-06$ & 15.03 & 9.00 & 0.499 & $9.82 \mathrm{E}-03$ & $<100$ & - & 251 & $4.59 \mathrm{E}-03$ & 972 & $5.71 \mathrm{E}-03$ & 1,022 & $2.34 \mathrm{E}-03$ & $2.28 \mathrm{E}-09$ \\
\hline BKV6-21.12 & 0 & 40 & $9.4 \mathrm{E}-06$ & 19.14 & 9.00 & 0.498 & $9.81 \mathrm{E}-03$ & $<100$ & - & 266 & $4.80 \mathrm{E}-03$ & 847 & $4.83 \mathrm{E}-03$ & 1,072 & $2.51 \mathrm{E}-03$ & 1.93E-09 \\
\hline BKV6-21.13 & 0 & 40 & $8.7 \mathrm{E}-06$ & 22.08 & 9.00 & 0.498 & $9.80 \mathrm{E}-03$ & $<100$ & - & 263 & 4.35E-03 & 837 & $4.38 \mathrm{E}-03$ & 1,138 & $2.57 \mathrm{E}-03$ & 1.75E-09 \\
\hline BKV6-21.14 & 0 & 40 & 9.3E-06 & 25.90 & 9.00 & 0.498 & $9.80 \mathrm{E}-03$ & $<100$ & - & 267 & 4.77E-03 & 804 & $4.52 \mathrm{E}-03$ & 1,102 & $2.62 \mathrm{E}-03$ & $1.80 \mathrm{E}-09$ \\
\hline BKV6-21.15 & 0 & 40 & $9.2 \mathrm{E}-06$ & 28.87 & 9.00 & 0.497 & 9.79E-03 & $<100$ & - & 270 & $4.78 \mathrm{E}-03$ & 824 & $4.60 \mathrm{E}-03$ & 1,089 & $2.54 \mathrm{E}-03$ & 1.84E-09 \\
\hline BKV6-21.16 & 0 & 40 & 9.2E-06 & 32.07 & 9.00 & 0.497 & $9.78 \mathrm{E}-03$ & $<100$ & - & 272 & $4.80 \mathrm{E}-03$ & 808 & 4.47E-03 & 1,083 & $2.49 \mathrm{E}-03$ & 1.79E-09 \\
\hline & & & & & & & & & & & & & & & & \\
\hline & & & & & & & & & & & & & & & & \\
\hline & & & & & & & & & & & & & & & & \\
\hline & & & & & & & & & & & & & & & & \\
\hline & & & & & & & & & & & & & & & & \\
\hline
\end{tabular}


Table B1. SPFT Results for BKV6 Glass.

\begin{tabular}{|c|c|c|c|c|c|c|c|c|c|c|c|c|c|c|c|c|}
\hline Sample ID & \begin{tabular}{|c|}
$\begin{array}{c}\text { Influent } \\
\text { [Si] }\end{array}$ \\
\end{tabular} & $\mathrm{T}\left({ }^{\circ} \mathrm{C}\right)$ & \begin{tabular}{|c}
$\begin{array}{c}\text { Flow Rate } \\
\left(\mathrm{m}^{3} / \mathrm{d}\right)\end{array}$ \\
\end{tabular} & Time, days & $\mathrm{pH}\left(23^{\circ} \mathrm{C}\right)$ & \begin{tabular}{|c|} 
Glass \\
Mass (g)
\end{tabular} & SA $\left(\mathrm{m}^{2}\right)$ & [B] & B Rate & [Al] & Al Rate & [Na] & Na Rate & [Si] & Si Rate & IEX Rate \\
\hline \multicolumn{17}{|l|}{$\underline{\operatorname{Exp} \# 22}$} \\
\hline BKV6-22.A & 0 & 40 & - & - & 10.00 & - & - & $<100$ & - & $<25$ & - & $<50$ & - & $<500$ & - & - \\
\hline BKV6-22.2 & 0 & 40 & 9.3E-06 & 4.08 & 10.00 & 0.500 & $9.84 \mathrm{E}-03$ & $<100$ & - & 250 & $4.42 \mathrm{E}-03$ & 1,483 & 8.55E-03 & 1,013 & $2.22 \mathrm{E}-03$ & 3.41E-09 \\
\hline BKV6-22.3 & 0 & 40 & 9.3E-06 & 7.08 & 10.00 & 0.499 & $9.83 \mathrm{E}-03$ & $<100$ & - & 370 & $6.78 \mathrm{E}-03$ & 1,621 & $9.41 \mathrm{E}-03$ & 1,521 & $4.44 \mathrm{E}-03$ & 3.76E-09 \\
\hline BKV6-22.6 & 0 & 40 & 9.4E-06 & 10.18 & 10.00 & 0.499 & 9.82E-03 & $<100$ & - & 411 & 7.62E-03 & 1,399 & 8.11E-03 & 1,766 & 5.52E-03 & 3.24E-09 \\
\hline BKV6-22.8 & 0 & 40 & $9.4 \mathrm{E}-06$ & 15.03 & 10.00 & 0.499 & $9.82 \mathrm{E}-03$ & $<100$ & - & 438 & 8.17E-03 & 1,297 & 7.51E-03 & 1,792 & 5.64E-03 & 3.00E-09 \\
\hline BKV6-22.12 & 0 & 40 & $9.4 \mathrm{E}-06$ & 19.14 & 10.00 & 0.498 & $9.81 \mathrm{E}-03$ & $<100$ & - & 459 & 8.59E-03 & 1,261 & 7.30E-03 & 1,831 & $5.81 \mathrm{E}-03$ & 2.91E-09 \\
\hline BKV6-22.13 & 0 & 40 & $9.4 \mathrm{E}-06$ & 22.08 & 10.00 & 0.498 & $9.80 \mathrm{E}-03$ & $<100$ & - & 455 & $8.50 \mathrm{E}-03$ & 1,277 & 7.38E-03 & 1,883 & $6.03 \mathrm{E}-03$ & 2.95E-09 \\
\hline BKV6-22.14 & 0 & 40 & 9.3E-06 & 25.90 & 10.00 & 0.498 & $9.80 \mathrm{E}-03$ & $<100$ & - & 449 & 8.32E-03 & 1,249 & 7.17E-03 & 1,846 & 5.83E-03 & 2.86E-09 \\
\hline BKV6-22.15 & 0 & 40 & $9.2 \mathrm{E}-06$ & 28.87 & 10.00 & 0.497 & 9.79E-03 & $<100$ & - & 450 & $8.28 \mathrm{E}-03$ & 1,213 & $6.89 \mathrm{E}-03$ & 1,815 & $5.65 \mathrm{E}-03$ & $2.75 \mathrm{E}-09$ \\
\hline BKV6-22.16 & 0 & 40 & $9.3 \mathrm{E}-06$ & 32.07 & 10.00 & 0.497 & $9.78 \mathrm{E}-03$ & $<100$ & - & 417 & 7.71E-03 & 1,211 & 6.95E-03 & 1,822 & $5.74 \mathrm{E}-03$ & 2.77E-09 \\
\hline \multicolumn{17}{|l|}{$\underline{\operatorname{Exp} \# 23}$} \\
\hline BKV6-23.A & 0 & 40 & - & - & 11.00 & - & - & $<100$ & - & $<25$ & - & 58 & - & $<500$ & - & - \\
\hline BKV6-23.2 & 0 & 40 & $9.4 \mathrm{E}-06$ & 4.08 & 11.00 & 0.498 & $9.81 \mathrm{E}-03$ & 315 & $1.43 \mathrm{E}-02$ & 1,545 & 3.02E-02 & 5,817 & $3.48 \mathrm{E}-02$ & 5,892 & $2.36 \mathrm{E}-02$ & 8.19E-09 \\
\hline BKV6-23.3 & 0 & 40 & 9.6E-06 & 7.08 & 11.00 & 0.497 & $9.79 \mathrm{E}-03$ & 349 & $1.68 \mathrm{E}-02$ & 1,704 & $3.40 \mathrm{E}-02$ & 6,215 & 3.79E-02 & 6,385 & $2.63 \mathrm{E}-02$ & 8.41E-09 \\
\hline BKV6-23.6 & 0 & 40 & $9.2 \mathrm{E}-06$ & 10.18 & 11.00 & 0.496 & 9.77E-03 & 365 & $1.72 \mathrm{E}-02$ & 1,770 & $3.40 \mathrm{E}-02$ & 5,047 & $2.96 \mathrm{E}-02$ & 6,619 & 2.63E-02 & 4.93E-09 \\
\hline BKV6-23.8 & 0 & 40 & $9.4 \mathrm{E}-06$ & 15.03 & 11.00 & 0.494 & $9.74 \mathrm{E}-03$ & 362 & $1.76 \mathrm{E}-02$ & 1,762 & 3.49E-02 & 4,962 & $3.00 \mathrm{E}-02$ & 6,556 & $2.68 \mathrm{E}-02$ & 4.95E-09 \\
\hline BKV6-23.12 & 0 & 40 & $9.1 \mathrm{E}-06$ & 19.14 & 11.00 & 0.493 & $9.71 \mathrm{E}-03$ & 341 & $1.56 \mathrm{E}-02$ & 1,675 & $3.20 \mathrm{E}-02$ & 4,652 & $2.71 \mathrm{E}-02$ & 6,193 & 2.43E-02 & 4.59E-09 \\
\hline BKV6-23.13 & 0 & 40 & $9.0 \mathrm{E}-06$ & 22.08 & 11.00 & 0.492 & $9.69 \mathrm{E}-03$ & 335 & $1.51 \mathrm{E}-02$ & 1,612 & $3.05 \mathrm{E}-02$ & 4,536 & $2.62 \mathrm{E}-02$ & 6,096 & 2.37E-02 & 4.42E-09 \\
\hline BKV6-23.14 & 0 & 40 & $9.3 \mathrm{E}-06$ & 25.90 & 11.00 & 0.491 & $9.67 \mathrm{E}-03$ & 325 & $1.50 \mathrm{E}-02$ & 1,564 & 3.07E-02 & 4,378 & $2.62 \mathrm{E}-02$ & 5,942 & 2.39E-02 & 4.47E-09 \\
\hline BKV6-23.15 & 0 & 40 & 9.3E-06 & 28.87 & 11.00 & 0.490 & $9.65 \mathrm{E}-03$ & 319 & $1.45 \mathrm{E}-02$ & 1,520 & $2.98 \mathrm{E}-02$ & 4,402 & 2.63E-02 & 5,779 & 2.32E-02 & 4.70E-09 \\
\hline BKV6-23.16 & 0 & 40 & $9.7 \mathrm{E}-06$ & 32.07 & 11.00 & 0.489 & $9.63 \mathrm{E}-03$ & 312 & $1.48 \mathrm{E}-02$ & 1,494 & 3.07E-02 & 4,216 & $2.64 \mathrm{E}-02$ & 5,702 & $2.40 \mathrm{E}-02$ & 4.65E-09 \\
\hline \multicolumn{17}{|l|}{$\underline{\operatorname{Exp} \# 24}$} \\
\hline BKV6-24.A & 0 & 40 & - & - & 12.00 & - & - & $<100$ & - & $<25$ & - & $<50$ & - & $<500$ & - & - \\
\hline BKV6-24.2 & 0 & 40 & $9.5 \mathrm{E}-06$ & 4.08 & 12.00 & 0.498 & $9.81 \mathrm{E}-03$ & 888 & $5.26 \mathrm{E}-02$ & 4,283 & $8.50 \mathrm{E}-02$ & 12,353 & $7.48 \mathrm{E}-02$ & 16,378 & $7.00 \mathrm{E}-02$ & 8.87E-09 \\
\hline BKV6-24.3 & 0 & 40 & $8.9 \mathrm{E}-06$ & 7.08 & 12.00 & 0.495 & $9.75 \mathrm{E}-03$ & 980 & 5.53E-02 & 4,679 & 8.76E-02 & 13,162 & 7.51E-02 & 17,537 & 7.08E-02 & 7.89E-09 \\
\hline BKV6-24.6 & 0 & 40 & $9.5 \mathrm{E}-06$ & 10.18 & 12.00 & 0.492 & $9.70 \mathrm{E}-03$ & 942 & $5.70 \mathrm{E}-02$ & 4,418 & $8.90 \mathrm{E}-02$ & 12,612 & 7.75E-02 & 16,547 & 7.18E-02 & 8.17E-09 \\
\hline BKV6-24.8 & 0 & 40 & 9.5E-06 & 15.03 & 12.00 & 0.487 & $9.62 \mathrm{E}-03$ & 1,164 & 7.27E-02 & 5,521 & $1.12 \mathrm{E}-01$ & 14,992 & $9.31 \mathrm{E}-02$ & 20,790 & $9.16 \mathrm{E}-02$ & 8.12E-09 \\
\hline BKV6-24.12 & 0 & 40 & 9.4E-06 & 19.14 & 12.00 & 0.482 & 9.52E-03 & 1,203 & 7.52E-02 & 5,554 & 1.13E-01 & 15,877 & $9.83 \mathrm{E}-02$ & 21,357 & $9.39 \mathrm{E}-02$ & 9.21E-09 \\
\hline BKV6-24.13 & 0 & 40 & $9.4 \mathrm{E}-06$ & 22.08 & 12.00 & 0.478 & $9.44 \mathrm{E}-03$ & 1,179 & $7.46 \mathrm{E}-02$ & 5,542 & $1.14 \mathrm{E}-01$ & 16,032 & $1.01 \mathrm{E}-01$ & 20,793 & $9.27 \mathrm{E}-02$ & 1.04E-08 \\
\hline BKV6-24.14 & 0 & 40 & $8.2 \mathrm{E}-06$ & 25.90 & 12.00 & 0.475 & $9.36 \mathrm{E}-03$ & 1,177 & $6.51 \mathrm{E}-02$ & 5,537 & 9.97E-02 & 15,228 & $8.35 \mathrm{E}-02$ & 21,009 & $8.18 \mathrm{E}-02$ & 7.38E-09 \\
\hline BKV6-24.15 & 0 & 40 & $7.9 \mathrm{E}-06$ & 28.87 & 12.00 & 0.471 & $9.29 \mathrm{E}-03$ & 1,311 & 7.16E-02 & 5,997 & $1.06 \mathrm{E}-01$ & 17,711 & $9.50 \mathrm{E}-02$ & 23,487 & 8.97E-02 & 9.38E-09 \\
\hline BKV6-24.16 & 0 & 40 & $9.5 \mathrm{E}-06$ & 32.07 & 12.00 & 0.468 & $9.23 \mathrm{E}-03$ & 1,066 & $6.88 \mathrm{E}-02$ & 4,873 & 1.03E-01 & 14,018 & $9.06 \mathrm{E}-02$ & 18,461 & $8.44 \mathrm{E}-02$ & 8.70E-09 \\
\hline & & & & & & & & & & & & & & & & \\
\hline & & & & & & & & & & & & & & & & \\
\hline & & & & & & & & & & & & & & & & \\
\hline & & & & & & & & & & & & & & & & \\
\hline
\end{tabular}


Table B1. SPFT Results for BKV6 Glass.

\begin{tabular}{|c|c|c|c|c|c|c|c|c|c|c|c|c|c|c|c|c|}
\hline & & & & & & & & & & & & & & & & \\
\hline Sample ID & \begin{tabular}{|c}
$\begin{array}{c}\text { Influent } \\
\text { [Si] }\end{array}$ \\
\end{tabular} & $\mathrm{T}\left({ }^{\circ} \mathrm{C}\right)$ & \begin{tabular}{|c|}
$\begin{array}{c}\text { Flow Rate } \\
\left(\mathbf{m}^{3} / \mathbf{d}\right)\end{array}$ \\
\end{tabular} & Time, days & $\mathrm{pH}\left(23^{\circ} \mathrm{C}\right)$ & $\begin{array}{c}\text { Glass } \\
\text { Mass (g) } \\
\end{array}$ & $\mathrm{SA}\left(\mathrm{m}^{2}\right)$ & [B] & B Rate & [Al] & Al Rate & [Na] & Na Rate & [Si] & Si Rate & IEX Rate \\
\hline \multicolumn{17}{|l|}{ Exp \#25 } \\
\hline BKV6-25.A & $<500$ & 70 & - & - & 9.00 & - & - & $<25$ & - & 21 & - & 380 & - & $<500$ & - & - \\
\hline BKV6-25.1 & $<500$ & 70 & $4.8 \mathrm{E}-05$ & 0.93 & 9.00 & 0.505 & $9.94 \mathrm{E}-03$ & 68 & $1.42 \mathrm{E}-02$ & 285 & 2.62E-02 & 2,030 & $4.98 \mathrm{E}-02$ & 1,245 & 1.63E-02 & $1.42 \mathrm{E}-08$ \\
\hline BKV6-25.2 & $<500$ & 70 & $4.2 \mathrm{E}-05$ & 1.77 & 9.00 & 0.504 & 9.93E-03 & 149 & 3.61E-02 & 679 & 5.75E-02 & 2,800 & $6.45 \mathrm{E}-02$ & 2,752 & 4.35E-02 & $1.13 \mathrm{E}-08$ \\
\hline BKV6-25.3 & $<500$ & 70 & 3.9E-05 & 4.78 & 9.00 & 0.503 & $9.90 \mathrm{E}-03$ & 179 & $4.26 \mathrm{E}-02$ & 796 & $6.40 \mathrm{E}-02$ & 2,455 & $5.22 \mathrm{E}-02$ & 3,347 & 5.19E-02 & 3.83E-09 \\
\hline BKV6-25.5 & $<500$ & 70 & $4.2 \mathrm{E}-05$ & 8.73 & 9.00 & 0.502 & $9.88 \mathrm{E}-03$ & 178 & $4.51 \mathrm{E}-02$ & 795 & 6.84E-02 & 2,396 & 5.43E-02 & 3,308 & $5.48 \mathrm{E}-02$ & 3.67E-09 \\
\hline BKV6-25.7 & $<500$ & 70 & $3.1 \mathrm{E}-05$ & 9.73 & 9.00 & 0.501 & $9.86 \mathrm{E}-03$ & 178 & 3.35E-02 & 798 & 5.09E-02 & 2,258 & 3.75E-02 & 3,296 & 4.04E-02 & 1.56E-09 \\
\hline BKV6-25.10 & $<500$ & 70 & 3.5E-05 & 14.50 & 9.00 & 0.500 & $9.85 \mathrm{E}-03$ & 141 & 2.85E-02 & 626 & 4.45E-02 & 1,830 & $3.25 \mathrm{E}-02$ & 2,594 & $3.40 \mathrm{E}-02$ & $1.60 \mathrm{E}-09$ \\
\hline BKV6-25.11 & $<500$ & 70 & $5.1 \mathrm{E}-05$ & 15.45 & 9.00 & 0.500 & $9.84 \mathrm{E}-03$ & 76 & $1.85 \mathrm{E}-02$ & 350 & 3.56E-02 & 927 & $1.80 \mathrm{E}-02$ & 1,438 & $2.24 \mathrm{E}-02$ & - \\
\hline BKV6-25.12 & $<500$ & 70 & $4.2 \mathrm{E}-05$ & 16.50 & 9.00 & 0.499 & 9.83E-03 & 145 & 3.55E-02 & 642 & 5.49E-02 & 1,844 & 3.94E-02 & 2,698 & $4.29 \mathrm{E}-02$ & 1.55E-09 \\
\hline BKV6-25.13 & $<500$ & 70 & 4.2E-05 & 17.51 & 9.00 & 0.498 & $9.81 \mathrm{E}-03$ & 152 & $3.71 \mathrm{E}-02$ & 681 & $5.80 \mathrm{E}-02$ & 2,027 & $4.41 \mathrm{E}-02$ & 2,871 & 4.59E-02 & 2.76E-09 \\
\hline \multicolumn{17}{|l|}{$\underline{\operatorname{Exp} \# 26}$} \\
\hline BKV6-26.A & 34,678 & 70 & - & - & 9.00 & - & - & $<25$ & - & 22 & - & 159 & - & 34,678 & - & - \\
\hline BKV6-26.1 & 34,678 & 70 & $1.4 \mathrm{E}-05$ & 0.93 & 9.00 & 0.501 & $9.86 \mathrm{E}-03$ & 33 & 7.85E-04 & 105 & 2.37E-03 & 2,414 & $1.97 \mathrm{E}-02$ & 34,726 & $3.08 \mathrm{E}-04$ & 7.56E-09 \\
\hline BKV6-26.2 & 34,678 & 70 & $4.4 \mathrm{E}-05$ & 1.77 & 9.00 & 0.501 & $9.86 \mathrm{E}-03$ & 64 & $1.21 \mathrm{E}-02$ & 232 & $1.94 \mathrm{E}-02$ & 3,701 & $9.98 \mathrm{E}-02$ & 35,355 & $1.38 \mathrm{E}-02$ & $3.50 \mathrm{E}-08$ \\
\hline BKV6-26.3 & 34,678 & 70 & 4.3E-05 & 4.78 & 9.00 & 0.500 & $9.85 \mathrm{E}-03$ & 67 & $1.27 \mathrm{E}-02$ & 310 & $2.61 \mathrm{E}-02$ & 1,911 & 4.83E-02 & 34,450 & - & $1.42 \mathrm{E}-08$ \\
\hline BKV6-26.5 & 34,678 & 70 & 4.3E-05 & 8.73 & 9.00 & 0.500 & $9.84 \mathrm{E}-03$ & 62 & 1.12E-02 & 249 & 2.07E-02 & 1,307 & 3.19E-02 & 35,251 & $1.16 \mathrm{E}-02$ & 8.26E-09 \\
\hline BKV6-26.7 & 34,678 & 70 & 4.0E-05 & 9.73 & 9.00 & 0.499 & $9.83 \mathrm{E}-03$ & 68 & $1.20 \mathrm{E}-02$ & 273 & 2.09E-02 & 1,206 & $2.66 \mathrm{E}-02$ & 35,108 & 7.92E-03 & 5.84E-09 \\
\hline BKV6-26.10 & 34,678 & 70 & $3.3 \mathrm{E}-05$ & 14.50 & 9.00 & 0.499 & $9.83 \mathrm{E}-03$ & 46 & 4.83E-03 & 188 & 1.15E-02 & 769 & $1.29 \mathrm{E}-02$ & 33,861 & - & 3.23E-09 \\
\hline BKV6-26.11 & 34,678 & 70 & $5.6 \mathrm{E}-05$ & 15.45 & 9.00 & 0.499 & $9.82 \mathrm{E}-03$ & 31 & $2.22 \mathrm{E}-03$ & 143 & 1.43E-02 & 478 & $1.15 \mathrm{E}-02$ & 33,935 & - & 3.70E-09 \\
\hline BKV6-26.12 & 34,678 & 70 & 4.3E-05 & 16.50 & 9.00 & 0.499 & 9.82E-03 & 61 & $1.07 \mathrm{E}-02$ & 254 & $2.08 \mathrm{E}-02$ & 944 & $2.15 \mathrm{E}-02$ & 34,805 & - & 4.33E-09 \\
\hline BKV6-26.13 & 34,678 & 70 & $3.9 \mathrm{E}-05$ & 17.51 & 9.00 & 0.498 & $9.81 \mathrm{E}-03$ & 60 & $9.76 \mathrm{E}-03$ & 248 & 1.86E-02 & 1,037 & $2.21 \mathrm{E}-02$ & 35,302 & - & 4.94E-09 \\
\hline \multicolumn{17}{|l|}{ Exp \#27 } \\
\hline BKV6-27.A & 67,624 & 70 & - & - & 9.00 & - & - & $<25$ & - & 12 & - & $<100$ & - & 67,624 & - & - \\
\hline BKV6-27.1 & \begin{tabular}{|l|}
67,624 \\
\end{tabular} & 70 & $4.9 \mathrm{E}-05$ & 0.93 & 9.00 & 0.502 & $9.88 \mathrm{E}-03$ & 26 & 3.65E-04 & 71 & 6.09E-03 & 2,954 & $9.01 \mathrm{E}-02$ & 67,636 & $2.68 \mathrm{E}-04$ & $3.58 \mathrm{E}-08$ \\
\hline BKV6-27.2 & 67,624 & 70 & 4.3E-05 & 1.77 & 9.00 & 0.502 & $9.88 \mathrm{E}-03$ & 27 & 7.03E-04 & 98 & 7.77E-03 & 2,553 & $6.74 \mathrm{E}-02$ & 65,205 & - & $2.66 \mathrm{E}-08$ \\
\hline BKV6-27.3 & 67,624 & 70 & $4.2 \mathrm{E}-05$ & 4.78 & 9.00 & 0.502 & $9.87 \mathrm{E}-03$ & 28 & $1.01 \mathrm{E}-03$ & 111 & 8.69E-03 & 1,640 & 4.11E-02 & 65,678 & - & $1.60 \mathrm{E}-08$ \\
\hline BKV6-27.5 & \begin{tabular}{|l|}
67,624 \\
\end{tabular} & 70 & $4.1 \mathrm{E}-05$ & 5.52 & 9.00 & 0.501 & 9.87E-03 & 25 & 3.71E-05 & 100 & 7.54E-03 & 1,243 & $2.98 \mathrm{E}-02$ & 67,456 & - & 1.19E-08 \\
\hline BKV6-27.7 & 67,624 & 70 & 4.3E-05 & 6.52 & 9.00 & 0.501 & 9.87E-03 & 38 & $4.03 \mathrm{E}-03$ & 115 & $9.18 \mathrm{E}-03$ & 1,292 & $3.26 \mathrm{E}-02$ & 67,039 & - & 1.14E-08 \\
\hline BKV6-27.10 & 67,624 & 70 & $3.5 \mathrm{E}-05$ & 8.16 & 9.00 & 0.501 & $9.86 \mathrm{E}-03$ & $<25$ & - & 93 & 5.96E-03 & 662 & $1.27 \mathrm{E}-02$ & 61,625 & - & 5.53E-09 \\
\hline BKV6-27.11 & 67,624 & 70 & 5.5E-05 & 9.10 & 9.00 & 0.501 & $9.86 \mathrm{E}-03$ & $<25$ & - & 59 & $5.41 \mathrm{E}-03$ & 379 & $9.79 \mathrm{E}-03$ & 65,106 & - & 6.07E-09 \\
\hline BKV6-27.12 & 67,624 & 70 & 4.2E-05 & 10.16 & 9.00 & 0.501 & $9.86 \mathrm{E}-03$ & $<25$ & - & 105 & $8.20 \mathrm{E}-03$ & 701 & $1.62 \mathrm{E}-02$ & 68,284 & $1.29 \mathrm{E}-02$ & 6.62E-09 \\
\hline BKV6-27.13 & 67,624 & 70 & 4.2E-05 & 11.17 & 9.00 & 0.501 & $9.86 \mathrm{E}-03$ & $<25$ & - & 94 & 7.22E-03 & 727 & $1.68 \mathrm{E}-02$ & 68,882 & $2.45 \mathrm{E}-02$ & 7.14E-09 \\
\hline & & & & & & & & & & & & & & & & \\
\hline & & & & & & & & & & & & & & & & \\
\hline & & & & & & & & & & & & & & & & \\
\hline & & & & & & & & & & & & & & & & \\
\hline
\end{tabular}


Table B1. SPFT Results for BKV6 Glass.

\begin{tabular}{|c|c|c|c|c|c|c|c|c|c|c|c|c|c|c|c|c|}
\hline Sample ID & \begin{tabular}{|c|} 
Influent \\
{$[\mathrm{Si}]$}
\end{tabular} & $T\left({ }^{\circ} \mathbf{C}\right)$ & \begin{tabular}{|c|}
$\begin{array}{c}\text { Flow Rate } \\
\left(\mathbf{m}^{3} / \mathbf{d}\right)\end{array}$ \\
\end{tabular} & Time, days & $\mathrm{pH}\left(23^{\circ} \mathrm{C}\right)$ & $\begin{array}{c}\text { Glass } \\
\text { Mass (g) }\end{array}$ & $\mathrm{SA}\left(\mathrm{m}^{2}\right)$ & [B] & B Rate & [Al] & Al Rate & {$[\mathrm{Na}]$} & Na Rate & {$[\mathrm{Si}]$} & Si Rate & IEX Rate \\
\hline \multicolumn{17}{|l|}{ Exp \#28 } \\
\hline BKV6-28.A & \begin{tabular}{|l|}
95,812 \\
\end{tabular} & 70 & - & - & 9.00 & - & - & $<25$ & - & 50 & - & $<100$ & - & 95,812 & - & - \\
\hline BKV6-28.1 & \begin{tabular}{|l|}
95,812 \\
\end{tabular} & 70 & $9.6 \mathrm{E}-06$ & 0.93 & 9.00 & 1.002 & $1.97 \mathrm{E}-02$ & 30 & $1.54 \mathrm{E}-04$ & 53 & $2.73 \mathrm{E}-05$ & 1,821 & $5.27 \mathrm{E}-03$ & 95,773 & - & $2.04 \mathrm{E}-09$ \\
\hline BKV6-28.2 & \begin{tabular}{|l|}
95,812 \\
\end{tabular} & 70 & $9.8 \mathrm{E}-06$ & 1.77 & 9.00 & 1.002 & $1.97 \mathrm{E}-02$ & 111 & $2.95 \mathrm{E}-03$ & 310 & $2.67 \mathrm{E}-03$ & 10,268 & $3.19 \mathrm{E}-02$ & 98,555 & $6.24 \mathrm{E}-03$ & $1.16 \mathrm{E}-08$ \\
\hline BKV6-28.3 & \begin{tabular}{|l|}
95,812 \\
\end{tabular} & 70 & $9.1 \mathrm{E}-06$ & 4.78 & 9.00 & 1.002 & 1.97E-02 & 67 & $1.33 \mathrm{E}-03$ & 128 & 7.44E-04 & 9,219 & $2.66 \mathrm{E}-02$ & 95,287 & - & $1.01 \mathrm{E}-08$ \\
\hline BKV6-28.5 & \begin{tabular}{|l|}
95,812 \\
\end{tabular} & 70 & $3.7 \mathrm{E}-05$ & 8.73 & 9.00 & 1.002 & $1.97 \mathrm{E}-02$ & $<25$ & - & 73 & $8.71 \mathrm{E}-04$ & 3,570 & $4.13 \mathrm{E}-02$ & 81,166 & - & 1.66E-08 \\
\hline BKV6-28.7 & \begin{tabular}{|l|}
95,812 \\
\end{tabular} & 70 & $4.3 \mathrm{E}-05$ & 9.73 & 9.00 & 1.002 & $1.97 \mathrm{E}-02$ & $<25$ & - & 76 & $1.14 \mathrm{E}-03$ & 2,265 & 2.98E-02 & 87,736 & - & $1.24 \mathrm{E}-08$ \\
\hline BKV6-28.10 & \begin{tabular}{|l|}
95,812 \\
\end{tabular} & 70 & $3.6 \mathrm{E}-05$ & 14.50 & 9.00 & 1.002 & $1.97 \mathrm{E}-02$ & $<25$ & - & 44 & - & $\begin{array}{ll}1,147 \\
\end{array}$ & $1.19 \mathrm{E}-02$ & 91,751 & - & $5.59 \mathrm{E}-09$ \\
\hline BKV6-28.11 & \begin{tabular}{|l|}
95,812 \\
\end{tabular} & 70 & $5.4 \mathrm{E}-05$ & 15.45 & 9.00 & 1.001 & $1.97 \mathrm{E}-02$ & $<25$ & - & 29 & - & 681 & $1.00 \mathrm{E}-02$ & 86,615 & - & $5.65 \mathrm{E}-09$ \\
\hline BKV6-28.12 & \begin{tabular}{|l|}
95,812 \\
\end{tabular} & 70 & $4.3 \mathrm{E}-05$ & 16.50 & 9.00 & 1.001 & $1.97 \mathrm{E}-02$ & $<25$ & - & 63 & $5.60 \mathrm{E}-04$ & 1,241 & $1.56 \mathrm{E}-02$ & 93,433 & - & 6.89E-09 \\
\hline BKV6-28.13 & \begin{tabular}{|l|}
95,812 \\
\end{tabular} & 70 & $3.9 \mathrm{E}-05$ & 17.51 & 9.00 & 1.001 & $1.97 \mathrm{E}-02$ & $<25$ & - & 55 & $2.01 \mathrm{E}-04$ & 1,233 & $1.41 \mathrm{E}-02$ & 100,588 & $4.32 \mathrm{E}-02$ & $6.36 \mathrm{E}-09$ \\
\hline \multicolumn{17}{|l|}{ Exp \#29 } \\
\hline BKV6-29.A & 114,135 & 70 & - & - & 9.00 & - & - & $<25$ & - & $<10$ & - & $<100$ & - & 114,135 & - & - \\
\hline BKV6-29.1 & 114,135 & 70 & $4.8 \mathrm{E}-05$ & 0.93 & 9.00 & 1.002 & $1.97 \mathrm{E}-02$ & 32 & $1.15 \mathrm{E}-03$ & 49 & $1.97 \mathrm{E}-03$ & 3,784 & 5.62E-02 & 124,072 & $1.10 \mathrm{E}-01$ & $2.20 \mathrm{E}-08$ \\
\hline BKV6-29.2 & 114,135 & 70 & 4.3E-05 & 1.77 & 9.00 & 1.002 & $1.97 \mathrm{E}-02$ & $<25$ & - & 50 & $1.77 \mathrm{E}-03$ & 3,723 & 4.93E-02 & 109,426 & - & 1.99E-08 \\
\hline BKV6-29.3 & 114,135 & 70 & $4.2 \mathrm{E}-05$ & 4.78 & 9.00 & 1.002 & $1.97 \mathrm{E}-02$ & $<25$ & - & 45 & $1.58 \mathrm{E}-03$ & 2,020 & $2.60 \mathrm{E}-02$ & 104,992 & - & $1.12 \mathrm{E}-08$ \\
\hline BKV6-29.5 & \begin{tabular}{|l|}
114,135 \\
\end{tabular} & 70 & 4.4E-05 & 8.73 & 9.00 & 1.002 & $1.97 \mathrm{E}-02$ & $<25$ & - & 24 & $6.43 \mathrm{E}-04$ & 2,060 & $2.76 \mathrm{E}-02$ & 122,084 & $8.11 \mathrm{E}-02$ & $1.22 \mathrm{E}-08$ \\
\hline BKV6-29.7 & 114,135 & 70 & $4.3 \mathrm{E}-05$ & 9.73 & 9.00 & 1.002 & $1.97 \mathrm{E}-02$ & $<25$ & - & 22 & $5.65 \mathrm{E}-04$ & 1,835 & $2.40 \mathrm{E}-02$ & 128,592 & $1.45 \mathrm{E}-01$ & $1.10 \mathrm{E}-08$ \\
\hline BKV6-29.10 & 114,135 & 70 & $3.4 \mathrm{E}-05$ & 14.50 & 9.00 & 1.002 & $1.97 \mathrm{E}-02$ & $<25$ & - & 28 & $6.57 \mathrm{E}-04$ & 1,869 & $1.91 \mathrm{E}-02$ & 118,231 & $3.21 \mathrm{E}-02$ & $8.65 \mathrm{E}-09$ \\
\hline BKV6-29.11 & 114,135 & 70 & $5.4 \mathrm{E}-05$ & 15.45 & 9.00 & 1.002 & $1.97 \mathrm{E}-02$ & $<25$ & - & 13 & $1.47 \mathrm{E}-04$ & 741 & $1.11 \mathrm{E}-02$ & 108,547 & - & $6.45 \mathrm{E}-09$ \\
\hline BKV6-29.12 & 114,135 & 70 & $4.3 \mathrm{E}-05$ & 16.50 & 9.00 & 1.002 & $1.97 \mathrm{E}-02$ & $<25$ & - & 22 & $5.55 \mathrm{E}-04$ & 1,021 & $1.26 \mathrm{E}-02$ & 108,339 & - & $6.54 \mathrm{E}-09$ \\
\hline BKV6-29.13 & 114,135 & 70 & $2.5 \mathrm{E}-05$ & 17.51 & 9.00 & 1.002 & $1.97 \mathrm{E}-02$ & $<25$ & - & 26 & $4.11 \mathrm{E}-04$ & 1,111 & 8.07E-03 & 111,637 & - & 4.06E-09 \\
\hline \multicolumn{17}{|l|}{ Exp \#30 } \\
\hline BKV6-30.A & \begin{tabular}{|l|}
121,562 \\
\end{tabular} & 70 & - & - & 9.00 & - & - & $<25$ & - & $<10$ & - & $<100$ & - & 121,562 & - & - \\
\hline BKV6-30.1 & \begin{tabular}{|l|}
121,562 \\
\end{tabular} & 70 & $4.7 \mathrm{E}-05$ & 0.93 & 9.00 & 1.000 & $1.97 \mathrm{E}-02$ & 32 & 1.13E-03 & 159 & 7.42E-03 & 3,369 & $4.95 \mathrm{E}-02$ & 130,630 & $9.95 \mathrm{E}-02$ & $1.93 \mathrm{E}-08$ \\
\hline BKV6-30.2 & 121,562 & 70 & $4.2 \mathrm{E}-05$ & 1.77 & 9.00 & 1.000 & 1.97E-02 & $<25$ & - & 91 & $3.54 \mathrm{E}-03$ & 3,997 & $5.21 \mathrm{E}-02$ & 122,780 & $1.18 \mathrm{E}-02$ & $2.09 \mathrm{E}-08$ \\
\hline BKV6-30.3 & 121,562 & 70 & $4.2 \mathrm{E}-05$ & 4.78 & 9.00 & 1.000 & $1.97 \mathrm{E}-02$ & $<25$ & - & 31 & $9.13 \mathrm{E}-04$ & 1,934 & $2.45 \mathrm{E}-02$ & 118,236 & - & $1.07 \mathrm{E}-08$ \\
\hline BKV6-30.5 & 121,562 & 70 & $4.3 \mathrm{E}-05$ & 5.52 & 9.00 & 1.000 & $1.97 \mathrm{E}-02$ & $<25$ & - & 12 & $7.40 \mathrm{E}-05$ & 1,402 & 1.79E-02 & 122,671 & $1.11 \mathrm{E}-02$ & $8.53 \mathrm{E}-09$ \\
\hline BKV6-30.7 & 121,562 & 70 & $4.2 \mathrm{E}-05$ & 6.52 & 9.00 & 1.000 & $1.97 \mathrm{E}-02$ & $<25$ & - & 17 & $2.91 \mathrm{E}-04$ & 1,651 & $2.10 \mathrm{E}-02$ & 132,507 & $1.08 \mathrm{E}-01$ & $9.75 \mathrm{E}-09$ \\
\hline BKV6-30.10 & 121,562 & 70 & $3.5 \mathrm{E}-05$ & 8.16 & 9.00 & 1.000 & $1.97 \mathrm{E}-02$ & $<25$ & - & 10 & 9.63E-06 & 1,055 & $1.08 \mathrm{E}-02$ & 115,938 & - & $5.56 \mathrm{E}-09$ \\
\hline BKV6-30.11 & 121,562 & 70 & $5.3 \mathrm{E}-05$ & 9.10 & 9.00 & 1.000 & $1.97 \mathrm{E}-02$ & $<25$ & - & 12 & $1.35 \mathrm{E}-04$ & 555 & 7.69E-03 & 104,961 & - & $5.03 \mathrm{E}-09$ \\
\hline BKV6-30.12 & 121,562 & 70 & $4.2 \mathrm{E}-05$ & 10.16 & 9.00 & 1.000 & $1.97 \mathrm{E}-02$ & $<25$ & - & 14 & $1.65 \mathrm{E}-04$ & 915 & $1.10 \mathrm{E}-02$ & 112,888 & - & $5.83 \mathrm{E}-09$ \\
\hline BKV6-30.13 & 121,562 & 70 & $4.2 \mathrm{E}-05$ & 11.17 & 9.00 & 1.000 & $1.97 \mathrm{E}-02$ & $<25$ & - & 15 & $2.01 \mathrm{E}-04$ & 1,289 & $1.59 \mathrm{E}-02$ & 119,620 & - & $7.74 \mathrm{E}-09$ \\
\hline & & & & & & & & & & & & & & & & \\
\hline & & & & & & & & & & & & & & & & \\
\hline & & & & & & & & & & & & & & & & \\
\hline & & & & & & & & & & & & & & & & \\
\hline & & & & & & & & & & & & & & & & \\
\hline
\end{tabular}


Table B1. SPFT Results for BKV6 Glass.

\begin{tabular}{|c|c|c|c|c|c|c|c|c|c|c|c|c|c|c|c|c|}
\hline Sample ID & \begin{tabular}{|c|}
$\begin{array}{c}\text { Influent } \\
\text { [Si }]\end{array}$ \\
\end{tabular} & $T\left({ }^{\circ} \mathrm{C}\right)$ & \begin{tabular}{|c|c|c|c|c|}
$\left(\mathbf{m}^{3} / \mathbf{d}\right)$ \\
\end{tabular} & Time, days & $\mathrm{pH}\left(23^{\circ} \mathrm{C}\right)$ & $\begin{array}{c}\text { Glass } \\
\text { Mass (g) } \\
\end{array}$ & $\mathrm{SA}\left(\mathrm{m}^{2}\right)$ & {$[\mathrm{B}]$} & B Rate & {$[\mathrm{Al}]$} & Al Rate & {$[\mathrm{Na}]$} & Na Rate & {$[\mathrm{Si}]$} & Si Rate & IEX Rate \\
\hline \multicolumn{17}{|l|}{ Exp\#31 } \\
\hline BKV6-31.A & 0 & 70 & - & - & 7.00 & - & - & $<100$ & - & 137 & - & $<50$ & & $<500$ & - & - \\
\hline BKV6-31.1 & 0 & 70 & $3.9 \mathrm{E}-05$ & 1.05 & 7.00 & 1.008 & $1.98 \mathrm{E}-02$ & $<100$ & - & 25 & - & 5,670 & 7.06E-02 & - & - & $2.82 \mathrm{E}-08$ \\
\hline BKV6-31.2 & 0 & 70 & $3.8 \mathrm{E}-05$ & 1.88 & 7.00 & 1.007 & $1.98 \mathrm{E}-02$ & $<100$ & - & 70 & - & 6,819 & $8.11 \mathrm{E}-02$ & 638 & $1.19 \mathrm{E}-03$ & $3.24 \mathrm{E}-08$ \\
\hline BKV6-31.3 & 0 & 70 & 3.7E-05 & 2.09 & 7.00 & 1.007 & $1.98 \mathrm{E}-02$ & $<100$ & - & 45 & - & 6,590 & 7.71E-02 & 522 & $1.85 \mathrm{E}-04$ & $3.08 \mathrm{E}-08$ \\
\hline BKV6-31.6 & 0 & 70 & $4.0 \mathrm{E}-05$ & 3.25 & 7.00 & 1.007 & $1.98 \mathrm{E}-02$ & $<100$ & - & 47 & - & 3,084 & $3.86 \mathrm{E}-02$ & - & - & $1.54 \mathrm{E}-08$ \\
\hline BKV6-31.7 & 0 & 70 & $3.8 \mathrm{E}-05$ & 5.98 & 7.00 & 1.006 & $1.98 \mathrm{E}-02$ & $<100$ & - & 46 & - & 3,126 & $3.75 \mathrm{E}-02$ & - & - & $1.50 \mathrm{E}-08$ \\
\hline BKV6-31.8 & 0 & 70 & $3.9 \mathrm{E}-05$ & 7.23 & 7.00 & 1.005 & 1.98E-02 & $<100$ & - & 43 & - & 2,858 & $3.45 \mathrm{E}-02$ & - & - & $1.38 \mathrm{E}-08$ \\
\hline BKV6-31.9 & 0 & 70 & $3.9 \mathrm{E}-05$ & 8.93 & 7.00 & 1.005 & $1.98 \mathrm{E}-02$ & $<100$ & - & 42 & - & 2,613 & $3.17 \mathrm{E}-02$ & - & - & $1.26 \mathrm{E}-08$ \\
\hline BKV6-31.10 & 0 & 70 & $3.8 \mathrm{E}-05$ & 9.97 & 7.00 & 1.004 & $1.98 \mathrm{E}-02$ & $<100$ & - & 38 & - & 2,503 & $3.00 \mathrm{E}-02$ & - & - & $1.20 \mathrm{E}-08$ \\
\hline BKV6-31.11 & 0 & 70 & $3.8 \mathrm{E}-05$ & 10.26 & 7.00 & 1.004 & $1.98 \mathrm{E}-02$ & $<100$ & - & 61 & - & 2,428 & $2.88 \mathrm{E}-02$ & - & - & $1.15 \mathrm{E}-08$ \\
\hline \multicolumn{17}{|l|}{ Exp \#32 } \\
\hline BKV6-32.A & 0 & 70 & - & - & 8.00 & - & - & $<100$ & - & $<25$ & - & 102 & - & $<500$ & - & - \\
\hline BKV6-32.1 & 0 & 70 & $4.5 \mathrm{E}-05$ & 1.05 & 8.00 & 1.000 & $1.97 \mathrm{E}-02$ & $<100$ & - & 144 & $5.58 \mathrm{E}-03$ & 5,948 & $8.35 \mathrm{E}-02$ & 704 & $2.11 \mathrm{E}-03$ & $3.33 \mathrm{E}-08$ \\
\hline BKV6-32.2 & 0 & 70 & $3.8 \mathrm{E}-05$ & 1.88 & 8.00 & 0.999 & $1.97 \mathrm{E}-02$ & $<100$ & - & 250 & $9.06 \mathrm{E}-03$ & 6,627 & 7.99E-02 & 1,115 & $5.46 \mathrm{E}-03$ & $3.19 \mathrm{E}-08$ \\
\hline BKV6-32.3 & 0 & 70 & 3.7E-05 & 2.09 & 8.00 & 0.999 & $1.97 \mathrm{E}-02$ & $<100$ & - & 266 & $\begin{array}{l}9.37 \mathrm{E}-03 \\
\end{array}$ & 6,218 & 7.23E-02 & $\begin{array}{ll}1,196 \\
\end{array}$ & $5.96 \mathrm{E}-03$ & $2.89 \mathrm{E}-08$ \\
\hline BKV6-32.6 & 0 & 70 & 3.6E-05 & 3.25 & 8.00 & 0.999 & $1.97 \mathrm{E}-02$ & $<100$ & - & 334 & $1.18 \mathrm{E}-02$ & 3,238 & $3.64 \mathrm{E}-02$ & 1,524 & $8.60 \mathrm{E}-03$ & $1.45 \mathrm{E}-08$ \\
\hline BKV6-32.7 & 0 & 70 & $3.7 \mathrm{E}-05$ & 5.98 & 8.00 & 0.998 & $1.96 \mathrm{E}-02$ & $<100$ & - & 350 & $1.26 \mathrm{E}-02$ & 3,407 & $3.91 \mathrm{E}-02$ & 1,611 & $9.51 \mathrm{E}-03$ & $1.56 \mathrm{E}-08$ \\
\hline BKV6-32.8 & 0 & 70 & 3.6E-05 & 7.23 & 8.00 & 0.997 & $1.96 \mathrm{E}-02$ & $<100$ & - & 354 & $1.24 \mathrm{E}-02$ & 3,143 & $3.49 \mathrm{E}-02$ & 1,614 & $9.28 \mathrm{E}-03$ & $1.39 \mathrm{E}-08$ \\
\hline BKV6-32.9 & 0 & 70 & $3.7 \mathrm{E}-05$ & 8.93 & 8.00 & 0.997 & $1.96 \mathrm{E}-02$ & $<100$ & - & 371 & $\begin{array}{l}1.33 \mathrm{E}-02 \\
\end{array}$ & 2,941 & 3.33E-02 & 1,637 & $9.68 \mathrm{E}-03$ & 1.33E-08 \\
\hline BKV6-32.10 & 0 & 70 & $3.8 \mathrm{E}-05$ & 9.97 & 8.00 & 0.996 & $1.96 \mathrm{E}-02$ & $<100$ & - & 319 & $1.19 \mathrm{E}-02$ & 2,771 & $3.28 \mathrm{E}-02$ & 1,657 & $1.03 \mathrm{E}-02$ & $1.31 \mathrm{E}-08$ \\
\hline BKV6-32.11 & 0 & 70 & $3.8 \mathrm{E}-05$ & 10.26 & 8.00 & 0.996 & $1.96 \mathrm{E}-02$ & $<100$ & - & 394 & 1.49E-02 & 2,853 & $3.38 \mathrm{E}-02$ & 1,715 & $1.08 \mathrm{E}-02$ & $1.35 \mathrm{E}-08$ \\
\hline \multicolumn{17}{|l|}{ Exp \#33 } \\
\hline BKV6-33.A & 0 & 70 & - & - & 9.00 & - & - & $<100$ & - & 53 & - & 166 & - & 589 & - & - \\
\hline BKV6-33.1 & 0 & 70 & $3.4 \mathrm{E}-05$ & 1.05 & 9.00 & 0.505 & $9.94 \mathrm{E}-03$ & - & - & 555 & $3.56 \mathrm{E}-02$ & 2,813 & $5.72 \mathrm{E}-02$ & 2,085 & $2.34 \mathrm{E}-02$ & $2.49 \mathrm{E}-08$ \\
\hline BKV6-33.2 & 0 & 70 & $3.7 \mathrm{E}-05$ & 1.88 & 9.00 & 0.504 & 9.93E-03 & 142 & $1.08 \mathrm{E}-02$ & 776 & $5.61 \mathrm{E}-02$ & 3,349 & $7.53 \mathrm{E}-02$ & 3,503 & $4.99 \mathrm{E}-02$ & $2.57 \mathrm{E}-08$ \\
\hline BKV6-33.3 & 0 & 70 & 4.0E-05 & 2.09 & 9.00 & 0.504 & 9.92E-03 & 159 & $1.66 \mathrm{E}-02$ & 811 & $6.35 \mathrm{E}-02$ & 3,358 & $8.13 \mathrm{E}-02$ & 4,020 & $6.34 \mathrm{E}-02$ & $2.58 \mathrm{E}-08$ \\
\hline BKV6-33.6 & 0 & 70 & $3.7 \mathrm{E}-05$ & 3.25 & 9.00 & 0.504 & $9.91 \mathrm{E}-03$ & 189 & $2.28 \mathrm{E}-02$ & 924 & $6.65 \mathrm{E}-02$ & 2,932 & $6.43 \mathrm{E}-02$ & 3,700 & $5.24 \mathrm{E}-02$ & $1.66 \mathrm{E}-08$ \\
\hline BKV6-33.7 & 0 & 70 & 3.6E-05 & 5.98 & 9.00 & 0.502 & 9.89E-03 & 229 & $3.23 \mathrm{E}-02$ & 1,086 & $7.76 \mathrm{E}-02$ & 3,238 & $7.02 \mathrm{E}-02$ & 4,368 & $6.26 \mathrm{E}-02$ & $1.52 \mathrm{E}-08$ \\
\hline BKV6-33.8 & 0 & 70 & $3.3 \mathrm{E}-05$ & 7.23 & 9.00 & 0.500 & $9.86 \mathrm{E}-03$ & 229 & $2.97 \mathrm{E}-02$ & 1,121 & $7.35 \mathrm{E}-02$ & 3,190 & $6.33 \mathrm{E}-02$ & 4,376 & $5.75 \mathrm{E}-02$ & $1.34 \mathrm{E}-08$ \\
\hline BKV6-33.9 & 0 & 70 & 3.6E-05 & 8.93 & 9.00 & 0.499 & $9.83 \mathrm{E}-03$ & 206 & $2.70 \mathrm{E}-02$ & 979 & $7.08 \mathrm{E}-02$ & 2,878 & 6.31E-02 & 3,935 & $5.64 \mathrm{E}-02$ & $1.44 \mathrm{E}-08$ \\
\hline BKV6-33.10 & 0 & 70 & 3.5E-05 & 9.97 & 9.00 & 0.498 & $9.81 \mathrm{E}-03$ & 195 & $2.37 \mathrm{E}-02$ & 812 & $5.64 \mathrm{E}-02$ & 2,480 & $5.23 \mathrm{E}-02$ & 3,921 & $5.46 \mathrm{E}-02$ & $1.14 \mathrm{E}-08$ \\
\hline BKV6-33.11 & 0 & 70 & $3.7 \mathrm{E}-05$ & 10.26 & 9.00 & 0.498 & $9.80 \mathrm{E}-03$ & 214 & $2.97 \mathrm{E}-02$ & 1,025 & $7.61 \mathrm{E}-02$ & 2,639 & $5.89 \mathrm{E}-02$ & 4,092 & $6.05 \mathrm{E}-02$ & $1.17 \mathrm{E}-08$ \\
\hline & & & & & & & & & & & & & & & & \\
\hline & & & & & & & & & & & & & & & & \\
\hline & & & & & & & & & & & & & & & & \\
\hline & & & & & & & & & & & & & & & & \\
\hline & & & & & & & & & & & & & & & & \\
\hline
\end{tabular}


Table B1. SPFT Results for BKV6 Glass.

\begin{tabular}{|c|c|c|c|c|c|c|c|c|c|c|c|c|c|c|c|c|}
\hline Sample ID & \begin{tabular}{|c|} 
Influent \\
{$[\mathrm{Si}]$}
\end{tabular} & $\mathrm{T}\left({ }^{\circ} \mathrm{C}\right)$ & \begin{tabular}{c|} 
Flow Rate \\
$\left(\mathbf{m}^{3} / \mathbf{d}\right)$
\end{tabular} & Time, days & $\mathrm{pH}\left(23^{\circ} \mathrm{C}\right)$ & $\begin{array}{c}\text { Glass } \\
\text { Mass (g) }\end{array}$ & $\mathrm{SA}\left(\mathrm{m}^{2}\right)$ & {$[\mathrm{B}]$} & B Rate & {$[\mathbf{A l}]$} & Al Rate & [Na] & Na Rate & {$[\mathrm{Si}]$} & Si Rate & IEX Rate \\
\hline \multicolumn{17}{|l|}{ Exp \#34 } \\
\hline BKV6-34.A & 0 & 70 & - & - & 10.00 & - & - & $<100$ & - & $<25$ & - & 111 & - & $<500$ & - & - \\
\hline BKV6-34.1 & 0 & 70 & $3.5 \mathrm{E}-05$ & 1.05 & 10.00 & 0.509 & $1.00 \mathrm{E}-02$ & 186 & $2.09 \mathrm{E}-02$ & 900 & $6.35 \mathrm{E}-02$ & 3,418 & $7.31 \mathrm{E}-02$ & 3,663 & 5.07E-02 & $2.08 \mathrm{E}-08$ \\
\hline BKV6-34.2 & 0 & 70 & $3.9 \mathrm{E}-05$ & 1.88 & 10.00 & 0.508 & $1.00 \mathrm{E}-02$ & 309 & $5.60 \mathrm{E}-02$ & 1,447 & $1.14 \mathrm{E}-01$ & 4,655 & $1.11 \mathrm{E}-01$ & 5,536 & $8.92 \mathrm{E}-02$ & $2.20 \mathrm{E}-08$ \\
\hline BKV6-34.3 & 0 & 70 & $3.8 \mathrm{E}-05$ & 2.09 & 10.00 & 0.507 & $9.98 \mathrm{E}-03$ & 337 & $6.27 \mathrm{E}-02$ & 1,547 & 1.21E-01 & 4,777 & $1.13 \mathrm{E}-01$ & 5,988 & $9.60 \mathrm{E}-02$ & $1.99 \mathrm{E}-08$ \\
\hline BKV6-34.6 & 0 & 70 & $3.7 \mathrm{E}-05$ & 3.25 & 10.00 & 0.506 & 9.96E-03 & 399 & $7.67 \mathrm{E}-02$ & 1,844 & $1.39 \mathrm{E}-01$ & 5,118 & $1.17 \mathrm{E}-01$ & 7,014 & $1.10 \mathrm{E}-01$ & $1.60 \mathrm{E}-08$ \\
\hline BKV6-34.7 & 0 & 70 & 3.7E-05 & 5.98 & 10.00 & 0.502 & 9.91E-03 & 426 & $8.44 \mathrm{E}-02$ & 1,942 & $1.49 \mathrm{E}-01$ & 5,513 & $1.28 \mathrm{E}-01$ & 7,413 & $1.18 \mathrm{E}-01$ & $1.72 \mathrm{E}-08$ \\
\hline BKV6-34.8 & 0 & 70 & $3.9 \mathrm{E}-05$ & 7.23 & 10.00 & 0.499 & 9.85E-03 & 428 & $8.87 \mathrm{E}-02$ & 1,926 & 1.54E-01 & 5,403 & $1.31 \mathrm{E}-01$ & 7,396 & $1.23 \mathrm{E}-01$ & $1.67 \mathrm{E}-08$ \\
\hline BKV6-34.9 & 0 & 70 & $3.2 \mathrm{E}-05$ & 8.93 & 10.00 & 0.497 & $9.80 \mathrm{E}-03$ & 427 & $7.38 \mathrm{E}-02$ & 1,929 & 1.29E-01 & 5,475 & $1.10 \mathrm{E}-01$ & 7,433 & $1.03 \mathrm{E}-01$ & $1.46 \mathrm{E}-08$ \\
\hline BKV6-34.10 & 0 & 70 & $3.9 \mathrm{E}-05$ & 9.97 & 10.00 & 0.495 & 9.76E-03 & 418 & $8.79 \mathrm{E}-02$ & 1,881 & $1.54 \mathrm{E}-01$ & 5,268 & $1.30 \mathrm{E}-01$ & 7,267 & $1.24 \mathrm{E}-01$ & $1.68 \mathrm{E}-08$ \\
\hline BKV6-34.11 & 0 & 70 & $2.7 \mathrm{E}-05$ & 10.26 & 10.00 & 0.494 & 9.73E-03 & 449 & $6.69 \mathrm{E}-02$ & 2,069 & $1.17 \mathrm{E}-01$ & 5,720 & $9.80 \mathrm{E}-02$ & 7,909 & $\begin{array}{l}9.38 \mathrm{E}-02 \\
\end{array}$ & $1.24 \mathrm{E}-08$ \\
\hline \multicolumn{17}{|l|}{ Exp \#35 } \\
\hline BKV6-35.A & 0 & 70 & - & - & 11.00 & - & - & $<100$ & - & $<25$ & - & 62 & - & $<500$ & - & - \\
\hline BKV6-35.1 & 0 & 70 & 3.7E-05 & 1.05 & 11.00 & 0.508 & $1.00 \mathrm{E}-02$ & 510 & $1.06 \mathrm{E}-01$ & 2,409 & $1.84 \mathrm{E}-01$ & 7,883 & $1.84 \mathrm{E}-01$ & 9,409 & $1.52 \mathrm{E}-01$ & $3.11 \mathrm{E}-08$ \\
\hline BKV6-35.2 & 0 & 70 & $3.7 \mathrm{E}-05$ & 1.88 & 11.00 & 0.505 & $9.96 \mathrm{E}-03$ & 831 & $1.89 \mathrm{E}-01$ & 3,694 & $2.84 \mathrm{E}-01$ & 11,518 & 2.70E-01 & 14,400 & $2.37 \mathrm{E}-01$ & $3.23 \mathrm{E}-08$ \\
\hline BKV6-35.3 & 0 & 70 & $3.9 \mathrm{E}-05$ & 2.09 & 11.00 & 0.504 & 9.92E-03 & 853 & $2.03 \mathrm{E}-01$ & 3,819 & $3.06 \mathrm{E}-01$ & 11,751 & $2.87 \mathrm{E}-01$ & 14,606 & $2.51 \mathrm{E}-01$ & $3.35 \mathrm{E}-08$ \\
\hline BKV6-35.6 & 0 & 70 & $3.6 \mathrm{E}-05$ & 3.25 & 11.00 & 0.501 & 9.87E-03 & 1,033 & $2.35 \mathrm{E}-01$ & 4,387 & $3.28 \mathrm{E}-01$ & 13,251 & $3.02 \mathrm{E}-01$ & 17,411 & $2.81 \mathrm{E}-01$ & $2.69 \mathrm{E}-08$ \\
\hline BKV6-35.7 & 0 & 70 & 3.7E-05 & 5.98 & 11.00 & 0.492 & 9.74E-03 & 1,044 & $2.49 \mathrm{E}-01$ & 4,393 & $3.45 \mathrm{E}-01$ & 13,457 & $3.22 \mathrm{E}-01$ & 17,403 & $2.95 \mathrm{E}-01$ & $2.91 \mathrm{E}-08$ \\
\hline BKV6-35.8 & 0 & 70 & $3.6 \mathrm{E}-05$ & 7.23 & 11.00 & 0.485 & 9.59E-03 & 1,009 & $2.36 \mathrm{E}-01$ & 4,200 & 3.24E-01 & 13,104 & $3.08 \mathrm{E}-01$ & 16,770 & $2.79 \mathrm{E}-01$ & $2.89 \mathrm{E}-08$ \\
\hline BKV6-35.9 & 0 & 70 & $3.6 \mathrm{E}-05$ & 8.93 & 11.00 & 0.479 & $9.47 \mathrm{E}-03$ & 998 & $2.36 \mathrm{E}-01$ & 4,258 & $3.32 \mathrm{E}-01$ & 12,774 & $3.04 \mathrm{E}-01$ & 16,756 & $2.81 \mathrm{E}-01$ & $2.72 \mathrm{E}-08$ \\
\hline BKV6-35.10 & 0 & 70 & $3.8 \mathrm{E}-05$ & 9.97 & 11.00 & 0.474 & $9.37 \mathrm{E}-03$ & 1,055 & $2.66 \mathrm{E}-01$ & 4,429 & $3.67 \mathrm{E}-01$ & 13,529 & $3.41 \mathrm{E}-01$ & 17,707 & $3.16 \mathrm{E}-01$ & $3.01 \mathrm{E}-08$ \\
\hline BKV6-35.11 & 0 & 70 & 3.8E-05 & 10.26 & 11.00 & 0.472 & $9.30 \mathrm{E}-03$ & 1,061 & $2.71 \mathrm{E}-01$ & 4,485 & $3.76 \mathrm{E}-01$ & 13,525 & $3.45 \mathrm{E}-01$ & 17,581 & $3.18 \mathrm{E}-01$ & 2.99E-08 \\
\hline \multicolumn{17}{|l|}{ Exp\#36 } \\
\hline BKV6-36.A & 0 & 70 & - & - & 12.00 & - & - & $<100$ & - & 25 & - & 147 & - & 509 & - & \\
\hline BKV6-36.1 & 0 & 70 & $3.4 \mathrm{E}-05$ & 1.05 & 12.00 & 0.501 & 9.88E-03 & 1,136 & $2.50 \mathrm{E}-01$ & 5,397 & $3.88 \mathrm{E}-01$ & 16,348 & $3.56 \mathrm{E}-01$ & 20,886 & $3.25 \mathrm{E}-01$ & $4.23 \mathrm{E}-08$ \\
\hline BKV6-36.2 & 0 & 70 & $3.4 \mathrm{E}-05$ & 1.88 & 12.00 & 0.496 & 9.79E-03 & 1,948 & $4.48 \mathrm{E}-01$ & 9,052 & 6.55E-01 & 26,733 & $5.87 \mathrm{E}-01$ & 33,583 & $5.30 \mathrm{E}-01$ & $5.56 \mathrm{E}-08$ \\
\hline BKV6-36.3 & 0 & 70 & $3.6 \mathrm{E}-05$ & 2.09 & 12.00 & 0.493 & 9.72E-03 & 2,087 & $5.10 \mathrm{E}-01$ & 9,595 & 7.36E-01 & 27,734 & $6.46 \mathrm{E}-01$ & 35,498 & $5.94 \mathrm{E}-01$ & $5.40 \mathrm{E}-08$ \\
\hline BKV6-36.6 & 0 & 70 & 3.6E-05 & 3.25 & 12.00 & 0.485 & $9.60 \mathrm{E}-03$ & 2,515 & $6.34 \mathrm{E}-01$ & 10,851 & $8.50 \mathrm{E}-01$ & 33,033 & 7.86E-01 & 41,301 & 7.07E-01 & $6.09 \mathrm{E}-08$ \\
\hline BKV6-36.7 & 0 & 70 & $3.6 \mathrm{E}-05$ & 5.98 & 12.00 & 0.462 & 9.24E-03 & 2,842 & $7.36 \mathrm{E}-01$ & 12,164 & $9.76 \mathrm{E}-01$ & 36,519 & $8.90 \mathrm{E}-01$ & 47,045 & $8.25 \mathrm{E}-01$ & $6.13 \mathrm{E}-08$ \\
\hline BKV6-36.8 & 0 & 70 & $3.5 \mathrm{E}-05$ & 7.23 & 12.00 & 0.444 & $8.85 \mathrm{E}-03$ & 2,861 & $7.58 \mathrm{E}-01$ & 12,206 & $1.00 \mathrm{E}+00$ & 36,145 & $9.00 \mathrm{E}-01$ & 47,333 & $8.49 \mathrm{E}-01$ & $5.67 \mathrm{E}-08$ \\
\hline BKV6-36.9 & 0 & 70 & $3.4 \mathrm{E}-05$ & 8.93 & 12.00 & 0.428 & $8.52 \mathrm{E}-03$ & 2,855 & $7.63 \mathrm{E}-01$ & 12,154 & $1.01 \mathrm{E}+00$ & 37,190 & $9.35 \mathrm{E}-01$ & 46,786 & $8.47 \mathrm{E}-01$ & $6.86 \mathrm{E}-08$ \\
\hline BKV6-36.10 & 0 & 70 & $3.7 \mathrm{E}-05$ & 9.97 & 12.00 & 0.415 & $8.25 \mathrm{E}-03$ & 2,755 & $8.28 \mathrm{E}-01$ & 11,478 & $1.07 \mathrm{E}+00$ & 35,214 & $9.96 \mathrm{E}-01$ & 44,977 & $9.15 \mathrm{E}-01$ & $6.71 \mathrm{E}-08$ \\
\hline BKV6-36.11 & 0 & 70 & $3.7 \mathrm{E}-05$ & 10.26 & 12.00 & 0.409 & $8.09 \mathrm{E}-03$ & 2,688 & $8.26 \mathrm{E}-01$ & 11,481 & $1.09 \mathrm{E}+00$ & 35,227 & $1.02 \mathrm{E}+00$ & 43,810 & $9.13 \mathrm{E}-01$ & $7.74 \mathrm{E}-08$ \\
\hline & & & & & & & & & & & & & & & & \\
\hline & & & & & & & & & & & & & & & & \\
\hline & & & & & & & & & & & & & & & & \\
\hline & & & & & & & & & & & & & & & & \\
\hline & & & & & & & & & & & & & & & & \\
\hline
\end{tabular}


Table B1. SPFT Results for BKV6 Glass.

\begin{tabular}{|c|c|c|c|c|c|c|c|c|c|c|c|c|c|c|c|c|}
\hline Sample ID & \begin{tabular}{|c|}
$\begin{array}{c}\text { Influent } \\
\text { [Si] }\end{array}$ \\
\end{tabular} & $\mathrm{T}\left({ }^{\circ} \mathrm{C}\right)$ & \begin{tabular}{c|}
$\begin{array}{c}\text { Flow Rate } \\
\left(\mathbf{m}^{3} / \mathbf{d}\right)\end{array}$ \\
\end{tabular} & Time, days & $\mathrm{pH}\left(23^{\circ} \mathrm{C}\right)$ & $\begin{array}{c}\text { Glass } \\
\text { Mass (g) }\end{array}$ & $\mathrm{SA}\left(\mathrm{m}^{2}\right)$ & [B] & B Rate & {$[\mathrm{Al}]$} & Al Rate & [Na] & Na Rate & {$[\mathrm{Si}]$} & Si Rate & IEX Rate \\
\hline \multicolumn{17}{|l|}{ Exp \#37 } \\
\hline BKV6-37A & $<500$ & 90 & - & - & 9.00 & - & - & $<25$ & - & $<25$ & - & $<500$ & - & $<500$ & - & - \\
\hline BKV6-37.1 & $<500$ & 90 & $4.1 \mathrm{E}-05$ & 1.81 & 9.00 & 0.499 & 9.84E-03 & 327 & $8.77 \mathrm{E}-02$ & 1,402 & 0.119473 & 8,387 & $2.08 \mathrm{E}-01$ & 6,009 & $1.05 \mathrm{E}-01$ & $4.82 \mathrm{E}-08$ \\
\hline BKV6-37.2 & $<500$ & 90 & $5.5 \mathrm{E}-05$ & 3.02 & 9.00 & 0.497 & 9.80E-03 & 315 & $1.13 \mathrm{E}-01$ & 1,410 & 0.160759 & 5,324 & $1.71 \mathrm{E}-01$ & 5,940 & 1.39E-01 & $2.31 \mathrm{E}-08$ \\
\hline BKV6-37.3 & $<500$ & 90 & 7.6E-05 & 4.01 & 9.00 & 0.495 & $9.75 \mathrm{E}-03$ & 313 & $1.55 \mathrm{E}-01$ & 1,368 & 0.215464 & 3,942 & $1.68 \mathrm{E}-01$ & 5,799 & $1.88 \mathrm{E}-01$ & $5.40 \mathrm{E}-09$ \\
\hline BKV6-37.6 & $<500$ & 90 & 5.7E-05 & 7.92 & 9.00 & 0.493 & $9.71 \mathrm{E}-03$ & 391 & $1.48 \mathrm{E}-01$ & 1,599 & 0.190291 & 4,998 & $1.66 \mathrm{E}-01$ & 7,056 & $1.75 \mathrm{E}-01$ & 7.12E-09 \\
\hline BKV6-37.7 & $<500$ & 90 & $6.0 \mathrm{E}-05$ & 9.86 & 9.00 & 0.489 & $9.65 \mathrm{E}-03$ & 364 & $1.47 \mathrm{E}-01$ & 1,505 & 0.191811 & 4,598 & $1.62 \mathrm{E}-01$ & 6,568 & $1.74 \mathrm{E}-01$ & $5.88 \mathrm{E}-09$ \\
\hline BKV6-37.10 & $<500$ & 90 & $5.7 \mathrm{E}-05$ & 13.81 & 9.00 & 0.485 & $9.57 \mathrm{E}-03$ & 337 & $1.29 \mathrm{E}-01$ & 1,376 & 0.167707 & 4,029 & $1.33 \mathrm{E}-01$ & 6,284 & $1.58 \mathrm{E}-01$ & 1.59E-09 \\
\hline BKV6-37.11 & $<500$ & 90 & $5.9 \mathrm{E}-05$ & 14.87 & 9.00 & 0.482 & $9.51 \mathrm{E}-03$ & 335 & $1.34 \mathrm{E}-01$ & 1,484 & 0.18884 & 4,129 & $1.43 \mathrm{E}-01$ & 6,209 & $1.63 \mathrm{E}-01$ & $3.58 \mathrm{E}-09$ \\
\hline BKV6-37.12 & $<500$ & 90 & $5.6 \mathrm{E}-05$ & 15.29 & 9.00 & 0.480 & $9.46 \mathrm{E}-03$ & 323 & $1.23 \mathrm{E}-01$ & 1,479 & 0.179272 & 4,054 & $1.33 \mathrm{E}-01$ & 6,160 & $1.54 \mathrm{E}-01$ & $4.22 \mathrm{E}-09$ \\
\hline BKV6-37.13 & $<500$ & 90 & $5.8 \mathrm{E}-05$ & 16.48 & 9.00 & 0.478 & $9.42 \mathrm{E}-03$ & 330 & $1.31 \mathrm{E}-01$ & 1,485 & 0.187373 & 4,038 & $1.38 \mathrm{E}-01$ & 6,167 & $1.60 \mathrm{E}-01$ & $2.90 \mathrm{E}-09$ \\
\hline \multicolumn{17}{|l|}{ Exp \#38 } \\
\hline BKV6-38A & 42,880 & 90 & - & - & 9.00 & - & - & $<25$ & - & $<25$ & - & $<100$ & - & 42,880 & - & - \\
\hline BKV6-38.1 & 42,880 & 90 & $4.1 \mathrm{E}-05$ & 1.81 & 9.00 & 0.501 & $9.85 \mathrm{E}-03$ & 90 & $1.89 \mathrm{E}-02$ & 297 & $2.35 \mathrm{E}-02$ & 7,046 & $1.83 \mathrm{E}-01$ & 49,197 & $1.21 \mathrm{E}-01$ & $6.56 \mathrm{E}-08$ \\
\hline BKV6-38.2 & 42,880 & 90 & 4.7E-05 & 3.02 & 9.00 & 0.500 & $9.84 \mathrm{E}-03$ & 62 & $1.21 \mathrm{E}-02$ & 239 & $2.12 \mathrm{E}-02$ & 3,882 & $1.14 \mathrm{E}-01$ & 54,005 & $2.43 \mathrm{E}-01$ & 4.06E-08 \\
\hline BKV6-38.3 & 42,880 & 90 & 7.4E-05 & 4.01 & 9.00 & 0.500 & $9.84 \mathrm{E}-03$ & 56 & $1.60 \mathrm{E}-02$ & 262 & $3.68 \mathrm{E}-02$ & 3,158 & $1.45 \mathrm{E}-01$ & 49,370 & $2.22 \mathrm{E}-01$ & 5.13E-08 \\
\hline BKV6-38.6 & 42,880 & 90 & $6.0 \mathrm{E}-05$ & 4.89 & 9.00 & 0.499 & 9.83E-03 & 88 & $2.65 \mathrm{E}-02$ & 332 & $3.86 \mathrm{E}-02$ & 2,641 & $9.71 \mathrm{E}-02$ & 49,365 & $1.80 \mathrm{E}-01$ & $2.82 \mathrm{E}-08$ \\
\hline BKV6-38.7 & 42,880 & 90 & $6.0 \mathrm{E}-05$ & 6.84 & 9.00 & 0.498 & 9.81E-03 & 77 & $2.17 \mathrm{E}-02$ & 321 & $3.73 \mathrm{E}-02$ & 1,739 & $6.28 \mathrm{E}-02$ & 45,644 & $\begin{array}{l}7.68 \mathrm{E}-02 \\
\end{array}$ & $1.64 \mathrm{E}-08$ \\
\hline BKV6-38.10 & 42,880 & 90 & $6.0 \mathrm{E}-05$ & 8.71 & 9.00 & 0.498 & 9.80E-03 & 58 & $1.41 \mathrm{E}-02$ & 277 & $3.21 \mathrm{E}-02$ & 1,642 & $5.97 \mathrm{E}-02$ & 46,468 & $1.01 \mathrm{E}-01$ & $1.82 \mathrm{E}-08$ \\
\hline BKV6-38.11 & 42,880 & 90 & 4.3E-05 & 9.77 & 9.00 & 0.497 & 9.79E-03 & 57 & $9.76 \mathrm{E}-03$ & 283 & $2.34 \mathrm{E}-02$ & 1,806 & $4.71 \mathrm{E}-02$ & 47,592 & $9.42 \mathrm{E}-02$ & $1.49 \mathrm{E}-08$ \\
\hline BKV6-38.12 & 42,880 & 90 & $5.9 \mathrm{E}-05$ & 10.69 & 9.00 & 0.497 & $9.78 \mathrm{E}-03$ & 58 & $1.37 \mathrm{E}-02$ & 297 & $3.39 \mathrm{E}-02$ & 1,366 & $4.81 \mathrm{E}-02$ & 46,010 & $8.62 \mathrm{E}-02$ & $1.37 \mathrm{E}-08$ \\
\hline BKV6-38.13 & 42,880 & 90 & $6.2 \mathrm{E}-05$ & 11.88 & 9.00 & 0.496 & $9.77 \mathrm{E}-03$ & 69 & $1.94 \mathrm{E}-02$ & 332 & $4.03 \mathrm{E}-02$ & 1,141 & $4.16 \mathrm{E}-02$ & 47,785 & $1.42 \mathrm{E}-01$ & $8.85 \mathrm{E}-09$ \\
\hline \multicolumn{17}{|l|}{ Exp \#39 } \\
\hline BKV6-39A & $\begin{array}{ll}85,823 \\
\end{array}$ & 90 & - & - & 9.00 & - & - & $<25$ & - & $\begin{array}{c}<25 \\
\end{array}$ & - & $<100$ & - & 85,823 & - & \\
\hline BKV6-39.1 & 85,823 & 90 & $5.8 \mathrm{E}-06$ & 1.81 & 9.00 & 0.501 & 9.86E-03 & 31 & $2.55 \mathrm{E}-04$ & 112 & $1.06 \mathrm{E}-03$ & 4,414 & $1.60 \mathrm{E}-02$ & 88,331 & 6.73E-03 & $6.27 \mathrm{E}-09$ \\
\hline BKV6-39.2 & 85,823 & 90 & $5.1 \mathrm{E}-05$ & 3.02 & 9.00 & 0.501 & 9.86E-03 & 47 & $8.00 \mathrm{E}-03$ & 120 & 1.03E-02 & 9,270 & $3.01 \mathrm{E}-01$ & 93,284 & $1.77 \mathrm{E}-01$ & $1.17 \mathrm{E}-07$ \\
\hline BKV6-39.3 & 85,823 & 90 & $6.5 \mathrm{E}-05$ & 4.01 & 9.00 & 0.501 & 9.85E-03 & $<25$ & - & 93 & $\begin{array}{l}9.38 \mathrm{E}-03 \\
\end{array}$ & 3,673 & $1.49 \mathrm{E}-01$ & 90,571 & $1.44 \mathrm{E}-01$ & $6.27 \mathrm{E}-08$ \\
\hline BKV6-39.6 & 85,823 & 90 & $5.3 \mathrm{E}-05$ & 7.92 & 9.00 & 0.501 & $9.85 \mathrm{E}-03$ & 32 & $2.49 \mathrm{E}-03$ & 147 & $1.35 \mathrm{E}-02$ & 2,178 & 7.01E-02 & 89,016 & $7.81 \mathrm{E}-02$ & $2.70 \mathrm{E}-08$ \\
\hline BKV6-39.7 & 85,823 & 90 & $6.1 \mathrm{E}-05$ & 9.86 & 9.00 & 0.500 & 9.84E-03 & 47 & $9.47 \mathrm{E}-03$ & 117 & $1.18 \mathrm{E}-02$ & 1,258 & $4.53 \mathrm{E}-02$ & 86,851 & $2.92 \mathrm{E}-02$ & $1.43 \mathrm{E}-08$ \\
\hline BKV6-39.10 & 85,823 & 90 & $5.9 \mathrm{E}-05$ & 13.81 & 9.00 & 0.500 & 9.84E-03 & 31 & $2.39 \mathrm{E}-03$ & 87 & $\begin{array}{l}7.70 \mathrm{E}-03 \\
\end{array}$ & 1,240 & $4.30 \mathrm{E}-02$ & 90,959 & $1.40 \mathrm{E}-01$ & $1.62 \mathrm{E}-08$ \\
\hline BKV6-39.11 & 85,823 & 90 & $4.9 \mathrm{E}-05$ & 14.87 & 9.00 & 0.499 & 9.83E-03 & $<25$ & - & 67 & $4.30 \mathrm{E}-03$ & 1,602 & $4.74 \mathrm{E}-02$ & 92,136 & $1.44 \mathrm{E}-01$ & $2.05 \mathrm{E}-08$ \\
\hline BKV6-39.12 & 85,823 & 90 & $5.5 \mathrm{E}-05$ & 15.79 & 9.00 & 0.499 & 9.83E-03 & $<25$ & - & 139 & $1.32 \mathrm{E}-02$ & 1,895 & $6.32 \mathrm{E}-02$ & 89,557 & $9.53 \mathrm{E}-02$ & $2.54 \mathrm{E}-08$ \\
\hline BKV6-39.13 & 85,823 & 90 & $5.8 \mathrm{E}-05$ & 16.98 & 9.00 & 0.499 & 9.82E-03 & 41 & $6.71 \mathrm{E}-03$ & 210 & $2.25 \mathrm{E}-02$ & 1,576 & $5.47 \mathrm{E}-02$ & 90,950 & $1.38 \mathrm{E}-01$ & $1.92 \mathrm{E}-08$ \\
\hline & & & & & & & & & & & & & & & & \\
\hline & & & & & & & & & & & & & & & & \\
\hline & & & & & & & & & & & & & & & & \\
\hline & & & & & & & & & & & & & & & & \\
\hline & & & & & & & & & & & & & & & & \\
\hline
\end{tabular}


Table B1. SPFT Results for BKV6 Glass.

\begin{tabular}{|c|c|c|c|c|c|c|c|c|c|c|c|c|c|c|c|c|}
\hline Sample ID & \begin{tabular}{|c|}
$\begin{array}{c}\text { Influent } \\
{[\mathrm{Si}]}\end{array}$ \\
\end{tabular} & $\mathrm{T}\left({ }^{\circ} \mathrm{C}\right)$ & \begin{tabular}{c|}
$\begin{array}{c}\text { Flow Rate } \\
\left(\mathbf{m}^{3} / \mathbf{d}\right)\end{array}$ \\
\end{tabular} & Time, days & $\mathrm{pH}\left(23^{\circ} \mathrm{C}\right)$ & $\begin{array}{c}\text { Glass } \\
\text { Mass (g) }\end{array}$ & $\mathrm{SA}\left(\mathrm{m}^{2}\right)$ & [B] & B Rate & [Al] & Al Rate & {$[\mathrm{Na}]$} & Na Rate & {$[\mathrm{Si}]$} & Si Rate & IEX Rate \\
\hline \multicolumn{17}{|l|}{ Exp \#40 } \\
\hline BKV6-40A & 118,013 & 90 & - & - & 9.00 & - & - & $<25$ & - & $<25$ & - & $<100$ & - & 118,013 & - & - \\
\hline BKV6-40.1 & 118,013 & 90 & $4.6 \mathrm{E}-05$ & 1.81 & 9.00 & 1.000 & $1.97 \mathrm{E}-02$ & 66 & $6.63 \mathrm{E}-03$ & 83 & $2.82 \mathrm{E}-03$ & 10,337 & $1.50 \mathrm{E}-01$ & 132,984 & $1.59 \mathrm{E}-01$ & $5.74 \mathrm{E}-08$ \\
\hline BKV6-40.2 & 118,013 & 90 & $3.6 \mathrm{E}-05$ & 3.02 & 9.00 & 0.999 & $1.97 \mathrm{E}-02$ & $<25$ & - & 31 & $2.31 \mathrm{E}-04$ & 6,906 & $7.78 \mathrm{E}-02$ & 173,119 & 4.57E-01 & $3.18 \mathrm{E}-08$ \\
\hline BKV6-40.3 & 118,013 & 90 & $6.3 \mathrm{E}-05$ & 4.01 & 9.00 & 0.999 & $1.97 \mathrm{E}-02$ & $<25$ & - & 27 & $1.37 \mathrm{E}-04$ & $\begin{array}{ll}6,903 \\
\end{array}$ & $1.37 \mathrm{E}-01$ & 159,293 & 6.04E-01 & $5.70 \mathrm{E}-08$ \\
\hline BKV6-40.6 & 118,013 & 90 & $2.0 \mathrm{E}-06$ & 7.92 & 9.00 & 0.999 & $1.97 \mathrm{E}-02$ & 26 & 5.62E-06 & 140 & $2.38 \mathrm{E}-04$ & 10,665 & $6.67 \mathrm{E}-03$ & 140,770 & $1.04 \mathrm{E}-02$ & $2.66 \mathrm{E}-09$ \\
\hline BKV6-40.7 & \begin{tabular}{|l|}
118,013 \\
\end{tabular} & 90 & $9.0 \mathrm{E}-06$ & 9.86 & 9.00 & 0.999 & $1.97 \mathrm{E}-02$ & $<25$ & - & 100 & $7.10 \mathrm{E}-04$ & 8,832 & $2.52 \mathrm{E}-02$ & 129,165 & $2.33 \mathrm{E}-02$ & $1.02 \mathrm{E}-08$ \\
\hline BKV6-40.10 & 118,013 & 90 & $5.0 \mathrm{E}-05$ & 13.81 & 9.00 & 0.999 & $1.97 \mathrm{E}-02$ & $<25$ & - & - & - & 2,626 & $4.03 \mathrm{E}-02$ & 159,649 & $4.81 \mathrm{E}-01$ & - \\
\hline BKV6-40.11 & 118,013 & 90 & $6.8 \mathrm{E}-05$ & 14.87 & 9.00 & 0.999 & $1.97 \mathrm{E}-02$ & $<25$ & - & - & - & 3,647 & 7.72E-02 & 149,209 & $4.92 \mathrm{E}-01$ & - \\
\hline BKV6-40.12 & \begin{tabular}{|l|}
118,013 \\
\end{tabular} & 90 & $8.6 \mathrm{E}-05$ & 15.79 & 9.00 & 0.999 & $1.97 \mathrm{E}-02$ & $<25$ & - & 39 & $1.31 \mathrm{E}-03$ & 2,189 & $5.74 \mathrm{E}-02$ & 142,502 & 4.87E- 01 & - \\
\hline BKV6-40.13 & 118,013 & 90 & $9.3 \mathrm{E}-05$ & 16.98 & 9.00 & 0.999 & $1.97 \mathrm{E}-02$ & $<25$ & - & 46 & $2.08 \mathrm{E}-03$ & 2,041 & $5.81 \mathrm{E}-02$ & 154,490 & $7.92 \mathrm{E}-01$ & - \\
\hline \multicolumn{17}{|l|}{ Exp \#41 } \\
\hline BKV6-41A & 125,864 & 90 & - & - & 9.00 & - & - & $<25$ & - & $<25$ & - & $<100$ & - & 125,864 & - & - \\
\hline BKV6-41.1 & 125,864 & 90 & $4.6 \mathrm{E}-05$ & 1.81 & 9.00 & 0.999 & $1.97 \mathrm{E}-02$ & 41 & $2.54 \mathrm{E}-03$ & 73 & $2.30 \mathrm{E}-03$ & 9,583 & $1.39 \mathrm{E}-01$ & 148,424 & $2.39 \mathrm{E}-01$ & $5.43 \mathrm{E}-08$ \\
\hline BKV6-41.2 & 125,864 & 90 & $5.2 \mathrm{E}-05$ & 3.02 & 9.00 & 0.999 & $1.97 \mathrm{E}-02$ & $<25$ & - & - & - & 6,075 & $9.97 \mathrm{E}-02$ & 179,075 & $6.44 \mathrm{E}-01$ & $4.16 \mathrm{E}-08$ \\
\hline BKV6-41.3 & \begin{tabular}{|l|}
125,864 \\
\end{tabular} & 90 & $7.9 \mathrm{E}-05$ & 4.01 & 9.00 & 0.999 & $1.97 \mathrm{E}-02$ & $<25$ & - & - & - & 5,940 & $1.48 \mathrm{E}-01$ & 162,461 & $6.71 \mathrm{E}-01$ & - \\
\hline BKV6-41.6 & 125,864 & 90 & 7.3E-05 & 7.92 & 9.00 & 0.999 & $1.97 \mathrm{E}-02$ & $<25$ & - & 32 & $5.60 \mathrm{E}-04$ & 4,799 & 1.11E-01 & 157,102 & $5.34 \mathrm{E}-01$ & - \\
\hline BKV6-41.7 & 125,864 & 90 & $5.9 \mathrm{E}-05$ & 9.86 & 9.00 & 0.999 & $1.97 \mathrm{E}-02$ & $<25$ & - & 37 & 7.50E-04 & 3,212 & $5.94 \mathrm{E}-02$ & 161,707 & $4.96 \mathrm{E}-01$ & - \\
\hline BKV6-41.10 & 125,864 & 90 & $6.0 \mathrm{E}-05$ & 13.81 & 9.00 & 0.999 & $1.97 \mathrm{E}-02$ & $<25$ & - & 56 & $2.00 \mathrm{E}-03$ & 1,723 & $3.15 \mathrm{E}-02$ & 142,749 & $2.37 \mathrm{E}-01$ & - \\
\hline BKV6-41.11 & 125,864 & 90 & $6.1 \mathrm{E}-05$ & 14.87 & 9.00 & 0.999 & $1.97 \mathrm{E}-02$ & $<25$ & - & 84 & $3.79 \mathrm{E}-03$ & 2,209 & $4.15 \mathrm{E}-02$ & 143,476 & $2.51 \mathrm{E}-01$ & $1.74 \mathrm{E}-08$ \\
\hline BKV6-41.12 & 125,864 & 90 & $6.0 \mathrm{E}-05$ & 15.79 & 9.00 & 0.999 & $1.97 \mathrm{E}-02$ & $<25$ & - & 49 & $1.50 \mathrm{E}-03$ & 3,415 & $6.41 \mathrm{E}-02$ & 162,507 & 5.13E- 01 & $2.75 \mathrm{E}-08$ \\
\hline BKV6-41.13 & 125,864 & 90 & $5.6 \mathrm{E}-05$ & 16.98 & 9.00 & 0.999 & $1.97 \mathrm{E}-02$ & $<25$ & - & 52 & $1.62 \mathrm{E}-03$ & 3,141 & $5.47 \mathrm{E}-02$ & 172,336 & $6.06 \mathrm{E}-01$ & - \\
\hline \multicolumn{17}{|l|}{ Exp \#42 } \\
\hline BKV6-42A & \begin{tabular}{|l|}
134,759 \\
\end{tabular} & 90 & - & - & 9.00 & - & - & $<25$ & - & $<25$ & - & $<100$ & - & 134,759 & - & - \\
\hline BKV6-42.1 & 134,759 & 90 & $4.3 \mathrm{E}-05$ & 1.81 & 9.00 & 1.001 & $1.97 \mathrm{E}-02$ & 38 & $1.88 \mathrm{E}-03$ & 76 & $2.28 \mathrm{E}-03$ & 12,231 & $1.66 \mathrm{E}-01$ & 164,516 & $2.95 \mathrm{E}-01$ & $6.54 \mathrm{E}-08$ \\
\hline BKV6-42.2 & \begin{tabular}{|l|}
134,759 \\
\end{tabular} & 90 & $2.9 \mathrm{E}-05$ & 3.02 & 9.00 & 1.001 & $1.97 \mathrm{E}-02$ & $<25$ & - & 56 & $9.39 \mathrm{E}-04$ & 7,232 & $6.56 \mathrm{E}-02$ & 186,033 & $3.42 \mathrm{E}-01$ & $2.63 \mathrm{E}-08$ \\
\hline BKV6-42.3 & 134,759 & 90 & $6.4 \mathrm{E}-05$ & 4.01 & 9.00 & 1.001 & $1.97 \mathrm{E}-02$ & $<25$ & - & 36 & $7.75 \mathrm{E}-04$ & 7,342 & $1.49 \mathrm{E}-01$ & 167,316 & $4.86 \mathrm{E}-01$ & $6.05 \mathrm{E}-08$ \\
\hline BKV6-42.6 & 134,759 & 90 & $5.0 \mathrm{E}-08$ & 7.92 & 9.00 & 1.001 & $1.97 \mathrm{E}-02$ & $<25$ & - & - & - & - & - & - & - & - \\
\hline BKV6-42.7 & 134,759 & 90 & $4.8 \mathrm{E}-05$ & 9.86 & 9.00 & 1.001 & $1.97 \mathrm{E}-02$ & $<25$ & - & 26 & $3.02 \mathrm{E}-05$ & 5,076 & $7.71 \mathrm{E}-02$ & 162,062 & $3.07 \mathrm{E}-01$ & - \\
\hline BKV6-42.10 & \begin{tabular}{|l|}
134,759 \\
\end{tabular} & 90 & $6.0 \mathrm{E}-05$ & 13.81 & 9.00 & 1.001 & $1.97 \mathrm{E}-02$ & $<25$ & - & 46 & $1.30 \mathrm{E}-03$ & 2,124 & $3.91 \mathrm{E}-02$ & 151,852 & $2.39 \mathrm{E}-01$ & - \\
\hline BKV6-42.11 & 134,759 & 90 & $5.6 \mathrm{E}-05$ & 14.87 & 9.00 & 1.001 & $1.97 \mathrm{E}-02$ & $<25$ & - & 34 & $5.46 \mathrm{E}-04$ & 2,806 & $4.87 \mathrm{E}-02$ & 153,339 & $2.42 \mathrm{E}-01$ & - \\
\hline BKV6-42.12 & 134,759 & 90 & 5.7E-05 & 15.79 & 9.00 & 1.001 & $1.97 \mathrm{E}-02$ & $<25$ & - & 40 & $9.34 \mathrm{E}-04$ & 3,729 & $6.68 \mathrm{E}-02$ & 167,365 & $4.35 \mathrm{E}-01$ & - \\
\hline BKV6-42.13 & 134,759 & 90 & $6.3 \mathrm{E}-05$ & 16.98 & 9.00 & 1.001 & $1.97 \mathrm{E}-02$ & $<25$ & - & 35 & $6.29 \mathrm{E}-04$ & 3,097 & $6.02 \mathrm{E}-02$ & 178,323 & 6.35E-01 & - \\
\hline & & & & & & & & & & & & & & & & \\
\hline & & & & & & & & & & & & & & & & \\
\hline & & & & & & & & & & & & & & & & \\
\hline & & & & & & & & & & & & & & & & \\
\hline & & & & & & & & & & & & & & & & \\
\hline
\end{tabular}


Table B1. SPFT Results for BKV6 Glass.

\begin{tabular}{|c|c|c|c|c|c|c|c|c|c|c|c|c|c|c|c|c|}
\hline Sample ID & \begin{tabular}{|c|}
$\begin{array}{c}\text { Influent } \\
\text { [Si] }\end{array}$ \\
\end{tabular} & $\mathrm{T}\left({ }^{\circ} \mathrm{C}\right)$ & $\begin{array}{c}\begin{array}{c}\text { Flow Rate } \\
\left(\mathbf{m}^{3} / \mathbf{d}\right)\end{array} \\
\end{array}$ & Time, days & $\mathrm{pH}\left(23^{\circ} \mathrm{C}\right)$ & \begin{tabular}{|c|} 
Glass \\
Mass (g) \\
\end{tabular} & $\mathrm{SA}\left(\mathbf{m}^{2}\right)$ & {$[\mathrm{B}]$} & B Rate & [Al] & Al Rate & {$[\mathrm{Na}]$} & Na Rate & {$[\mathrm{Si}]$} & Si Rate & IEX Rate \\
\hline \multicolumn{17}{|l|}{ Exp\#43 } \\
\hline BKV6-43.A & 0 & 90 & - & - & 7.00 & - & - & $<500$ & - & $<10$ & - & $<50$ & - & $<1000$ & - & - \\
\hline BKV6-43.1 & 0 & 90 & 5.6E-05 & 1.08 & 7.00 & 0.496 & $9.77 \mathrm{E}-03$ & $<500$ & - & 73 & 7.38E-03 & 11,331 & $4.04 \mathrm{E}-01$ & 641 & - & $1.61 \mathrm{E}-07$ \\
\hline BKV6-43.2 & 0 & 90 & $5.8 \mathrm{E}-05$ & 2.32 & 7.00 & 0.492 & $9.71 \mathrm{E}-03$ & $<500$ & - & 76 & $8.15 \mathrm{E}-03$ & 7,371 & $2.76 \mathrm{E}-01$ & 463 & - & $1.10 \mathrm{E}-07$ \\
\hline BKV6-43.3 & 0 & 90 & $5.5 \mathrm{E}-05$ & 3.80 & 7.00 & 0.488 & $9.64 \mathrm{E}-03$ & $<500$ & - & 79 & $8.21 \mathrm{E}-03$ & 4,681 & $1.67 \mathrm{E}-01$ & 382 & - & $6.68 \mathrm{E}-08$ \\
\hline BKV6-43.4 & 0 & 90 & $5.9 \mathrm{E}-05$ & 4.95 & 7.00 & 0.485 & $9.56 \mathrm{E}-03$ & $<500$ & - & 68 & 7.49E-03 & 3,736 & $1.45 \mathrm{E}-01$ & 365 & - & 5.77E-08 \\
\hline BKV6-43.5 & 0 & 90 & $5.9 \mathrm{E}-05$ & 6.79 & 7.00 & 0.480 & 9.47E-03 & $<500$ & - & 62 & $\begin{array}{l}6.63 \mathrm{E}-03 \\
\end{array}$ & 2,956 & $1.14 \mathrm{E}-01$ & 315 & - & $4.55 \mathrm{E}-08$ \\
\hline BKV6-43.6 & 0 & 90 & $6.1 \mathrm{E}-05$ & 8.12 & 7.00 & 0.475 & $9.38 \mathrm{E}-03$ & $<500$ & - & 57 & $6.32 \mathrm{E}-03$ & 2,599 & $1.04 \mathrm{E}-01$ & 277 & - & $4.17 \mathrm{E}-08$ \\
\hline BKV6-43.7 & 0 & 90 & $5.6 \mathrm{E}-05$ & 10.00 & 7.00 & 0.470 & $9.28 \mathrm{E}-03$ & $<500$ & - & 61 & $6.44 \mathrm{E}-03$ & 2,255 & $8.43 \mathrm{E}-02$ & 213 & - & $3.37 \mathrm{E}-08$ \\
\hline BKV6-43.8 & 0 & 90 & $6.1 \mathrm{E}-05$ & 10.80 & 7.00 & 0.466 & $9.20 \mathrm{E}-03$ & $<500$ & - & 58 & $6.49 \mathrm{E}-03$ & 2,113 & $8.58 \mathrm{E}-02$ & 196 & - & 3.43E-08 \\
\hline BKV6-43.9 & 0 & 90 & 5.6E-05 & 10.95 & 7.00 & 0.465 & $9.16 \mathrm{E}-03$ & $<500$ & - & 74 & $8.11 \mathrm{E}-03$ & 2,032 & 7.64E-02 & - & - & 3.05E-08 \\
\hline BKV6-43.10 & 0 & 90 & 7.5E-05 & 11.09 & 7.00 & 0.465 & $9.15 \mathrm{E}-03$ & $<500$ & - & 68 & 9.83E-03 & 2,058 & $1.04 \mathrm{E}-01$ & 14 & - & 4.17E-08 \\
\hline \multicolumn{17}{|l|}{ Exp\#46 } \\
\hline BKV6-44.A & 0 & 90 & - & - & 8.00 & - & - & $<500$ & - & $<10$ & - & $<50$ & - & $<1000$ & - & - \\
\hline BKV6-44.1 & 0 & 90 & $5.6 \mathrm{E}-05$ & 1.08 & 8.00 & 0.495 & 9.75E-03 & $<500$ & - & 294 & $3.35 \mathrm{E}-02$ & $\begin{array}{ll}9,451 \\
\end{array}$ & $3.37 \mathrm{E}-01$ & 1,452 & $1.18 \mathrm{E}-02$ & $1.35 \mathrm{E}-07$ \\
\hline BKV6-44.2 & 0 & 90 & $5.6 \mathrm{E}-05$ & 2.32 & 8.00 & 0.491 & $9.70 \mathrm{E}-03$ & $<500$ & - & 381 & $4.42 \mathrm{E}-02$ & 6,409 & 2.31E-01 & 1,845 & $2.22 \mathrm{E}-02$ & $9.21 \mathrm{E}-08$ \\
\hline BKV6-44.3 & 0 & 90 & $5.6 \mathrm{E}-05$ & 3.80 & 8.00 & 0.487 & $9.62 \mathrm{E}-03$ & $<500$ & - & 405 & $4.75 \mathrm{E}-02$ & 4,603 & $1.67 \mathrm{E}-01$ & 1,851 & $2.26 \mathrm{E}-02$ & $6.66 \mathrm{E}-08$ \\
\hline BKV6-44.4 & 0 & 90 & $6.5 \mathrm{E}-05$ & 4.95 & 8.00 & 0.483 & $9.54 \mathrm{E}-03$ & $<500$ & - & 378 & 5.19E-02 & 3,603 & $1.53 \mathrm{E}-01$ & 1,774 & $2.41 \mathrm{E}-02$ & $6.10 \mathrm{E}-08$ \\
\hline BKV6-44.5 & 0 & 90 & $6.0 \mathrm{E}-05$ & 6.79 & 8.00 & 0.478 & $9.45 \mathrm{E}-03$ & $<500$ & - & 381 & $4.84 \mathrm{E}-02$ & 2,986 & $1.17 \mathrm{E}-01$ & 1,780 & $2.25 \mathrm{E}-02$ & 4.66E-08 \\
\hline BKV6-44.6 & 0 & 90 & $5.8 \mathrm{E}-05$ & 8.12 & 8.00 & 0.474 & $9.35 \mathrm{E}-03$ & $<500$ & - & 373 & 4.69E-02 & 2,706 & $1.04 \mathrm{E}-01$ & 1,714 & $2.04 \mathrm{E}-02$ & 4.17E-08 \\
\hline BKV6-44.7 & 0 & 90 & $5.8 \mathrm{E}-05$ & 10.00 & 8.00 & 0.469 & $9.26 \mathrm{E}-03$ & $<500$ & - & 361 & $4.58 \mathrm{E}-02$ & 2,390 & $9.31 \mathrm{E}-02$ & 1,413 & $1.19 \mathrm{E}-02$ & $3.72 \mathrm{E}-08$ \\
\hline BKV6-44.8 & 0 & 90 & $5.4 \mathrm{E}-05$ & 10.80 & 8.00 & 0.465 & $9.18 \mathrm{E}-03$ & $<500$ & - & 353 & $4.21 \mathrm{E}-02$ & 2,206 & $8.07 \mathrm{E}-02$ & 1,618 & $1.68 \mathrm{E}-02$ & $3.22 \mathrm{E}-08$ \\
\hline BKV6-44.9 & 0 & 90 & $7.8 \mathrm{E}-05$ & 10.95 & 8.00 & 0.464 & $9.14 \mathrm{E}-03$ & $<500$ & - & 360 & $6.16 \mathrm{E}-02$ & 2,205 & $1.16 \mathrm{E}-01$ & 1,679 & $2.64 \mathrm{E}-02$ & $4.61 \mathrm{E}-08$ \\
\hline BKV6-44.10 & 0 & 90 & $5.0 \mathrm{E}-05$ & 11.09 & 8.00 & 0.464 & $9.13 \mathrm{E}-03$ & $<500$ & - & 360 & $4.00 \mathrm{E}-02$ & 2,204 & 7.49E-02 & 1,447 & $1.13 \mathrm{E}-02$ & 2.99E-08 \\
\hline \multirow{2}{*}{\multicolumn{17}{|c|}{ Exp\#45 }} \\
\hline & & & & & & & & & & & & & & & & \\
\hline BKV6-45.A & 0 & 90 & - & - & 9.00 & - & - & $<500$ & - & 13 & - & $<50$ & - & $<1000$ & - & - \\
\hline BKV6-45.1 & 0 & 90 & 7.0E-05 & 1.08 & 9.00 & 0.497 & $9.78 \mathrm{E}-03$ & 281 & - & 1,153 & 1.69E-01 & 6,250 & 2.79E-01 & 5,108 & $1.34 \mathrm{E}-01$ & 4.24E-04 \\
\hline BKV6-45.2 & 0 & 90 & 5.8E-05 & 2.32 & 9.00 & 0.494 & $9.74 \mathrm{E}-03$ & 374 & - & 1,601 & $1.94 \mathrm{E}-01$ & 6,025 & 2.23E-01 & 6,939 & $1.60 \mathrm{E}-01$ & 6.03E-04 \\
\hline BKV6-45.3 & 0 & 90 & $5.7 \mathrm{E}-05$ & 3.80 & 9.00 & 0.491 & $9.68 \mathrm{E}-03$ & 358 & - & 1,601 & $1.94 \mathrm{E}-01$ & 5,335 & $1.96 \mathrm{E}-01$ & 6,908 & $1.59 \mathrm{E}-01$ & $6.03 \mathrm{E}-04$ \\
\hline BKV6-45.4 & 0 & 90 & $5.9 \mathrm{E}-05$ & 4.95 & 9.00 & 0.488 & 9.63E-03 & 376 & - & 1,603 & $2.01 \mathrm{E}-01$ & 5,177 & $1.97 \mathrm{E}-01$ & 7,092 & $1.70 \mathrm{E}-01$ & $6.04 \mathrm{E}-04$ \\
\hline BKV6-45.5 & 0 & 90 & $5.9 \mathrm{E}-05$ & 6.79 & 9.00 & 0.485 & $9.56 \mathrm{E}-03$ & 363 & - & 1,573 & 1.99E-01 & 5,063 & $1.95 \mathrm{E}-01$ & 6,949 & $1.68 \mathrm{E}-01$ & $5.92 \mathrm{E}-04$ \\
\hline BKV6-45.6 & 0 & 90 & $5.5 \mathrm{E}-05$ & 8.12 & 9.00 & 0.481 & $9.49 \mathrm{E}-03$ & 356 & - & 1,565 & $1.87 \mathrm{E}-01$ & 4,776 & 1.73E-01 & 6,868 & $1.56 \mathrm{E}-01$ & 5.89E-04 \\
\hline BKV6-45.7 & 0 & 90 & $6.2 \mathrm{E}-05$ & 10.00 & 9.00 & 0.478 & $9.42 \mathrm{E}-03$ & 352 & - & 1,530 & $2.07 \mathrm{E}-01$ & 4,778 & $1.97 \mathrm{E}-01$ & 6,838 & $1.76 \mathrm{E}-01$ & $5.75 \mathrm{E}-04$ \\
\hline BKV6-45.8 & 0 & 90 & $5.7 \mathrm{E}-05$ & 10.80 & 9.00 & 0.475 & $9.37 \mathrm{E}-03$ & 353 & - & 1,537 & $1.92 \mathrm{E}-01$ & 4,748 & $1.80 \mathrm{E}-01$ & 6,894 & $1.64 \mathrm{E}-01$ & 5.78E-04 \\
\hline BKV6-45.9 & 0 & 90 & $5.2 \mathrm{E}-05$ & 10.95 & 9.00 & 0.474 & $9.34 \mathrm{E}-03$ & 340 & - & 1,467 & $1.67 \mathrm{E}-01$ & 4,605 & $1.59 \mathrm{E}-01$ & 6,572 & $1.41 \mathrm{E}-01$ & $5.50 \mathrm{E}-04$ \\
\hline BKV6-45.10 & 0 & 90 & $3.1 \mathrm{E}-05$ & 11.09 & 9.00 & 0.474 & 9.33E-03 & 341 & - & 1,468 & $1.01 \mathrm{E}-01$ & 4,606 & $9.68 \mathrm{E}-02$ & 6,573 & $8.58 \mathrm{E}-02$ & $5.50 \mathrm{E}-04$ \\
\hline
\end{tabular}


Table B1. SPFT Results for BKV6 Glass.

\begin{tabular}{|c|c|c|c|c|c|c|c|c|c|c|c|c|c|c|c|c|}
\hline Sample ID & \begin{tabular}{|c|}
$\begin{array}{c}\text { Influent } \\
\text { [Si] }\end{array}$ \\
\end{tabular} & $\mathrm{T}\left({ }^{\circ} \mathrm{C}\right)$ & \begin{tabular}{|c}
$\begin{array}{c}\text { Flow Rate } \\
\left(\mathrm{m}^{3} / \mathbf{d}\right)\end{array}$ \\
\end{tabular} & Time, days & $\mathrm{pH}\left(23^{\circ} \mathrm{C}\right)$ & \begin{tabular}{|c|} 
Glass \\
Mass (g)
\end{tabular} & $\mathrm{SA}\left(\mathbf{m}^{2}\right)$ & [B] & B Rate & [Al] & Al Rate & [Na] & Na Rate & [Si] & Si Rate & IEX Rate \\
\hline \multicolumn{17}{|l|}{ Exp\#46 } \\
\hline BKV6-46.A & 0 & 90 & - & - & 10.00 & - & - & $<500$ & - & 13 & - & $<50$ & - & $<1000$ & - & - \\
\hline BKV6-46.1 & 0 & 90 & $5.8 \mathrm{E}-05$ & 1.08 & 10.00 & 0.500 & 9.85E-03 & 461 & - & 2,001 & $2.44 \mathrm{E}-01$ & 9,296 & $3.45 \mathrm{E}-01$ & 8,247 & $1.96 \mathrm{E}-01$ & $1.44 \mathrm{E}-07$ \\
\hline BKV6-46.2 & 0 & 90 & $5.9 \mathrm{E}-05$ & 2.32 & 10.00 & 0.496 & $9.79 \mathrm{E}-03$ & 577 & $3.23 \mathrm{E}-02$ & 2,477 & 3.09E-01 & 9,053 & $3.44 \mathrm{E}-01$ & 10,092 & $2.52 \mathrm{E}-01$ & $1.25 \mathrm{E}-07$ \\
\hline BKV6-46.3 & 0 & 90 & $5.6 \mathrm{E}-05$ & 3.80 & 10.00 & 0.491 & $9.70 \mathrm{E}-03$ & 599 & $3.97 \mathrm{E}-02$ & 2,636 & $3.14 \mathrm{E}-01$ & 8,309 & $3.01 \mathrm{E}-01$ & 10,497 & $2.51 \mathrm{E}-01$ & $1.04 \mathrm{E}-07$ \\
\hline BKV6-46.4 & 0 & 90 & $6.0 \mathrm{E}-05$ & 4.95 & 10.00 & 0.487 & $9.61 \mathrm{E}-03$ & 606 & $4.60 \mathrm{E}-02$ & 2,591 & 3.35E-01 & 8,155 & $3.21 \mathrm{E}-01$ & 10,552 & $2.74 \mathrm{E}-01$ & $1.10 \mathrm{E}-07$ \\
\hline BKV6-46.5 & 0 & 90 & $5.8 \mathrm{E}-05$ & 6.79 & 10.00 & 0.481 & $9.50 \mathrm{E}-03$ & 587 & $3.69 \mathrm{E}-02$ & 2,577 & $3.26 \mathrm{E}-01$ & 8,177 & $3.14 \mathrm{E}-01$ & 10,336 & $2.62 \mathrm{E}-01$ & $1.11 \mathrm{E}-07$ \\
\hline BKV6-46.6 & 0 & 90 & $5.9 \mathrm{E}-05$ & 8.12 & 10.00 & 0.475 & $9.39 \mathrm{E}-03$ & 569 & $3.01 \mathrm{E}-02$ & 2,450 & 3.19E-01 & 7,455 & $2.95 \mathrm{E}-01$ & 10,005 & $2.60 \mathrm{E}-01$ & $1.06 \mathrm{E}-07$ \\
\hline BKV6-46.7 & 0 & 90 & 5.7E-05 & 10.00 & 10.00 & 0.470 & $9.28 \mathrm{E}-03$ & 566 & $2.84 \mathrm{E}-02$ & 2,491 & $3.16 \mathrm{E}-01$ & 7,178 & $2.77 \mathrm{E}-01$ & 10,094 & $2.56 \mathrm{E}-01$ & 9.93E-08 \\
\hline BKV6-46.8 & 0 & 90 & $5.8 \mathrm{E}-05$ & 10.80 & 10.00 & 0.466 & 9.19E-03 & 615 & $5.05 \mathrm{E}-02$ & 2,477 & $3.24 \mathrm{E}-01$ & 7,037 & $2.80 \mathrm{E}-01$ & 10,545 & $2.77 \mathrm{E}-01$ & 9.17E-08 \\
\hline BKV6-46.9 & 0 & 90 & $5.5 \mathrm{E}-05$ & 10.95 & 10.00 & 0.464 & $9.14 \mathrm{E}-03$ & 615 & $4.80 \mathrm{E}-02$ & 2,425 & 3.02E-01 & 7,406 & $2.81 \mathrm{E}-01$ & 10,586 & $2.65 \mathrm{E}-01$ & $9.29 \mathrm{E}-08$ \\
\hline BKV6-46.10 & 0 & 90 & $6.0 \mathrm{E}-05$ & 11.09 & 10.00 & 0.464 & $9.13 \mathrm{E}-03$ & 610 & $5.02 \mathrm{E}-02$ & 2,425 & 3.29E-01 & 7,395 & $3.05 \mathrm{E}-01$ & 10,617 & $2.90 \mathrm{E}-01$ & $1.02 \mathrm{E}-07$ \\
\hline \multicolumn{17}{|l|}{ Exp \#47 } \\
\hline BKV6-47.A & 0 & 90 & - & - & 11.00 & - & - & $<500$ & - & 23 & - & $<50$ & - & $<1000$ & - & - \\
\hline BKV6-47.1 & 0 & 90 & $5.7 \mathrm{E}-05$ & 1.08 & 11.00 & 0.501 & 9.89E-03 & 1,232 & 2.92E-01 & 5,236 & $6.23 \mathrm{E}-01$ & 19,007 & 6.89E-01 & 21,822 & 5.49E-01 & 1.59E-07 \\
\hline BKV6-47.2 & 0 & 90 & $5.6 \mathrm{E}-05$ & 2.32 & 11.00 & 0.491 & $9.72 \mathrm{E}-03$ & 1,583 & $4.30 \mathrm{E}-01$ & 6,341 & $7.51 \mathrm{E}-01$ & 20,720 & $7.48 \mathrm{E}-01$ & 26,339 & $6.65 \mathrm{E}-01$ & $1.27 \mathrm{E}-07$ \\
\hline BKV6-47.3 & 0 & 90 & $5.9 \mathrm{E}-05$ & 3.80 & 11.00 & 0.478 & 9.49E-03 & 1,494 & 4.27E-01 & 5,989 & 7.67E-01 & 18,166 & 7.09E-01 & 25,257 & 6.88E-01 & 1.13E-07 \\
\hline BKV6-47.4 & 0 & 90 & $5.8 \mathrm{E}-05$ & 4.95 & 11.00 & 0.467 & $9.26 \mathrm{E}-03$ & 1,433 & 4.07E-01 & 5,828 & 7.57E-01 & 18,073 & 7.16E-01 & 23,781 & $6.56 \mathrm{E}-01$ & $1.23 \mathrm{E}-07$ \\
\hline BKV6-47.5 & 0 & 90 & $5.7 \mathrm{E}-05$ & 6.79 & 11.00 & 0.453 & $9.01 \mathrm{E}-03$ & 1,371 & $3.85 \mathrm{E}-01$ & 5,506 & $7.25 \mathrm{E}-01$ & 16,893 & $6.78 \mathrm{E}-01$ & 22,773 & $6.35 \mathrm{E}-01$ & $1.17 \mathrm{E}-07$ \\
\hline BKV6-47.6 & 0 & 90 & $6.0 \mathrm{E}-05$ & 8.12 & 11.00 & 0.441 & $8.76 \mathrm{E}-03$ & 1,334 & 3.93E-01 & 5,310 & 7.45E-01 & 16,638 & 7.12E-01 & 22,178 & 6.59E-01 & $1.27 \mathrm{E}-07$ \\
\hline BKV6-47.7 & 0 & 90 & $5.9 \mathrm{E}-05$ & 10.00 & 11.00 & 0.426 & $8.48 \mathrm{E}-03$ & 1,463 & $4.64 \mathrm{E}-01$ & 5,815 & $8.34 \mathrm{E}-01$ & 17,646 & 7.72E-01 & 23,950 & $7.29 \mathrm{E}-01$ & $1.23 \mathrm{E}-07$ \\
\hline BKV6-47.8 & 0 & 90 & $5.8 \mathrm{E}-05$ & 10.80 & 11.00 & 0.415 & $8.24 \mathrm{E}-03$ & 1,571 & 5.23E-01 & 5,928 & 8.63E-01 & 19,000 & $8.43 \mathrm{E}-01$ & 25,585 & 7.93E-01 & $1.28 \mathrm{E}-07$ \\
\hline BKV6-47.9 & 0 & 90 & $5.1 \mathrm{E}-05$ & 10.95 & 11.00 & 0.412 & $8.13 \mathrm{E}-03$ & 1,541 & $4.48 \mathrm{E}-01$ & 5,582 & 7.16E-01 & 18,557 & $7.26 \mathrm{E}-01$ & 24,787 & $6.76 \mathrm{E}-01$ & $1.11 \mathrm{E}-07$ \\
\hline BKV6-47.10 & 0 & 90 & $4.6 \mathrm{E}-05$ & 11.09 & 11.00 & 0.411 & $8.09 \mathrm{E}-03$ & 1,532 & 4.04E-01 & 5,569 & 6.49E-01 & 18,412 & $6.54 \mathrm{E}-01$ & 24,709 & 6.13E-01 & $1.00 \mathrm{E}-07$ \\
\hline \multicolumn{17}{|l|}{$\underline{\operatorname{Exp} \# 48}$} \\
\hline BKV6-48.A & 0 & 90 & - & - & 12.00 & - & - & $<500$ & - & 76 & - & $<50$ & - & $<1000$ & - & - \\
\hline BKV6-48.1 & 0 & 90 & $5.6 \mathrm{E}-05$ & 1.08 & 12.00 & 0.489 & $9.68 \mathrm{E}-03$ & 2,486 & $7.88 \mathrm{E}-01$ & 10,310 & $1.22 \mathrm{E}+00$ & 31,612 & $1.14 \mathrm{E}+00$ & 41,957 & $1.07 \mathrm{E}+00$ & $1.41 \mathrm{E}-07$ \\
\hline BKV6-48.2 & 0 & 90 & $5.7 \mathrm{E}-05$ & 2.32 & 12.00 & 0.465 & $9.30 \mathrm{E}-03$ & 3,851 & $1.43 \mathrm{E}+00$ & 15,856 & $2.01 \mathrm{E}+00$ & 46,636 & $1.80 \mathrm{E}+00$ & 62,863 & $1.74 \mathrm{E}+00$ & $1.52 \mathrm{E}-07$ \\
\hline BKV6-48.3 & 0 & 90 & $5.9 \mathrm{E}-05$ & 3.80 & 12.00 & 0.432 & $8.70 \mathrm{E}-03$ & 3,925 & $1.61 \mathrm{E}+00$ & 15,707 & $2.20 \mathrm{E}+00$ & 47,210 & $2.02 \mathrm{E}+00$ & 62,745 & $1.91 \mathrm{E}+00$ & $1.63 \mathrm{E}-07$ \\
\hline BKV6-48.4 & 0 & 90 & $6.0 \mathrm{E}-05$ & 4.95 & 12.00 & 0.401 & $8.08 \mathrm{E}-03$ & 3,956 & $1.79 \mathrm{E}+00$ & 15,646 & $2.41 \mathrm{E}+00$ & 50,347 & $2.37 \mathrm{E}+00$ & 62,134 & $2.08 \mathrm{E}+00$ & $2.32 \mathrm{E}-07$ \\
\hline BKV6-48.5 & 0 & 90 & $5.6 \mathrm{E}-05$ & 6.79 & 12.00 & 0.364 & $7.40 \mathrm{E}-03$ & 3,780 & $1.73 \mathrm{E}+00$ & 14,642 & $2.30 \mathrm{E}+00$ & 47,625 & $2.28 \mathrm{E}+00$ & 58,656 & $2.01 \mathrm{E}+00$ & $2.22 \mathrm{E}-07$ \\
\hline BKV6-48.6 & 0 & 90 & $6.1 \mathrm{E}-05$ & 8.12 & 12.00 & 0.331 & $6.72 \mathrm{E}-03$ & 3,484 & $1.86 \mathrm{E}+00$ & 13,701 & $2.55 \mathrm{E}+00$ & 43,418 & $2.47 \mathrm{E}+00$ & 54,614 & $2.21 \mathrm{E}+00$ & $2.41 \mathrm{E}-07$ \\
\hline BKV6-48.7 & 0 & 90 & $5.7 \mathrm{E}-05$ & 10.00 & 12.00 & 0.297 & $6.06 \mathrm{E}-03$ & 3,289 & $1.81 \mathrm{E}+00$ & 12,789 & $2.46 \mathrm{E}+00$ & 40,208 & $2.37 \mathrm{E}+00$ & 53,089 & $2.23 \mathrm{E}+00$ & $2.25 \mathrm{E}-07$ \\
\hline BKV6-48.8 & 0 & 90 & $5.8 \mathrm{E}-05$ & 10.80 & 12.00 & 0.275 & $5.56 \mathrm{E}-03$ & 3,005 & $1.81 \mathrm{E}+00$ & 12,371 & $2.65 \mathrm{E}+00$ & 37,869 & $2.48 \mathrm{E}+00$ & 49,350 & $2.30 \mathrm{E}+00$ & $2.70 \mathrm{E}-07$ \\
\hline BKV6-48.9 & 0 & 90 & $6.8 \mathrm{E}-05$ & 10.95 & 12.00 & 0.268 & $5.33 \mathrm{E}-03$ & 2,842 & $2.08 \mathrm{E}+00$ & 11,102 & $2.93 \mathrm{E}+00$ & 34,551 & $2.79 \mathrm{E}+00$ & 46,139 & $2.65 \mathrm{E}+00$ & $2.84 \mathrm{E}-07$ \\
\hline BKV6-48.10 & 0 & 90 & $8.2 \mathrm{E}-05$ & 11.09 & 12.00 & 0.265 & $5.24 \mathrm{E}-03$ & 2,854 & $2.56 \mathrm{E}+00$ & 11,261 & $3.64 \mathrm{E}+00$ & 35,657 & $3.52 \mathrm{E}+00$ & 46,723 & $3.28 \mathrm{E}+00$ & $3.86 \mathrm{E}-07$ \\
\hline
\end{tabular}


Table B2. SPFT Results for Castable Refractory (BKVM).

\begin{tabular}{|c|c|c|c|c|c|c|c|c|c|c|c|}
\hline Sample ID & $\begin{array}{c}\text { Influent } \\
{[\mathrm{Si}]}\end{array}$ & $\begin{array}{c}\mathrm{T} \\
\left({ }^{\circ} \mathrm{C}\right) \\
\end{array}$ & $\begin{array}{c}\text { Flow } \\
\text { Rate } \\
\left(\mathrm{m}^{3} / \mathbf{d}\right)\end{array}$ & $\begin{array}{c}\text { Time, } \\
\text { days }\end{array}$ & $\begin{array}{c}\mathbf{p H} \\
\left(23^{\circ} \mathrm{C}\right)\end{array}$ & $\begin{array}{c}\text { Glass } \\
\text { Mass (g) }\end{array}$ & $\mathrm{SA}\left(\mathrm{m}^{2}\right)$ & [Al] & Al Rate & [Si] & Si Rate \\
\hline \multicolumn{12}{|l|}{ BKVM } \\
\hline \multicolumn{12}{|l|}{ Exp \#1 } \\
\hline BKVM-7.A & 0 & 23 & - & - & 7.00 & - & - & $<25$ & - & $<500$ & \\
\hline BKVM-7.1 & 0 & 23 & $2.1 \mathrm{E}-05$ & 1.86 & 7.00 & 1.007 & $1.33 \mathrm{E}+00$ & 135 & $4.58 \mathrm{E}-06$ & 712 & $2.55 \mathrm{E}-05$ \\
\hline BKVM-7.3 & 0 & 23 & $2.7 \mathrm{E}-05$ & 4.81 & 7.00 & 1.006 & $1.33 \mathrm{E}+00$ & 92 & $3.64 \mathrm{E}-06$ & 975 & 7.39E-05 \\
\hline BKVM-7.7 & 0 & 23 & $1.6 \mathrm{E}-05$ & 6.97 & 7.00 & 1.006 & $1.33 \mathrm{E}+00$ & 105 & $2.52 \mathrm{E}-06$ & 720 & $1.99 \mathrm{E}-05$ \\
\hline BKVM-7.10 & 0 & 23 & $1.4 \mathrm{E}-05$ & 9.04 & 7.00 & 1.006 & $1.33 \mathrm{E}+00$ & 97 & $2.00 \mathrm{E}-06$ & 507 & $5.87 \mathrm{E}-07$ \\
\hline BKVM-7.14 & 0 & 23 & $1.7 \mathrm{E}-05$ & 11.88 & 7.00 & 1.005 & $1.33 \mathrm{E}+00$ & 113 & $2.89 \mathrm{E}-06$ & 333 & - \\
\hline BKVM-7.16 & 0 & 23 & $3.0 \mathrm{E}-05$ & 18.05 & 7.00 & 1.005 & $1.33 \mathrm{E}+00$ & 102 & $4.65 \mathrm{E}-06$ & 236 & - \\
\hline BKVM-7.17 & 0 & 23 & $1.9 \mathrm{E}-05$ & 23.79 & 7.00 & 1.005 & $1.33 \mathrm{E}+00$ & 113 & $3.25 \mathrm{E}-06$ & 192 & - \\
\hline BKVM-7.18 & 0 & 23 & $7.4 \mathrm{E}-06$ & 25.95 & 7.00 & 1.005 & $1.33 \mathrm{E}+00$ & 111 & $1.25 \mathrm{E}-06$ & 204 & - \\
\hline \multicolumn{12}{|l|}{ Exp \#2 } \\
\hline BKVM-8.A & 0 & 23 & - & - & 8.00 & - & - & $<25$ & - & $<500$ & - \\
\hline BKVM-8.1 & 0 & 23 & $2.1 \mathrm{E}-05$ & 1.86 & 8.00 & 1.002 & $1.32 \mathrm{E}+00$ & 1,156 & $4.69 \mathrm{E}-05$ & 351 & - \\
\hline BKVM-8.3 & 0 & 23 & $2.9 \mathrm{E}-05$ & 4.81 & 8.00 & 1.002 & $1.32 \mathrm{E}+00$ & 1,066 & 5.99E-05 & 736 & 3.91E-05 \\
\hline BKVM-8.7 & 0 & 23 & $1.6 \mathrm{E}-05$ & 6.97 & 8.00 & 1.001 & $1.32 \mathrm{E}+00$ & 1,028 & $3.18 \mathrm{E}-05$ & 960 & $4.20 \mathrm{E}-05$ \\
\hline BKVM-8.10 & 0 & 23 & $1.5 \mathrm{E}-05$ & 9.04 & 8.00 & 1.001 & $1.32 \mathrm{E}+00$ & 848 & $2.43 \mathrm{E}-05$ & 897 & 3.38E-05 \\
\hline BKVM-8.14 & 0 & 23 & $1.8 \mathrm{E}-05$ & 11.88 & 8.00 & 1.000 & $1.32 \mathrm{E}+00$ & 851 & $2.89 \mathrm{E}-05$ & 725 & $2.27 \mathrm{E}-05$ \\
\hline BKVM-8.16 & 0 & 23 & 3.1E-05 & 18.05 & 8.00 & 0.999 & $1.32 \mathrm{E}+00$ & 874 & 5.33E-05 & 547 & $8.52 \mathrm{E}-06$ \\
\hline BKVM-8.17 & 0 & 23 & $1.9 \mathrm{E}-05$ & 23.79 & 8.00 & 0.999 & $1.32 \mathrm{E}+00$ & 976 & $3.67 \mathrm{E}-05$ & 443 & - \\
\hline BKVM-8.18 & 0 & 23 & $7.8 \mathrm{E}-06$ & 25.95 & 8.00 & 0.998 & $1.32 \mathrm{E}+00$ & 1,042 & $1.57 \mathrm{E}-05$ & 433 & - \\
\hline \multicolumn{12}{|l|}{ Exp \#3 } \\
\hline BKVM-9.A & 0 & 23 & - & - & 9.00 & - & - & 60 & - & $<500$ & - \\
\hline BKVM-9.1 & 0 & 23 & $1.9 \mathrm{E}-05$ & 1.86 & 9.00 & 0.506 & $6.68 \mathrm{E}-01$ & 8,765 & $6.64 \mathrm{E}-04$ & 666 & $3.65 \mathrm{E}-05$ \\
\hline BKVM-9.3 & 0 & 23 & $2.9 \mathrm{E}-05$ & 4.81 & 9.00 & 0.505 & 6.67E-01 & 4,651 & $5.23 \mathrm{E}-04$ & 1,582 & $3.55 \mathrm{E}-04$ \\
\hline BKVM-9.7 & 0 & 23 & 1.6E-05 & 6.97 & 9.00 & 0.504 & $6.66 \mathrm{E}-01$ & 3,217 & 1.96E-04 & 1,605 & $1.98 \mathrm{E}-04$ \\
\hline BKVM-9.10 & 0 & 23 & $1.5 \mathrm{E}-05$ & 9.04 & 9.00 & 0.503 & 6.65E-01 & 3,138 & $1.80 \mathrm{E}-04$ & 1,454 & $1.61 \mathrm{E}-04$ \\
\hline BKVM-9.14 & 0 & 23 & $1.8 \mathrm{E}-05$ & 11.88 & 9.00 & 0.503 & 6.64E-01 & 2,772 & $1.90 \mathrm{E}-04$ & 1,186 & $1.39 \mathrm{E}-04$ \\
\hline BKVM-9.16 & 0 & 23 & $3.1 \mathrm{E}-05$ & 18.05 & 9.00 & 0.502 & 6.63E-01 & 2,246 & $2.65 \mathrm{E}-04$ & 1,013 & $1.80 \mathrm{E}-04$ \\
\hline BKVM-9.17 & 0 & 23 & $1.9 \mathrm{E}-05$ & 23.79 & 9.00 & 0.500 & 6.61E-01 & 2,258 & $1.64 \mathrm{E}-04$ & 1,337 & $1.80 \mathrm{E}-04$ \\
\hline BKVM-9.18 & 0 & 23 & $7.2 \mathrm{E}-06$ & 25.95 & 9.00 & 0.499 & $6.59 \mathrm{E}-01$ & 2,074 & 5.79E-05 & 1,129 & $5.21 \mathrm{E}-05$ \\
\hline
\end{tabular}


Table B2. SPFT Results for Castable Refractory (BKVM).

\begin{tabular}{|c|c|c|c|c|c|c|c|c|c|c|c|}
\hline Sample ID & $\begin{array}{c}\text { Influent } \\
\text { [Si] }\end{array}$ & $\begin{array}{c}\mathrm{T} \\
\left({ }^{\circ} \mathrm{C}\right)\end{array}$ & $\begin{array}{c}\text { Flow } \\
\text { Ratat } \\
\left(\mathbf{m}^{3} / \mathbf{d}\right)\end{array}$ & $\begin{array}{l}\text { Time, } \\
\text { days }\end{array}$ & $\begin{array}{c}\mathrm{pH} \\
\left(23^{\circ} \mathrm{C}\right)\end{array}$ & $\begin{array}{l}\text { Glass } \\
\text { Mass (g) }\end{array}$ & SA $\left(m^{2}\right)$ & [Al] & Al Rate & [Si] & Si Rate \\
\hline \multicolumn{12}{|l|}{ Exp \#4 } \\
\hline BKVM-10.A & 0 & 23 & - & - & 10.00 & - & - & 29 & - & $<500$ & - \\
\hline BKVM-10.1 & 0 & 23 & $2.1 \mathrm{E}-05$ & 1.86 & 10.00 & 0.5031 & $6.65 \mathrm{E}-01$ & 11,511 & $9.48 \mathrm{E}-04$ & 2,972 & $5.88 \mathrm{E}-04$ \\
\hline BKVM-10.3 & 0 & 23 & 2.9E-05 & 4.81 & 10.00 & 0.5003 & $6.62 \mathrm{E}-01$ & 9,410 & $1.08 \mathrm{E}-03$ & 5,323 & $1.59 \mathrm{E}-03$ \\
\hline BKVM-10.7 & 0 & 23 & 1.6E-05 & 6.97 & 10.00 & 0.4981 & $6.58 \mathrm{E}-01$ & 7,659 & $4.81 \mathrm{E}-04$ & 3,400 & $5.27 \mathrm{E}-04$ \\
\hline BKVM-10.10 & 0 & 23 & $1.5 \mathrm{E}-05$ & 9.04 & 10.00 & 0.4966 & $6.56 \mathrm{E}-01$ & 5,572 & $3.27 \mathrm{E}-04$ & 2,891 & $4.06 \mathrm{E}-04$ \\
\hline BKVM-10.14 & 0 & 23 & $1.8 \mathrm{E}-05$ & 11.88 & 10.00 & 0.4957 & $6.55 \mathrm{E}-01$ & 2,069 & $1.44 \mathrm{E}-04$ & 1,024 & $1.07 \mathrm{E}-04$ \\
\hline BKVM-10.16 & 0 & 23 & $3.1 \mathrm{E}-05$ & 18.05 & 10.00 & 0.4948 & $\begin{array}{l}6.54 \mathrm{E}-01 \\
\end{array}$ & 1,093 & $1.32 \mathrm{E}-04$ & 743 & $8.71 \mathrm{E}-05$ \\
\hline BKVM-10.17 & 0 & 23 & $1.9 \mathrm{E}-05$ & 23.79 & 10.00 & 0.4930 & $\begin{array}{l}6.52 \mathrm{E}-01 \\
\end{array}$ & 1,603 & $1.21 \mathrm{E}-04$ & $\begin{array}{ll}1,687 \\
\end{array}$ & $2.62 \mathrm{E}-04$ \\
\hline BKVM-10.18 & 0 & 23 & 7.8E-06 & 25.95 & 10.00 & 0.4915 & $6.49 \mathrm{E}-01$ & 1,264 & $3.91 \mathrm{E}-05$ & 1,980 & $1.35 \mathrm{E}-04$ \\
\hline \multicolumn{12}{|l|}{ Exp \#5 } \\
\hline BKVM-11.A & 0 & 23 & - & - & 11.00 & - & - & 48 & - & 947 & - \\
\hline BKVM-11.1 & 0 & 23 & 2.1E-05 & 1.86 & 11.00 & 0.5002 & 6.61E-01 & 17,313 & $1.41 \mathrm{E}-03$ & 6,292 & $1.26 \mathrm{E}-03$ \\
\hline BKVM-11.3 & 0 & 23 & $2.9 \mathrm{E}-05$ & 4.81 & 11.00 & 0.4955 & $6.56 \mathrm{E}-01$ & 13,942 & $1.60 \mathrm{E}-03$ & 8,474 & $2.50 \mathrm{E}-03$ \\
\hline BKVM-11.7 & 0 & 23 & $1.6 \mathrm{E}-05$ & 6.97 & 11.00 & 0.4920 & $6.51 \mathrm{E}-01$ & 9,031 & $5.73 \mathrm{E}-04$ & 5,059 & $7.57 \mathrm{E}-04$ \\
\hline BKVM-11.10 & 0 & 23 & $1.5 \mathrm{E}-05$ & 9.04 & 11.00 & 0.4896 & $6.47 \mathrm{E}-01$ & 5,748 & $3.38 \mathrm{E}-04$ & 5,236 & $7.33 \mathrm{E}-04$ \\
\hline BKVM-11.14 & 0 & 23 & $1.7 \mathrm{E}-05$ & 11.88 & 11.00 & 0.4866 & $6.44 \mathrm{E}-01$ & 1,927 & $1.34 \mathrm{E}-04$ & 5,120 & $8.59 \mathrm{E}-04$ \\
\hline BKVM-11.16 & 0 & 23 & 3.0E-05 & 18.05 & 11.00 & 0.4814 & 6.38E-01 & 980 & $1.15 \mathrm{E}-04$ & 4,524 & $1.27 \mathrm{E}-03$ \\
\hline BKVM-11.17 & 0 & 23 & 1.9E-05 & 23.79 & 11.00 & 0.4729 & $6.28 \mathrm{E}-01$ & 773 & $5.71 \mathrm{E}-05$ & 7,252 & $1.43 \mathrm{E}-03$ \\
\hline BKVM-11.18 & 0 & 23 & $7.6 \mathrm{E}-06$ & 25.95 & 11.00 & 0.4672 & 6.19E-01 & 641 & $1.91 \mathrm{E}-05$ & 7,557 & $6.14 \mathrm{E}-04$ \\
\hline \multicolumn{12}{|l|}{ Exp \#6 } \\
\hline BKVM-12.A & $\overline{0}$ & 23 & - & - & 12.00 & - & - & 65 & - & 1,111 & - \\
\hline BKVM-12.1 & 0 & 23 & $2.1 \mathrm{E}-05$ & 1.86 & 12.00 & 0.5028 & $6.65 \mathrm{E}-01$ & 23,890 & $1.93 \mathrm{E}-03$ & 11,139 & $2.35 \mathrm{E}-03$ \\
\hline BKVM-12.3 & 0 & 23 & $2.9 \mathrm{E}-05$ & 4.81 & 12.00 & 0.4948 & $6.57 \mathrm{E}-01$ & 20,991 & $2.43 \mathrm{E}-03$ & 14,464 & $4.47 \mathrm{E}-03$ \\
\hline BKVM-12.7 & 0 & 23 & 1.6E-05 & 6.97 & 12.00 & 0.4862 & $6.46 \mathrm{E}-01$ & 6,718 & $4.30 \mathrm{E}-04$ & 16,406 & $2.85 \mathrm{E}-03$ \\
\hline BKVM-12.10 & 0 & 23 & $1.5 \mathrm{E}-05$ & 9.04 & 12.00 & 0.4783 & $6.35 \mathrm{E}-01$ & 3,069 & $1.82 \mathrm{E}-04$ & 16,893 & $2.75 \mathrm{E}-03$ \\
\hline BKVM-12.14 & 0 & 23 & $1.8 \mathrm{E}-05$ & 11.88 & 12.00 & 0.4710 & $6.25 \mathrm{E}-01$ & 1,249 & $8.78 \mathrm{E}-05$ & 11,080 & $2.13 \mathrm{E}-03$ \\
\hline BKVM-12.16 & 0 & 23 & $2.5 \mathrm{E}-05$ & 18.05 & 12.00 & 0.4609 & $6.13 \mathrm{E}-01$ & 958 & $9.76 \mathrm{E}-05$ & 9,796 & $2.74 \mathrm{E}-03$ \\
\hline BKVM-12.17 & $\overline{0}$ & 23 & $1.9 \mathrm{E}-05$ & 23.79 & 12.00 & 0.4500 & $5.99 \mathrm{E}-01$ & 766 & $5.80 \mathrm{E}-05$ & 8,015 & $1.65 \mathrm{E}-03$ \\
\hline BKVM-12.18 & 0 & 23 & 7.6E-06 & 25.95 & 12.00 & 0.4441 & 5.89E-01 & 704 & $2.17 \mathrm{E}-05$ & 7,293 & $6.06 \mathrm{E}-04$ \\
\hline & & & & & & & & & & & \\
\hline & & & & & & & & & & & \\
\hline
\end{tabular}


Table B2. SPFT Results for Castable Refractory (BKVM).

\begin{tabular}{|c|c|c|c|c|c|c|c|c|c|c|c|}
\hline Sample ID & $\begin{array}{c}\text { Influent } \\
\text { [Si] }\end{array}$ & $\begin{array}{c}\mathrm{T} \\
\left({ }^{\circ} \mathrm{C}\right) \\
\end{array}$ & $\begin{array}{c}\text { Flow } \\
\text { Rate } \\
\left(\mathrm{m}^{3} / \mathbf{d}\right)\end{array}$ & $\begin{array}{c}\text { Time, } \\
\text { days }\end{array}$ & $\begin{array}{c}\mathbf{p H} \\
\left(23^{\circ} \mathrm{C}\right)\end{array}$ & $\begin{array}{c}\text { Glass } \\
\text { Mass (g) }\end{array}$ & $\mathrm{SA}\left(\mathrm{m}^{2}\right)$ & [Al] & Al Rate & [Si] & Si Rate \\
\hline \multicolumn{12}{|l|}{ Exp \#7 } \\
\hline BKVM-19.A & 0 & 40 & - & - & 7.00 & - & - & $<25$ & - & $<500$ & - \\
\hline BKVM-19.1 & 0 & 40 & $4.4 \mathrm{E}-05$ & 0.77 & 7.00 & 0.9999 & $1.32 \mathrm{E}+00$ & 55 & 2.63E-06 & 380 & - \\
\hline BKVM-19.2 & 0 & 40 & $4.1 \mathrm{E}-05$ & 4.95 & 7.00 & 0.9987 & $1.32 \mathrm{E}+00$ & 41 & $1.33 \mathrm{E}-06$ & 883 & $9.09 \mathrm{E}-05$ \\
\hline BKVM-19.3 & 0 & 40 & $4.1 \mathrm{E}-05$ & 7.95 & 7.00 & 0.9971 & $1.32 \mathrm{E}+00$ & 42 & $1.37 \mathrm{E}-06$ & 1,061 & $1.34 \mathrm{E}-04$ \\
\hline BKVM-19.6 & 0 & 40 & $4.1 \mathrm{E}-05$ & 14.01 & 7.00 & 0.9965 & $1.32 \mathrm{E}+00$ & 39 & $1.19 \mathrm{E}-06$ & 461 & - \\
\hline BKVM-19.7 & 0 & 40 & $4.1 \mathrm{E}-05$ & 14.96 & 7.00 & 0.9962 & $1.32 \mathrm{E}+00$ & 41 & $1.30 \mathrm{E}-06$ & 503 & $7.03 \mathrm{E}-07$ \\
\hline BKVM-19.8 & 0 & 40 & $4.1 \mathrm{E}-05$ & 16.78 & 7.00 & 0.9958 & $1.31 \mathrm{E}+00$ & 37 & $1.02 \mathrm{E}-06$ & 545 & $1.07 \mathrm{E}-05$ \\
\hline BKVM-19.9 & 0 & 40 & $4.1 \mathrm{E}-05$ & 17.95 & 7.00 & 0.9955 & $1.31 \mathrm{E}+00$ & 32 & $6.13 \mathrm{E}-07$ & 600 & $2.38 \mathrm{E}-05$ \\
\hline BKVM-19.10 & 0 & 40 & $4.1 \mathrm{E}-05$ & 18.83 & 7.00 & 0.9952 & $1.31 \mathrm{E}+00$ & 48 & $1.88 \mathrm{E}-06$ & 634 & 3.17E-05 \\
\hline BKVM-19.11 & 0 & 40 & $3.5 \mathrm{E}-05$ & 20.81 & 7.00 & 0.9948 & $1.31 \mathrm{E}+00$ & 31 & $4.38 \mathrm{E}-07$ & 635 & $2.72 \mathrm{E}-05$ \\
\hline \multicolumn{12}{|l|}{$\underline{\operatorname{Exp} \# 8}$} \\
\hline BKVM-20.A & 0 & 40 & - & - & 8.00 & - & - & $<25$ & - & $<500$ & - \\
\hline BKVM-20.1 & 0 & 40 & 4.6E-05 & 0.77 & 8.00 & 0.9999 & $1.32 \mathrm{E}+00$ & 633 & 5.56E-05 & 375 & - \\
\hline BKVM-20.2 & 0 & 40 & $4.0 \mathrm{E}-05$ & 4.95 & 8.00 & 0.9986 & $1.32 \mathrm{E}+00$ & 696 & 5.42E-05 & 950 & 1.05E-04 \\
\hline BKVM-20.3 & 0 & 40 & $4.1 \mathrm{E}-05$ & 7.95 & 8.00 & 0.9971 & $1.32 \mathrm{E}+00$ & 626 & $4.88 \mathrm{E}-05$ & 984 & 1.13E-04 \\
\hline BKVM-20.6 & 0 & 40 & $4.0 \mathrm{E}-05$ & 14.01 & 8.00 & 0.9964 & $1.32 \mathrm{E}+00$ & 721 & $5.64 \mathrm{E}-05$ & 589 & $2.08 \mathrm{E}-05$ \\
\hline BKVM-20.7 & 0 & 40 & $4.0 \mathrm{E}-05$ & 14.96 & 8.00 & 0.9962 & $1.32 \mathrm{E}+00$ & 754 & $5.88 \mathrm{E}-05$ & 532 & $7.38 \mathrm{E}-06$ \\
\hline BKVM-20.8 & 0 & 40 & $4.0 \mathrm{E}-05$ & 16.78 & 8.00 & 0.9958 & $1.31 \mathrm{E}+00$ & 784 & $6.14 \mathrm{E}-05$ & 465 & - \\
\hline BKVM-20.9 & 0 & 40 & $4.0 \mathrm{E}-05$ & 17.95 & 8.00 & 0.9956 & $1.31 \mathrm{E}+00$ & 807 & $6.31 \mathrm{E}-05$ & 396 & - \\
\hline BKVM-20.10 & 0 & 40 & $4.0 \mathrm{E}-05$ & 18.83 & 8.00 & 0.9954 & $1.31 \mathrm{E}+00$ & 842 & $6.62 \mathrm{E}-05$ & 370 & - \\
\hline BKVM-20.11 & 0 & 40 & $3.5 \mathrm{E}-05$ & 20.81 & 8.00 & 0.9952 & $1.31 \mathrm{E}+00$ & 831 & 5.63E-05 & 333 & - \\
\hline \multicolumn{12}{|l|}{ Exp \#9 } \\
\hline BKVM-21.A & 0 & 40 & - & - & 9.00 & - & - & $<25$ & - & $<500$ & - \\
\hline BKVM-21.1 & 0 & 40 & $4.0 \mathrm{E}-05$ & 0.77 & 9.00 & 0.4990 & 6.59E-01 & 2,218 & $3.50 \mathrm{E}-04$ & 152 & - \\
\hline BKVM-21.2 & 0 & 40 & $4.1 \mathrm{E}-05$ & 4.95 & 9.00 & 0.4986 & $6.58 \mathrm{E}-01$ & 2,426 & 3.89E-04 & 304 & - \\
\hline BKVM-21.3 & 0 & 40 & $4.1 \mathrm{E}-05$ & 7.95 & 9.00 & 0.4978 & $6.57 \mathrm{E}-01$ & 1,785 & $2.87 \mathrm{E}-04$ & 580 & $3.74 \mathrm{E}-05$ \\
\hline BKVM-21.6 & 0 & 40 & $4.1 \mathrm{E}-05$ & 14.01 & 9.00 & 0.4973 & $6.57 \mathrm{E}-01$ & 1,933 & $3.11 \mathrm{E}-04$ & 620 & $5.65 \mathrm{E}-05$ \\
\hline BKVM-21.7 & 0 & 40 & $4.1 \mathrm{E}-05$ & 14.96 & 9.00 & 0.4970 & 6.56E-01 & 2,147 & $3.46 \mathrm{E}-04$ & 675 & $8.20 \mathrm{E}-05$ \\
\hline BKVM-21.8 & 0 & 40 & $4.1 \mathrm{E}-05$ & 16.78 & 9.00 & 0.4965 & 6.56E-01 & 2,157 & $3.47 \mathrm{E}-04$ & 668 & 7.87E-05 \\
\hline BKVM-21.9 & 0 & 40 & $4.1 \mathrm{E}-05$ & 17.95 & 9.00 & 0.4961 & $6.55 \mathrm{E}-01$ & 2,153 & $3.46 \mathrm{E}-04$ & 662 & $7.61 \mathrm{E}-05$ \\
\hline BKVM-21.10 & 0 & 40 & $4.1 \mathrm{E}-05$ & 18.83 & 9.00 & 0.4958 & 6.55E-01 & 2,531 & $4.10 \mathrm{E}-04$ & 824 & $1.53 \mathrm{E}-04$ \\
\hline
\end{tabular}


Table B2. SPFT Results for Castable Refractory (BKVM).

\begin{tabular}{|c|c|c|c|c|c|c|c|c|c|c|c|}
\hline Sample ID & $\begin{array}{c}\text { Influent } \\
\text { [Si] }\end{array}$ & $\begin{array}{c}\mathrm{T} \\
\left({ }^{\circ} \mathrm{C}\right)\end{array}$ & $\begin{array}{c}\text { Flow } \\
\text { Rate } \\
\left(\mathbf{m}^{3} / \mathbf{d}\right)\end{array}$ & $\begin{array}{l}\text { Time, } \\
\text { days }\end{array}$ & $\begin{array}{c}\mathrm{pH} \\
\left(23^{\circ} \mathrm{C}\right)\end{array}$ & $\begin{array}{c}\text { Glass } \\
\text { Mass (g) }\end{array}$ & $\mathrm{SA}\left(\mathrm{m}^{2}\right)$ & [Al] & Al Rate & [Si] & Si Rate \\
\hline BKVM-21.11 & 0 & 40 & $3.5 \mathrm{E}-05$ & 20.81 & 9.00 & 0.4952 & $6.54 \mathrm{E}-01$ & 2,700 & $3.73 \mathrm{E}-04$ & 982 & $1.94 \mathrm{E}-04$ \\
\hline \multicolumn{12}{|l|}{ Exp \#10 } \\
\hline BKVM-22.A & 0 & 40 & - & - & 10.00 & - & - & $<25$ & - & $<500$ & - \\
\hline BKVM-22.1 & 0 & 40 & 4.3E-05 & 0.77 & 10.00 & 0.4989 & 6.59E-01 & 3,827 & $6.55 \mathrm{E}-04$ & 315 & - \\
\hline BKVM-22.2 & 0 & 40 & $4.1 \mathrm{E}-05$ & 4.95 & 10.00 & 0.4973 & 6.57E-01 & 4,435 & 7.30E-04 & 1,170 & $3.20 \mathrm{E}-04$ \\
\hline BKVM-22.3 & 0 & 40 & $4.1 \mathrm{E}-05$ & 7.95 & 10.00 & 0.4951 & $6.55 \mathrm{E}-01$ & 3,625 & 5.99E-04 & 1,546 & $5.01 \mathrm{E}-04$ \\
\hline BKVM-22.6 & $\overline{0}$ & 40 & $4.1 \mathrm{E}-05$ & 14.01 & 10.00 & 0.4939 & $6.52 \mathrm{E}-01$ & 3,348 & $5.53 \mathrm{E}-04$ & 1,381 & $4.23 \mathrm{E}-04$ \\
\hline BKVM-22.7 & 0 & 40 & $4.1 \mathrm{E}-05$ & 14.96 & 10.00 & 0.4932 & $6.51 \mathrm{E}-01$ & 3,291 & $5.46 \mathrm{E}-04$ & 1,419 & $4.43 \mathrm{E}-04$ \\
\hline BKVM-22.8 & 0 & 40 & $4.1 \mathrm{E}-05$ & 16.78 & 10.00 & 0.4922 & 6.50E-01 & 2,958 & 4.89E-04 & 1,349 & 4.08E-04 \\
\hline BKVM-22.9 & 0 & 40 & $4.1 \mathrm{E}-05$ & 17.95 & 10.00 & 0.4913 & 6.49E-01 & 2,846 & 4.72E-04 & 1,384 & 4.26E-04 \\
\hline BKVM-22.10 & 0 & 40 & $4.1 \mathrm{E}-05$ & 18.83 & 10.00 & 0.4907 & 6.48E-01 & 3,026 & $5.02 \mathrm{E}-04$ & 1,550 & $5.06 \mathrm{E}-04$ \\
\hline BKVM-22.11 & 0 & 40 & 3.5E-05 & 20.81 & 10.00 & 0.4896 & 6.47E-01 & 2,735 & $3.81 \mathrm{E}-04$ & 1,555 & 4.27E-04 \\
\hline \multicolumn{12}{|l|}{ Exp\#11 } \\
\hline BKVM-23.A & 0 & 40 & & & 11.00 & - & - & $<25$ & - & $<500$ & - \\
\hline BKVM-23.1 & 0 & 40 & $4.4 \mathrm{E}-05$ & 0.77 & 11.00 & 0.4987 & $6.58 \mathrm{E}-01$ & 6,759 & $1.20 \mathrm{E}-03$ & 1,047 & $2.80 \mathrm{E}-04$ \\
\hline BKVM-23.2 & 0 & 40 & $4.1 \mathrm{E}-05$ & 4.95 & 11.00 & 0.4966 & $6.56 \mathrm{E}-01$ & 5,083 & $8.22 \mathrm{E}-04$ & 1,547 & $4.90 \mathrm{E}-04$ \\
\hline BKVM-23.3 & 0 & 40 & $4.1 \mathrm{E}-05$ & 7.95 & 11.00 & 0.4940 & $6.53 \mathrm{E}-01$ & 4,012 & $6.55 \mathrm{E}-04$ & 1,697 & $5.67 \mathrm{E}-04$ \\
\hline BKVM-23.6 & 0 & 40 & $4.1 \mathrm{E}-05$ & 14.01 & 11.00 & 0.4926 & 6.51E-01 & 3,974 & 6.49E-04 & 1,691 & $5.64 \mathrm{E}-04$ \\
\hline BKVM-23.7 & 0 & 40 & $4.1 \mathrm{E}-05$ & 14.96 & 11.00 & 0.4918 & $6.50 \mathrm{E}-01$ & 4,117 & $6.75 \mathrm{E}-04$ & 1,922 & $6.76 \mathrm{E}-04$ \\
\hline BKVM-23.8 & 0 & 40 & $4.1 \mathrm{E}-05$ & 16.78 & 11.00 & 0.4904 & $6.48 \mathrm{E}-01$ & 3,601 & 5.89E-04 & 1,842 & $6.37 \mathrm{E}-04$ \\
\hline BKVM-23.9 & 0 & 40 & $4.1 \mathrm{E}-05$ & 17.95 & 11.00 & 0.4892 & $6.46 \mathrm{E}-01$ & 3,419 & $5.62 \mathrm{E}-04$ & 1,923 & $6.79 \mathrm{E}-04$ \\
\hline BKVM-23.10 & 0 & 40 & $4.1 \mathrm{E}-05$ & 18.83 & 11.00 & 0.4879 & $6.45 \mathrm{E}-01$ & 5,897 & $9.73 \mathrm{E}-04$ & 3,733 & $1.54 \mathrm{E}-03$ \\
\hline BKVM-23.11 & 0 & 40 & $3.5 \mathrm{E}-05$ & 20.81 & 11.00 & 0.4855 & $6.42 \mathrm{E}-01$ & 4,918 & $7.02 \mathrm{E}-04$ & $\begin{array}{ll}3,568 \\
\end{array}$ & $1.27 \mathrm{E}-03$ \\
\hline \multicolumn{12}{|l|}{ Exp \#12 } \\
\hline BKVM-24.A & 0 & 40 & - & - & 12.00 & - & - & $<25$ & - & $<500$ & - \\
\hline BKVM-24.1 & 0 & 40 & $4.7 \mathrm{E}-05$ & 0.77 & 12.00 & 0.4974 & $6.57 \mathrm{E}-01$ & 7,607 & $1.43 \mathrm{E}-03$ & 2,195 & $9.24 \mathrm{E}-04$ \\
\hline BKVM-24.2 & 0 & 40 & $4.1 \mathrm{E}-05$ & 4.95 & 12.00 & 0.4925 & 6.52E-01 & 10,081 & $1.67 \mathrm{E}-03$ & 3,542 & $1.45 \mathrm{E}-03$ \\
\hline BKVM-24.3 & 0 & 40 & $4.1 \mathrm{E}-05$ & 7.95 & 12.00 & 0.4861 & $6.44 \mathrm{E}-01$ & 8,109 & $1.36 \mathrm{E}-03$ & 4,337 & $1.86 \mathrm{E}-03$ \\
\hline BKVM-24.6 & $\overline{0}$ & 40 & $4.1 \mathrm{E}-05$ & 14.01 & 12.00 & 0.4808 & $6.37 \mathrm{E}-01$ & 3,330 & $5.61 \mathrm{E}-04$ & 8,885 & $4.10 \mathrm{E}-03$ \\
\hline BKVM-24.7 & 0 & 40 & $4.0 \mathrm{E}-05$ & 14.96 & 12.00 & 0.4762 & $6.31 \mathrm{E}-01$ & 3,123 & $5.17 \mathrm{E}-04$ & 10,180 & $4.66 \mathrm{E}-03$ \\
\hline BKVM-24.8 & 0 & 40 & $4.1 \mathrm{E}-05$ & 16.78 & 12.00 & 0.4686 & $6.22 \mathrm{E}-01$ & 2,555 & 4.39E-04 & 10,793 & $5.15 \mathrm{E}-03$ \\
\hline BKVM-24.9 & 0 & 40 & $4.1 \mathrm{E}-05$ & 17.95 & 12.00 & 0.4617 & $6.12 \mathrm{E}-01$ & 2,205 & $3.84 \mathrm{E}-04$ & 10,696 & $5.17 \mathrm{E}-03$ \\
\hline
\end{tabular}


Table B2. SPFT Results for Castable Refractory (BKVM).

\begin{tabular}{|c|c|c|c|c|c|c|c|c|c|c|c|}
\hline Sample ID & $\begin{array}{c}\text { Influent } \\
\text { [Si] }\end{array}$ & $\begin{array}{c}\mathrm{T} \\
\left({ }^{\circ} \mathrm{C}\right) \\
\end{array}$ & $\begin{array}{c}\text { Flow } \\
\text { Rate } \\
\left(\mathbf{m}^{3} / \mathbf{d}\right)\end{array}$ & $\begin{array}{l}\text { Time, } \\
\text { days }\end{array}$ & $\begin{array}{c}\mathbf{p H} \\
\left(23^{\circ} \mathrm{C}\right)\end{array}$ & $\begin{array}{c}\text { Glass } \\
\text { Mass (g) } \\
\end{array}$ & SA $\left(m^{2}\right)$ & [Al] & Al Rate & [Si] & Si Rate \\
\hline BKVM-24.10 & 0 & 40 & $4.1 \mathrm{E}-05$ & 18.83 & 12.00 & 0.4557 & $6.04 \mathrm{E}-01$ & 2,986 & $5.30 \mathrm{E}-04$ & 15,026 & 7.49E-03 \\
\hline BKVM-24.11 & 0 & 40 & $3.5 \mathrm{E}-05$ & 20.81 & 12.00 & 0.4467 & 5.94E-01 & 3,264 & 4.99E-04 & 13,223 & $5.65 \mathrm{E}-03$ \\
\hline \multicolumn{12}{|l|}{ Exp\#13 } \\
\hline BKVM-31.A & 0 & 70 & - & - & 7.00 & - & - & $<25$ & - & $<500$ & - \\
\hline BKVM-31.1 & 0 & 70 & $5.6 \mathrm{E}-05$ & 2.01 & 7.00 & 0.5032 & 6.65E-01 & 137 & $2.47 \mathrm{E}-05$ & 1,714 & 7.73E-04 \\
\hline BKVM-31.2 & 0 & 70 & $5.9 \mathrm{E}-05$ & 2.84 & 7.00 & 0.5022 & $6.63 \mathrm{E}-01$ & 148 & $2.86 \mathrm{E}-05$ & 1,827 & $8.88 \mathrm{E}-04$ \\
\hline BKVM-31.3 & $\overline{0}$ & 70 & $5.5 \mathrm{E}-05$ & 3.06 & 7.00 & 0.5017 & $6.62 \mathrm{E}-01$ & 85 & $1.30 \mathrm{E}-05$ & 1,944 & $9.10 \mathrm{E}-04$ \\
\hline BKVM-31.6 & 0 & 70 & $5.6 \mathrm{E}-05$ & 4.22 & 7.00 & 0.5007 & $6.61 \mathrm{E}-01$ & 45 & 4.53E-06 & 1,719 & 7.87E-04 \\
\hline BKVM-31.7 & 0 & 70 & $5.4 \mathrm{E}-05$ & 6.94 & 7.00 & 0.4985 & $6.59 \mathrm{E}-01$ & 32 & $1.51 \mathrm{E}-06$ & 1,581 & $6.72 \mathrm{E}-04$ \\
\hline BKVM-31.8 & 0 & 70 & $5.6 \mathrm{E}-05$ & 8.20 & 7.00 & 0.4970 & $6.57 \mathrm{E}-01$ & 36 & 2.36E-06 & 1,200 & $4.50 \mathrm{E}-04$ \\
\hline BKVM-31.9 & 0 & 70 & $5.5 \mathrm{E}-05$ & 9.88 & 7.00 & 0.4959 & $6.55 \mathrm{E}-01$ & 32 & 1.49E-06 & 1,089 & $3.75 \mathrm{E}-04$ \\
\hline BKVM-31.10 & 0 & 70 & $5.9 \mathrm{E}-05$ & 10.94 & 7.00 & 0.4951 & 6.54E-01 & 39 & $3.42 \mathrm{E}-06$ & 986 & 3.30E-04 \\
\hline BKVM-31.11 & 0 & 70 & $4.8 \mathrm{E}-05$ & 11.23 & 7.00 & 0.4948 & $6.53 \mathrm{E}-01$ & 44 & $3.75 \mathrm{E}-06$ & 970 & $2.63 \mathrm{E}-04$ \\
\hline \multicolumn{12}{|l|}{ Exp \#14 } \\
\hline BKVM-31.A & 0 & 70 & - & - & 8.00 & - & - & $<25$ & - & $<500$ & - \\
\hline BKVM-32.1 & 0 & 70 & $5.6 \mathrm{E}-05$ & 2.01 & 8.00 & 0.5033 & $6.65 \mathrm{E}-01$ & 1,582 & 3.44E-04 & 1,515 & $6.46 \mathrm{E}-04$ \\
\hline BKVM-32.2 & 0 & 70 & $5.9 \mathrm{E}-05$ & 2.84 & 8.00 & 0.5023 & $6.64 \mathrm{E}-01$ & 1,515 & $3.46 \mathrm{E}-04$ & 1,811 & $8.77 \mathrm{E}-04$ \\
\hline BKVM-32.3 & 0 & 70 & 5.5E-05 & 3.06 & 8.00 & 0.5018 & 6.63E-01 & 1,471 & $3.16 \mathrm{E}-04$ & 1,693 & 7.52E-04 \\
\hline BKVM-32.6 & 0 & 70 & 5.6E-05 & 4.22 & 8.00 & 0.5012 & 6.62E-01 & 1,173 & $2.57 \mathrm{E}-04$ & 1,075 & $3.71 \mathrm{E}-04$ \\
\hline BKVM-32.7 & 0 & 70 & $5.4 \mathrm{E}-05$ & 6.94 & 8.00 & 0.4998 & $6.60 \mathrm{E}-01$ & 1,012 & $2.13 \mathrm{E}-04$ & 1,061 & $3.48 \mathrm{E}-04$ \\
\hline BKVM-32.8 & 0 & 70 & $5.6 \mathrm{E}-05$ & 8.20 & 8.00 & 0.4987 & 6.59E-01 & 888 & $1.92 \mathrm{E}-04$ & 946 & $2.86 \mathrm{E}-04$ \\
\hline BKVM-32.9 & 0 & 70 & $5.5 \mathrm{E}-05$ & 9.88 & 8.00 & 0.4978 & $6.58 \mathrm{E}-01$ & 760 & $1.62 \mathrm{E}-04$ & 826 & $2.07 \mathrm{E}-04$ \\
\hline BKVM-32.10 & 0 & 70 & $5.9 \mathrm{E}-05$ & 10.94 & 8.00 & 0.4972 & $6.57 \mathrm{E}-01$ & 668 & $1.51 \mathrm{E}-04$ & 788 & $1.95 \mathrm{E}-04$ \\
\hline BKVM-32.11 & 0 & 70 & $4.8 \mathrm{E}-05$ & 11.23 & 8.00 & 0.4969 & $6.56 \mathrm{E}-01$ & 665 & $1.24 \mathrm{E}-04$ & 793 & $1.63 \mathrm{E}-04$ \\
\hline Exp\#15 & & & & & & & & 295 & & & \\
\hline BKVM-33.A & 0 & 70 & - & - & 9.00 & - & - & & - & 551 & - \\
\hline BKVM-33.1 & 0 & 70 & $5.5 \mathrm{E}-05$ & 2.01 & 9.00 & 0.4987 & 6.59E-01 & 11,587 & $2.46 \mathrm{E}-03$ & 3,026 & $1.56 \mathrm{E}-03$ \\
\hline BKVM-33.2 & 0 & 70 & $5.4 \mathrm{E}-05$ & 2.84 & 9.00 & 0.4966 & $6.56 \mathrm{E}-01$ & 8,566 & $1.80 \mathrm{E}-03$ & 4,289 & $2.34 \mathrm{E}-03$ \\
\hline BKVM-33.3 & $\overline{0}$ & 70 & $3.8 \mathrm{E}-05$ & 3.06 & 9.00 & 0.4956 & $6.55 \mathrm{E}-01$ & 7,838 & $1.16 \mathrm{E}-03$ & 3,983 & $1.52 \mathrm{E}-03$ \\
\hline BKVM-33.6 & 0 & 70 & $5.4 \mathrm{E}-05$ & 4.22 & 9.00 & 0.4938 & $6.53 \mathrm{E}-01$ & 4,371 & $8.89 \mathrm{E}-04$ & 3,484 & $1.84 \mathrm{E}-03$ \\
\hline BKVM-33.7 & 0 & 70 & $5.3 \mathrm{E}-05$ & 6.94 & 9.00 & 0.4892 & $6.48 \mathrm{E}-01$ & 2,972 & $5.81 \mathrm{E}-04$ & 3,402 & $1.78 \mathrm{E}-03$ \\
\hline BKVM-33.8 & 0 & 70 & $5.6 \mathrm{E}-05$ & 8.20 & 9.00 & 0.4856 & 6.43E-01 & 2,045 & 3.99E-04 & 3,283 & $1.80 \mathrm{E}-03$ \\
\hline
\end{tabular}


Table B2. SPFT Results for Castable Refractory (BKVM).

\begin{tabular}{|c|c|c|c|c|c|c|c|c|c|c|c|}
\hline Sample ID & $\begin{array}{c}\text { Influent } \\
\text { [Si] }\end{array}$ & $\begin{array}{c}\mathrm{T} \\
\left({ }^{\circ} \mathrm{C}\right)\end{array}$ & $\begin{array}{c}\text { Flow } \\
\text { Rate } \\
\left(\mathbf{m}^{3} / \mathbf{d}\right)\end{array}$ & $\begin{array}{l}\text { Time, } \\
\text { days }\end{array}$ & $\begin{array}{c}\mathrm{pH} \\
\left(23^{\circ} \mathrm{C}\right)\end{array}$ & $\begin{array}{c}\text { Glass } \\
\text { Mass (g) }\end{array}$ & $\mathrm{SA}\left(\mathrm{m}^{2}\right)$ & [Al] & Al Rate & [Si] & Si Rate \\
\hline BKVM-33.9 & 0 & 70 & $5.4 \mathrm{E}-05$ & 9.88 & 9.00 & 0.4826 & $6.38 \mathrm{E}-01$ & 1,623 & $2.98 \mathrm{E}-04$ & 3,068 & $1.63 \mathrm{E}-03$ \\
\hline BKVM-33.10 & 0 & 70 & $5.9 \mathrm{E}-05$ & 10.94 & 9.00 & 0.4803 & $6.35 \mathrm{E}-01$ & 1,200 & $2.20 \mathrm{E}-04$ & 2,550 & $1.40 \mathrm{E}-03$ \\
\hline BKVM-33.11 & 0 & 70 & $5.1 \mathrm{E}-05$ & 11.23 & 9.00 & 0.4794 & 6.33E-01 & 1,245 & $2.00 \mathrm{E}-04$ & 2,781 & $1.35 \mathrm{E}-03$ \\
\hline \multicolumn{12}{|l|}{ Exp\#16 } \\
\hline BKVM-34.A & 0 & 70 & - & - & 10.00 & - & - & 26 & - & $<500$ & - \\
\hline BKVM-34.1 & 0 & 70 & $5.7 \mathrm{E}-05$ & 2.01 & 10.00 & 0.4957 & $6.55 \mathrm{E}-01$ & 15,388 & $3.51 \mathrm{E}-03$ & 4,991 & $2.96 \mathrm{E}-03$ \\
\hline BKVM-34.2 & $\overline{0}$ & 70 & $5.8 \mathrm{E}-05$ & 2.84 & 10.00 & 0.4924 & $6.51 \mathrm{E}-01$ & 12,754 & $2.98 \mathrm{E}-03$ & 5,979 & $3.70 \mathrm{E}-03$ \\
\hline BKVM-34.3 & 0 & 70 & $5.6 \mathrm{E}-05$ & 3.06 & 10.00 & 0.4908 & 6.49E-01 & 12,135 & $2.76 \mathrm{E}-03$ & 5,701 & $3.42 \mathrm{E}-03$ \\
\hline BKVM-34.6 & 0 & 70 & $5.7 \mathrm{E}-05$ & 4.22 & 10.00 & 0.4851 & 6.43E-01 & 3,309 & 7.63E-04 & 10,938 & $6.99 \mathrm{E}-03$ \\
\hline BKVM-34.7 & 0 & 70 & $5.2 \mathrm{E}-05$ & 6.94 & 10.00 & 0.4692 & $6.26 \mathrm{E}-01$ & 1,990 & 4.33E-04 & 12,139 & 7.39E-03 \\
\hline BKVM-34.8 & 0 & 70 & $5.6 \mathrm{E}-05$ & 8.20 & 10.00 & 0.4569 & $6.08 \mathrm{E}-01$ & 1,532 & 3.67E-04 & 10,737 & 7.19E-03 \\
\hline BKVM-34.9 & 0 & 70 & $5.0 \mathrm{E}-05$ & 9.88 & 10.00 & 0.4479 & 5.95E-01 & 1,335 & 2.89E-04 & 9,396 & $5.67 \mathrm{E}-03$ \\
\hline BKVM-34.10 & 0 & 70 & $5.4 \mathrm{E}-05$ & 10.94 & 10.00 & 0.4409 & 5.85E-01 & 981 & $2.33 \mathrm{E}-04$ & 9,512 & $6.34 \mathrm{E}-03$ \\
\hline BKVM-34.11 & 0 & 70 & $5.9 \mathrm{E}-05$ & 11.23 & 10.00 & 0.4375 & 5.79E-01 & 874 & $2.27 \mathrm{E}-04$ & 9,889 & $7.25 \mathrm{E}-03$ \\
\hline \multicolumn{12}{|l|}{ Exp\#17 } \\
\hline BKVM-35.A & 0 & 70 & - & - & 11.00 & - & - & 130 & - & 537 & - \\
\hline BKVM-35.1 & 0 & 70 & $5.5 \mathrm{E}-05$ & 2.01 & 11.00 & 0.4933 & $6.54 \mathrm{E}-01$ & 24,580 & $5.40 \mathrm{E}-03$ & 13,095 & $8.00 \mathrm{E}-03$ \\
\hline BKVM-35.2 & 0 & 70 & $5.4 \mathrm{E}-05$ & 2.84 & 11.00 & 0.4848 & 6.44E-01 & 18,477 & $4.06 \mathrm{E}-03$ & 16,653 & 1.03E-02 \\
\hline BKVM-35.3 & 0 & 70 & $5.4 \mathrm{E}-05$ & 3.06 & 11.00 & 0.4803 & 6.36E-01 & 15,520 & $3.41 \mathrm{E}-03$ & 18,492 & $1.15 \mathrm{E}-02$ \\
\hline BKVM-35.6 & 0 & 70 & $5.6 \mathrm{E}-05$ & 4.22 & 11.00 & 0.4702 & $6.25 \mathrm{E}-01$ & 4,167 & $9.54 \mathrm{E}-04$ & 18,854 & $1.25 \mathrm{E}-02$ \\
\hline BKVM-35.7 & 0 & 70 & $5.3 \mathrm{E}-05$ & 6.94 & 11.00 & 0.4491 & $6.02 \mathrm{E}-01$ & 3,095 & $6.90 \mathrm{E}-04$ & 14,969 & $9.68 \mathrm{E}-03$ \\
\hline BKVM-35.8 & 0 & 70 & $5.8 \mathrm{E}-05$ & 8.20 & 11.00 & 0.4349 & $5.80 \mathrm{E}-01$ & 2,552 & 6.36E-04 & 10,711 & $7.70 \mathrm{E}-03$ \\
\hline BKVM-35.9 & 0 & 70 & $5.6 \mathrm{E}-05$ & 9.88 & 11.00 & 0.4257 & $5.66 \mathrm{E}-01$ & 2,260 & $5.56 \mathrm{E}-04$ & 8,721 & $6.16 \mathrm{E}-03$ \\
\hline BKVM-35.10 & 0 & 70 & $5.5 \mathrm{E}-05$ & 10.94 & 11.00 & 0.4190 & 5.56E-01 & 1,860 & $4.50 \mathrm{E}-04$ & 8,063 & $5.64 \mathrm{E}-03$ \\
\hline BKVM-35.11 & 0 & 70 & $5.8 \mathrm{E}-05$ & 11.23 & 11.00 & 0.4163 & 5.51E-01 & 1,655 & 4.23E-04 & 7,633 & $5.67 \mathrm{E}-03$ \\
\hline \multicolumn{12}{|l|}{ Exp \#18 } \\
\hline BKVM-36.A & 0 & 70 & - & - & 12.00 & - & - & 455 & - & 615 & - \\
\hline BKVM-36.1 & 0 & 70 & $5.5 \mathrm{E}-05$ & 2.01 & 12.00 & 0.4942 & 6.56E-01 & 39,093 & $8.55 \mathrm{E}-03$ & 20,051 & $1.24 \mathrm{E}-02$ \\
\hline BKVM-36.2 & $\overline{0}$ & 70 & $5.4 \mathrm{E}-05$ & 2.84 & 12.00 & 0.4791 & $6.39 \mathrm{E}-01$ & 24,375 & $5.33 \mathrm{E}-03$ & 31,627 & $1.99 \mathrm{E}-02$ \\
\hline BKVM-36.3 & 0 & 70 & $5.6 \mathrm{E}-05$ & 3.06 & 12.00 & 0.4703 & $6.25 \mathrm{E}-01$ & 17,990 & 4.12E-03 & 36,187 & $2.41 \mathrm{E}-02$ \\
\hline BKVM-36.6 & 0 & 70 & $5.7 \mathrm{E}-05$ & 4.22 & 12.00 & 0.4611 & $6.13 \mathrm{E}-01$ & 3,564 & 7.63E-04 & 15,101 & $1.02 \mathrm{E}-02$ \\
\hline BKVM-36.7 & 0 & 70 & $5.3 \mathrm{E}-05$ & 6.94 & 12.00 & 0.4408 & 5.91E-01 & 2,435 & $4.72 \mathrm{E}-04$ & 14,927 & $9.82 \mathrm{E}-03$ \\
\hline
\end{tabular}


Table B2. SPFT Results for Castable Refractory (BKVM).

\begin{tabular}{|c|c|c|c|c|c|c|c|c|c|c|c|}
\hline Sample ID & $\begin{array}{c}\text { Influent } \\
\text { [Si] }\end{array}$ & $\begin{array}{c}\mathrm{T} \\
\left({ }^{\circ} \mathrm{C}\right)\end{array}$ & $\begin{array}{c}\text { Flow } \\
\text { Ratat } \\
\left(\mathbf{m}^{3} / \mathbf{d}\right)\end{array}$ & $\begin{array}{l}\text { Time, } \\
\text { days }\end{array}$ & $\begin{array}{c}\mathrm{pH} \\
\left(23^{\circ} \mathrm{C}\right)\end{array}$ & $\begin{array}{l}\text { Glass } \\
\text { Mass (g) }\end{array}$ & $\mathrm{SA}\left(\mathrm{m}^{2}\right)$ & [Al] & Al Rate & [Si] & Si Rate \\
\hline BKVM-36.8 & 0 & 70 & $0.0 \mathrm{E}+00$ & 8.20 & 12.00 & 0.4326 & $5.75 \mathrm{E}-01$ & 1,825 & $0.00 \mathrm{E}+00$ & 13,516 & $0.00 \mathrm{E}+00$ \\
\hline BKVM-36.9 & 0 & 70 & $5.6 \mathrm{E}-05$ & 9.88 & 12.00 & 0.4229 & $5.62 \mathrm{E}-01$ & 1,730 & $3.36 \mathrm{E}-04$ & 13,456 & $9.75 \mathrm{E}-03$ \\
\hline BKVM-36.10 & 0 & 70 & $5.8 \mathrm{E}-05$ & 10.94 & 12.00 & 0.4122 & $5.49 \mathrm{E}-01$ & 1,511 & $2.94 \mathrm{E}-04$ & 12,585 & $9.61 \mathrm{E}-03$ \\
\hline BKVM-36.11 & 0 & 70 & 5.3E-05 & 11.23 & 12.00 & 0.4079 & $5.40 \mathrm{E}-01$ & 1,398 & $2.43 \mathrm{E}-04$ & 11,951 & $8.41 \mathrm{E}-03$ \\
\hline \multicolumn{12}{|l|}{ Exp \#19 } \\
\hline BKVM-43.A & 0 & 90 & - & - & 7.00 & - & - & $<10$ & - & $<500$ & - \\
\hline BKVM-43.1 & 0 & 90 & $7.4 \mathrm{E}-05$ & 1.12 & 7.00 & 0.4991 & $6.60 \mathrm{E}-01$ & 172 & 4.79E-05 & 4,525 & $3.43 \mathrm{E}-03$ \\
\hline BKVM-43.2 & 0 & 90 & $7.5 \mathrm{E}-05$ & 2.36 & 7.00 & 0.4947 & $6.55 \mathrm{E}-01$ & 102 & $2.76 \mathrm{E}-05$ & 4,253 & $3.25 \mathrm{E}-03$ \\
\hline BKVM-43.3 & 0 & 90 & $7.6 \mathrm{E}-05$ & 3.84 & 7.00 & 0.4902 & $6.49 \mathrm{E}-01$ & 74 & $1.97 \mathrm{E}-05$ & 3,525 & $2.68 \mathrm{E}-03$ \\
\hline BKVM-43.4 & 0 & 90 & $8.2 \mathrm{E}-05$ & 4.99 & 7.00 & 0.4867 & $6.44 \mathrm{E}-01$ & 56 & $1.53 \mathrm{E}-05$ & 2,790 & $2.21 \mathrm{E}-03$ \\
\hline BKVM-43.5 & 0 & 90 & 7.8E-05 & 6.84 & 7.00 & 0.4835 & $6.40 \mathrm{E}-01$ & 43 & $1.04 \mathrm{E}-05$ & 2,033 & $1.41 \mathrm{E}-03$ \\
\hline BKVM-43.6 & 0 & 90 & 7.7E-05 & 8.16 & 7.00 & 0.4813 & 6.36E-01 & 36 & $8.26 \mathrm{E}-06$ & 1,502 & $9.21 \mathrm{E}-04$ \\
\hline BKVM-43.7 & 0 & 90 & $7.7 \mathrm{E}-05$ & 10.04 & 7.00 & 0.4794 & $6.34 \mathrm{E}-01$ & 26 & $5.01 \mathrm{E}-06$ & 1,189 & $6.31 \mathrm{E}-04$ \\
\hline BKVM-43.8 & 0 & 90 & 8.1E-05 & 10.89 & 7.00 & 0.4782 & $6.32 \mathrm{E}-01$ & 31 & $6.98 \mathrm{E}-06$ & 1,110 & $5.93 \mathrm{E}-04$ \\
\hline BKVM-43.9 & 0 & 90 & $\begin{array}{l}8.1 \mathrm{E}-05 \\
\end{array}$ & 11.04 & 7.00 & 0.4778 & $6.31 \mathrm{E}-01$ & 26 & 5.52E-06 & 1,057 & $5.42 \mathrm{E}-04$ \\
\hline BKVM-43.10 & 0 & 90 & $8.5 \mathrm{E}-05$ & 11.18 & 7.00 & 0.4777 & $6.31 \mathrm{E}-01$ & 25 & $5.23 \mathrm{E}-06$ & 1,053 & $5.62 \mathrm{E}-04$ \\
\hline \multicolumn{12}{|l|}{ Exp \#20 } \\
\hline BKVM-44.A & 0 & 90 & - & - & 8.00 & - & - & $<10$ & - & $<500$ & - \\
\hline BKVM-44.1 & 0 & 90 & 6.9E-05 & 1.12 & 8.00 & 0.4999 & $6.61 \mathrm{E}-01$ & 1,973 & $5.40 \mathrm{E}-04$ & 3,660 & $2.50 \mathrm{E}-03$ \\
\hline BKVM-44.2 & 0 & 90 & $8.0 \mathrm{E}-05$ & 2.36 & 8.00 & 0.4965 & $6.57 \mathrm{E}-01$ & 1,626 & $5.15 \mathrm{E}-04$ & 3,005 & $2.30 \mathrm{E}-03$ \\
\hline BKVM-44.3 & 0 & 90 & 7.6E-05 & 3.84 & 8.00 & 0.4933 & $6.53 \mathrm{E}-01$ & 1,277 & 3.87E-04 & 2,507 & $1.77 \mathrm{E}-03$ \\
\hline BKVM-44.4 & 0 & 90 & 8.3E-05 & 4.99 & 8.00 & 0.4906 & $6.49 \mathrm{E}-01$ & 1,097 & $3.66 \mathrm{E}-04$ & 2,260 & $1.71 \mathrm{E}-03$ \\
\hline BKVM-44.5 & 0 & 90 & $7.9 \mathrm{E}-05$ & $\begin{array}{ll}6.84 \\
\end{array}$ & 8.00 & 0.4875 & $6.45 \mathrm{E}-01$ & 866 & $2.77 \mathrm{E}-04$ & 2,041 & $1.44 \mathrm{E}-03$ \\
\hline BKVM-44.6 & 0 & 90 & $7.5 \mathrm{E}-05$ & 8.16 & 8.00 & 0.4850 & $6.41 \mathrm{E}-01$ & 763 & $2.33 \mathrm{E}-04$ & 1,756 & $1.12 \mathrm{E}-03$ \\
\hline BKVM-44.7 & 0 & 90 & 7.7E-05 & 10.04 & 8.00 & 0.4827 & $6.38 \mathrm{E}-01$ & 631 & $1.98 \mathrm{E}-04$ & 1,478 & $8.98 \mathrm{E}-04$ \\
\hline BKVM-44.8 & 0 & 90 & 7.5E-05 & 10.89 & 8.00 & 0.4812 & $6.36 \mathrm{E}-01$ & 497 & $1.51 \mathrm{E}-04$ & 1,395 & $8.00 \mathrm{E}-04$ \\
\hline BKVM-44.9 & 0 & 90 & 7.8E-05 & 11.04 & 8.00 & 0.4808 & $6.35 \mathrm{E}-01$ & 477 & $1.50 \mathrm{E}-04$ & 1,298 & $7.39 \mathrm{E}-04$ \\
\hline BKVM-44.10 & 0 & 90 & $7.9 \mathrm{E}-05$ & 11.18 & 8.00 & 0.4805 & $6.34 \mathrm{E}-01$ & 174 & $5.35 \mathrm{E}-05$ & 2,332 & $1.72 \mathrm{E}-03$ \\
\hline \multicolumn{12}{|l|}{ Exp \#21 } \\
\hline BKVM-45.A & 0 & 90 & - & - & 9.00 & - & - & $<10$ & - & $<500$ & - \\
\hline BKVM-45.1 & 0 & 90 & $7.1 \mathrm{E}-05$ & 1.12 & 9.00 & 0.5016 & $6.63 \mathrm{E}-01$ & 10,743 & $3.03 \mathrm{E}-03$ & 3,917 & $2.78 \mathrm{E}-03$ \\
\hline BKVM-45.2 & 0 & 90 & 7.7E-05 & 2.36 & 9.00 & 0.4973 & $6.58 \mathrm{E}-01$ & 7,406 & $2.28 \mathrm{E}-03$ & 4,250 & $3.34 \mathrm{E}-03$ \\
\hline
\end{tabular}


Table B2. SPFT Results for Castable Refractory (BKVM).

\begin{tabular}{|c|c|c|c|c|c|c|c|c|c|c|c|}
\hline Sample ID & $\begin{array}{c}\text { Influent } \\
\text { [Si] }\end{array}$ & $\begin{array}{c}\mathrm{T} \\
\left({ }^{\circ} \mathrm{C}\right)\end{array}$ & $\begin{array}{c}\text { Flow } \\
\text { Rate } \\
\left(\mathbf{m}^{3} / \mathbf{d}\right)\end{array}$ & $\begin{array}{l}\text { Time, } \\
\text { days }\end{array}$ & $\begin{array}{c}\mathrm{pH} \\
\left(23^{\circ} \mathrm{C}\right)\end{array}$ & $\begin{array}{c}\text { Glass } \\
\text { Mass (g) }\end{array}$ & $\mathrm{SA}\left(\mathrm{m}^{2}\right)$ & [Al] & Al Rate & [Si] & Si Rate \\
\hline BKVM-45.3 & 0 & 90 & $7.4 \mathrm{E}-05$ & 3.84 & 9.00 & 0.4922 & $6.52 \mathrm{E}-01$ & 5,954 & $1.77 \mathrm{E}-03$ & 4,362 & $3.32 \mathrm{E}-03$ \\
\hline BKVM-45.4 & 0 & 90 & $7.9 \mathrm{E}-05$ & 4.99 & 9.00 & 0.4873 & $6.45 \mathrm{E}-01$ & 4,773 & $1.53 \mathrm{E}-03$ & 4,445 & $3.65 \mathrm{E}-03$ \\
\hline BKVM-45.5 & 0 & 90 & $7.7 \mathrm{E}-05$ & 6.84 & 9.00 & 0.4809 & 6.38E-01 & 3,728 & $1.19 \mathrm{E}-03$ & 4,536 & $3.71 \mathrm{E}-03$ \\
\hline BKVM-45.6 & 0 & 90 & 7.6E-05 & 8.16 & 9.00 & 0.4748 & $6.29 \mathrm{E}-01$ & 2,870 & $9.10 \mathrm{E}-04$ & 4,753 & $3.90 \mathrm{E}-03$ \\
\hline BKVM-45.7 & 0 & 90 & 7.8E-05 & 10.04 & 9.00 & 0.4676 & 6.20E-01 & 2,211 & 7.29E-04 & 4,839 & $4.14 \mathrm{E}-03$ \\
\hline BKVM-45.8 & 0 & 90 & $7.0 \mathrm{E}-05$ & 10.89 & 9.00 & 0.4627 & $6.13 \mathrm{E}-01$ & 1,743 & $5.24 \mathrm{E}-04$ & 5,029 & $3.95 \mathrm{E}-03$ \\
\hline BKVM-45.9 & $\overline{0}$ & 90 & $7.8 \mathrm{E}-05$ & 11.04 & 9.00 & 0.4611 & $6.09 \mathrm{E}-01$ & 1,576 & $5.29 \mathrm{E}-04$ & 5,039 & $4.42 \mathrm{E}-03$ \\
\hline BKVM-45.10 & 0 & 90 & $8.4 \mathrm{E}-05$ & 11.18 & 9.00 & 0.4603 & $6.08 \mathrm{E}-01$ & 788 & $2.85 \mathrm{E}-04$ & 6,001 & $5.80 \mathrm{E}-03$ \\
\hline \multicolumn{12}{|l|}{ Exp \#22 } \\
\hline BKVM-46.A & 0 & 90 & - & - & 10.00 & - & - & 10 & - & $<500$ & - \\
\hline BKVM-46.1 & 0 & 90 & 7.3E-05 & 1.12 & 10.00 & 0.4942 & $6.54 \mathrm{E}-01$ & 13,689 & $4.00 \mathrm{E}-03$ & 7,691 & $6.06 \mathrm{E}-03$ \\
\hline BKVM-46.2 & 0 & 90 & 7.3E-05 & 2.36 & 10.00 & 0.4856 & 6.45E-01 & 7,890 & $2.35 \mathrm{E}-03$ & 9,092 & 7.39E-03 \\
\hline BKVM-46.3 & 0 & 90 & $7.8 \mathrm{E}-05$ & 3.84 & 10.00 & 0.4737 & $6.30 \mathrm{E}-01$ & 5,744 & $1.87 \mathrm{E}-03$ & 10,012 & $8.94 \mathrm{E}-03$ \\
\hline BKVM-46.4 & 0 & 90 & $8.2 \mathrm{E}-05$ & 4.99 & 10.00 & 0.4619 & $6.15 \mathrm{E}-01$ & 4,777 & $1.68 \mathrm{E}-03$ & 10,289 & $9.95 \mathrm{E}-03$ \\
\hline BKVM-46.5 & 0 & 90 & $7.7 \mathrm{E}-05$ & 6.84 & 10.00 & 0.4471 & $5.97 \mathrm{E}-01$ & 3,700 & $1.25 \mathrm{E}-03$ & 10,357 & $9.59 \mathrm{E}-03$ \\
\hline BKVM-46.6 & 0 & 90 & $7.6 \mathrm{E}-05$ & 8.16 & 10.00 & 0.4341 & $5.79 \mathrm{E}-01$ & 3,144 & $1.08 \mathrm{E}-03$ & 9,729 & $9.18 \mathrm{E}-03$ \\
\hline BKVM-46.7 & 0 & 90 & $7.7 \mathrm{E}-05$ & 10.04 & 10.00 & 0.4188 & 5.59E-01 & 2,625 & $9.48 \mathrm{E}-04$ & 10,606 & $1.06 \mathrm{E}-02$ \\
\hline BKVM-46.8 & 0 & 90 & 7.6E-05 & 10.89 & 10.00 & 0.4075 & 5.43E-01 & 2,178 & $8.04 \mathrm{E}-04$ & 11,134 & $1.14 \mathrm{E}-02$ \\
\hline BKVM-46.9 & 0 & 90 & $6.1 \mathrm{E}-05$ & 11.04 & 10.00 & 0.4041 & 5.35E-01 & 2,019 & $6.01 \mathrm{E}-04$ & 10,526 & $8.64 \mathrm{E}-03$ \\
\hline BKVM-46.10 & 0 & 90 & $8.5 \mathrm{E}-05$ & 11.18 & 10.00 & 0.4027 & $5.32 \mathrm{E}-01$ & 1,150 & $4.80 \mathrm{E}-04$ & 11,355 & $1.32 \mathrm{E}-02$ \\
\hline \multicolumn{12}{|l|}{ Exp \#23 } \\
\hline BKVM-47.A & 0 & 90 & - & - & 11.00 & - & - & 24 & - & $<500$ & - \\
\hline BKVM-47.1 & 0 & 90 & $7.3 \mathrm{E}-05$ & 1.12 & 11.00 & 0.4859 & $6.48 \mathrm{E}-01$ & 17,894 & $5.30 \mathrm{E}-03$ & 24,329 & $2.04 \mathrm{E}-02$ \\
\hline BKVM-47.2 & 0 & 90 & $1.2 \mathrm{E}-05$ & 2.36 & 11.00 & 0.4750 & $6.32 \mathrm{E}-01$ & 8,718 & $4.27 \mathrm{E}-04$ & 29,392 & $4.09 \mathrm{E}-03$ \\
\hline BKVM-47.3 & 0 & 90 & $7.4 \mathrm{E}-05$ & 3.84 & 11.00 & 0.4527 & $6.07 \mathrm{E}-01$ & 6,886 & $2.21 \mathrm{E}-03$ & 24,913 & $2.27 \mathrm{E}-02$ \\
\hline BKVM-47.4 & 0 & 90 & 8.3E-05 & 4.99 & 11.00 & 0.4281 & 5.76E-01 & 5,952 & $2.24 \mathrm{E}-03$ & 19,724 & 2.09E-02 \\
\hline BKVM-47.5 & 0 & 90 & 7.8E-05 & 6.84 & 11.00 & 0.4023 & 5.42E-01 & 5,417 & $2.05 \mathrm{E}-03$ & 17,018 & $1.81 \mathrm{E}-02$ \\
\hline BKVM-47.6 & 0 & 90 & $7.9 \mathrm{E}-05$ & 8.16 & 11.00 & 0.3821 & 5.13E- 01 & 4,605 & $1.85 \mathrm{E}-03$ & 13,600 & $1.53 \mathrm{E}-02$ \\
\hline BKVM-47.7 & $\overline{0}$ & 90 & $7.7 \mathrm{E}-05$ & 10.04 & 11.00 & 0.3626 & $4.87 \mathrm{E}-01$ & 4,157 & $1.71 \mathrm{E}-03$ & 12,971 & $1.49 \mathrm{E}-02$ \\
\hline BKVM-47.8 & 0 & 90 & $7.2 \mathrm{E}-05$ & 10.89 & 11.00 & 0.3501 & $4.68 \mathrm{E}-01$ & 3,355 & $1.34 \mathrm{E}-03$ & 11,815 & $1.32 \mathrm{E}-02$ \\
\hline BKVM-47.9 & 0 & 90 & $9.6 \mathrm{E}-05$ & 11.04 & 11.00 & 0.3462 & 4.59E-01 & 3,163 & 1.73E-03 & 10,983 & $1.66 \mathrm{E}-02$ \\
\hline BKVM-47.10 & 0 & 90 & 4.3E-05 & 11.18 & 11.00 & 0.3451 & 4.56E-01 & 3,030 & 7.42E-04 & 10,380 & 7.03E-03 \\
\hline
\end{tabular}


Table B2. SPFT Results for Castable Refractory (BKVM).

\begin{tabular}{|c|c|c|c|c|c|c|c|c|c|c|c|}
\hline Sample ID & $\begin{array}{c}\text { Influent } \\
\text { [Si] }\end{array}$ & $\begin{array}{c}\mathrm{T} \\
\left({ }^{\circ} \mathrm{C}\right) \\
\end{array}$ & $\begin{array}{c}\text { Flow } \\
\text { Rate } \\
\left(\mathbf{m}^{3} / \mathbf{d}\right) \\
\end{array}$ & $\begin{array}{l}\text { Time, } \\
\text { days }\end{array}$ & $\begin{array}{c}\text { pH } \\
\left(23^{\circ} \mathrm{C}\right) \\
\end{array}$ & $\begin{array}{c}\text { Glass } \\
\text { Mass (g) } \\
\end{array}$ & $\mathrm{SA}\left(\mathbf{m}^{2}\right)$ & [Al] & Al Rate & [Si] & Si Rate \\
\hline \multicolumn{12}{|l|}{ Exp \#24 } \\
\hline BKVM-48.A & 0 & 90 & - & - & 12.00 & - & - & 59 & - & 567 & - \\
\hline BKVM-48.1 & 0 & 90 & 7.4E-05 & 1.12 & 12.00 & 0.4752 & 6.38E-01 & 31,488 & $9.66 \mathrm{E}-03$ & 39,142 & $3.42 \mathrm{E}-02$ \\
\hline BKVM-48.2 & 0 & 90 & 7.7E-05 & 2.36 & 12.00 & 0.3983 & 5.58E-01 & 17,445 & 6.34E-03 & 88,447 & $9.24 \mathrm{E}-02$ \\
\hline BKVM-48.3 & 0 & 90 & 7.9E-05 & 3.84 & 12.00 & 0.3310 & 4.65E-01 & 12,458 & $5.54 \mathrm{E}-03$ & 39,758 & $5.05 \mathrm{E}-02$ \\
\hline BKVM-48.4 & 0 & 90 & 7.8E-05 & 4.99 & 12.00 & 0.2910 & 4.01E-01 & 6,216 & 3.17E-03 & 32,889 & $4.80 \mathrm{E}-02$ \\
\hline BKVM-48.5 & 0 & 90 & $7.8 \mathrm{E}-05$ & 6.84 & 12.00 & 0.2441 & 3.42E-01 & 3,715 & 2.19E-03 & 32,636 & 5.54E-02 \\
\hline BKVM-48.6 & 0 & 90 & 7.6E-05 & 8.16 & 12.00 & 0.2037 & 2.86E-01 & 2,915 & $2.01 \mathrm{E}-03$ & 29,393 & $5.85 \mathrm{E}-02$ \\
\hline BKVM-48.7 & 0 & 90 & $7.8 \mathrm{E}-05$ & 10.04 & 12.00 & 0.1675 & 2.36E-01 & 2,147 & $1.82 \mathrm{E}-03$ & 22,424 & $5.48 \mathrm{E}-02$ \\
\hline BKVM-48.8 & 0 & 90 & 7.2E-05 & 10.89 & 12.00 & 0.1464 & 2.02E-01 & 1,748 & $1.57 \mathrm{E}-03$ & 18,805 & $4.90 \mathrm{E}-02$ \\
\hline BKVM-48.9 & 0 & 90 & 8.7E-05 & 11.04 & 12.00 & 0.1404 & 1.88E-01 & 1,603 & $1.87 \mathrm{E}-03$ & 16,711 & $5.64 \mathrm{E}-02$ \\
\hline BKVM-48.10 & 0 & 90 & $5.5 \mathrm{E}-05$ & 11.18 & 12.00 & 0.1387 & $1.84 \mathrm{E}-01$ & 1,566 & 1.19E-03 & 16,148 & 3.55E-02 \\
\hline
\end{tabular}


Appendix C

Product Consistency Test Results 
Table C1. BKV6 Glass PCT Test Results

\begin{tabular}{|c|c|c|c|c|c|c|c|c|c|c|c|c|}
\hline Sample ID & S/V Ratio, $\mathrm{m}^{-1}$ & Time & $\begin{array}{l}\text { Reaction Progress } \\
\left(\mathrm{mol} \mathrm{kg}^{-1}\right)\end{array}$ & $\begin{array}{c}\text { Norm. Al } \\
\left(\mathrm{mg} \mathrm{L}^{-1}\right)\end{array}$ & $\begin{array}{l}\text { Norm. B } \\
\left(\mathrm{mg} \mathrm{L}^{-1}\right)\end{array}$ & $\begin{array}{c}\text { Norm. Ca } \\
\left(\mathrm{mg} \mathrm{L}^{-1}\right)\end{array}$ & $\begin{array}{l}\text { Norm. Fe } \\
\left(\mathrm{mg} \mathrm{L}^{-1}\right)\end{array}$ & $\mid \begin{array}{l}\text { Norm. K } \\
\left(\mathrm{mg} \mathrm{L}^{-1}\right)\end{array}$ & $\begin{array}{l}\text { Norm. Na } \\
\left(\mathrm{mg} \mathrm{L}^{-1}\right)\end{array}$ & $\begin{array}{l}\text { Norm. Si } \\
\left(\mathrm{mg} \mathrm{L}^{-1}\right)\end{array}$ & $\begin{array}{l}\text { Norm. Ti } \\
\left(\mathrm{mg} \mathrm{L}^{-1}\right)\end{array}$ & $\begin{array}{l}\text { Norm. Zr } \\
\left(\mathrm{mg} \mathrm{L}^{-1}\right)\end{array}$ \\
\hline BKV6-10A-S.1.0F 7d & $2.0 \mathrm{E}+03$ & 7 & $7.2 \mathrm{E}-03$ & $1.9 \mathrm{E}+02$ & $4.9 \mathrm{E}+02$ & $1.5 \mathrm{E}+02$ & $2.2 \mathrm{E}+01$ & $1.7 \mathrm{E}+02$ & $5.1 \mathrm{E}+02$ & $5.2 \mathrm{E}+02$ & $7.4 \mathrm{E}+00$ & $1.0 \mathrm{E}+00$ \\
\hline BKV6-10A-S.2.0F 14d & $2.0 \mathrm{E}+03$ & 14 & 8.7E-03 & $1.8 \mathrm{E}+02$ & $5.9 \mathrm{E}+02$ & $3.1 \mathrm{E}+02$ & $2.6 \mathrm{E}+01$ & $4.9 \mathrm{E}+02$ & $7.1 \mathrm{E}+02$ & $5.9 \mathrm{E}+02$ & $6.7 \mathrm{E}+00$ & $1.6 \mathrm{E}+00$ \\
\hline BKV6-10A-S.3.0F 28d & $2.0 \mathrm{E}+03$ & 28 & $1.1 \mathrm{E}-02$ & $1.8 \mathrm{E}+02$ & $7.7 \mathrm{E}+02$ & $2.4 \mathrm{E}+02$ & $2.5 \mathrm{E}+01$ & $4.3 \mathrm{E}+02$ & $7.9 \mathrm{E}+02$ & $5.3 \mathrm{E}+02$ & $2.4 \mathrm{E}+01$ & $1.7 \mathrm{E}+00$ \\
\hline BKV6-10A-S.4.0F 56d & $2.0 \mathrm{E}+03$ & 56 & 9.7E-03 & $2.3 \mathrm{E}+02$ & $6.5 \mathrm{E}+02$ & $1.3 \mathrm{E}+02$ & $2.2 \mathrm{E}+01$ & $3.3 \mathrm{E}+02$ & $1.2 \mathrm{E}+03$ & $5.6 \mathrm{E}+02$ & $1.4 \mathrm{E}+01$ & $1.8 \mathrm{E}+00$ \\
\hline BKV6-10A-S.100F 100d & $2.0 \mathrm{E}+03$ & 100 & $9.6 \mathrm{E}-03$ & $3.7 \mathrm{E}+02$ & $6.5 \mathrm{E}+02$ & $1.3 \mathrm{E}+02$ & $3.9 \mathrm{E}+01$ & $3.9 \mathrm{E}+02$ & $1.3 \mathrm{E}+03$ & $5.8 \mathrm{E}+02$ & $1.3 \mathrm{E}+01$ & $2.2 \mathrm{E}+00$ \\
\hline BKV6-10A-S.5.0F 112d & $2.0 \mathrm{E}+03$ & 112 & 9.3E-03 & $3.0 \mathrm{E}+02$ & $6.3 \mathrm{E}+02$ & $7.3 \mathrm{E}+01$ & $2.4 \mathrm{E}+01$ & $3.7 \mathrm{E}+02$ & $1.3 \mathrm{E}+03$ & $5.4 \mathrm{E}+02$ & $1.0 \mathrm{E}+01$ & $3.6 \mathrm{E}+00$ \\
\hline BKV6-1A-S.1.0 7d & $2.0 \mathrm{E}+04$ & 7 & 2.2E-02 & $4.9 \mathrm{E}+02$ & $1.5 \mathrm{E}+03$ & $1.0 \mathrm{E}+02$ & $1.1 \mathrm{E}+02$ & $7.3 \mathrm{E}+02$ & $3.1 \mathrm{E}+03$ & $1.0 \mathrm{E}+03$ & $8.0 \mathrm{E}+01$ & $4.6 \mathrm{E}+01$ \\
\hline BKV6-1A-S.2.0 14d & $2.0 \mathrm{E}+04$ & 14 & $1.6 \mathrm{E}-02$ & $3.7 \mathrm{E}+02$ & $1.1 \mathrm{E}+03$ & $1.5 \mathrm{E}+01$ & $4.5 \mathrm{E}+01$ & $5.2 \mathrm{E}+02$ & $2.7 \mathrm{E}+03$ & $9.0 \mathrm{E}+02$ & $1.5 \mathrm{E}+01$ & $5.0 \mathrm{E}+00$ \\
\hline BKV6-1A-S.3.0 28d & $2.0 \mathrm{E}+04$ & 28 & $1.9 \mathrm{E}-02$ & $4.3 \mathrm{E}+02$ & $1.3 \mathrm{E}+03$ & $1.8 \mathrm{E}+02$ & $4.0 \mathrm{E}+01$ & $4.9 \mathrm{E}+02$ & $3.5 \mathrm{E}+03$ & $8.4 \mathrm{E}+02$ & $8.4 \mathrm{E}+00$ & $2.1 \mathrm{E}+00$ \\
\hline BKV6-1A-S.100 100d & $2.0 \mathrm{E}+04$ & 100 & 2.9E-02 & $5.6 \mathrm{E}+02$ & $1.9 \mathrm{E}+03$ & $5.7 \mathrm{E}+01$ & $5.7 \mathrm{E}+01$ & $1.1 \mathrm{E}+03$ & $7.0 \mathrm{E}+03$ & $1.0 \mathrm{E}+03$ & $5.4 \mathrm{E}+01$ & $3.2 \mathrm{E}+01$ \\
\hline BKV6-1A-S.5.0 112d & $2.0 \mathrm{E}+04$ & 112 & $2.3 \mathrm{E}-02$ & $1.5 \mathrm{E}+02$ & $1.6 \mathrm{E}+03$ & $7.7 \mathrm{E}+01$ & $7.8 \mathrm{E}+01$ & $5.4 \mathrm{E}+02$ & $3.8 \mathrm{E}+03$ & $5.5 \mathrm{E}+02$ & $8.3 \mathrm{E}+01$ & $5.1 \mathrm{E}+01$ \\
\hline \multicolumn{13}{|c|}{$\begin{array}{l}\text { S/V Ratio - Solution to Volume Ratio } \\
\text { Time in days } \\
\text { Norm. - Normalized Elemental Concentration in } \mathrm{mg} \mathrm{L}^{-1} \\
\text { Dashes - refer to samples where the elemental concentration was at or below the detection threshold. Therefore the normalized mass was not computed. } \\
\text { ND - refer not determined }\end{array}$} \\
\hline
\end{tabular}


Table C2. BKV7 Glass PCT Test Results

\begin{tabular}{|c|c|c|c|c|c|c|c|c|c|c|c|c|}
\hline Sample ID & S/V Ratio, $\mathrm{m}^{-1}$ & Time & $\begin{array}{c}\text { Reaction Progress } \\
\left(\mathrm{mol} \mathrm{kg}^{-1}\right)\end{array}$ & $\begin{array}{l}\text { Norm. Al } \\
\left(\mathrm{mg} \mathrm{L}^{-1}\right)\end{array}$ & $\begin{array}{l}\text { Norm. B } \\
\left(\mathrm{mg} \mathrm{L}^{-1}\right)\end{array}$ & $\begin{array}{c}\text { Norm. Ca } \\
\left(\mathrm{mg} \mathrm{L}^{-1}\right)\end{array}$ & $\begin{array}{l}\text { Norm. Fe } \\
\left(\mathrm{mg} \mathrm{L}^{-1}\right)\end{array}$ & $\begin{array}{c}\text { Norm. K } \\
\left(\mathrm{mg} \mathrm{L}^{-1}\right)\end{array}$ & $\begin{array}{c}\text { Norm. Na } \\
\left(\mathrm{mg} \mathrm{L}^{-1}\right)\end{array}$ & $\begin{array}{c}\text { Norm. Si } \\
\left(\mathrm{mg} \mathrm{L}^{-1}\right)\end{array}$ & $\begin{array}{c}\text { Norm. Ti } \\
\left(\mathrm{mg} \mathrm{L}^{-1}\right)\end{array}$ & $\begin{array}{c}\text { Norm. Zr } \\
\left(\mathrm{mg} \mathrm{L}^{-1}\right)\end{array}$ \\
\hline BKV7-10A-S.1.0 7d & 2000 & 7 & $6.1 \mathrm{E}-03$ & $2.42 \mathrm{E}+01$ & $4.12 \mathrm{E}+02$ & $1.43 \mathrm{E}+01$ & $6.88 \mathrm{E}+00$ & $2.10 \mathrm{E}+02$ & $5.75 \mathrm{E}+02$ & $4.32 \mathrm{E}+02$ & $5.1 \mathrm{E}+00$ & 3.0E-01 \\
\hline BKV7-10A-S.2.0 14d & 2000 & 14 & $6.6 \mathrm{E}-03$ & 7.34E+01 & $4.49 \mathrm{E}+02$ & $3.68 \mathrm{E}+01$ & $7.61 \mathrm{E}+00$ & $2.10 \mathrm{E}+02$ & $7.68 \mathrm{E}+02$ & $4.23 \mathrm{E}+02$ & $3.9 \mathrm{E}+00$ & $1.0 \mathrm{E}+00$ \\
\hline BKV7-10A-S.3.0 56d & 2000 & 56 & 7.4E-03 & $2.12 \mathrm{E}+02$ & $5.02 \mathrm{E}+02$ & $4.21 \mathrm{E}+00$ & $2.18 \mathrm{E}+01$ & $3.51 \mathrm{E}+02$ & $1.02 \mathrm{E}+03$ & $4.14 \mathrm{E}+02$ & $5.6 \mathrm{E}+00$ & $2.8 \mathrm{E}+00$ \\
\hline BKV7-10A-S.4.0F 100d & 2000 & 100 & $1.1 \mathrm{E}-02$ & $1.62 \mathrm{E}+02$ & $7.66 \mathrm{E}+02$ & $1.35 \mathrm{E}+02$ & $9.76 \mathrm{E}+00$ & $1.29 \mathrm{E}+03$ & $1.49 \mathrm{E}+03$ & $5.50 \mathrm{E}+02$ & $6.6 \mathrm{E}+00$ & $1.9 \mathrm{E}+00$ \\
\hline BKV7-10A-S.5.0F 112d & 2000 & 112 & $1.2 \mathrm{E}-02$ & $3.37 \mathrm{E}+01$ & $7.81 \mathrm{E}+02$ & $1.30 \mathrm{E}+02$ & $2.44 \mathrm{E}+00$ & $1.16 \mathrm{E}+03$ & $1.43 \mathrm{E}+03$ & $4.90 \mathrm{E}+02$ & $5.5 \mathrm{E}+00$ & $5.0 \mathrm{E}-01$ \\
\hline BKV7-1A-S.1.0 7d & 20000 & 7 & 1.9E-02 & $3.13 \mathrm{E}+02$ & $1.32 \mathrm{E}+03$ & $2.14 \mathrm{E}+01$ & $6.54 \mathrm{E}+01$ & $6.97 \mathrm{E}+02$ & $2.67 \mathrm{E}+03$ & $7.09 \mathrm{E}+02$ & $3.9 \mathrm{E}+01$ & $1.6 \mathrm{E}+01$ \\
\hline BKV7-1A-S.2.0 14d & 20000 & 14 & 2.1E-02 & $4.23 \mathrm{E}+02$ & $1.39 \mathrm{E}+03$ & $4.68 \mathrm{E}+01$ & $9.92 \mathrm{E}+01$ & $8.96 \mathrm{E}+02$ & $3.34 \mathrm{E}+03$ & $8.39 \mathrm{E}+02$ & $4.8 \mathrm{E}+01$ & $3.4 \mathrm{E}+01$ \\
\hline BKV7-1A-S.3.0 56d & 20000 & 56 & 2.5E-02 & $4.91 \mathrm{E}+02$ & $1.71 \mathrm{E}+03$ & $5.83 \mathrm{E}+01$ & $6.96 \mathrm{E}+01$ & $1.23 \mathrm{E}+03$ & $4.96 \mathrm{E}+03$ & $8.42 \mathrm{E}+02$ & $6.2 \mathrm{E}+01$ & $5.6 \mathrm{E}+01$ \\
\hline
\end{tabular}

S/V Ratio - Solution to Volume Ratio

Time in days

Norm. - Normalized Elemental Concentration in $\mathrm{mg} \mathrm{L}^{-1}$

Dashes - refer to samples where the elemental concentration was at or below the detection threshold. Therefore the normalized mass was not computed.

ND - refer not determined 
Table C3. BKV8 Glass PCT Test Results

\begin{tabular}{|c|c|c|c|c|c|c|c|c|c|c|c|c|}
\hline Sample ID & S/V Ratio, $\mathrm{m}^{-1}$ & Time & $\begin{array}{c}\text { Reaction Progress } \\
\left(\mathrm{mol} \mathrm{kg}^{-1}\right)\end{array}$ & $\begin{array}{c}\text { Norm. Al } \\
\left(\mathrm{mg} \mathrm{L}^{-1}\right)\end{array}$ & $\begin{array}{l}\text { Norm. B } \\
\left(\mathrm{mg} \mathrm{L}^{-1}\right)\end{array}$ & $\begin{array}{c}\text { Norm. Ca } \\
\left(\mathrm{mg} \mathrm{L}^{-1}\right)\end{array}$ & $\begin{array}{c}\text { Norm. Fe } \\
\left(\mathrm{mg} \mathrm{L}^{-1}\right)\end{array}$ & $\begin{array}{l}\text { Norm. K } \\
\left(\mathrm{mg} \mathrm{L}^{-1}\right)\end{array}$ & $\begin{array}{c}\text { Norm. Na } \\
\left(\mathrm{mg} \mathrm{L}^{-1}\right)\end{array}$ & $\begin{array}{c}\text { Norm. Si } \\
\left(\mathrm{mg} \mathrm{L}^{-1}\right)\end{array}$ & $\begin{array}{c}\text { Norm. Ti } \\
\left(\mathrm{mg} \mathrm{L}^{-1}\right)\end{array}$ & $\begin{array}{c}\text { Norm. Zr } \\
\left(\mathrm{mg} \mathrm{L}^{-1}\right)\end{array}$ \\
\hline BKV8-10A-S.1.0F 7d & $2.0 \mathrm{E}+03$ & 7 & $1.9 \mathrm{E}-02$ & $5.1 \mathrm{E}+02$ & $1.3 \mathrm{E}+03$ & $8.8 \mathrm{E}+01$ & $2.6 \mathrm{E}+01$ & $9.0 \mathrm{E}+02$ & $2.4 \mathrm{E}+03$ & $7.8 \mathrm{E}+02$ & ND & ND \\
\hline BKV8-10A-S.2.0F 14d & $2.0 \mathrm{E}+03$ & 14 & 3.8E-03 & $2.2 \mathrm{E}+02$ & $2.6 \mathrm{E}+02$ & $7.9 \mathrm{E}+01$ & $1.2 \mathrm{E}+01$ & $2.7 \mathrm{E}+02$ & $5.5 \mathrm{E}+02$ & $4.6 \mathrm{E}+02$ & ND & ND \\
\hline BKV8-10A-S.3.0F 28d & $2.0 \mathrm{E}+03$ & 28 & $5.2 \mathrm{E}-03$ & $6.2 \mathrm{E}+01$ & $3.5 \mathrm{E}+02$ & $1.7 \mathrm{E}+02$ & $7.5 \mathrm{E}+00$ & $6.4 \mathrm{E}+02$ & $6.9 \mathrm{E}+02$ & $4.8 \mathrm{E}+02$ & ND & ND \\
\hline BKV8-10A-S.4.0F 56d & $2.0 \mathrm{E}+03$ & 56 & 4.2E-03 & $2.1 \mathrm{E}+02$ & $2.9 \mathrm{E}+02$ & $1.0 \mathrm{E}+02$ & $1.3 \mathrm{E}+01$ & $4.5 \mathrm{E}+02$ & $1.0 \mathrm{E}+03$ & $4.6 \mathrm{E}+02$ & ND & ND \\
\hline BKV8-10A-S.100F 100d & $2.0 \mathrm{E}+03$ & 100 & 1.3E-04 & $5.3 \mathrm{E}+01$ & $8.9 \mathrm{E}+00$ & $2.2 \mathrm{E}+02$ & $5.9 \mathrm{E}+01$ & $2.4 \mathrm{E}+02$ & $3.0 \mathrm{E}+02$ & $3.8 \mathrm{E}+02$ & ND & ND \\
\hline BKV8-10A-S.5.0F 112d & $2.0 \mathrm{E}+03$ & 112 & $5.2 \mathrm{E}-03$ & $3.8 \mathrm{E}+02$ & $3.5 \mathrm{E}+02$ & $6.3 \mathrm{E}+01$ & $4.1 \mathrm{E}+01$ & $5.0 \mathrm{E}+02$ & $1.3 \mathrm{E}+03$ & $5.1 \mathrm{E}+02$ & ND & ND \\
\hline BKV8-1A-S.1.0F 7d & $2.0 \mathrm{E}+04$ & 7 & $5.1 \mathrm{E}-03$ & $5.1 \mathrm{E}+01$ & $3.4 \mathrm{E}+02$ & $1.3 \mathrm{E}+02$ & $1.4 \mathrm{E}+01$ & $3.7 \mathrm{E}+02$ & $4.4 \mathrm{E}+02$ & $4.9 \mathrm{E}+02$ & ND & ND \\
\hline BKV8-1A-S.2.0F 14d & $2.0 \mathrm{E}+04$ & 14 & $1.6 \mathrm{E}-02$ & $5.4 \mathrm{E}+02$ & $1.1 \mathrm{E}+03$ & $1.6 \mathrm{E}+01$ & $3.2 \mathrm{E}+01$ & $9.9 \mathrm{E}+02$ & $2.7 \mathrm{E}+03$ & $7.2 \mathrm{E}+02$ & ND & ND \\
\hline BKV8-1A-S.3.0F 28d & $2.0 \mathrm{E}+04$ & 28 & $1.9 \mathrm{E}-02$ & $7.0 \mathrm{E}+02$ & $1.3 \mathrm{E}+03$ & $1.2 \mathrm{E}+02$ & $1.1 \mathrm{E}+01$ & $1.2 \mathrm{E}+03$ & $3.5 \mathrm{E}+03$ & $9.0 \mathrm{E}+02$ & ND & ND \\
\hline BKV8-1A-S.4.0F 56d & $2.0 \mathrm{E}+04$ & 56 & $1.8 \mathrm{E}-02$ & $6.9 \mathrm{E}+02$ & $1.2 \mathrm{E}+03$ & $1.1 \mathrm{E}+02$ & $5.0 \mathrm{E}+00$ & $1.5 \mathrm{E}+03$ & $4.4 \mathrm{E}+03$ & $8.4 \mathrm{E}+02$ & ND & ND \\
\hline BKV8-1A-S.100F 100d & $2.0 \mathrm{E}+04$ & 100 & $6.8 \mathrm{E}-04$ & $6.2 \mathrm{E}+00$ & $4.6 \mathrm{E}+01$ & $1.2 \mathrm{E}+03$ & $2.1 \mathrm{E}+00$ & $7.6 \mathrm{E}+02$ & $1.4 \mathrm{E}+03$ & $4.2 \mathrm{E}+02$ & ND & ND \\
\hline BKV8-1A-S.5.0F 112d & $2.0 \mathrm{E}+04$ & 112 & 1.7E-02 & $6.4 \mathrm{E}+02$ & $1.2 \mathrm{E}+03$ & $1.8 \mathrm{E}+01$ & $6.7 \mathrm{E}+00$ & $2.2 \mathrm{E}+03$ & $4.8 \mathrm{E}+03$ & $7.8 \mathrm{E}+02$ & ND & ND \\
\hline \multicolumn{13}{|c|}{$\begin{array}{l}\text { S/V Ratio - Solution to Volume Ratio } \\
\text { Time in days } \\
\text { Norm. - Normalized Elemental Concentration in } \mathrm{mg} \mathrm{L}^{-1} \\
\text { Dashes - refer to samples where the elemental concentration was at or below the detection threshold. Therefore the normalized mass was not computed. } \\
\text { ND - refer not determined }\end{array}$} \\
\hline
\end{tabular}


Table C3. BKVZ Glass PCT Test Results

\begin{tabular}{|c|c|c|c|c|c|c|c|c|c|c|c|c|}
\hline Sample ID & S/V Ratio, $\mathrm{m}^{-1}$ & Time & $\begin{array}{c}\text { Reaction Progress } \\
\left(\mathrm{mol} \mathrm{kg}^{-1}\right)\end{array}$ & $\begin{array}{c}\text { Norm. Al } \\
\left(\mathrm{mg} \mathrm{L}^{-1}\right)\end{array}$ & \begin{tabular}{|l|} 
Norm. B \\
$\left(\mathrm{mg} \mathrm{L}^{-1}\right)$
\end{tabular} & $\begin{array}{c}\text { Norm. Ca } \\
\left(\mathrm{mg} \mathrm{L}^{-1}\right)\end{array}$ & $\begin{array}{c}\text { Norm. Fe } \\
\left(\mathrm{mg} \mathrm{L}^{-1}\right)\end{array}$ & $\begin{array}{l}\text { Norm. K } \\
\left(\mathrm{mg} \mathrm{L}^{-1}\right)\end{array}$ & $\begin{array}{c}\text { Norm. Na } \\
\left(\mathrm{mg} \mathrm{L}^{-1}\right)\end{array}$ & $\begin{array}{c}\text { Norm. Si } \\
\left(\mathrm{mg} \mathrm{L}^{-1}\right)\end{array}$ & $\begin{array}{c}\text { Norm. Ti } \\
\left(\mathrm{mg} \mathrm{L}^{-1}\right)\end{array}$ & $\begin{array}{c}\text { Norm. Zr } \\
\left(\mathrm{mg} \mathrm{L}^{-1}\right)\end{array}$ \\
\hline BKVZ-10A-S.1.0F 7d & $2.0 \mathrm{E}+03$ & 7 & $3.8 \mathrm{E}-04$ & $3.7 \mathrm{E}+00 \mid$ & $2.5 \mathrm{E}+01$ & $1.5 \mathrm{E}+02$ & $8.4 \mathrm{E}-01$ & $(1.0 \mathrm{E}+02)$ & $3.8 \mathrm{E}+02$ & $2.8 \mathrm{E}+02$ & $(3.0 \mathrm{E}-01) \mid$ & - \\
\hline BKVZ-10A-S.2.0F 14d & $2.0 \mathrm{E}+03$ & 14 & $2.4 \mathrm{E}-03$ & $2.1 \mathrm{E}+01$ & $1.6 \mathrm{E}+02$ & $1.4 \mathrm{E}+02$ & $7.2 \mathrm{E}+00$ & $(2.4 \mathrm{E}+02)$ & $4.7 \mathrm{E}+02$ & $3.1 \mathrm{E}+02$ & $(1.8 \mathrm{E}+00)$ & (8.9E-01) \\
\hline BKVZ-10A-S.3.0F 21d & $2.0 \mathrm{E}+03$ & 21 & $1.3 \mathrm{E}-03$ & $9.2 \mathrm{E}+01$ & $8.8 \mathrm{E}+01$ & $1.2 \mathrm{E}+02$ & $1.9 \mathrm{E}+01$ & $(1.2 \mathrm{E}+02)$ & $5.1 \mathrm{E}+02$ & $3.2 \mathrm{E}+02$ & $(4.3 \mathrm{E}-01)$ & $(1.4 \mathrm{E}+01)$ \\
\hline BKVZ-10A-S.4.0F 28d & $2.0 \mathrm{E}+03$ & 28 & $7.4 \mathrm{E}-03$ & $6.6 \mathrm{E}+00$ & $5.0 \mathrm{E}+02$ & $1.9 \mathrm{E}+02$ & - & $(1.1 \mathrm{E}+03)$ & $6.4 \mathrm{E}+02$ & $4.7 \mathrm{E}+02$ & $(2.6 \mathrm{E}-01)$ & - \\
\hline BKVZ-10A-S.5.0F 56d & $2.0 \mathrm{E}+03$ & 56 & 7.6E-03 & $4.1 \mathrm{E}+01$ & $5.2 \mathrm{E}+02$ & $1.6 \mathrm{E}+02$ & $9.5 \mathrm{E}-01$ & $(1.1 \mathrm{E}+03)$ & $8.3 \mathrm{E}+02$ & $4.6 \mathrm{E}+02$ & $(3.2 \mathrm{E}-01)$ & $(2.1 \mathrm{E}-01)$ \\
\hline BKVZ-10A-S.100F 100d & $2.0 \mathrm{E}+03$ & 100 & 7.6E-03 & $1.2 \mathrm{E}+02$ & $5.2 \mathrm{E}+02$ & $1.9 \mathrm{E}+02$ & $2.6 \mathrm{E}+00$ & $(1.0 \mathrm{E}+03)$ & $8.0 \mathrm{E}+02$ & $4.8 \mathrm{E}+02$ & $(4.5 \mathrm{E}-01)$ & $(1.4 \mathrm{E}+00)$ \\
\hline BKVZ-10A-S.6.0F 112d & $2.0 \mathrm{E}+03$ & 112 & $7.9 \mathrm{E}-03$ & $3.3 \mathrm{E}+02$ & $5.4 \mathrm{E}+02$ & $3.2 \mathrm{E}+02$ & $1.7 \mathrm{E}+01$ & $(1.1 \mathrm{E}+03)$ & $8.1 \mathrm{E}+02$ & $4.9 \mathrm{E}+02$ & $(1.3 \mathrm{E}+00)$ & $(5.1 \mathrm{E}+00)$ \\
\hline BKVZ-1A-S.1.0F 7d & $2.0 \mathrm{E}+04$ & 7 & 7.7E-03 & $4.2 \mathrm{E}+02$ & $5.2 \mathrm{E}+02$ & $1.2 \mathrm{E}+02$ & $2.3 \mathrm{E}+01$ & $(3.8 \mathrm{E}+02)$ & $1.7 \mathrm{E}+03$ & $5.3 \mathrm{E}+02$ & $(1.3 \mathrm{E}+00)$ & $(3.1 \mathrm{E}+00)$ \\
\hline BKVZ-1A-S.2.0F 14d & $2.0 \mathrm{E}+04$ & 14 & $7.7 \mathrm{E}-03$ & $4.3 \mathrm{E}+02$ & $5.2 \mathrm{E}+02$ & $1.1 \mathrm{E}+02$ & $3.0 \mathrm{E}+02$ & $(4.1 \mathrm{E}+02)$ & $1.8 \mathrm{E}+03$ & $5.2 \mathrm{E}+02$ & $(1.7 \mathrm{E}+00)$ & $(5.4 \mathrm{E}+00)$ \\
\hline BKVZ-1A-S.3.0F 21d & $2.0 \mathrm{E}+04$ & 21 & $8.6 \mathrm{E}-03$ & $4.6 \mathrm{E}+02$ & $5.8 \mathrm{E}+02$ & $1.0 \mathrm{E}+02$ & $3.9 \mathrm{E}+01$ & $(1.4 \mathrm{E}+02)$ & $1.9 \mathrm{E}+03$ & $5.5 \mathrm{E}+02$ & $(2.4 \mathrm{E}+00)$ & $(1.2 \mathrm{E}+02)$ \\
\hline BKVZ-1A-S.4.0F 28d & $2.0 \mathrm{E}+04$ & 28 & $1.4 \mathrm{E}-02$ & $4.4 \mathrm{E}+02$ & $9.6 \mathrm{E}+02$ & $1.4 \mathrm{E}+02$ & $2.4 \mathrm{E}+01$ & $(1.6 \mathrm{E}+03)$ & $2.0 \mathrm{E}+03$ & $6.3 \mathrm{E}+02$ & $(2.3 \mathrm{E}+00)$ & $(8.1 \mathrm{E}+00)$ \\
\hline BKVZ-1A-S.6.0F 112d & $2.0 \mathrm{E}+04$ & 112 & $1.5 \mathrm{E}-02$ & $3.0 \mathrm{E}+02$ & $1.0 \mathrm{E}+03$ & $9.5 \mathrm{E}+02$ & $3.0 \mathrm{E}+01$ & $(1.6 \mathrm{E}+03)$ & $3.5 \mathrm{E}+03$ & $6.0 \mathrm{E}+02$ & $(2.2 \mathrm{E}+00)$ & $(6.8 \mathrm{E}+00)$ \\
\hline
\end{tabular}

S/V Ratio - Solution to Volume Ratio

$\Omega \quad$ Time in days

$\stackrel{\text { N }}{\Omega} \quad$ Norm. - Normalized Elemental Concentration in $\mathrm{mg} \mathrm{L}^{-1}$

Dashes - refer to samples where the elemental concentration was at or below the detection threshold. Therefore the normalized mass was not computed. 


\section{Distribution}

No. of

Copies

OFFSITE

2 AMEC

L. Thompson

J. Wise

2 DMJM Technology

J. Reddick

K. Wiemers

\section{ONSITE}

9 CH2M HILL Hanford Group, Inc.

D. W. Hamilton (3)

M. W. Leonard

F. M. Mann

D. L. Parker

G. L. Parsons

R. E. Raymond

CH2M HILL Document Control
No. of

Copies

\section{ONSITE}

24 Pacific Northwest National Laboratory

B2-67

B2-67

L. M. Bagaasen (10)

K6-28

S. R. Baum

P7-22

T. M Brouns

K6-69

J. V. Crum

K6-24

$\mathrm{H} 0-50$

H0-50

M. L. Elliott

K6-28

K. N. Geizler

P7-22

P. R. Hrma

K6-24

D.-S. Kim

K6-24

B. P. McGrail

K6-81

E. M. Pierce

K6-81

L. R. Reed

K6-81

E. A. Rodriguez

K6-81

H.T. Schaef

K6-81

J. D. Vienna

K6-24

D. M. Wellman

K6-81

3 U.S. Department of Energy/Office of River Protection

M. E. Burandt

H6-60

B. M. Mauss

H6-60

S. A. Wiegman

H6-60 